Luciano Maldonado Ferreira

\title{
APLICAÇÃO DA TEORIA DA CONFIABILIDADE NA OBTENÇÃO DE LIMITES PARA O PESO DE VEÍCULOS DE CARGA EM PONTES DE CONCRETO
}

Tese apresentada à Escola de Engenharia de São Carlos da Universidade de São Paulo, como parte dos requisitos para obtenção do Título de Doutor em Engenharia de Estruturas.

Orientador: Prof. Mounir Khalil El Debs 
FOLHA DE JULGAMENTO

Candidato: Engenheiro LUCIANO MALDONADO FERREIRA

Tese defendida e julgada em 29/05/2006 perante a Comissão Julgadora:
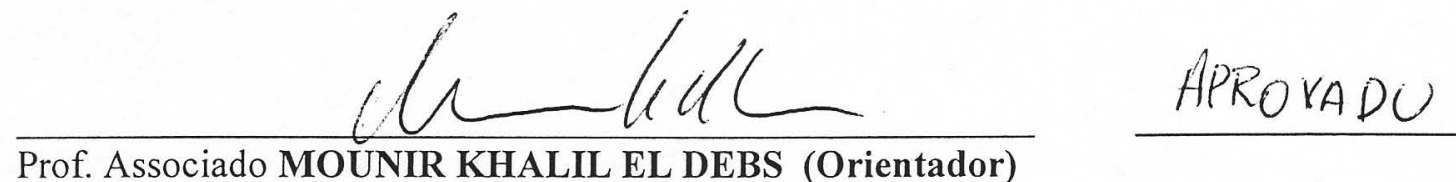

Prof. Associado MOUNIR KHALIL EL DEBS (Orientador)

(Escola de Engenharia de São Carlos/USP)

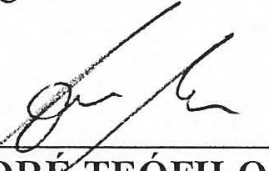

Prof. Dr. ANDRÉ TEÓFILO BECK

AFCOVADO

(Escola de Engenharia de São Carlos/USP)

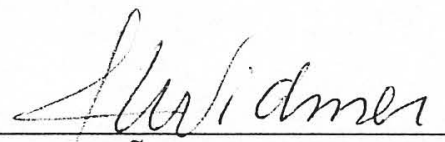

Prof. Titular JOÃO ALEXANDRE WIDMER

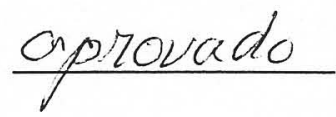

(Escola de Engenharia de São Carlos/USP)

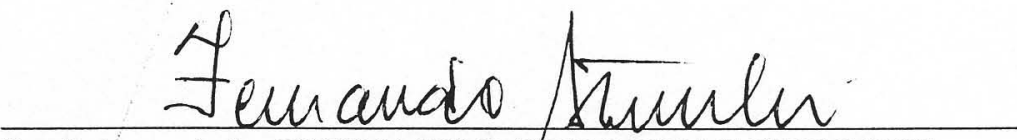

Prof. Associado FERNANDO REBOUÇAS STUCCHI

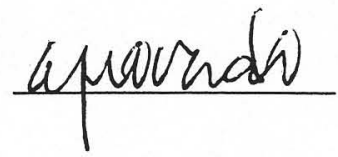

(Escola Politécnica/USP)

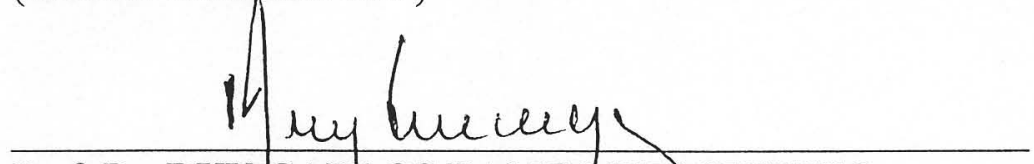

Prof. Dr. RUY CARLOS RAMOS DE MENEZES

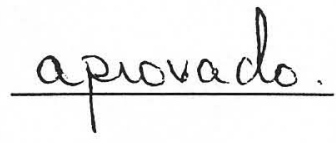

(Universidade Hederäl do Rio Grande do Sul/UFRGS)
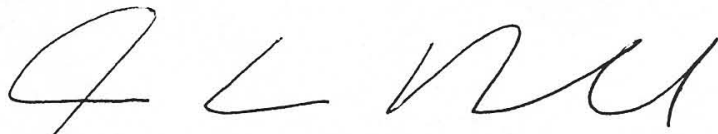

Prof. Associado MARCIO ANTONIO RAMALHO

Cơordenadora do Programa de Pós-Graduação em

Engenharia Civil (Engenharia de Estruturas)

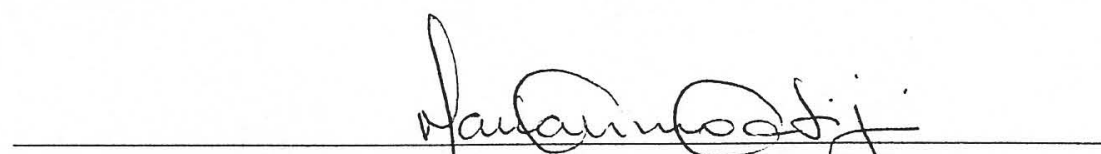

Profa. Titular MARIA DO CARMO CALIYURI

Presidente da Comissão de Pós-Graduação 
A meus pais, Lenize e Luiz, e meus avós, Ana e Lázaro. 
Ao professor Mounir Khalil El Debs, pela valiosa orientação, pelos ensinamentos transmitidos, pelo incentivo à realização desta pesquisa e pela sincera amizade compartilhada ao longo dos anos.

Ao professor Andrzej S. Nowak, por me receber e fornecer o apoio necessário na University of Michigan, etapa muito importante para o desenvolvimento do trabalho e para o crescimento pessoal do autor.

Aos professores do Departamento de Estruturas da Escola de Engenharia de São Carlos, em especial a Toshiaki Takeya e Paulo dos Santos Neto.

Ao professor João Alexandre Widmer, do Departamento de Transportes da Escola de Engenharia de São Carlos, e ao engenheiro Luís Wilson Marques, da Transervice Consultoria em Transportes S/C Ltda, pela colaboração no estudo dos veículos de carga nacionais.

Ao professor José Reynaldo A. Setti e à doutoranda Juliana Jerônimo de Araújo, ambos do Departamento de Transportes da Escola de Engenharia de São Carlos, pelo intercâmbio de informações relativas a modelos de carregamento móvel.

A Rodrigo de Azevêdo Neves, pelo auxílio sobre teoria da confiabilidade.

Às concessionárias de rodovias: Autoban, Autovias, Centrovias e Rodonorte, pelo fornecimento de dados relativos à pesagem de caminhões.

À minha namorada, Fernanda Giannotti da Silva, que esteve a meu lado e me deu forças em todos os momentos.

Aos amigos e à minha família.

À Capes, pelas bolsas de estudo tanto no Brasil quanto no exterior. 
Resumo

FERREIRA, L.M. (2006). Aplicação da teoria da confiabilidade na obtenção de limites para o peso de veículos de carga em pontes de concreto. Tese (Doutorado) - Escola de Engenharia de São Carlos, Universidade de São Paulo, São Carlos, 2006.

O aumento nos limites de pesos estabelecidos pela legislação brasileira e o surgimento de novas Combinações de Veículos de Carga nos últimos anos tornam necessária a verificação da segurança estrutural das pontes quando submetidas ao tráfego real. Este trabalho verifica o desempenho das obras de arte sob jurisdição do DER-SP através do índice de confiabilidade $\beta$ e obtém limites para o peso de caminhões de modo a não comprometer sua integridade estrutural. São consideradas as superestruturas das pontes em concreto armado ou protendido, classes 36 e 45 . Verificase o estado limite último nas seções transversais mais solicitadas por momento fletor positivo e negativo. No caso de pontes em concreto protendido, acrescenta-se o estado limite de formação de fissuras. Para a representação do tráfego real, é desenvolvido um modelo de carregamento móvel com base em pesagens de caminhões efetuadas em rodovias do estado de São Paulo. Admite-se a presença simultânea de veículos sobre a ponte e diferentes relações entre seus pesos. Os parâmetros estatísticos da resistência são determinados através da técnica de Monte Carlo. Apresenta-se os limites de peso em forma de equações, denominadas ECPLs (equações comprimento-peso limite), aplicáveis a quaisquer grupo de eixos consecutivos. Os resultados indicam restrições à circulação de algumas composições, especialmente ao rodotrem de 740 kN e 19,80 metros de comprimento. Considerando-se apenas o estado limite de serviço, as obras de arte classe 45 apresentam menores limites de peso devido à ponderação de ações durante o projeto.

Palavras-chave: pontes de concreto; confiabilidade; carga móvel 
FERREIRA, L.M. (2006). Development of truck weight limits for concrete bridges using reliability theory. Ph.D. Thesis - Escola de Engenharia de São Carlos, Universidade de São Paulo, São Carlos, 2006.

The increase in gross weight limits allowed by Brazilian legislation and the appearance of new truck configurations in last years require the assessment of bridges structural safety when submitted to real traffic. This thesis verifies the performance of the bridges under DER-SP jurisdiction using the reliability index $\beta$ and obtains truck weight limits in order to guarantee its structural integrity. The superstructure of reinforced and prestressed concrete bridges, classes 36 and 45, is considered. The ultimate limit state is verified in cross sections submitted to critical positive and negative bending moments. In case of prestressed bridges, the tension limit state in concrete is added. To represent the real traffic, a live load model is developed based on weighting data collected from stations located at highways of the state of Sao Paulo. Multiple presence of vehicles over the bridge and different relations between weights are admitted. The statistical parameters of resistance are determined using the Monte Carlo technique. The gross weight limits are presented in the form of equations, known as bridge formulas, to be applied on any group of two or more consecutive axles. The results indicate restrictions to the traffic of some vehicles, especially the $740 \mathrm{kN}$ and 19,80 meters length roadtrain. Considering only the serviceability limit state, bridges class 45 exhibit lower weight limits due to the load factors recommended by the code during design.

Keywords: concrete bridges; reliability; live load model; bridge formula 
Figura 2.1 - Comparação entre a bridge formula oficial (para vários N), a TTI formula e a equação do TRB

Figura 2.2 - Comparação entre a TTI formula, o TRB e a equação de Ghosn (2000)

Figura 2.3 - Definição do índice de confiabilidade

Figura 2.4 - Probabilidade de falha e margem de segurança 17

Figura 2.5 - Alternativas para a redução da probabilidade de falha 18

Figura 2.6 - Aproximação FORM para funções não-lineares de estado limite $\quad 20$

Figura 2.7 - Divisão da função distribuição acumulada 22

Figura 2.8 - Exemplo de um sistema em série $\quad 24$

Figura 2.9 - Exemplo de um sistema em paralelo $\quad 25$

Figura 2.10 - Carregamento HS-20 da AASHTO (1996) 32

Figura 2.11 - Índices de confiabilidade obtidos a partir da AASHTO (1996) 33

Figura 2.12 - Cauda superior da distribuição de momentos fletores 37

Figura 2.13 - Extrapolação para vida útil de 50 anos 38

Figura 2.14 - Extrapolação para momento fletor negativo para vão de 9 metros $\quad 44$

Figura 2.15 - Média dos máximos momentos fletores para vãos únicos devido a um caminhão isolado

Figura 2.16 - Média dos máximos momentos fletores em 75 anos devido a um ou dois caminhões em uma faixa de tráfego 47

Figura 2.17 - Carga móvel de projeto na AASHTO LRFD 49

Figura 2.18 - Bias para momento fletor positivo, 75 anos de vida útil 49

Figura 2.19 - Bias para força cortante, 75 anos de vida útil 49

Figura 2.20 - Bias para momento fletor negativo, 75 anos de vida útil 50

Figura 2.21 - Coeficiente de impacto em função das deformações 51

Figura 3.1 - Discretização do tabuleiro de uma ponte $\quad 72$

Figura 3.2 - Carregamento crítico para momento máximo na longarina $\quad 73$

Figura 3.3 - Dimensões das lajes para dimensionamento 83

Figura 3.4 - Seção transversal dividida em fatias na zona comprimida 91

Figura 3.5 - Relação tensão $x$ deformação do concreto à compressão 92

Figura 3.6 - Relações tensão $x$ deformação das armaduras ativa e passiva $\quad 92$

Figura 3.7 - Resultados obtidos para a ponte de 5 vigas, ordem 2 (SA TE V20 TR2) 93

Figura 3.8 - Papel de probabilidade normal $-\mathrm{f}_{\mathrm{ck}}=15 \mathrm{MPa} \quad 99$

Figura 3.9 - Papel de probabilidade lognormal - $\mathrm{f}_{\mathrm{ck}}=15 \mathrm{MPa} \quad 99$

Figura 3.10 - Papel de probabilidade normal - $\mathrm{f}_{\mathrm{ck}}=18 \mathrm{MPa} \quad 99$

Figura 3.11 - Papel de probabilidade lognormal - $\mathrm{f}_{\mathrm{ck}}=18 \mathrm{MPa} \quad 100$

Figura 3.12 - Papel de probabilidade normal $-\mathrm{f}_{\mathrm{ck}}=20 \mathrm{MPa} \quad 101$

Figura 3.13 - Papel de probabilidade lognormal - $\mathrm{f}_{\mathrm{ck}}=20 \mathrm{MPa} \quad 101$

Figura 3.14 - Papel de probabilidade normal - $\mathrm{f}_{\mathrm{ck}}=25 \mathrm{MPa} \quad 101$

Figura 3.15 - Papel de probabilidade normal - $\mathrm{f}_{\mathrm{ck}}=30 \mathrm{MPa} \quad 102$

Figura 3.16 - Papel de probabilidade normal - $\mathrm{f}_{\mathrm{ck}}=35 \mathrm{MPa} \quad 102$

Figura 3.17 - Bias para a resistência à compressão do concreto 102 
Figura 3.18 - Coeficiente de variação para a resistência à compressão do concreto

Figura 3.19 - Bias recomendada para a resistência à compressão do concreto

Figura 3.20 - Coeficiente de variação recomendado para a resistência à compressão do concreto

Figura 3.21 - Relações momento-curvatura para a ponte de 2 vigas, ordem 1 (SA TE V10 TR2)

Figura 4.1 - Ilustração da nomenclatura dos caminhões

Figura 4.2 - Rodotrem com comprimento de até 30m e PBTC de até $740 \mathrm{kN}$

Figura 4.3 - Bitrenzão com comprimento de até 30m e PBTC de até $740 \mathrm{kN}$

Figura 4.4 - Bitrem com comprimento de até 19,80m e PBTC de até 570 kN

Figura 4.5 - Resumo das planilhas de pesagem

Figura 4.6 - Proporção entre os caminhões previamente selecionados 114

Figura 4.7 - Caminhão $2 \mathrm{I} 3$ para $450 \mathrm{kN}$

Figura 4.8 - Caminhão 2S3 curto para 415 kN 116

Figura 4.9 - Caminhão 2S3 longo para $415 \mathrm{kN} \quad 116$

Figura 4.10 - Caminhão $3 S 3$ curto para $450 \mathrm{kN} \quad 116$

Figura 4.11 - Caminhão 3S3 longo para $450 \mathrm{kN} \quad 116$

Figura 4.12 - Caminhão 2S2 para $330 \mathrm{kN} \quad 117$

Figura 4.13 - Bitrem para $570 \mathrm{kN} \quad 117$

Figura 4.14 - Distribuição de peso bruto para o caminhão 3S3 118

Figura 4.15 - Extrapolação para diversos períodos (3S3) 119

Figura 4.16 - Extrapolação segundo Nowak (1999) para o caminhão 3S3 120

Figura 4.17 - Extrapolação para o caminhão 2I3 121

Figura 4.18 - Extrapolação para o caminhão 2S3 curto 121

Figura 4.19 - Extrapolação para o caminhão 2S3 longo 121

Figura 4.20 - Extrapolação para o caminhão 3S3 curto 122

Figura 4.21 - Extrapolação para o caminhão 3S3 longo 122

Figura 4.22 - Extrapolação para o caminhão 2S2 122

Figura 4.23 - Extrapolação para o bitrem 123

Figura 4.24 - Caminhão 3S3 curto 124

Figura 4.25 - Sentido do tráfego e disposição das faixas 127

Figura 4.26 - Resultados do weight-in-motion durante o fechamento e a operação de uma balança fixa

Figura 6.1 - Comparação entre os momentos fletores máximos para 2 carregamentos: $\mathrm{M}_{\text {(caso a) }}>\mathrm{M}_{\text {(caso b) }}$. 151

Figura 6.2 - Representação de um veículo real no software STRAP 152

Figura 6.3 - PBTC para a ponte de 2 vigas SA TE V10 TR2 (concreto armado, classe 45)

Figura 6.4 - PBTC - LAJE - Momento fletor positivo 154

Figura 6.5 - PBTC - LAJE - Momento fletor negativo 154

Figura 6.6 - PBTC - VIGA T - 2 VIGAS - Momento fletor positivo 155

Figura 6.7 - PBTC - VIGA T - 2 VIGAS - Momento fletor negativo 155

Figura 6.8 - PBTC - VIGA T - 5 VIGAS - Momento fletor positivo 155

Figura 6.9 - PBTC - VIGA T - 5 VIGAS - Momento fletor negativo 156

Figura 6.10 - PBTC - SEÇÃO CELULAR - Momento fletor positivo 156

Figura 6.11 - PBTC - SEÇÃO CELULAR - Momento fletor negativo 156

Figura 6.12 - PBTC - LAJE - ELU - Concreto protendido 157

Figura 6.13 - PBTC - VIGA T - 5 VIGAS - ELU - Concreto protendido 158

Figura 6.14 - PBTC - SEÇÃO CELULAR - ELU - Concreto protendido 158 
Figura 6.15 - PBTC - LAJE - ELS - Concreto protendido

Figura 6.16 - PBTC - VIGA T - 5 VIGAS - ELS - Concreto protendido

Figura 6.17 - PBTC - SEÇÃO CELULAR - ELS - Concreto protendido

Figura 6.18 - Limites inferiores das curvas W x B - LAJE

Figura 6.19 - Limites inferiores das curvas W x B - VIGA T - 2 VIGAS

Figura 6.20 - Limites inferiores das curvas W x B - VIGA T - 5 VIGAS (com transversinas)

Figura 6.21 - Limites inferiores das curvas W x B - VIGA T - 5 VIGAS (sem transversinas)

Figura 6.22 - Limites inferiores das curvas W x B - VIGA T - SEÇÃO

Figura 6.23 - Limites inferiores das curvas W x B - LAJE

169

Figura 6.24 - Limites inferiores das curvas W x B - VIGA T - 5 VIGAS (com transversinas)

Figura 6.25 - Limites inferiores das curvas W x B - VIGA T - 5 VIGAS (sem transversinas)

Figura 6.26 - Limites inferiores das curvas W x B - VIGA T - SEÇÃO CELULAR

Figura 6.27 - Limites inferiores das curvas W x B - LAJE

Figura 6.28 - Limites inferiores das curvas W x B - VIGA T - 5 VIGAS (com transversinas)

Figura 6.29 - Limites inferiores das curvas W x B - VIGA T - 5 VIGAS (sem transversinas)

Figura 6.30 - Limites inferiores das curvas W x B - VIGA T - SEÇÃO CELULAR

Figura 6.31 - Casos críticos para o estado limite último

Figura 6.32 - ECPLs para o estado limite último

Figura 6.33 - Casos críticos para o estado limite de serviço 177

Figura 6.34 - ECPLs para o estado limite de serviço 177

Figura 6.35 - Comparação entre equações para o ELU 
Lista de tabelas

Tabela 2.1 - Parâmetros estatísticos da carga permanente 36

Tabela 2.2 - Dados para análise do carregamento movel 42

Tabela 2.3 - Valores de $\mathrm{W}_{0,95} \quad 42$

Tabela 2.4 - Parâmetros para os caminhões em uma faixa de tráfego 46

Tabela 2.5 - Parâmetros para pontes com duas faixas de tráfego 48

Tabela 2.6 - Probabilidade de 2 caminhões na mesma faixa 53

Tabela 2.7 - Parâmetros estatísticos da resistência à compressão do concreto 56

Tabela 2.8 - Parâmetros estatísticos da armadura passiva 56

Tabela 2.9 - Parâmetros estatísticos da armadura de protensão 57

Tabela 2.10 - Parâmetros estatísticos das dimensões 57

Tabela 2.11 - Parâmetros estatísticos da resistência usados por Nowak (1999) 58

Tabela 2.12 - Parâmetros estatísticos da resistência 58

Tabela 2.13 - Parâmetros estatísticos da resistência à flexão 59

Tabela 2.14 - Parâmetros estatísticos da resistência à flexão 59

Tabela 3.1 - Características geométricas dos casos analisados - LAJE 63

Tabela 3.2 - Características geométricas dos casos analisados VIGA T - 2 VIGAS

Tabela 3.3 - Características geométricas dos casos analisados VIGA T - 5 VIGAS

Tabela 3.4 - Características geométricas dos casos analisados $\begin{array}{ll}\text { SEÇÃO CELULAR } & 70\end{array}$

Tabela 3.5 - Resultados da análise estrutural - LAJE 77

Tabela 3.6 - Resultados da análise estrutural - VIGA T - 2 VIGAS 78

Tabela 3.7 - Resultados da análise estrutural - VIGA T - 5 VIGAS 79

Tabela 3.8 - Resultados da análise estrutural - SEÇÃO CELULAR $\quad 79$

Tabela 3.9 - Resumo dos casos selecionados 80

Tabela 3.10 - Coeficientes de ponderação das ações 82

Tabela 3.11 - Resistência característica do concreto à compressão (concreto armado) 82

Tabela 3.12 - Coeficientes para cálculo do ELS 86

Tabela 3.13 - Graus de protensão e estados limites a verificar 87

Tabela 3.14 - $\mathrm{f}_{\text {ck }}$ para as pontes de concreto protendido em MPa 87

Tabela 3.15 - Seção transversal das pontes em 5 vigas 91

Tabela 3.16 - Momento fletor resistente nominal (kN.m) - LAJE 93

Tabela 3.17 - Momento fletor resistente nominal (kN.m) - VIGA T - 2 VIGAS 94

Tabela 3.18 - Momento fletor resistente nominal (kN.m) - VIGA T - 5 VIGAS 94

Tabela 3.19 - Momento fletor resistente nominal (kN.m) - SEÇÃO CELULAR 95

Tabela 3.20 - Momento fletor resistente nominal (kN.m) - LAJE 95

Tabela 3.21 - Momento fletor resistente nominal (kN.m) - VIGA T - 5 VIGAS 95

Tabela 3.22 - Momento fletor resistente nominal (kN.m) - SEÇÃO CELULAR 96

Tabela 3.23 - Números de amostras rompidas aos 28 dias 98

Tabela 3.24 - Parâmetros estatísticos da armadura 105

Tabela 3.25 - Parâmetros estatísticos da seção transversal da viga 105

Tabela 3.26 - Resumo dos parâmetros estatísticos para simulação 106

Tabela 3.27 - Bias e coeficiente de variação - LAJE 107 
Tabela 3.28 - Bias e coeficiente de variação - VIGA T - 2 VIGAS 108

Tabela 3.29 - Bias e coeficiente de variação - VIGA T - 5 VIGAS 108

Tabela 3.30 - Bias e coeficiente de variação - SEÇÃO CELULAR 109

Tabela 3.31 - Bias e coeficiente de variação - LAJE 109

Tabela 3.32 - Bias e coeficiente de variação - VIGA T - 5 VIGAS 109

Tabela 3.33 - Bias e coeficiente de variação - SEÇÃO CELULAR 110

Tabela 3.34 - Parâmetros estatísticos do fator de análise 110

Tabela 4.1 - Estimação dos máximos pesos brutos (kN). 123

Tabela 4.2 - Probabilidades de ocorrência simultânea 126

Tabela 4.3 - Momento fletor devido ao caminhão principal em relação ao momento fletor causado por um caminhão isolado 126

Tabela 4.4 - Probabilidades de ocorrência simultânea adotadas 127

Tabela 4.5 - Peso por eixo $(\mathrm{kN})$ e coeficiente de variação dos caminhões para análise de presença simultânea $\quad 128$

Tabela 4.6 - Bias para momento positivo - LAJE 131

Tabela 4.7 - Bias para momento positivo - VIGA T - 2 VIGAS 131

Tabela 4.8 - Bias para momento positivo - VIGA T - 5 VIGAS 132

Tabela 4.9 - Bias para momento positivo - CELULAR 132

Tabela 5.1 - Índices de confiabilidade - LAJE $\quad 141$

Tabela 5.2 - Índices de confiabilidade - VIGA T - 2 VIGAS 142

Tabela 5.3 - Índices de confiabilidade - VIGA T - 5 VIGAS 142

Tabela 5.4 - Índices de confiabilidade - CELULAR 143

Tabela 5.5 - Índices de confiabilidade - LAJE. 144

Tabela 5.6 - Índices de confiabilidade - VIGA T - 5 VIGAS 144

Tabela 5.7 - Índices de confiabilidade - CELULAR 144

Tabela 5.8 - Índices de confiabilidade - LAJE. 147

Tabela 5.9 - Índices de confiabilidade - VIGA T - 5 VIGAS 147

Tabela 5.10 - Índices de confiabilidade - CELULAR 147

Tabela 6.1 - Configurações de eixos para verificação 161

Tabela 6.2 - Comparação entre o caminhão real e a representação adotada momento fletor positivo

Tabela 6.3 - Comparação entre o caminhão real e a representação adotada momento fletor negativo 165

Tabela 6.4 - Relações entre índices de confiabilidade e probabilidades de falha $\quad 174$

Tabela 6.5 - Índices de confiabilidade $x$ probabilidades de falha 175

Tabela 6.6 - Pesos brutos provenientes das ECPLs para o ELU 176

Tabela 6.7 - Pesos brutos provenientes das ECPLs para o ELS 178

Tabela 6.8 - Situação de alguns veículos de acordo com o ELU $\quad 179$

Tabela 6.9 - Situação de alguns veículos de acordo com o ELS 180 
AASHTO American Association of State Highway and Transportation Officials ABNT Associação Brasileira de Normas Técnicas

AET Autorização Especial de Trânsito

CA Concreto armado

CEB Comitê Euro-International du Beton

CONTRAN Conselho Nacional de Trânsito

CP Concreto protendido

CTR Com transversinas

CV Coeficiente de variação

CVC Combinação de Veículos de Carga

DER Departamento de Estradas de Rodagem

ECPL Equação comprimento-peso limite

EESC Escola de Engenharia de São Carlos

ELF Estado limite de fadiga

ELS Estado limite de serviço

ELU Estado limite último

FORM First Order Reliability Method

LFD Load Factor Design

LRFD Load and Resistance Factor Design

M. Momento fletor negativo

$\mathrm{M}_{+} \quad$ Momento fletor positivo

MC Maciça

OHBDC Ontario Highway Bridge Design Code

PBTC Peso bruto total combinado

SORM Second Order Relibility Method

STR Sem transversinas

STRAP Structural Analysis Programs

TE Tabuleiro estreito

TL Tabuleiro largo

TRB Transportation Research Board

VZ Vazada 


\section{INTRODUÇÃO}

1.1 Considerações iniciais

1.2 Objetivos

1.3 Justificativas

1.4 Metodologia

1.5 Organização do texto

2 REVISÃO BIBLIOGRÁFICA 8

2.1 Histórico da bridge formula 8

$\begin{array}{lr}2.2 \text { Teoria da confiabilidade } & 13\end{array}$

$\begin{array}{ll}\text { 2.2.1 Introdução } & 13\end{array}$

2.2.2 Confiabilidade de elementos estruturais $\quad 14$

2.2.3 Técnicas de simulação 20

2.2.3.1 Método de Monte Carlo 20

2.2.3.2 Amostragem por hipercubo latino (latin hypercube) 21

2.2.3.3 Método de Rosenblueth $(2 \mathrm{~K}+1)$

2.2.4 Análise de sensibilidade $\quad 22$

2.2.5 Confiabilidade dos sistemas estruturais das pontes 23

2.2.5.1 Sistemas em série $\quad 24$

2.2.5.2 Sistemas em paralelo $\quad 25$

2.2.5.3 Geração dos modos de falha 26

2.2.5.4 Método da superfície de resposta 27

2.2.5.5 Redundância nas superestruturas de pontes $\quad 27$

2.3 Determinação do $\beta$ desejável ( $\beta_{\text {alvo }}$ ) para elementos individuais 30

2.4 Carga permanente $\quad 34$

2.5 Carga móvel 36

2.5.1 O modelo de Nowak e Lind (1979) 37

2.5.2 O modelo de Ghosn e Moses (1985) 38

2.5.3 O modelo de Moses e Ghosn (1985) 39

2.5.4 O modelo de Nowak (1999) 43

2.5.4.1 Momentos fletores e forças cortantes em pontes com 1
faixa de tráfego

2.5.4.2 Momentos fletores e forças cortantes em pontes com 2
faixas de tráfego

2.5.5 O modelo de Crespo-Minguillón e Casas (1997) 51

2.5.6 O modelo de Hwang e Koh (2000) 52

2.6 Resistência das seções transversais $\quad 54$

3 RESISTÊNCIA DOS ELEMENTOS ESTRUTURAIS 60

$\begin{array}{ll}3.1 \text { Pontes típicas consideradas } & 60\end{array}$

$\begin{array}{ll}3.2 \text { Software utilizado para análise estrutural } & 71\end{array}$

$\begin{array}{ll}3.3 \text { Aspectos da modelagem } & 73\end{array}$

$\begin{array}{ll}3.3 .1 \text { Laje } & 73\end{array}$

$\begin{array}{ll}\text { 3.3.2 Viga T } & 74\end{array}$

3.3.3 Seção celular $\quad 74$

$\begin{array}{ll}3.4 \text { Ações consideradas no dimensionamento } & 75\end{array}$ 
$\begin{array}{ll}3.5 \text { Esforços solicitantes } & 76\end{array}$

3.6 Dimensionamento da área de aço longitudinal 80

$\begin{array}{ll}\text { 3.6.1 Concreto armado } & 80\end{array}$

3.6.2 Concreto protendido $\quad 85$

$\begin{array}{ll}3.7 \text { Resultados do dimensionamento } & 89\end{array}$

$\begin{array}{lr}\text { 3.7.1 Concreto armado } & 90\end{array}$

3.7.2 Concreto protendido 90

$\begin{array}{ll}3.8 \text { Momento fletor resistente nominal } & 91\end{array}$

$\begin{array}{ll}3.8 .1 \text { Procedimento de cálculo } & 91\end{array}$

3.8.2 Resultados $\quad 92$

3.8.2.1 Concreto armado $\quad 92$

3.8.2.2 Concreto protendido $\quad 95$

3.9 Implementação da técnica de Monte Carlo 96

3.9.1 Parâmetros estatísticos das propriedades dos materiais e das dimensões 96

3.9.1.1 Parâmetros estatísticos da resistência à compressão do concreto 97

3.9.1.2 Parâmetros estatísticos das armaduras passiva e ativa $\quad 104$

3.9.1.3 Parâmetros estatísticos das dimensões da seção transversal 105

3.9.1.4 Síntese dos parâmetros estatísticos dos materiais e das dimensões 105

3.9.2 Momento fletor resistente médio 106

3.9.2.1 Concreto armado 107

$\begin{array}{ll}\text { 3.9.2.2 Concreto protendido } & 109\end{array}$

3.9.3 Parâmetros estatísticos do fator de análise 110

4 CARREGAMENTO MÓVEL 111

$\begin{array}{ll}4.1 \text { Descrição dos dados } & 111\end{array}$

$\begin{array}{ll}4.2 \text { Planilhas de pesagem } & 111\end{array}$

$\begin{array}{ll}4.3 \text { Caminhões típicos } & 115\end{array}$

4.3.1 Distâncias entre eixos 115

4.3.2 Extrapolação dos máximos pesos brutos 117

$\begin{array}{ll}4.4 \text { Situações críticas de carregamento } & 124\end{array}$

4.4.1 Caminhão isolado 124

4.4.2 Presença simultânea de 2 caminhões $\quad 125$

4.4.3 Presença simultânea de 3 ou mais caminhões $\quad 129$

$\begin{array}{ll}4.5 \text { Momentos fletores máximos } & 130\end{array}$

$\begin{array}{ll}4.6 \text { Simulação real do tráfego } & 133\end{array}$

4.7 Limitações do modelo proposto 134

5 ANÁLISE DE CONFIABILIDADE 137

$\begin{array}{ll}5.1 \text { Determinação da segurança } & 137\end{array}$

$\begin{array}{ll}\text { 5.1.1 Procedimento de cálculo } & 137\end{array}$

$\begin{array}{ll}\text { 5.1.2 Combinação de carregamentos } & 139\end{array}$

$\begin{array}{ll}5.1 .3 \text { Índices de confiabilidade } & 140\end{array}$

$\begin{array}{ll}\text { 5.1.3.1 Concreto armado } & 140\end{array}$

5.1.3.2 Concreto protendido 143

$\begin{array}{ll}5.2 \text { Momentos fletores limites } & 148\end{array}$

6 OBTENÇÃO DAS ECPLs 149 
$\begin{array}{ll}\text { 6.1 Requisitos necessários para a equação } & 149\end{array}$

6.2 Representação de um veículo para as ECPLs 150

6.3 Procedimento de cálculo 151

6.4 Curvas W versus B 152

6.4.1 Concreto armado (CA), classe $45 \quad 154$

6.4.2 Concreto protendido (CP), classe $45 \quad 157$

6.4.2.1 Estado limite último, classe 45

6.4.2.2 Estado limite de formação de fissuras, classe $45 \quad 158$

$\begin{array}{ll}\text { 6.5 Carregamento distribuído } \mathrm{x} \text { veículos reais } & 160\end{array}$

$\begin{array}{ll}6.6 \text { Resumo das curvas W x B } & 166\end{array}$

$\begin{array}{ll}\text { 6.6.1 Concreto armado } & 167\end{array}$

6.6.2 Concreto protendido 169

6.6.2.1 Estado limite último 169

6.6.2.2 Estado limite de formação de fissuras $\quad 171$

$\begin{array}{ll}6.7 \text { Fixação de } \beta_{\text {alvo }} & 172 \\ & 173\end{array}$

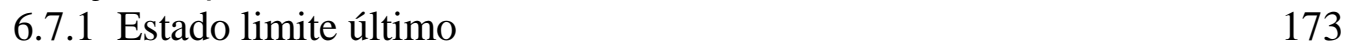

$\begin{array}{ll}\text { 6.7.2 Estado limite de serviço } & 174\end{array}$

$\begin{array}{ll}6.8 \text { Equações propostas } & 174\end{array}$

6.8.1 Estado limite último 175

6.8.2 Estado limite de serviço 177

$\begin{array}{ll}6.9 \text { Emprego das ECPLs } & 178\end{array}$

7 CONSIDERAÇÕES FINAIS E CONCLUSÕES 181

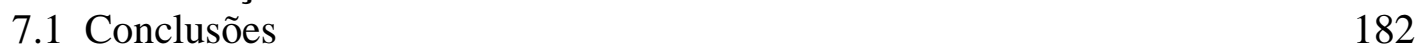

$\begin{array}{ll}7.2 \text { Sugestões para futuras pesquisas } & 183\end{array}$

$\begin{array}{ll}\text { REFERÊNCIAS BIBLIOGRÁFICAS } & 185\end{array}$

$\begin{array}{lr}\text { BIBLIOGRAFIA COMPLEMENTAR } & 190\end{array}$

APÊNDICE A - Pesagem de veículos: Autoban, Autovias e Rodonorte 193

APÊNDICE B - Alterações no modelo de carregamento móvel 202

APÊNDICE C - Presença simultânea de 3 veículos 206

APÊNDICE D - ECPLs para a passagem de veículo isolado 214

$\begin{array}{ll}\text { APÊNDICE E - Tabelas complementares } & 219\end{array}$ 


\subsection{Considerações iniciais}

Atualmente, é notável o crescente uso de processos probabilísticos na quantificação da segurança em diversos tipos de estruturas. Motivada pela busca por projetos otimizados, em que se tenham medidas mais realistas do grau de segurança, a utilização da teoria da confiabilidade vem se tornando uma aliada poderosa para os engenheiros estruturais.

Uma das áreas que desperta para essa nova realidade é a engenharia de pontes. De um lado, as transportadoras têm interesse na circulação de composições cada vez mais pesadas nas rodovias nacionais. Por outro lado, os órgãos responsáveis pela administração da infra-estrutura viária precisam se prevenir contra eventuais danos que as estruturas das pontes já construídas venham a sofrer devido à circulação de tais composições. A falta de manutenção adequada e o conseqüente estado de deterioração das obras de arte são agravantes nesse cenário. Portanto, torna-se necessário adotar critérios eficientes e confiáveis para a determinação da real capacidade portante dessas estruturas.

É importante salientar que não existe estrutura totalmente segura: incertezas que estão além do controle dos projetistas fazem com que exista um risco inerente. De acordo com Moses (1999), o objetivo das prescrições estabelecidas em normas não é garantir segurança absoluta, e sim atingir um nível de risco aceitável, consistente com as necessidades econômicas e de segurança pública.

No Brasil, os limites máximos de peso relacionados a veículos de carga são determinados através de resoluções do Conselho Nacional de Trânsito (CONTRAN). Em 1998, a resolução $\mathrm{n}^{\circ} 12$ estipulava o limite de $450 \mathrm{kN}$ para o peso bruto total, 100 
kN para eixos isolados e 85 kN/eixo para eixos em tandem. No entanto, a circulação de Combinações de Veículos de Carga (CVCs) de até $740 \mathrm{kN}$ era permitida através de Autorização Especial de Trânsito (AET) de acordo com a resolução n ${ }^{\circ}$ 68. Destaca-se que a origem de tais limites de peso não provém de uma análise da segurança efetiva das pontes nacionais. Há que se considerar ainda que os limites impostos pela legislação são reconhecidamente ultrapassados por boa parte dos caminhões.

Sob requerimento do Departamento de Estradas de Rodagem do Estado de São Paulo (DER-SP), o Departamento de Estruturas da Escola de Engenharia de São Carlos (EESC-USP) realizou um relatório técnico intitulado “Análise das consequências do tráfego de CVCs (Combinações de Veículos de Carga) sobre as obras de arte especiais da rede viária do DER-SP” (EL DEBS et al., 2001). O objetivo era comparar os esforços solicitantes provenientes das CVCs e os esforços obtidos através dos veículos normativos das classes 24, 36 e 45 sobre os sistemas estruturais mais comuns existentes nas rodovias do estado de São Paulo. O resultado desse trabalho indicou restrições ao tráfego de tais composições e serviu como referência na elaboração de normas para emissão de AET, conforme Portaria SUP/DER-036 de12/04/2002.

Posteriormente, outros dois trabalhos foram desenvolvidos baseados na comparação de esforços solicitantes. O primeiro tinha o objetivo de determinar o máximo peso bruto total de uma determinada composição de 9 eixos e 19,8 metros tendo em vista a segurança das mesmas obras de arte especiais (EL DEBS et al., 2003a). O segundo verificou as consequências do tráfego de uma composição com comprimento de 20,43 metros, 8 eixos e peso de $655 \mathrm{kN}$ sobre as obras de arte especiais do anel de integração do Paraná (EL DEBS et al., 2003b). Apesar da análise não incluir métodos probabilísticos, ressalta-se a importância do tema. Nesse contexto, destaca-se a necessidade de um procedimento que possa ser aplicado de maneira mais geral, sem a análise estrutural de diversas pontes para cada caminhão individualmente.

Em 21/10/2005, o CONTRAN aprovou a resolução $n^{\circ} 184$, que eleva o peso bruto das Combinações de Veículos de Carga com duas ou mais unidades, incluída a unidade tratora, de $450 \mathrm{kN}$ para $570 \mathrm{kN}$, dispensando assim a necessidade de AET para essas composições e ratificando decisão já prevista na resolução nº 164 de 10/09/2004. Determina-se ainda que as CVCs com peso bruto total combinado (PBTC) superior a $570 \mathrm{kN}$ e inferior ou igual a $740 \mathrm{kN}$ deverão ter comprimento igual ou superior a 25 metros, não podendo ultrapassar a 30 metros. Nota-se, dessa forma, uma preocupação 
com a integridade estrutural das obras de arte.

Nos Estados Unidos, de acordo com a legislação federal o máximo peso permitido para caminhões é $356 \mathrm{kN}$. Os eixos simples devem ser limitados a $89 \mathrm{kN}$ e os eixos tandem a 151 kN. Além disso, a legislação impõe que o peso de um grupo de dois ou mais eixos consecutivos seja restringido através da chamada bridge formula ${ }^{1}$ ou truck weight formula:

$\mathrm{W}=2,224 \cdot\left[\frac{\mathrm{B} \cdot \mathrm{N}}{0,3048 \cdot(\mathrm{N}-1)}+12 \cdot \mathrm{N}+36\right]$

onde:

$\mathrm{W}$ : peso bruto total em $\mathrm{kN}$ para qualquer grupo de dois ou mais eixos consecutivos;

B: comprimento, em metros, do grupo de eixos consecutivos;

$\mathrm{N}$ : número de eixos do grupo em questão.

Embora a equação (1.1) seja considerada excessivamente restritiva, a maneira como determina o máximo peso em função da distância entre o grupo de eixos é bastante conveniente e de fácil uso. Utilizando sua idéia original e introduzindo processos probabilísticos é possível aprimorá-la, tornando-a capaz de fornecer de maneira realista o máximo carregamento a que as pontes existentes podem estar sujeitas de maneira segura. Esse procedimento é sugerido por Ghosn (2000), que desenvolve uma bridge formula através da teoria da confiabilidade baseando-se no desempenho de pontes existentes sob condições reais de tráfego.

\subsection{Objetivos}

O objetivo principal deste trabalho é propor limites para o peso de caminhões em pontes de concreto armado ou protendido, classes 36 e 45, através da teoria da confiabilidade. As equações desenvolvidas, aplicáveis a qualquer grupo de eixos consecutivos, podem contribuir de maneira prática na decisão de autorizar ou não que certas configurações de CVCs, especialmente curtas e pesadas, trafeguem em

\footnotetext{
${ }^{1}$ A palavra bridge refere-se à configuração interna do veículo, e não à estrutura da ponte.
} 
determinados trechos da malha rodoviária brasileira. Neste trabalho, essas equações serão denominadas ECPLs (equações comprimento-peso limite).

Visando ao alcance dessa meta, várias etapas intermediárias foram desenvolvidas, caracterizando-se como objetivos específicos. São eles:

$\checkmark$ Obtenção e análise dos parâmetros estatísticos da resistência à compressão do concreto para várias classes de $\mathrm{f}_{\mathrm{ck}}$, com base em resultados de ensaios de corposde-prova cilíndricos;

$\checkmark$ Determinação dos parâmetros estatísticos da resistência à flexão de seções transversais mais solicitadas por momento fletor positivo e negativo;

$\checkmark$ Desenvolvimento de um modelo de carregamento móvel a partir de pesagens de veículos de carga em rodovias concedidas à iniciativa privada, de modo a prever a máxima solicitação a que as pontes estão sujeitas ao longo de sua vida útil. Compara-se o modelo proposto e o carregamento normativo brasileiro, de modo a verificar como os critérios atuais de projeto refletem as condições reais de tráfego;

$\checkmark$ Quantificação da segurança em seções transversais submetidas à representação do tráfego real por intermédio do índice de confiabilidade $\beta$.

\subsection{Justificativas}

A pesquisa proposta tem interesse prático, haja visto que o tráfego de caminhões com peso bruto total superior ao peso dos veículos normativos estipulados na NBR7188 (1984) pode colocar em risco a segurança estrutural das pontes existentes. Os resultados dos relatórios técnicos elaborados por El Debs et al. (2001, 2003a, 2003b) confirmam essa possibilidade e comprovam a atualidade do tema proposto. São necessários então estudos que auxiliem na missão de disciplinar a circulação de veículos pesados e colaborar na política de restrições ao tráfego.

Um outro aspecto a ser destacado é o fato de que apenas a consideração do peso bruto se demonstra incapaz de fornecer indicações da segurança de uma obra de arte. A relação entre peso bruto e comprimento de aplicação do carregamento é fundamental para uma correta interpretação do problema. Por exemplo, um caminhão de 740 kN pode danificar ou não uma estrutura, dependendo do seu comprimento e da disposição das suas cargas. Quanto mais concentradas as ações, maior o risco. A definição da 
relação comprimento/peso bruto admissível é exatamente a função das ECPLs.

Por outro lado, a aplicação da teoria da confiabilidade em diversas áreas da engenharia tem se mostrado como uma tendência mundial. Inclusive, diversas normas internacionais sobre estruturas já norteiam suas prescrições baseadas nesse tipo de análise. Ghosn (2000) ainda salienta que um procedimento mais racional para se obter a real capacidade portante das pontes deve ser baseado na teoria da confiabilidade.

Nota-se, portanto, que a ligação entre ECPL e confiabilidade pode render resultados confiáveis e de fácil implementação no meio técnico.

\subsection{Metodologia}

O trabalho se inicia através da seleção de pontes típicas, que devem representar a infra-estrutura existente. Nesse aspecto, o Departamento de Estruturas da Escola de Engenharia de São Carlos dispõem de um levantamento das obras de arte da malha viária, com base em material disponibilizado pelo DER-SP, utilizado em El Debs et al. (2001, 2003a, 2003b). Contemplam-se pontes em laje, pontes em 2 vigas, pontes em 5 vigas e pontes em seção celular. A análise estrutural se dá através do software comercial STRAP (Structural Analysis Programs) - versão 9.0.

As seções transversais a serem utilizadas na determinação da segurança são dimensionadas à flexão para as classes 36 e 45. Devido a mudanças nas normas brasileiras ao longo dos anos, vários períodos são considerados, tanto para concreto armado quanto para protendido. A cada período correspondem específicos coeficientes de segurança e hipóteses de cálculo. Consideram-se também valores representativos da resistência característica do concreto à compressão em cada período.

As incertezas na determinação da resistência em cada seção transversal de interesse são consideradas através de simulações numéricas, uma vez que não se têm dados suficientes sobre provas-de-carga. Utiliza-se a técnica de Monte Carlo para o cálculo dos valores médios e dos coeficientes de variação da resistência à flexão. Para períodos recentes, os parâmetros estatísticos da resistência à compressão do concreto foram determinados a partir dos resultados de ensaios fornecidos pelo setor produtivo e da utilização de papéis de probabilidade. Para pontes mais antigas, foi utilizado o modelo da NB-1 (1978).

Desenvolve-se um modelo de carregamento móvel com base em pesagens de 
caminhões efetuadas pela Centrovias Sistemas Rodoviários S/A nas rodovias SP-310 e SP-225. Os máximos pesos brutos são extrapolados para o período de vida útil das estruturas através do uso do papel de probabilidade normal. Consideram-se os efeitos de 1 ou 2 caminhões sobre as pontes. As probabilidades de presença simultânea foram obtidas através da literatura disponível. O procedimento, elaborado durante estágio de 6 meses na University of Michigan, Estados Unidos, admite caminhões em fila, caminhões lado a lado e diferentes proporções entre seus pesos. Pontes de tabuleiro estreito e tabuleiro largo também são diferenciadas.

A segurança, medida em termos do índice de confiabilidade $\beta$, é calculada através do método de Rackwitz-Fiessler. Em todas as pontes verifica-se o estado limite último. Nas pontes de concreto protendido, acrescenta-se o estado limite de formação de fissuras.

A análise dos resultados permite a fixação de um índice de confiabilidade desejável, entendido como o valor mínimo que o efeito dos caminhões considerados seguros devem respeitar em todas as obras de arte.

Nesse contexto, a ECPL representa uma envoltória admissível para as relações entre peso bruto e comprimento do grupo de eixos, de modo a garantir que o índice de confiabilidade seja sempre maior ou igual ao desejável.

\subsection{Organização do texto}

Divide-se o conteúdo do trabalho em 7 capítulos e 5 apêndices.

O segundo capítulo contém a revisão bibliográfica sobre assuntos ligados à tese e fornece subsídios para seu desenvolvimento.

A análise da resistência dos elementos estruturais, desde a seleção de pontes típicas até a obtenção de seus parâmetros estatísticos, está no capítulo 3.

O estudo do modelo de carregamento móvel é descrito no capítulo 4.

No capítulo 5 é realizada a análise de confiabilidade.

As equações recomendadas, os passos para sua obtenção, a fixação dos índices de confiabilidade desejáveis e a verificação de alguns caminhões típicos são mostrados no capítulo 6.

O capítulo 7 contém a discussão e as conclusões do trabalho, assim como recomendações para futuros estudos. 
O apêndice A compara os dados sobre pesagem de caminhões provenientes da Centrovias com os fornecidos por outras concessionárias: Autoban, Autovias e Rodonorte. Afere-se assim, a aplicabilidade do modelo de carregamento móvel proposto para outras regiões de circulação. O efeito que alterações no modelo de carregamento móvel (substituição do caminhão principal e modificação das probabilidades de presença simultânea) promovem nos índices de confiabilidade em algumas pontes é tratado sucintamente no apêndice B. O acréscimo de um terceiro veículo de carga sobre a ponte e suas implicações em termos de segurança e nas ECPLs é descrito no apêndice C. O apêndice D mostra quais seriam as equações obtidas caso se garanta que apenas 1 caminhão passará sobre a ponte por vez. Esse caso pode ser de interesse na análise do tráfego de veículos especiais. O apêndice E compreende as tabelas complementares dos diversos capítulos. 
Este capítulo apresenta tópicos relacionados à segurança de pontes sob o ponto de vista da teoria da confiabilidade. Inicia-se com um histórico da legislação americana e uma breve revisão sobre a teoria da confiabilidade, inclusive com a discussão do grau de confiabilidade necessário. Em seguida, estudam-se as variáveis aleatórias envolvidas: carga permanente, carga móvel e a resistência dos elementos estruturais.

\subsection{Histórico da bridge formula}

De acordo com Noel et al. (1986), a primeira legislação federal dos Estados Unidos a respeito do peso de caminhões estava contida no Federal Aid Highway Act de 1956. Esse documento estipulava que nenhum recurso seria fornecido para o Sistema Interestadual de rodovias em estados que permitissem a circulação de veículos com pesos superiores a 80,06 kN para eixos simples, $142,3 \mathrm{kN}$ para eixos tandem e 325,9 kN para o peso bruto total.

Em 1964, o Highway Research Board preparou e enviou ao Congresso o House Document 354, contendo um estudo detalhado sobre a indústria de transportes e as regulamentações relativas à operação de caminhões pesados. Além disso, reconhecia o grande capital investido nesses caminhões e sua importância para o comércio do país. A recomendação mais importante constante nesse documento foi a Table $B$, uma tabulação de pesos admissíveis para grupos de eixos, dependendo do número de eixos e do comprimento total do grupo de eixos em questão, a ser adotada para o Sistema Interestadual. Outra sugestão foi o aumento do limite de peso dos eixos simples para $88,96 \mathrm{kN}$ e dos eixos tandem para $151,2 \mathrm{kN}$.

Apenas em 1975 o Congresso Americano atendeu a essas recomendações, ao 
mesmo tempo em que autorizou o aumento do peso bruto total do veículo para $356 \mathrm{kN}$. Acredita-se que o propósito foi restabelecer a perda de produtividade da indústria com a imposição do limite de velocidade de 88,5 km/h em dezembro de 1973.

A legislação mais recente sobre o assunto é a Surface Transportation Assistance Act, de 1982, que mantém os limites de peso estabelecidos em 1975 e determina que o peso de grupos de eixos consecutivos seja regulado através da bridge formula (v. equação 1.1). Cabe destacar que a equação (1.1) é a mesma que deu origem aos valores estipulados na Table B.

O objetivo era evitar acréscimo superior a 5\% na tensão admissível de projeto para pontes projetadas com o veículo HS-20 (critério utilizado nas rodovias interestaduais) e a 30\% nas pontes projetadas com o veículo H-15 (utilizado principalmente em rodovias secundárias, sujeitas a baixo tráfego de caminhões pesados). De acordo com Ghosn (2000), essa equação é considerada bastante conservadora, pois algumas localidades (a província de Ontário e o estado de Michigan, entre outras) permitem cargas superiores às fornecidas pela equação (1.1) para pontes projetadas de acordo com os mesmos procedimentos (AASHTO, 1996) e essas estruturas não vêm apresentando problemas estruturais, nem mesmo deterioração acentuada.

Entre as críticas cabíveis à bridge formula, James et al. (1986) citam:

a) Caso o limite de $356 \mathrm{kN}$ para o peso bruto total do veículo seja removido ou aumentado, a equação (1.1) não proporciona segurança às pontes HS-20. Ou seja, a bridge formula oficial não foi desenvolvida para $\mathrm{W}>356 \mathrm{kN}$. Ressalta-se que esse limite é “aparentemente arbitrário”, ainda de acordo com James et al. (1986);

b) Alguns veículos curtos de múltiplos eixos que respeitam a equação (1.1) podem causar acréscimos de tensão consideravelmente maiores que 30\% nas pontes H-15. Esse fato é alertado apenas através de uma nota de rodapé no House Document 354;

c) Apesar do peso por eixo diminuir quando o número de eixos aumenta, mantendo-se constante o peso e o comprimento do veículo, os momentos fletores em pontes de viga podem ser superiores. Trata-se, portanto, de uma inconsistência da formulação.

Buscando corrigir essas deficiências, James et al. (1986) propõe uma nova equação, conhecida como TTI formula: 


$$
\begin{array}{ll}
\mathrm{W}=(34+3,28 \cdot \mathrm{B}) \cdot 4,448 & \text { para } \mathrm{B} \leq 17 \mathrm{~m} \\
\mathrm{~W}=(62+1,64 \cdot \mathrm{B}) \cdot 4,448 & \text { para } \mathrm{B}>17 \mathrm{~m}
\end{array}
$$

De acordo com Moses e Ghosn (1987) e Ghosn (2000), a TTI formula é mais eficaz ao satisfazer os mesmos acréscimos de tensão convencionados anteriormente. Vale salientar que James et al. (1986) não consideraram nenhuma eventual deterioração devido à idade das pontes e mantém os limites de peso para eixos simples e tandem estipulados pela legislação (limites estes estabelecidos tendo-se em vista critérios de desgaste do pavimento e que não dizem respeito à segurança estrutural das pontes). Mesmo assim, os autores prevêem um aumento na deterioração do pavimento das pontes caso sua proposta fosse colocada em prática.

Considerando apenas as pontes HS-20 (ignoram-se as pontes $\mathrm{H}-15$, que possuem menor capacidade, permitindo-se portanto caminhões mais pesados), James et al. (1986) ainda propõe uma terceira fórmula, posteriormente adotada pelo TRB (1990):

$$
\begin{array}{ll}
\mathrm{W}=(26+6,55 \cdot \mathrm{B}) \cdot 4,448 & \text { para } \mathrm{B} \leq 7 \mathrm{~m} \\
\mathrm{~W}=(62+1,64 \cdot \mathrm{B}) \cdot 4,448 & \text { para } \mathrm{B}>7 \mathrm{~m}
\end{array}
$$

O estudo desenvolvido pelo TRB (1990), que reuniu especialistas de diversas áreas ligadas ao transporte rodoviário e cujo objetivo era analisar propostas de mudanças nas leis que restringiam o peso de caminhões, também propôs programas especiais para a circulação de caminhões com peso bruto total acima de 356 kN e até 9 eixos que satisfizessem a equação (1.1). Esses programas seriam recomendados somente se acompanhados de taxas que cobrissem os custos públicos adicionais resultantes do uso desses caminhões pesados e de medidas para garantia da segurança.

Uma comparação entre a bridge formula oficial (Table B), a TTI formula e a equação proposta pelo TRB pode ser vista na figura 2.1. 


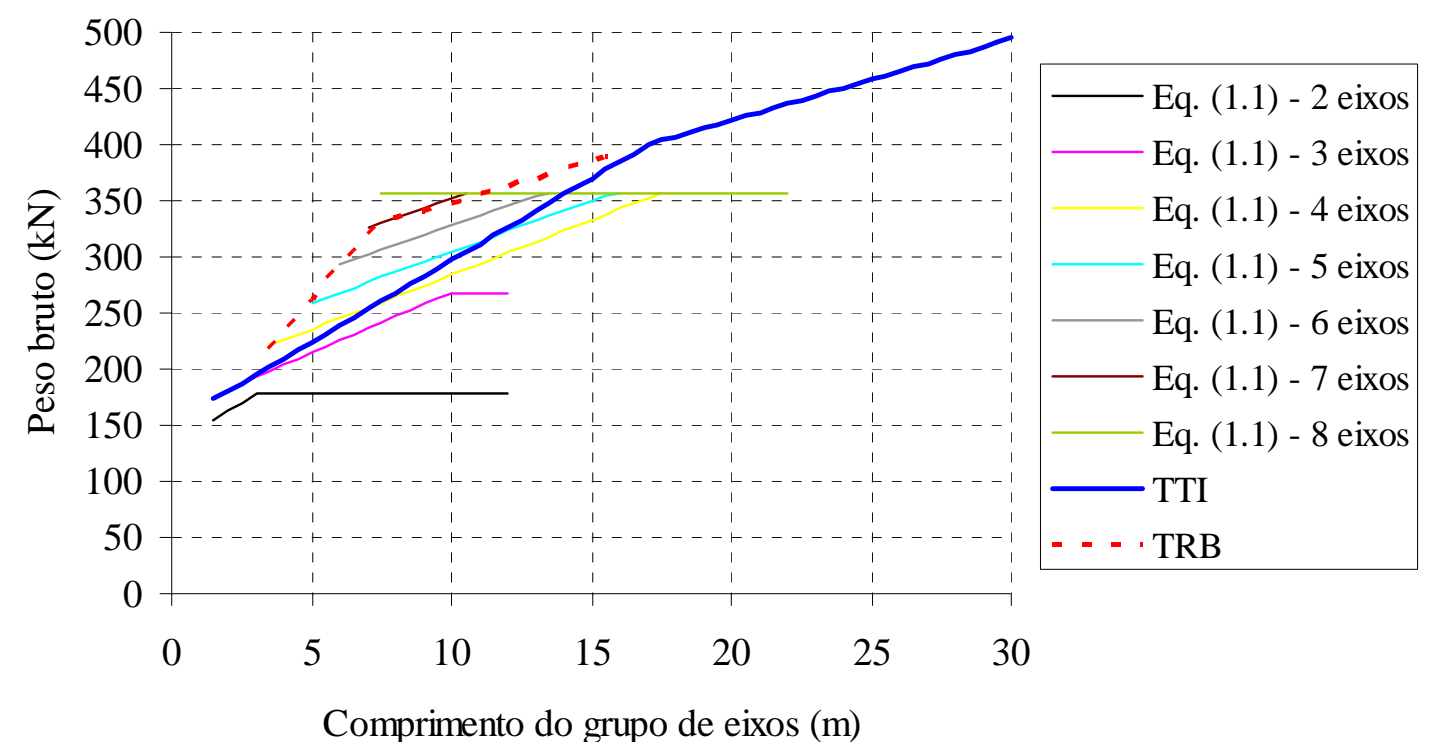

Figura 2.1 - Comparação entre a bridge formula oficial (para vários $N$ ), a TTI formula e a equação do TRB.

Analisando-se a figura 2.1, nota-se que a TTI formula é mais restritiva que a bridge formula oficial para grupos com mais de 4 eixos e comprimentos curtos, conforme objetivo proposto por seus autores. Outra observação é que a equação proposta pelo TRB (1990) é bastante permissiva em relação às demais, embora continue sendo recomendado o limite de $356 \mathrm{kN}$ para o peso bruto total (caminhões mais pesados necessitariam de permissão especial).

No entanto, a origem dos percentuais de acréscimo de tensão permitidos (5\% e 30\%) não está bem documentada; parecem ser arbitrários, sem que haja uma justificativa coerente para os valores adotados. Ghosn (2000) indica a aplicação da teoria da confiabilidade para a obtenção de resultados mais racionais, considerando-se as condições reais de tráfego (probabilidade de presença simultânea de veículos nas pontes e sua posição relativa) e as resistências efetivas dos elementos estruturais. Dessa forma, Ghosn et al. (1995) e Ghosn (2000) obtém:

$$
\begin{array}{ll}
\mathrm{W}=(30+5,38 \cdot \mathrm{B}) \cdot 4,448 & \text { para } \mathrm{B} \leq 15 \mathrm{~m} \\
\mathrm{~W}=(72+2,62 \cdot \mathrm{B}) \cdot 4,448 & \text { para } \mathrm{B}>15 \mathrm{~m}
\end{array}
$$

Na figura 2.2 comparam-se as equações (2.1), (2.2) e (2.3). 


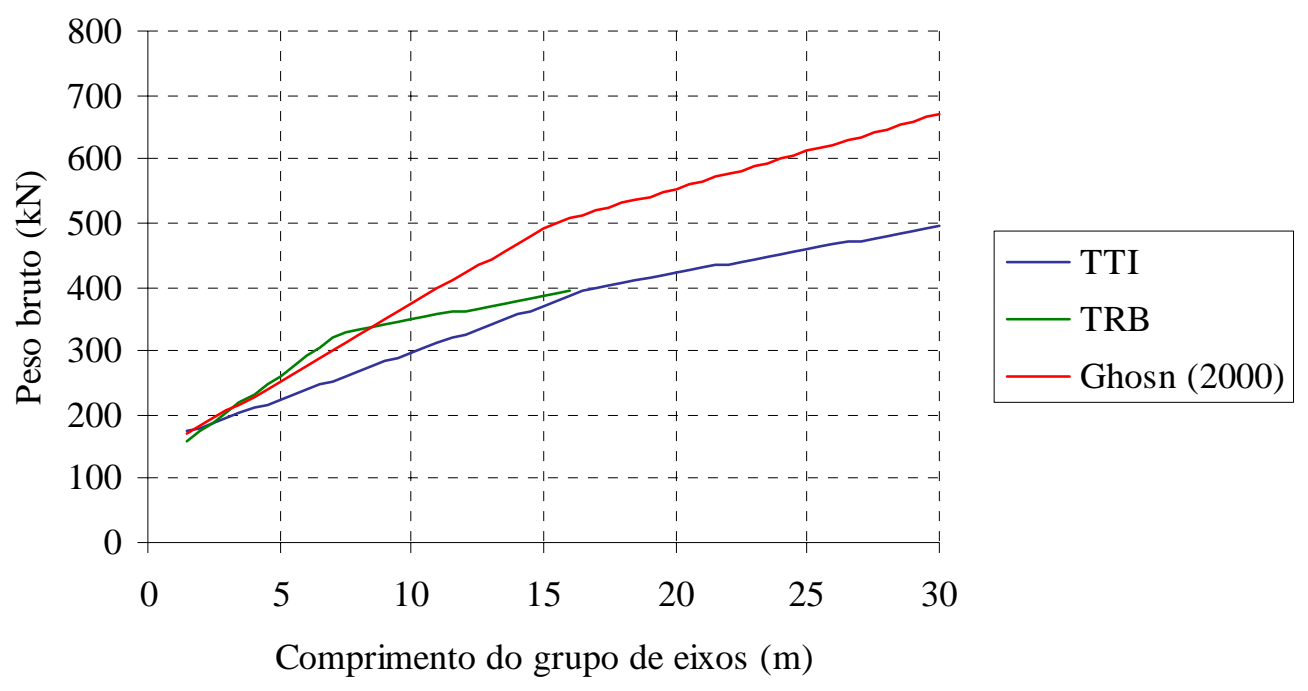

Figura 2.2 - Comparação entre a TTI formula, o TRB e a equação de Ghosn (2000).

A figura 2.2 mostra que a teoria da confiabilidade, nesse caso, forneceu resultados sensivelmente menos conservadores. Caso fosse colocada em prática, tal equação seria vantajosa para o setor de transportes, a custo de diversas pontes com menor capacidade se tornarem inseguras e necessitarem de reforço ou substituição. $O$ problema passaria então para a esfera econômica.

O campo de aplicação da teoria da confiabilidade em pontes é basicamente a determinação de riscos em estruturas sob carregamentos usuais ou a calibração de coeficientes parciais de segurança (IMBSEN et al., 1987; MOSES e VERMA, 1987; NOWAK, 1999; MOSES, 2001). Segundo Ghosn (2000), o processo para obtenção de uma bridge formula é inverso, uma vez que se procura o carregamento compatível que satisfaça um certo nível de segurança desejável.

O procedimento para a obtenção da bridge formula utilizando-se a teoria da confiabilidade é descrito sucintamente por Ghosn (2000) da seguinte forma:

a) Escolha do critério de segurança. Sugere-se o uso do índice de confiabilidade $\beta$ para avaliação da capacidade portante de elementos estruturais das pontes sob atuação do momento fletor. Os efeitos da força cortante e da fadiga são tratados separadamente;

b) Adoção de um nível de confiabilidade desejável $\left(\beta_{\text {alvo }}\right)$ para o elemento estrutural mais solicitado. Ressalta-se que devido às reservas de resistências e à redundância, a ruína de um membro não causará necessariamente a ruína da ponte (GHOSN e MOSES, 1998); 
c) Escolha de uma série de pontes típicas, com diferentes critérios de projeto, vãos, configurações, materiais (concreto, aço, madeira) e capacidade portante, formando uma amostra representativa das pontes do país. Para reduzir a quantidade de dados a serem manipulados, Ghosn (2000) desenvolve sua bridge formula tendo como referência elementos de pontes em aço simplesmente apoiados. O efeito da formulação em outras configurações de pontes é verificado em um segundo estágio;

d) Através da teoria da confiabilidade segue-se a determinação da envoltória de esforços que produza o $\beta_{\text {alvo }}$ desejável;

e) Calibração da bridge formula de maneira que o efeito do tráfego produzido pela equação não ultrapasse a envoltória obtida anteriormente;

f) Verificação das conseqüências da implantação da bridge formula no conjunto de pontes da malha viária, incluindo-se o efeito da fadiga;

g) Contagem do número de pontes deficientes sob a nova regulamentação. Esse total deve ser compatível com os recursos disponíveis para manutenção.

\subsection{Teoria da confiabilidade}

\subsubsection{Introdução}

São inúmeras as incertezas ligadas ao projeto e construção de qualquer estrutura. Thoft-Christensen e Baker (1982) enumeram três:

a) Incerteza física: variabilidades inerentes ao carregamento, às propriedades dos materiais e às dimensões;

b) Incerteza estatística: ligada a escolha apropriada do tipo de distribuição de probabilidade e a determinação numérica dos seus parâmetros, baseadas em uma amostra de dados de tamanho limitado;

c) Incerteza do modelo: representa incertezas devido a simplificações, condições de contorno desconhecidas e efeito ignorado de outras variáveis.

Alguns autores ainda acrescentam uma quarta fonte de incerteza, proveniente do erro humano durante o projeto, construção e utilização de uma estrutura.

Dessa forma, não é possível se garantir segurança absoluta a uma estrutura, haja 
vista que é possível ocorrer uma determinada conjuntura ou somatória de efeitos que a leve a ruína (estado limite último) ou a não preencher seus requisitos como desejado (estado limite de utilização). Nesse contexto, a missão da engenharia é adotar um nível de segurança adequado tendo-se em vista as limitações financeiras existentes. A consideração das incertezas e a busca pela segurança "ideal” são objetivos da teoria da confiabilidade.

De acordo com Nowak e Collins (2000), confiabilidade de uma estrutura é a sua habilidade em atender a seus requisitos de projeto durante sua vida útil ou a probabilidade que a estrutura não irá falhar em desempenhar suas funções.

O correto entendimento da teoria da confiabilidade pressupõe o conhecimento de conceitos probabilísticos e estatísticos que não serão aqui tratados, mas que podem ser encontrados em livros específicos (ANG e TANG, 1975; BENJAMIN e CORNELL, 1970) ou mais superficialmente em livros sobre confiabilidade (NOWAK e COLLINS, 2000; THOFT-CHRISTENSEN e BAKER, 1982).

\subsubsection{Confiabilidade de elementos estruturais}

De acordo com Nowak e Collins (2000), estado limite é definido como a fronteira entre o comportamento desejável e indesejável de uma estrutura. Na teoria da confiabilidade, são três os estados limites considerados:

a) Estado limite último (ELU): relacionado à perda de capacidade portante;

b) Estado limite de serviço (ELS): relacionado à degradação gradual, conforto do usuário ou custo de manutenção. Como exemplos, têm-se os deslocamentos excessivos, a vibração excessiva, as deformações permanentes e a fissuração;

c) Estado limite de fadiga (ELF): relacionado à perda de resistência sob cargas repetidas. Embora a fadiga seja considerada um estado limite último segundo a NBR-6118 (2003), mantém-se aqui a separação indicada por Nowak e Collins (2000). De acordo com estudo realizado pelo CEB (1988), a análise de diversas estruturas reais mostrou que em nenhum caso o colapso ocorreu exclusivamente devido à fadiga, embora ela seja um dos fatores que colaboram para a deterioração progressiva e diminua a resistência de elementos estruturais. 
Matematicamente, os estados limites são representados por uma função, chamada função de estado limite. Considerando-se o estado limite último, a função de estado limite associa-se ao conceito de margem de segurança:

$\mathrm{Z}=\mathrm{R}-\mathrm{S}$

onde:

Z: margem de segurança;

R: capacidade ou resistência;

S: solicitação, demanda ou efeito total do carregamento.

No caso de pontes, $\mathrm{S}=\mathrm{G}+\mathrm{Q}+\mathrm{E}+\ldots$

onde:

G: efeito da carga permanente;

Q: efeito da carga móvel;

E: efeito de fenômenos naturais (vento, temperatura, terremoto, neve).

A fronteira entre o comportamento desejável e indesejável é dado por $Z=0$. Se $Z \geq 0$, a estrutura está segura; se $Z<0$ não há segurança. Portanto, a probabilidade de falha é dada pela probabilidade de que a resistência $R$ seja menor que o efeito do carregamento aplicado $S$, da seguinte forma:

$P_{f}=P[R<S]=P[Z \leq 0]=\int_{-\infty}^{0} f_{Z}(z) d z=F_{Z}(0)$

onde:

$\mathrm{f}_{\mathrm{Z}}(\mathrm{z})$ : função densidade de probabilidade da variável Z;

$\mathrm{F}_{\mathrm{Z}}(0)$ : valor da função distribuição acumulada em $\mathrm{Z}=0$.

Em termos de $R$ e $S$, a equação (2.6) pode também ser representada por:

$P_{f}=\int_{-\infty}^{+\infty} F_{R}(x) f_{s}(x) d x$

onde: 
$\mathrm{f}_{\mathrm{s}}(\mathrm{x})$ : função densidade de probabilidade da variável $S$;

$\mathrm{F}_{\mathrm{R}}(\mathrm{x})$ : função distribuição acumulada da variável $R$.

Ghosn e Frangopol (1999) afirmam que a equação (2.7) pode ser entendida como o exame de todos os $x$ valores que o efeito do carregamento $S$ pode tomar (portanto $x$ varia entre $-\infty$ e $+\infty$ ), sendo que para cada valor de $x$ são contados os casos em que $R$ é menor que $x, \mathrm{~F}_{\mathrm{R}}(\mathrm{x})$. Confiabilidade é definida como a probabilidade que $R$ seja maior que $S$, ou seja, $1-\mathrm{P}_{\mathrm{f}}$.

No entanto, o grande número de variáveis aleatórias envolvidas em muitos problemas práticos torna bastante difícil a obtenção da função conjunta de densidade de probabilidade e a integração da equação (2.6) é quase sempre inviável. Alternativamente, mede-se a segurança estrutural em função do índice de confiabilidade $\beta$, definido como a menor distância da origem do espaço das variáveis padronizadas até a superfície de falha (v. figura 2.3). No caso de duas variáveis apenas $(Z=R-S)$, a superfície de falha é uma linha correspondente a $\mathrm{z}(\mathrm{r}, \mathrm{s})=0$, onde:

$$
\begin{aligned}
& r=\frac{R-\mu_{R}}{\sigma_{R}} \\
& s=\frac{S-\mu_{S}}{\sigma_{S}}
\end{aligned}
$$

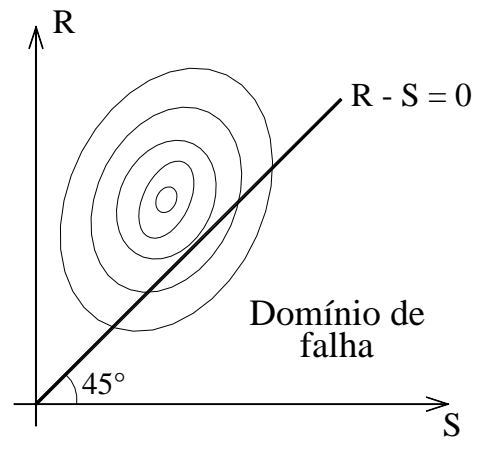

a) Espaço físico

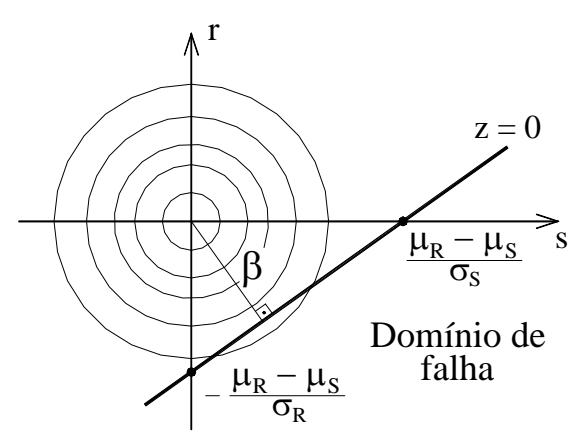

b) Espaço padronizado

Figura 2.3 - Definição do índice de confiabilidade.

Se $R$ e $S$ seguem distribuições normais independentes de probabilidade, o índice de confiabilidade se relaciona diretamente com a probabilidade de falha na forma: 
$\mathrm{P}_{\mathrm{f}}=\Phi\left[-\frac{\mu_{\mathrm{R}}-\mu_{\mathrm{S}}}{\sqrt{\sigma^{2}{ }_{\mathrm{R}}+\sigma^{2} \mathrm{~S}}}\right]=\Phi\left[-\frac{\mu_{\mathrm{Z}}}{\sigma_{\mathrm{Z}}}\right]=\Phi[-\beta]$

e

$\beta=\frac{\mu_{\mathrm{Z}}}{\sigma_{\mathrm{Z}}}$

onde:

$\Phi$ : distribuição normal padronizada;

$\mu$ : representa a média das respectivas variáveis;

$\sigma:$ representa o desvio-padrão das respectivas variáveis.

A figura 2.4 mostra as duas medidas da segurança. A probabilidade de falha é dada pela área hachurada. O índice de confiabilidade $\beta$ fornece o número de desviospadrão que a média da margem de segurança está distante do estado limite. Caso as variáveis envolvidas não sigam uma distribuição normal, a relação entre $\beta$ e a probabilidade de falha é apenas aproximada.

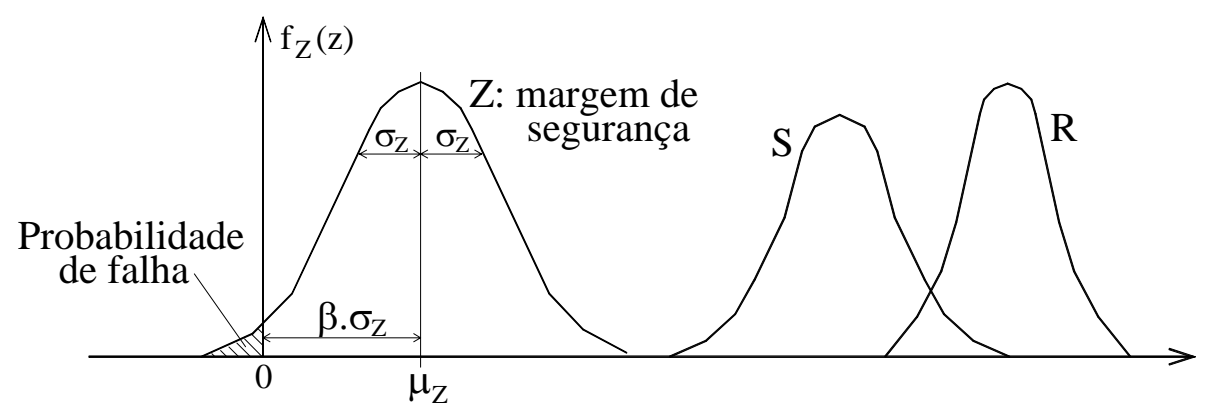

Figura 2.4 - Probabilidade de falha e margem de segurança.

A análise da figura 2.4 ainda revela que são duas as maneiras de se aumentar a segurança de uma estrutura:

a) A utilização de altos coeficientes de segurança, de modo a aumentar a distância entre as distribuições de probabilidade e assim reduzir a sobreposição entre elas (v. figura 2.5a);

b) A redução das incertezas, que torna as distribuições de probabilidade mais íngremes e assim reduz a probabilidade de falha (v. figura 2.5b). 


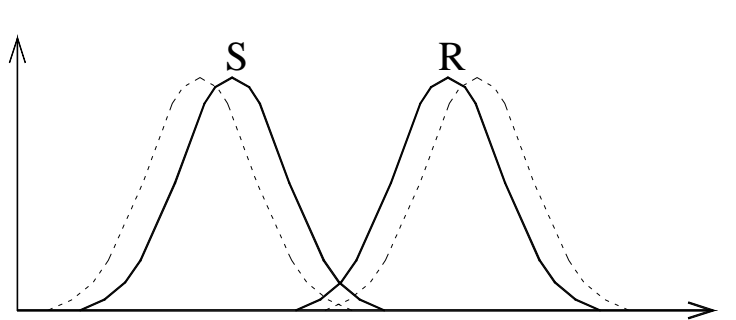

a) Altos coeficientes de segurança

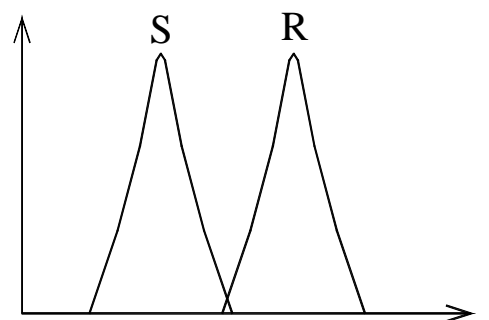

b) Incertezas reduzidas

Figura 2.5 - Alternativas para a redução da probabilidade de falha. (MOSES, 2001)

De acordo com Moses (2001), os dois fatores acima citados (coeficientes de segurança e magnitude das incertezas) geralmente são mais importantes no cálculo da probabilidade de falha do que propriamente o tipo de distribuição das variáveis (normal, lognormal, gumbel, etc).

No caso de funções lineares de estado limite:

$$
\mathrm{z}\left(\mathrm{X}_{1}, \ldots, \mathrm{X}_{\mathrm{n}}\right)=\mathrm{a}_{0}+\mathrm{a}_{1} \cdot \mathrm{X}_{1}+\ldots+\mathrm{a}_{\mathrm{n}} \cdot \mathrm{X}_{\mathrm{n}}=\mathrm{a}_{0}+\sum_{\mathrm{i}=1}^{\mathrm{n}} \mathrm{a}_{\mathrm{i}} \cdot \mathrm{X}_{\mathrm{i}}
$$

onde $\mathrm{a}_{\mathrm{i}}$ são termos constantes e $\mathrm{X}_{\mathrm{i}}$ são variáveis aleatórias não correlacionadas, $\beta$ é dado por:

$$
\beta=\frac{a_{0}+\sum_{i=1}^{n} a_{i} \cdot \mu_{X_{i}}}{\sqrt{\sum_{i=1}^{n}\left(a_{i} \cdot \sigma_{x_{i}}\right)^{2}}}
$$

No caso de funções não-lineares de estado limite, essas funções podem ser linearizadas através da série de Taylor e a equação (2.13) continua sendo aplicada.

$$
\mathrm{z}\left(\mathrm{X}_{1}, \ldots, \mathrm{X}_{\mathrm{n}}\right) \approx \mathrm{z}\left(\mathrm{x}_{1}^{*}, \ldots, \mathrm{X}_{\mathrm{n}}^{*}\right)+\left.\sum_{\mathrm{i}=1}^{\mathrm{n}}\left(\mathrm{X}_{\mathrm{i}} \cdot \mathrm{x}_{\mathrm{i}}^{*}\right) \cdot \frac{\partial \mathrm{z}}{\partial \mathrm{X}_{\mathrm{i}}}\right|_{\left(\mathrm{x}_{1}^{*}, \ldots \mathrm{x}_{\mathrm{n}}^{*}\right)}
$$

onde $\left(\mathrm{x}_{1}^{*}, \ldots, \mathrm{x}_{\mathrm{n}}^{*}\right)$ é o ponto acerca do qual se dará a expansão.

Inicialmente, escolhia-se para expansão o ponto correspondente à média das variáveis. Esse procedimento mostrou-se dependente da formulação da função de estado 
limite, ou seja, eram obtidos diferentes betas para diferentes estados limites relacionados ao mesmo problema. Em 1974, Hasofer e Lind corrigiram essa deficiência, propondo que a função de estado limite seja avaliada no ponto de projeto, definido na superficie de falha $\mathrm{z}=0$. Como o ponto de projeto não é conhecido a priori, são necessárias iterações para o cálculo do índice de confiabilidade. Trata-se de um problema de otimização restrita (minimização de uma distância sujeito a condição de $\mathrm{z}=0$ ), cujo algoritmo mais conhecido é o de Rackwitz-Fiessler.

Por definição, o índice de confiabilidade deve ser determinado no espaço das variáveis aleatórias normalizado e não correlacionado. No caso de variáveis aleatórias que não sigam distribuições normais, a idéia básica é transformar sua média e seu desvio-padrão em valores equivalentes à distribuição normal, ou seja, são usados na análise parâmetros da distribuição normal equivalente no ponto de projeto.

Em muitas aplicações, algumas variáveis são correlacionadas, podendo afetar significativamente o valor de $\beta$. Como exemplo, Thoft-Christensen e Baker (1982) citam uma viga submetida a duas cargas estatisticamente independentes. Embora essas cargas sejam independentes, o valor da força cortante e do momento fletor em um determinado ponto da estrutura são variáveis correlacionadas. Nesse caso, elas devem ser transformadas em variáveis não correlacionadas equivalentes.

Maiores detalhes sobre o método de Rackwitz-Fiessler, a transformação em distribuição normal equivalente e a transformação de variáveis correlacionadas podem ser encontrados, por exemplo, em Neves (2004), Nowak e Collins (2000) e ThoftChristensen e Baker (1982).

Uma vez obtido o índice de confiabilidade e o ponto de projeto, a probabilidade de falha pode ser calculada através dos seguintes métodos:

a) FORM (First Order Reliability Method): a função de estado limite é substituída por um hiper-plano tangente a ela no ponto de projeto. A probabilidade de falha é dada por: $P_{\mathrm{f}}=\Phi(-\beta)$. No caso de funções lineares de estado limite e variáveis normais e não correlacionadas, o resultado é exato. Em se tratando de funções não-lineares, a aproximação depende da curvatura da função na vizinhança do ponto de projeto (v. figura 2.6); 


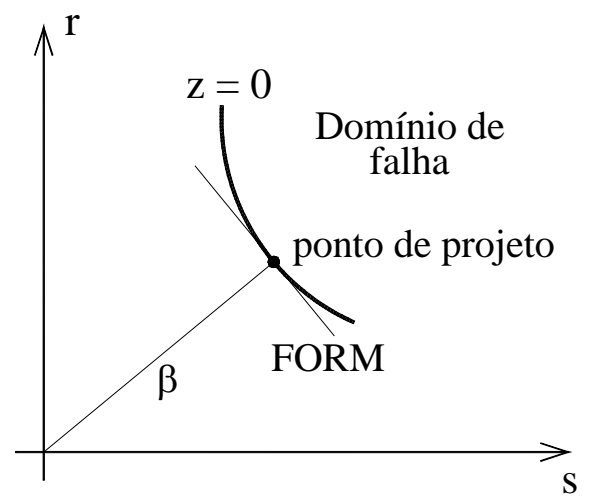

a) A favor da segurança

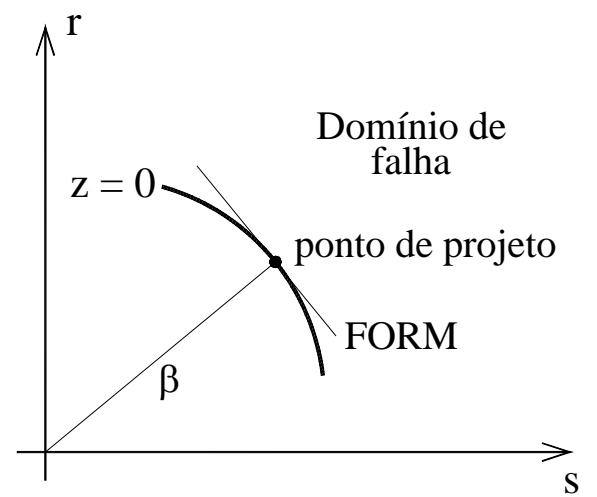

b) Contra a segurança

Figura 2.6 - Aproximação FORM para funções não-lineares de estado limite.

b) SORM (Second Order Reliability Method): a função de estado limite é aproximada por uma hiper-superfície de grau 2 que concorda com sua curvatura no ponto de projeto. Normalmente esse procedimento produz uma melhor representação das regiões seguras e das regiões de falha e portanto pode resultar em melhores aproximações das probabilidades de falha.

\subsubsection{Técnicas de simulação}

De acordo com Nowak e Collins (2000), a idéia básica dessas técnicas é simular numericamente algum fenômeno e observar o número de vezes que um evento de interesse acontece. Esse procedimento é bastante útil quando as funções de estado limite são muito complicadas (altamente não-lineares). A seguir, apresenta-se uma breve descrição de algumas técnicas. Outros aspectos importantes podem ser encontrados em Nowak e Collins (2000), Tabsh (1990) e Tantawi (1986), entre outros.

\subsubsection{Método de Monte Carlo}

Resumidamente, o método de Monte Carlo consiste na atribuição de valores numéricos para as variáveis envolvidas no problema, a partir da geração de números aleatórios uniformemente distribuídos entre 0 e 1 e das respectivas distribuições de probabilidade. Por exemplo, no caso de uma variável que siga a distribuição normal:

$$
\mathrm{z}_{\mathrm{i}}=\Phi^{-1}\left(\mathrm{u}_{\mathrm{i}}\right)
$$


e

$\mathrm{x}_{\mathrm{i}}=\mu_{\mathrm{X}}+\mathrm{z}_{\mathrm{i}} \cdot \sigma_{\mathrm{X}}$

onde:

$\mathrm{z}_{\mathrm{i}}$ : número aleatório de uma distribuição normal padrão;

$\mathrm{u}_{\mathrm{i}}$ : número aleatório de uma distribuição uniforme entre 0 e 1 ;

$\Phi^{-1}$ : inverso da função distribuição normal acumulada;

$\mathrm{x}_{\mathrm{i}}$ : realização de um valor da variável aleatória $X$;

$\mu_{\mathrm{X}}, \sigma_{\mathrm{X}}:$ média e desvio padrão da variável $X$.

Repetindo-se esse procedimento para todas as variáveis, inúmeras vezes, é possível se estimar, por exemplo:

a) O valor de uma variável aleatória, a partir tanto de uma função claramente definida quanto de um algoritmo qualquer;

b) A probabilidade de falha, como sendo a proporção entre o número de vezes que a função de estado limite é menor que zero e o número total de simulações;

c) O índice de confiabilidade, a partir da plotagem da função de estado limite em um papel de probabilidade.

Dois detalhes que merecem ser ressaltados são o cuidado na geração de números aleatórios (Press et al., 1996) e o grande número de simulações necessárias para a obtenção de resultados confiáveis, podendo resultar em um tempo de processamento elevado.

\subsubsection{Amostragem por hipercubo latino (latin hypercube sampling)}

Conforme salientado acima, para problemas muito complexos o método de Monte Carlo pode se tornar inviável do ponto de vista prático devido ao tempo de processamento. Nesse contexto, o método de amostragem por hipercubo latino é uma técnica que reduz o número de simulações necessárias para a obtenção de resultados razoáveis. Nessa técnica, o intervalo de possíveis valores de cada variável é dividido em faixas (v. figura 2.7), e um valor representativo é extraído de cada faixa. Os valores 
representativos são então combinados de maneira que cada valor representativo seja considerado apenas uma vez no processo de simulação. Assim, todos os possíveis valores das variáveis aleatórias participam da estimativa.

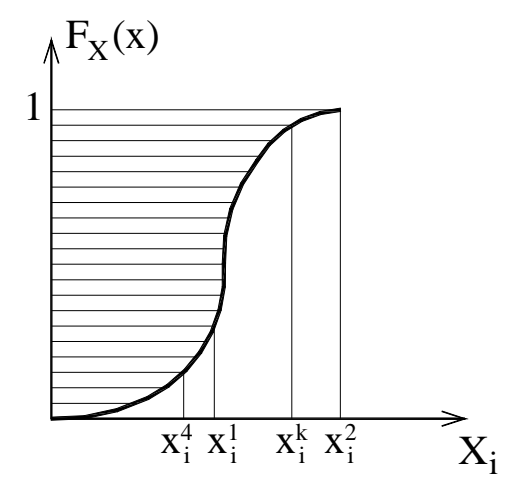

Figura 2.7 - Divisão da função distribuição acumulada. (TABSH, 1990)

\subsubsection{Método de Rosenblueth $(2 K+1)$}

De acordo com Nowak e Collins (2000), dentre os métodos de estimativa de pontos, o proposto por Rosenblueth em 1975 é um dos de mais fácil implementação. A idéia básica é avaliar a função de variáveis aleatórias em $2 K+1$ pontos chaves e então usar esta informação para estimar a média e o coeficiente de variação da função. Entretanto, a função distribuição acumulada não pode ser obtida por este método. Como vantagens, não é necessário se conhecer as distribuições de probabilidade das variáveis aleatórias que fazem parte do problema (apenas os 2 primeiros momentos são necessários) e o número de vezes que a função deve ser avaliada (simulações) é relativamente pequeno se comparado com as demais técnicas de simulação.

\subsubsection{Análise de sensibilidade}

Uma vez obtido o índice de confiabilidade, a identificação dos parâmetros mais importantes que afetam a segurança é conseguida através de uma análise de sensibilidade, cujo objetivo é relacionar a magnitude dos erros e a confiabilidade estrutural (NOWAK, 1999). Segundo Ghosn (2000), a análise de sensibilidade é utilizada para se estudar os efeitos que as diversas suposições e os erros nos dados de entrada geram na bridge formula proposta. Por exemplo, pode-se variar o índice de 
confiabilidade desejável ( $\left.\beta_{\text {alvo}}\right)$, mantendo-se os mesmos dados para os demais parâmetros, e verificar sua influência na bridge formula obtida. Outros parâmetros passíveis de serem verificados através de uma análise de sensibilidade são: fator de crescimento no tráfego, tipo de ponte, resistência dos elementos estruturais, etc.

É preciso ressaltar que quando a análise da segurança das pontes é baseada na confiabilidade de seus componentes e elementos críticos, o índice de confiabilidade mais baixo é geralmente usado como o índice de confiabilidade para a ponte inteira. A simplificação implícita nesse procedimento reside no fato que a confiabilidade do sistema depende da confiabilidade de cada sistema de componentes e do modo como esses elementos podem se combinar para produzir o colapso do sistema (modo de falha). Portanto, uma análise mais completa e sofisticada deve estudar a confiabilidade dos sistemas estruturais.

\subsubsection{Confiabilidade dos sistemas estruturais das pontes}

Geralmente a análise estrutural de pontes se faz assumindo comportamento elástico linear, embora os elementos sejam dimensionados no estado limite último. Dessa forma, a influência da não-linearidade do material na redistribuição de esforços em um sistema estrutural de pontes é ignorada. Ghosn e Frangopol (1999) afirmam que apesar desse conservadorismo ser geralmente desejável na prática da engenharia, a avaliação da real capacidade portante das pontes resultante desse procedimento não é precisa e portanto produz estimativas equivocadas dos índices de confiabilidade. Esse aspecto pode ser constatado através da comparação entre os índices de confiabilidade de elementos individuais de pontes assumindo comportamento elástico linear e o índice de confiabilidade do sistema estrutural considerando-se redistribuição do carregamento.

Diversos fatores afetam a confiabilidade dos sistemas estruturais:

a) A disposição dos elementos estruturais (em série ou em paralelo);

b) O nível de dutilidade dos elementos;

c) A correlação entre as capacidades dos elementos e/ou a correlação entre as cargas afetam a confiabilidade do sistema quando comparada com a confiabilidade de elementos individuais. 


\subsubsection{Sistemas em série}

Sistema em série é aquele em que a ruína de qualquer elemento irá produzir a ruína de todo o sistema. Treliças estaticamente determinadas são exemplos de estruturas em que a ruína de qualquer elemento produz a ruína de toda a ponte. De acordo com Ghosn e Frangopol (1999), geralmente o nível de dutilidade dos elementos não influencia a confiabilidade dos sistemas formados por elementos em série (a treliça entrará em colapso independentemente se algum elemento romper de maneira frágil ou dútil).
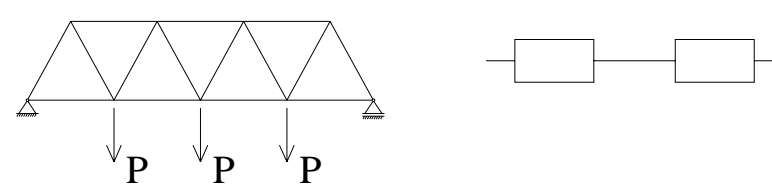

Figura 2.8 - Exemplo de um sistema em série. (NOWAK e COLLINS, 2000)

No caso de dois elementos em série, o sistema irá "sobreviver" somente se ambos são seguros e assim, o domínio seguro do sistema é a intersecção dos domínios seguros dos elementos 1 e 2. A confiabilidade do sistema é então expressa por (GHOSN e FRANGOPOL, 1999):

$\mathrm{P}_{\mathrm{s}, \text { sistema }}=\mathrm{P}_{\mathrm{s}, 1} \cdot \mathrm{P}_{\mathrm{s}, 2}=\left(1-\mathrm{P}_{\mathrm{f}, 1}\right) \cdot\left(1-\mathrm{P}_{\mathrm{f}, 2}\right)$

Caso haja correlação entre as cargas aplicadas em cada elemento ou correlação entre as resistências (o que ocorre normalmente em pontes), o cálculo da confiabilidade dos sistemas se torna mais complicado. Por exemplo, quando a função de estado limite para um certo elemento é menor que zero, há chance que a função de outro elemento também seja menor que zero. Um procedimento que fornece os limites inferiores e superiores para a confiabilidade do sistema quando as variáveis são correlacionadas é conhecido como "limites de Ditlevsen” (GHOSN e FRANGOPOL, 1999).

Quando a ruína de um sistema estrutural de ponte é modelada por modos em série, a probabilidade de ruína de todo o sistema é maior que a probabilidade de ruína de cada membro tomado independentemente, o que implica um índice de confiabilidade do sistema menor que o índice de confiabilidade de cada membro isoladamente. Ainda, 
a probabilidade de ruína do sistema diminui (ou a confiabilidade aumenta) quando o coeficiente de correlação aumenta. Por outro lado, a probabilidade de ruína aumenta (a confiabilidade diminui) com o aumento do número de elementos.

\subsubsection{Sistemas em paralelo}

De acordo com Ghosn e Frangopol (1999), sistema em paralelo é aquele em que a ruína completa da estrutura requer a ruína de todos os seus componentes. Estruturas estaticamente indeterminadas e pontes formadas por vigas justapostas são exemplos de sistemas em paralelo (v. figura 2.9). A ruína associada a um sistema em paralelo é chamada modo de falha. Um sistema pode possuir vários possíveis modos de falha, sendo que a ruína de qualquer um dos modos resulta em ruína do sistema. Assim, diferentes modos de falha constituem-se em “elementos” de um sistema em série.
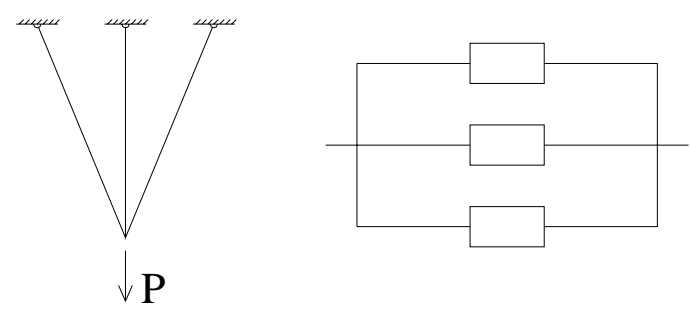

Figura 2.9 - Exemplo de um sistema em paralelo.

A confiabilidade de sistemas em paralelo é afetada pela dutilidade dos elementos. Considerando um sistema formado por dois elementos perfeitamente dúteis em paralelo, a ruína do sistema irá acontecer somente se os dois elementos falharem, sendo que a resistência do sistema é igual à soma das resistências dos elementos. Quando um elemento atinge seu limite, ele não recebe cargas adicionais e os outros membros do sistema irão suportar a carga adicional apenas. Por outro lado, quando um elemento frágil atinge sua capacidade, ele transfere a carga que suportava para os elementos adjacentes, que então suportarão sua própria carga, a carga transferida pelo elemento rompido e o carregamento adicional.

Vale ressaltar que a confiabilidade de sistemas dúteis em paralelo diminui com o aumento do coeficiente de correlação, e quanto maior o número de elementos, maior a confiabilidade do sistema. 
Ghosn e Frangopol (1999) ilustram os conceitos aqui discutidos através de uma ponte de duas vigas formada por dois vãos contínuos de 45,75 m e $61 \mathrm{~m}$. O carregamento móvel é representado por uma carga concentrada (vãos relativamente longos). Assumindo-se comportamento perfeitamente plástico, o sistema estrutural irá falhar devido à formação de um mecanismo de colapso. Neste caso, dois diferentes mecanismos são possíveis:

a) Rótula plástica no meio do primeiro vão e no apoio central;

b) Rótula plástica no meio do segundo vão e no apoio central.

Cada mecanismo de colapso pode ser representado por uma função de estado limite, sendo que o índice de confiabilidade é calculado para cada um dos dois modos. Os resultados obtidos são 3,43 para o primeiro modo e 3,47 para o segundo modo. Vale destacar que os valores encontrados são bem superiores ao menor índice de confiabilidade encontrado para um elemento ( $\beta=1,52$ para momento fletor no meio do segundo vão), o que confirma que o beta calculado sem a consideração do sistema estrutural como um todo reduz significativamente o verdadeiro nível de segurança.

No exemplo em questão, a estrutura irá falhar se ocorrer pelo menos um dos mecanismos de colapso (ou ambos). Assim, a ruína do sistema estrutural é modelada por dois modos correlacionados (existem variáveis comuns às duas equações de estado limite) em série, e a probabilidade de ruína de todo o sistema será maior que a probabilidade de ruína de cada um dos modos independentemente, ou seja, o índice de confiabilidade de todo o sistema será menor que o beta de cada modo isoladamente. Nesse caso, o índice de confiabilidade para o sistema resulta igual a 3,26.

\subsubsection{Geração dos modos de falha}

De acordo com Ghosn e Frangopol (1999), a análise de confiabilidade de sistemas estruturais somente é possível se todos os modos de falha puderem ser identificados. Considerando-se que as pontes são formadas por um grande número de componentes individuais, a procura de todos os modos pode se tornar bastante complicada. Por outro lado, muitos modos de falha têm probabilidade de ruína muito baixa, e assim não influenciam a confiabilidade do sistema como um todo. Diversos 
métodos foram desenvolvidos para o cálculo da confiabilidade dos sistemas usando diferentes aproximações. Entre eles, destaca-se o método da superfície de resposta.

\subsubsection{Método da superfície de resposta}

O método da superfície de resposta é uma técnica de simulação numérica para o cálculo da confiabilidade do sistema quando as equações de estado limite não podem ser explicitamente formuladas (GHOSN et al., 1994; GHOSN e FRANGOPOL, 1999; NEVES, 2004). A utilização desse método requer a existência de um programa de análise não-linear que modele o comportamento da estrutura de maneira determinista. Os resultados da análise determinista para valores pré-determinados das variáveis aleatórias são usados em uma análise de regressão para obter a superfície de resposta em torno da vizinhança do ponto de projeto, que relaciona o comportamento da estrutura com as variáveis aleatórias envolvidas. Uma vez obtida a superfície de resposta, a mesma é usada para a obtenção de uma equação da margem de segurança e em seguida é determinado o índice de confiabilidade.

Como a obtenção da superfície de resposta depende dos valores das variáveis aleatórias que deram origem à resposta mecânica, um processo iterativo se faz necessário. Assim, primeiramente o cálculo se dá em torno dos valores nominais das variáveis e posteriormente é refeito em pontos próximos do ponto de falha. O processo é repetido até que o índice de confiabilidade tenha convergência para um valor estável.

É importante destacar que o método da superfície de resposta converge rapidamente para o índice de confiabilidade correspondente ao modo de falha mais crítico (o modo com menor $\beta$ ). Para obter o segundo (menos crítico) modo de falha, o algoritmo precisa ser modificado para eliminar as contribuições do primeiro modo.

\subsubsection{Redundância nas superestruturas de pontes}

Redundância é a habilidade da estrutura em continuar a funcionar de maneira segura e quase normalmente, a despeito da ruína de um de seus principais elementos de sustentação (NOWAK e ZHOU, 1990) ou ainda a diferença entre o índice de confiabilidade do sistema estrutural da ponte e o índice de confiabilidade de seus elementos (GHOSN e MOSES, 1998). A ruína de um certo elemento pode ser causada 
por uma carga móvel de elevada magnitude, à fadiga ou ainda devido à colisão de algum veículo.

De maneira geral, as diversas normas de pontes ignoram o efeito do sistema estrutural integrado e lidam apenas com elementos individuais, ou seja, desprezam a interação entre os componentes estruturais que formam o sistema. A fim de preencher esta lacuna, diversos estudos pretendem relacionar o nível de redundância com a capacidade dos diversos elementos estruturais através da introdução dos chamados coeficientes de sistema (GHOSN e MOSES, 1998; GHOSN et al., 1994; GHOSN et al., 1997). Os coeficientes de sistema são multiplicadores da resistência nominal dos elementos estruturais, determinados a partir do grau de segurança e da redundância do sistema completo da ponte. De acordo com Ghosn et al. (1994), os coeficientes de sistema "premiam" projetos redundantes permitindo menores capacidades dos elementos que fazem parte deste sistema, enquanto "penalizam” projetos nãoredundantes requerendo um dimensionamento mais conservativo dos componentes estruturais.

Ghosn e Moses (1998) enumeram os estados limites a serem verificados para garantir adequada redundância e segurança do sistema:

a) Ruína de um elemento: verificação da segurança de um elemento individual através de análise elástica;

b) Estado limite último: definido como a capacidade última do sistema estrutural intacto. Corresponde, por exemplo, à formação de um mecanismo de colapso ou ao esmagamento do concreto em um de seus elementos principais;

c) Estado limite de funcionalidade: definido como o máximo deslocamento aceitável devido à carga móvel em um elemento longitudinal principal, fixado por Ghosn e Moses (1998) em vão/100;

d) Estado limite da estrutura danificada: capacidade última da ponte após o dano de um de seus principais elementos portantes. Em uma ponte de vigas, corresponde à retirada do modelo da viga mais carregada.

Uma medida da redundância é dada pela diferença entre o índice de confiabilidade do sistema ( $\beta_{\text {últ }}, \beta_{\text {func }}, \beta_{\text {danif }}$, referentes aos itens $b, c$ e $d$, respectivamente) e o índice de confiabilidade do elemento mais crítico ( $\beta_{\text {elemento }}$, item 
a). Assim, considerando-se os estados limites em questão:

$$
\begin{aligned}
& \Delta \beta_{\mathrm{u}}=\beta_{\text {últ }}-\beta_{\text {elemento }} \\
& \Delta \beta_{\mathrm{f}}=\beta_{\text {func }}-\beta_{\text {elemento }} \\
& \Delta \beta_{\mathrm{d}}=\beta_{\text {danif }}-\beta_{\text {elemento }}
\end{aligned}
$$

De acordo com Ghosn et al. (1994), esses índices de confiabilidade relativos fornecem medidas da segurança adicional proporcionada pelo sistema estrutural completo em comparação com a segurança nominal obtida quando uma verificação convencional da segurança dos elementos é realizada. Portanto, um sistema estrutural terá adequado nível de redundância se os índices de confiabilidade relativos forem adequados.

A partir da análise de sistemas estruturais existentes reconhecidamente redundantes (na prática, todas as pontes de duas vigas e mesmo as de três vigas são consideradas não-redundantes), Ghosn e Moses (1998) concluíram que uma ponte irá proporcionar adequado nível de redundância se todas as seguintes condições forem satisfeitas:

$$
\begin{gathered}
\Delta \beta_{\mathrm{u}} \geq 0,85 \\
\Delta \beta_{\mathrm{f}} \geq 0,25 \\
\Delta \beta_{\mathrm{d}} \geq-2,70
\end{gathered}
$$

O valor $\Delta \beta$ negativo para a situação da estrutura sem um de seus elementos principais (estrutura danificada) indica que essa estrutura não necessita ter o mesmo nível de confiabilidade da estrutura intacta.

A partir dos valores de $\Delta \beta$ desejáveis calculam-se os coeficientes de sistema de acordo com o esquema longitudinal (simplesmente apoiado ou contínuo), a seção transversal, o material (aço ou concreto protendido), o número de vigas e o espaçamento entre as vigas. Os valores variam entre 0,80 e 1,20. Maiores detalhes podem se encontrados em Ghosn e Moses (1998). 


\subsection{Determinação do $\beta$ desejável ( $\left.\beta_{\text {alvo }}\right)$ para elementos individuais}

De maneira geral, as normas recomendam para elementos estruturais índices de confiabilidade que variam de dois a quatro. Desde que haja adequada redundância, o índice de confiabilidade da estrutura como um todo será maior (GHOSN e MOSES, 1998).

Ghosn et al. (1995) afirmam que o cálculo da segurança estrutural em pontes difere daquele usado em outras aplicações porque o carregamento de caminhões aumenta com o passar do tempo devido a novas legislações e ao aumento do volume de tráfego. Ao mesmo tempo, a resistência de elementos estruturais diminui devido à degradação e à manutenção inadequada. Portanto, para pontes novas, $\beta$ é relativamente alto, da ordem de 3,5, reduzindo-se para cerca de 2,5 em idades mais avançadas. Nesse contexto, Moses (2001) conclui que a confiabilidade é uma grandeza que varia com o tempo, sujeita às influências do tráfego, manutenção, deterioração e também sujeita à modificação de acordo com dados adicionais obtidos acerca de cada ponte especificamente.

De acordo com Moses (1999), o $\beta$ desejável pode ser ajustado de acordo com o tipo de falha (deslocamentos, ruptura dútil, ruptura frágil, etc) e ainda com o correspondente custo marginal de se aumentar o coeficiente de segurança. Por exemplo, betas maiores para detalhes de ligações de baixo custo comparadas a índices menores para grandes elementos de custo elevado. O tipo de carregamento também é fator que influencia o $\beta_{\text {alvo }}$ : maiores betas são impostos para cargas gravitacionais em relação a cargas provenientes de fenômenos naturais devido a fatores econômicos. Por fim, os índices de confiabilidade impostos durante o projeto são maiores que os índices usados na avaliação de estruturas existentes, pois custa mais reforçar uma estrutura existente do que aumentar a sua capacidade antes da construção.

Em Nowak (1999) e Ghosn (2000), um único $\beta_{\text {alvo }}$ é usado para pontes de todos os vãos, seguindo a filosofia que cada tipo de estrutura deve ter um nível de confiabilidade uniforme para todas as suas aplicações. No caso de pontes, um único

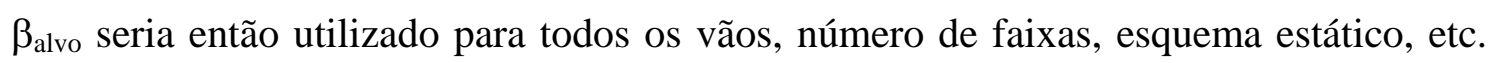
Também existem pesquisadores que sugerem betas mais elevados no caso de grandes vãos ou para pontes que suportam tráfego mais pesado, embora esse procedimento ainda não seja aplicável. Um ponto de vista contraditório é apresentado em Moses e Verma 
(1987): como o custo adicional para aumentar a capacidade de pontes com pequenos vãos é muito menor que o custo para elevar a capacidade de pontes com grandes vãos, maiores betas para pontes de pequenos vãos poderiam ser desejáveis. Outra alternativa é a escolha do índice de confiabilidade baseada na redundância do sistema estrutural da ponte em questão (GHOSN e MOSES, 1998): elementos estruturais que fazem parte de pontes não-redundantes deveriam ter maiores índices de confiabilidade.

Bruhwiler e Bailey (2002) propõem um método para a determinação do beta desejável na avaliação de pontes existentes. A filosofia é definir $\beta_{\text {alvo como função do }}$ risco associado com a ruína das pontes, baseando-se em dados históricos de riscos associados às ruínas e o risco aceito pelo público em atividades do cotidiano. O procedimento envolve os seguintes passos:

a) Identificação dos cenários de risco (por exemplo, colapso do vão central devido à formação de um mecanismo causado por dois caminhões extremamente pesados);

b) Definição das conseqüências de um certo cenário com respeito a perdas humanas (número de mortes, ligado ao volume de tráfego e às características da ponte) e à importância econômica da ponte;

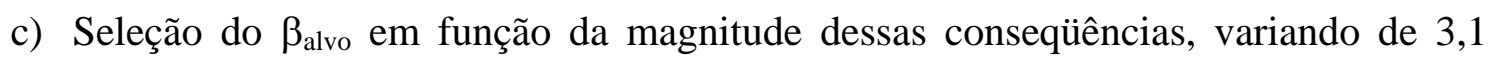
$\left(P_{f}=10^{-3}\right)$ a $4,7\left(P_{f}=10^{-6}\right)$.

De acordo com Ghosn e Frangopol (1999), alguns estudiosos propõem uma análise econômica na escolha do $\beta$ para projeto. Segundo essa filosofia, o $\beta$ ótimo é aquele que minimiza o custo da ponte, levando em consideração o custo de construção e o custo à sociedade de uma eventual ruína.

No entanto, $\beta_{\text {alvo }}$ geralmente é obtido a partir de projetos existentes, cujas pontes apresentam desempenho satisfatório, em vez de serem baseados em critérios sócioeconômicos de taxas aceitáveis de falha. Moses e Verma (1987) afirmam que, caso se julgue que as estruturas que serviram de referência estão super-dimensionadas, o $\beta_{\text {alvo }}$ pode ser reduzido, ao mesmo tempo que pode ser elevado se for constatado que essas pontes possuem margem de segurança insatisfatória. Moses (1999) afirma que uma vantagem de se obter $\beta$ a partir de projetos existentes é que pequenas mudanças nos dados de entrada têm pequena influência no resultado final.

Para a elaboração de sua bridge formula, Ghosn et al. (1995) obtém $\beta_{\text {alvo }}$ 
considerando momentos fletores em vigas de pontes de aço, simplesmente apoiadas, projetadas de acordo com o método das tensões admissíveis (working stress design, critério de projeto usado na maioria das pontes existentes nos EUA) e carregamento HS-20 (AASHTO, 1996).

O método das tensões admissíveis é dado pela seguinte equação:

$$
\mathrm{R}_{\mathrm{n}}=\frac{1}{0,55} \cdot\left(\mathrm{G}_{\mathrm{n}}+\mathrm{Q}_{\mathrm{n}}+\mathrm{I}_{\mathrm{n}}\right)
$$

onde:

$\mathrm{R}_{\mathrm{n}}$ : resistência nominal necessária;

$\mathrm{G}_{\mathrm{n}}$ : efeito da carga permanente em um elemento;

$\mathrm{Q}_{\mathrm{n}}$ : efeito estático da carga móvel em um elemento obtido com o veículo de projeto e o fator de distribuição de carregamento da AASHTO (1996);

$I_{n}$ : efeito dinâmico especificado pela AASHTO (1996).

O carregamento HS-20 está na figura 2.10.

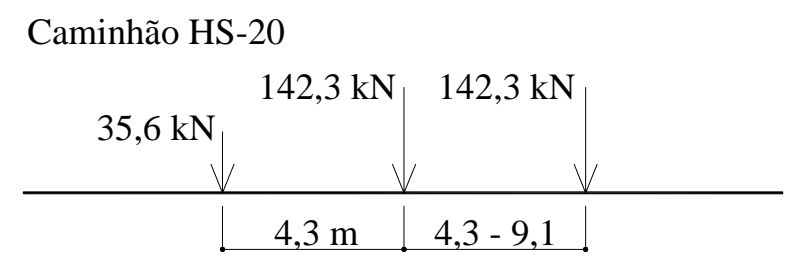

Carregamento de faixa HS-20

$80,1 \mathrm{kN}$ para momento fletor $115,6 \mathrm{kN}$ para força cortante

$9,3 \mathrm{kN} / \mathrm{m}$

Carregamento militar

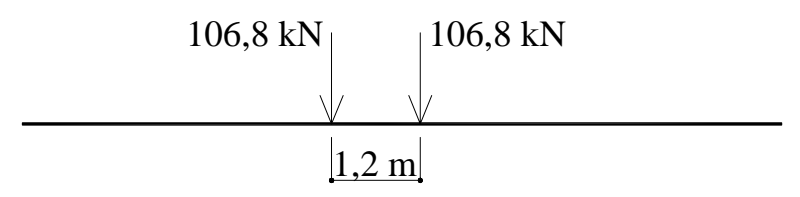

Conversão de unidades utilizada: $1 \mathrm{ft}=0,3048 \mathrm{~m}$ $1000 \mathrm{lb}=4,448 \mathrm{kN}$

Figura 2.10 - Carregamento HS-20 da AASHTO (1996).

Os índices de confiabilidade obtidos através desse procedimento, mostrados na 
figura 2.11, variam de 2,5 (vão de $9 \mathrm{~m}$ ) a 4,2 (vão de 61m), indicando que pontes com pequenos vãos apresentam maior risco quando projetadas com os critérios acima descritos. A justificativa para esse fato reside no método de cálculo, que utiliza apenas um coeficiente de segurança, independentemente se a carga pode ser estimada com maior ou menor precisão (carga permanente e carga móvel). Vãos pequenos, possuindo relativamente menor carga permanente, possuem portanto betas menores. A média do índice de confiabilidade para todos os vãos é 3,58. Nesses cálculos, foi considerado um fator de crescimento do tráfego, de maneira a prever um aumento no peso de caminhões e no volume de tráfego com o passar dos anos.

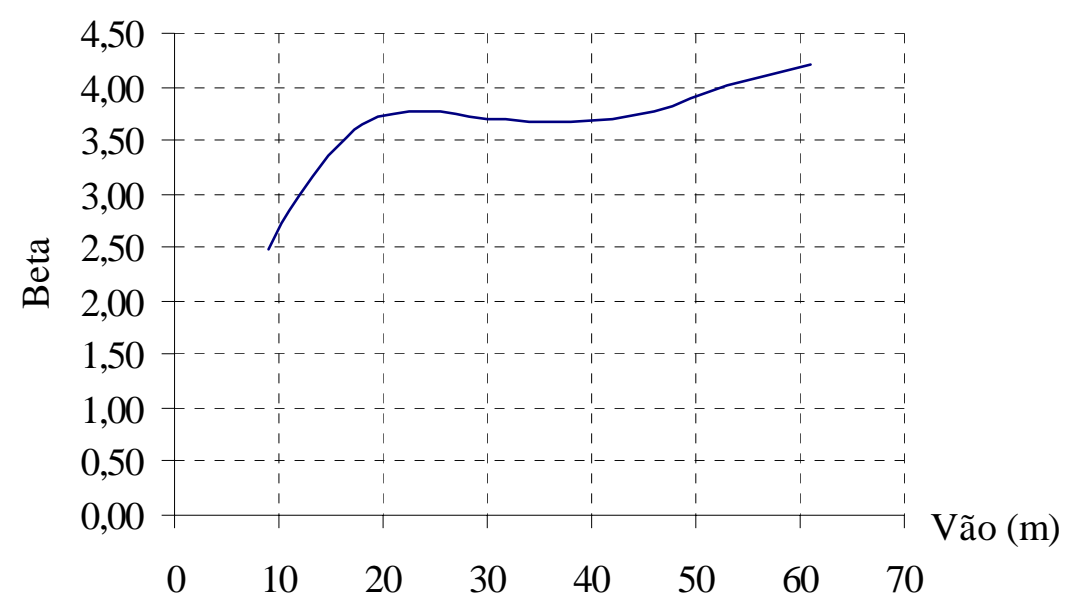

Figura 2.11 - Índices de confiabilidade obtidos a partir do método das tensões admissíveis da AASHTO (1996).

Analisando-se a figura 2.11, comprova-se a falta de uniformidade na segurança das pontes projetadas pelo método das tensões admissíveis da AASHTO. Apesar da variação nos índices de confiabilidade ser menor no método LFD (load factor design), também da AASHTO, Moses e Verma (1987) ainda não os consideram uniformes ou consistentes. A resistência nominal pelo método LFD é dada por:

$$
\mathrm{R}_{\mathrm{n}}=1,3 \cdot\left[\mathrm{G}_{\mathrm{n}}+\frac{5}{3}\left(\mathrm{Q}_{\mathrm{n}}+\mathrm{I}_{\mathrm{n}}\right)\right]
$$

De acordo com esses autores, as razões para a falta de uniformidade são o veículo de projeto e os coeficientes de majoração das cargas (carga permanente e carga móvel) presentes na AASHTO. Após calibrarem novos coeficientes para majoração da 
carga e minoração da resistência, Moses e Verma (1987) mostram que é possível a obtenção de betas praticamente uniformes.

Considerando que as pontes de pequeno vão apresentam desempenho

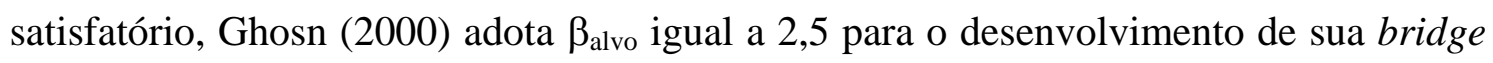
formula (menor valor proveniente de sua análise, obtido para vão de $9 \mathrm{~m}$ ). Caso não fosse considerado crescimento no tráfego, esse valor corresponderia a $\beta_{\mathrm{alvo}}=3$.

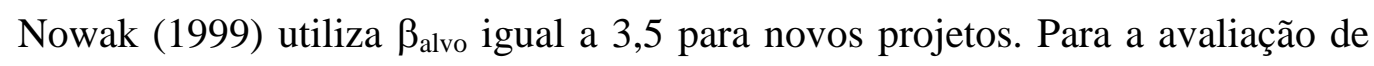
pontes existentes, em geral admite-se um valor inferior. Por exemplo, Moses e Verma (1987) utilizam um $\beta_{\text {alvo }}$ de 2,3 na calibração de coeficientes parciais para a avaliação da capacidade portante de pontes existentes quando não é considerado crescimento no tráfego (pontes de aço e concreto protendido). No entanto, Moses e Verma (1987) requerem inspeção detalhada nas pontes a cada dois anos. Para pontes de concreto armado, com objetivos semelhantes, Imbsen et al. (1987) utilizam 2,8.

No caso de pontes em concreto protendido, os estados limites de serviço em geral são predominantes e devem ser verificados em conjunto com o estado limite último. Um estudo desenvolvido por Nowak e El-Hor (1995) em vigas padronizadas pela AASHTO demonstrou que a tensão de tração a tempo infinito é crítica. A compressão excessiva, que pode causar elevadas deformações permanentes à estrutura, também deve ser observada.

Considerando-se que as conseqüências devido a uma falha nos estados limites de serviço são menores em relação ao estado limite último, o índice de confiabilidade requerido é menor também. Nowak, Szerszen e Park (1998) recomendam $\beta_{\text {alvo igual a }}$ 1,0 para a tensão de tração e 3,0 para a compressão excessiva.

\subsection{Carga permanente}

O cálculo do índice de confiabilidade necessita de dados estatísticos das variáveis envolvidas na equação (2.4). Para vãos pequenos e médios, as variáveis de maior interesse restringem-se à carga permanente, à carga móvel e à resistência dos elementos estruturais. Com essa justificativa e a fim de simplificar a análise, os efeitos de fenômenos naturais e outras ações, como a colisão de veículos, não serão considerados.

Deve-se ressaltar que, embora a carga permanente não varie com o passar do 
tempo, ela deve ser tratada com variável aleatória, uma vez que seus valores exatos não são precisamente conhecidos (devido a variações nas densidades dos materiais e variações nas dimensões dos elementos estruturais) e o seu efeito na estrutura envolve certo grau de incerteza (devido à diferença entre as condições de apoio reais e as consideradas no projeto, à continuidade e ao efeito das etapas de construção nas tensões geradas na estrutura). De acordo com Ghosn (1999), as incertezas decorrentes da análise estrutural são chamadas de “incertezas da modelagem”. Embora essas incertezas sejam significativas para todas as ações, é no caso da carga móvel e de outras ações transientes que seu efeito é mais notado. Ghosn (1999) ainda afirma que não há métodos usuais para a consideração das incertezas de modelagem nem mesmo dados estatísticos disponíveis. Um procedimento possível é a introdução de uma nova variável aleatória, cujos dados seriam obtidos da comparação entre os resultados da análise estrutural e a resposta experimental das pontes (GHOSN, 1999). Essas incertezas aqui discutidas fazem com que o risco calculado não seja o real, e sim um "risco de referência”, embora os resultados obtidos sejam consistentes.

O efeito da carga permanente deve incluir o peso próprio da estrutura, o revestimento da pista e outros elementos não-estruturais conectados permanentemente à estrutura. Imbsen et al. (1987), através de uma análise de sensibilidade, comprovam que a parcela mais importante da carga permanente (a que mais influi no índice de confiabilidade) é o peso próprio da estrutura. Porém, de maneira geral, variações nos parâmetros da carga permanente produzem menor variação no índice de confiabilidade do que variações nos parâmetros da resistência e da carga móvel, indicando que maior empenho deve ser dispendido na avaliação dessas duas últimas variáveis.

Devido aos diferentes graus de variabilidade, Nowak (1999) separa os componentes da carga permanente da seguinte forma:

a) Peso de componentes pré-fabricados (aço e concreto pré-moldado);

b) Peso de elementos moldados no local;

c) Peso do asfalto;

d) Demais (guarda-corpo, iluminação, etc).

Todas as componentes da carga permanente são tratadas como variáveis aleatórias que seguem uma distribuição normal. Os parâmetros estatísticos sugeridos 
por Nowak (1999), mostrados na tabela 2.1, são:

a) $\operatorname{Bias}(\lambda)$ : relação entre a média e o valor nominal (de projeto);

b) Coeficiente de variação $(\mathrm{CV})$ : relação entre o desvio-padrão e a média da variável aleatória.

Os coeficientes de variação mostrados na tabela 2.1 levam em consideração o erro humano, conforme recomendado em Ellingwood et al. (1980), e também as incertezas de modelagem.

Tabela 2.1 - Parâmetros estatísticos da carga permanente. (NOWAK, 1999)

\begin{tabular}{|c|c|c|}
\hline Componente & $\lambda$ & $\mathrm{CV}$ \\
\hline Pré-fabricados & 1,03 & 0,08 \\
\hline Moldados no local & 1,05 & 0,10 \\
\hline Asfalto & $8,9 \mathrm{~cm}^{*}$ & 0,25 \\
\hline Demais & $1,03-1,05$ & $0,08-0,10$ \\
\hline
\end{tabular}

* Espessura média

\subsection{Carga móvel}

De acordo com Crespo-Minguillón e Casas (1997), a ação do tráfego de veículos é a principal causa da deterioração por fadiga em pontes de vão pequeno e médio, além de ser a parcela das ações externas mais importante para a análise do estado limite último. Por outro lado, sua modelagem é bastante difícil devido à grande aleatoriedade e são poucos os dados estatísticos coletados a partir do tráfego real. No caso de novos projetos, em geral as informações sobre o tráfego de caminhões a serem utilizadas se referem a outras localidades, pois não se tem dados específicos para uma ponte antes da mesma ser construída e aberta ao tráfego.

O máximo efeito da carga móvel ocorre devido à presença simultânea de vários caminhões pesados. Cada evento de carregamento sobre a ponte é caracterizado pelo número de caminhões e sua posição relativa, seu peso bruto, e o espaçamento e o peso dos eixos. Dessa forma, Ghosn (2000) afirma que todos esses fatores são variáveis aleatórias e precisam ser levados em consideração no modelo para o cálculo do máximo efeito sobre a estrutura.

No caso do estado limite último é de interesse o máximo efeito do carregamento 
durante a vida útil da estrutura. Como os dados disponíveis são limitados a algumas semanas de tráfego, é preciso de alguma forma prever os máximos esforços para períodos mais longos.

São diversos os modelos para consideração do efeito do carregamento móvel. Em linhas gerais, eles se baseiam na teoria dos processos estocásticos, na simulação de configurações estáticas do tráfego ou na simulação do tráfego real. A seguir, serão descritos alguns métodos.

\subsubsection{O modelo de Nowak e Lind (1979)}

Este método utiliza dados de uma inspeção do tráfego em Ontário, 1975. Para a previsão do máximo esforço nas pontes em 50 anos de vida útil, os momentos fletores calculados a partir dos dados do tráfego real são extrapolados, pois o período de medição é bem inferior à vida útil considerada. Assumindo-se que a cauda superior da distribuição $\left(L_{50}\right)$ seja exponencial:

$$
\mathrm{F}_{\mathrm{L}_{50}}(\mathrm{x})=1-\mathrm{e}^{-\mathrm{x}}
$$

Na escala exponencial, essa extrapolação corresponde a uma linha reta. Assim, uma linha reta é ajustada a cauda superior da distribuição de momentos fletores (para vários vãos, simplesmente apoiados ou contínuos), determinada a partir dos 6 caminhões mais pesados na amostra (v. figura 2.12).

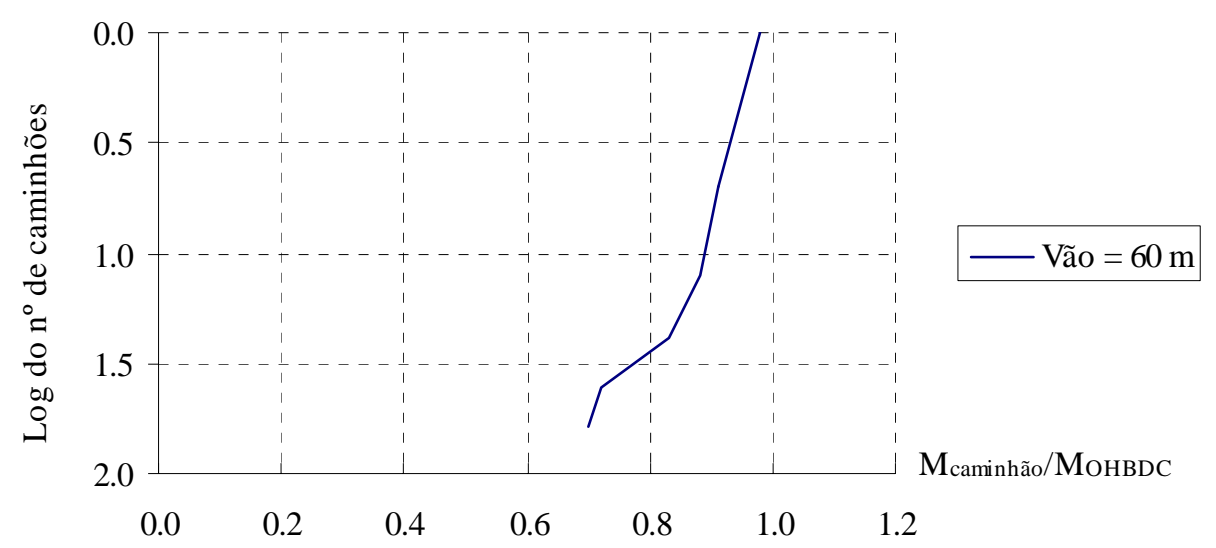

Figura 2.12 - Cauda superior da distribuição de momentos fletores.

(NOWAK e ZHOU, 1985) 
A escala horizontal corresponde à relação entre o momento fletor do caminhão da amostra e o momento fletor obtido de acordo com a norma canadense (OHBDC) da época. A escala vertical é o logaritmo do número de caminhões que excedem ou igualam a relação de momentos fletores. Por exemplo, a maior relação corresponde a zero na escala vertical, pois apenas 1 caminhão na amostra causa momento igual ou superior, e $\ln (1)=0$. A segunda maior relação corresponde a $\ln (2)=0,693$, pois 2 caminhões da amostra igualam ou superam o segundo maior momento fletor e assim sucessivamente.

Considerando que a população de caminhões em 50 anos será 600 vezes maior que a amostra, a média do máximo momento fletor corresponde a $\ln (600)=6,397$ na escala vertical. A extrapolação pode ser vista na figura 2.13. A análise também considerou que 1 ou os 2 caminhões mais pesados da amostra podem ser desprezados.

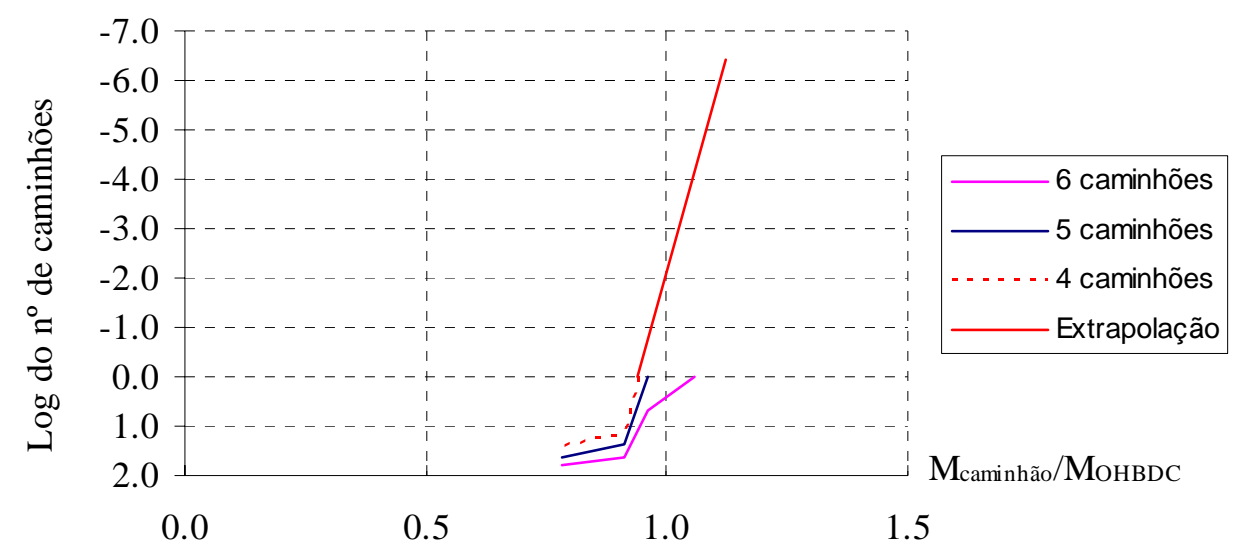

Figura 2.13 - Extrapolação para vida útil de 50 anos.

(NOWAK e ZHOU, 1985)

\subsubsection{O modelo de Ghosn e Moses (1985)}

Ghosn e Moses (1985) ressaltam a teoria dos processos estocásticos como uma ferramenta útil para a análise de estruturas submetidas a carregamentos aleatórios. A técnica utilizada é baseada no modelo de renovação de Markov, capaz de ser adaptado para considerar tanto o modelo de chegada de caminhões à ponte (medido ou idealizado) quanto às características dos caminhões (pesos e espaçamento dos eixos). A distribuição de probabilidade do máximo efeito da carga móvel é determinada para o tempo de vida útil da estrutura. Todas as possíveis localizações dos caminhões na ponte 
e seus pesos são testados. Maiores detalhes sobre o modelo de renovação de Markov podem ser encontrados em Ghosn e Moses (1985) e Moses e Ghosn (1985). Um procedimento mais simples, usando o processo de Poisson para representar a chegada dos caminhões à ponte, pode ser visto em Ghosn (1999).

De acordo com Crespo-Minguillón e Casas (1997), os procedimentos para simplificar as expressões teóricas fazem com que seu uso seja válido apenas para vãos pequenos e médios.

\subsubsection{O modelo de Moses e Ghosn (1985)}

Em Moses e Ghosn (1985) são desenvolvidos programas de simulação para estudar o carregamento de caminhões em pontes de vãos pequenos e médios, cujos resultados são utilizados em diversos outros estudos (entre eles, GHOSN, 2000; GHOSN et al, 1995; MOSES e VERMA, 1987).

Nesses programas, a superfície da ponte é dividida em regiões e um evento de carregamento ocorre quando há pelo menos um caminhão em qualquer região. O primeiro caminhão que chega à ponte e que faz parte de um evento de carregamento é considerado o caminhão “principal”, cuja probabilidade de estar em uma certa faixa de tráfego é obtida das estatísticas do tráfego para uma localidade. Por exemplo, na rodovia I-90 (duas faixas de trafego), em Ohio, Estados Unidos, 83\% dos caminhões viajam pela faixa da direita.

As possíveis combinações de veículos são obtidas e associadas a uma probabilidade de ocorrência, calculada a partir de dados de campo: por exemplo, a partir de medidas de peso em movimento (weight-in-motion). Essa probabilidade depende da localidade e do tráfego. Devido ao fato das medidas de campo se restringirem a rodovias com duas faixas de tráfego, os resultados obtidos por Moses e Ghosn (1985) valem apenas para pontes com duas faixas. Como ilustração, na mesma estrada em Ohio, dado um caminhão principal na faixa da direita, a probabilidade do segundo caminhão também estar na faixa da direita é de 83,5\%. Ainda, dado que o caminhão principal está na faixa da direita e que o caminhão seguinte está na faixa da esquerda, a probabilidade dos caminhões ocuparem regiões adjacentes (estarem lado a lado) é 5,8\%.

Moses e Ghosn (1985) consideram apenas dois tipos de caminhões nos eventos de carregamento. Dependendo do tipo, cada caminhão é associado a um peso e a uma 
probabilidade obtida dos histogramas de peso bruto. Dado as posições dos caminhões e o peso de todos os caminhões no evento, o máximo efeito é calculado através da linha de influência da ponte e associado a uma probabilidade (probabilidade da faixa ocupada pelo caminhão principal, vezes a probabilidade condicional das faixas ocupadas pelos caminhões seguintes, vezes a probabilidade da posição longitudinal do veículo na ponte, vezes a probabilidade dos pesos brutos). Esse procedimento assume independência entre as posições relativas dos caminhões e os pesos brutos e entre os pesos brutos dos diferentes caminhões no evento.

O cálculo do esforço na seção mais solicitada é executado para todas as combinações de caminhões na ponte e para todos os pesos dos caminhões. Seguindo essa metodologia, é obtido um histograma que fornece o efeito (momento fletor, por exemplo) associado a sua probabilidade. A distribuição de probabilidade do máximo efeito para a vida útil de projeto da estrutura, dependente do número de eventos de carregamento por dia e da vida útil, é dada por (Thoft-Christensen e Baker, 1982):

$$
\mathrm{G}_{\mathrm{m}}(\mathrm{T})=\mathrm{F}_{\mathrm{x}}(\mathrm{x})^{\mathrm{N}}
$$

onde:

$\mathrm{G}_{\mathrm{m}}(\mathrm{T})$ : distribuição acumulada do máximo momento fletor para a vida útil da ponte;

$\mathrm{F}_{\mathrm{X}}(\mathrm{x})$ : probabilidade acumulada para um evento de carregamento;

$\mathrm{N}$ : número de eventos para a vida útil da estrutura.

Em geral, considera-se uma vida útil de projeto para as pontes de 50 ou 75 anos, embora Moses e Ghosn (1985) demonstrem que o máximo efeito atinge um valor limite com aproximadamente 25 anos, mantendo-se praticamente inalterado a partir daí.

Através de uma análise de sensibilidade, os autores demonstraram que uma boa representação da cauda do histograma de peso em uma certa localidade pode ser obtido do valor do peso bruto correspondente ao percentil de 95\% de todos os pesos brutos coletados na localidade, chamado $\mathrm{W}_{0,95}$.

Como resultado das simulações, a média do momento fletor total obtido com o máximo carregamento na vida útil da ponte para um tráfego de caminhões geral em uma certa localidade é dada aproximadamente por: 
$\mathrm{M}=\mathrm{a} \cdot \mathrm{m} \cdot \mathrm{W}_{0,95} \cdot \mathrm{H}$

onde:

a: representa o momento fletor máximo devido ao caminhão padrão usado no estudo com peso bruto igual a uma unidade. Depende do tipo de caminhão e do vão;

m: fator de correção que reflete a variação entre o efeito de um caminhão aleatório sobre a ponte e o efeito produzido pelo caminhão utilizado na simulação. É mais significativo para vãos pequenos, onde o espaçamento e o pesos dos eixos torna-se mais importante. Também é função do vão;

$\mathrm{W}_{0,95}$ : percentil característico de $95 \%$ do peso bruto dos caminhões. É considerado aleatório para refletir possíveis erros na estimativa da variável e para refletir valores diferentes de uma localidade para outra;

H: relação entre a mediana do máximo momento fletor durante a vida útil e o máximo momento fletor devido a um caminhão padrão com peso bruto igual a $\mathrm{W}_{0,95}$. Assim, H é a variável aleatória que considera a presença simultânea de mais de um caminhão sobre a ponte. $\mathrm{H}$ também reflete a probabilidade que o peso do veículo exceda o percentil de 95\%. É função do volume de caminhões e do vão.

A equação (2.24) fornece o máximo momento fletor estático em uma ponte devido à carga móvel durante a vida útil de uma ponte. Para obter o efeito do carregamento em uma viga de ponte submetida à ação dinâmica do tráfego, duas novas variáveis precisam ser inseridas: o coeficiente de impacto (i) e o coeficiente de distribuição por viga $(g)$. Além disso, prevendo-se um possível crescimento no peso e no volume de tráfego dos caminhões ao longo da vida útil da estrutura, os autores consideram um fator de crescimento do tráfego através da variável Gr (assume-se com média 1,15 e coeficiente de variação 10\%). Dessa forma, a equação (2.24) torna-se:

$\mathrm{M}=\mathrm{a} \cdot \mathrm{m} \cdot \mathrm{H} \cdot \mathrm{W}_{0,95} \cdot \mathrm{i} \cdot \mathrm{g} \cdot \mathrm{Gr}$

Os valores das variáveis aleatórias encontrados nas tabelas 2.2 e 2.3 foram obtidos para uma vida útil de 50 anos baseando-se em dados de peso em movimento 
coletados de várias localidades nos Estados Unidos.

Tabela 2.2 - Dados para análise do carregamento móvel. (GHOSN, 2000)

\begin{tabular}{|c|c|c|c|c|c|}
\hline Vão & $\mathbf{a}$ & \multicolumn{2}{|c|}{$\mathbf{m}$} & \multicolumn{2}{c|}{$\mathbf{H}$} \\
\hline$(\mathrm{m})$ & $(\mathrm{kN} \cdot \mathrm{m})$ & Média & $\mathrm{CV}(\%)$ & Média & $\mathrm{CV}(\%)$ \\
\hline 9 & 8,23 & 0,92 & 15 & 2,63 & 10 \\
\hline 12 & 11,62 & 0,93 & 12 & 2,69 & 10 \\
\hline 18 & 18,40 & 0,94 & 6 & 2,75 & 10 \\
\hline 24 & 18,17 & 0,93 & 9 & 2,78 & 7 \\
\hline 30 & 24,95 & 0,95 & 7 & 2,80 & 7 \\
\hline 38 & 33,09 & 0,96 & 6 & 2,86 & 7 \\
\hline 46 & 41,90 & 0,96 & 5 & 2,87 & 7 \\
\hline 53 & 50,04 & 0,97 & 4 & 2,98 & 7 \\
\hline 61 & 58,85 & 0,97 & 4 & 3,05 & 7 \\
\hline
\end{tabular}

Tabela 2.3 - Valores de $\mathrm{W}_{0,95} \cdot(\mathrm{GHOSN}, 2000)$

\begin{tabular}{|c|c|c|}
\hline Vão (m) & $\mathrm{W}_{0,95}(\mathrm{kN})$ & $\mathrm{CV}(\%)$ \\
\hline$\leq 18$ & 209 & 15 \\
\hline$>18$ & 334 & 10 \\
\hline
\end{tabular}

O coeficiente de distribuição fornece a parcela do efeito do carregamento móvel que é absorvida pela viga mais solicitada. É um procedimento aproximado prescrito na AASHTO (1994) e na AASHTO (1996), que pode substituir métodos mais refinados, como elementos finitos ou análise de grelha. Para momentos fletores e forças cortantes em vigas internas, o coeficiente de distribuição por viga dado pela AASHTO (1996) é:

$g=\frac{S}{D}$

onde:

g: fator que multiplica o efeito do carregamento de uma única linha longitudinal de rodas (uma linha de rodas é definida como metade do carregamento total de uma faixa de tráfego);

s: espaçamento entre as vigas, de centro a centro;

D: constante que depende do tipo e da geometria da ponte.

Por exemplo, quando uma ponte é projetada para duas ou mais faixas de tráfego e o espaçamento entre as vigas é menor que 4,3 m, $D$ é igual a 1,68 para o caso de vigas 
de aço com seção transversal tipo I. Assim, considerando-se uma ponte com duas faixas de tráfego, vão de 29 m e espaçamento entre vigas igual a 1,12 m (PCI, 1997):

$\mathrm{g}=\frac{1,12}{1,68}=0,67$ linhas de roda/viga $=0,33$ faixas de tráfego/viga

Considerando-se um caminhão HS-25, cujo momento fletor máximo no meio do vão por faixa de tráfego é 2427,5 kN.m, e coeficiente de impacto igual a 0,23, o momento fletor em uma viga interna é: $M=2427,48 \cdot 0,33 \cdot(1+0,23)=985,3 \mathrm{kN} \cdot \mathrm{m}$. As fórmulas fornecidas pela AASHTO (1996) não são válidas para pontes esconsas.

No entanto, dados estatísticos baseados em medidas de campo e análises teóricas demonstram certa discrepância com os valores fornecidos em norma. Ghosn (2000) indica para pontes de aço uma bias de 0,90 em relação aos valores da AASHTO (1996) e CV igual a 8\%. Para pontes de concreto armado em viga T a bias sugerida é 1,01 com CV de 5\% e para pontes de concreto protendido a bias é 0,96 e CV de 8\%. Valores mais precisos do coeficiente de distribuição por viga podem ser encontrados na AASHTO (1994).

O coeficiente de impacto é função da rugosidade do pavimento. Três valores diferentes são recomendados por Moses e Verma (1987): 1,1 (superfície suave), 1,2 (superfície média) e 1,3 (superfície rugosa), todos associados a um coeficiente de variação de 10\%. Considerando-se pontes de aço e concreto protendido, Moses e Ghosn (1985) propõem 1,2 e CV igual a 8\% a partir de medidas da passagem de caminhões pesados. Para pontes de concreto armado em viga $\mathrm{T}$ recomenda-se coeficiente de impacto médio igual a 1,15 e CV igual a 10\%.

\subsubsection{O modelo de Nowak (1999)}

Na calibração de coeficientes parciais para a AASHTO (1994), Nowak (1999) utiliza os resultados de uma inspeção no tráfego de caminhões realizada em 1975 pelo Ministério do Transporte de Ontário. Nesse estudo, foram observados cerca de 10.000 caminhões (apenas caminhões que pareciam possuir elevado peso bruto foram medidos e incluídos na base de dados), representando 2 semanas de tráfego. Vale observar que naquela época a população de caminhões de Ontário era representativa dos caminhões 
que circulavam nos Estados Unidos.

De acordo com Nowak (1999), são várias as incertezas na análise devido à limitação e desvios nos dados obtidos do tráfego, entre elas: a amostra de caminhões estudada é pequena se comparada com o número real de caminhões durante a vida útil (75 anos), alguns caminhões sobrecarregados propositadamente evitam as estações de pesagem, e as futuras tendências em distribuições de pesos e eixos são desconhecidas. No trabalho, é assumido que a legislação não irá mudar no futuro e a população de caminhões irá permanecer inalterada.

Para cada caminhão da amostra são calculados momentos fletores e forças cortantes. São considerados vãos simplesmente apoiados e dois vãos idênticos contínuos. As funções distribuição acumulada são plotadas em um papel de probabilidade normal. Os máximos momentos fletores e forças cortantes para vários períodos (superiores a 2 semanas) são determinados por extrapolação. Por exemplo, em 75 anos o número de caminhões será aproximadamente $\mathrm{N}=20$ milhões, cujo nível de probabilidade é $1 / \mathrm{N}$, ou seja, $5 \cdot 10^{-8}$. Esse valor corresponde a $\mathrm{z}=5,33$ $(\mathrm{z}=-\Phi(1 / \mathrm{N}))$ na escala vertical. Na figura 2.14 é mostrada a extrapolação para momento fletor negativo em um vão de 9 metros.

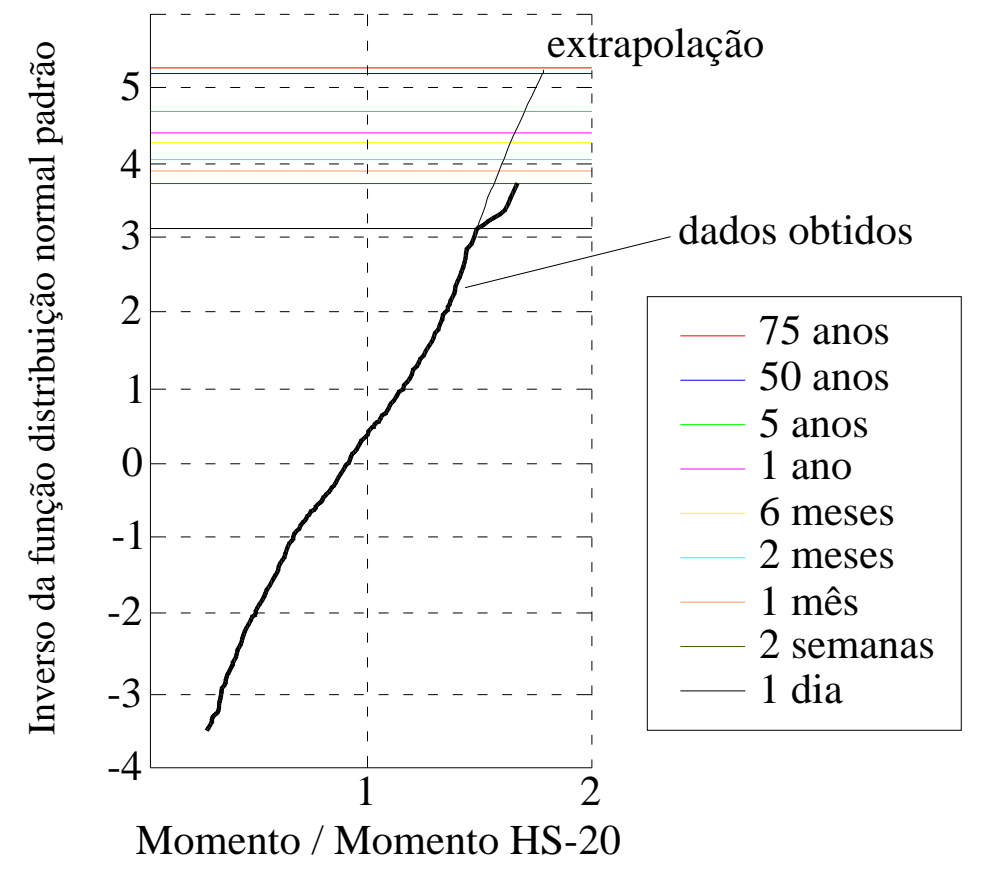

Figura 2.14 - Extrapolação para momento fletor negativo para vão de 9 metros. (NOWAK, 1999) 
A partir dos gráficos, são feitas tabelas que fornecem a relação entre o esforço causado pelo caminhão observado e o esforço obtido com o carregamento HS-20 (bias), para vários vãos e períodos. Uma dessas tabelas é ilustrada na figura 2.15, que mostra a média dos momentos fletores máximos para vãos únicos devido a um caminhão isolado. Gráficos semelhantes podem ser obtidos para força cortante em vãos únicos e momento fletor negativo em vãos contínuos. A partir desses dados o coeficiente de variação também é determinado.

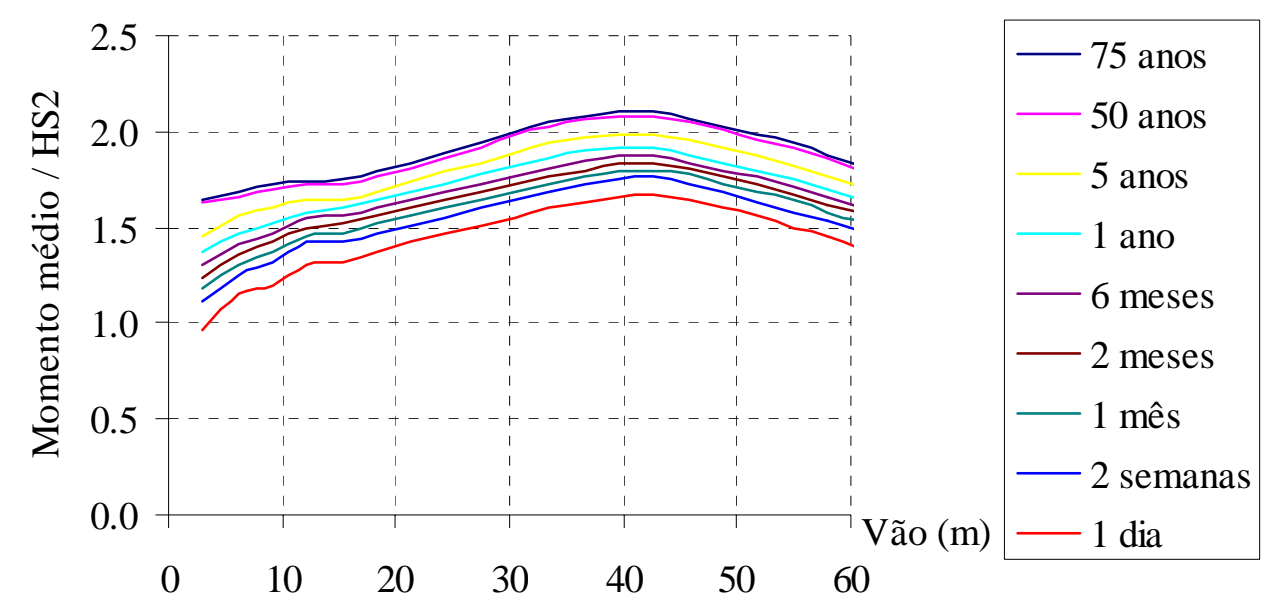

Figura 2.15 - Média dos máximos momentos fletores para vãos únicos devido a um caminhão isolado. (NOWAK, 1999)

\subsubsection{Momentos fletores e forças cortantes em pontes com 1 faixa de tráfego}

Para pontes com uma faixa de tráfego, o máximo efeito (momento fletor ou força cortante) é causado por um caminhão isolado ou por dois (ou mais) caminhões em fila. No caso de múltipla presença, é necessário o conhecimento da distância entre os veículos e a relação entre seus pesos. Por exemplo, Nowak e Hong (1991) alertam que os caminhões podem possuir similaridades (serem do mesmo dono, com a mesma configuração de eixos e mesma carga), podem viajar em grupos e, portanto, podem ser altamente correlacionados quanto ao peso. Salienta-se que grau de correlação é entendido como o grau de dependência linear entre duas variáveis aleatórias.

Dessa forma, o máximo efeito é o maior dos seguintes casos:

a) Caminhão isolado, com efeito igual ao máximo momento fletor (ou força cortante) em 75 anos; 
b) Dois caminhões (um atrás do outro), com pesos inferiores ao do caminhão isolado e com headways (distância do eixo traseiro do veículo que está na frente ao eixo dianteiro do caminhão que vem atrás) variando entre 4,5 e 30,5 metros. Para headways inferiores a 15 metros os caminhões estão muito próximos (veículos parados ou com velocidade reduzida) e assim não é considerada a parcela dinâmica. Três graus de correlação entre os pesos foram considerados: sem correlação $(\rho=0)$, correlação parcial $(\rho=0,5)$ e correlação total $(\rho=1)$.

As seguintes hipóteses foram assumidas com base em observações e julgamento técnico:

A cada 50 caminhões, 1 é seguido por outro a uma distância inferior a 30 metros;

$\checkmark$ A cada 150 caminhões, 1 é seguido por outro com correlação parcial de peso;

$\checkmark$ A cada 500 caminhões, 1 é seguido por outro com correlação total de peso;

Os parâmetros dos dois caminhões ( $\mathrm{T}_{1}$ e $\mathrm{T}_{2}$ ) estão na tabela 2.4.

Tabela 2.4 - Parâmetros para os caminhões em uma faixa de tráfego. (NOWAK, 1999)

\begin{tabular}{|c|c|c|c|c|c|}
\hline $\mathbf{N}^{\mathbf{0}}$ de caminhões & Correlação & Caminhão & $\mathbf{N}$ & $\mathbf{z}$ & $\mathbf{T}$ \\
\hline 1 & - & - & 20.000 .000 & 5,33 & 75 anos \\
\hline \multirow{3}{*}{2} & \multirow{2}{*}{$2=0$} & $\mathrm{~T}_{1}$ & 300.000 & 4,50 & 1 ano \\
\cline { 3 - 6 } & & $\mathrm{T}_{2}$ & 1 & 0,00 & média \\
\cline { 2 - 6 } & \multirow{2}{*}{$\rho=0,5$} & $\mathrm{~T}_{1}$ & 150.000 & 4,36 & 6 meses \\
\cline { 3 - 6 } & \multirow{2}{*}{$\rho=1$} & $\mathrm{~T}_{2}$ & 1.000 & 3,09 & 1 dia \\
\cline { 3 - 6 } & & $\mathrm{T}_{1}$ & 30.000 & 3,99 & 1 mês \\
\cline { 3 - 6 } & & $\mathrm{T}_{2}$ & 30.000 & 3,99 & 1 mês \\
\hline
\end{tabular}

Os momentos fletores e as forças cortantes máximas são calculadas por simulação. Por exemplo, para momentos fletores em vãos únicos, 1 caminhão isolado é crítico para vãos até cerca de 43 metros (v. figura 2.16). 


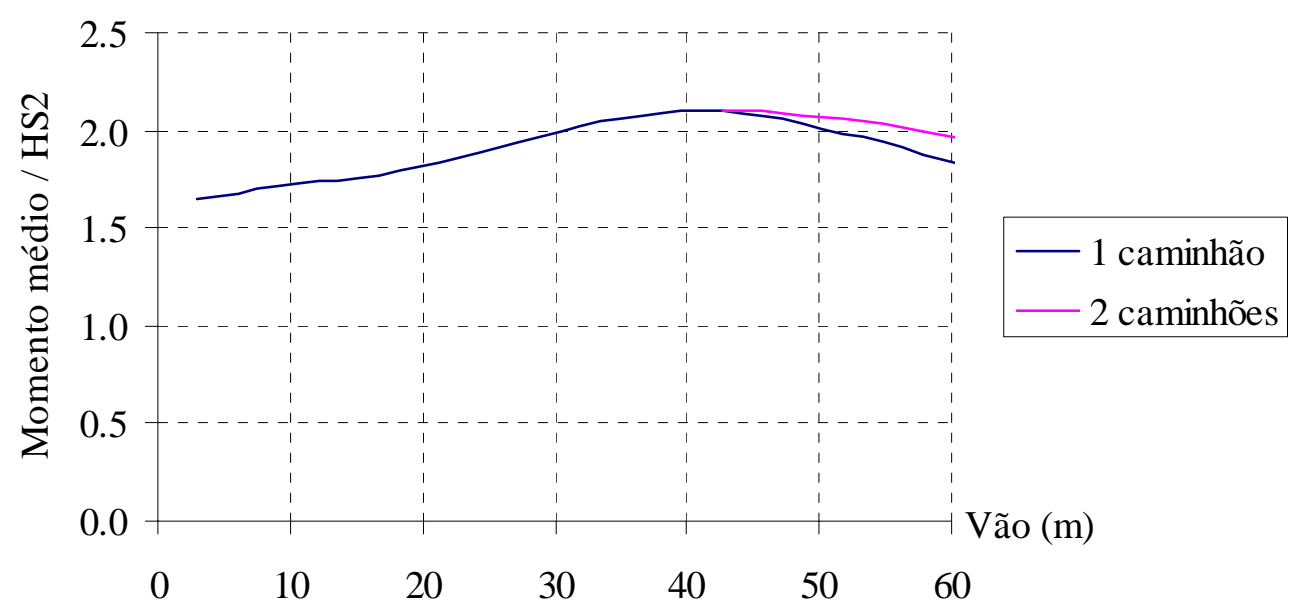

Figura 2.16 - Média dos máximos momentos fletores em 75 anos devido a um ou dois caminhões em uma faixa de tráfego. (NOWAK, 1999)

\subsubsection{Momentos fletores e forças cortantes em pontes com 2 faixas de tráfego}

Nowak (1999) analisou a distribuição do carregamento entre vigas (fator de distribuição por vigas) através do método dos elementos finitos, considerando comportamento linear das vigas e da laje. Foram estudados vãos variando de 9 a 61 metros e cinco casos de espaçamento entre as vigas: $1,2 \mathrm{~m}, 1,8 \mathrm{~m}, 2,4 \mathrm{~m}, 3,0 \mathrm{~m}$ e $3,7 \mathrm{~m}$. Para cada caso possível, os fatores de distribuição por viga foram calculados para várias posições transversais do caminhão, resultando em "linhas de influência” para o cálculo do efeito conjunto de caminhões em faixas adjacentes através de superposição. A comparação entre os resultados encontrados, os valores sugeridos pela AASHTO (1996) e outros pesquisadores podem ser vistos em Nowak (1999). Nowak e Szerszen (1998) advertem que a proposta da AASHTO (1996) é bastante simples, mas não é precisa, fornecendo valores muito conservativos para grandes vãos e grandes espaçamentos entre as vigas, enquanto que para pequenos vãos e espaçamentos os valores estipulados estão contra a segurança.

Em pontes com 2 faixas, o máximo momento fletor é o maior entre dois casos:

a) Uma faixa totalmente carregada e a outra sem carregamento;

b) Ambas as faixas carregadas, com 3 graus de correlação: sem correlação $(\rho=0)$, correlação parcial $(\rho=0,5)$ e correlação total $(\rho=1)$. 
Através de observações, constatou-se na média que:

$\checkmark$ Todo décimo quinto caminhão está na ponte simultaneamente com outro caminhão lado-a-lado;

$\checkmark$ Considerando as ocorrências simultâneas, a cada 10 vezes os caminhões são parcialmente correlacionados e a cada 30 vezes eles estão totalmente correlacionados com relação ao peso.

Os parâmetros para carregamento das faixas estão na tabela 2.5 .

Tabela 2.5 - Parâmetros para pontes com duas faixas de tráfego. (NOWAK, 1999)

\begin{tabular}{|c|c|c|c|c|c|}
\hline $\begin{array}{c}\mathbf{N}^{\mathbf{0}} \text { de faixas } \\
\text { carregadas }\end{array}$ & Correlação & Faixa & $\mathbf{N}$ & $\mathbf{z}$ & $\mathbf{T}$ \\
\hline 1 & - & - & 20.000 .000 & 5,33 & 75 anos \\
\hline \multirow{3}{*}{2} & $\rho=0$ & $\mathrm{~L}_{1}$ & 1.500 .000 & 4,83 & 5 anos \\
\cline { 3 - 6 } & & $\mathrm{L}_{2}$ & 1 & 0,00 & média \\
\cline { 2 - 6 } & \multirow{2}{*}{$\rho=0,5$} & $\mathrm{~L}_{1}$ & 150.000 & 4,36 & 6 meses \\
\cline { 3 - 7 } & \multirow{2}{*}{$\rho=1$} & $\mathrm{~L}_{2}$ & 1.000 & 3,09 & 1 dia \\
\cline { 3 - 7 } & & $\mathrm{L}_{1}$ & 50.000 & 4,11 & 2 meses \\
\cline { 3 - 7 } & & $\mathrm{L}_{2}$ & 50.000 & 4,11 & 2 meses \\
\hline
\end{tabular}

Os resultados das simulações indicam que, para vigas interiores, o caso com dois caminhões totalmente correlacionados lado-a-lado é crítico, mas com período de recorrência igual a 2 meses em vez de 75 anos.

De acordo com Nowak (1999), a relação entre a média (valor obtido através de inspeção no tráfego) e o valor nominal especificado pela AASHTO (1996) não é consistente, variando entre 1,5 e 2,1. Ainda segundo esse autor, é desejável que as normas especifiquem um fator de bias uniforme. Com esse objetivo, vários modelos de carga móvel foram testados em Nowak (1999) para serem utilizados na AASHTO (1994). O novo modelo adotado está na figura 2.17, com a bias variando entre 1,2 e 1,5, dependendo do tipo de esforço solicitante. A figura 2.18 compara a bias para momento fletor positivo considerando a AASHTO (1996) e o modelo proposto. Na figura 2.19 a mesma comparação é feita para força cortante e na figura 2.20 para momento fletor negativo. Os três gráficos comprovam a maior uniformidade do modelo proposto. 
Caminhão e carga distribuída

\begin{tabular}{|c|c|c|c|}
\hline $35,6 \mathrm{kN}$ & $142,3 \mathrm{kN}$ & $142,3 \mathrm{kN}$ & $9,3 \mathrm{kN} / \mathrm{m}$ \\
\hline & $4,3 \mathrm{~m}$ & $4,3-9,1$ & \\
\hline
\end{tabular}

Tandem e carga distribuída

$\frac{111,\left.2 \mathrm{kN}\right|^{111,2 \mathrm{kN}}}{1,2 \mathrm{~m} .}$

Carregamento alternativo para momento negativo (reduzir para 90\%)

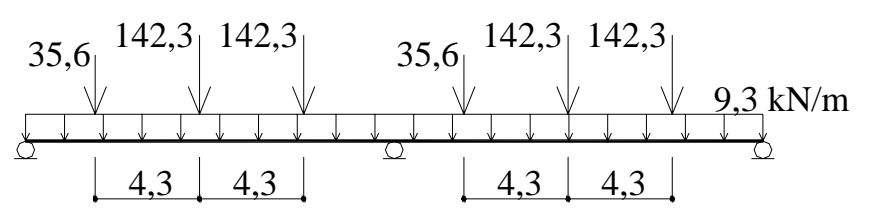

Conversão de unidades utilizada: $1 \mathrm{ft}=0,3048 \mathrm{~m}$ $1000 \mathrm{lb}=4,448 \mathrm{kN}$

Figura 2.17 - Carga móvel de projeto na AASHTO LRFD. (NOWAK, 1999)

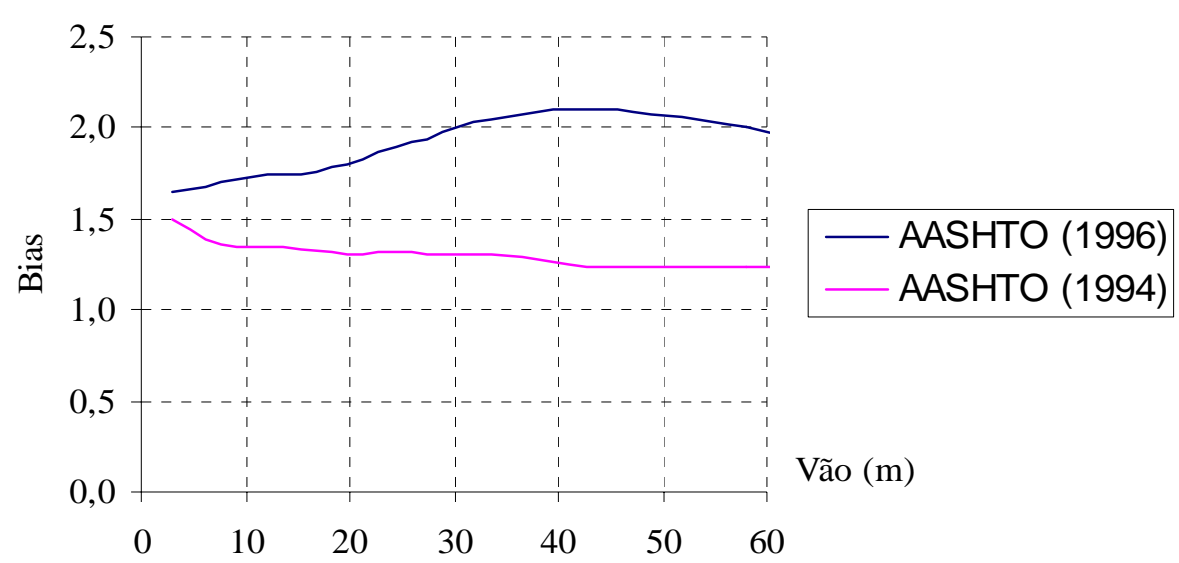

Figura 2.18 - Bias para momento fletor positivo, 75 anos de vida útil. (NOWAK, 1999)

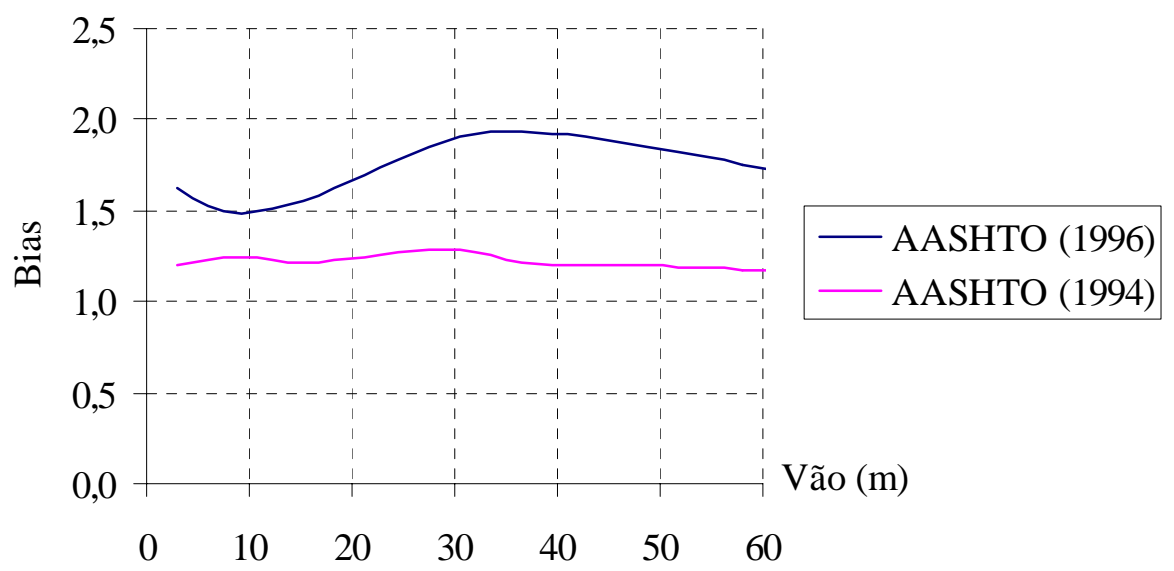

Figura 2.19 - Bias para força cortante, 75 anos de vida útil. (NOWAK, 1999) 


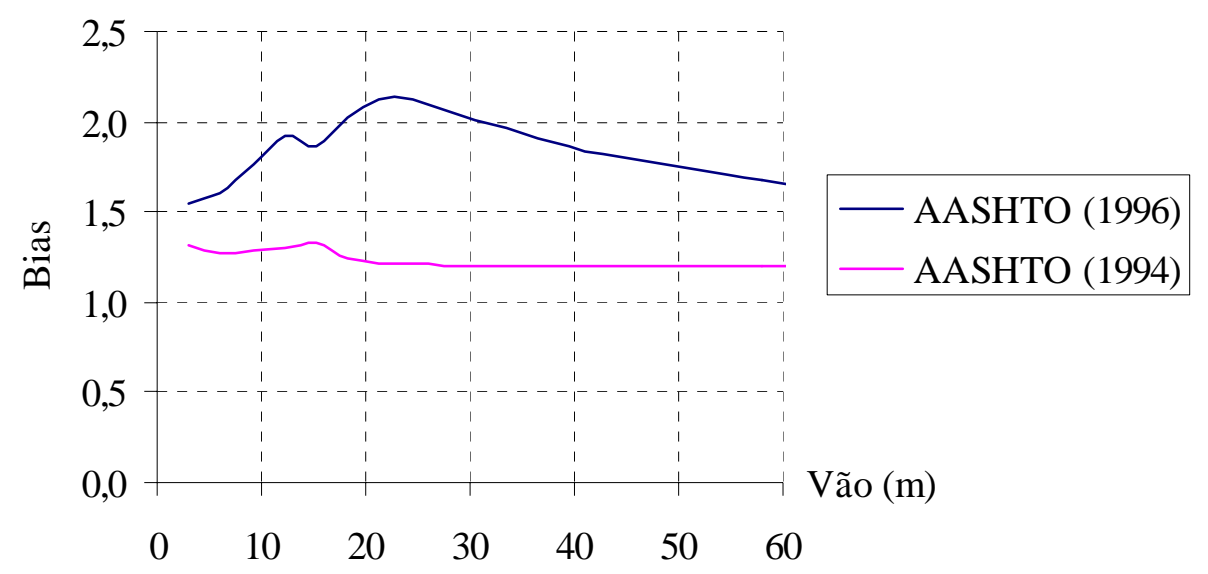

Figura 2.20 - Bias para momento fletor negativo, 75 anos de vida útil. (NOWAK, 1999)

Nowak (1999) e Hwang e Nowak (1991) também desenvolvem um modelo baseado em simulações para a consideração do efeito dinâmico, considerado como um carregamento estático equivalente a ser adicionado à carga móvel. O carregamento dinâmico é tido como função de três parâmetros: rugosidade da superfície da ponte, dinâmica da ponte (freqüência de vibração) e dinâmica do veículo (sistema de suspensão).

O coeficiente de carregamento dinâmico é definido como o máximo deslocamento dinâmico dividido pelo máximo deslocamento estático. Foram consideradas pontes de 5 vigas, com elementos de aço ou concreto protendido. Dois tipos de veículos (3 e 5 eixos) foram usados, compostos por um corpo, sistema de suspensão e pneus. Para cada caminhão foram consideradas três variáveis aleatórias: o peso bruto, a distância entre eixos e a velocidade. A rugosidade da superfície da ponte foi representada por série de Fourier. O máximo valor do coeficiente de carregamento dinâmico para 75 anos é calculado através de simulações de Monte Carlo.

Os resultados indicaram que o coeficiente de carregamento dinâmico diminui com o aumento do peso bruto do veículo, pois o deslocamento estático aumenta e o deslocamento dinâmico é quase constante (v. figura 2.21). O carregamento dinâmico, como uma parcela da carga móvel, também é menor para 2 caminhões em comparação com um único caminhão. Em geral, o efeito dinâmico é reduzido para um maior número de eixos. 


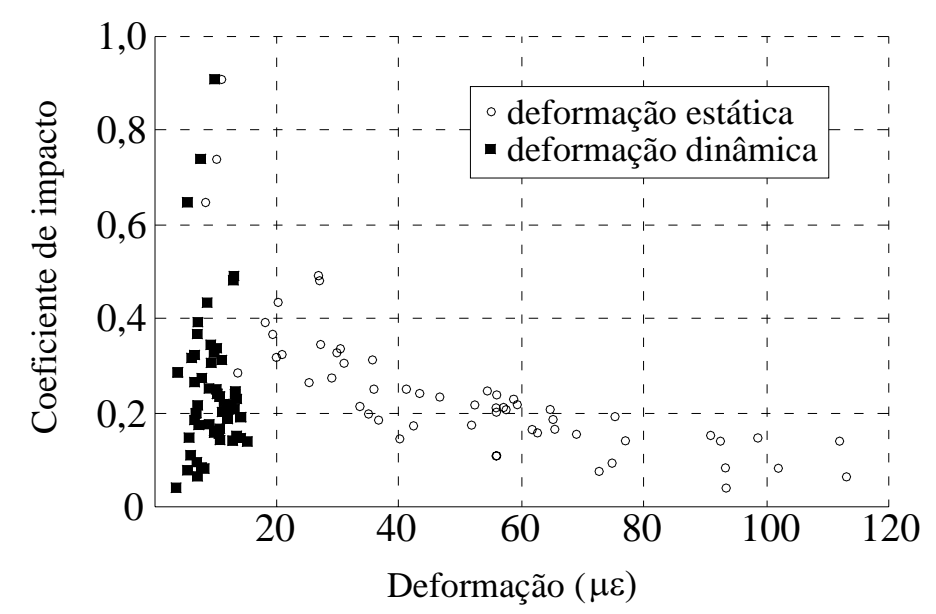

Figura 2.21 - Coeficiente de impacto em função das deformações. (NOWAK, 2004)

A média do coeficiente de carregamento dinâmico obtida para um único caminhão é 0,15 da média da carga móvel e para dois caminhões lado a lado, é 0,10. O coeficiente de variação é 0,8. O estudo propõe um coeficiente de carregamento dinâmico nominal igual a 0,33 , a ser aplicado ao efeito do caminhão apenas, sem coeficiente para a carga distribuída especificada no modelo de carga móvel. Para pontes de madeira, o coeficiente é reduzido em 50\%.

\subsubsection{O modelo de Crespo-Minguillón e Casas (1997)}

De acordo com Crespo-Minguillón e Casas (1997), os modelos de tráfego existentes não são completamente gerais, uma vez que são orientados ou para a previsão dos efeitos máximos em um período de tempo definido ou para a definição dos efeitos de fadiga. As suposições e as simplificações adotadas (devido às ferramentas computacionais ou aos dados do tráfego necessários) em modelos que tentam tratar das duas possibilidades não os tornam suficientemente confiáveis. Por outro lado, os modelos de carregamento disponíveis são direcionados ou para a definição das ações em novas pontes ou para a avaliação de pontes existentes. Assim, Crespo-Minguillón e Casas (1997) concluem que um modelo completo, válido para todo efeito de carregamento (carregamento máximo em um período de referência, fadiga, carregamento freqüente para a verificação dos estados limites de utilização), para qualquer situação (projeto de uma nova ponte ou para a avaliação de uma estrutura existente), considerando as correlações mais importantes presentes no tráfego real, não está disponível atualmente. 
Os autores desenvolvem um modelo para o estudo da ação do tráfego nas pontes com os seguintes objetivos:

a) Proporcionar um modelo amplo, válido para a análise dos estados limites último e de serviço mais importantes (resistência à flexão e estado limite de fissuração inaceitável), além do estado limite de fadiga. Esta meta é atingida através de dois passos: (1) o efeito do fluxo real de tráfego sobre a ponte é simulado em função do tempo e; (2) os máximos resultados obtidos no passo anterior para períodos curtos são extrapolados para valores máximos representativos de longos períodos de retorno;

b) Incluir as correlações mais importantes existentes no tráfego real: correlações entre veículos em uma faixa, entre diferentes faixas, entre o dia da semana e as condições do tráfego, o tipo dos veículos, etc;

c) Ser adaptável às características específicas de uma certa localidade (importante na avaliação de pontes existentes);

d) Não necessitar de grandes quantidades de dados sobre o fluxo real de tráfego;

e) Não permitir sobreposição de veículos;

f) Possibilitar a análise do efeito do carregamento em pontes de vão pequeno, médio e grande.

O efeito do trafego sobre a ponte é simulado a cada 0,20 segundos, durante 1 semana. O cálculo dos momentos fletores é realizado através da superfície de influência da estrutura.

Dentre os diversos modelos pesquisados, o trabalho de Crespo-Minguillón e Casas (1997) mostra-se o mais completo e abrangente, revelando o grande potencial dos modelos de simulação do tráfego real para a análise de pontes. No entanto, os autores não fornecem nenhum tipo de comparação com outros métodos. Detalhes sobre as hipóteses assumidas e os procedimentos matemáticos e estatísticos, incluindo a extrapolação dos resultados para a vida útil da estrutura, fogem ao escopo deste estudo.

\subsubsection{O modelo de Hwang e Koh (2000)}

Hwang e Koh (2000) utilizam como base para o desenvolvimento de seu 
modelo, dados de pesagem em movimento (weight-in motion) em 3 localidades, cerca de 100 mil no total. As informações sobre múltipla presença de veículos sobre as pontes são obtidas através de gravações em vídeo. Foram considerados na análise apenas os tipos de caminhões mais pesados e que aparecem em maior número; os demais foram desprezados. Dessa forma, foram considerados 7 tipos de caminhões.

Para cada localidade e tipo de caminhão, os $10 \%$ maiores pesos brutos foram plotados em papel de probabilidade normal. Utilizando regressão linear e considerando a relação entre o número de caminhões observados e o previsto para a vida útil da estrutura (75 anos), os máximos pesos brutos foram extrapolados. Esse procedimento é similar ao utilizado por Nowak (1999) descrito no item 2.5.4.

Os maiores pesos brutos provenientes da extrapolação para cada tipo de caminhão foram usados para o cálculo de máximos momentos fletores em estruturas simplesmente apoiadas.

A presença simultânea de veículos foi considerada apenas em uma mesma faixa, quando a distância entre eles era igual ou menor a 15 metros. No entanto, no cálculo dos momentos fletores os veículos foram dispostos a 5 metros de distância um do outro. As probabilidades de ocorrência, demonstradas através de gravações em vídeo, estão na tabela 2.6.

Tabela 2.6 - Probabilidade de 2 caminhões na mesma faixa. (HWANG e KOH, 2000)

\begin{tabular}{|c|c|c|c|}
\hline Pesos & Tráfego normal & Tráfego congestionado & Média $^{*}$ \\
\hline Não correlacionados & $1 / 85$ & $1 / 37$ & $1 / 70$ \\
\hline Correlação total & $1 / 403$ & $1 / 207$ & $1 / 348$ \\
\hline
\end{tabular}

Assumindo-se que o congestionamento ocorra por 4 horas em um dia.

Utilizando-se essas probabilidades, a porcentagem de cada veículo e a vida útil desejada, a extrapolação dos pesos brutos permite o cálculo dos momentos fletores para cada caso (pesos não correlacionados e pesos com correlação total). No primeiro caso, o caminhão principal é seguido por um caminhão com peso médio e no segundo caso os caminhões possuem pesos iguais.

Os resultados demonstram que um único caminhão produz o máximo esforço para vãos pequenos e 2 caminhões com correlação total de peso governam no caso de vãos maiores.

Os autores sugerem uma combinação de caminhão e carga distribuída para a 
obtenção dos esforços em projetos (normas), mas ressaltam que a carga distribuída deve ter sua magnitude diminuída com o aumento do vão, de modo que os momentos fletores calculados não superestimem o efeito do tráfego real. Ainda recomendam que os dados do tráfego sejam obtidos em diferentes localidades devido à sua elevada variabilidade.

\subsection{Resistência das seções transversais}

A resistência de qualquer elemento estrutural é função de determinadas variáveis aleatórias. A lei que relaciona essas variáveis e fornece o valor da resistência pode ser substituída na equação (2.4), procedendo-se então a determinação do índice de confiabilidade. Por exemplo, no caso de flexão simples na ruína e armadura apenas na borda tracionada (seção subarmada), a resistência nominal pode ser dada aproximadamente por:

$\mathrm{M}_{\text {res }}=\mathrm{A}_{\mathrm{s}} \cdot \mathrm{f}_{\mathrm{y}} \cdot(\mathrm{d}-0,4 \cdot \mathrm{x})$

onde:

$\mathrm{A}_{\mathrm{S}}$ : área de aço;

$\mathrm{f}_{\mathrm{y}}$ : resistência ao escoamento do aço;

d: distância da borda comprimida ao centro de gravidade da armadura (altura útil);

x: profundidade da linha neutra.

Introduzindo-se um fator que considere a aproximação teórica imbutida no desenvolvimento da equação (2.27), as variáveis que a compõe podem fazer parte diretamente da função de estado limite. Em outra opção, mais comumente usada, a resistência se mantém como uma única variável, sendo representada pela sua média (valor nominal multiplicado pela bias) e pelo coeficiente de variação.

A capacidade portante de elementos estruturais depende basicamente da resistência do material empregado e das dimensões da peça. De acordo com Nowak (1999), as incertezas são basicamente de três tipos:

a) Material: resistência, módulo de elasticidade, tensão de fissuração e composição química; 
b) Fabricação: geometria e dimensões;

c) Análise: método de análise aproximado, idealização da distribuição de tensões e deformações.

A resistência de elementos estruturais é então obtida a partir do produto da resistência nominal e três parâmetros:

$\mathrm{R}=\mathrm{R}_{\mathrm{n}} \cdot \mathrm{M} \cdot \mathrm{F} \cdot \mathrm{P}$

onde:

M: fator do material;

F: fator de fabricação;

P: fator de análise.

A bias ( $\lambda$ ) e o coeficiente da variação (CV) de $R$ são dados por:

$\lambda_{\mathrm{R}}=\lambda_{\mathrm{FM}} \cdot \lambda_{\mathrm{P}}$

$\mathrm{CV}_{\mathrm{R}}=\left(\mathrm{CV}_{\mathrm{FM}}{ }^{2}+\mathrm{CV}_{\mathrm{P}}{ }^{2}\right)^{1 / 2}$

onde:

$\lambda_{\mathrm{FM}}$ : bias dos fatores de fabricação $F$ e do material $M$ combinados;

$\lambda_{\mathrm{P}}$ : bias do fator de análise $P$;

$\mathrm{CV}_{\mathrm{FM}}$ : coeficiente de variação dos fatores $F$ e $M$;

$\mathrm{CV}_{\mathrm{P}}$ : coeficiente de variação do fator $P$.

Nowak (1999) afirma que as incertezas envolvidas na resistência vêm sendo modeladas através de ensaios, observação de estruturas existentes e julgamento de especialistas, com resultados disponíveis para materiais e elementos usuais. No entanto, peças de pontes são geralmente compostas de diversos materiais, que requerem métodos de análises especiais. O tamanho dessas peças, em geral considerável, torna onerosa a verificação do modelo analítico. Como alternativa, os modelos de resistência são desenvolvidos utilizando-se os dados disponíveis de ensaios de materiais e simulações numéricas. Os resultados das simulações possibilitam a determinação das bias e dos coeficientes de variação da resistência. 
Alguns parâmetros estatísticos das propriedades dos materiais e das dimensões das peças fornecidos por diversos trabalhos são encontrados nas tabelas 2.7 a 2.10.

Tabela 2.7 - Parâmetros estatísticos da resistência à compressão do concreto.

\begin{tabular}{|c|c|c|c|c|c|}
\hline Variável & $\begin{array}{c}\text { Valor } \\
\text { nominal }\end{array}$ & Bias & $\mathrm{CV}$ & $\begin{array}{c}\text { Tipo de } \\
\text { distribuição }\end{array}$ & Fonte \\
\hline \multirow{17}{*}{$\mathrm{f}_{\mathrm{c}}(\mathrm{MPa})$} & 20,7 & $0,92^{*}$ & 0,18 & Normal & \multirow{2}{*}{$\begin{array}{l}\text { Mirza et al. } \\
\text { (1979) }\end{array}$} \\
\hline & 34,5 & $0,805^{*}$ & 0,15 & Normal & \\
\hline & 20,7 & 1,35 & 0,10 & Normal & \multirow{6}{*}{$\begin{array}{c}\text { Nowak e Szerszen } \\
(2001)\end{array}$} \\
\hline & 24,1 & 1,21 & 0,10 & Normal & \\
\hline & 27,6 & 1,235 & 0,10 & Normal & \\
\hline & 31,0 & 1,14 & 0,10 & Normal & \\
\hline & 34,5 & 1,15 & 0,10 & Normal & \\
\hline & 41,3 & 1,12 & 0,10 & Normal & \\
\hline & 20,7 & 1,33 & 0,145 & Normal & \multirow{6}{*}{$\begin{array}{l}\text { Nowak et al. } \\
\text { (2005) }\end{array}$} \\
\hline & 24,1 & 1,24 & 0,115 & Normal & \\
\hline & 27,6 & 1,21 & 0,155 & Normal & \\
\hline & 31,0 & 1,19 & 0,160 & Normal & \\
\hline & 34,5 & 1,22 & 0,125 & Normal & \\
\hline & 41,3 & 1,22 & 0,075 & Normal & \\
\hline & \multicolumn{2}{|c|}{ Valor médio } & Desvio-padrão & & \\
\hline & \multicolumn{2}{|c|}{$\mathrm{f}_{\mathrm{ck}}+1,65 \cdot \sigma$} & $4,5,5$ ou 7 & Normal & NB-1 (1978) \\
\hline & \multicolumn{2}{|c|}{$\mathrm{f}_{\mathrm{ck}}+8$} & 5 & Lognormal & $\begin{array}{c}\text { Vismann e Zilch } \\
\text { (1995) }\end{array}$ \\
\hline
\end{tabular}

${ }^{*}$ A ser comparado com $0,85 \cdot \mathrm{f}_{\mathrm{C}}$

$\sigma:$ desvio-padrão

Tabela 2.8 - Parâmetros estatísticos da armadura passiva.

\begin{tabular}{|c|c|c|c|c|c|}
\hline Variável & $\begin{array}{c}\text { Valor } \\
\text { nominal }\end{array}$ & Bias & $\mathbf{C V}$ & $\begin{array}{c}\text { Tipo de } \\
\text { distribuição }\end{array}$ & Fonte \\
\hline \multirow[t]{2}{*}{$\mathrm{E}_{\mathrm{s}}(\mathrm{MPa})$} & 199810 & 1,00 & 0,06 & Lognormal & $\begin{array}{c}\text { Nowak, Yamani e } \\
\text { Tabsh (1994) }\end{array}$ \\
\hline & 200000 & 1,00 & 0,013 & Lognormal & Frangopol et al. (1996) \\
\hline & \multicolumn{2}{|c|}{ Valor médio } & & & \\
\hline \multirow{3}{*}{$A_{s}\left(\mathrm{~cm}^{2}\right)$} & \multicolumn{2}{|c|}{$A_{s, n o m}$} & 0,015 & Normal & $\begin{array}{c}\text { Nowak, Yamani e } \\
\text { Tabsh (1994) }\end{array}$ \\
\hline & \multicolumn{2}{|c|}{$A_{\mathrm{s}, \mathrm{nom}}$} & 0,025 & Normal & $\begin{array}{c}\text { Vismann e Zilch } \\
\text { (1995) }\end{array}$ \\
\hline & & & Desvio-padrão & & \\
\hline $\mathrm{f}_{\mathrm{y}}(\mathrm{MPa})$ & \multicolumn{2}{|c|}{$\mathrm{f}_{\mathrm{yk}}+60$} & 30 & Lognormal & $\begin{array}{c}\text { Vismann e Zilch } \\
\text { (1995) }\end{array}$ \\
\hline
\end{tabular}


Tabela 2.9 - Parâmetros estatísticos da armadura de protensão.

\begin{tabular}{|c|c|c|c|c|c|}
\hline Variável & $\begin{array}{c}\text { Valor } \\
\text { nominal }\end{array}$ & Bias & CV & $\begin{array}{c}\text { Tipo de } \\
\text { distribuição }\end{array}$ & Fonte \\
\hline $\mathrm{A}_{\mathrm{sp}}$ & $\mathrm{A}_{\mathrm{sp}, \mathrm{nom}}$ & 1,00 & 0,0125 & Normal & $\begin{array}{c}\text { Nowak, Yamani e } \\
\text { Tabsh (1994) }\end{array}$ \\
\hline $\mathrm{f}_{\mathrm{pu}}(\mathrm{MPa})$ & 1860,3 & 1,04 & 0,025 & Lognormal & $\begin{array}{c}\text { Siriaksorn }{ }^{2}(1980, \text { apud } \\
\text { Eamon, 2000) }\end{array}$ \\
\hline $\mathrm{f}_{\mathrm{y}}$ & $\mathrm{f}_{\mathrm{y}}$ & 1,03 & 0,022 & Lognormal & $\begin{array}{c}\text { Siriaksorn }{ }^{2}(1980, \text { apud } \\
\text { Eamon, 2000) }\end{array}$ \\
\hline
\end{tabular}

Tabela 2.10 - Parâmetros estatísticos das dimensões.

\begin{tabular}{|c|c|c|c|c|}
\hline Variável & Bias & $\mathbf{C V}$ & $\begin{array}{c}\text { Tipo de } \\
\text { distribuição }\end{array}$ & Fonte \\
\hline $\mathrm{d}(\mathrm{cm})$ & 1,00 & $1,778 / \mathrm{d}$ & Normal & \multirow{3}{*}{$\begin{array}{c}\text { Nowak, Yamani e } \\
\text { Tabsh (1994) }\end{array}$} \\
\hline $\mathrm{h}(\mathrm{cm})$ & 1,00 & $1,016 / \mathrm{h}$ & Normal & \\
\hline $\mathrm{h}_{\mathrm{f}}(\mathrm{cm})$ & 1,00 & $1,016 / \mathrm{h}_{\mathrm{f}}$ & Normal & \\
\hline $\mathrm{b}_{\text {viga }}$ (moldada no local) & 1,01 & 0,04 & Normal & \multirow{6}{*}{$\begin{array}{c}\text { Nowak e Szerszer } \\
(2001)\end{array}$} \\
\hline $\mathrm{d}_{\text {viga }}$ (concreto armado) & 0,99 & 0,04 & Normal & \\
\hline $\mathrm{d}_{\text {viga }}$ (concreto protendido) & 1,00 & 0,025 & Normal & \\
\hline $\mathrm{d}_{\text {laje }}$ (moldada no local) & 0,92 & 0,12 & Normal & \\
\hline $\mathrm{d}_{\text {laje }}$ (pré-moldada) & 1,00 & 0,06 & Normal & \\
\hline \multirow[t]{2}{*}{$\mathrm{d}_{\text {laje }}$ (protendida) } & 0,96 & 0,08 & Normal & \\
\hline & & \begin{tabular}{|l|} 
Desvio-padrão \\
\end{tabular} & & \\
\hline $\mathrm{h}, \mathrm{b}(\mathrm{cm})$ & 1,00 & 0,5 & Normal & $\begin{array}{c}\text { Vismann e Zilch } \\
\text { (1995) }\end{array}$ \\
\hline
\end{tabular}

A comparação entre os trabalhos de Mirza et al. (1979), Nowak e Szerszen (2001) e Nowak et al. (2005) mostra uma melhora na qualidade do concreto nos últimos 20 anos (menor coeficiente de variação). Portanto, destaca-se a necessidade de novos resultados acerca das diversas variáveis aleatórias, haja visto o progresso observado nos diversos ramos da construção civil. Vale ressaltar que esses dados foram obtidos para condições americanas. A coleta de dados para as condições brasileiras se faz necessária.

A partir desses dados é obtida a média do momento fletor último através da técnica de Monte Carlo para cada seção transversal de interesse, cuja divisão pela resistência nominal à flexão, fornece a bias dos fatores de fabricação $F$ e do material $M$ $\left(\lambda_{\mathrm{FM}}\right)$. Através do desvio-padrão, obtém-se o coeficiente de variação $\left(\mathrm{CV}_{\mathrm{FM}}\right)$. Os parâmetros estatísticos do fator de análise são fornecidos em Ellingwood et al. (1980).

${ }^{2}$ Siriaksorn, A. (1980). Serviceability and reliability analysis of partially prestressed concrete beams. PhD dissertation, The University of Illinois at Chicago Circle. 
A força cortante última e as relações entre força cortante e deformação por cisalhamento também podem ser obtidas por simulação. Maiores detalhes podem ser vistos em Nowak, Yamani e Tabsh (1994) e Nowak (1999).

Na tabela 2.8 estão os parâmetros estatísticos utilizados por Nowak (1999). A resistência $R$ é considerada como uma variável aleatória lognormal.

Tabela 2.11 - Parâmetros estatísticos da resistência usados por Nowak (1999).

\begin{tabular}{|c|c|c|c|c|c|c|}
\hline Elemento estrutural & $\lambda_{\mathrm{FM}}$ & $\mathrm{CV}_{\mathrm{FM}}$ & $\lambda_{\mathrm{P}}$ & $\mathrm{CV}_{\mathrm{P}}$ & $\lambda_{\mathrm{R}}$ & $\mathrm{CV}_{\mathrm{R}}$ \\
\hline Vigas de aço $^{*}$ & & & & & & \\
\hline Momento fletor (seção compacta $^{*}$ ) & 1,095 & 0,075 & 1,02 & 0,06 & 1,12 & 0,10 \\
\hline Momento fletor (não-compacta $^{*}$ ) & 1,085 & 0,075 & 1,03 & 0,06 & 1,12 & 0,10 \\
\hline Força cortante $^{\text {Vigas compostas }}$ & 1,12 & 0,08 & 1,02 & 0,07 & 1,14 & 0,105 \\
\hline Momento fletor & 1,07 & 0,08 & 1,05 & 0,06 & 1,12 & 0,10 \\
\hline Força cortante & 1,12 & 0,08 & 1,02 & 0,07 & 1,14 & 0,105 \\
\hline Vigas de concreto armado & & & & & & \\
\hline Momento fletor & 1,12 & 0,12 & 1,02 & 0,06 & 1,14 & 0,13 \\
\hline Força cortante (com estribos) & 1,13 & 0,12 & 1,075 & 0,10 & 1,20 & 0,155 \\
\hline Força cortante (sem estribos) & 1,165 & 0,135 & 1,20 & 0,10 & 1,40 & 0,17 \\
\hline Vigas de concreto protendido & & & & & & \\
\hline Momento fletor & 1,04 & 0,045 & 1,01 & 0,06 & 1,05 & 0,075 \\
\hline Força cortante (com estribos) & 1,07 & 0,10 & 1,075 & 0,10 & 1,15 & 0,14 \\
\hline
\end{tabular}

*A distinção entre seção compacta e não-compacta depende da esbeltez da alma e das flanges, além das condições de contravetamento.

Nowak e Szerszen (2001), em um estudo para a revisão dos coeficientes de minoração da resistência do Building Code Requirements for Structural Concrete (ACI 318-99), utilizando-se de novos dados estatísticos das variáveis envolvidas no cálculo da resistência, chegaram aos seguintes valores (tabela 2.12):

Tabela 2.12 - Parâmetros estatísticos da resistência. (NOWAK e SZERSZEN, 2001)

\begin{tabular}{|c|c|c|c|}
\hline Vigas de concreto armado & Esforço & $\lambda_{\mathrm{R}}$ & $\mathrm{CV}_{\mathrm{R}}$ \\
\hline Moldada no local & Momento fletor & 1,190 & 0,089 \\
\hline Moldada no local & Força cortante & 1,230 & 0,109 \\
\hline Pré-moldada & Momento fletor & 1,205 & 0,081 \\
\hline Pré-moldada & Força cortante & 1,242 & 0,105 \\
\hline Vigas de concreto protendido & & & \\
\hline Pré-moldada & Momento fletor & 1,084 & 0,073 \\
\hline Pré-moldada & Força cortante & 1,194 & 0,103 \\
\hline
\end{tabular}


Moses e Verma (1987) fornecem bias e coeficientes de variação para elementos fletidos de aço e concreto protendido. Os valores, obtidos em relação à capacidade nominal especificada pela AASHTO, podem ser vistos na tabela 2.13. Ghosn et al. (1995) fornecem parâmetros para vigas de concreto protendido e vigas de concreto armado seção $\mathrm{T}$ (tabela 2.14), determinada pelo método das tensões admissíveis da AASHTO (1996).

Tabela 2.13 - Parâmetros estatísticos da resistência à flexão. (MOSES e VERMA, 1987)

\begin{tabular}{|c|c|c|}
\hline Elementos & Bias & Coeficiente de variação \\
\hline Aço (sem corrosão) & 1,10 & $12 \%$ \\
\hline Aço (corrosão parcial) & 1,05 & $16 \%$ \\
\hline Aço (corrosão severa) & 1,00 & $20 \%$ \\
\hline Concreto protendido & 1,05 & $9 \%$ \\
\hline
\end{tabular}

Tabela 2.14 - Parâmetros estatísticos da resistência à flexão. (GHOSN et al., 1995)

\begin{tabular}{|c|c|c|}
\hline Elementos & Bias & Coeficiente de variação \\
\hline Concreto protendido & 1,15 & $8 \%$ \\
\hline Concreto armado (Vigas T) & 1,10 & $12 \%$ \\
\hline
\end{tabular}




\section{RESISTENNCIA DOS ELEMENTOS ESTRUTURAIS}

O primeiro passo para o cálculo das equações comprimento-peso limite (ECPLs) é a obtenção da resistência dos elementos estruturais mais solicitados de pontes que representem o universo das estruturas existentes. Assim, as etapas envolvem a seleção de pontes típicas, sua modelagem e análise em computador, seu dimensionamento ao momento fletor, o cálculo do momento fletor resistente nominal e a implementação da técnica de Monte Carlo para a obtenção de seus parâmetros estatísticos. O procedimento inclui a análise da resistência à compressão de concretos com diversos $\mathrm{f}_{\mathrm{ck}}$.

\subsection{Pontes típicas consideradas}

As obras de arte a serem consideradas neste estudo são provenientes basicamente de El Debs et al. (2001). Admite-se que os elementos estruturais analisados tenham sido adequadamente dimensionados e executados, além de não apresentar patologias de execução ou deterioração que possam comprometer sua capacidade estrutural.

Os grupos estruturais representativos do universo de obras de arte especiais da rede viária sob jurisdição do DER foram determinados a partir da classificação em função das características principais, tais como classe, geometria, dimensões do tabuleiro e tipologia estrutural. O levantamento foi feito com base em 8 CDs disponibilizados pelo DER. A documentação técnica é composta por 17.542 arquivos, cada um correspondendo à digitalização de uma das pranchas de desenhos dos projetos das pontes.

A partir da análise dessa documentação foi feito o cadastramento de cada obra identificada em um Banco de Dados utilizando o software Microsoft Access. O 
resultado final da análise foi a identificação e o cadastramento de 2.276 pontes, sendo que em 1.146 obras os dados cadastrados estão completos.

Desse montante, os casos selecionados para análise foram escolhidos tomando-se como base as seguintes diretrizes:

a) Procurou-se atender mais diretamente aos tipos estruturais mais comuns;

b) Buscaram-se as envoltórias das situações reais, mesmo que através de situações fictícias.

Ainda salientam-se os seguintes aspectos:

a) As pontes contínuas com vãos iguais servem de referência, apesar de na prática os vãos serem geralmente desiguais;

b) As pontes de cinco vigas sem transversinas foram incluídas embora não apareçam no cadastro por serem de utilização mais recente;

c) Pode-se considerar que a seção com mais de três células e a seção de laje vazada sejam equivalentes em termos de distribuição de esforços;

d) Nas pontes de viga de seção T, o número e a altura de transversinas foram adotados de forma a conduzir ao menor travamento transversal. A altura das transversinas foi padronizada para todos os casos com $80 \%$ da altura das longarinas e largura de 0,20 metros;

e) Não foram incluídos os passeios das pontes nessas análises, pelo fato de a carga nesses elementos ser igual para os carregamentos normativos e para os carregamentos com veículos especiais;

f) Na maioria das vezes, as dimensões das seções transversais foram ajustadas a partir de médias das dimensões reais;

g) Para facilitar a comparação dos casos analisados, procurou-se padronizar os valores das dimensões;

h) Nem sempre as dimensões saíram diretamente do levantamento; em alguns casos foram feitas extrapolações em função das relações altura/vão dos casos reais.

As pontes típicas já previamente selecionadas foram complementadas em El Debs et al. (2003b), adicionando-se estruturas de 1 e 3 células, não analisadas anteriormente. 
Finalmente, todas as estruturas analisadas são consideradas retas, não-esconsas e com apoios nivelados. Estruturas que fujam a essas características não serão contempladas pelas ECPLs e portanto necessitam de análise estrutural individual.

Dessa forma, os casos a serem considerados inicialmente nesse trabalho podem ser vistos nas tabelas 3.1 a 3.4. Os símbolos TE e TL utilizados nas tabelas significam respectivamente tabuleiro estreito (8 metros) e tabuleiro largo (12 metros). 
Tabela 3.1 - Características geométricas dos casos analisados - LAJE.

(EL DEBS et al., 2003b)

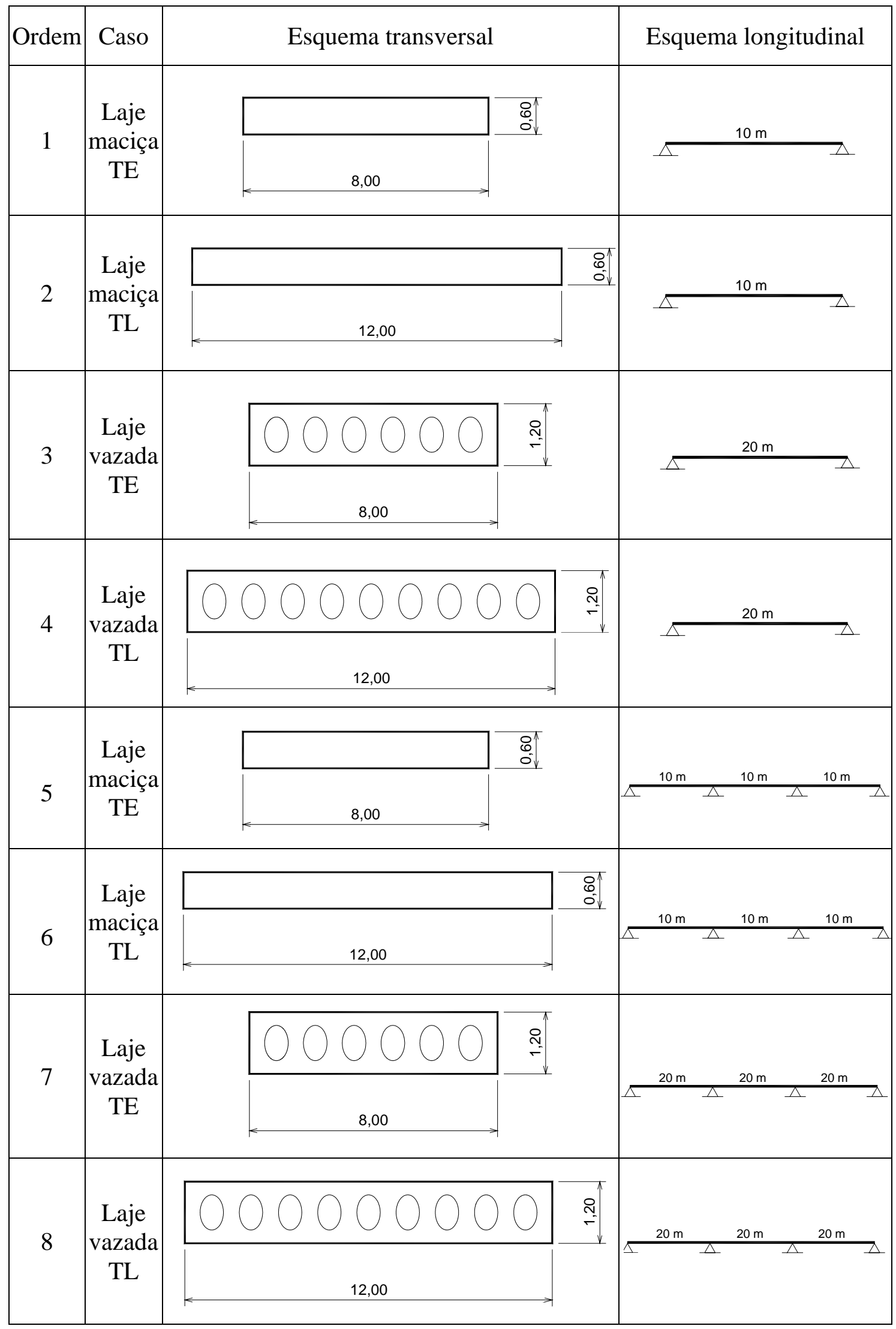


Tabela 3.2 - Características geométricas dos casos analisados VIGA T - 2 VIGAS. (EL DEBS et al., 2003b)

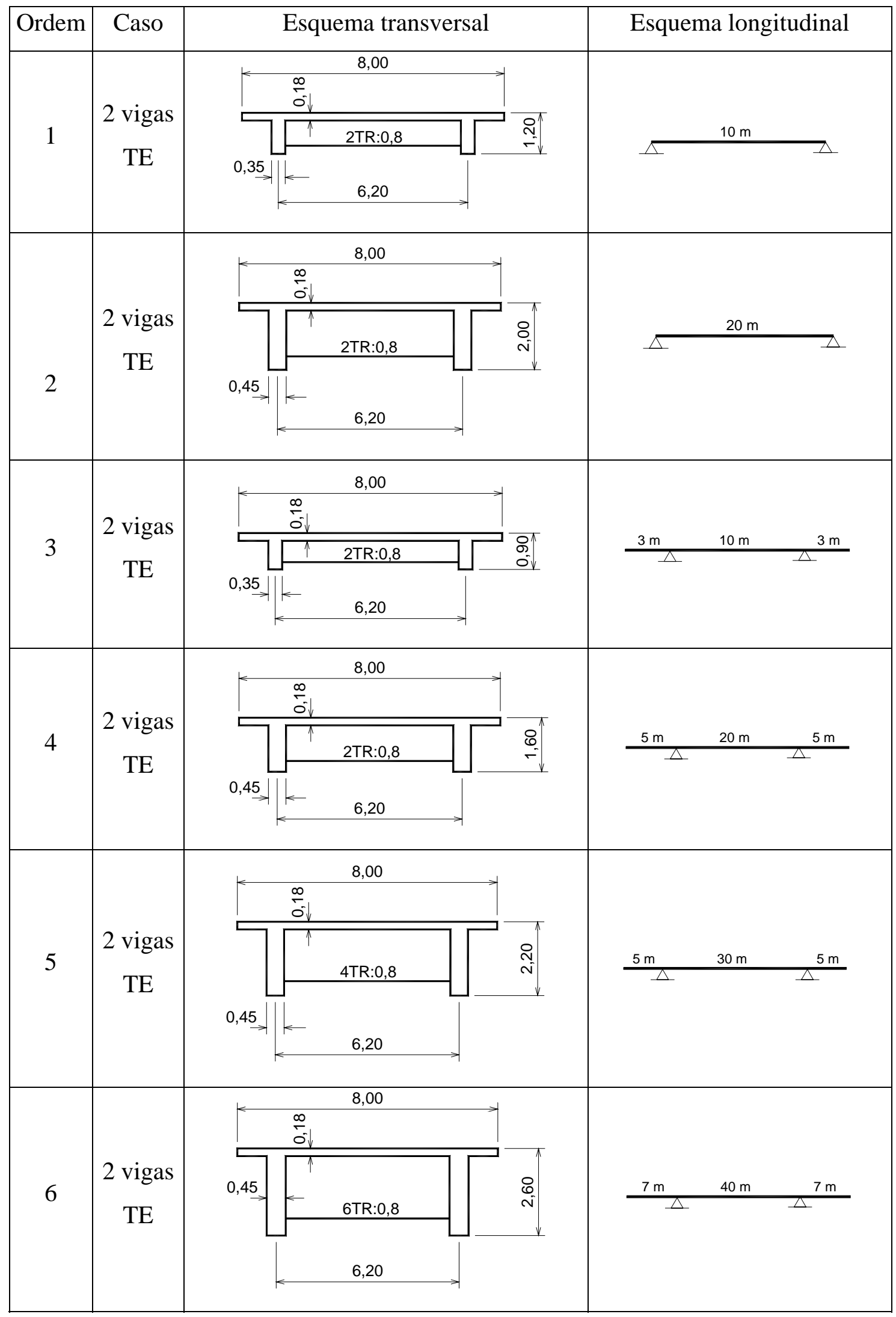


Tabela 3.2 (continuação) - Características geométricas dos casos analisados VIGA T - 2 VIGAS. (EL DEBS et al., 2003b)

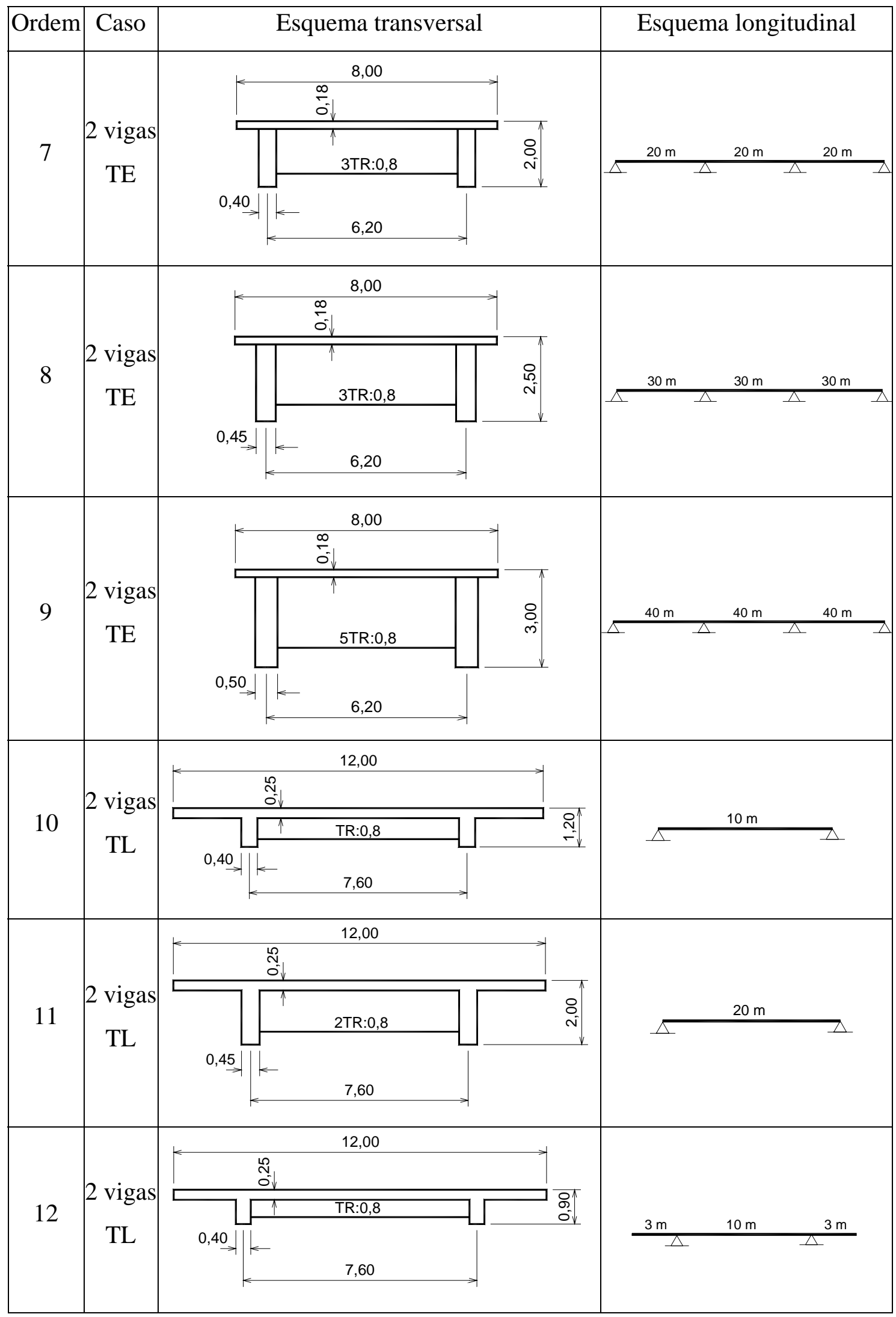


Tabela 3.2 (continuação) - Características geométricas dos casos analisados VIGA T - 2 VIGAS. (EL DEBS et al., 2003b)

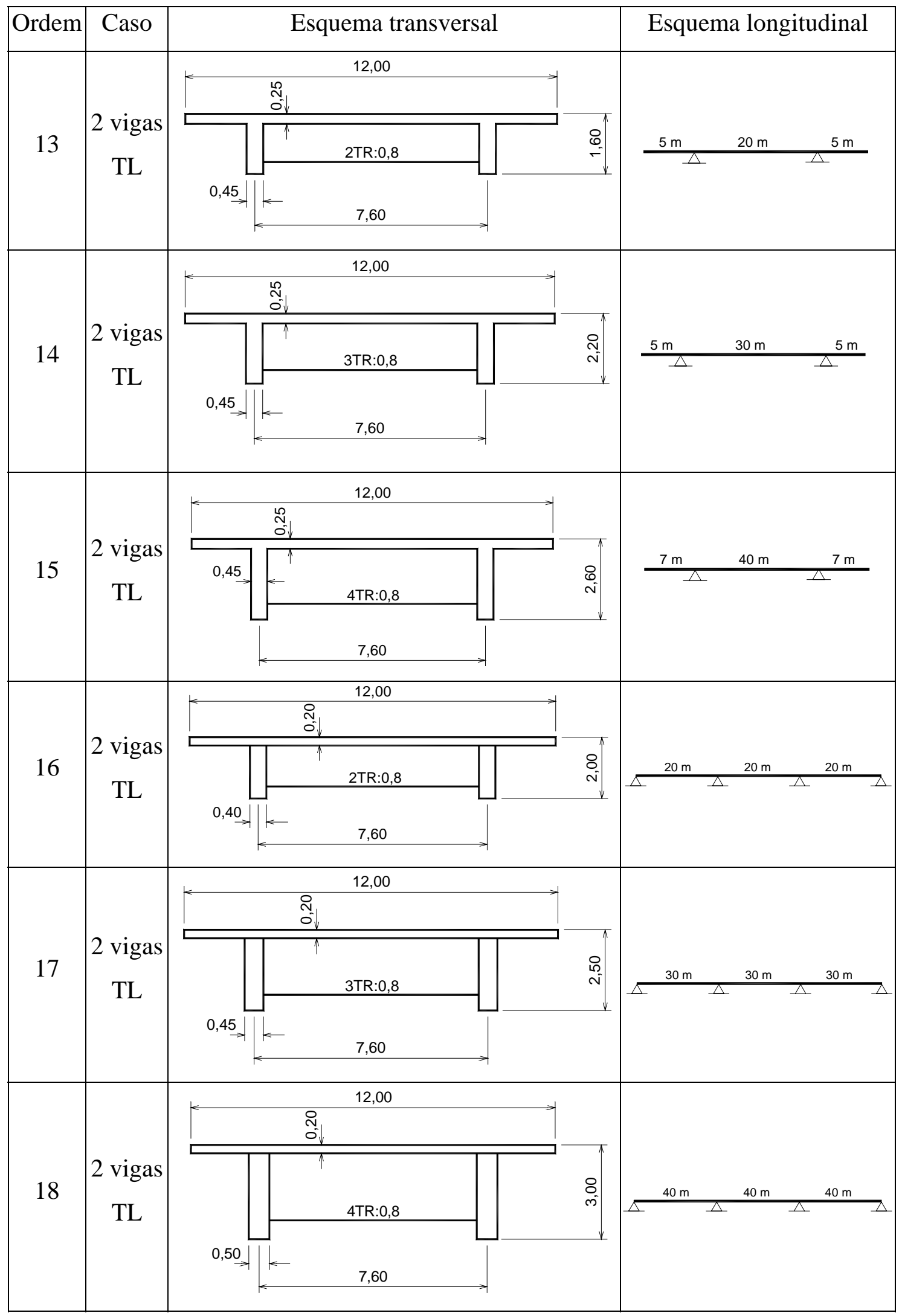


Tabela 3.2 (continuação) - Características geométricas dos casos analisados VIGA T - 2 VIGAS. (EL DEBS et al., 2003b)

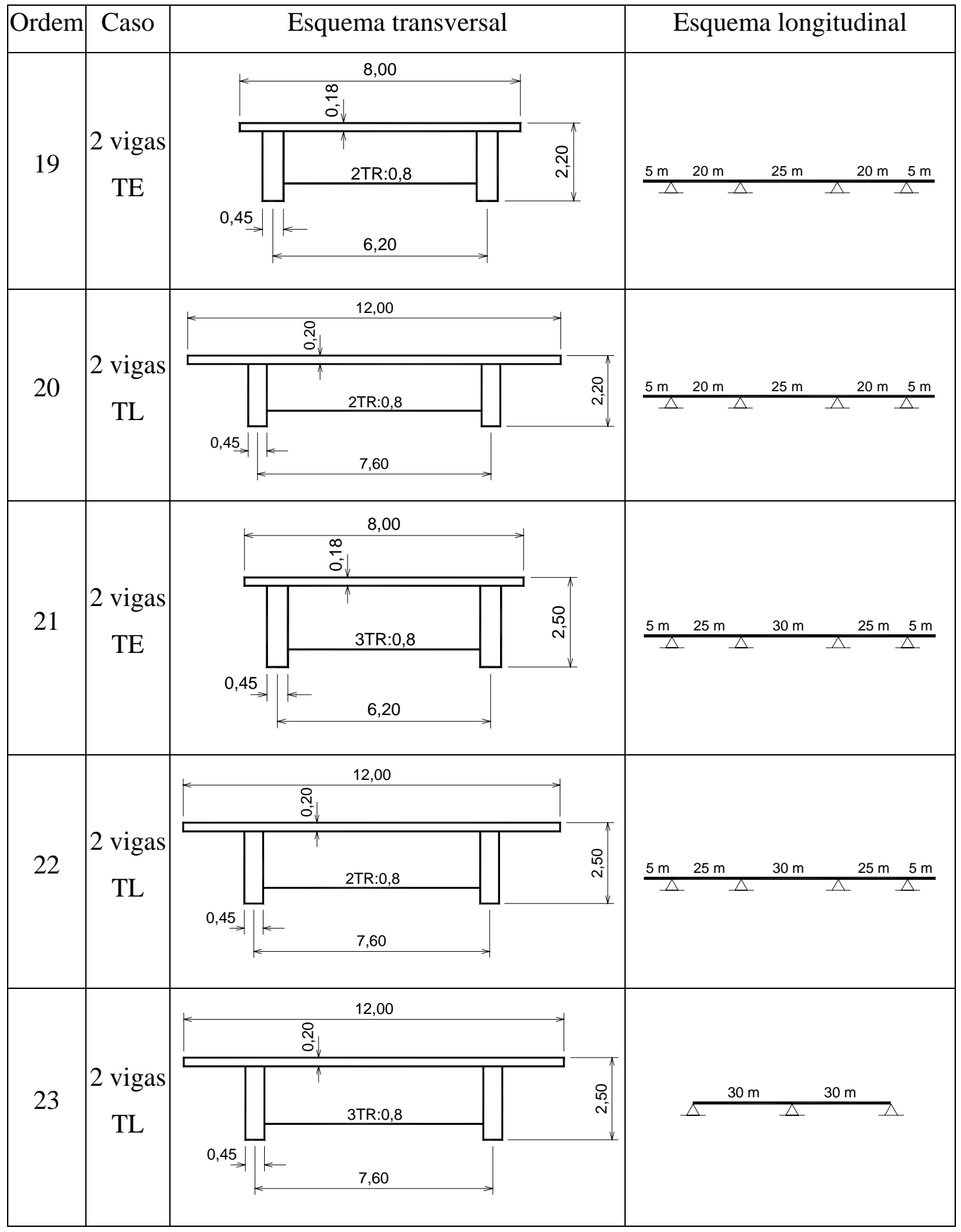


Tabela 3.3 - Características geométricas dos casos analisados VIGA T - 5 VIGAS. (EL DEBS et al., 2003b)

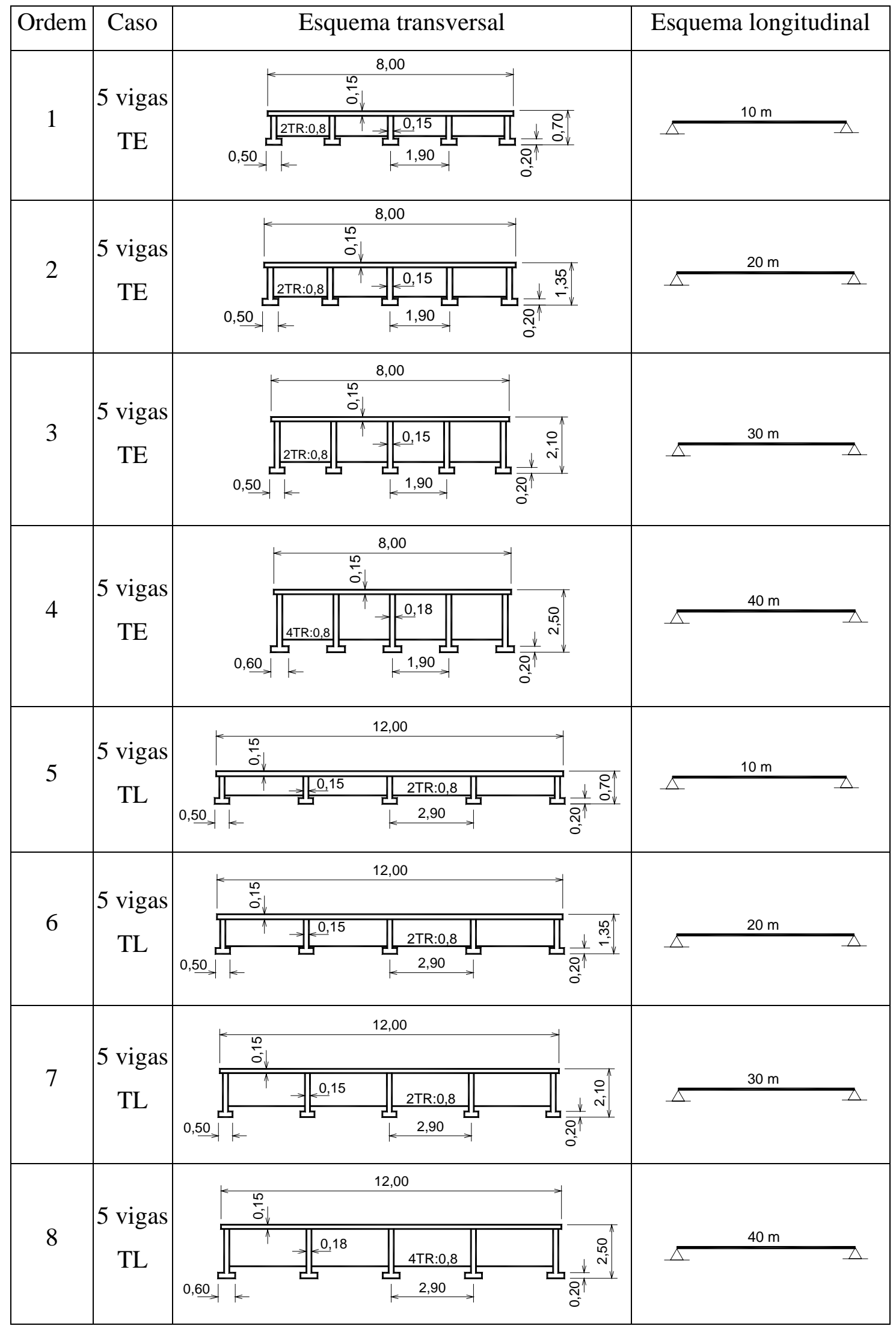


Tabela 3.3 (continuação) - Características geométricas dos casos analisados VIGA T - 5 VIGAS. (EL DEBS et al., 2003b)

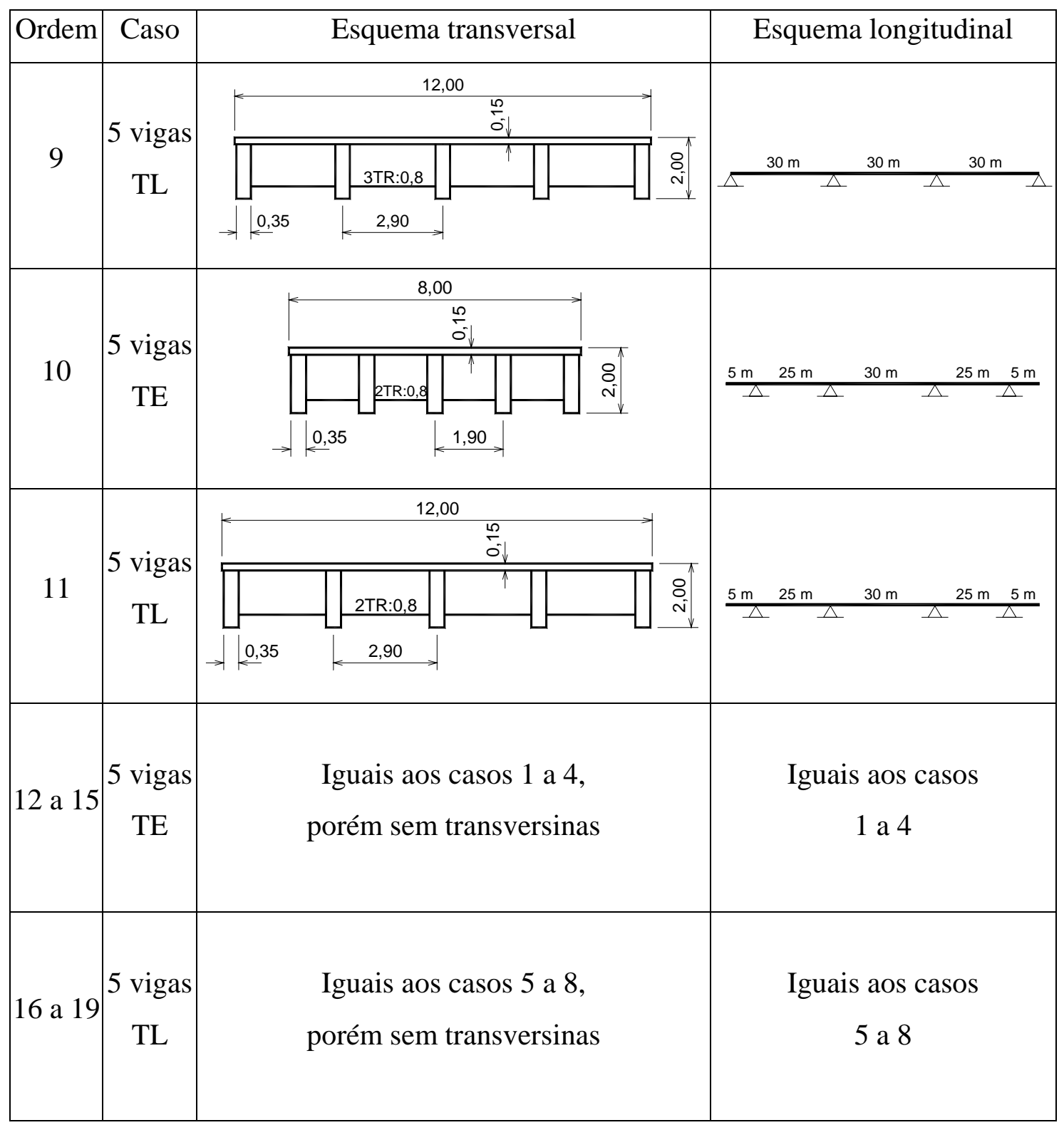


Tabela 3.4 - Características geométricas dos casos analisados SEÇÃO CELULAR. (EL DEBS et al., 2003b)

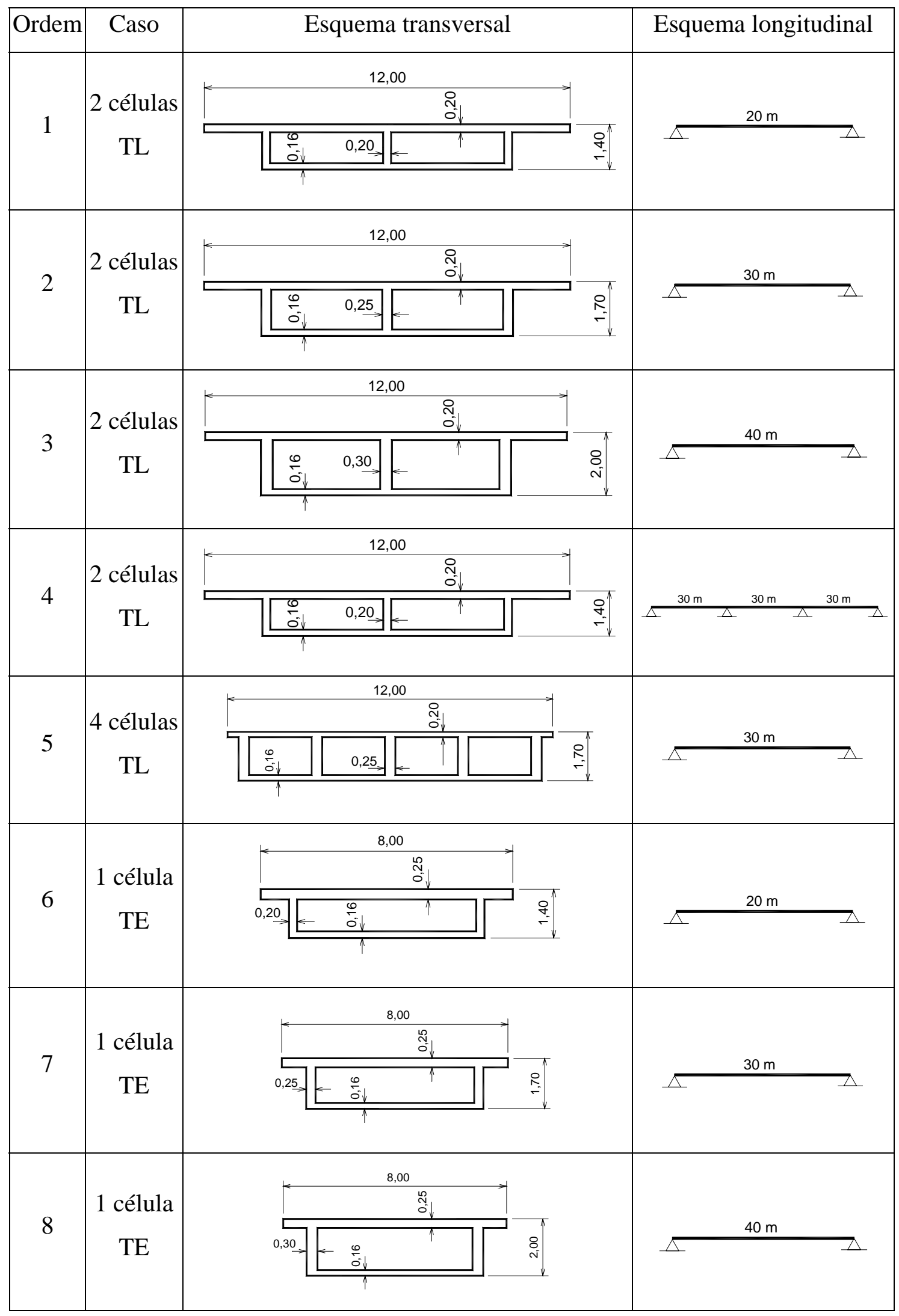


Tabela 3.4 (continuação) - Características geométricas dos casos analisados SEÇÃO CELULAR. (EL DEBS et al., 2003b)

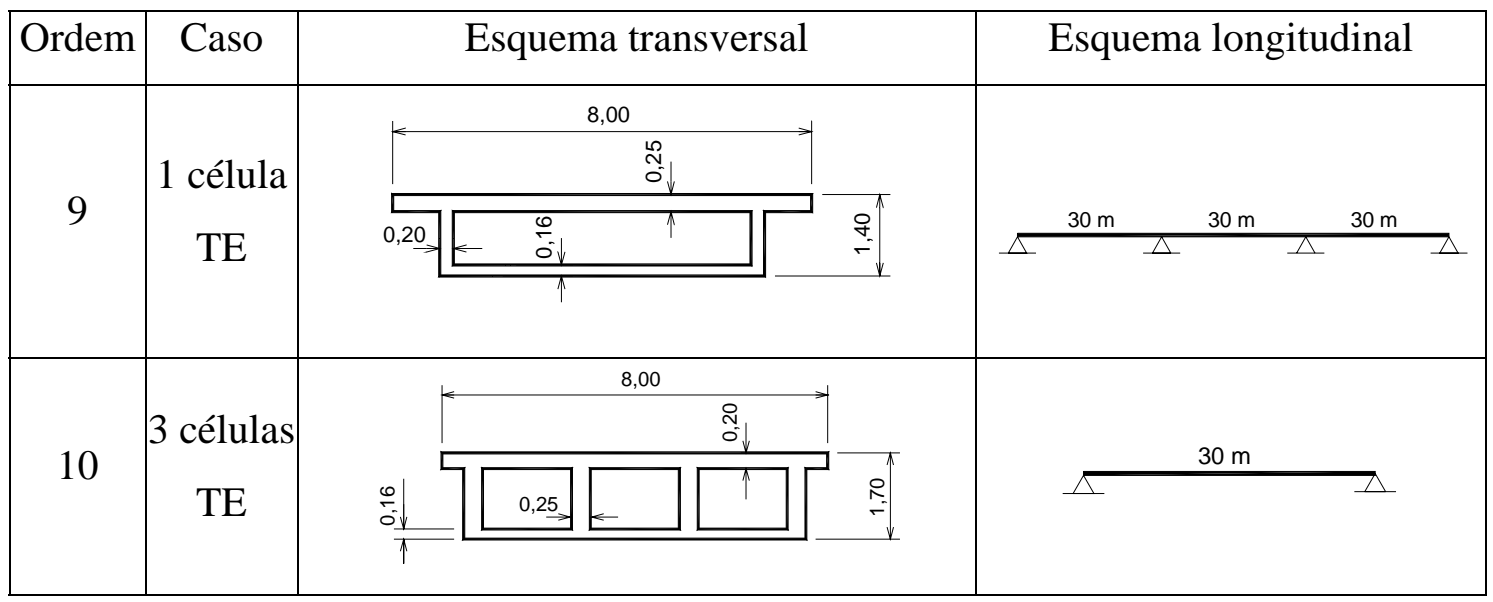

\subsection{Software utilizado para análise estrutural}

A determinação dos esforços solicitantes foi feita por meio da utilização do programa STRAP (Structural Analysis Programs) - Versão 9.0. Trata-se de um pacote comercial baseado no Método dos Elementos Finitos que permite a modelagem de uma grande gama de sistemas estruturais, tanto para análise de estruturas planas como tridimensionais.

A figura 3.1 ilustra a discretização em nós, vigas (barras azuis) e laje maciça (elementos de placa vermelhos), de um dos tabuleiros modelados (vão de 20m, largura de $12 \mathrm{~m}$ e balanços de $5 \mathrm{~m})$.

Vale ressaltar que a modelagem da estrutura e a aplicação dos carregamentos permanentes são realizadas dentro do módulo principal do programa. Os demais carregamentos de interesse foram definidos dentro do Módulo de Pontes, o qual está inserido no pacote completo do programa STRAP. Dentre esses carregamentos, citamse os veículos considerados para o presente estudo e os carregamentos distribuídos no tabuleiro, referentes à multidão. 


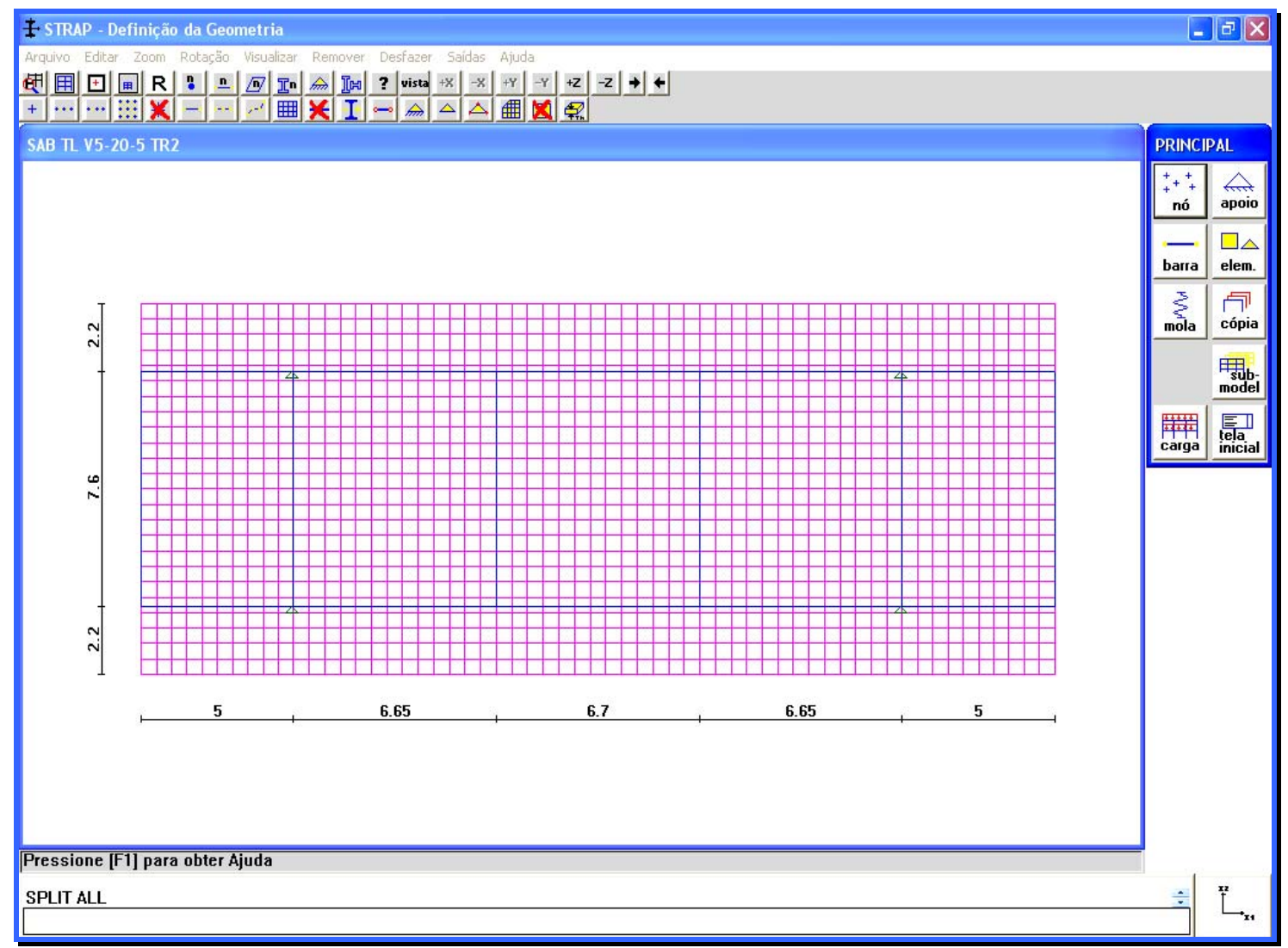

Figura 3.1 - Discretização do tabuleiro de uma ponte.

O módulo de pontes requer a divisão do tabuleiro em faixas de rolamento sobre as quais será aplicado o carregamento móvel. Seguindo orientações de El Debs et al. (2001), manteve-se a largura recomendada de 2 metros para cada faixa (correspondente à distância transversal entre rodas dos veículos normativos).

As cargas distribuídas e os veículos de interesse gerados são associados às faixas, com a opção de permutar o carregamento entre elas. Dessa forma, o programa busca a combinação crítica de carregamento para o esforço em questão em qualquer ponto da estrutura.

A figura 3.2 mostra a localização de um carregamento hipotético que maximiza o momento fletor no meio do vão da longarina. Ainda pode ser vista a numeração das faixas de tráfego na ponte (tabuleiro largo), em um total de 6 (6 x 2 metros). 


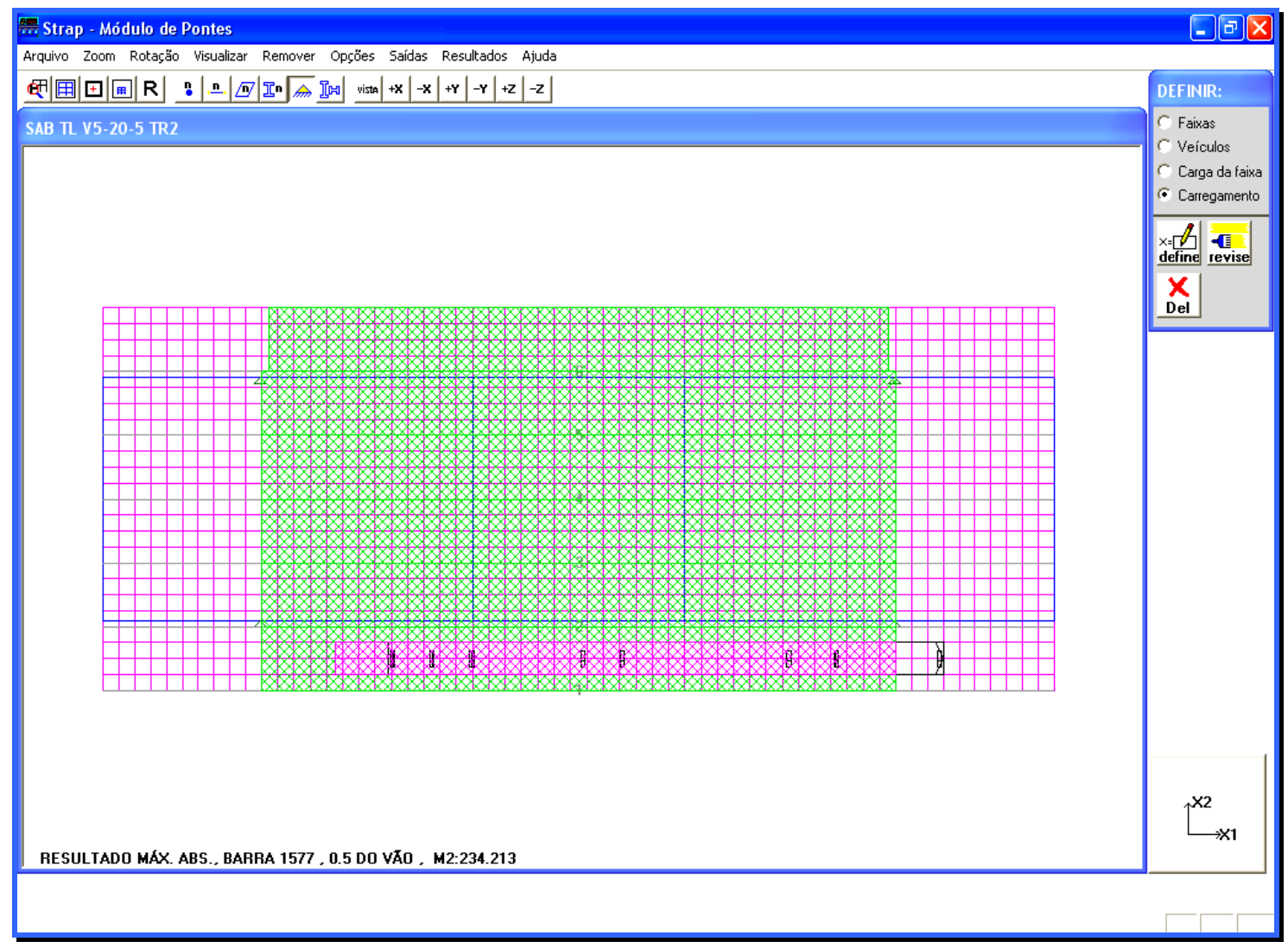

Figura 3.2 - Carregamento crítico para momento máximo na longarina.

\subsection{Aspectos da modelagem}

A seguir, as características e hipóteses adotadas para a modelagem das diversas pontes são comentadas. As seções transversais consideradas são: laje, viga T e seção celular.

\subsubsection{Laje}

As pontes de laje, maciças ou vazadas, foram modeladas apenas através de elementos de placa com apoios discretos ao longo das duas bordas apoiadas. Foram sempre adotadas seções maciças (mesmo quando na realidade essas possuíam seções transversais vazadas) para otimização da discretização e do processamento, haja vista que esse procedimento não provoca distorções nos resultados. De acordo com o vão, as seções transversais consideradas no modelo foram:

a) Pontes com vão de 10 metros: seção transversal maciça com altura total de 0,60 m; 
b) Pontes com vão de 20 metros: seção transversal maciça com altura total de 1,20 m. Neste caso, a determinação do peso próprio foi feita com base em uma seção transversal maciça, com altura igual a $0,80 \mathrm{~m}$, de maneira a garantir uma resposta similar àquela que seria obtida com a seção transversal vazada real.

\subsubsection{Viga $T$}

As pontes de viga $\mathrm{T}$ foram modeladas com vigas ortogonais (longarinas e transversinas) por meio de barras e o tabuleiro foi modelado através de elementos de placa. O acoplamento entre os elementos de barra e de placa dá-se por um único plano que contém os centros geométricos de ambos os elementos. Nesse caso, é possível admitir que a inércia dos elementos de placa praticamente não altera a inércia das vigas.

As transversinas foram consideradas nas regiões dos apoios, em posições intermediárias a esses mesmos apoios, bem como nas extremidades das longarinas, apenas para os casos de vigas com balanço.

\subsubsection{Seção celular}

a) Pontes de uma ou duas células: simplesmente apoiadas e contínuas

Tanto para as pontes simplesmente apoiadas como para as contínuas, no caso de uma ou duas células, adotou-se a discretização por meio de uma única barra e elementos de placa para o tabuleiro. A ligação entre viga e tabuleiro foi feita garantindo entre esses elementos rigidez à torção, além da flexão. Nos apoios extremos das barras foram considerados vínculos de garfo.

b) Pontes de 3 ou mais células: simplesmente apoiadas

Para as pontes simplesmente apoiadas, de três ou mais células, barras foram dispostas nas direções longitudinal e transversal da ponte, com o objetivo de simular comportamentos equivalentes aos das seções celulares estudadas.

As longarinas foram locadas na posição das almas das células da seção original. Assim, uma seção celular com $n$ células passa a ser representada por uma seção 
transversal composta por $n+1$ vigas longitudinais. As propriedades das seções transversais das longarinas foram determinadas com base na largura de influência entre duas longarinas sucessivas e paralelas entre si. No caso das longarinas intermediárias, a seção transversal resultante foi tipo I.

As transversinas foram consideradas nas posições de ocorrências dos diafragmas existentes na ponte. Paralelamente, a cada $1 / 4$ da distância entre elas, foram adicionadas barras intermediárias para simular o efeito de travamento oriundo das lajes superior e inferior. Assim, as transversinas que simulam os diafragmas de extremidades resultaram em seções transversais $C$, enquanto as transversinas que simulam os diafragmas intermediários resultaram em seções transversais I. Já as barras intermediárias resultaram em seções transversais que levam em consideração apenas as lajes superior e inferior das células, ou seja, uma seção I desconsiderando-se a correspondente alma.

\subsection{Ações consideradas no dimensionamento}

Inicialmente, cabe relembrar que as ECPLs serão calculadas para as seções transversais mais críticas das superestruturas das pontes. Ressalta-se, no entanto, que no caso de estruturas contínuas o momento fletor positivo máximo será aproximado pelo momento fletor no meio do vão correspondente. Considerando que há proporcionalidade na taxa de armadura entre essas regiões, admite-se que esse procedimento é adequado aos objetivos propostos.

O estudo contempla apenas o efeito das ações verticais das cargas móveis, como é usual na análise de veículos especiais sobre as pontes. No entanto, o tráfego de veículos pode acarretar ações horizontais, como a força de frenagem. Normalmente avaliada como uma fração do peso do veículo de referência, a força de frenagem produzida por veículos pertencentes ao tráfego real pode ser maior que a produzida pelos veículos normativos. Esta força produz efeitos importantes apenas nos aparelhos de apoio e na infraestrutura das pontes. Normalmente, as pontes apresentam capacidade de absorver excessos de forças desse tipo, mediante reservas de resistência ou caminhos alternativos de força, como a mobilização de empuxos passivos em pontes com sistema estrutural com balanços e cortinas. Entretanto, a mobilização desses caminhos alternativos faz com que os aparelhos de apoios e os pilares funcionem de forma não prevista no projeto. Este aspecto alerta sobre a necessidade de inspeção nas pontes, 
incluindo não só a superestrutura, como também os aparelhos de apoio e a infraestrutura.

Outras ações, como a ação horizontal do vento e a temperatura, também não serão levadas em consideração.

Para a pavimentação foi considerado um carregamento uniformemente distribuído por unidade de área de $2,4 \mathrm{kN} / \mathrm{m}^{2}$ (correspondente a $10 \mathrm{~cm}$ de asfalto) sobre os elementos de placa.

Considerando que a maior parte das obras de arte especiais tenha sido construída a partir de 1960, as duas normas que versam sobre as cargas em pontes rodoviárias, são:

a) NB-6 de 1960 (válida até 1984), que especifica as seguintes classes:

Classe 12

Classe 24

Classe 36

b) NBR-7188 de 1984 (em vigor atualmente), que especifica as classes:

Classe 12

Classe 30

Classe 45

Neste trabalho consideram-se apenas as pontes classes 36 e 45, por serem a grande maioria nas principais rodovias brasileiras.

O efeito dinâmico das cargas é levado em consideração empregando-se a expressão da norma de pontes de concreto NBR-7187 $(\varphi=1,4-0,007 \cdot 1)$, onde $l$ é o vão em metros.

\subsection{Esforços solicitantes}

Neste trabalho apenas a estrutura principal será tratada. Considerando-se que sejam mantidos os limites de peso por eixo determinados pela legislação, as cargas por roda do tráfego normal devem ser inferiores às cargas por roda dos veículos das classes 36 e 45. Dessa forma, supondo-se que as lajes tenham sido adequadamente dimensionadas para esses veículos, a não verificação dessas regiões é justificável.

Quanto aos esforços, será considerado apenas o momento fletor. Relatórios 
anteriores (EL DEBS et al., 2003a e 2003b) demonstram que a força cortante é menos crítica, assim como o momento de torção nas pontes celulares. Assume-se assim que, uma vez respeitados os limites para a flexão, os demais esforços estejam automaticamente verificados.

Os resultados do processamento a serem utilizados no dimensionamento para cada tipo de seção transversal estão nas tabelas 3.5 a 3.8 .

Tabela 3.5 - Resultados da análise estrutural - LAJE.

\begin{tabular}{|c|c|c|c|c|c|c|c|c|c|}
\hline \multirow{2}{*}{$\mathbf{n}$} & \multirow{2}{*}{ Arquivo } & \multicolumn{3}{|c|}{ Momento positivo (kN.m/m) } & \multicolumn{3}{|c|}{ Momento negativo (kN.m/m) } \\
\cline { 3 - 11 } & & $\varphi$ & $\mathrm{M}_{\text {perm }}$ & $\mathrm{M}_{36}$ & $\mathrm{M}_{45}$ & $\varphi$ & $\mathrm{M}_{\text {perm }}$ & $\mathrm{M}_{36}$ & $\mathrm{M}_{45}$ \\
\hline 1 & SA TE V10 MC & 1,33 & 221,3 & 173,4 & 221,9 & - & - & - & - \\
\hline 2 & SA TL V10 MC & 1,33 & 223,6 & 158,4 & 204,0 & - & - & - & - \\
\hline 3 & SA TE V20 VZ & 1,26 & 1129,0 & 396,4 & 519,1 & - & - & - & - \\
\hline 4 & SA TL V20 VZ & 1,26 & 1138,0 & 358,3 & 480,4 & - & - & - & - \\
\hline 5 & C3 TE V10/10/10 MC & 1,33 & 127,9 & 141,7 & 180,5 & 1,33 & 153,2 & 131,3 & 155,9 \\
\hline 6 & C3 TL V10/10/10 MC & 1,33 & 128,8 & 138,8 & 177,4 & 1,33 & 154,1 & 131,4 & 156,2 \\
\hline 7 & C3 TE V20/20/20 VZ & 1,26 & 665,7 & 324,7 & 423,7 & 1,26 & 800,5 & 276,4 & 327,9 \\
\hline 8 & C3 TL V20/20/20 VZ & 1,26 & 671,0 & 301,8 & 401,8 & 1,26 & 810,8 & 273,7 & 329,3 \\
\hline
\end{tabular}

OBS:

1) Os resultados da tabela correspondem ao momento fletor nas bordas da laje, apesar de na ponte de ordem 7 o momento fletor negativo no centro do tabuleiro ser levemente mais crítico.

2) Nas pontes contínuas (C3), o momento fletor positivo refere-se ao tramo externo.

\section{Legenda:}

$\mathrm{n}: \quad$ Ordem

$\mathrm{M}_{\text {perm }}$ : Momento fletor devido às ações permanentes $(\mathrm{kN} . \mathrm{m} / \mathrm{m})$

$\mathrm{M}_{36}$ : $\quad$ Momento fletor devido ao trem-tipo da classe $36(\mathrm{kN} . \mathrm{m} / \mathrm{m})$

$\mathrm{M}_{45}$ : Momento fletor devido ao trem-tipo da classe $45(\mathrm{kN} . \mathrm{m} / \mathrm{m})$

$\varphi$ : $\quad$ Coeficiente de impacto

SA: Simplesmente apoiada

C3: $\quad$ Contínua com 3 tramos iguais

TE: Tabuleiro estreito

TL: Tabuleiro largo

$\mathrm{V}$ _: $\quad$ Ṽ̃o(s)

MC: tabuleiro maciço

VZ: tabuleiro vazado 
Tabela 3.6 - Resultados da análise estrutural - VIGA T - 2 VIGAS.

\begin{tabular}{|c|c|c|c|c|c|c|c|c|c|}
\hline \multirow{2}{*}{$\mathbf{n}$} & \multirow{2}{*}{ Arquivo } & \multicolumn{4}{|c|}{ Momento positivo (kN.m) } & \multicolumn{4}{|c|}{ Momento negativo (kN.m) } \\
\hline & & $\varphi$ & $\mathrm{M}_{\text {perm }}$ & $\mathrm{M}_{36}$ & $\mathrm{M}_{45}$ & $\varphi$ & $\mathrm{M}_{\text {perm }}$ & $\mathrm{M}_{36}$ & $\mathrm{M}_{45}$ \\
\hline 1 & SA TE & 1,33 & 518,7 & 693,9 & 877,7 & - & - & - & - \\
\hline 2 & SA TE V & 26 & 2727,9 & 35,3 & & - & - & 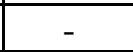 & - \\
\hline 3 & SAB TE V3/10/3 TR2 & 1,33 & 262,0 & 51,7 & 829,0 & 1,36 & 165,6 & 170,2 & 86,8 \\
\hline 4 & SAB TE V5/ & 1,26 & 1650,0 & 1859,4 & 2346,0 & 1,33 & 611,6 & 131,6 & 411,9 \\
\hline 5 & SAB TE V5 & 1,19 & 5334,4 & 3447,4 & 4319,0 & 1,33 & 732,0 & 1205,1 & 1488,9 \\
\hline 6 & SAB TE V7/40/7 TR6 & 1,12 & 10405,8 & 5377,4 & 6732,3 & 1,30 & 1525,3 & 1997,4 & 2459,1 \\
\hline 7 & C3 TE V20/ & 1,26 & 1518,7 & 1604,6 & 2003,0 & 1,26 & 1964,1 & 1305,9 & 1572,2 \\
\hline 8 & C3 TE & 1,19 & 391 & 3,8 & 3619,9 & 1,19 & 5100,0 & & 3055,5 \\
\hline 9 & C3 TE & 1,12 & 8192,1 & 4513,2 & 5588,2 & 1,12 & 10787,9 & 4208,0 & 4991,6 \\
\hline 10 & SA TL & 1,33 & 797,6 & 829,4 & 1074,9 & 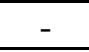 & - & 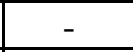 & - \\
\hline 11 & SA TI & 1,26 & 3995,5 & 2390,2 & 3075,6 & - & - & - & - \\
\hline 1. & $\overline{\mathrm{AB} T L}$ & 1,33 & 413,4 & 707,2 & 924,8 & 1,36 & 254,2 & 488,5 & 317,2 \\
\hline 13 & $\mathrm{R} 2$ & 1,26 & 249 & 2228,4 & 2903,9 & 1,33 & 882,4 & 1329,6 & 1681,8 \\
\hline 14 & SAB TL & 1,19 & 7620,8 & 4407,0 & 5729,3 & 1,33 & 1017,6 & 1458,5 & 1829,0 \\
\hline 15 & SAB TL & 1,12 & 14264,8 & 6963,2 & 9065,5 & 1,30 & 2099,0 & 2474,7 & 3103,0 \\
\hline 16 & C3 TL V20/ & 1,26 & 1966,6 & 1984,4 & 2541,3 & 1,26 & 2583,8 & 1731,2 & 2178,8 \\
\hline 1 & C3 TL V & 1,19 & 5076,2 & 3810,1 & 4876,8 & 1,19 & 6631,0 & 3483,8 & 4367,3 \\
\hline 18 & C3 TL V & 1,12 & 10128,1 & 5935,2 & 7581,1 & 1,12 & 13400,1 & 5785,1 & 7237,1 \\
\hline 19 & $\begin{array}{c}\text { C3B TE V5-20/25/20-5 } \\
\text { TR3 }\end{array}$ & 1,25 & 1 &, 7 &, 0 & 25 & 2623,0 & 61,0 & 1873,4 \\
\hline 20 & $\begin{array}{c}\text { C3B TL V5-20/25/20-5 } \\
\text { TR2 }\end{array}$ & 1,25 & 2031,0 & 2181,6 & 2791,2 & 1,25 & 3383,5 & 2084,2 & 2620,2 \\
\hline 21 & $\begin{array}{c}\text { C3B TE V5-25/30/25-5 } \\
\text { TR3 }\end{array}$ & 1,21 & 2255,1 & 320,4 & 2880,4 & 1,21 & 4185,1 & 159,3 & 2574,0 \\
\hline 22 & $\begin{array}{c}\text { C3B TL V5-25/30/25-5 } \\
\text { TR2 }\end{array}$ & 1,21 & 2845,5 & 2943,9 & 3760,0 & 1,21 & 5340,2 & 2916,2 & 3656,8 \\
\hline 23 & C2 TL V30/30 TR3 & 19 & 265,5 & 701,0 & 4738,3 & 1,19 & 8249,3 & 3626,6 & ] \\
\hline
\end{tabular}

\section{OBS:}

1) Nas pontes C3, o momento fletor positivo refere-se ao tramo externo.

2) Nas pontes C3B, o momento fletor positivo refere-se ao tramo central e o momento fletor negativo ao apoio interno.

\section{Legenda:}

SAB: Simplesmente apoiada com balanços

C3B: Contínua com 3 tramos desiguais e balanços
C2: $\quad$ Contínua com 2 tramos iguais

TR: Número de transversinas 
Tabela 3.7 - Resultados da análise estrutural - VIGA T - 5 VIGAS.

\begin{tabular}{|c|c|c|c|c|c|c|c|c|c|}
\hline \multirow{2}{*}{$\mathbf{n}$} & \multirow{2}{*}{ Arquivo } & \multicolumn{3}{|c|}{ Momento positivo (kN.m) } & \multicolumn{3}{c|}{ Momento negativo (kN.m) } \\
\cline { 3 - 11 } & & $\varphi$ & $\mathbf{M}_{\text {perm }}$ & $\mathbf{M}_{36}$ & $\mathrm{M}_{45}$ & $\varphi$ & $\mathrm{M}_{\text {perm }}$ & $\mathrm{M}_{36}$ & $\mathbf{M}_{45}$ \\
\hline 1 & SA TE V10 TR2 & 1,33 & 192,3 & 287,0 & 365,9 & - & - & - & - \\
\hline 2 & SA TE V20 TR2 & 1,26 & 912,9 & 834,9 & 1048,9 & - & - & - & - \\
\hline 3 & SA TE V30 TR2 & 1,19 & 2408,5 & 1578,9 & 1958,2 & - & - & - & - \\
\hline 4 & SA TE V40 TR4 & 1,12 & 5193,7 & 2439,8 & 3009,1 & - & - & - & - \\
\hline 5 & SA TL V10 TR2 & 1,33 & 266,5 & 375,6 & 487,5 & - & - & - & - \\
\hline 6 & SA TL V20 TR2 & 1,26 & 1212,0 & 1025,6 & 1350,2 & - & - & - & - \\
\hline 7 & SA TL V30 TR2 & 1,19 & 3084,1 & 1934,9 & 2555,5 & - & - & - & - \\
\hline 8 & SA TL V40 TR4 & 1,12 & 6485,0 & 3026,1 & 3935,0 & - & - & - & - \\
\hline 9 & C3 TL V30/30/30 TR2 & 1,19 & 2370,6 & 1579,7 & 2086,7 & 1,19 & 3146,3 & 1387,3 & 1808,0 \\
\hline 10 & C3B TE V5-25/30/25-5 & 1,21 & 1121,2 & 954,3 & 1195,1 & 1,21 & 2115,9 & 897,4 & 1089,9 \\
\hline \multirow{2}{*}{11} & C3B TL V5-25/30/25-5 & 1,21 & 1367,9 & 1279,2 & 1681,6 & 1,21 & 2580,3 & 1192,0 & 1546,0 \\
\hline 12 & SA TE V10 STR & 1,33 & 182,4 & 299,5 & 381,2 & - & - & - & - \\
\hline 13 & SA TE V20 STR & 1,26 & 870,3 & 841,9 & 1061,9 & - & - & - & - \\
\hline 14 & SA TE V30 STR & 1,19 & 2294,7 & 1575,7 & 1968,4 & - & - & - & - \\
\hline 15 & SA TE V40 STR & 1,12 & 4836,1 & 2463,0 & 3055,5 & - & - & - & - \\
\hline 16 & SA TL V10 STR & 1,33 & 253,1 & 464,4 & 592,1 & - & - & - & - \\
\hline 17 & SA TL V20 STR & 1,26 & 1162,7 & 1259,4 & 1610,3 & - & - & - & - \\
\hline 18 & SA TL V30 STR & 1,19 & 2956,1 & 2301,2 & 2951,1 & - & - & - & - \\
\hline 19 & SA TL V40 STR & 1,12 & 6002,0 & 3480,2 & 4504,8 & - & - & - & - \\
\hline
\end{tabular}

OBS:

1) Os resultados para seção transversal em 5 vigas são relativos à viga intermediária, apesar de nos casos de tabuleiro estreito e vão igual a 10 metros a viga de extremidade ser a mais crítica. Em alguns casos de vigas simplesmente apoiadas, apesar do esforço proveniente do trem-tipo normativo ser maior para a viga de extremidade, o efeito da carga permanente torna a viga intermediária mais crítica em qualquer combinação de ações.

2) Nas pontes C3, o momento fletor positivo refere-se ao tramo externo.

3) Nas pontes C3B, o momento fletor positivo refere-se ao tramo central e o momento fletor negativo ao apoio interno.

Legenda: STR: Sem transversinas

Tabela 3.8 - Resultados da análise estrutural - SEÇÃO CELULAR.

\begin{tabular}{|c|c|c|c|c|c|c|c|c|c|}
\hline \multirow{2}{*}{$\mathbf{n}$} & \multirow{2}{*}{ Arquivo } & \multicolumn{4}{|c|}{ Momento positivo (kN.m) } & \multicolumn{3}{c|}{ Momento negativo (kN.m) } \\
\cline { 3 - 10 } & & $\varphi$ & $\mathbf{M}_{\text {perm }}$ & $\mathbf{M}_{36}$ & $\mathbf{M}_{45}$ & $\varphi$ & $\mathbf{M}_{\text {perm }}$ & $\mathbf{M}_{36}$ & $\mathbf{M}_{45}$ \\
\hline 1 & SA TL V20 STR & 1,26 & 7609,4 & 3318,8 & 4627,3 & - & - & - & - \\
\hline 2 & SA TL V30 STR & 1,19 & 18188,2 & 6620,4 & 9278,9 & - & - & - & - \\
\hline 3 & SA TL V40 STR & 1,12 & 34692,3 & 10966,6 & 15423,4 & - & - & - & - \\
\hline 4 & C3 TL V30/30/30 STR & 1,19 & 10248,2 & 5253,5 & 7362,0 & 1,19 & 13667,0 & 5225,0 & 7386,4 \\
\hline 5 & SA TL V30 TR2 & 1,19 & 3715,2 & 1603,7 & 2226,9 & - & - & - & - \\
\hline 6 & SA TE V20 STR & 1,26 & 5189,8 & 2694,0 & 3587,3 & - & - & - & - \\
\hline 7 & SA TE V30 STR & 1,19 & 12426,5 & 5224,0 & 6961,6 & - & - & - & - \\
\hline 8 & SA TE V40 STR & 1,12 & 23717,3 & 8535,0 & 11375,2 & - & - & - & - \\
\hline 9 & C3 TE V30/30/30 STR & 1,19 & 6998,3 & 4148,0 & 5525,4 & 1,19 & 9340,7 & 3948,4 & 5262,9 \\
\hline 10 & SA TE V30 TR2 & 1,19 & 3152,9 & 1612,3 & 2134,0 & - & - & - & - \\
\hline
\end{tabular}

OBS:

1) Nas pontes C3, o momento fletor positivo refere-se ao tramo externo.

2) Os resultados para as pontes de 3 e 4 células são relativos à “viga” intermediária. 


\subsection{Dimensionamento da área de aço longitudinal}

Uma vez obtidos os esforços de flexão, segue-se a determinação das áreas de aço longitudinais para cada elemento estrutural. Do total de estruturas em questão, algumas são consideradas apenas em concreto armado, algumas apenas em concreto protendido e algumas poderão atender aos 2 casos. No caso de pontes simplesmente apoiadas, com exceção das pontes em 2 vigas, para vãos de 10 m adotou-se concreto armado, para vãos de $20 \mathrm{~m}$, concreto armado e protendido, e a partir dos $30 \mathrm{~m}$ apenas concreto protendido. No caso das estruturas contínuas e das pontes em 2 vigas, considerou-se somente concreto armado. Um resumo dos casos selecionados está na tabela 3.9.

Tabela 3.9 - Resumo dos casos selecionados.

\begin{tabular}{|c|c|c|c|c|c|}
\hline \multirow{2}{*}{ Sistema estrutural } & \multicolumn{4}{|c|}{ Simplesmente apoiada } & \multirow{3}{*}{ Contínua } \\
\cline { 2 - 5 } & \multicolumn{4}{|c|}{ Vão (m) } & \\
\cline { 2 - 5 } & 10 & 20 & 30 & 40 & \\
\hline Laje & CA & CA/CP & - & - & CA \\
\hline 2 vigas & CA & CA & - & - & CA \\
\hline 5 vigas & CA & CA/CP & CP & CP & CA \\
\hline Seção celular & - & CA/CP & CP & CP & CA \\
\hline
\end{tabular}

Legenda:

CA: Concreto armado

CP: Concreto protendido

A definição dos casos se baseou no campo de aplicação dos concretos armado e protendido, de acordo com o vão. No caso de estruturas contínuas de concreto protendido, a necessidade de traçar o cabo ao longo da viga, etapa relativamente subjetiva do projetista, e o aparecimento de esforços hiperestáticos de protensão dificultariam a análise de estruturas “existentes”. Esse fato, aliado à pequena porcentagem do sistema estrutural no universo das obras de arte especiais, resultou em sua não consideração para o desenvolvimento deste trabalho.

A seguir, são descritas as principais considerações sobre cada tipo de projeto.

\subsubsection{Concreto armado}

a) Introdução da segurança 
A segurança das pontes com relação à resistência (estado limite último), era feita antigamente, antes de 1978, considerando um coeficiente de segurança único (global) de 1,65 para as cargas permanentes e de 2,0 para as cargas móveis, tendo em vista a natureza distinta desses dois carregamentos. Assim, as cargas móveis possuíam um coeficiente de segurança 1,2 (aproximadamente 2,0/1,65) vezes o coeficiente de segurança único (global) das cargas usuais (cargas permanentes e outras cargas variáveis).

A NB-1 de 1978 não é explícita neste aspecto e a norma de ações e segurança nas estruturas NBR-8681, de 1984, não faz esta diferenciação. Assim, nas pontes projetadas entre 1978 e 1984, época da mudança da NB-6, a consideração deste coeficiente adicional de 1,2 ficou por conta da interpretação do projetista. Como a não consideração do coeficiente 1,2 corresponderia a projetar a ponte com menor capacidade portante, pode-se julgar que esta hipótese dificilmente tenha acontecido. Desta forma, neste estudo considerou-se o coeficiente de 1,2 no cálculo do efeito das ações móveis referente à Classe 36.

A partir de 1984, com as cargas da nova NB-6 (NBR-7188), pode-se supor que as pontes foram projetadas sem a diferença de coeficientes, uma vez que a classe de maior carga passou da Classe 36 para a Classe 45 (aproximadamente, 36 x 1,2).

Com a entrada em vigor da nova NB-2 (NBR-7187, de 1987), aparece novamente uma diferença na segurança com a consideração do coeficiente de ponderação de 1,35 para as ações permanentes e de 1,50 para as ações da carga móvel em se tratando do estado limite último. No entanto, como a NB-1/78 especificava coeficiente de ponderação de 1,40 para as ações permanentes e de 1,40 para as ações variáveis, as pontes projetadas após 1986 podem ter sido projetadas com qualquer uma das duas alternativas.

A partir de 2003, a nova NBR-8681 (ações e segurança nas estruturas) mantém o coeficiente de 1,50 para as cargas móveis, mas estabelece 1,30 para ações permanentes em pontes cujo peso próprio da estrutura supera $75 \%$ da totalidade das ações permanentes.

Levando todos esses aspectos em consideração, o resumo dos casos considerados inicialmente para análise está na tabela 3.10. Destaca-se que o caso de classe 45 entre os anos de 1984 e 1986 é de pouca probabilidade de ocorrência e, portanto, de menor interesse. 
Tabela 3.10 - Coeficientes de ponderação das ações.

\begin{tabular}{|c|c|c|c|c|c|}
\hline Período & Até 1977 & 1978 a 1983 & 1984 a 1986 & 1987 a 2002 & A partir de 2003 \\
\hline Classe & 36 & 36 & 45 & 45 & 45 \\
\hline$\gamma_{\mathrm{g}}$ & 1,65 & 1,40 & 1,40 & 1,35 & 1,30 \\
\hline$\gamma_{\mathrm{q}}$ & 2,00 & 1,68 & 1,40 & 1,50 & 1,50 \\
\hline
\end{tabular}

Os estados limites de serviço não serão abordados. Considera-se que a fissuração em pontes de concreto armado não é crítica e os deslocamentos verticais devido à carga permanente podem ser controlados durante a construção da ponte através de uma contra-flecha.

b) Materiais, características geométricas e hipóteses de cálculo

Devido à existência de diversos períodos, as características dos materiais, a geometria das peças e as hipóteses de cálculo devem atender às exigências de diferentes normas.

A resistência característica do concreto adotada para cada período pode ser vista na tabela 3.11. Embora seja um parâmetro variável, de acordo com cada projeto, buscou-se adotar valores representativos para cada época. Ressalta-se que o mesmo $\mathrm{f}_{\mathrm{ck}}$ será adotado para todos os tipos de pontes.

Tabela 3.11 - Resistência característica do concreto à compressão (concreto armado).

\begin{tabular}{|c|c|c|c|c|c|}
\hline Período & Até 1977 & 1978 a 1983 & 1984 a 1986 & 1987 a 2002 & A partir de 2003 \\
\hline Classe & 36 & 36 & 45 & 45 & 45 \\
\hline $\mathrm{f}_{\mathrm{ck}}(\mathrm{MPa})$ & 18 & 18 & 20 & 20 & 25 \\
\hline
\end{tabular}

Adotou-se em todos os casos aço CA-50A e a altura útil foi suposta igual a 90\% da altura total.

Admitindo-se que o primeiro período tenha início em 1960 e se estenda até 1978, seu dimensionamento deve seguir as prescrições da NB-1 (1960), que traz em seu texto, entre outras, as seguintes hipóteses:

A ruptura se dá quando a tensão de compressão no concreto, suposta uniformemente distribuída com altura igual à posição da linha neutra, atinja o valor $\sigma_{R}$ 
(correspondente ao valor característico $\mathrm{f}_{\mathrm{ck}}$ );

$\checkmark$ Encurtamento de ruptura convencional do concreto igual a 0,15\%;

$\checkmark$ Não há limite para a deformação da armadura de tração.

No entanto, o anexo da EB3 (1967) modifica dispositivos da NB-1 (1960), sendo já utilizado em livros como Rocha (1968) e Pfeil (1969). Dessa forma, optou-se neste trabalho por dimensionar as pontes projetadas antes de 1978 de acordo com esta nova regulamentação. Entre suas hipóteses de cálculo para o caso de flexão simples, o encurtamento de ruptura do concreto é igual a 0,35\%, com tensões uniformemente distribuídas em uma zona de compressão de altura 0,75 da distância da borda comprimida à linha neutra e tensão de cálculo dada por $\mathrm{f}_{\mathrm{ck}}$. Destaca-se que não são usados coeficientes parciais de segurança para minoração da resistência, pois as peças são calculadas em função da carga de ruptura.

A partir de 1978 admite-se que o encurtamento específico de ruptura do concreto é $0,35 \%$ e as tensões seguem um diagrama retangular com ordenada igual a $0,85 \cdot \mathrm{f}_{\mathrm{cd}}$ e altura de $0,8 \cdot \mathrm{x}$, onde $x$ é a profundidade da linha neutra.

As dimensões das lajes vazadas utilizadas no dimensionamento estão na figura 3.3. A mesa inferior possui $12 \mathrm{~cm}$ de altura no caso de estruturas simplesmente apoiadas (ordem 3 e 4 da tabela 3.1) e 15 cm em lajes contínuas (ordem 7 e 8).

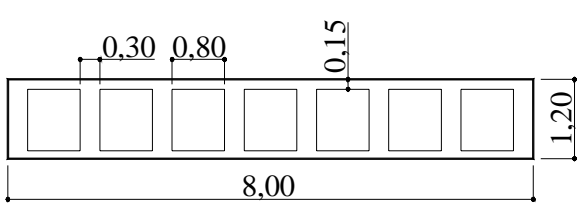

a) Tabuleiro estreito

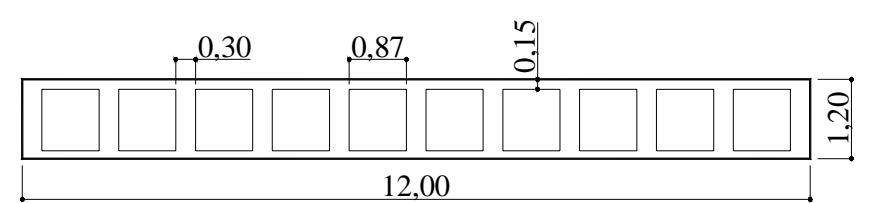

b) Tabuleiro largo

Figura 3.3 - Dimensões das lajes para dimensionamento.

A largura da mesa das seções $\mathrm{T}$ assume diferentes valores em função de cada período. Vale ressaltar que devido à existência do tabuleiro, que proporciona uma solidarização entre as seções $\mathrm{T}$, foi sempre considerada flexão reta mesmo no caso de seções que resultem assimétricas.

Para fins de dimensionamento, quando necessário, nas regiões de momento fletor negativo foi adicionado um engrossamento da seção transversal. Esse engrossamento é usual em projeto, mas de maneira geral visa atender às limitações 
impostas pela força cortante. Como este estudo não contempla tal esforço, o critério aqui adotado foi a mínima largura necessária para que a seção (retangular) trabalhe com armadura simples para momento fletor negativo em todos os períodos considerados.

No caso de seção transversal em 5 vigas, será admitido que todas as longarinas são armadas igualmente e que não possuem mesa inferior no caso de concreto armado.

As pontes de seção celular serão armadas como viga. Aquelas que foram modeladas como uma única barra terão sua seção composta por uma mesa com largura igual à soma das larguras colaborantes das suas nervuras, e largura da alma correspondente a soma das larguras das nervuras. De maneira similar às pontes de 2 vigas, houve um engrossamento das almas das células, além de um aumento na espessura da mesa inferior, nas regiões de momento negativo.

c) Consideração da fadiga

A aplicação repetida do carregamento móvel pode levar a ruína dos elementos estruturais mesmo quando o nível de solicitação é inferior àquele correspondente ao estado limite último. Dessa forma, a máxima variação de tensões, especialmente nas armaduras ativa e passiva, deve estar dentro de limites prescritos pelas normas técnicas. Principalmente em estruturas contínuas, onde há inversão de sinal nos esforços solicitantes, é comum aumentar-se a área de aço de modo a satisfazer a verificação de fadiga da armadura. Esse procedimento pode ser considerado relativamente simples, pois do ponto de vista do projeto basta seguir as indicações normativas.

No entanto, a análise de fadiga de elementos estruturais submetidos ao tráfego real de veículos torna-se mais complicada. Laman e Nowak (1996) utilizam resultados de pesagem em movimento (weigh-in-motion) para o desenvolvimento de um carregamento móvel destinado à verificação da fadiga em pontes de aço. Szerszen et al. (1999) realizam uma análise de confiabilidade para fadiga em pontes de aço, demonstrando a diminuição de beta com o passar dos anos. A análise é estendida em Szerszen e Nowak (2000) para o estudo de pontes de concreto, considerando-se sua degradação na zona de compressão (a fadiga da armadura tracionada e a diminuição da aderência aço-concreto são ignoradas).

Em resumo, não são muitos os trabalhos que abordam o problema da fadiga, especialmente em pontes de concreto, e os estudos existentes não fornecem indicações 
práticas para sua consideração. Além disso, a análise requer medições do tráfego, que possui características significativamente variáveis de lugar para lugar, inviabilizando a utilização de resultados obtidos por pesquisadores de outros países. A análise da fadiga em pontes de concreto submetidas ao tráfego real de caminhões foge ao escopo deste trabalho e requer portanto um estudo específico, que fica como sugestão para futuras pesquisas.

A maneira encontrada nesta tese para contornar este problema é a não verificação da fadiga durante o dimensionamento (uma eventual majoração das áreas de aço devido à ação repetida do carregamento móvel não será considerada) e posteriormente também ao longo da análise de confiabilidade. Em síntese, a questão da fadiga ficará a parte e se deve ter isso em mente ao analisar os resultados obtidos. De qualquer forma, assume-se estar a favor da segurança, principalmente no caso de pontes com pouco tempo de exposição ao tráfego e que possuam características usuais. Considerando-se que a resistência à fadiga diminui com o aumento do número de ciclos, as pontes possuem maior capacidade portante em suas primeiras idades. Esse fator não está sendo considerado e portanto o índice de confiabilidade calculado estará subestimado para pontes “jovens”. No entanto, salienta-se que essas afirmações partem do princípio que os critérios normativos para o cálculo da fadiga durante o projeto das estruturas existentes estejam adequados.

\subsubsection{Concreto protendido}

a) Introdução da segurança e grau de protensão

De acordo com informações obtidas do meio técnico, cerca de 95\% dos projetos de pontes em concreto protendido se utilizam de protensão limitada e apenas 5\% deles fazem uso de protensão completa. Visando a atender grande parte dos casos e a reduzir o número de análises, neste trabalho todas as pontes de concreto protendido terão protensão limitada. Admitem-se ainda peças com aderência posterior (pós-tração).

Como é usual em projetos de concreto protendido, o dimensionamento será feito com base nos estados limites de serviço e posteriormente se dará a verificação do estado limite último.

Até 1984, o projeto das pontes de concreto protendido, na superposição dos 
efeitos das ações permanentes com o efeito da carga móvel, para verificar as condições de protensão completa ou limitada, considerava o coeficiente de 1,2 (acrescido do impacto) no efeito da carga móvel, já comentado no item 3.4.1.

Entre 1984 e 1986, considera-se que não há diferença no tratamento das ações permanentes e do carregamento móvel, e portanto o coeficiente é 1,0 para os dois casos.

Em 1987, a NBR-7187 estabelece que, na combinação quase-permanente de ações o efeito da carga móvel deve ser multiplicado por 0,4, enquanto que na combinação freqüente o fator multiplicativo é 0,8 , em se tratando de pontes rodoviárias. Destaca-se que essas recomendações contradizem as prescrições da NBR-8681 (1984), que fornece 0,2 e 0,4, respectivamente. De acordo com informações de projetistas, a norma de ações e segurança nas estruturas de 1984 não foi utilizada, nesse aspecto, para o cálculo de pontes.

A partir de 2003, seguem-se as recomendações da nova NBR-8681. Os coeficientes multiplicativos da carga móvel são 0,3 para a combinação quasepermanente e 0,5 para a combinação freqüente.

O resumo das situações previstas está na tabela 3.12. Em todos os casos deve ainda ser considerado o coeficiente de impacto.

Tabela 3.12 - Coeficientes para cálculo do ELS.

\begin{tabular}{|c|c|c|c|c|c|}
\hline Período & Até 1978 & 1978 a 1983 & 1984 a 1986 & 1987 a 2002 & A partir de 2003 \\
\hline Classe & 36 & 36 & 45 & 45 & 45 \\
\hline$\gamma_{\mathrm{g}}$ & 1,00 & 1,00 & 1,00 & - & - \\
\hline$\gamma_{\mathrm{q}}$ & 1,20 & 1,20 & 1,00 & - & - \\
\hline$\psi_{1}$ & - & - & - & 0,80 & 0,50 \\
\hline$\psi_{2}$ & - & - & - & 0,40 & 0,30 \\
\hline
\end{tabular}

Legenda:

$\psi_{1}$ : fator para a combinação de utilização de grande frequência

$\psi_{2}$ : fator para a combinação de utilização quase-permanente

A associação dos graus de protensão, das combinações de ações e dos estados limites de utilização a serem verificados se inicia a partir de 1987, mediante recomendações da NBR-7187 e de estudos preliminares da NBR-7197. As disposições relativas à protensão limitada consideradas neste trabalho, de 1987 em diante, estão contidas na tabela 3.13 . 
Tabela 3.13 - Graus de protensão e estados limites a verificar. (NBR-7197, 1989)

\begin{tabular}{|c|c|c|c|}
\hline \multirow{2}{*}{ Protensão } & \multicolumn{3}{|c|}{ Combinação de ações } \\
\cline { 2 - 4 } & Quase-permanente & Freqüente & Rara \\
\hline Completa & - & descompressão & formação de fissuras \\
\hline Limitada & descompressão & formação de fissuras & - \\
\hline Parcial & descompressão $^{*}$ & abertura de fissuras & - \\
\hline
\end{tabular}

*Dispensada pela NBR-6118 (2003)

A verificação do estado limite último utiliza os mesmos coeficientes empregados para as pontes de concreto armado (v. tabela 3.10).

Observa-se que algumas das premissas de projeto adotadas neste trabalho, devido a seu caráter relativamente subjetivo, podem variar de acordo com os diferentes escritórios de cálculo e as demais regiões do país.

b) Materiais, características geométricas e hipóteses de cálculo

De maneira idêntica ao que ocorre no caso de concreto armado, a existência de diversos períodos faz com que os aspectos relativos ao projeto devam atender às exigências de diferentes normas.

$\mathrm{O} \mathrm{f}_{\mathrm{ck}}$ adotado para as estruturas de concreto protendido, geralmente maior que aquele utilizado em obras de concreto armado, pode ser visto na tabela 3.14. Para sua definição, admite-se que as pontes em laje e em seção celular são moldadas no local, enquanto que as pontes em 5 vigas são formadas por elementos pré-moldados de canteiro. Nesse último caso, considera-se uma resistência inferior do concreto para a laje do tabuleiro.

Tabela $3.14-\mathrm{f}_{\mathrm{ck}}$ para as pontes de concreto protendido em MPa.

\begin{tabular}{|c|c|c|c|c|c|}
\hline Período & Até 1977 & 1978 a 1983 & 1984 a 1986 & 1987 a 2002 & A partir de 2003 \\
\hline Classe & 36 & 36 & 45 & 45 & 45 \\
\hline $\begin{array}{c}\text { Laje } \\
5 \text { vigas } \\
\text { Celular }\end{array}$ & 25 & 25 & 30 & 30 & 35 \\
\hline $\begin{array}{c}5 \text { vigas } \\
\text { tabuleiro) }\end{array}$ & 18 & 18 & 20 & 20 & 25 \\
\hline
\end{tabular}

Até 1986, seguindo as prescrições da NBR-116 (Cálculo e execução de obras de 
concreto protendido), as tensões no concreto em serviço devem respeitar aos seguintes limites:

Imediatamente após a aplicação da protensão:

Tração: $\sigma_{\mathrm{t}} \leq \mathrm{f}_{\mathrm{ct}}$

Compressão: $\left|\sigma_{\mathrm{c}}\right| \leq \frac{2}{3} \cdot \mathrm{f}_{\mathrm{cj}}$, sendo $\mathrm{f}_{\mathrm{cj}} \leq \mathrm{f}_{\mathrm{ck}}$

Após todas as perdas de protensão:

Tração: $\sigma_{\mathrm{t}} \leq 2 \cdot \mathrm{f}_{\mathrm{ct}}$ para protensão limitada (para protensão completa, $\sigma_{\mathrm{t}} \leq 0$ )

Compressão: $\left|\sigma_{\mathrm{c}}\right| \leq \frac{\mathrm{f}_{\mathrm{ck}}}{2}$

onde:

$\mathrm{f}_{\mathrm{ct}}$ : tensão mínima de ruptura do concreto à tração simples, podendo ser dada por $\frac{\mathrm{f}_{\mathrm{ck}}}{10}$.

Deve também ser feita a verificação das tensões considerando-se apenas a carga permanente após as perdas de protensão, devendo ser obedecidas às condições de protensão completa. No caso de pontes rodoviárias, a NBR-116 estabelece ainda que não são permitidas tensões de tração sob a ação de metade das cargas acidentais acrescidas do impacto.

A partir de 1987, devem-se respeitar os estados limites enunciados na tabela 3.13, além do estado limite de compressão excessiva logo após a aplicação da protensão. Admite-se a resistência do concreto à tração na flexão igual a $1,2 \cdot \mathrm{f}_{\mathrm{ctk}}$, onde $\mathrm{f}_{\text {ctk }}$ é a resistência característica do concreto à tração direta.

Também existem limites para as tensões na armadura de protensão por ocasião do estiramento de acordo com cada período. Até 1986, admite-se aço CP 140/125 e a partir de 1987, serão utilizadas cordoalhas de 7 fios CP-190 RB 12,7.

As perdas totais de protensão serão estimadas com o valor de $22 \%$ e às perdas iniciais incluindo a deformação imediata do concreto devido ao estiramento dos cabos restantes será atribuída $8 \%$.

Em todos os casos será considerada apenas uma etapa de protensão com $\mathrm{f}_{\mathrm{cj}}$ igual a $0,85 \cdot \mathrm{f}_{\mathrm{ck}}$ (cimento CP-II, estiramento dos cabos 10 dias após a moldagem), embora existam obras em que os elementos pré-moldados de canteiro recebem o 
restante de sua força de protensão na posição definitiva.

Após as determinações da força de protensão, da área de armadura ativa e das tensões em serviço, o estado limite último é verificado seguindo as orientações do item 3.6.1. Nesta fase do trabalho, o diagrama de tensões no concreto é admitido retangular e considera-se o patamar de escoamento no aço protendido. A armadura construtiva depende do tipo da seção transversal, sendo composta de 4 barras nas nervuras das pontes em laje, 6 barras em cada elemento das pontes de 5 vigas e nas pontes em seção celular são utilizadas cerca de 2 barras a cada $30 \mathrm{~cm}$. Visando a minimizar a área de armadura passiva, empregam-se barras com 12,5 mm de diâmetro (CA-50A). No entanto, quando necessário, essa área pré-determinada foi aumentada até a satisfação do momento fletor de cálculo. Nas pontes em seção celular, a largura colaborante considerada é a própria largura do tabuleiro.

No caso das vigas pré-moldadas, utiliza-se na verificação o $\mathrm{f}_{\mathrm{ck}}$ da laje do tabuleiro. Salienta-se ainda que não é considerada nenhuma redistribuição de tensões entre o concreto moldado no local e o concreto pré-moldado.

c) Consideração da fadiga

Com relação à análise das estruturas protendidas submetidas a condições reais de tráfego, as mesmas considerações feitas anteriormente sobre fadiga em pontes de concreto armado se aplicam nesse caso também. Portanto, o problema da fadiga também ficará a parte nas pontes de concreto protendido.

\subsection{Resultados do dimensionamento}

O dimensionamento foi desenvolvido em planilhas do Microsoft Excel para todos os períodos e para todas as seções transversais. Salienta-se que a área de aço necessária não é transformada em barras, no caso do concreto armado, e cordoalhas, no caso de concreto protendido. Dessa forma, não se conta com uma pequena reserva de resistência que possuem as estruturas reais.

Salienta-se que pequenas alterações nas hipóteses de cálculo, na resistência característica do concreto e na altura da seção transversal não trazem mudanças significativas ao resultado do trabalho, porque em qualquer circunstância o momento 
fletor resistente deve satisfazer ao momento fletor de cálculo. Em linhas gerais, o dimensionamento apenas fixa os valores nominais das diversas variáveis para o posterior cálculo do momento fletor resistente médio.

\subsubsection{Concreto armado}

No caso das pontes de 2 vigas, os esquemas longitudinais com $40 \mathrm{~m}$ de vão e balanços de 7 m (ordens 6 e 15 da tabela 3.2) requerem aumento na altura de seção transversal em pelo menos um dos períodos para que não seja necessária armadura dupla para momento fletor positivo, demonstrando que elas estão mal prédimensionadas. Considerando-se que o vão é um tanto longo para aplicação em concreto armado, que as seções já estão com altura elevada (podendo interferir no tráfego que circula sob a ponte) e sua pouca representatividade no total das estruturas existentes, elas serão retiradas da análise. A coerência com o critério adotado acima também leva à exclusão das pontes de ordem 9 e 18, que possuem 3 vãos contínuos com 40 m cada.

\subsubsection{Concreto protendido}

No caso das pontes de concreto protendido, foi necessária a revisão das dimensões das seções transversais presentes nas tabelas 3.3 (5 vigas) e 3.4 (seção celular). Destacam-se as seguintes modificações:

a) 5 vigas: as seções transversais não contemplavam a mesa superior dos elementos pré-moldados, padronizada agora como retangular de largura $1,20 \mathrm{~m}$ e altura $15 \mathrm{~cm}$. A mesa inferior foi fixada com largura de $0,60 \mathrm{~cm}$ e altura de $0,30 \mathrm{~cm}$. A altura da laje do tabuleiro varia entre 0,15 cm e 0,20 cm. A largura das almas (condizentes com a presença de cabos e a necessidade de cobrimento mínimo) e a altura da seção completa estão na tabela 3.15. Ressalta-se que, de maneira geral, a necessidade de transporte para a posição definitiva faz com que as alturas das vigas sejam maiores se comparadas a sistemas moldados totalmente no local; 
Tabela 3.15 - Seção transversal das pontes em 5 vigas.

\begin{tabular}{|c|c|c|c|}
\hline \multirow{2}{*}{ Dimensão } & \multicolumn{3}{|c|}{ Vão } \\
\cline { 2 - 4 } & $20 \mathrm{~m}$ & $30 \mathrm{~m}$ & $40 \mathrm{~m}$ \\
\hline Largura da alma (m) & 0,20 & 0,22 & 0,22 \\
\hline Altura total $(\mathrm{m})$ & 1,30 & 1,95 & 2,50 \\
\hline
\end{tabular}

b) Seção celular: as pontes com $20 \mathrm{~m}$ de vão tiveram sua altura reduzida para 1,20 m e a altura das pontes de $40 \mathrm{~m}$ foi fixada em 2,20 m.

\subsection{Momento fletor resistente nominal}

Considera-se que resistência nominal é aquela obtida sem quaisquer coeficientes de segurança. Dessa forma, as propriedades do concreto e do aço são utilizadas com seu valor característico.

\subsubsection{Procedimento de cálculo}

O cálculo do momento fletor resistente foi desenvolvido através da elaboração de um programa em linguagem Fortran. Primeiramente, a seção transversal é dividida em uma série de fatias retangulares (v. figura 3.4). Assume-se a deformação e a tensão constantes em cada fatia. Após uma tentativa inicial, a posição da linha neutra é procurada através de iterações até se atingir o equilíbrio de forças.

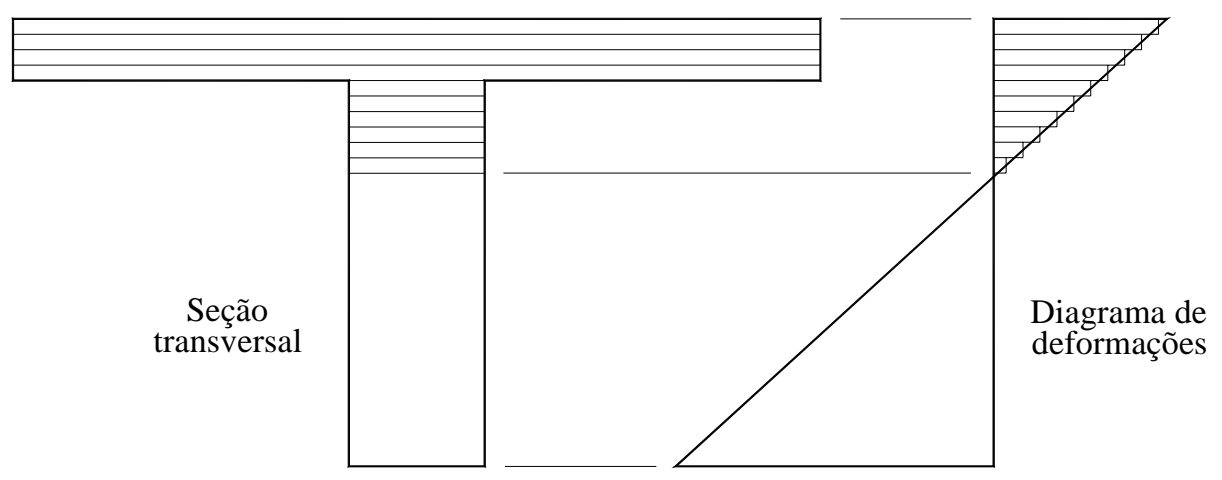

Figura 3.4 - Seção transversal dividida em fatias na zona comprimida.

A divisão da seção transversal em fatias de $0,5 \mathrm{~cm}$ apresentou bons resultados comparando-se com soluções analíticas, além de consumir pequeno tempo 
computacional. As aproximações provenientes do método residem na suposição de deformação e tensão constantes em cada fatia e na fixação da linha neutra entre duas fatias consecutivas. No entanto, os resultados encontrados não justificam maior refinamento do modelo.

As propriedades dos materiais são baseadas na NBR-6118 (2003), conforme figuras 3.5 e 3.6 .

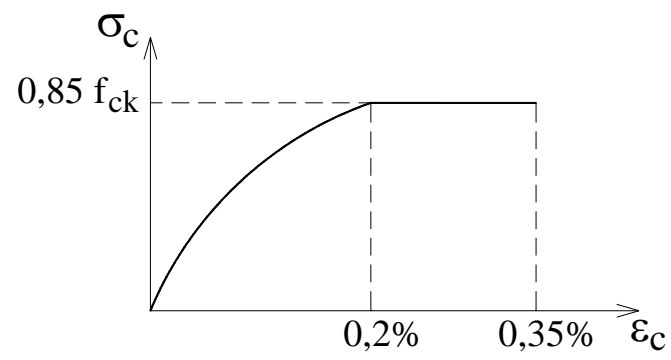

Figura 3.5 - Relação tensão $x$ deformação do concreto à compressão.

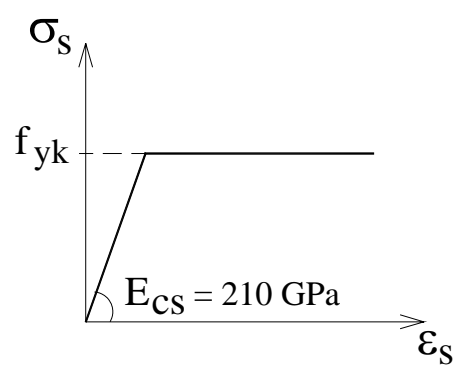

a) Armadura passiva

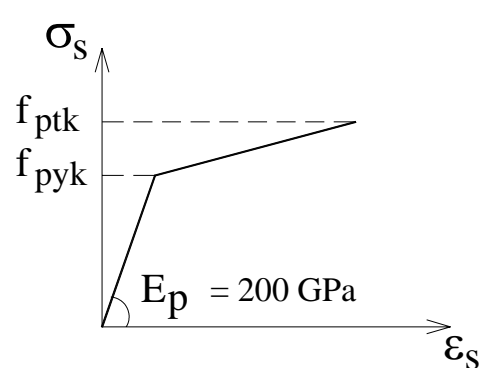

b) Armadura ativa

Figura 3.6 - Relações tensão $x$ deformação das armaduras ativa e passiva.

O momento fletor resistente em seções de concreto protendido é calculado da mesma forma que em concreto armado, bastando a consideração do pré-alongamento.

\subsubsection{Resultados}

Dentre os 5 intervalos de tempo determinados inicialmente, apenas um deles considerado crítico (menor momento fletor resistente) para cada classe será levado adiante nos cálculos.

\subsubsection{Concreto armado}

Para a classe 36, o período crítico não é bem definido e depende de cada caso. 
Em relação à classe 45, o período de 1984 a 1986 foi excluído da análise por ser de baixa probabilidade de ocorrência. Dentre os últimos 2 períodos restantes, aquele que se inicia a partir de 2003 possui sistematicamente menor resistência e portanto apenas ele será considerado nos cálculos. Ressalta-se, no entanto, que a diferença entre os diversos períodos não é significativa.

A título de ilustração, as relações momento-curvatura que podem ser obtidas a partir da divisão da seção transversal em fatias são exemplificadas na figura 3.7. O procedimento consiste em aumentar gradativamente a deformação na fibra superior da seção até se atingir o limite de 0,35\%. Nesse caso, utilizou-se 140 passos de deformação e a contribuição do concreto tracionado antes da fissuração foi desprezada.

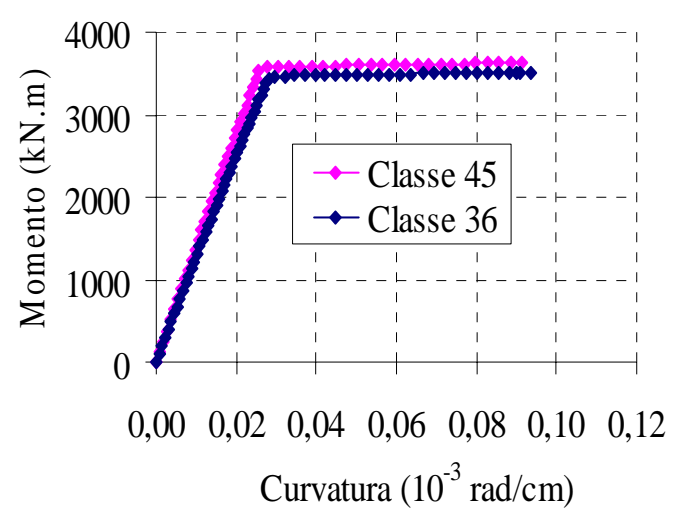

Figura 3.7 - Relação momento-curvatura para a ponte de 5 vigas, ordem 2 (SA TE V20 TR2).

Os momentos fletores últimos nominais para as pontes de concreto armado estão nas tabelas 3.16 a 3.19 .

Tabela 3.16 - Momento fletor resistente nominal (kN.m) - LAJE.

\begin{tabular}{|c|c|c|c|c|c|}
\hline \multirow{2}{*}{$\mathbf{n}$} & \multirow{2}{*}{ Arquivo } & \multicolumn{2}{|c|}{ Momento positivo } & \multicolumn{2}{c|}{ Momento negativo } \\
\cline { 3 - 6 } & & Classe 36 & Classe 45 & Classe 36 & Classe 45 \\
\hline 1 & SA TE V10 MC & 809,8 & 850,4 & - & - \\
\hline 2 & SA TL V10 MC & 774,8 & 811,1 & - & - \\
\hline 3 & SA TE V20 VZ & 1962,5 & 1990,9 & - & - \\
\hline 4 & SA TL V20 VZ & 2004,9 & 2035,9 & - & - \\
\hline 5 & C3 TE V10/10/10 MC & 576,3 & 607,7 & 590,8 & 588,5 \\
\hline 6 & C3 TL V10/10/10 MC & 569,8 & 601,6 & 592,4 & 590,4 \\
\hline 7 & C3 TE V20/20/20 VZ & 1312,6 & 1339,9 & 1384,8 & 1335,5 \\
\hline 8 & C3 TL V20/20/20 VZ & 1342,2 & 1377,3 & 1461,9 & 1415,8 \\
\hline
\end{tabular}


Tabela 3.17 - Momento fletor resistente nominal (kN.m) - VIGA T - 2 VIGAS.

\begin{tabular}{|c|c|c|c|c|c|}
\hline \multirow{2}{*}{$n$} & \multirow{2}{*}{ Arquivo } & \multicolumn{2}{c|}{ Momento positivo } & \multicolumn{2}{c|}{ Momento negativo } \\
\cline { 3 - 6 } & & Classe 36 & Classe 45 & Classe 36 & Classe 45 \\
\hline 1 & SA TE V10 TR2 & 2611,6 & 2771,7 & - & - \\
\hline 2 & SA TE V20 TR2 & 9110,2 & 9270,0 & - & - \\
\hline 3 & SAB TE V3/10/3 TR2 & 2122,1 & 2307,3 & 1490,6 & 1674,1 \\
\hline 4 & SAB TE V5/20/5 TR2 & 7232,0 & 7554,5 & 3883,6 & 4267,8 \\
\hline 5 & SAB TE V5/30/5 TR4 & 16421,4 & 16861,5 & 4332,0 & 4551,8 \\
\hline 7 & C3 TE V20/20/20 TR3 & 6308,3 & 6564,8 & 6299,0 & 6522,9 \\
\hline 8 & C3 TE V30/30/30 TR3 & 13016,3 & 13151,6 & 13952,1 & 14293,9 \\
\hline 10 & SA TL V10 TR1 & 3413,6 & 3640,4 & - & - \\
\hline 11 & SA TL V20 TR2 & 12195,8 & 12546,3 & - & - \\
\hline 12 & SAB TL V3/10/3 TR1 & 2515,8 & 2766,4 & 1676,6 & 1886,5 \\
\hline 13 & SAB TL V5/20/5 TR2 & 9491,9 & 10034,1 & 4795,3 & 5346,3 \\
\hline 14 & SAB TL V5/30/5 TR3 & 22580,7 & 23085,7 & 5433,7 & 5809,8 \\
\hline 16 & C3 TL V20/20/20 TR2 & 7943,7 & 8383,8 & 8282,2 & 8864,6 \\
\hline 17 & C3 TL V30/30/30 TR3 & 16952,7 & 17429,6 & 18487,4 & 19432,9 \\
\hline 19 & C3B TE V5-20/25/20-5 & 6732,8 & 7005,4 & 7915,1 & 8178,6 \\
\hline 20 & C3B TL V5-20/25/20-5 & 8464,6 & 8957,2 & 10388,8 & 11004,4 \\
\hline 21 & C3B TE V5-25/30/25-5 & 9018,6 & 9306,5 & 11667,5 & 11980,2 \\
\hline 22 & C3B TL V5-25/30/25-5 & 11398,6 & 11996,3 & 15257,0 & 16110,6 \\
\hline 23 & C2 TL V30/30 TR3 & 15355,5 & 15942,6 & 21413,0 & 22251,8 \\
\hline
\end{tabular}

Tabela 3.18 - Momento fletor resistente nominal (kN.m) - VIGA T - 5 VIGAS.

\begin{tabular}{|c|c|c|c|c|c|}
\hline \multirow{2}{*}{$\mathbf{n}$} & \multirow{2}{*}{ Arquivo } & \multicolumn{2}{c|}{ Momento positivo } & \multicolumn{2}{c|}{ Momento negativo } \\
\cline { 3 - 6 } & & Classe 36 & Classe 45 & Classe 36 & Classe 45 \\
\hline 1 & SA TE V10 TR2 & 1049,4 & 1123,9 & - & - \\
\hline 2 & SA TE V20 TR2 & 3507,4 & 3626,5 & - & - \\
\hline 5 & SA TL V10 TR2 & 1403,0 & 1517,2 & - & - \\
\hline 6 & SA TL V20 TR2 & 4446,5 & 4715,2 & - & - \\
\hline 9 & C3 TL V30/30/30 TR2 & 7427,3 & 7760,7 & 8162,3 & 8667,2 \\
\hline 10 & $\begin{array}{c}\text { C3B TE V5-25/30/25-5 } \\
\text { TR2 }\end{array}$ & \multirow{2}{*}{4012,4} & 4136,0 & 5468,0 & 5576,0 \\
\hline \multirow{2}{*}{11} & $\begin{array}{c}\text { C3B TL V5-25/30/25-5 } \\
\text { TR2 }\end{array}$ & \multirow{2}{*}{5157,5} & 5506,3 & 6892,9 & \multirow{2}{*}{7274,3} \\
\hline 12 & SA TE V10 STR & 1066,3 & 1144,4 & - & - \\
\hline 13 & SA TE V20 STR & 3453,9 & 3591,6 & - & - \\
\hline 16 & SA TL V10 STR & 1616,3 & 1742,9 & - & - \\
\hline 17 & SA TL V20 STR & 4952,5 & 5208,5 & - & - \\
\hline
\end{tabular}


Tabela 3.19 - Momento fletor resistente nominal (kN.m) - SEÇÃO CELULAR.

\begin{tabular}{|c|c|c|c|c|c|}
\hline \multirow{2}{*}{$\mathbf{n}$} & \multirow{2}{*}{ Arquivo } & \multicolumn{2}{|c|}{ Momento positivo } & \multicolumn{2}{c|}{ Momento negativo } \\
\cline { 3 - 6 } & & Classe 36 & Classe 45 & Classe 36 & Classe 45 \\
\hline 1 & SA TL V20 STR & 20369,3 & 21298,1 & - & - \\
\hline 4 & C3 TL V30/30/30 STR & 28920,6 & 30378,1 & 34308,0 & 36040,8 \\
\hline 6 & SA TE V20 STR & 14990,6 & 15533,8 & - & - \\
\hline 9 & C3 TE V30/30/30 STR & 21058,0 & 21899,8 & 24217,5 & 25065,2 \\
\hline
\end{tabular}

\subsubsection{Concreto protendido}

No caso de concreto protendido, o período até 1978 e de 1978 a 1984 fornecem resultados bastante próximos. Nas pontes classe 45, mantendo-se o critério de menor probabilidade de ocorrência, o período entre 1984 e 1986 será desconsiderado. Os 2 períodos restantes se alternam quanto ao menor momento fletor resistente.

Os resultados obtidos para as pontes de concreto protendido podem ser vistos nas tabelas 3.20 a 3.22 .

Tabela 3.20 - Momento fletor resistente nominal (kN.m) - LAJE.

\begin{tabular}{|c|c|c|c|}
\hline \multirow{2}{*}{$\mathbf{n}$} & \multirow{2}{*}{ Arquivo } & \multicolumn{2}{|c|}{ Momento positivo } \\
\cline { 3 - 4 } & & Classe 36 & Classe 45 \\
\hline 3 & SA TE V20 VZ & 2154,6 & 2060,5 \\
\hline 4 & SA TL V20 VZ & 2165,3 & 2083,9 \\
\hline
\end{tabular}

Tabela 3.21 - Momento fletor resistente nominal (kN.m) - VIGA T - 5 VIGAS.

\begin{tabular}{|c|c|c|c|}
\hline \multirow{2}{*}{$\mathbf{n}$} & \multirow{2}{*}{ Arquivo } & \multicolumn{2}{|c|}{ Momento positivo } \\
\cline { 3 - 4 } & & Classe 36 & Classe 45 \\
\hline 2 & SA TE V20 TR2 & 4453,5 & 4247,0 \\
\hline 3 & SA TE V30 TR2 & 9898,6 & 9396,8 \\
\hline 4 & SA TE V40 TR4 & 19506,3 & 18670,8 \\
\hline 6 & SA TL V20 TR2 & 6038,5 & 5853,5 \\
\hline 7 & SA TL V30 TR2 & 12990,7 & 12733,2 \\
\hline 8 & SA TL V40 TR4 & 23614,7 & 23268,5 \\
\hline 13 & SA TE V20 STR & 4362,5 & 4305,9 \\
\hline 14 & SA TE V30 STR & 9678,0 & 9179,7 \\
\hline 15 & SA TE V40 STR & 18733,1 & 17907,9 \\
\hline 17 & SA TL V20 STR & 6295,0 & 6144,0 \\
\hline 18 & SA TL V30 STR & 13140,0 & 12659,4 \\
\hline 19 & SA TL V40 STR & 23013,4 & 22969,8 \\
\hline
\end{tabular}


Tabela 3.22 - Momento fletor resistente nominal (kN.m) - SEÇÃO CELULAR.

\begin{tabular}{|c|c|c|c|}
\hline \multirow{2}{*}{$\mathbf{n}$} & \multirow{2}{*}{ Arquivo } & \multicolumn{2}{|c|}{ Momento positivo } \\
\cline { 3 - 4 } & & Classe 36 & Classe 45 \\
\hline 1 & SA TL V20 STR & 19675,3 & 20365,4 \\
\hline 2 & SA TL V30 STR & 42942,5 & 44427,3 \\
\hline 3 & SA TL V40 STR & 78630,5 & 79834,3 \\
\hline 5 & SA TL V30 TR2 & 11468,0 & 11701,1 \\
\hline 6 & SA TE V20 STR & 15573,6 & 15908,2 \\
\hline 7 & SA TE V30 STR & 33321,0 & 33705,3 \\
\hline 8 & SA TE V40 STR & 59907,4 & 59826,0 \\
\hline 10 & SA TE V30 TR2 & 10551,0 & 10681,3 \\
\hline
\end{tabular}

\subsection{Implementação da técnica de Monte Carlo}

Conforme já descrita no capítulo 2, a resistência dos elementos estruturais é considerada uma variável aleatória devido a incertezas nas propriedades dos materiais, nas dimensões das peças e nos métodos de análises. A avaliação dos seus parâmetros estatísticos, tais como bias, coeficiente de variação, sua função densidade de probabilidade e função distribuição acumulada, requer grande quantidade de ensaios de materiais e peças, sendo portanto de custo bastante elevado.

Como alternativa, o comportamento dos elementos estruturais pode ser determinado através de simulações. Particularmente, este trabalho fará uso da técnica de Monte Carlo.

Ressalta-se, no entanto, a importância da realização de provas-de-carga. Por exemplo, a partir de testes em pontes existentes, Nowak (2004) mostra que as condições de contorno reais podem ser diferentes das assumidas em projeto. Em se tratando de estruturas metálicas, a grande maioria das pontes projetadas como simplesmente apoiadas funcionam na prática com engaste parcial.

\subsubsection{Parâmetros estatísticos das propriedades dos materiais e das dimensões}

As variáveis básicas são a resistência do concreto à compressão, as propriedades do aço e as dimensões das seções transversais. Os parâmetros estatísticos a serem utilizados nas simulações serão obtidos basicamente a partir da literatura disponível e também a partir de dados de ensaios apenas no caso da compressão do concreto. Ressalta-se que a variabilidade corresponde a uma construção com nível médio de qualidade. 


\subsubsection{Parâmetros estatísticos da resistência à compressão do concreto}

De acordo com Mirza et al. (1979), as principais razões para a variação na resistência à compressão do concreto são as variações nas propriedades dos materiais e na proporção entre eles, as variações na mistura, transporte, lançamento e métodos de cura, além de variações nos procedimentos de ensaios.

Devido ao fato das características de obtenção do concreto variarem de lugar para lugar (tipo de cimento, agregados, dosagem, controle, etc, são peculiares de cada localidade) pode não ser correto a utilização de resultados obtidos em outros países.

Para as pontes antigas, não se tem notícia de resultados de ensaios provenientes de obras executadas, nem tampouco indicações estatísticas sobre tipo de distribuição, bias, etc. Portanto, para as pontes executadas até 1986, será utilizado o modelo de dosagem da NB-1 (1978). A resistência do concreto é descrita através de uma distribuição normal:

$\mathrm{f}_{\mathrm{c} 28}=\mathrm{f}_{\mathrm{ck}}+1,65 \cdot \sigma_{\mathrm{d}}$

onde:

$\sigma_{\mathrm{d}}:$ desvio-padrão de dosagem.

Caso não seja conhecido o desvio-padrão, a norma permite considerar $\sigma_{\mathrm{d}}=4 \mathrm{MPa}$ em casos de controle rigoroso da produção do concreto. Assume-se que as obras de arte se enquadrem nessa situação.

Buscando conhecer as características do concreto produzido atualmente, que podem então ser utilizadas para as pontes construídas a partir de 2003, e como aproximação para as pontes do período anterior (1987 a 2002), iniciou-se uma coleta de dados sobre a resistência à compressão do concreto a partir de corpos-de-prova cilíndricos de $10 \mathrm{~cm}$ de diâmetro e $20 \mathrm{~cm}$ de altura. Os dados fornecidos referem-se a uma empresa com filiais em diversas localidades e a amostra corresponde ao concreto utilizado em inúmeras obras. São moldados, em regra, 2 corpos-de-prova de cada caminhão betoneira, sendo 1 deles rompido aos 7 dias e o outro aos 28 dias. A compactação se dá em 2 camadas com 12 golpes em cada uma e a cura é submersa. Embora o número de ensaios (v. tabela 3.23) ainda seja limitado, recomendando-se a continuação da coleta em futuros estudos, os resultados fornecem indicativos 
importantes.

Tabela 3.23 - Números de amostras rompidas aos 28 dias.

\begin{tabular}{|c|c|}
\hline$f_{\mathrm{ck}}(\mathrm{MPa})$ & Número de amostras \\
\hline 15 & 181 \\
\hline 18 & 199 \\
\hline 20 & 403 \\
\hline 25 & 303 \\
\hline 30 & 180 \\
\hline 35 & 42 \\
\hline
\end{tabular}

Seguindo indicações de diversos trabalhos (NOWAK e COLLINS, 2000; NOWAK e SZERSZEN, 2001; NOWAK et al., 2005; SCHNEIDER, 1997), os dados são plotados em papéis de probabilidade, que auxiliam na escolha do tipo de distribuição e na determinação dos parâmetros estatísticos mais importantes. Trata-se de uma forma conveniente de se representar a distribuição de probabilidade acumulada. $\mathrm{O}$ eixo horizontal representa a variável básica (no caso, a resistência à compressão do concreto) e o eixo vertical representa a probabilidade. Maiores detalhes sobre a construção e o uso de papéis de probabilidade são descritos em livros como Nowak e Collins (2000) e Schneider (1997).

Uma propriedade básica do papel de probabilidade é que qualquer série de dados que seja descrita pelo mesmo tipo de distribuição do papel em questão é representada por uma linha reta. Por exemplo, qualquer função de distribuição normal é representada por uma linha reta no papel de probabilidade normal e, por sua vez, qualquer linha reta representa uma função de distribuição normal.

Em síntese, o procedimento consiste inicialmente na plotagem dos dados (resistência aos 28 dias) em um papel de probabilidade qualquer. Caso os dados se aproximem de uma linha reta, a distribuição está determinada. O passo seguinte é desenhar a melhor reta através dos pontos, que irá fornecer os parâmetros da distribuição (média e desvio-padrão). Como do ponto de vista da confiabilidade a parte mais importante da função distribuição acumulada é a cauda inferior, sugere-se que a linha reta seja ajustada apenas para essa parte dos dados, negligenciando também algum valor muito inferior aos demais.

Considerando-se que a resistência à compressão do concreto segue tradicionalmente uma função normal ou lognormal (v. tabela 2.7), os 2 papéis de 
probabilidade foram testados para cada valor da resistência nominal. Inicialmente, apresentam-se os gráficos para os concretos com $\mathrm{f}_{\mathrm{ck}}$ igual a $15 \mathrm{MPa}$ e $18 \mathrm{MPa}$, conforme figuras 3.8 a 3.11. Em cada gráfico são mostrados a bias (v. definição no item 2.4) e o coeficiente de variação (CV).

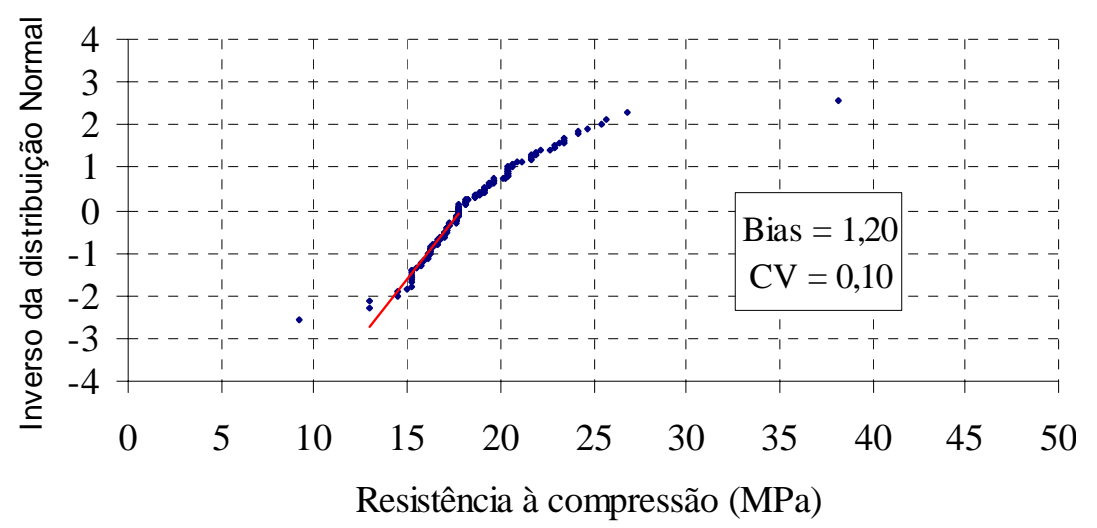

Figura 3.8 - Papel de probabilidade normal - $\mathrm{f}_{\mathrm{ck}}=15 \mathrm{MPa}$.

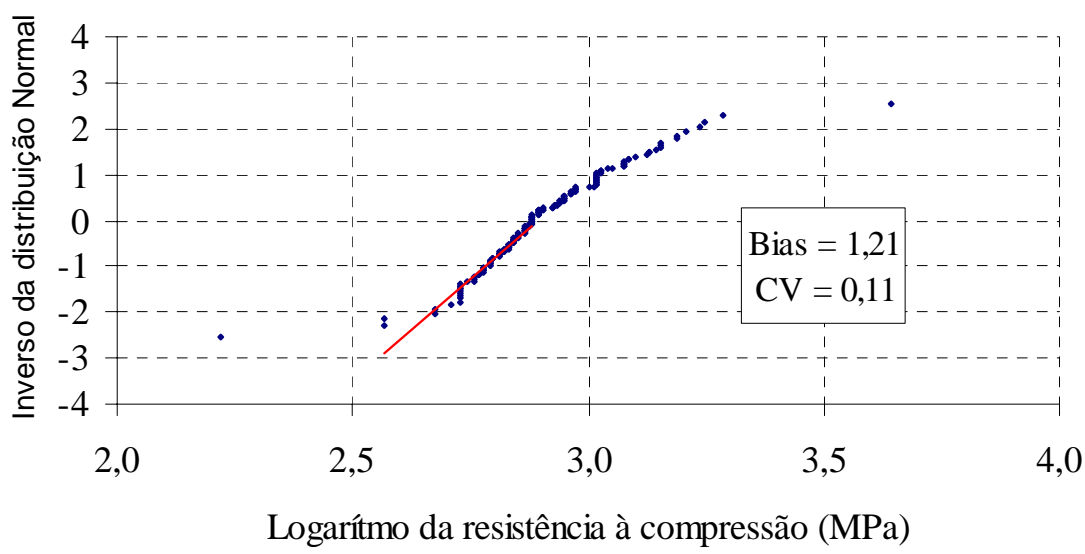

Figura 3.9 - Papel de probabilidade lognormal - $\mathrm{f}_{\mathrm{ck}}=15 \mathrm{MPa}$.

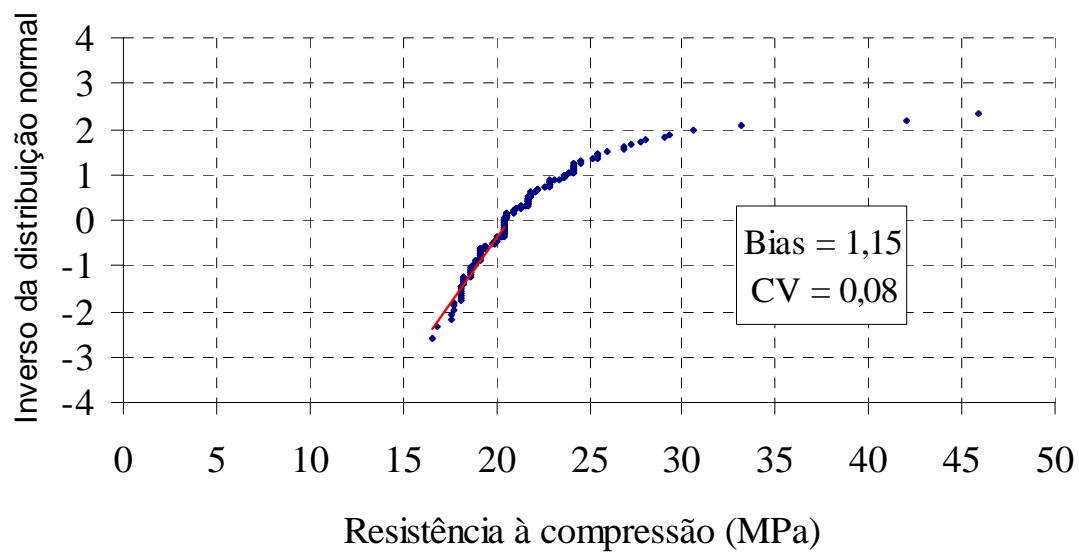

Figura 3.10 - Papel de probabilidade normal $-\mathrm{f}_{\mathrm{ck}}=18 \mathrm{MPa}$. 


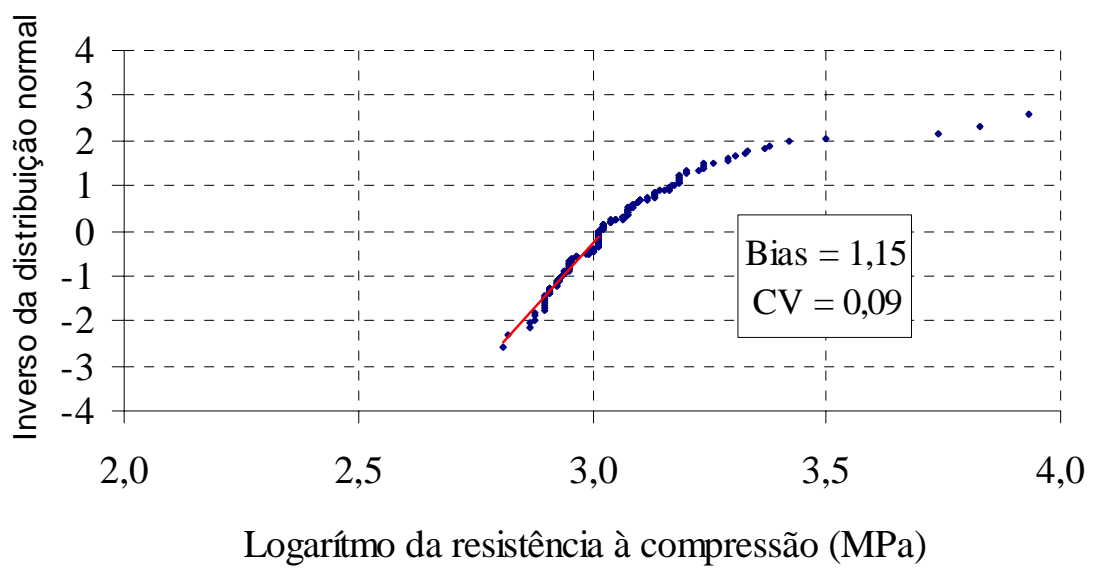

Figura 3.11 - Papel de probabilidade lognormal - $\mathrm{f}_{\mathrm{ck}}=18 \mathrm{MPa}$.

A análise das figuras 3.8 e 3.9 mostra que para $\mathrm{f}_{\mathrm{ck}}=15 \mathrm{MPa}$ a distribuição lognormal se demonstra mais apropriada para representar a amostra de dados. Esta observação concorda com Mirza et al. (1979), que afirma que alguns pesquisadores indicam a distribuição lognormal para concretos com menor controle de qualidade e, portanto, maior coeficiente de variação.

Para concretos com $\mathrm{f}_{\mathrm{ck}}=18 \mathrm{MPa}$, a diferença nas figuras 3.10 e 3.11 é pouco notada e se torna mais difícil a identificação do tipo de distribuição, que poderia ser auxiliada com um número maior de amostras. Ainda nesse caso, recomenda-se a distribuição lognormal.

Em concretos com resistência característica igual a $20 \mathrm{MPa}$ a distribuição normal é a que mais se adequa aos dados (v. figuras 3.12 e 3.13), sendo utilizada também em outros estudos.

Concretos com resistência superior seguem a tendência observada e são descritos pela distribuição normal (v. figuras 14 a 16). Ressalta-se que no caso de $\mathrm{f}_{\mathrm{ck}}=35 \mathrm{MPa}$ o número de amostras é muito reduzido e assim os resultados devem ser vistos com maior precaução. 


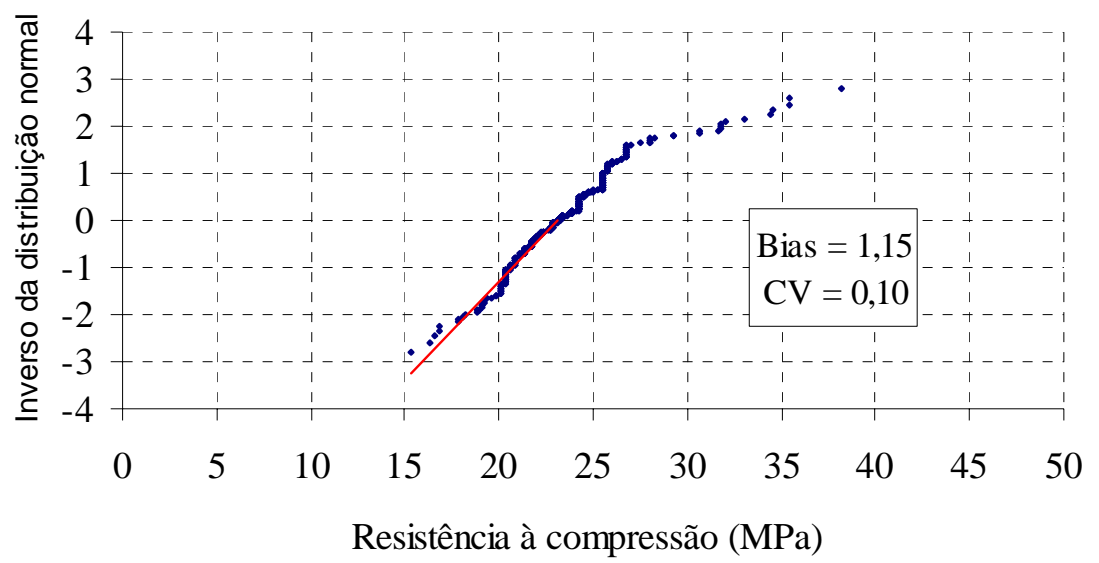

Figura 3.12 - Papel de probabilidade normal $-\mathrm{f}_{\mathrm{ck}}=20 \mathrm{MPa}$.

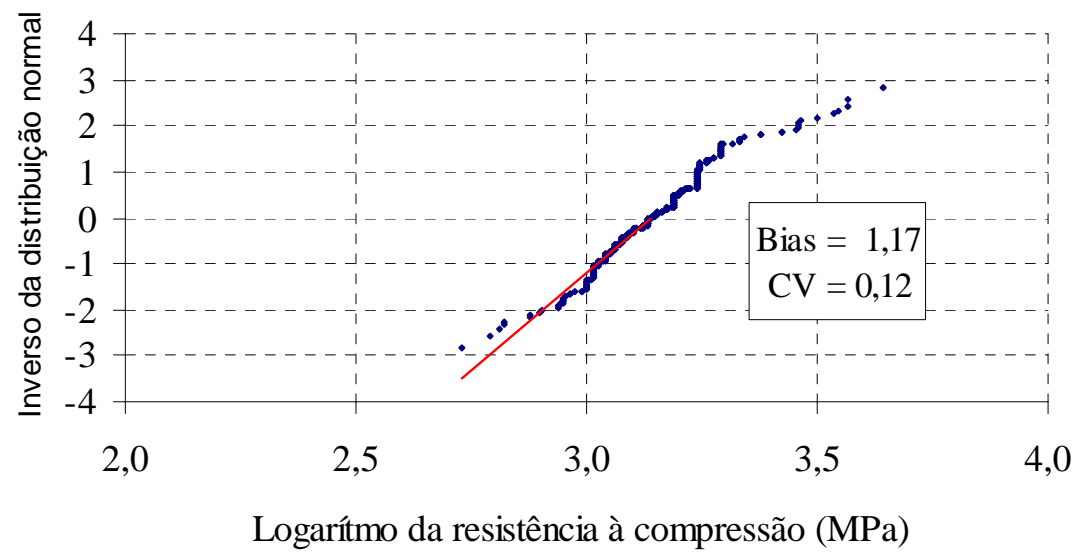

Figura 3.13 - Papel de probabilidade lognormal - $\mathrm{f}_{\mathrm{ck}}=20 \mathrm{MPa}$.

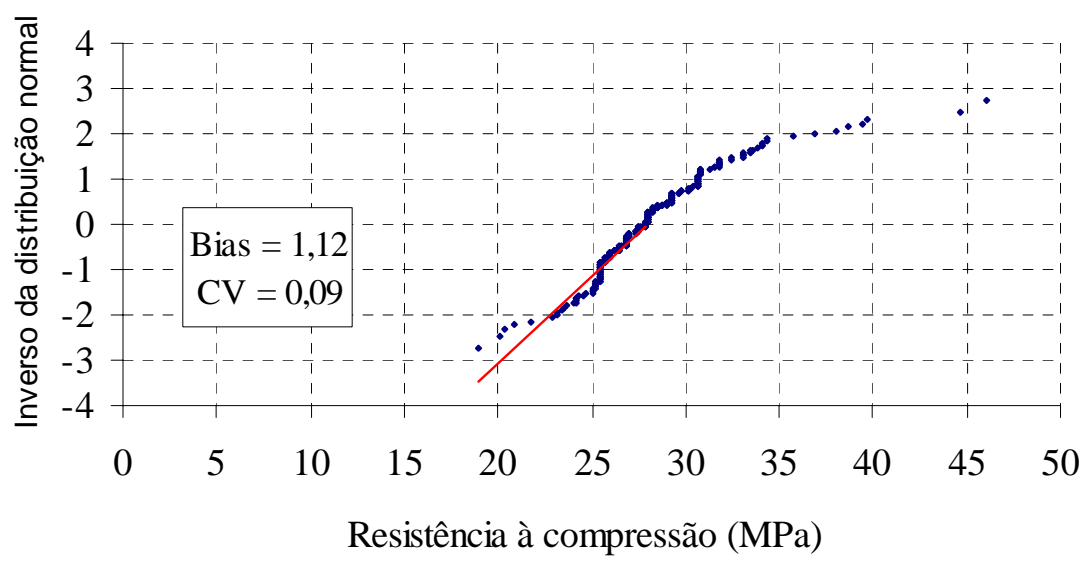

Figura 3.14 - Papel de probabilidade normal $-\mathrm{f}_{\mathrm{ck}}=25 \mathrm{MPa}$. 


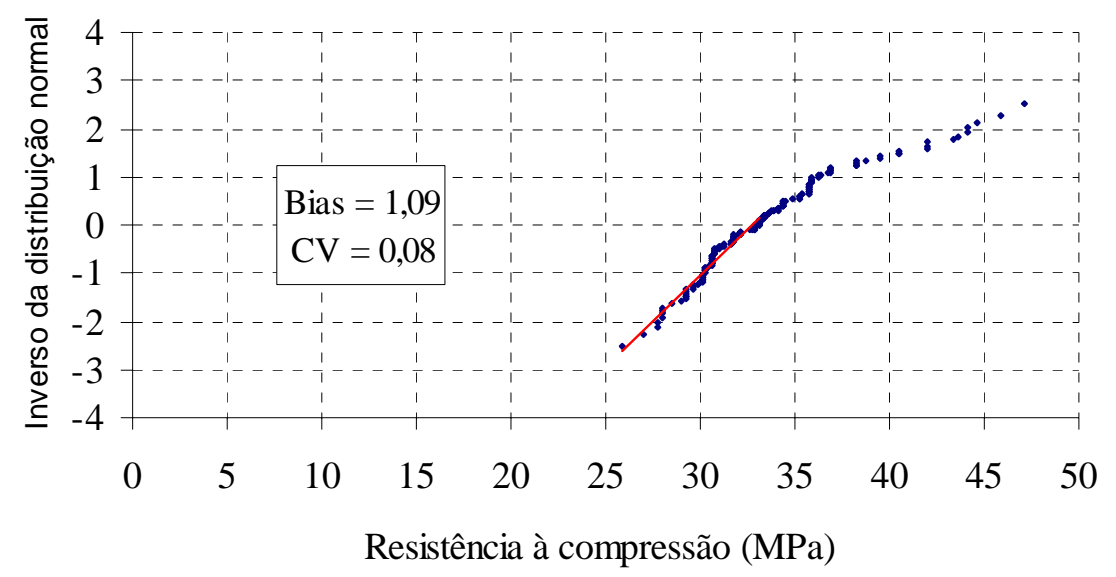

Figura 3.15 - Papel de probabilidade normal $-\mathrm{f}_{\mathrm{ck}}=30 \mathrm{MPa}$.

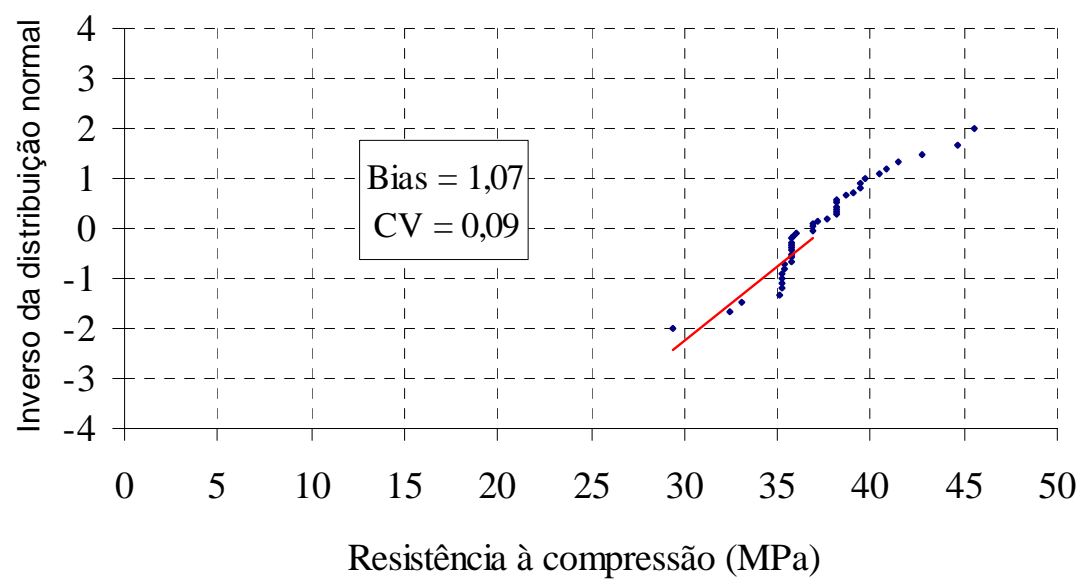

Figura 3.16 - Papel de probabilidade normal $-\mathrm{f}_{\mathrm{ck}}=35 \mathrm{MPa}$.

A bias e o coeficiente de variação em função do $f_{c k}$ para os dados obtidos e dois outros trabalhos encontrados na literatura estão nas figuras 3.17 e 3.18 , respectivamente.

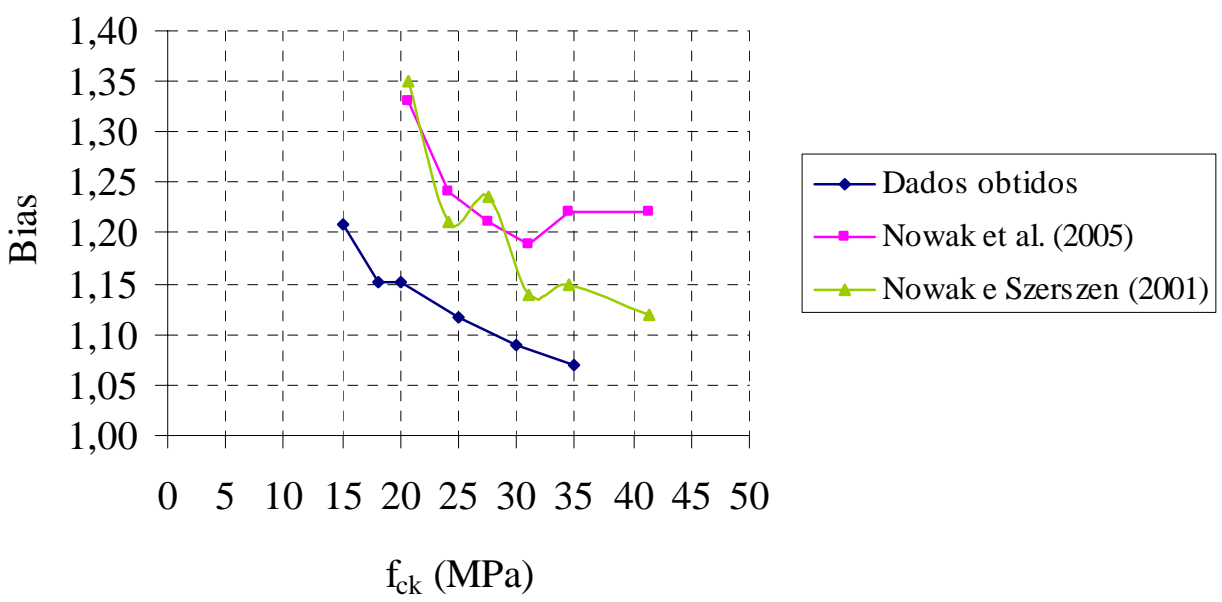

Figura 3.17 - Bias para a resistência à compressão do concreto. 


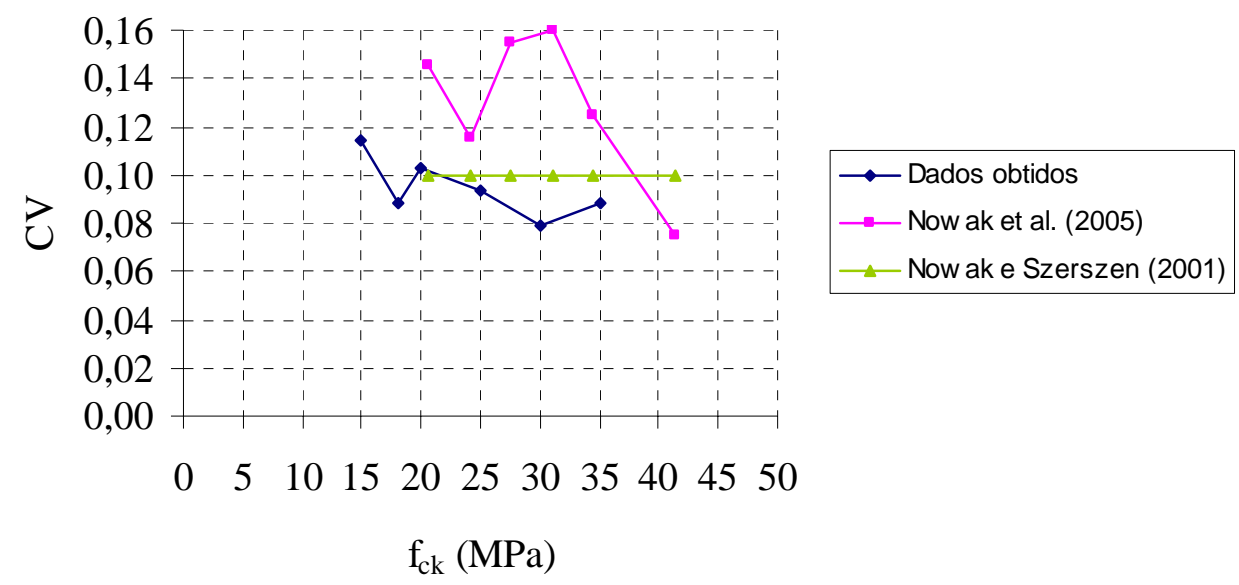

Figura 3.18 - Coeficiente de variação para a resistência à compressão do concreto.

Os resultados obtidos demonstram o aumento da bias em função da diminuição da resistência (v. figura 3.17), conforme já esperado. De certa forma, é uma maneira de se precaver contra resultados muito baixos, haja visto que os coeficientes de variação (v. figura 3.18) são maiores para as menores resistências nominais.

A comparação dos dados obtidos com o trabalho de Nowak et al. (2005) revela um melhor controle da produção para o concreto nacional, evidenciado pelo menor coeficiente de variação. Ainda destaca-se a significativa diferença entre os valores médios das resistências. De qualquer forma, salienta-se que essas conclusões são válidas para os casos aqui discutidos.

Uma limitação do trabalho de Nowak e Szerszen (2001) é o reduzido número de dados para algumas classes de resistência (cerca de 30 amostras). Destaca-se que o coeficiente de variação constante não é razoável.

Com base nos resultados obtidos, são sugeridas curvas da resistência média à compressão (v. figura 3.19) e do coeficiente de variação (v. figura 3.20), em função do $\mathrm{f}_{\mathrm{ck}}$. Sua utilização pode ser de interesse em outros trabalhos relativos à análise de confiabilidade, inclusive quanto à calibração de coeficientes parciais de segurança para normalização.

Por fim, os dados analisados referem-se a concreto fabricado em usina e serão utilizados no decorrer deste trabalho. 


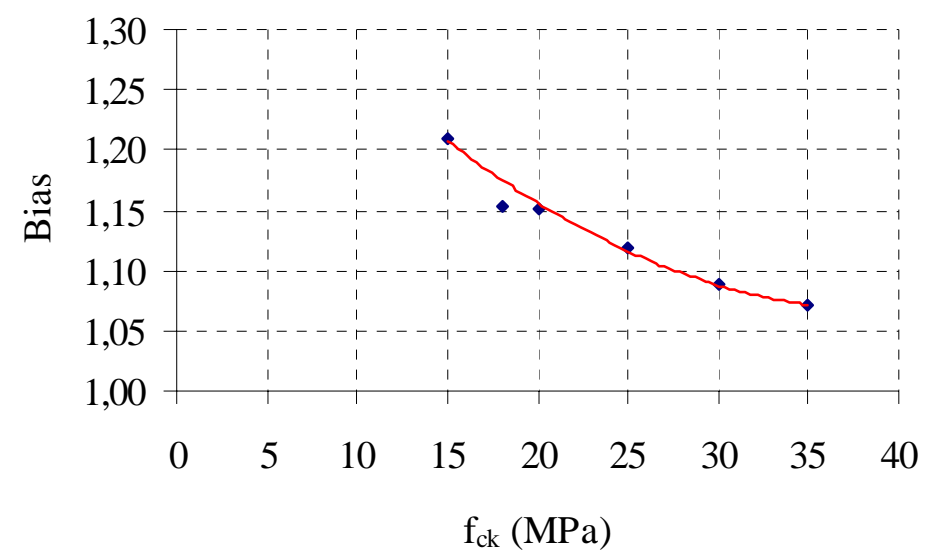

Figura 3.19 - Bias recomendada para a resistência à compressão do concreto.

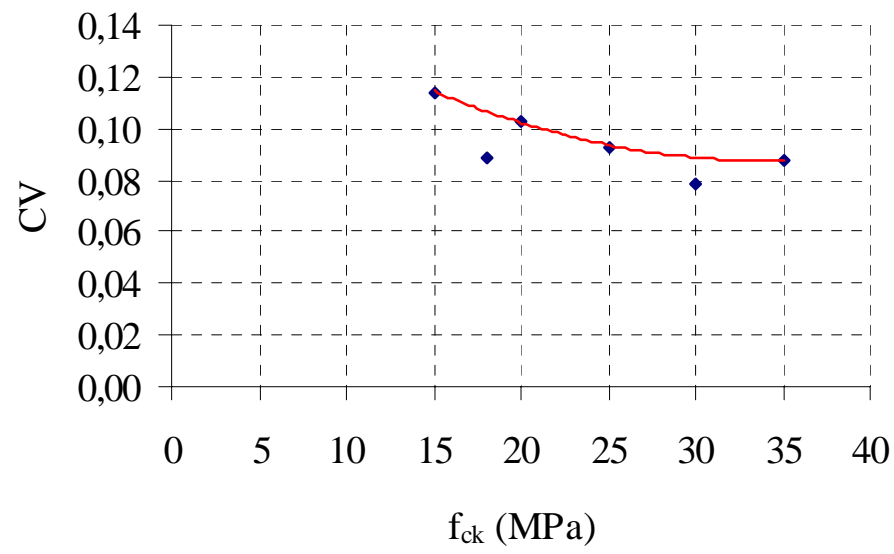

Figura 3.20 - Coeficiente de variação recomendado para a resistência à compressão do concreto.

\subsubsection{Parâmetros estatísticos das armaduras passiva e ativa}

$\mathrm{Na}$ falta de dados estatísticos referentes à construção nacional sobre os parâmetros das armaduras, serão utilizados valores fornecidos pela bibliografia, conforme tabela 3.24 .

Nos trabalhos consultados não foram encontrados dados estatísticos sobre o módulo de elasticidade da armadura de protensão. Dessa forma, seu valor será considerado determinístico. A resistência ao escoamento da armadura ativa será calculada como 90\% de sua resistência à tração. 
Tabela 3.24 - Parâmetros estatísticos da armadura.

\begin{tabular}{|c|c|c|c|c|}
\hline Variável & Bias & $\mathbf{C V}$ & $\begin{array}{c}\text { Tipo de } \\
\text { distribuição }\end{array}$ & Fonte \\
\hline $\mathrm{E}_{\mathrm{s}}(\mathrm{MPa})$ & 1,00 & 0,06 & Lognormal & \multirow{3}{*}{$\begin{array}{l}\text { Nowak, Yamani e } \\
\text { Tabsh (1994) }\end{array}$} \\
\hline$A_{s}\left(\mathrm{~cm}^{2}\right)$ & 1,00 & 0,015 & Normal & \\
\hline$A_{p}\left(\mathrm{~cm}^{2}\right)$ & 1,00 & 0,0125 & Normal & \\
\hline \multirow[t]{2}{*}{$\mathrm{f}_{\mathrm{pu}}(\mathrm{MPa})$} & 1,03 & 0,022 & Lognormal & $\begin{array}{l}\text { Siriaksorn }^{3}(1980, \\
\text { apud Eamon, 2000) }\end{array}$ \\
\hline & Valor médio & Desvio padrão & & \\
\hline $\mathrm{f}_{\mathrm{y}}(\mathrm{MPa})$ & $\mathrm{f}_{\mathrm{yk}}+60$ & 30 & Lognormal & $\begin{array}{c}\text { Vismann e Zilch } \\
(1995)\end{array}$ \\
\hline
\end{tabular}

Utilizados os mesmos parâmetros estatísticos da resistência ao escoamento

\subsubsection{Parâmetros estatísticos das dimensões da seção transversal}

Os parâmetros estatísticos adotados para as dimensões dos elementos estruturais estão na tabela 3.25. A largura colaborante da laje, cujo valor é sugerido pelas normas, será considerada uma variável determinística, sendo sua incerteza representada posteriormente pelo fator de análise.

Tabela 3.25 - Parâmetros estatísticos da seção transversal da viga.

\begin{tabular}{|c|c|c|c|c|}
\hline Variável & Bias & $\mathbf{C V}$ & $\begin{array}{c}\text { Tipo de } \\
\text { distribuição }\end{array}$ & Fonte \\
\hline $\mathrm{h}(\mathrm{cm})$ & 1,00 & $0,5 / h$ & Normal & \multirow{2}{*}{$\begin{array}{c}\text { Vismann e Zilch } \\
\text { (1995) }\end{array}$} \\
\hline $\mathrm{h}_{\mathrm{f}}(\mathrm{cm})$ & 1,00 & $0,5 / \mathrm{h}_{\mathrm{f}}$ & Normal & \\
\hline $\mathrm{b}_{\text {viga }}$ (moldada no local) & 1,01 & 0,04 & Normal & \multirow{3}{*}{$\begin{array}{c}\text { Nowak e Szerszen } \\
\text { (2001) }\end{array}$} \\
\hline $\mathrm{d}_{\text {viga }}$ (concreto armado) & 0,99 & 0,04 & Normal & \\
\hline $\mathrm{d}_{\text {viga }}$ (concreto protendido) & 1,00 & 0,025 & Normal & \\
\hline
\end{tabular}

\subsubsection{Síntese dos parâmetros estatísticos dos materiais e das dimensões}

O resumo dos parâmetros estatísticos adotados por este trabalho e que serão utilizados nas simulações está na tabela 3.26. Embora a maior parte dos dados tenham sido extraídos da bibliografia, a variável que apresenta maior variabilidade (resistência

\footnotetext{
${ }^{3}$ Siriaksorn, A. (1980). Serviceability and reliability analysis of partially prestressed concrete beams. PhD dissertation, The University of Illinois at Chicago Circle.
} 
do concreto) reflete, pelo menos para as estruturas mais recentes, as características da construção de uma região do país.

Tabela 3.26 - Resumo dos parâmetros estatísticos para simulação.

\begin{tabular}{|c|c|c|c|c|}
\hline \multicolumn{2}{|c|}{ Variável } & Valor médio & $\mathbf{C V}$ & $\begin{array}{c}\text { Tipo de } \\
\text { distribuição }\end{array}$ \\
\hline \multicolumn{2}{|c|}{$\overline{h_{f}(\mathrm{~cm})}$} & $\mathrm{h}_{\mathrm{f}}$ & $0,5 / h_{f}$ & Normal \\
\hline \multicolumn{2}{|c|}{$\mathrm{h}(\mathrm{cm})$} & $\mathrm{h}$ & $0,5 / h$ & Normal \\
\hline \multicolumn{2}{|c|}{$\mathrm{b}_{\mathrm{f}}$} & $b_{f}$ & - & - \\
\hline \multicolumn{2}{|c|}{$\mathrm{b}_{\mathrm{w}}$} & $1,01 \cdot b_{w}$ & 0,04 & Normal \\
\hline \multicolumn{2}{|c|}{ d (concreto armado) } & $0,99 \cdot d$ & 0,04 & Normal \\
\hline \multicolumn{2}{|c|}{ d (concreto protendido) } & $1,00 \cdot d$ & 0,025 & Normal \\
\hline \multicolumn{2}{|c|}{$A_{s}$} & $A_{s}$ & 0,015 & Normal \\
\hline \multicolumn{2}{|c|}{$A_{p}$} & $A_{p}$ & 0,0125 & Normal \\
\hline \multirow{6}{*}{$\mathrm{f}_{\mathrm{c}}(\mathrm{MPa})$} & $\mathrm{f}_{\mathrm{ck}}=18^{*}$ & 24,6 & 0,163 & Normal \\
\hline & $f_{c k}=25^{*}$ & 31,6 & 0,127 & Normal \\
\hline & $\mathrm{f}_{\mathrm{ck}}=20^{* *}$ & 23,0 & 0,103 & Normal \\
\hline & $\mathrm{f}_{\mathrm{ck}}=25^{* *}$ & 28,0 & 0,093 & Normal \\
\hline & $\mathrm{f}_{\mathrm{ck}}=30^{* *}$ & 32,7 & 0,089 & Normal \\
\hline & $\mathrm{f}_{\mathrm{ck}}=35^{* *}$ & 37,5 & 0,088 & Normal \\
\hline \multicolumn{2}{|c|}{$\mathrm{f}_{\mathrm{y}}\left(\mathrm{kN} / \mathrm{cm}^{2}\right)$} & 56 & 0,054 & Lognormal \\
\hline \multicolumn{2}{|c|}{$\mathrm{f}_{\mathrm{pu}}\left(\mathrm{kN} / \mathrm{cm}^{2}\right)$} & $1,03 \cdot \mathrm{f}_{\mathrm{pu}}$ & 0,022 & Lognormal \\
\hline \multicolumn{2}{|c|}{$\mathrm{E}_{\mathrm{s}}$} & 21000 & 0,06 & Lognormal \\
\hline \multicolumn{2}{|c|}{$\mathrm{E}_{\mathrm{p}}$} & 20000 & - & - \\
\hline
\end{tabular}

*Até 1983

** A partir de 1987

\subsubsection{Momento fletor resistente médio}

A realização dos cálculos é feita através da adaptação do programa já existente para cálculo do momento resistente nominal.

Adotou-se para cada seção transversal 20.000 simulações através do método de Monte Carlo, número suficiente para fornecer a distribuição de probabilidade da resistência. Faz-se uso da biblioteca IMSL do Fortran para geração dos números aleatórios normalmente distribuídos. Esses números, gerados todos de uma só vez para cada simulação, são obtidos através da função dnnor, que inicialmente produz números 
aleatórios uniformemente distribuídos entre 0 e 1 e depois os transformam utilizando-se o inverso da distribuição de probabilidade acumulada normal.

\subsubsection{Concreto armado}

Inicialmente, mostram-se as relações momento-curvatura que podem ser obtidas a partir das simulações (v. figura 3.22). A média e o desvio-padrão em cada ponto resultam em uma curva média, uma curva média mais um desvio-padrão e uma curva média menos um desvio-padrão.
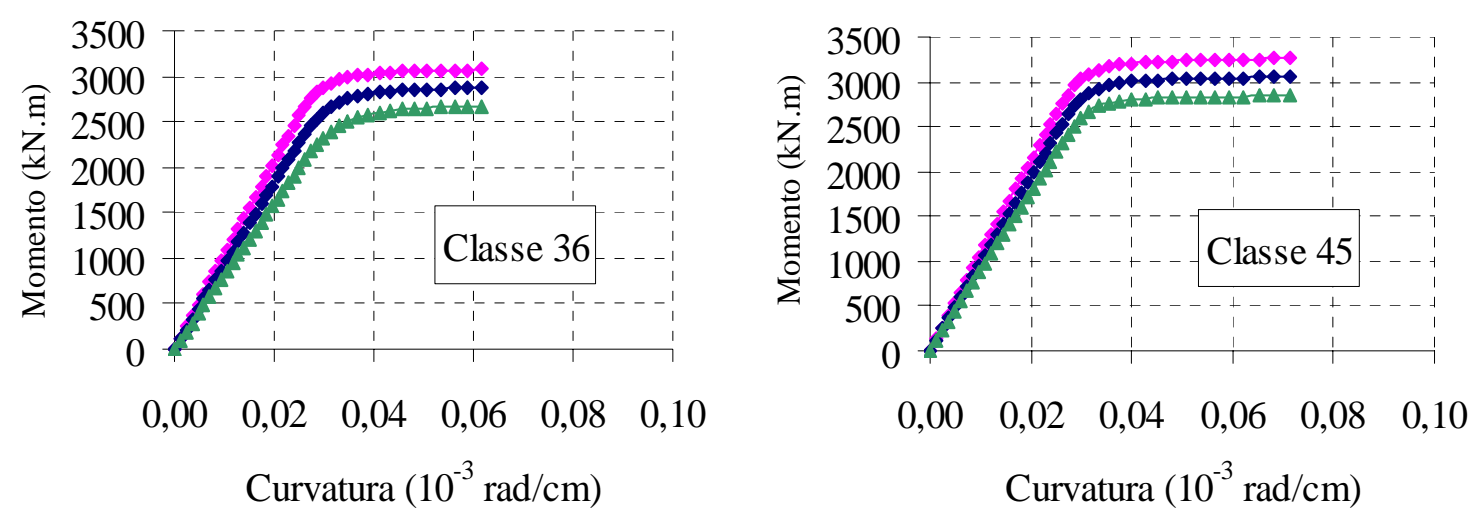

Figura 3.22 - Relações momento-curvatura para a ponte de 2 vigas, ordem 1

(SA TE V10 TR2).

Os resultados, fornecidos em termos da bias $\left(\lambda_{\mathrm{FM}}\right)$ e do coeficiente de variação (CV) dos fatores de fabricação e dos materiais combinados, estão nas tabelas 3.27 a 3.30 .

Tabela 3.27 - Bias e coeficiente de variação - LAJE.

\begin{tabular}{|c|c|c|c|c|c|c|c|c|c|}
\hline \multirow{3}{*}{$\mathbf{n}$} & \multirow{2}{*}{ Arquivo } & \multicolumn{4}{|c|}{ Momento positivo } & \multicolumn{4}{c|}{ Momento negativo } \\
\cline { 3 - 10 } & & \multicolumn{2}{|c|}{ Classe 36} & \multicolumn{2}{c|}{ Classe 45} & \multicolumn{2}{c|}{ Classe 36 } & \multicolumn{2}{c|}{ Classe 45 } \\
\cline { 3 - 10 } & & $\lambda_{\text {FM }}$ & CV & $\lambda_{\text {FM }}$ & CV & $\lambda_{\text {FM }}$ & CV & $\lambda_{\text {FM }}$ & CV \\
\hline 1 & SA TE V10 MC & 1,126 & 0,069 & 1,107 & 0,068 & - & - & - & - \\
\hline 2 & SA TL V10 MC & 1,125 & 0,069 & 1,107 & 0,068 & - & - & - & - \\
\hline 3 & SA TE V20 VZ & 1,125 & 0,070 & 1,107 & 0,068 & - & - & - & - \\
\hline 4 & SA TL V20 VZ & 1,123 & 0,069 & 1,107 & 0,069 & - & - & - & - \\
\hline 5 & C3 TE V10/10/10 MC & 1,119 & 0,068 & 1,107 & 0,068 & 1,119 & 0,068 & 1,108 & 0,069 \\
\hline 6 & C3 TL V10/10/10 MC & 1,119 & 0,068 & 1,108 & 0,069 & 1,120 & 0,069 & 1,108 & 0,069 \\
\hline 7 & C3 TE V20/20/20 VZ & 1,115 & 0,069 & 1,108 & 0,068 & 1,116 & 0,068 & 1,108 & 0,068 \\
\hline 8 & C3 TL V20/20/20 VZ & 1,116 & 0,069 & 1,107 & 0,069 & 1,116 & 0,068 & 1,108 & 0,069 \\
\hline
\end{tabular}


Tabela 3.28 - Bias e coeficiente de variação - VIGA T - 2 VIGAS.

\begin{tabular}{|c|c|c|c|c|c|c|c|c|c|}
\hline \multirow{2}{*}{$\mathbf{n}$} & \multirow{2}{*}{ Arquivo } & \multicolumn{4}{|c|}{ Momento positivo } & \multicolumn{3}{c|}{ Momento negativo } \\
\cline { 3 - 10 } & & \multicolumn{2}{c|}{ Classe 36 } & \multicolumn{2}{c|}{ Classe 45} & \multicolumn{2}{c|}{ Classe 36} & \multicolumn{2}{c|}{ Classe 45} \\
\cline { 3 - 10 } & & $\lambda_{\text {FM }}$ & CV & $\lambda_{\text {FM }}$ & CV & $\lambda_{\text {FM }}$ & CV & $\lambda_{\text {FM }}$ & CV \\
\hline 1 & SA TE V10 TR2 & 1,114 & 0,069 & 1,108 & 0,068 & - & - & - & - \\
\hline 2 & SA TE V20 TR2 & 1,113 & 0,069 & 1,108 & 0,068 & - & - & - & - \\
\hline 3 & SAB TE V3/10/3 TR2 & 1,120 & 0,069 & 1,108 & 0,068 & 1,146 & 0,076 & 1,106 & 0,068 \\
\hline 4 & SAB TE V5/20/5 TR2 & 1,114 & 0,069 & 1,108 & 0,069 & 1,142 & 0,074 & 1,106 & 0,068 \\
\hline 5 & SAB TE V5/30/5 TR4 & 1,139 & 0,075 & 1,109 & 0,069 & 1,124 & 0,069 & 1,108 & 0,068 \\
\hline 7 & C3 TE V20/20/20 TR3 & 1,112 & 0,068 & 1,109 & 0,068 & 1,145 & 0,075 & 1,107 & 0,068 \\
\hline 8 & C3 TE V30/30/30 TR3 & 1,111 & 0,069 & 1,108 & 0,068 & 1,148 & 0,077 & 1,107 & 0,068 \\
\hline 10 & SA TL V10 TR1 & 1,115 & 0,069 & 1,109 & 0,068 & - & - & - & - \\
\hline 11 & SA TL V20 TR2 & 1,113 & 0,068 & 1,109 & 0,069 & - & - & - & - \\
\hline 12 & SAB TL V3/10/3 TR1 & 1,124 & 0,069 & 1,107 & 0,068 & 1,148 & 0,078 & 1,106 & 0,069 \\
\hline 13 & SAB TL V5/20/5 TR2 & 1,116 & 0,068 & 1,108 & 0,069 & 1,149 & 0,078 & 1,106 & 0,068 \\
\hline 14 & SAB TL V5/30/5 TR3 & 1,114 & 0,069 & 1,109 & 0,069 & 1,130 & 0,070 & 1,108 & 0,068 \\
\hline 16 & C3 TL V20/20/20 TR2 & 1,113 & 0,069 & 1,108 & 0,068 & 1,148 & 0,077 & 1,106 & 0,069 \\
\hline 17 & C3 TL V30/30/30 TR3 & 1,113 & 0,069 & 1,109 & 0,068 & 1,147 & 0,077 & 1,106 & 0,068 \\
\hline 19 & C3B TE V5-20/25/20-5 & 1,112 & 0,069 & 1,110 & 0,068 & 1,145 & 0,076 & 1,107 & 0,068 \\
\hline 20 & C3B TL V5-20/25/20-5 & 1,113 & 0,069 & 1,108 & 0,069 & 1,146 & 0,075 & 1,106 & 0,068 \\
\hline 21 & C3B TE V5-25/30/25-5 & 1,111 & 0,069 & 1,109 & 0,068 & 1,148 & 0,076 & 1,107 & 0,068 \\
\hline 22 & C3B TL V5-25/30/25-5 & 1,112 & 0,069 & 1,110 & 0,069 & 1,148 & 0,077 & 1,105 & 0,068 \\
\hline 23 & C2 TL V30/30 TR3 & 1,112 & 0,069 & 1,110 & 0,069 & 1,146 & 0,076 & 1,106 & 0,068 \\
\hline
\end{tabular}

Tabela 3.29 - Bias e coeficiente de variação - VIGA T - 5 VIGAS.

\begin{tabular}{|c|c|c|c|c|c|c|c|c|c|}
\hline \multirow{3}{*}{$\mathbf{n}$} & \multirow{3}{*}{ Arquivo } & \multicolumn{4}{|c|}{ Momento positivo } & \multicolumn{4}{|c|}{ Momento negativo } \\
\hline & & \multicolumn{2}{|c|}{ Classe 36} & \multicolumn{2}{|c|}{ Classe 45} & \multicolumn{2}{|c|}{ Classe 36} & \multicolumn{2}{|c|}{ Classe 45} \\
\hline & & $\lambda_{\mathrm{FM}}$ & $\mathrm{CV}$ & $\lambda_{\mathrm{FM}}$ & $\mathrm{CV}$ & $\lambda_{\mathrm{FM}}$ & $\mathrm{CV}$ & $\lambda_{\mathrm{FM}}$ & $\mathrm{CV}$ \\
\hline 1 & SA TE V10 TR2 & 1,116 & 0,069 & 1,107 & 0,068 & - & - & - & - \\
\hline 2 & SA TE V20 TR2 & 1,115 & 0,069 & 1,109 & 0,069 & - & - & - & - \\
\hline 5 & SA TL V10 TR2 & 1,116 & 0,069 & 1,108 & 0,068 & - & - & - & - \\
\hline 6 & SA TL V20 TR2 & 1,114 & 0,068 & 1,108 & 0,069 & - & - & - & - \\
\hline 9 & C3 TL V30/30/30 TR2 & 1,111 & 0,069 & 1,109 & 0,069 & 1,147 & 0,077 & 1,107 & 0,068 \\
\hline 10 & $\begin{array}{c}\text { C3B TE V5-25/30/25-5 } \\
\text { TR2 }\end{array}$ & 1,112 & 0,069 & 109 & 069 & 1,143 & 0,074 & 1,106 & 0,068 \\
\hline 11 & $\begin{array}{c}\text { C3B TL V5-25/30/25-5 } \\
\text { TR2 }\end{array}$ & 1,113 & 0,069 & 1,109 & 0,069 & 1,143 & 0,074 & 1,106 & 0,068 \\
\hline 12 & SA TE V10 STR & 1,115 & 0,068 & 1,109 & 0,068 & - & - & - & - \\
\hline 13 & SA TE V20 STR & 1,114 & 0,069 & 1,108 & 0,069 & - & - & - & - \\
\hline 16 & SA TL V10 STR & 1,118 & 0,068 & 1,107 & 0,068 & - & - & - & - \\
\hline 17 & SA TL V20 STR & 1,114 & 0,069 & 1,108 & 0,068 & - & - & - & - \\
\hline
\end{tabular}


Tabela 3.30 - Bias e coeficiente de variação - SEÇÃO CELULAR.

\begin{tabular}{|c|c|c|c|c|c|c|c|c|c|}
\hline \multirow{3}{*}{$\mathbf{n}$} & \multirow{3}{*}{ Arquivo } & \multicolumn{4}{|c|}{ Momento positivo } & \multicolumn{4}{c|}{ Momento negativo } \\
\cline { 3 - 10 } & & \multicolumn{2}{|c|}{ Classe 36} & \multicolumn{2}{c|}{ Classe 45 } & \multicolumn{2}{c|}{ Classe 36 } & \multicolumn{2}{c|}{ Classe 45 } \\
\cline { 3 - 10 } & & $\lambda_{\mathrm{FM}}$ & $\mathrm{CV}$ & $\lambda_{\mathrm{FM}}$ & $\mathrm{CV}$ & $\lambda_{\mathrm{FM}}$ & $\mathrm{CV}$ & $\lambda_{\mathrm{FM}}$ & $\mathrm{CV}$ \\
\hline 1 & SA TL V20 STR & 1,115 & 0,069 & 1,108 & 0,068 & - & - & - & - \\
\hline 4 & $\mathrm{C}$ TL V30/30/30 STR & 1,114 & 0,078 & 1,108 & 0,068 & 1,123 & 0,072 & 1,107 & 0,069 \\
\hline 6 & SA TE V20 STR & 1,117 & 0,068 & 1,108 & 0,068 & - & - & - & - \\
\hline 9 & C3 TE V30/30/30 STR & 1,118 & 0,075 & 1,107 & 0,068 & 1,126 & 0,076 & 1,107 & 0,068 \\
\hline
\end{tabular}

\subsubsection{Concreto protendido}

As tabelas 3.31, 3.32 e 3.33 mostram os resultados obtidos para concreto protendido. Observa-se que, devido aos parâmetros estatísticos das propriedades dos materiais e das dimensões, as seções de concreto protendido apresentam menores bias e menores coeficientes de variação.

Tabela 3.31 - Bias e coeficiente de variação - LAJE.

\begin{tabular}{|c|c|c|c|c|c|}
\hline \multirow{2}{*}{$\mathbf{*}$} & \multirow{2}{*}{ Arquivo } & \multicolumn{4}{|c|}{ Momento positivo } \\
\cline { 3 - 6 } & & \multicolumn{2}{|c|}{ Classe 36} & \multicolumn{2}{c|}{ Classe 45 } \\
\cline { 3 - 6 } & $\lambda_{\mathrm{FM}}$ & $\mathrm{CV}$ & $\lambda_{\mathrm{FM}}$ & $\mathrm{CV}$ \\
\hline 3 & SA TE V20 VZ & 1,048 & 0,034 & 1,042 & 0,034 \\
\hline 4 & SA TL V20 VZ & 1,048 & 0,034 & 1,041 & 0,034 \\
\hline
\end{tabular}

Tabela 3.32 - Bias e coeficiente de variação - VIGA T - 5 VIGAS.

\begin{tabular}{|c|c|c|c|c|c|}
\hline \multirow{2}{*}{$\mathbf{n}$} & \multirow{2}{*}{ Arquivo } & \multicolumn{3}{|c|}{ Momento positivo } \\
\cline { 3 - 6 } & & \multicolumn{2}{|c|}{ Classe 36} & \multicolumn{2}{c|}{ Classe 45} \\
\cline { 3 - 6 } & & $\lambda_{\text {FM }}$ & CV & $\lambda_{\text {FM }}$ & CV \\
\hline 2 & SA TE V20 TR2 & 1,051 & 0,036 & 1,042 & 0,034 \\
\hline 3 & SA TE V30 TR2 & 1,048 & 0,035 & 1,040 & 0,034 \\
\hline 4 & SA TE V40 TR4 & 1,046 & 0,036 & 1,038 & 0,035 \\
\hline 6 & SA TL V20 TR2 & 1,053 & 0,036 & 1,038 & 0,035 \\
\hline 7 & SA TL V30 TR2 & 1,049 & 0,036 & 1,036 & 0,035 \\
\hline 8 & SA TL V40 TR4 & 1,048 & 0,036 & 1,037 & 0,035 \\
\hline 13 & SA TE V20 STR & 1,051 & 0,035 & 1,045 & 0,034 \\
\hline 14 & SA TE V30 STR & 1,047 & 0,035 & 1,038 & 0,034 \\
\hline 15 & SA TE V40 STR & 1,046 & 0,036 & 1,038 & 0,035 \\
\hline 17 & SA TL V20 STR & 1,054 & 0,036 & 1,041 & 0,034 \\
\hline 18 & SA TL V30 STR & 1,050 & 0,036 & 1,036 & 0,034 \\
\hline 19 & SA TL V40 STR & 1,047 & 0,036 & 1,036 & 0,035 \\
\hline
\end{tabular}


Tabela 3.33 - Bias e coeficiente de variação - SEÇÃO CELULAR.

\begin{tabular}{|c|c|c|c|c|c|}
\hline \multirow{2}{*}{$\mathbf{n}$} & \multirow{2}{*}{ Arquivo } & \multicolumn{3}{|c|}{ Momento positivo } \\
\cline { 3 - 6 } & & \multicolumn{2}{|c|}{ Classe 36} & \multicolumn{2}{c|}{ Classe 45} \\
\cline { 3 - 6 } & & $\lambda_{\mathrm{FM}}$ & $\mathrm{CV}$ & $\lambda_{\mathrm{FM}}$ & $\mathrm{CV}$ \\
\hline 1 & SA TL V20 STR & 1,050 & 0,034 & 1,052 & 0,034 \\
\hline 2 & SA TL V30 STR & 1,046 & 0,034 & 1,047 & 0,034 \\
\hline 3 & SA TL V40 STR & 1,040 & 0,034 & 1,041 & 0,033 \\
\hline 5 & SA TL V30 TR2 & 1,043 & 0,034 & 1,043 & 0,034 \\
\hline 6 & SA TE V20 STR & 1,051 & 0,034 & 1,052 & 0,034 \\
\hline 7 & SA TE V30 STR & 1,047 & 0,034 & 1,046 & 0,034 \\
\hline 8 & SA TE V40 STR & 1,043 & 0,033 & 1,042 & 0,033 \\
\hline 10 & SA TE V30 TR2 & 1,044 & 0,034 & 1,044 & 0,033 \\
\hline
\end{tabular}

\subsubsection{Parâmetros estatísticos do fator de análise}

Os parâmetros do fator de análise adotado é aquele fornecido por Ellingwood et al. (1980) e já utilizado em diversos trabalhos (NOWAK, 1999; NOWAK, YAMANI e TABSH, 1994; NOWAK e SZERSZEN, 2003). Para a resistência à flexão, seus valores estão na tabela 3.34. Utilizando-se as equações (2.29) e (2.30) do capítulo 2, obtém-se os parâmetros estatísticos da resistência a serem utilizados na análise de confiabilidade.

Tabela 3.34 - Parâmetros estatísticos do fator de análise.

\begin{tabular}{|c|c|c|}
\hline Material & Bias $\left(\lambda_{\mathrm{P}}\right)$ & Coeficiente de variação $\left(\mathrm{CV}_{\mathrm{P}}\right)$ \\
\hline Concreto armado & 1,02 & 0,06 \\
\hline Concreto protendido & 1,01 & 0,06 \\
\hline
\end{tabular}


O desenvolvimento de um modelo de carregamento móvel requer a análise das condições reais do tráfego de caminhões e sua aplicação à avaliação da capacidade portante das pontes. A descrição dos dados de campo obtidos, suas características e o processo que os torna disponíveis para o cálculo do índice de confiabilidade são mostrados a seguir.

\subsection{Descrição dos dados}

Foram obtidos dados referentes à pesagem de caminhões junto a Centrovias Sistemas Rodoviários S/A, concessionária dos seguintes trechos rodoviários pertencentes ao Estado de São Paulo:

$\checkmark$ SP-310 - Rodovia Washington Luiz: entre as cidades de Cordeirópolis e São Carlos;

$\checkmark$ SP-225 - Rodovia Eng. Paulo Nilo Romano: entre as cidades de Itirapina e Bauru;

$\checkmark$ SP-225 - Rodovia Comandante João Ribeiro de Barros: entre Jaú e Bauru.

A empresa realiza as pesagens através de 2 balanças móveis que operam alternadamente em 4 bases fixas na SP-310 e 2 bases na SP-225. Os dados analisados se estendem de janeiro de 2001 até outubro de 2002, em um total de 184.603 pesagens, sendo 126.389 no primeiro ano e 58.214 em 2002.

\subsection{Planilhas de pesagem}

As informações mais relevantes que constam nas planilhas são a placa do 
veículo, o dia e a hora da pesagem, o peso bruto total combinado (PBTC) e o peso bruto por eixo. Os veículos são identificados através de um código, ainda não padronizado nacionalmente, da seguinte forma:

nSm: um cavalo mecânico com $n$ eixos transporta uma unidade rebocada do tipo semi-reboque $(S)$ de $m$ eixos, sendo o total de eixos da composição dado por $n+m$ (v. figura 4.1a). A substituição da letra $S$ pela letra $I$ indica que os $m$ eixos do semi-reboque estão espaçados de pelo menos 2,40m, aumentando assim sua carga permitida por eixo de $85 \mathrm{kN}$ (eixos em tandem) para $100 \mathrm{kN}$ (eixos isolados);

nCm: um caminhão plataforma com $n$ eixos transporta um reboque acoplado de $m$ eixos (v. figura 4.1b). Caso $m$ esteja omitido, o caminhão plataforma está circulando sem nenhuma unidade rebocada.

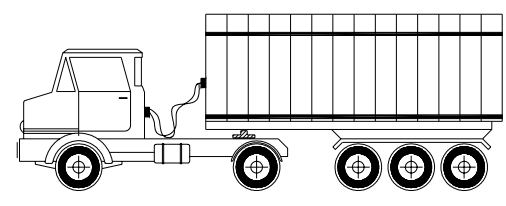

a) $2 \mathrm{S3}$
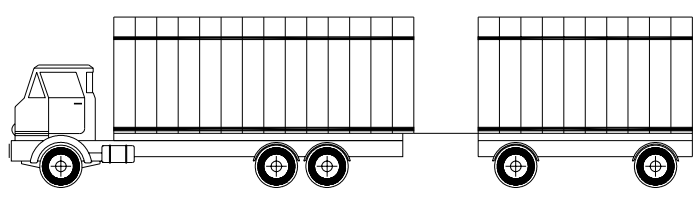

b) $3 \mathrm{C} 2$

Figura 4.1 - Ilustração da nomenclatura dos caminhões.

Do total de caminhões amostrados, em cerca de 2\% os códigos não aparecem nas planilhas, dificultando sua classificação. No entanto, observando-se a disposição dos eixos carregados é possível identificar boa parte desses veículos. Incluem-se nos 2\% as combinações de veículos de carga com múltiplos eixos, de utilização mais recente, cuja configuração não se encaixa nas siglas mostradas acima. Esses caminhões são conhecidos apenas pelo seu nome popular, embora haja propostas para unificação da nomenclatura (WIDMER, 2004). Três exemplos desses caminhões estão nas figuras 4.2 a 4.4. Destaca-se que estão em circulação rodotrens com 19,80 m de comprimento e 740 kN. Apesar da resolução nº 184 do CONTRAN os considerar veículos irregulares, a lei é omissa quanto ao destino dos caminhões já existentes. 


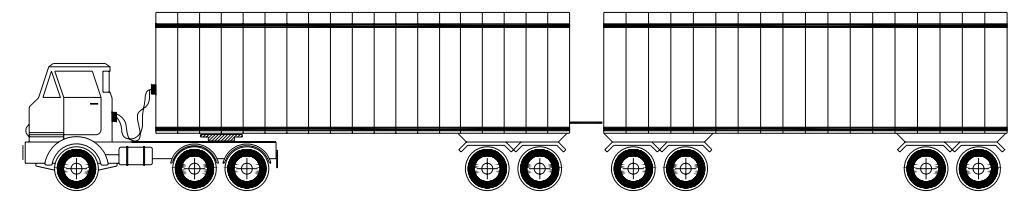

Figura 4.2 - Rodotrem com comprimento de até 30m e PBTC de até 740 kN.

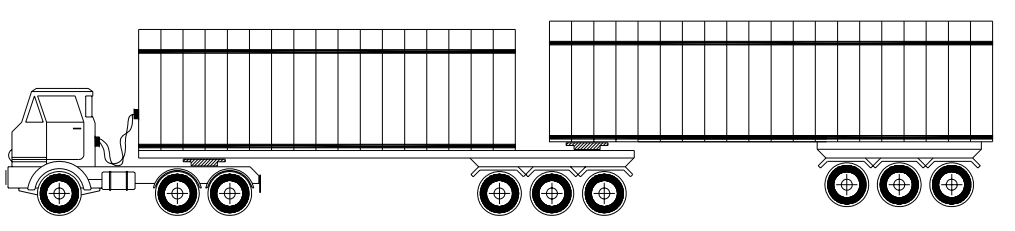

Figura 4.3 - Bitrenzão com comprimento de até 30m e PBTC de até 740 kN.

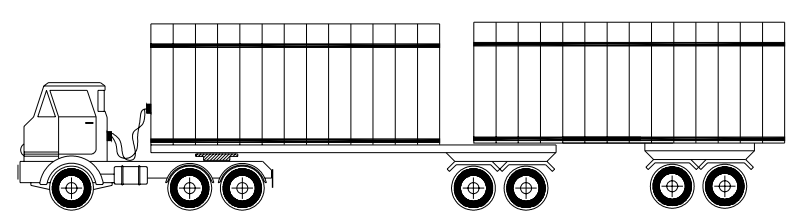

Figura 4.4 - Bitrem com comprimento de até 19,80m e PBTC de até 570 kN.

Por representarem mais de 55\% dos casos em que o código é omitido das tabelas e por serem grande parte dos veículos vendidos atualmente, os bitrens foram identificados um a um. Assim, a porcentagem de veículos não classificados através de códigos se reduz para $0,9 \%$ do total.

Os caminhões a serem considerados no desenvolvimento do modelo de carga móvel serão apenas aqueles que aparecem com maior peso e em maior número nas planilhas de pesagem da Centrovias, conforme procedimento já adotado por outros autores (HWANG e $\mathrm{KOH}, 2000$ ). Considera-se que a não inclusão de todos os caminhões na análise não traz prejuízos ao modelo proposto, haja visto que os veículos que serão utilizados, além de serem críticos, são representativos do universo de caminhões existentes.

Na figura 4.5 é mostrada a proporção dos caminhões que aparecem nas planilhas em número superior a $1 \%$ do total de veículos amostrados e que possuem ocorrências de PBTC maiores que o peso do veículo normativo da classe 45 (2I3, 2S3, 3S3, 2S2 e bitrem), os caminhões não classificados (rodotrem, bitrenzão, entre outros) e aqueles que, embora classificados, não tem interesse sob o ponto de vista da segurança das pontes (outros) devido ao reduzido número de ocorrências ou principalmente devido ao 
seu baixo peso bruto. O limite de $450 \mathrm{kN}$ (referente a classe 45) é arbitrário e tem a função de selecionar previamente os caminhões com maior potencial para comprometer a segurança estrutural das obras de arte.

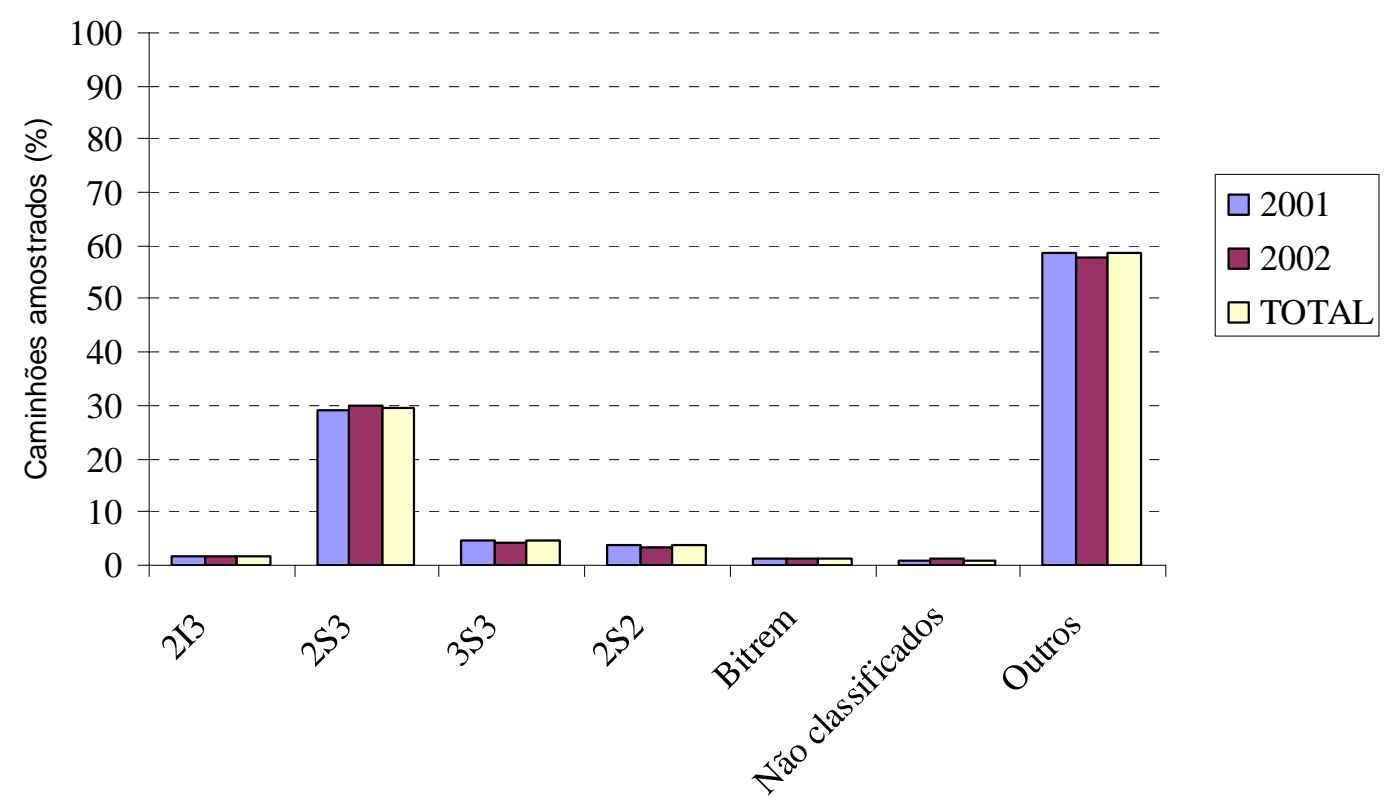

Figura 4.5 - Resumo das planilhas de pesagem.

A proporção entre os caminhões selecionados para a determinação do modelo de carregamento móvel está na figura 4.6.

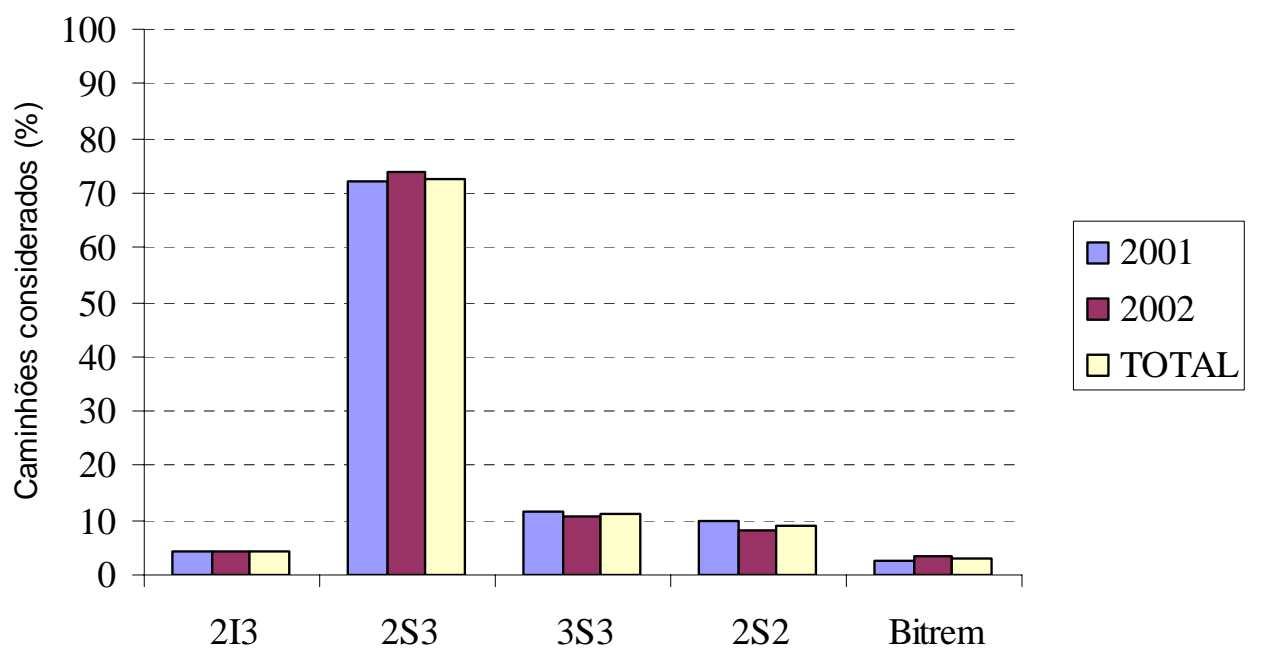

Figura 4.6 - Proporção entre os caminhões previamente selecionados. 


\subsection{Caminhões típicos}

As planilhas de pesagem, apesar de informarem a configuração de cada caminhão, não indicam a distância entre eixos. Sabe-se que mesmo dentro de uma certa classificação, a distância entre eixos varia de veículo para veículo, às vezes significativamente. Por exemplo, os caminhões 2S3 e 3S3 possuem duas disposições a serem verificadas: uma curta, basculante, que destina-se ao transporte de areia e brita, e outra mais longa, destinada ao transporte de mercadorias de menor densidade. Ainda dentro de cada versão, curta ou longa, existe variabilidade.

Não há conhecimento sobre dados a respeito da distribuição da distância entre eixos obtidos a partir de coletas de campo. Alternativamente, este trabalho utiliza distâncias típicas e representativas, determinadas através do catálogo virtual da empresa Randon S/A Implementos e Sistemas Automotivos, por intermédio de consulta junto a Transervice Consultoria em Transportes S/C Ltda e também através de fotografias.

Considerando-se o período limitado da pesagem dos veículos, outra metodologia a ser desenvolvida é a extrapolação do máximo peso bruto para cada caminhão tendo-se em vista a vida útil da estrutura.

\subsubsection{Distâncias entre eixos}

Os caminhões pré-selecionados para análise são esquematizados nas figuras 4.7 a 4.13. Acompanham os desenhos as cargas permitidas por eixo de acordo com a legislação em vigor.

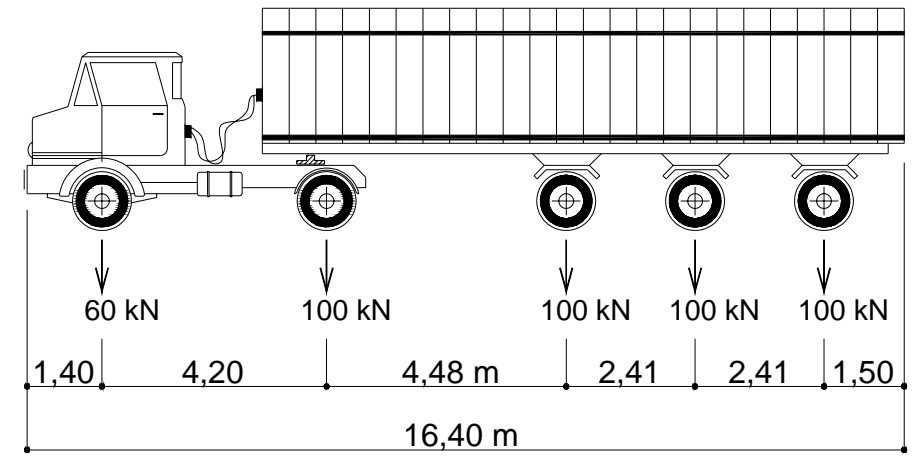

Figura 4.7 - Caminhão 2I3 para 450 kN. 


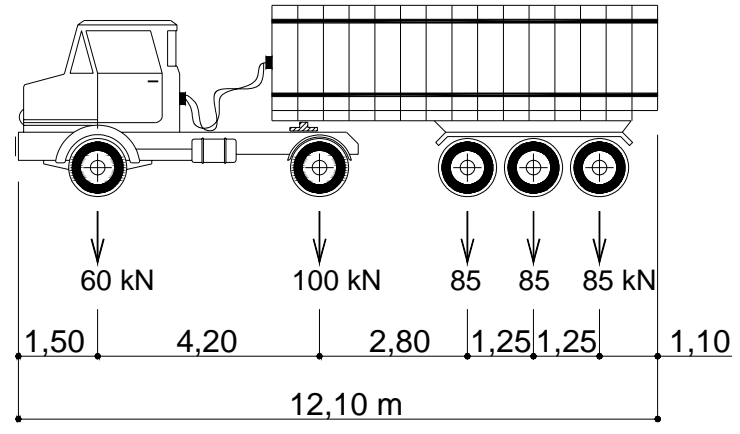

Figura 4.8 - Caminhão 2S3 curto para 415 kN.

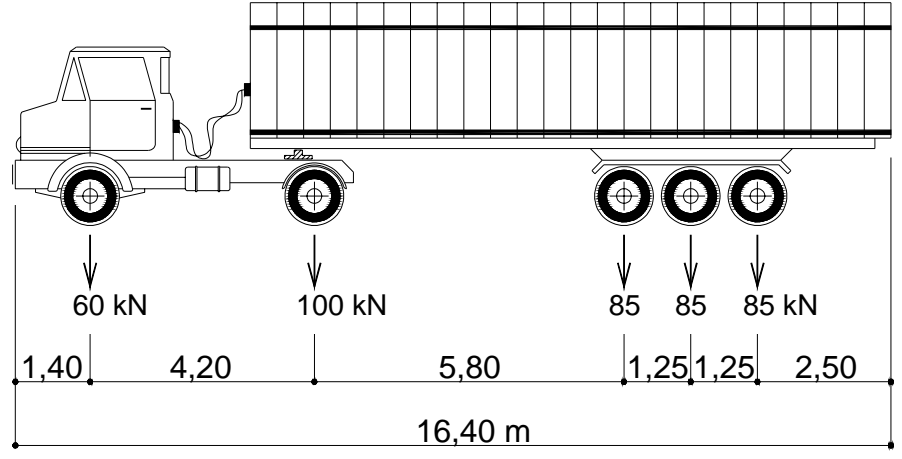

Figura 4.9 - Caminhão 2S3 longo para 415 kN.

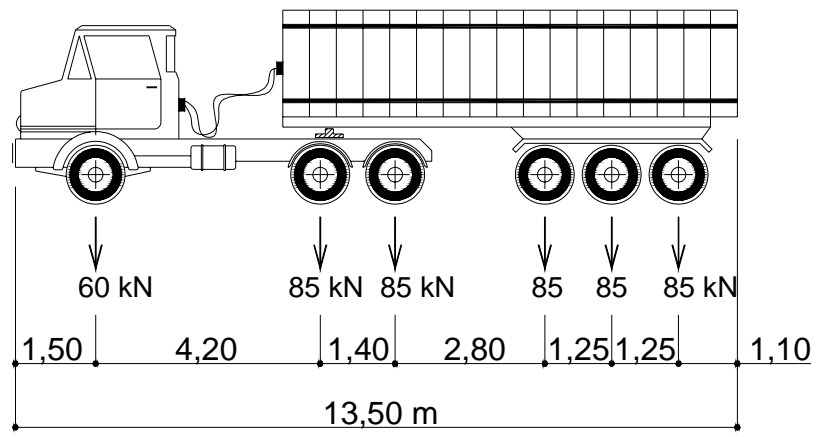

Figura 4.10 - Caminhão 3S3 curto para 450 kN.

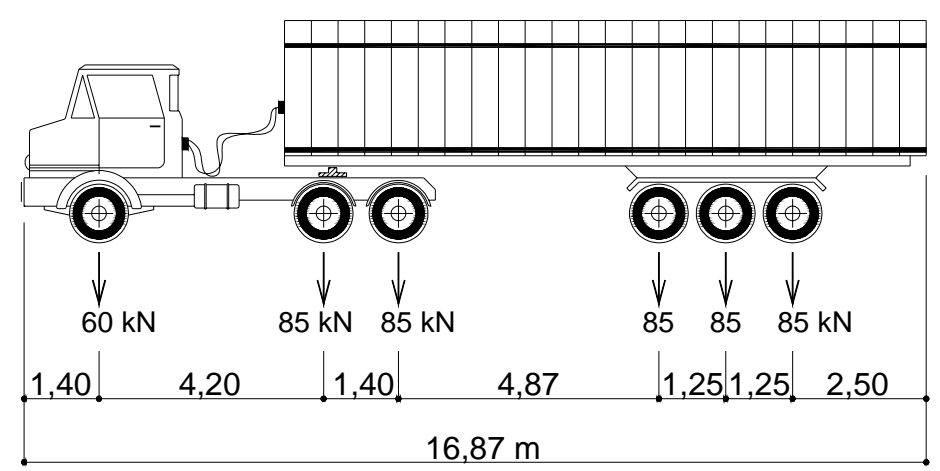

Figura 4.11 - Caminhão $3 S 3$ longo para 450 kN. 


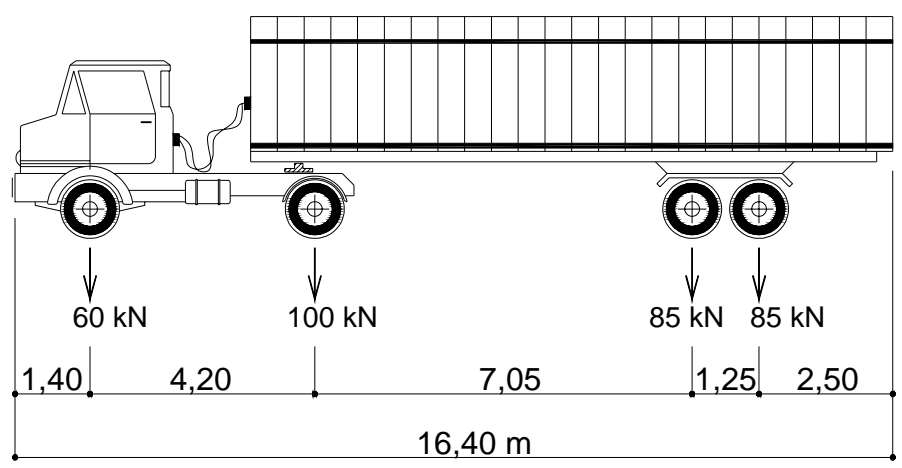

Figura 4.12 - Caminhão 2S2 para 330 kN.

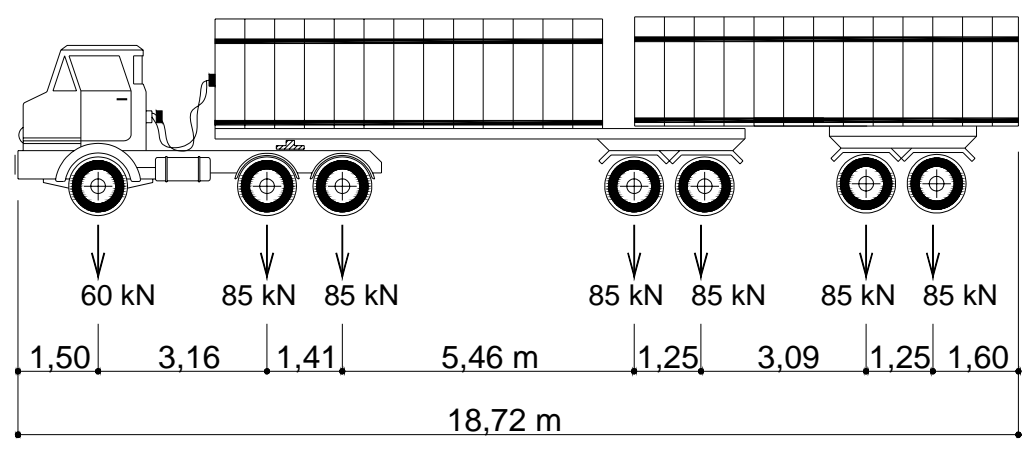

Figura 4.13 - Bitrem para 570 kN.

\subsubsection{Extrapolação dos máximos pesos brutos}

Inicialmente, os resultados da pesagem para cada caminhão foram plotados em papel de probabilidade normal. Apesar das distribuições não seguirem estritamente uma distribuição normal, esse procedimento é bastante conveniente, pois possibilita uma visualização geral dos dados e indica tendências para períodos mais longos do que o efetivamente medido (vida útil da estrutura). Além disso, é o método seguido por outros pesquisadores para o desenvolvimento de modelos de carregamento móvel, entre eles, Hwang e Koh (2000) e Nowak (1999).

Os dados obtidos para os caminhões 3S3 estão plotados na figura 4.14. 


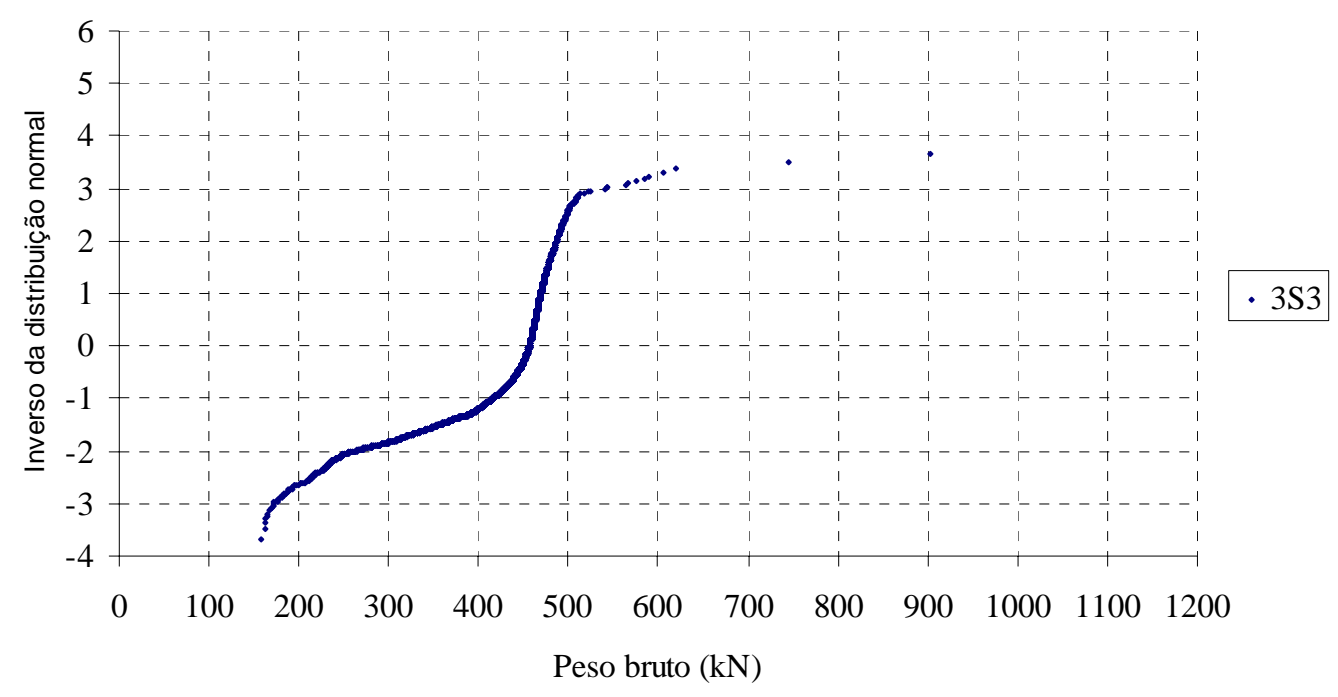

Figura 4.14 - Distribuição de peso bruto para o caminhão 3S3.

A extrapolação requer que seja conhecido o número total de caminhões que circulam diariamente na área de obtenção das pesagens, ou seja, o trecho sob concessão da Centrovias. Nesse sentido, foram obtidas planilhas com o volume diário de veículos comerciais (incluindo ônibus) nas praças de pedágio, de agosto de 2000 até julho de 2001. As localizações desses pontos são as seguintes:

a) Itirapina (SP-310): cobrança de pedágio em 1 sentido;

b) Rio Claro (SP-310): cobrança de pedágio em 1 sentido;

c) Brotas (SP-225): cobrança de pedágio em 1 sentido;

d) Jaú (SP-225): cobrança de pedágio em 2 sentidos;

e) Dois Córregos (SP-225): cobrança de pedágio em 1 sentido.

Embora a entrada e saída de caminhões se dê em pontos desconhecidos, e que muitos veículos trafegam de uma rodovia para outra (sendo anotados portanto nas 2 rodovias), admite-se que a soma dos maiores volumes médios diários de cada rodovia (Itirapina e Jaú) indique com boa aproximação o total de caminhões no trecho. Assim, considera-se que o número de caminhões por dia seja 8.000.

Fixando-se a vida útil em 50 anos, o número total de caminhões nesse período é 146.000.000 (8.000 • 365 • 50). Sabendo-se a porcentagem de cada tipo de caminhão (v. figura 4.5) e que o nível de probabilidade correspondente a $\mathrm{N}$ é $1 / \mathrm{N}$, sendo $\mathrm{z}=\Phi^{-1}(1 / \mathrm{N})$ e $\Phi^{-1}$ igual ao inverso da distribuição normal padrão, o valor que a 
extrapolação deve atingir está determinado. A idéia é que caso todos os caminhões fossem amostrados durante 50 anos, o caminhão mais pesado estaria na cota $z$.

Por exemplo, a porcentagem do caminhão $3 S 3$ no total de pesagens é 4,55\%. Dessa forma, em 50 anos:

$\mathrm{N}_{3 \mathrm{~S} 3}=0,0455 \cdot 146.000 .000=6.643 .000$

$1 / \mathrm{N}_{3 \mathrm{~S} 3}=1,505 \cdot 10^{-7}$

$\mathrm{Z}=5,12$

O procedimento, que pode ser realizado para qualquer período de tempo, está na figura 4.15 .

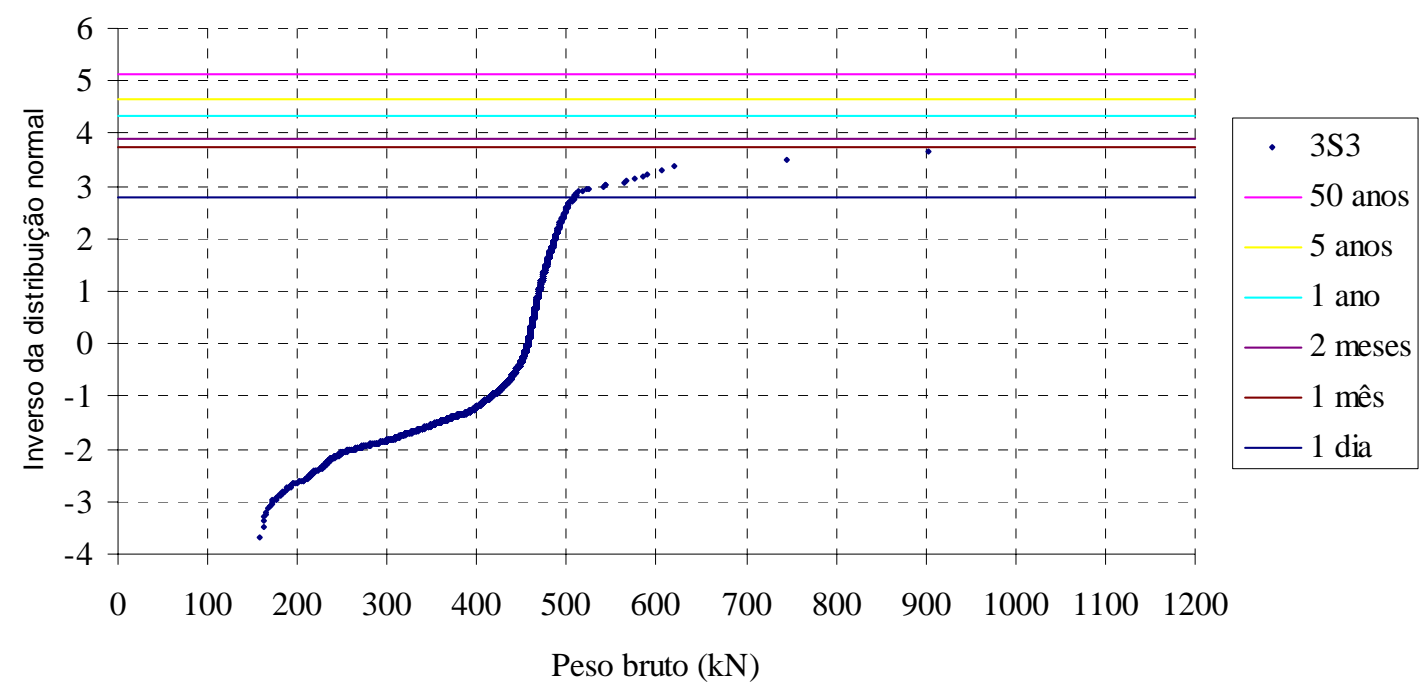

Figura 4.15 - Extrapolação para diversos períodos (3S3).

Nowak (1999) desenvolve a extrapolação de momentos fletores através do traçado manual de uma linha seguindo a tendência dos pontos extremos superiores da distribuição (v. figura 2.14). No caso deste trabalho, que primeiramente irá extrapolar pesos brutos para depois obter os momentos fletores, a simples utilização do método de Nowak (1999) resulta em valores muito elevados para alguns tipos de veículos (v. figura 4.16), não compatíveis com as capacidades volumétricas desses caminhões. Isto ocorre devido a maior variabilidade na cauda superior da distribuição. 


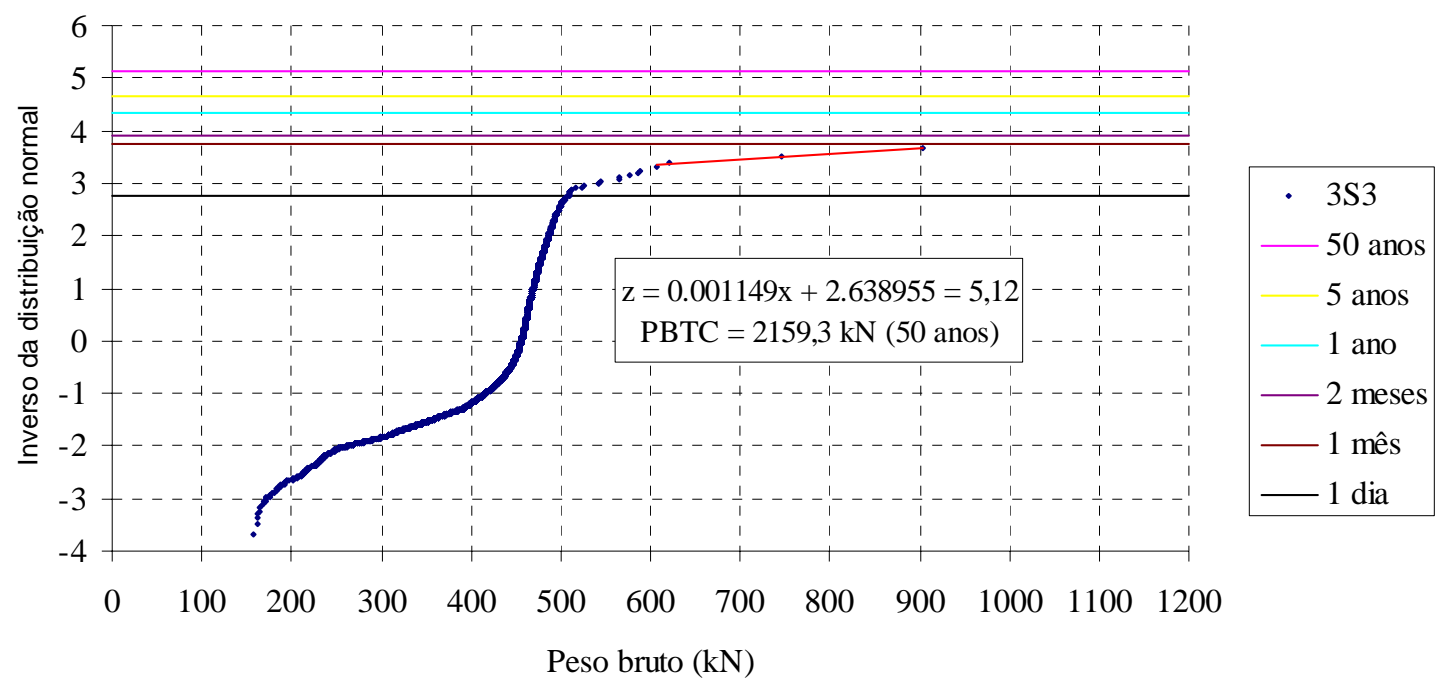

Figura 4.16 - Extrapolação segundo Nowak (1999) para o caminhão $3 S 3$.

Caminhões excessivamente pesados em relação aos demais são casos extraordinários, que por si só já representam extremos da distribuição durante a vida útil. O traçado da extrapolação seguindo rigorosamente esses pontos seria, de certa forma, proporcionar muita importância a eles em detrimento aos demais, além de ser um processo subjetivo. Procedimento mais racional é a utilização de uma regressão linear considerando-se um certo número de pontos da cauda superior.

No desenvolvimento de um modelo de carga móvel para a Coréia, Hwang e Koh (2000) consideram 10\% dos caminhões (os 10\% mais pesados) para efetuar a regressão linear.

Devido a grande variação na quantidade de cada tipo de caminhão, julga-se mais adequado para esse trabalho efetuar uma regressão linear através dos 100 caminhões mais pesados, independentemente de sua classificação.

No caso dos caminhões 2S3 e 3S3, que possuem versões curta e longa, será admitido que $20 \%$ deles sejam curtos e $80 \%$ sejam longos, conforme indicação de levantamento realizado na Rodovia Washington Luiz, km 40, em abril de 2005. Isso irá diminuir o número de ocorrências em 50 anos e, portanto, reduz os valores $z$ para extrapolação dos pesos desses veículos.

As pesagens e a extrapolação para os diversos caminhões estão nas figuras 4.17 a 4.23. Observa-se que a forma das caudas inferiores se deve a pesagem de caminhões vazios. 


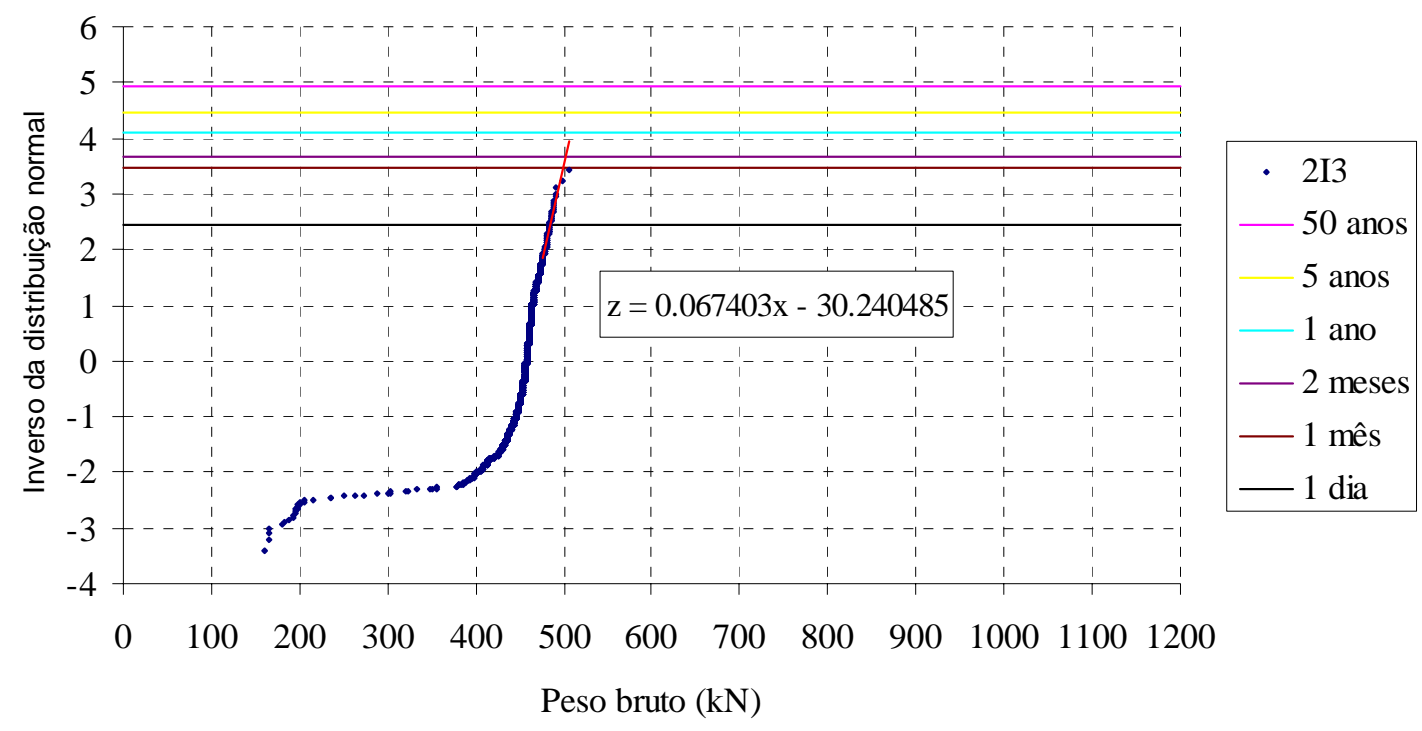

Figura 4.17 - Extrapolação para o caminhão 2I3.

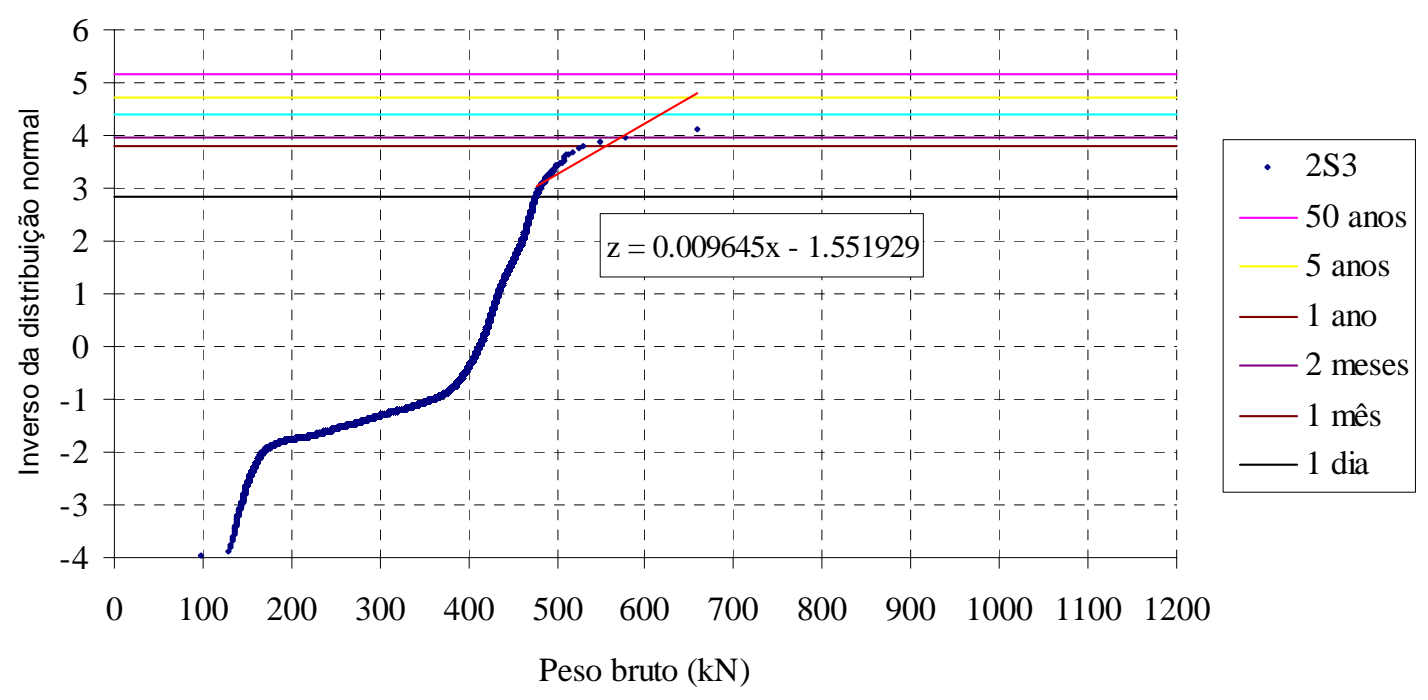

Figura 4.18 - Extrapolação para o caminhão 2S3 curto.

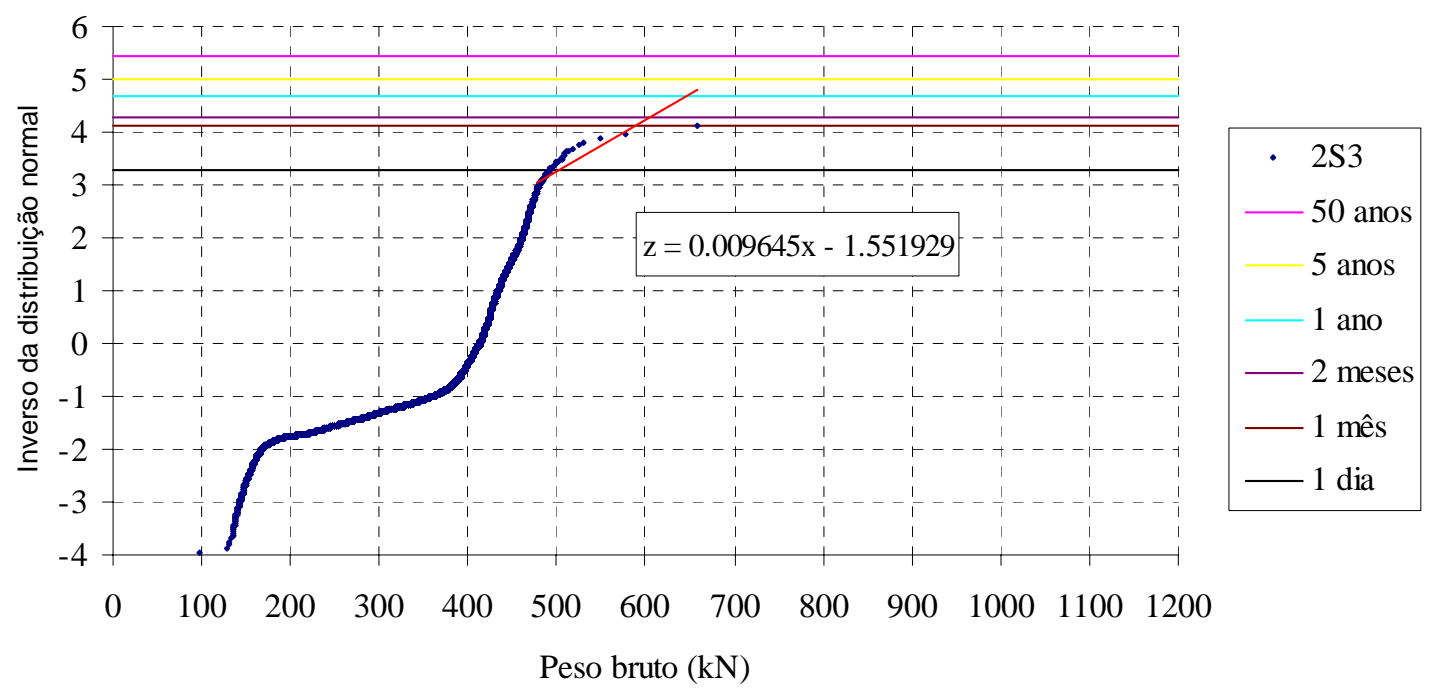

Figura 4.19 - Extrapolação para o caminhão 2S3 longo. 


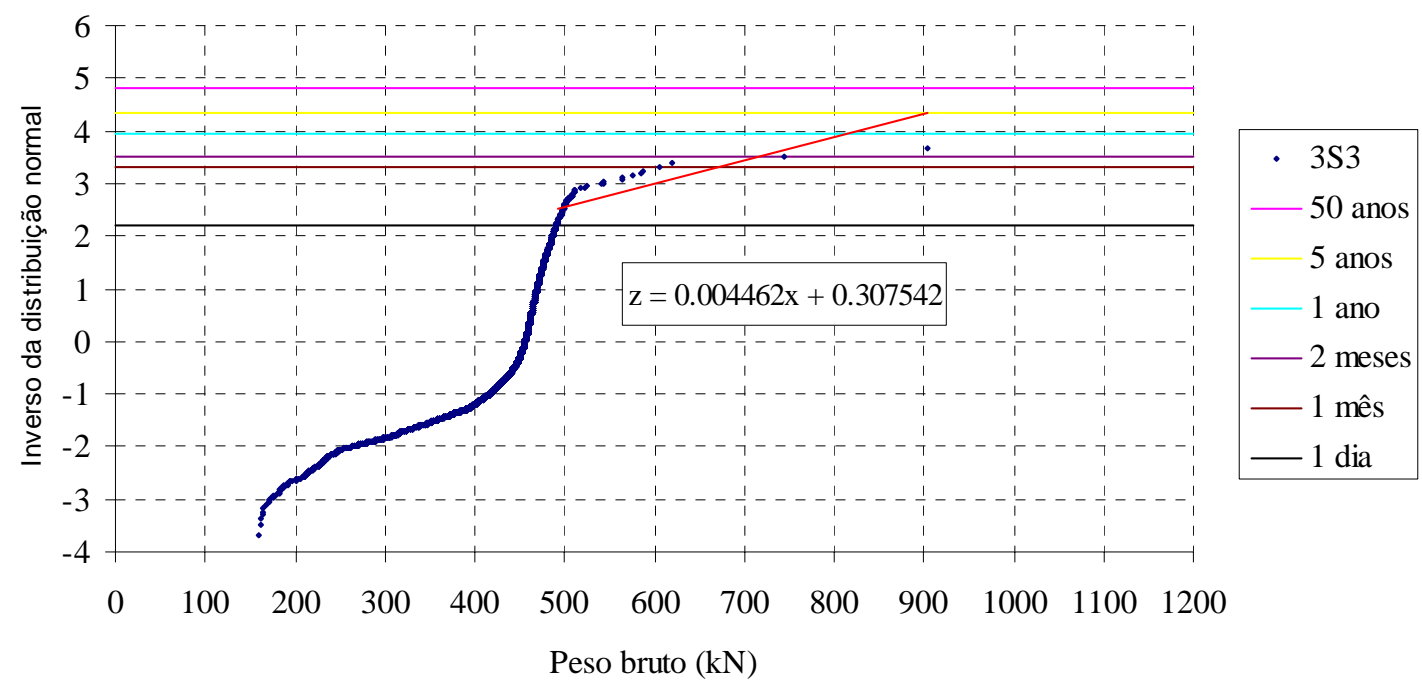

Figura 4.20 - Extrapolação para o caminhão 3S3 curto.

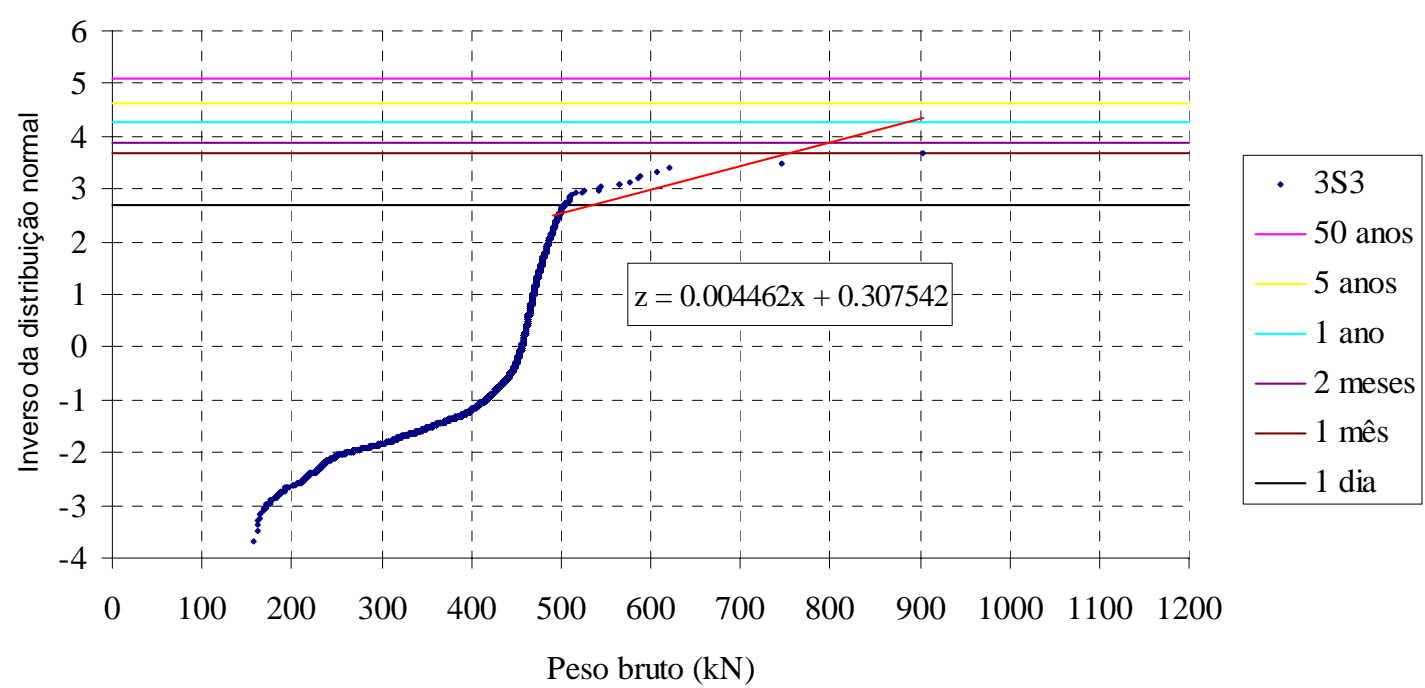

Figura 4.21- Extrapolação para o caminhão 3S3 longo.

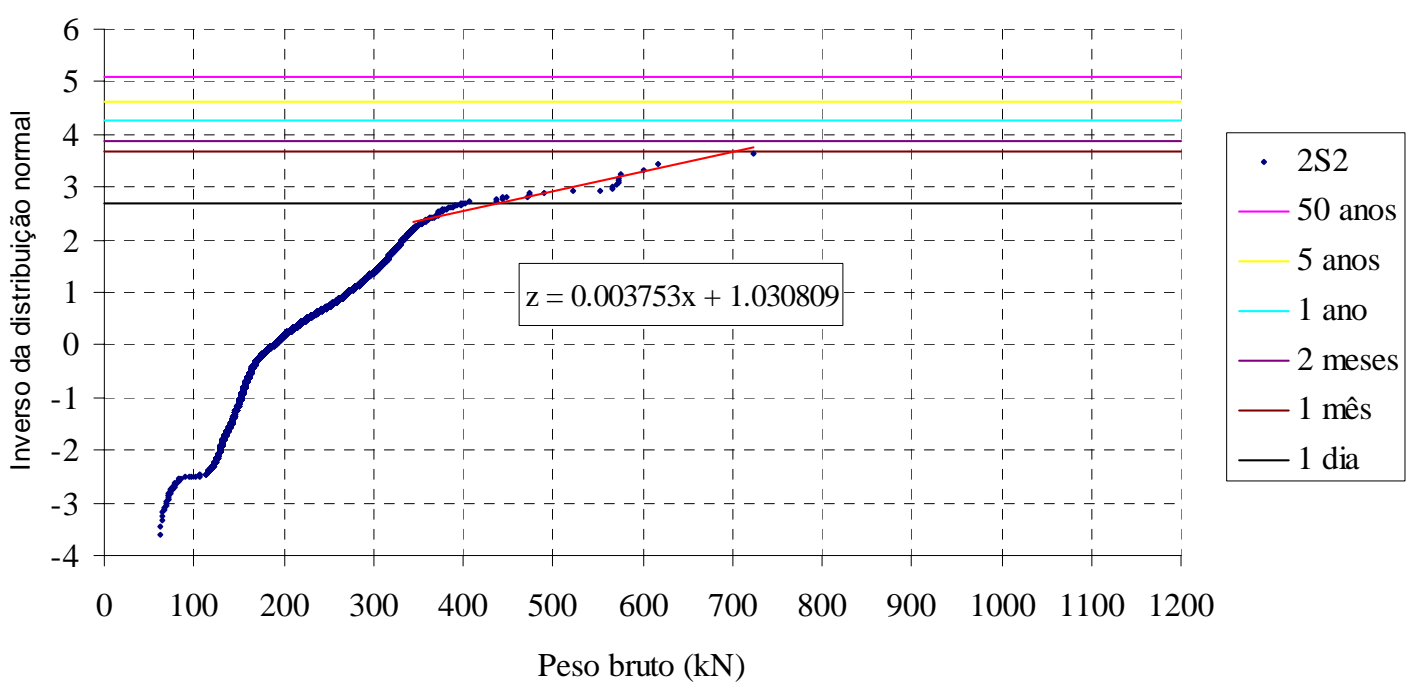

Figura 4.22 - Extrapolação para o caminhão 2S2. 


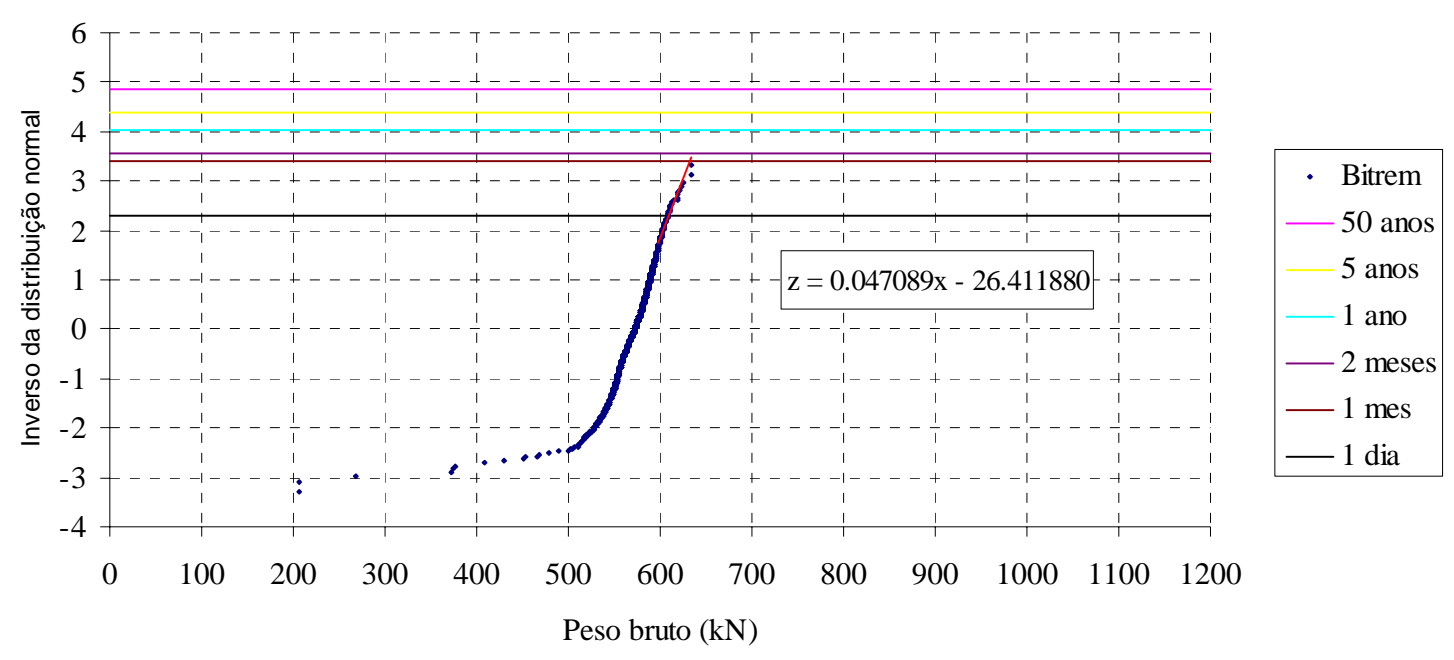

Figura 4.23 - Extrapolação para o bitrem.

Os dados obtidos mostram que os caminhões $2 \mathrm{I} 3$ e o bitrem possuem menor variabilidade na cauda superior da distribuição, fazendo com que a extrapolação não aumente de maneira excessiva seus pesos brutos. Tal comportamento justifica-se pelo tipo de carga transportada por esses veículos, que se destinam a regiões que obrigam a circulação em rodovias com controle permanente de pesagem e dificultam assim que a lei seja desobedecida. A época de obtenção das pesagens também pode influir nos resultados apresentados.

De forma a complementar o estudo sobre as características do tráfego, o apêndice A descreve os dados obtidos em outras regiões de circulação e outros períodos de coleta. A comparação entre as diversas planilhas de pesagem permite um melhor entendimento sobre a variabilidade da composição do tráfego, valida o modelo de carregamento móvel proposto por este estudo e amplia seu campo de aplicação.

Os máximos pesos brutos estimados para 50 anos de vida útil estão na tabela 4.1.

Tabela 4.1 - Estimação dos máximos pesos brutos $(\mathrm{kN})$.

\begin{tabular}{|c|c|}
\hline Caminhão & PBTC para 50 anos \\
\hline 2I3 & 521,8 \\
\hline 2S3 curto & 696,9 \\
\hline 2S3 longo & 723,9 \\
\hline 3S3 curto & 1009,1 \\
\hline 3S3 longo & 1069,6 \\
\hline 2S2 & 1081,6 \\
\hline Bitrem & 664,1 \\
\hline
\end{tabular}


O resultado mostra que o caminhão mais pesado é o 2S2, apesar de sua carga permitida ser apenas $330 \mathrm{kN}$.

Os dados também permitem a análise dos pesos por eixo. Porém, devido a sua grande aleatoriedade, a distribuição do peso bruto se dará a partir da seguinte equação:

$$
\mathrm{P}_{\text {eixo }}=\frac{\text { peso legal do eixo }}{\sum \text { peso legal dos eixos do veículo }} \cdot \text { peso total }
$$

\subsection{Situações críticas de carregamento}

A situação crítica para a análise da segurança de obras de arte pode ser resultante da passagem de um único caminhão ou da presença simultânea de 2 ou mais veículos.

\subsubsection{Caminhão isolado}

Nessa hipótese, admite-se que a presença de apenas um caminhão isolado sobre a ponte seja crítica para o cálculo dos momentos fletores devido ao tráfego real. Dentre os veículos previamente selecionados, convencionou-se adotar um único tipo a ser utilizado em todas as estruturas.

Considerando-se os pesos da tabela 4.1, os veículos foram inicialmente dispostos nas posições críticas para a obtenção do máximo momento fletor positivo em pontes simplesmente apoiadas. Os resultados indicaram que, apesar do caminhão 2S2 ser o mais pesado, a configuração curta do veículo 3S3 o torna mais crítico. Os testes feitos nas demais pontes típicas demonstram que esse caminhão também pode ser utilizado em estruturas contínuas na previsão de esforços máximos. Dessa forma, o caminhão da figura 4.24 será testado em todas as obras de arte representativas da rede viária do DER-SP.

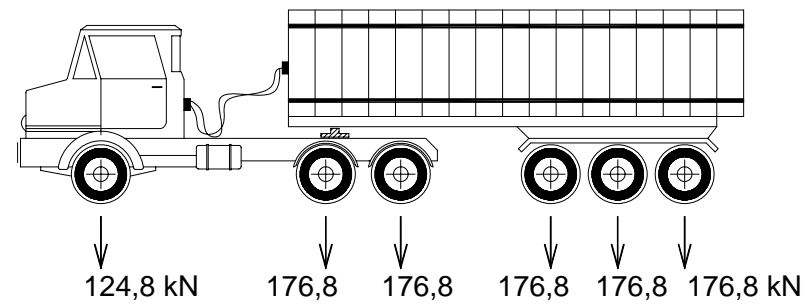

Figura 4.24 - Caminhão $3 S 3$ curto. 
O coeficiente de variação será calculado considerando-se que o peso bruto máximo em 50 anos de vida útil é o valor médio de uma nova distribuição, conforme indicação de Nowak (1999). O desvio-padrão é dado pela inclinação da regressão linear na cota correspondente a 50 anos. Assim, no caso do caminhão 3S3, tem-se:

$\mathrm{CV}_{3 \mathrm{~S} 3}=\frac{224,1}{1009,1}=0,222(50$ anos $)$

Será admitido que o coeficiente de variação do peso do caminhão será o coeficiente de variação do momento fletor, pois a distância entre os eixos e o peso por eixo serão variáveis consideradas determinísticas.

\subsubsection{Presença simultânea de 2 caminhões}

A análise de 2 caminhões sobre as pontes requer a determinação de sua posição relativa e da proporção entre seus pesos. Considerando-se que a probabilidade da passagem sobre a ponte de caminhões suficientemente próximos e em posições relativas que levem a uma situação de máximo momento fletor é menor, em relação a um caminhão isolado (menor número de ocorrências), seus pesos brutos também devem ser inferiores.

Não se dispõe de dados estatísticos brasileiros que forneçam qual a probabilidade da ocorrência simultânea sobre as pontes. Ressalta-se que sua obtenção é bastante trabalhosa e ainda assim de caráter apenas qualitativo. A inspeção visual, por exemplo, através de câmeras de vídeo, apesar de fornecer a freqüência, não indica a relação entre os pesos dos veículos. Necessita-se também de longos períodos de observação, em épocas distintas. Portanto, este estudo é baseado em trabalhos de pesquisadores estrangeiros.

Nowak (1999) utiliza as seguintes probabilidades de ocorrência simultânea (v. item 2.5.4): 
Tabela 4.2 - Probabilidades de ocorrência simultânea. (NOWAK, 1999)

\begin{tabular}{|c|c|c|}
\hline Pesos & 1 faixa de tráfego & 2 faixas de tráfego $^{* *}$ \\
\hline Não correlacionados & $1 / 50$ & $1 / 15$ \\
\hline Correlação parcial & $1 / 150$ & $1 / 150$ \\
\hline Correlação total & $1 / 500$ & $1 / 450$ \\
\hline
\end{tabular}

* Um caminhão atrás do outro

** Caminhões lado a lado

A porcentagem do momento fletor causado pelo caminhão principal, resultante do procedimento de Nowak (1999), em relação ao máximo momento fletor positivo causado por um caminhão isolado está na tabela 4.3.

Tabela 4.3 - Momento fletor devido ao caminhão principal em relação ao momento fletor causado por um caminhão isolado. (NOWAK, 1999)

\begin{tabular}{|c|c|c|}
\hline Pesos & 1 faixa de tráfego & 2 faixas de tráfego \\
\hline Não correlacionados & $88 \%$ a $92 \%$ & $93 \%$ a $95 \%$ \\
\hline Correlação parcial & $88 \%$ a $90 \%$ & $88 \%$ a $90 \%$ \\
\hline Correlação total & $84 \%$ a $86 \%$ & $86 \%$ a $88 \%$ \\
\hline
\end{tabular}

A presença simultânea de veículos na Coréia foi estudada por Hwang e Koh (2000). Por exemplo, a probabilidade de um caminhão estar seguindo o outro na mesma faixa de tráfego (v. tabela 2.6), no caso de tráfego médio e pesos não correlacionados, indica que a cada 70 passagens ocorrerá 1 presença simultânea com distância inferior a 15 m. As duas situações verificadas são:

a) Não correlação de pesos: o peso do caminhão principal é obtido utilizando-se a média da tabela 2.6, da seguinte forma: $\mathrm{z}=\Phi^{-1}\left(\frac{1}{\mathrm{~N} / 70}\right)$, onde $\mathrm{N}$ é o número de ocorrências de um tipo de caminhão em 75 anos e $\Phi^{-1}$ é o inverso da distribuição normal padrão. Obtido $z$, basta buscar no papel de probabilidade normal o correspondente peso bruto. Ao caminhão secundário é atribuído um peso médio, fixando-se $z=0$. Em se tratando dos dados coreanos, esse procedimento atribui ao caminhão principal de 85\% a 90\% do máximo peso bruto em 75 anos;

b) Correlação total de pesos: assume-se que os 2 caminhões possuem os mesmos pesos. Nesse caso, o peso de cada caminhão varia entre 80\% e 85\% do máximo peso bruto em 75 anos, dependendo do veículo que está sendo analisado. 
Tendo-se como referência os trabalhos descritos anteriormente, as probabilidades de presença simultânea adotadas para este estudo estão na tabela 4.4. No entanto, assume-se que os pesos dos veículos não são correlacionados.

Tabela 4.4 - Probabilidades de ocorrência simultânea adotadas.

\begin{tabular}{|c|c|c|c|c|}
\hline \multirow{2}{*}{ Hipótese } & \multicolumn{2}{|c|}{ Caminhões em fila } & \multicolumn{2}{c|}{ Caminhões lado a lado } \\
\cline { 2 - 5 } & $\mathrm{TE}$ & $\mathrm{TL}$ & $\mathrm{TE}$ & $\mathrm{TL}$ \\
\hline 1 & $1 / 75$ & $1 / 75$ & $1 / 50$ & $1 / 75$ \\
\hline 2 & $1 / 500$ & $1 / 500$ & $1 / 500$ & $1 / 500$ \\
\hline
\end{tabular}

De acordo com a tabela 4.4, as duas situações a serem analisadas são 2 caminhões com probabilidade de 1/500 (hipótese 2) e 2 caminhões com pesos diferentes (hipótese 1), sendo um deles com probabilidade que varia entre 1/75 e 1/50, e o outro com peso médio.

Destaca-se que as pontes com tabuleiro estreito (TE) foram idealizadas em El Debs et al. (2001) para representar 2 faixas de tráfego em sentidos opostos (pista simples) e que as pontes de tabuleiro largo (TL) podem simular 4 faixas de tráfego, sendo as 2 primeiras faixas adjacentes de mesmo sentido e as outras duas de sentido contrário. Dessa forma, nota-se na tabela 4.4 que foi considerada, na hipótese 1, uma maior probabilidade para o cruzamento de caminhões em pista simples (1/50) em relação às ultrapassagens em pista dupla (1/75).

Observando-se que o objetivo da análise estrutural a ser realizada para o cálculo do índice de confiabilidade é reproduzir condições mais realistas de tráfego, as faixas (lanes) de tráfego idealizadas no software STRAP terão agora largura de 3 metros, em vez dos 2 metros utilizados no cálculo dos esforços solicitantes para dimensionamento. As disposições das faixas para tabuleiro estreito e largo estão na figura 4.25.

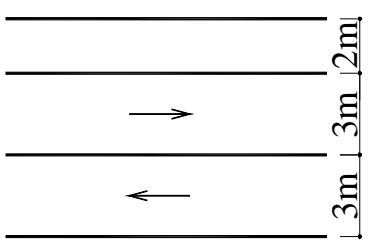

a) Tabuleiro estreito

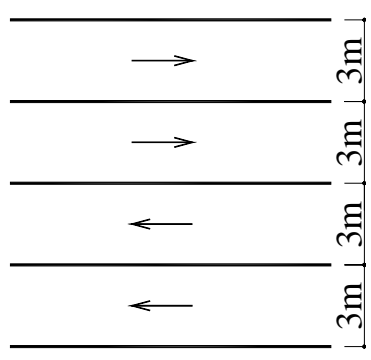

b) Tabuleiro largo

Figura 4.25 - Sentido do tráfego e disposição das faixas. 
Embora as pontes de tabuleiro estreito resultem assimétricas, a circulação de caminhões nesta configuração é possível. Além disso, proporciona-se uma padronização com as pontes de tabuleiro largo através da coincidência das faixas de tráfego externas.

No caso de caminhões em fila, 2 alternativas são verificadas:

a) Distância entre os caminhões igual a 5 ou 10 metros, porém sem a consideração do coeficiente de impacto;

b) Distância entre os caminhões variando entre 15 e 30 metros, de 5 em 5 metros, adicionando-se posteriormente a parcela dinâmica.

Admite-se para este trabalho que o caminhão principal seja um $3 S 3$ curto. Ocorrendo uma presença simultânea, será considerado que o segundo caminhão seja um 2S3 curto, pois o total de caminhões 2S3 representa aproximadamente 30\% do total de caminhões observados.

Os caminhões, seu respectivo peso por eixo e coeficiente de variação, de acordo com cada hipótese de presença simultânea, estão na tabela 4.5.

Tabela 4.5 - Peso por eixo $(\mathrm{kN})$ e coeficiente de variação dos caminhões para análise de presença simultânea.

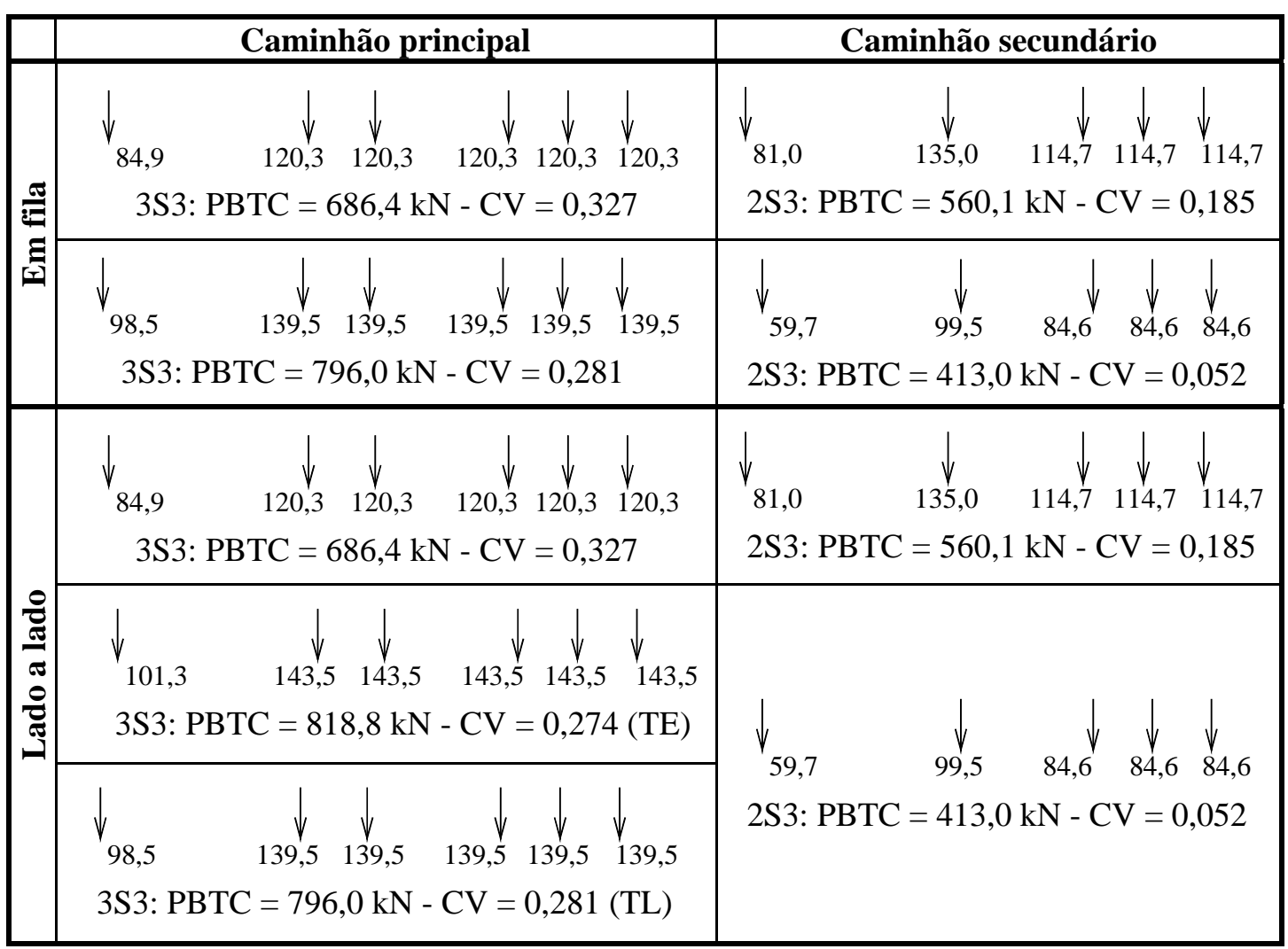


Vale ressaltar que o caso de veículos lado a lado refere-se a caminhões em faixas adjacentes, porém em quaisquer posições relativas que levem a uma situação de máximo momento fletor.

Os coeficientes de variação para cada caminhão foram calculados de maneira análoga à apresentada no item 4.4.1. O coeficiente de variação do momento fletor, resultante da presença simultânea de 2 caminhões sobre a ponte é calculado para cada caso da tabela 4.5 da seguinte forma:

$\mathrm{CV}=\frac{\sqrt{\left(\sigma_{1}^{2}+\sigma_{2}^{2}\right)}}{\mathrm{M}_{\text {total }}}=\frac{\sqrt{\left(\left(\mathrm{M}_{1} \cdot \mathrm{CV}_{1}\right)^{2}+\left(\mathrm{M}_{2} \cdot \mathrm{CV}_{2}\right)^{2}\right)}}{\mathrm{M}_{1}+\mathrm{M}_{2}}$

onde:

$\mathrm{M}_{\text {total }}$ : momento fletor devido a presença de 2 caminhões sobre a estrutura;

$\mathrm{M}_{1}$ : parcela do momento fletor devido ao caminhão principal;

$\mathrm{M}_{2}$ : parcela do momento fletor devido ao caminhão secundário;

$\sigma_{1}$ : desvio-padrão no momento fletor devido ao caminhão principal;

$\sigma_{2}$ : desvio-padrão no momento fletor devido ao caminhão secundário;

$\mathrm{CV}_{1}$ : coeficiente de variação do peso do caminhão principal;

$\mathrm{CV}_{2}$ : coeficiente de variação do peso do caminhão secundário.

No apêndice B, altera-se o caminhão principal e são atribuídas outras probabilidades de ocorrência simultânea. O efeito dessas modificações em termos do índice de confiabilidade é verificado em pontes de 2 vigas simplesmente apoiadas.

\subsubsection{Presença simultânea de 3 ou mais caminhões}

A literatura consultada não traz indicações a respeito da probabilidade da presença de 3 ou mais caminhões sobre as pontes. Sua incidência é considerada bastante baixa e de difícil investigação. Além disso, a posição de um terceiro veículo coincidirá com ordenadas menores da linha de influência.

De qualquer forma, esse caso é pertinente apenas em pontes longas e/ou pontes com várias faixas de tráfego. Em se tratando de pontes longas, predomina o peso próprio e o efeito da carga móvel torna-se menos importante. Em pontes de menor 
comprimento e com menos faixas, nem sequer existe espaço para o posicionamento de 3 caminhões.

Assim, considera-se que o caso de 3 ou mais caminhões não seja imprescindível para a análise do carregamento móvel e a segurança das pontes possa ser confiavelmente medida através do posicionamento de 1 ou 2 veículos apenas. No entanto, este estudo contempla a inserção de um terceiro caminhão em pontes de tabuleiro largo e descreve sua implicação na obtenção das ECPLs. Em se tratando de um complemento do trabalho, esse tema é abordado no apêndice C.

\subsection{Momentos fletores máximos}

O modelo de carregamento móvel proposto foi analisado em todas as pontes típicas selecionadas. O resultado é mostrado no apêndice E, tabelas E1 a E4. Nota-se que, em geral, o caso de 2 caminhões lado a lado governa as pontes de tabuleiro largo. Em se tratando de tabuleiro estreito, na maioria das vezes 1 veículo isolado ou 2 caminhões lado a lado são críticos.

O coeficiente de impacto médio a ser utilizado nas análises é aquele sugerido por Nowak (1999). No caso de 1 caminhão isolado, a parcela dinâmica do momento fletor é tomada igual a $15 \%$ do momento fletor estático e no caso de 2 caminhões, o valor recomendado é $10 \%$. O coeficiente de variação em ambos os casos é igual a 0,80. Lembra-se que quando os caminhões estão em fila com distância inferior a 15 m não será adicionada a parcela dinâmica.

As bias para as classes 36 e 45, obtidas a partir do maior momento fletor para cada ponte (apenas os casos em que a parcela dinâmica se faz presente foi considerada), são apresentadas nas tabelas 4.6 a 4.9. De acordo com Nowak (1999), a meta de um carregamento normativo deve ser proporcionar uma bias aproximadamente constante. Na calibração da AASHTO (1994), atingem-se valores entre 1,2 e 1,5. 
Tabela 4.6 - Bias para momento positivo - LAJE.

\begin{tabular}{|c|c|c|c|c|c|}
\hline \multirow{2}{*}{$\mathbf{n}$} & \multirow{2}{*}{ Arquivo } & \multicolumn{2}{|c|}{ Momento positivo } & \multicolumn{2}{|c|}{ Momento negativo } \\
\hline & & Classe 36 & Classe 45 & Classe 36 & Classe 45 \\
\hline 1 & SA TE V10 MC & 1,46 & 1,14 & - & - \\
\hline 2 & SA TL V10 MC & 1,43 & 1,11 & - & - \\
\hline 3 & SA TE V20 VZ & 1,54 & 1,18 & - & - \\
\hline 4 & SA TL V20 VZ & 1,33 & 0,99 & - & - \\
\hline 5 & C3 TE V10/10/10 MC & 1,38 & 1,09 & 1,51 & 1,27 \\
\hline 6 & C3 TL V10/10/10 MC & 1,33 & 1,04 & 1,50 & 1,26 \\
\hline 7 & C3 TE V20/20/20 VZ & 1,47 & 1,13 & 1,15 & 0,97 \\
\hline 8 & C3 TL V20/20/20 VZ & 1,29 & 0,97 & 1,11 & 0,92 \\
\hline & MÍNIMO & 1,29 & 0,97 & 1,11 & 0,92 \\
\hline & MÁXIMO & 1,54 & 1,18 & 1,51 & 1,27 \\
\hline & MÉDIA & 1,40 & 1,08 & 1,32 & 1,11 \\
\hline
\end{tabular}

Tabela 4.7 - Bias para momento positivo - VIGA T - 2 VIGAS.

\begin{tabular}{|c|c|c|c|c|c|}
\hline \multirow{2}{*}{$\mathbf{n}$} & \multirow{2}{*}{ Arquivo } & \multicolumn{2}{|c|}{ Momento positivo } & \multicolumn{2}{|c|}{ Momento negativo } \\
\hline & & Classe 36 & Classe 45 & Classe 36 & Classe 45 \\
\hline 1 & SA TE V10 TR2 & 1,55 & 1,23 & - & - \\
\hline 2 & SA TE V20 TR2 & 1,55 & 1,24 & - & - \\
\hline 3 & SAB TE V3/10/3 TR2 & 1,52 & 1,20 & 1,63 & 1,30 \\
\hline 4 & SAB TE V5/20/5 TR2 & 1,54 & 1,22 & 1,49 & 1,19 \\
\hline 5 & SAB TE V5/30/5 TR4 & 1,42 & 1,13 & 1,42 & 1,15 \\
\hline 7 & C3 TE V20/20/20 TR3 & 1,51 & 1,21 & 1,19 & 0,99 \\
\hline 8 & C3 TE V30/30/30 TR3 & 1,40 & 1,13 & 1,07 & 0,90 \\
\hline 10 & SA TL V10 TR1 & 1,63 & 1,26 & - & - \\
\hline 11 & SA TL V20 TR2 & 1,53 & 1,19 & - & - \\
\hline 12 & SAB TL V3/10/3 TR1 & 1,62 & 1,24 & 1,80 & 1,42 \\
\hline 13 & SAB TL V5/20/5 TR2 & 1,50 & 1,15 & 1,55 & 1,22 \\
\hline 14 & SAB TL V5/30/5 TR3 & 1,34 & 1,03 & 1,47 & 1,18 \\
\hline 16 & C3 TL V20/20/20 TR2 & 1,50 & 1,17 & 1,14 & 0,90 \\
\hline 17 & C3 TL V30/30/30 TR3 & 1,34 & 1,05 & 0,95 & 0,76 \\
\hline 19 & C3B TE V5-20/25/20-5 TR3 & 1,52 & 1,22 & 1,13 & 0,94 \\
\hline 20 & C3B TL V5-20/25/20-5 TR2 & 1,48 & 1,15 & 1,07 & 0,85 \\
\hline 21 & C3B TE V5-25/30/25-5 TR3 & 1,44 & 1,16 & 1,09 & 0,92 \\
\hline 22 & C3B TL V5-25/30/25-5 TR2 & 1,41 & 1,10 & 0,98 & 0,78 \\
\hline 23 & C2 TL V30/30 TR3 & 1,40 & 1,09 & 0,96 & 0,77 \\
\hline & MÍNIMO & 1,34 & 1,03 & 0,95 & 0,76 \\
\hline & MÁXIMO & 1,63 & 1,26 & 1,80 & 1,42 \\
\hline & MÉDIA & 1,48 & 1,17 & 1,26 & 1,02 \\
\hline
\end{tabular}


Tabela 4.8 - Bias para momento positivo - VIGA T - 5 VIGAS.

\begin{tabular}{|c|c|c|c|c|c|}
\hline \multirow{2}{*}{$\mathbf{n}$} & \multirow{2}{*}{ Arquivo } & \multicolumn{2}{c|}{ Momento positivo } & \multicolumn{2}{c|}{ Momento negativo } \\
\cline { 3 - 6 } & Classe 36 & Classe 45 & Classe 36 & Classe 45 \\
\hline 1 & SA TE V10 TR2 & 1,65 & 1,29 & - & - \\
\hline 2 & SA TE V20 TR2 & 1,58 & 1,26 & - & - \\
\hline 3 & SA TE V30 TR2 & 1,45 & 1,17 & - & - \\
\hline 4 & SA TE V40 TR4 & 1,28 & 1,04 & - & - \\
\hline 5 & SA TL V10 TR2 & 1,59 & 1,23 & - & - \\
\hline 6 & SA TL V20 TR2 & 1,55 & 1,18 & - & - \\
\hline 7 & SA TL V30 TR2 & 1,41 & 1,07 & - & - \\
\hline 8 & SA TL V40 TR4 & 1,22 & 0,94 & - & - \\
\hline 9 & C3 TL V30/30/30 TR2 & 1,33 & 1,01 & 0,89 & 0,68 \\
\hline 10 & C3B TE V5-25/30/25-5 TR2 & 1,50 & 1,20 & 1,03 & 0,85 \\
\hline 11 & C3B TL V5-25/30/25-5 TR2 & 1,37 & 1,04 & 0,90 & 0,70 \\
\hline 12 & SA TE V10 STR & 1,69 & 1,33 & - & - \\
\hline 13 & SA TE V20 STR & 1,67 & 1,33 & - & - \\
\hline 14 & SA TE V30 STR & 1,52 & 1,22 & - & - \\
\hline 15 & SA TE V40 STR & 1,34 & 1,08 & - & - \\
\hline 16 & SA TL V10 STR & 1,48 & 1,16 & - & - \\
\hline 17 & SA TL V20 STR & 1,50 & 1,17 & - & - \\
\hline 18 & SA TL V30 STR & 1,37 & 1,07 & - & - \\
\hline 19 & SA TL V40 STR & 1,23 & 0,95 & - & - \\
\hline & MÍNIMO & 1,22 & 0,94 & 0,89 & 0,68 \\
\hline & MÁXIMO & 1,69 & 1,33 & 1,03 & 0,85 \\
\hline & MÉDIA & 1,46 & 1,14 & 0,94 & 0,74 \\
\hline
\end{tabular}

Tabela 4.9 - Bias para momento positivo - CELULAR.

\begin{tabular}{|c|c|c|c|c|c|}
\hline \multirow{2}{*}{$\mathbf{n}$} & \multirow{2}{*}{ Arquivo } & \multicolumn{2}{|c|}{ Momento positivo } & \multicolumn{2}{|c|}{ Momento negativo } \\
\hline & & Classe 36 & Classe 45 & Classe 36 & Classe 45 \\
\hline 1 & SA TL V20 STR & 1,35 & 0,97 & - & - \\
\hline 2 & SA TL V30 STR & 1,14 & 0,82 & - & - \\
\hline 3 & SA TL V40 STR & 0,97 & 0,69 & - & - \\
\hline 4 & C3 TL V30/30/30 STR & 1,10 & 0,79 & 0,69 & 0,49 \\
\hline 5 & SA TL V30 TR2 & 1,20 & 0,86 & - & - \\
\hline 6 & SA TE V20 STR & 1,66 & 1,25 & - & - \\
\hline 7 & SA TE V30 STR & 1,45 & 1,09 & - & - \\
\hline 8 & SA TE V40 STR & 1,25 & 0,94 & - & - \\
\hline 9 & C3 TE V30/30/30 STR & 1,40 & 1,05 & 0,91 & 0,68 \\
\hline 10 & SA TE V30 TR2 & 1,44 & 1,09 & - & - \\
\hline & MÍNIMO & 0,97 & 0,69 & 0,69 & 0,49 \\
\hline & MÁXIMO & 1,66 & 1,25 & 0,91 & 0,68 \\
\hline & MÉDIA & 1,30 & 0,95 & 0,80 & 0,59 \\
\hline
\end{tabular}

A análise das tabelas acima possibilita os seguintes comentários:

a) Laje: os valores médios da bias para momento fletor positivo e negativo são semelhantes. Nas pontes com menor comprimento de tramo, a bias para momento 
fletor negativo é maior que a observada para momento fletor positivo;

b) 2 vigas: nas pontes simplesmente apoiadas com balanços, a bias para momento fletor negativo é bastante elevada. Isto se deve à forma da linha de influência e devido às elevadas cargas por eixo do carregamento móvel proposto. Destaca-se que nas pontes contínuas com balanços, analisa-se o apoio interno e não o balanço;

c) 5 vigas: em se tratando de tabuleiro estreito, as pontes sem transversinas apresentam maior bias. Nas pontes de tabuleiro largo, de maneira geral observa-se o contrário;

d) Celular: as pontes em seção celular possuem geralmente menores bias se comparadas às demais.

Considerando-se todas as pontes, na classe 36, a bias varia entre 0,69 e 1,80. Na classe 45, os valores estão entre 0,49 e 1,42. A grande variabilidade apresentada justifica-se pela diversidade de sistemas estruturais, esquemas longitudinais, vãos e largura de tabuleiro. Destaca-se que, devido às características do carregamento normativo brasileiro, a bias tende a diminuir com o aumento do vão.

Conclui-se que o trem-tipo atual (classe 45) resulta em diferentes níveis de segurança das seções transversais de acordo com as características da ponte. No entanto, a variação se reduz bastante quando se considera, por exemplo, apenas pontes simplesmente apoiadas.

Por fim, as pontes com maiores bias não são necessariamente as mais críticas para a obtenção das ECPLs devido à presença do peso próprio.

\subsection{Simulação real do tráfego}

A simulação do tráfego de veículos comerciais sobre a infra-estrutura viária pode auxiliar significativamente em diversos aspectos relacionados ao estudo da segurança das obras de arte. Entre outras contribuições, a simulação pode fornecer:

a) A seqüência de carregamentos para o estudo da fadiga;

b) A probabilidade de ocorrências simultâneas;

c) Cenários produzidos por futuros aumentos no volume e na composição do tráfego. 
Atualmente, é desenvolvida uma pesquisa ${ }^{4}$ sobre esse tema no Departamento de Transportes da Escola de Engenharia de São Carlos. Os componentes das operações de controle de tráfego, das características do fluxo de tráfego e do comportamento dos motoristas foram recalibrados a partir de medidas de campo. O estudo, que utiliza o modelo de simulação microscópica de tráfego CORSIM, será testado em um sistema de rodovias no estado de São Paulo.

\subsection{Limitações do modelo proposto}

De maneira geral, as limitações do modelo de carregamento móvel desenvolvido neste trabalho advém da falta de dados estatísticos a respeito das diversas variáveis.

Uma das ressalvas a ser feita é em relação à ausência da distância entre eixos nas planilhas de pesagem da Centrovias. Sabe-se que são diversas as possibilidades mesmo dentro de uma certa classificação dos veículos. No caso dos caminhões 2S3 e 3S3, que possuem configurações curta e longa, essa deficiência é mais notada.

Mesmo considerando-se confiáveis os dados das concessionárias de rodovias e que veículos bastante sobrecarregados foram amostrados (o caminhão mais pesado possui aproximadamente $900 \mathrm{kN}$ ), é de conhecimento geral que inúmeros veículos que trafegam acima do limite permitido pela legislação, especialmente os casos mais extremos, não passam pelas balanças e de alguma forma burlam o sistema de pesagem. Além disso, as balanças móveis funcionam basicamente durante o dia, possibilitando aos motoristas trafegar livremente em alguns trechos durante o período noturno.

Nesse contexto, indica-se como sugestão a pesagem de veículos em movimento (weigh-in-motion) utilizando-se a ponte como uma balança. Dentre suas principais características, podem-se destacar (NOWAK, 2004):

a) Fornece a distância entre eixos, o peso por eixo e o peso total de cada veículo, a velocidade, o volume de tráfego e as ocorrências de múltipla presença sobre a ponte (embora nesse último caso ele não registre os veículos individualmente);

b) Resultados suficientemente precisos (20\% para peso por eixo e 5\% para peso bruto);

c) Não detectado pelos motoristas;

${ }^{4}$ ARAÚJO, J.J. Simulação dos impactos do tráfego de veículos comerciais sobre a infra-estrutura rodoviária. Tese (Doutorado) - Escola de Engenharia de São Carlos, Universidade de São Paulo, São Carlos. Em andamento. 
d) Todo o tráfego é efetivamente medido durante alguns dias;

e) Medição sob velocidade normal dos veículos, sem interferência com o tráfego;

f) Relativa facilidade na instalação e operação, dependendo da experiência da equipe de engenheiros.

O comportamento do tráfego e a eficiência do sistema weigh-in-motion são demonstrados na figura 4.26. Medições realizadas na estrada I-94, Estados Unidos, mostram que o número e o peso dos caminhões que excedem aos limites legais aumentam consideravelmente durante períodos em que a balança fixa não está operando.
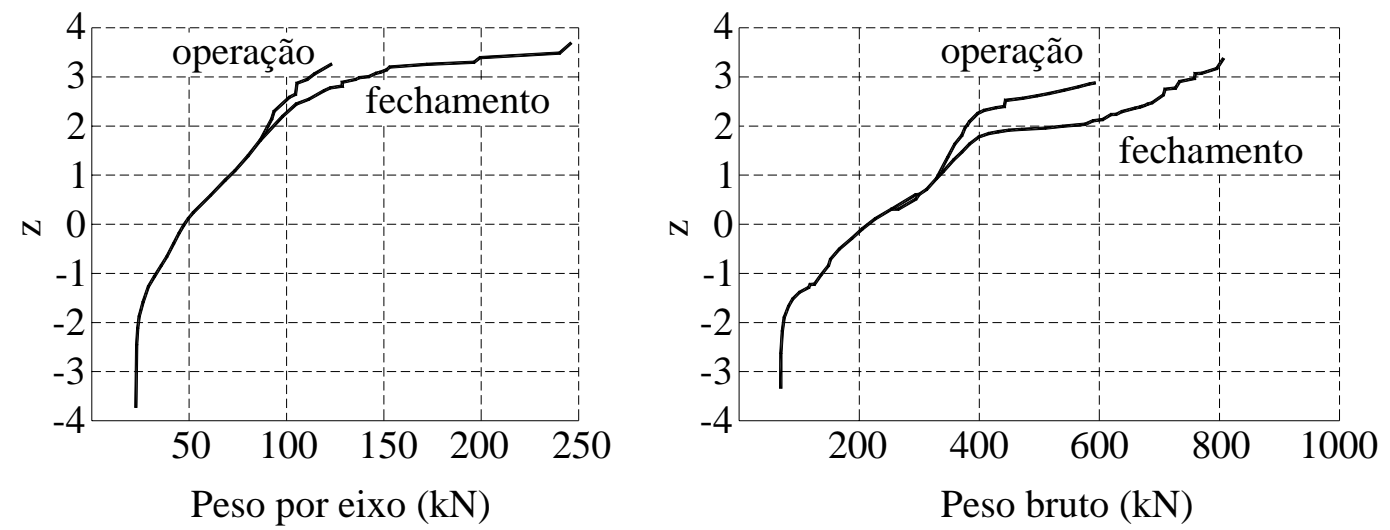

Figura 4.26 - Resultados do weigh-in-motion durante o fechamento e a operação de uma balança fixa. (NOWAK, 2004)

Quanto às probabilidades de presença simultânea, mesmo em países estrangeiros os dados são bastante limitados. Há que se considerar que o volume de tráfego e a extensão da área de coleta dos dados são fatores que interferem no número de ocorrências conjuntas de 2 ou mais caminhões sobre as pontes. Dessa forma, qualquer levantamento que seja feito pode ser adequado especificamente para a localidade em questão.

A extrapolação dos dados em papel de probabilidade normal, apesar de ser uma etapa relativamente subjetiva e sem grande aprofundamento teórico, tem a vantagem de evitar cálculos excessivamente complicados, além de já ter sido utilizada com sucesso em diversos trabalhos.

De maneira geral, as limitações aqui citadas não inviabilizam o trabalho, pois segue-se um procedimento internacionalmente aceito, o número de pesagens levado em 
conta é relativamente grande (184.603) e os dados não disponíveis foram estimados utilizando-se julgamento técnico, buscando-se estar o mais próximo possível da realidade.

Certamente, o modelo de carregamento móvel é passível de aperfeiçoamento e pode ser melhorado assim que novos dados estatísticos sejam obtidos a partir do tráfego real e com o amadurecimento dos conceitos aqui introduzidos.

Sabe-se que as características dos caminhões são variáveis de lugar para lugar e, portanto, os resultados aqui obtidos são mais apropriados às regiões com tráfego semelhante ao utilizado no modelo de carregamento móvel. 
A análise de confiabilidade a ser desenvolvida possui 2 funções:

a) Determinar o índice de confiabilidade da seção mais solicitada (momento fletor positivo e negativo) de cada obra de arte submetida ao carregamento real;

b) Uma vez determinado o índice de confiabilidade desejável, fornecer o momento fletor devido ao carregamento móvel para que não seja ultrapassado o nível de segurança pré-estabelecido.

\subsection{Determinação da segurança}

Na análise de confiabilidade será admitido que o efeito total do carregamento (soma do efeito de diversas ações) é uma variável normal, enquanto a resistência (produto de variáveis aleatórias) será considerada uma variável lognormal. Utiliza-se, portanto, o teorema do limite central (NOWAK e COLLINS, 2000), que enuncia que a soma de variáveis aleatórias independentes tende a uma distribuição normal a medida que o número de variáveis aumenta, desde que nenhuma delas seja dominante. Como conseqüência, o produto de variáveis aleatórias se aproxima de uma distribuição lognormal.

Embora neste trabalho a quantidade de ações seja relativamente pequena para a satisfação do teorema do limite central, mantém-se a metodologia de Nowak (1999) para fins de comparação dos resultados e fixação do índice de confiabilidade desejável.

O método a ser utilizado é o procedimento matricial de Rackwitz-Fiessler.

\subsubsection{Procedimento de cálculo}


Os passos para a obtenção do índice de confiabilidade pelo método de RackwitzFiessler, aplicado ao problema em questão, são: (NOWAK e COLLINS, 2000)

1) Formular a função de estado limite: $Z=R-S$

2) Adotar um ponto de projeto inicial para $n$-1 variáveis e resolver a variável remanescente para $\mathrm{z}=0: \mathrm{r}^{*}=\mathrm{s} *$

3) Para cada ponto de projeto correspondente a uma variável que não siga a distribuição normal, determinar a média $\left(\mu_{R}^{\mathrm{e}}\right)$ e o desvio-padrão $\left(\sigma_{\mathrm{R}}^{\mathrm{e}}\right)$ equivalentes

$$
\sigma_{\mathrm{R}}^{\mathrm{e}}=\mathrm{r}^{*} \cdot \sigma_{\ln \mathrm{R}} \quad \mu_{\mathrm{R}}^{\mathrm{e}}=\mathrm{r}^{*} \cdot\left(1-\ln \left(\mathrm{r}^{*}\right)+\mu_{\ln \mathrm{R}}\right)
$$

onde:

$$
\sigma_{\ln R}=\sqrt{\ln \left(1+\frac{\sigma_{R}^{2}}{\mu_{R}^{2}}\right)} \quad \mu_{\ln R}=\ln \left(\mu_{R}\right)-\frac{\sigma_{\ln R}^{2}}{2}
$$

4) Determinar as variáveis padronizadas

$$
\mathrm{z}_{1}^{*}=\frac{\mathrm{r}^{*}-\mu_{\mathrm{R}}^{\mathrm{e}}}{\sigma_{\mathrm{R}}^{\mathrm{e}}} \quad \mathrm{z}_{2}^{*}=\frac{\mathrm{q}^{*}-\mu_{\mathrm{q}}}{\sigma_{\mathrm{q}}}
$$

5) Calcular as derivadas parciais da função de estado limite com respeito às variáveis padronizadas

$$
\mathrm{G}_{\mathrm{i}=-}-\left.\frac{\partial \mathrm{g}}{\partial \mathrm{Z}_{\mathrm{i}}}\right|_{\text {ponto de projeto }} \mathrm{G}_{1=}-\sigma_{\mathrm{R}}^{\mathrm{e}} \quad \mathrm{G}_{2=} \sigma_{\mathrm{Q}}
$$

6) Calcular $\beta$

$$
\beta=\frac{\{G\}^{T}\left\{z^{*}\right\}}{\sqrt{\{G\}^{T}\{G\}}}=\frac{\mu_{\mathrm{R}}^{\mathrm{e}}-\mu_{\mathrm{Q}}}{\sqrt{\left(\sigma_{\mathrm{R}}^{\mathrm{e}}\right)^{2}+\sigma_{\mathrm{Q}}^{2}}}
$$

7) Determinar um vetor contendo os fatores de sensibilidade

$$
\{\alpha\}=\frac{\{G\}}{\sqrt{\{G\}^{T}\{G\}}} \quad \alpha_{1}=\frac{-\sigma_{R}^{e}}{\sqrt{\left(\sigma_{R}^{e}\right)^{2}+\sigma_{Q}^{2}}} \quad \alpha_{2}=\frac{\sigma_{Q}}{\sqrt{\left(\sigma_{R}^{e}\right)^{2}+\sigma_{Q}^{2}}}
$$

8) Determinar um novo ponto de projeto para $n-1$ variáveis padronizadas

$$
\mathrm{z}_{\mathrm{i}}^{*}=\alpha_{\mathrm{i}} \cdot \beta
$$

9) Calcular o novo ponto de projeto nas coordenadas originais para $n-1$ variáveis

$$
\mathrm{r}^{*}=\mu_{\mathrm{r}}^{\mathrm{e}}+\mathrm{z}_{1}^{*} \cdot \sigma_{\mathrm{r}}^{\mathrm{e}}=\mu_{\mathrm{r}}^{\mathrm{e}}+\alpha_{1} \cdot \beta \cdot \sigma_{\mathrm{r}}^{\mathrm{e}}
$$

10) Determinar o valor da variável remanescente fixando $\mathrm{z}=0$ 
11) Repetir os passos 3-10 até $\beta$ e o ponto de projeto convergirem

Quando o objetivo for calcular a média do efeito do carregamento que satisfaz um determinado beta, basta isolar $\mu_{\mathrm{Q}}$ no passo número 6 .

\subsubsection{Combinação de carregamentos}

Quanto às combinações de ações, assume-se que a carga móvel é o produto de dois parâmetros $(Q P)$, onde $Q$ é o efeito do carregamento móvel estático e $P$ é o fator de análise da carga móvel. Nowak (1999) indica que a média de $P$ é 1,0 e o coeficiente de variação é 0,12 . O coeficiente de variação de $Q P$ é dado por:

$\mathrm{CV}_{\mathrm{QP}}=\left(\mathrm{CV}_{\mathrm{Q}}{ }^{2}+\mathrm{CV}_{\mathrm{P}}^{2}\right)^{1 / 2}$

onde:

$\mathrm{CV}_{\mathrm{Q}}$ : coeficiente de variação de $\mathrm{Q}$;

$\mathrm{CV}_{\mathrm{P}}$ : coeficiente de variação de $\mathrm{P}$.

A média de $Q P+I$ (efeito da carga móvel incluindo o impacto) é conseguida multiplicando-se a média de $Q$ pela média de $P$ (igual a 1,0$)$ e por $(1+\mathrm{I})$, onde $I$ é a média do carregamento dinâmico (entendido como uma porcentagem do efeito estático da carga móvel). O desvio-padrão é dado por:

$\sigma_{\mathrm{QP}+\mathrm{I}}=\left(\sigma_{\mathrm{QP}}^{2}+\sigma_{\mathrm{I}}^{2}\right)^{1 / 2}$

onde:

$\sigma_{\mathrm{QP}}=\mathrm{CV}_{\mathrm{QP}} \cdot \mathrm{m}_{\mathrm{LP}}$

$\sigma_{\mathrm{I}}=\mathrm{CV}_{\mathrm{I}} \cdot \mathrm{m}_{\mathrm{I}}$

$\mathrm{m}_{\mathrm{QP}}$; $\mathrm{m}_{\mathrm{I}}$ : média de $Q P$ e da parcela dinâmica, respectivamente.

$\mathrm{CV}_{\mathrm{QP}+\mathrm{I}}=\frac{\sigma_{\mathrm{QP}+\mathrm{I}}}{\mathrm{m}_{\mathrm{QP}+\mathrm{I}}}$ 
Para pontes com uma faixa de tráfego, Nowak (1999) utiliza $\mathrm{CV}_{\mathrm{QP}+\mathrm{I}}=0,19$ para a maioria dos vãos e 0,205 para vãos muito pequenos. Em pontes com duas faixas de tráfego, $\mathrm{CV}_{\mathrm{QP}+\mathrm{I}}=0,18$ na maioria dos vãos e 0,19 em vãos muito pequenos.

Neste trabalho, o coeficiente de variação da carga móvel, do fator de análise e da parcela dinâmica, todos combinados, depende do carregamento móvel crítico para cada ponte (1 ou 2 caminhões) e assim, é calculado especificamente para cada obra de arte analisada.

Considerando-se agora também a carga permanente, as incertezas envolvidas na análise dos esforços solicitantes são dadas pelo fator de análise $E$, cuja média é 1,0 e o coeficiente de variação é 0,04 para vãos únicos e 0,06 para vão contínuos (NOWAK, 1999). O efeito total do carregamento $(S)$ é então dado por:

$\mathrm{S}=\mathrm{E} \cdot\left(\mathrm{G}_{1}+\mathrm{G}_{2}+\mathrm{Q}+\mathrm{I}\right)$

onde:

$\mathrm{G}_{1}$ : efeito do peso próprio da estrutura;

$\mathrm{G}_{2}$ : efeito do peso próprio do revestimento asfáltico;

O coeficiente de variação de $S$ é:

$\mathrm{CV}_{\mathrm{S}}=\left(\mathrm{CV}_{\mathrm{E}}^{2}+\mathrm{CV}_{\mathrm{G} 1+\mathrm{G} 2+\mathrm{Q}+\mathrm{I}}^{2}\right)^{1 / 2}$

e

$\sigma_{\mathrm{G} 1+\mathrm{G} 2+\mathrm{Q}+\mathrm{I}}=\left(\sigma_{\mathrm{G} 1}^{2}+\sigma_{\mathrm{G} 2}^{2}+\sigma_{\mathrm{QP}+\mathrm{I}}^{2}\right)^{1 / 2}$

\subsection{3 Índices de confiabilidade}

\subsubsection{Concreto armado}

A resistência $R$ da seção transversal foi determinada no capítulo 3 em função da variabilidade das propriedades mecânicas e das dimensões dos materiais. A solicitação $S$ é a soma dos efeitos do peso próprio da estrutura, do peso próprio do asfalto e da carga móvel, parcelas estática e dinâmica.

Nas tabelas E5 a E8 do apêndice E estão todas as variáveis que fazem parte da 
análise de confiabilidade e são relativas a concreto armado (momento fletor positivo e negativo). O valor médio do momento fletor devido ao peso próprio do asfalto advém diretamente da análise estrutural considerando-se uma capa de $10 \mathrm{~cm}$ de espessura (a mesma usada para dimensionamento). Quanto ao peso próprio da estrutura, adotou-se bias igual a 1,05 e coeficiente de variação de 0,10 , conforme tabela 2.1 , referentes a concreto moldado no local (mesmo nos casos de viga pré-moldada de canteiro).

Os resultados da análise de confiabilidade para as pontes classe 36 e 45 estão nas tabelas 5.1 a 5.4 .

Tabela 5.1 - Índices de confiabilidade - LAJE.

\begin{tabular}{|c|c|c|c|c|c|}
\hline \multirow{2}{*}{$\mathbf{n}$} & \multirow{2}{*}{ Arquivo } & \multicolumn{2}{|c|}{ Momento positivo } & \multicolumn{2}{|c|}{ Momento negativo } \\
\hline & & Classe 36 & Classe 45 & Classe 36 & Classe 45 \\
\hline 1 & SA TE V10 MC & 4,06 & 4,31 & - & - \\
\hline 2 & SA TL V10 MC & 3,98 & 4,22 & - & - \\
\hline 3 & SA TE V20 VZ & 4,20 & 4,22 & - & - \\
\hline 4 & SA TL V20 VZ & 4,41 & 4,42 & - & - \\
\hline 5 & C3 TE V10/10/10 MC & 3,82 & 4,12 & 3,44 & 3,33 \\
\hline 6 & C3 TL V10/10/10 MC & 3,93 & 4,22 & 3,46 & 3,36 \\
\hline 7 & C3 TE V20/20/20 VZ & 3,96 & 4,08 & 4,68 & 4,33 \\
\hline 8 & C3 TL V20/20/20 VZ & 4,41 & 4,57 & 4,79 & 4,46 \\
\hline & MÍNIMO & 3,82 & 4,08 & 3,44 & 3,33 \\
\hline & MÁXIMO & 4,41 & 4,57 & 4,79 & 4,46 \\
\hline & MÉDIA & 4,10 & 4,27 & 4,09 & 3,87 \\
\hline
\end{tabular}


Tabela 5.2 - Índices de confiabilidade - VIGA T - 2 VIGAS.

\begin{tabular}{|c|c|c|c|c|c|}
\hline \multirow{2}{*}{$\mathbf{n}$} & \multirow{2}{*}{ Arquivo } & \multicolumn{2}{|c|}{ Momento positivo } & \multicolumn{2}{|c|}{ Momento negativo } \\
\hline & & Classe 36 & Classe 45 & Classe 36 & Classe 45 \\
\hline 1 & SA TE V10 TR2 & 3,11 & 3,47 & - & - \\
\hline 2 & SA TE V20 TR2 & 3,37 & 3,48 & - & - \\
\hline 3 & SAB TE V3/10/3 TR2 & 3,17 & 3,65 & 2,73 & 3,28 \\
\hline 4 & SAB TE V5/20/5 TR2 & 3,21 & 3,47 & 3,33 & 3,80 \\
\hline 5 & SAB TE V5/30/5 TR4 & 3,78 & 3,86 & 3,62 & 3,88 \\
\hline 7 & C3 TE V20/20/20 TR3 & 3,07 & 3,32 & 4,38 & 4,52 \\
\hline 8 & C3 TE V30/30/30 TR3 & 3,50 & 3,56 & 4,78 & 4,88 \\
\hline 10 & SA TL V10 TR1 & 3,07 & 3,47 & - & - \\
\hline 11 & SA TL V20 TR2 & 3,43 & 3,60 & - & - \\
\hline 12 & SAB TL V3/10/3 TR1 & 3,09 & 3,63 & 2,51 & 3,08 \\
\hline 13 & SAB TL V5/20/5 TR2 & 3,50 & 3,85 & 3,27 & 3,85 \\
\hline 14 & SAB TL V5/30/5 TR3 & 4,11 & 4,25 & 3,64 & 3,98 \\
\hline 16 & C3 TL V20/20/20 TR2 & 3,29 & 3,63 & 4,74 & 5,15 \\
\hline 17 & C3 TL V30/30/30 TR3 & 3,79 & 3,98 & 5,17 & 5,49 \\
\hline 19 & C3B TE V5-20/25/20-5 TR3 & 2,96 & 3,22 & 4,55 & 4,70 \\
\hline 20 & C3B TL V5-20/25/20-5 TR2 & 3,27 & 3,62 & 5,02 & 5,35 \\
\hline 21 & C3B TE V5-25/30/25-5 TR3 & 3,16 & 3,37 & 4,80 & 4,89 \\
\hline 22 & C3B TL V5-25/30/25-5 TR2 & 3,39 & 3,74 & 5,16 & 5,50 \\
\hline 23 & C2 TL V30/30 TR3 & 3,49 & 3,74 & 5,15 & 5,37 \\
\hline & MÍNIMO & 2,96 & 3,22 & 2,51 & 3,08 \\
\hline & MÁXIMO & 4,11 & 4,25 & 5,17 & 5,50 \\
\hline & MÉDIA & 3,35 & 3,63 & 4,19 & 4,52 \\
\hline
\end{tabular}

Tabela 5.3 - Índices de confiabilidade - VIGA T - 5 VIGAS.

\begin{tabular}{|c|c|c|c|c|c|}
\hline \multirow{2}{*}{$\mathbf{n}$} & \multirow{2}{*}{ Arquivo } & \multicolumn{2}{|c|}{ Momento positivo } & \multicolumn{2}{|c|}{ Momento negativo } \\
\hline & & Classe 36 & Classe 45 & Classe 36 & Classe 45 \\
\hline 1 & SA TE V10 TR2 & 2,92 & 3,33 & - & - \\
\hline 2 & SA TE V20 TR2 & 3,05 & 3,24 & - & - \\
\hline 5 & SA TL V10 TR2 & 3,12 & 3,60 & - & - \\
\hline 6 & SA TL V20 TR2 & 3,12 & 3,48 & - & - \\
\hline 9 & C3 TL V30/30/30 TR2 & 3,84 & 4,16 & 5,29 & 5,72 \\
\hline 10 & C3B TE V5-25/30/25-5 TR2 & 2,97 & 3,16 & 5,01 & 5,05 \\
\hline 11 & C3B TL V5-25/30/25-5 TR2 & 3,57 & 4,02 & 5,43 & 5,76 \\
\hline 12 & SA TE V10 STR & 2,55 & 2,96 & - & - \\
\hline 13 & SA TE V20 STR & 2,77 & 2,99 & - & - \\
\hline 16 & SA TL V10 STR & 3,45 & 3,89 & - & - \\
\hline 17 & SA TL V20 STR & 3,22 & 3,54 & - & - \\
\hline & MÍNIMO & 2,55 & 2,96 & 5,01 & 5,05 \\
\hline & MÁXIMO & 3,84 & 4,16 & 5,43 & 5,76 \\
\hline & MÉDIA & 3,14 & 3,49 & 5,24 & 5,51 \\
\hline
\end{tabular}


Tabela 5.4 - Índices de confiabilidade - CELULAR.

\begin{tabular}{|c|c|c|c|c|c|}
\hline \multirow{2}{*}{$\mathbf{n}$} & \multirow{2}{*}{ Arquivo } & \multicolumn{2}{|c|}{ Momento positivo } & \multicolumn{2}{|c|}{ Momento negativo } \\
\hline & & Classe 36 & Classe 45 & Classe 36 & Classe 45 \\
\hline 1 & SA TL V20 STR & 3,96 & 4,26 & - & - \\
\hline 4 & C3 TL V30/30/30 STR & 4,66 & 5,23 & 5,92 & 6,34 \\
\hline 6 & SA TE V20 STR & 3,57 & 3,79 & - & - \\
\hline 9 & C3 TE V30/30/30 STR & 3,83 & 4,16 & 5,26 & 5,60 \\
\hline & MÍNIMO & 3,57 & 3,79 & 5,26 & 5,60 \\
\hline & MÁXIMO & 4,66 & 5,23 & 5,92 & 6,34 \\
\hline & MÉDIA & 4,01 & 4,36 & 5,59 & 5,97 \\
\hline
\end{tabular}

Os resultados demonstram que as pontes classe 36 possuem menores índices de confiabilidade se comparadas às pontes de classe 45. Essa diferença é mais notada em menores vãos, pois a relação carga permanente sobre carga móvel é menor. Salienta-se que para uma mesma estrutura, as pontes classes 36 e 45 foram dimensionadas com o mesmo peso próprio.

Em termos de momento fletor positivo, dentro de uma mesma classe e sistema estrutural, as pontes de menor vão apresentam geralmente menores betas e portanto menores níveis de segurança. Essa conclusão também foi obtida por Ghosn (2000).

Os momentos fletores negativos nos balanços apresentam os índices de confiabilidade bastante baixos. Verifica-se essa afirmação em pontes simplesmente apoiadas com balanços. Nas pontes contínuas com 3 tramos desiguais e balanços, a análise é efetuada no apoio interno.

Os índices de confiabilidade entre pontes semelhantes de tabuleiro estreito e tabuleiro largo dependem do sistema estrutural e do vão.

No caso das pontes de 5 vigas e tabuleiro estreito, a segurança é maior nas pontes com transversinas em relação às pontes sem transversinas. Nas pontes de tabuleiro largo, ocorre o inverso.

\subsubsection{Concreto protendido}

a) Estado limite último

Os parâmetros estatísticos das resistências e das solicitações estão descritos no apêndice E, tabelas E9 a E11. As considerações sobre o peso próprio da estrutura e do revestimento asfáltico são as mesmas já comentadas no item sobre concreto armado. 
As tabelas 5.5 a 5.7 mostram os resultados da análise de confiabilidade.

Tabela 5.5 - Índices de confiabilidade - LAJE.

\begin{tabular}{|c|c|c|c|}
\hline \multirow{2}{*}{$\mathbf{N}$} & \multirow{2}{*}{ Arquivo } & \multicolumn{2}{|c|}{ Momento positivo } \\
\cline { 3 - 4 } & & Classe 36 & Classe 45 \\
\hline 3 & SA TE V20 VZ & 5,76 & 5,26 \\
\hline 4 & SA TL V20 VZ & 6,42 & 5,99 \\
\hline & MÉDIA & 6,09 & 5,62 \\
\hline
\end{tabular}

Tabela 5.6 - Índices de confiabilidade - VIGA T - 5 VIGAS.

\begin{tabular}{|c|c|c|c|}
\hline \multirow{2}{*}{$\mathbf{n}$} & \multirow{2}{*}{ Arquivo } & \multicolumn{2}{|c|}{ Momento positivo } \\
\cline { 3 - 4 } & & Classe 36 & Classe 45 \\
\hline 2 & SA TE V20 TR2 & 3,91 & 3,47 \\
\hline 3 & SA TE V30 TR2 & 4,50 & 3,98 \\
\hline 4 & SA TE V40 TR4 & 5,73 & 5,24 \\
\hline 6 & SA TL V20 TR2 & 4,35 & 3,98 \\
\hline 7 & SA TL V30 TR2 & 4,67 & 4,39 \\
\hline 8 & SA TL V40 TR4 & 5,26 & 5,04 \\
\hline 13 & SA TE V20 STR & 3,55 & 3,41 \\
\hline 14 & SA TE V30 STR & 4,30 & 3,77 \\
\hline 15 & SA TE V40 STR & 5,43 & 4,94 \\
\hline 17 & SA TL V20 STR & 4,03 & 3,75 \\
\hline 18 & SA TL V30 STR & 4,32 & 3,91 \\
\hline 19 & SA TL V40 STR & 4,86 & 4,76 \\
\hline & MíNIMO & 3,55 & 3,41 \\
\hline & MÁXIMO & 5,73 & 5,24 \\
\hline \multicolumn{2}{r}{ MÉDIA } & 4,58 & 4,22 \\
\hline
\end{tabular}

Tabela 5.7 - Índices de confiabilidade - CELULAR.

\begin{tabular}{|c|c|c|c|}
\hline \multirow{2}{*}{$\mathbf{n}$} & \multirow{2}{*}{ Arquivo } & \multicolumn{2}{|c|}{ Momento positivo } \\
\hline & & Classe 36 & Classe 45 \\
\hline 1 & SA TL V20 STR & 4,81 & 5,16 \\
\hline 2 & SA TL V30 STR & 5,22 & 5,57 \\
\hline 3 & SA TL V40 STR & 5,74 & 5,92 \\
\hline 5 & SA TL V30 TR2 & 4,43 & 4,61 \\
\hline 6 & SA TE V20 STR & 3,44 & 3,63 \\
\hline 7 & SA TE V30 STR & 3,78 & 3,88 \\
\hline 8 & SA TE V40 STR & 4,89 & 4,87 \\
\hline 10 & SA TE V30 TR2 & 4,34 & 4,46 \\
\hline & MÍNIMO & 3,44 & 3,63 \\
\hline & MÁXIMO & 5,74 & 5,92 \\
\hline & MÉDIA & 4,58 & 4,76 \\
\hline
\end{tabular}

Em geral, os índices de confiabilidade obtidos para pontes de concreto protendido considerando-se o estado limite último são maiores que os valores 
encontrados para as estruturas de concreto armado. Atribui-se esse fato às diferenças no pré-dimensionamento, no procedimento de cálculo das seções transversais e também na menor variabilidade dos parâmetros estatísticos das propriedades dos materiais e das dimensões.

As pontes de tabuleiro largo tendem a possuir maior nível de segurança em relação às pontes de tabuleiro estreito. No caso das pontes em 5 vigas, as pontes com transversinas apresentam maiores índices de confiabilidade em relação às estruturas sem transversinas.

Como nas pontes em concreto armado, os betas aumentam com o aumento do vão. No entanto, nas pontes em laje e nas pontes em 5 vigas, os índices de confiabilidade são maiores para a classe 36 devido à diferença nas hipóteses para verificação dos estados limites de serviço.

b) Estado limite de formação de fissuras

Admitindo-se o cálculo simplificado no estádio Ia, a função de estado limite é obtida a partir da combinação freqüente de ações:

$\sigma_{1 \mathrm{~g} 1}+\sigma_{1 \mathrm{~g} 2}+\psi_{1} \cdot \sigma_{1 \mathrm{q}}+\sigma_{1 \mathrm{P} \infty}=1,2 \cdot \mathrm{f}_{\mathrm{ct}}$

onde:

$\sigma_{1 \mathrm{~g} 1}:$ tensão na borda inferior devido ao peso próprio;

$\sigma_{\lg 2}$ : tensão na borda inferior devido ao revestimento asfáltico;

$\psi_{1}$ : fator para a combinação de serviço de grande freqüência;

$\sigma_{1 \mathrm{P} \infty}$ : tensão na borda inferior devido à protensão, após as perdas;

$\mathrm{f}_{\mathrm{ct}}$ : resistência à tração direta do concreto.

Transformando a equação (5.9) em termos de momentos fletores e da força de protensão:

$\mathrm{M}_{\mathrm{g} 1}+\mathrm{M}_{\mathrm{g} 2}+\psi_{1} \cdot \mathrm{M}_{\mathrm{q}}+\frac{\mathrm{P}_{\infty} \cdot \mathrm{I}}{\mathrm{A} \cdot \mathrm{y}_{1}}+\mathrm{P}_{\infty} \cdot \mathrm{e}_{\mathrm{p}}=\mathrm{M}_{\mathrm{r}}$

onde: 
$\mathrm{M}_{\mathrm{g} 1}, \mathrm{M}_{\mathrm{g} 2}, \mathrm{M}_{\mathrm{q}}$ : momentos fletores devido ao peso próprio, ao asfalto e à carga móvel $\mathrm{P}_{\infty}$ : força de protensão após as perdas;

I : momento de inércia da seção transversal;

A : área da seção transversal;

$\mathrm{y}_{1}$ : distância do centro de gravidade da seção transversal até a borda inferior;

$\mathrm{e}_{\mathrm{p}}$ : excentricidade da força de protensão;

$\mathrm{M}_{\mathrm{r}}$ : momento de fissuração.

Atribuindo o sinal negativo à força de protensão e rearranjando os termos:

$$
\left(M_{r}+\frac{P_{\infty} \cdot I}{A \cdot y_{1}}+P_{\infty} \cdot e_{p}\right)-\left(M_{g 1}+M_{g 2}+\psi_{1} \cdot M_{q}\right)=0
$$

Dessa forma, o primeiro parênteses corresponde à resistência $R$ e o segundo parênteses corresponde à solicitação $S$.

Antes do início da análise de confiabilidade, utiliza-se a técnica de Monte Carlo para a obtenção dos parâmetros estatísticos da resistência. Considera-se a força de protensão uma variável determinística e o momento de fissuração médio é calculado a partir da seguinte expressão:

$$
\mathrm{M}_{\mathrm{r}, \mathrm{m}}=\frac{1,2 \cdot \mathrm{f}_{\mathrm{ct}, \mathrm{m}} \cdot \mathrm{I}_{\mathrm{c}}}{\mathrm{y}_{\mathrm{t}}}
$$

onde:

$\mathrm{f}_{\mathrm{ct}, \mathrm{m}}=0,3 \cdot \mathrm{f}_{\mathrm{c}, \mathrm{m}}{ }^{2 / 3}$

Os parâmetros estatísticos dos materiais, das dimensões e o número de simulações são os mesmos já descritos anteriormente.

Destaca-se que foi utilizado o modelo de carga móvel desenvolvido no capítulo 4 e atribuiu-se $\psi_{1}=1$. Embora se utilize a mesma combinação utilizada no estado limite último para a verificação de um estado limite de serviço, a redução na severidade das consequências é considerada através da escolha de betas desejáveis menos conservadores. 
Os índices de confiabilidade calculados estão nas tabelas 5.8 a 5.11 e os dados sobre as variáveis básicas estão no apêndice E (v. tabelas E12 a E14).

Tabela 5.8 - Índices de confiabilidade - LAJE.

\begin{tabular}{|c|c|c|c|}
\hline \multirow{2}{*}{$\mathbf{n}$} & \multirow{2}{*}{ Arquivo } & \multicolumn{2}{|c|}{ Momento positivo } \\
\cline { 3 - 4 } & & Classe 36 & Classe 45 \\
\hline 3 & SA TE V20 VZ & 1,14 & 1,05 \\
\hline 4 & SA TL V20 VZ & 1,77 & 1,75 \\
\hline \multicolumn{2}{|c}{ MÉDIA } & 1,46 & 1,40 \\
\hline
\end{tabular}

Tabela 5.9 - Índices de confiabilidade - VIGA T - 5 VIGAS.

\begin{tabular}{|c|c|c|c|}
\hline \multirow{2}{*}{$\mathbf{n}$} & \multirow{2}{*}{ Arquivo } & \multicolumn{2}{|c|}{ Momento positivo } \\
\hline & & Classe 36 & Classe 45 \\
\hline 2 & SA TE V20 TR2 & 0,12 & $-0,24$ \\
\hline 3 & SA TE V30 TR2 & 0,40 & 0,18 \\
\hline 4 & SA TE V40 TR4 & 1,06 & 0,86 \\
\hline 6 & SA TL V20 TR2 & 0,35 & 0,21 \\
\hline 7 & SA TL V30 TR2 & 0,59 & 0,51 \\
\hline 8 & SA TL V40 TR4 & 0,95 & 0,97 \\
\hline 13 & SA TE V20 STR & $-0,09$ & $-0,26$ \\
\hline 14 & SA TE V30 STR & 0,29 & $-0,04$ \\
\hline 15 & SA TE V40 STR & 0,89 & 0,69 \\
\hline 17 & SA TL V20 STR & 0,15 & $-0,22$ \\
\hline 18 & SA TL V30 STR & 0,37 & 0,18 \\
\hline 19 & SA TL V40 STR & 0,70 & 0,82 \\
\hline & MÍNIMO & $-0,09$ & $-0,26$ \\
\hline & MÁXIMO & 1,06 & 0,97 \\
\hline & MÉDIA & 0,48 & 0,31 \\
\hline
\end{tabular}

Tabela 5.10 - Índices de confiabilidade - CELULAR.

\begin{tabular}{|c|c|c|c|}
\hline \multirow{2}{*}{$\mathbf{n}$} & \multirow{2}{*}{ Arquivo } & \multicolumn{2}{|c|}{ Momento positivo } \\
\cline { 3 - 4 } & & Classe 36 & Classe 45 \\
\hline 1 & SA TL V20 STR & 1,16 & 1,04 \\
\hline 2 & SA TL V30 STR & 1,04 & 0,89 \\
\hline 3 & SA TL V40 STR & 1,19 & 1,05 \\
\hline 5 & SA TL V30 TR2 & 1,26 & 1,22 \\
\hline 6 & SA TE V20 STR & 0,32 & 0,17 \\
\hline 7 & SA TE V30 STR & 0,27 & 0,11 \\
\hline 8 & SA TE V40 STR & 0,53 & 0,34 \\
\hline 10 & SA TE V30 TR2 & 0,64 & 0,49 \\
\hline \multicolumn{2}{c}{ MÍNIMO } & 0,27 & 0,11 \\
\hline \multicolumn{2}{c}{ MÁXIMO } & 1,26 & 1,22 \\
\hline \multicolumn{2}{c}{ MÉDIA } & 0,80 & 0,66 \\
\hline
\end{tabular}

Destaca-se, inicialmente, a diferença entre os resultados provenientes do estado 
limite último e do estado limite de serviço. As tabelas também indicam que os menores índices de confiabilidade relativos ao estado limite de formação de fissuras são negativos e inferiores aos encontrados por Nowak, Szerszen e Park (1998).

Seguindo tendência que já ocorria no caso de concreto armado e no estado limite último no caso de concreto protendido, as pontes em laje apresentam maiores índices de confiabilidade se comparadas à pontes semelhantes de outros sistema estruturais.

O efeito favorável das transversinas nas pontes em 5 vigas é novamente verificado.

\subsection{Momentos fletores limites}

Os momentos fletores limites correspondentes a vários betas podem ser calculados através dos dados fornecidos nas tabelas do apêndice E. Subtraindo-se os efeitos do peso próprio e do revestimento asfáltico, são obtidos os máximos momentos fletores devido ao carregamento móvel.

Vale ressaltar que são supostos os mesmos coeficientes de variação do carregamento utilizados para o cálculo do índice de confiabilidade no item anterior. 
Neste capítulo é descrito o desenvolvimento das equações comprimento-peso limite (ECPLs). O procedimento é aplicado a possíveis $\beta_{\text {alvo, demonstrando sua }}$ influência nos pesos brutos admissíveis. Após a fixação dos betas desejáveis para o estado limite último e o estado limite de serviço, recomenda-se a equação a ser utilizada nas obras de arte. Por fim, são realizadas algumas aplicações práticas da equação proposta em veículos reais, comparando-se os resultados com os limites de peso estabelecidos pela legislação.

\subsection{Requisitos necessários para a equação}

Os requisitos básicos de eficiência que a equação proposta deve buscar são:

a) Todos os veículos (ou grupos de eixos) que causem índices de confiabilidade inferiores aos determinados ( $\beta_{\text {alvo }}$ ) devem ter seus pesos restringidos;

b) A equação não deve limitar o peso de veículos (ou grupo de eixos) além do limite proveniente do índice de confiabilidade desejável;

c) Ser simples e de fácil uso.

De acordo com James et al. (1986), a fórmula perfeita seria aquela que permitisse todo veículo trafegar com um peso cujo efeito coincidisse com os momentos fletores pré-estipulados. No entanto, pontes críticas em relação às demais limitam o peso bruto admissível e comandam as ECPLs.

Em resumo, as equações devem ser obtidas de maneira que representem, o mais fielmente possível, o efeito que caminhões reais causam à estrutura e que o índice de 
confiabilidade pré-estabelecido seja atingido.

\subsection{Representação de um veículo para as ECPLs}

Considerando-se que a equação deve ser genérica, ou seja, aplicável a qualquer veículo, é preciso adotar uma distribuição do peso do grupo de eixos ao longo de seu comprimento tal que os momentos fletores provenientes dos caminhões reais e da distribuição assumida sejam aproximadamente iguais e a favor da segurança. Em outras palavras, o objetivo é garantir que o momento fletor máximo devido ao caminhão seja menor ou igual ao momento fletor da distribuição de pesos que o represente.

De acordo com James et al. (1986), são 4 as alternativas possíveis:

a) Veículos teóricos: são desenvolvidos alguns cenários de espaçamentos entre eixos e pesos por eixo críticos para o cálculo do momento fletor. No entanto, os veículos teóricos não são representativos dos veículos reais e restringem severamente seus pesos admissíveis. Por isso, essa alternativa é descartada por seus autores;

b) Carregamento uniformemente distribuído ao longo do comprimento do grupo de eixos;

c) Cargas uniformemente espaçadas e igualmente carregadas ao longo do comprimento do grupo de eixos;

d) Pesos brutos para alguns veículos reais selecionados.

Considerando-se as alternativas $b$ e $c$, James et al. (1986) constatam que, para intensidades e comprimentos iguais de carregamento, os momentos fletores máximos provenientes de cargas uniformemente distribuídas são sempre maiores que aqueles obtidos através de qualquer número $n$ de forças igualmente espaçadas e carregadas (v. figura 6.1). Essa afirmação indica que a situação mais crítica para a representação de um veículo seria a utilização da hipótese descrita no item $b$. No entanto, desenvolvem sua equação representando um caminhão através de nove eixos igualmente espaçados e carregados, pois os momentos fletores obtidos com veículos reais, daquela época, são ainda menores. Dessa forma, o procedimento está a favor da segurança, porém de maneira menos conservadora em relação à alternativa $b$.

Baseando-se em James et al. (1986), Ghosn (2000) opta por utilizar 
carregamento uniformemente distribuído.
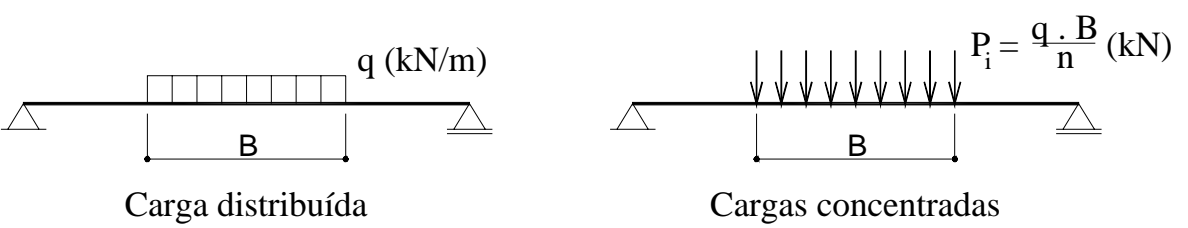

Figura 6.1 - Comparação entre os momentos fletores máximos para 2 carregamentos:

$$
\mathrm{M}_{\text {distribuída }}>\mathrm{M}_{\text {concentrada }} \text {. }
$$

Neste trabalho, representa-se os veículos reais através de uma carga uniformemente distribuída. Entretanto, visando a adaptação às características do programa STRAP, o carregamento uniformemente distribuído para o cálculo das ECPLs é representado através de 11 eixos igualmente espaçados e carregados.

\subsection{Procedimento de cálculo}

As etapas para a obtenção das ECPLs, a serem aplicadas a cada obra de arte da base de dados do DER-SP (momentos fletores positivos e negativos), são as seguintes:

1) Assumir que um grupo de eixos que satisfaz à equação possui peso $W$ e comprimento $B$;

2) Adotar uma distribuição do peso $W$ ao longo do comprimento $B$ tal que os momentos fletores provenientes dos caminhões reais e da distribuição assumida sejam aproximadamente iguais. Neste trabalho, conforme comentado no item anterior, os caminhões reais são representados por um carregamento uniformemente distribuído através de 11 eixos igualmente espaçados e carregados (v. figura 6.2);

3) Variar $B$ entre 2,5 e 30 metros;

4) Para cada $B$, calcular o momento fletor $\left(M_{r}\right)$ equivalente a um carregamento unitário uniformemente distribuído ao longo de seu comprimento, atribuindo-se a cada eixo $\frac{1 \cdot \mathrm{B}}{11}$. A carga de cada eixo é então dividida em 2 linhas de rodas;

5) Obter o momento fletor correspondente ao índice de confiabilidade desejável ( $\left.\beta_{\text {alvo }}\right)$ e subtrair os efeitos da carga permanente (peso próprio da estrutura e peso do revestimento asfáltico) e da parcela dinâmica da carga móvel. Considerando-se que 
o caminhão da ECPL pode não estar isolado ao trafegar sobre as pontes, subtrair também o momento fletor correspondente ao caminhão que o acompanha (veículo secundário). O momento fletor resultante é chamado $\mathrm{M}_{\mathrm{t}}$;

6) Calcular o peso limite com: $W=\frac{M_{t}}{M_{r}} \cdot B$;

7) Após repetir as etapas anteriores para diversos valores de $B$, plotar as curvas $W$ versus $B$. Acrescentando-se todas as pontes da base de dados, é obtida a envoltória que os pesos brutos devem respeitar para que se garanta um índice de confiabilidade maior ou igual a $\beta_{\mathrm{alv} o}$;

8) Encontrar uma expressão algébrica que represente, de maneira simples, a envoltória anteriormente obtida.
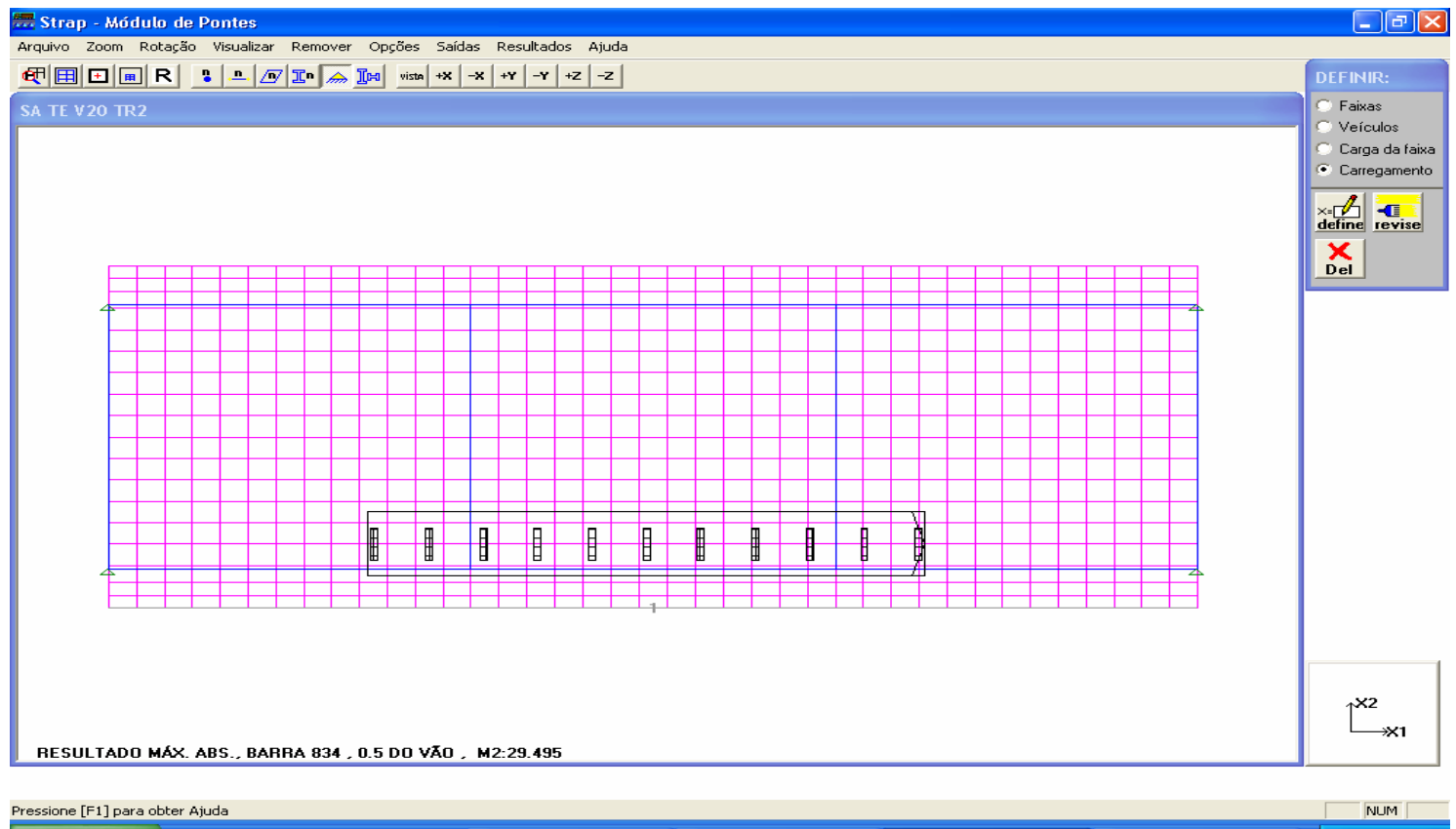

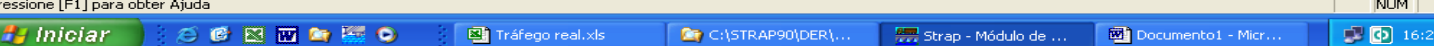

Figura 6.2 - Representação de um veículo real no software STRAP.

\subsection{Curvas $W$ versus $B$}

Durante a construção das curvas $W$ versus $B$ considera-se que o caminhão principal, a ser representado pelas ECPLs, é acompanhado por um veículo secundário. Essa hipótese corresponde a uma situação normal de tráfego, em que 2 veículos cruzam a ponte simultaneamente. As curvas obtidas caso se possa garantir que um veículo passe isoladamente sobre as obras de arte são mostradas no apêndice D. 
Na determinação do veículo secundário distinguem-se 2 situações:

a) Caso crítico de carregamento é devido a 1 veículo isolado ou 2 veículos lado a lado: o caminhão secundário é um 2S3 com probabilidade igual a 1/500 (peso aproximadamente igual a $560 \mathrm{kN}$ ), na faixa adjacente ao caminhão principal;

b) Caso crítico de carregamento é devido a 2 caminhões em fila: o veículo secundário se mantém idêntico, porém é disposto na mesma faixa de tráfego do caminhão principal.

O procedimento descrito neste capítulo é aplicado a todas as pontes (classes 36 e 45), esforço (momento fletor positivo e negativo) e estado limite (estado limite último e estado limite de formação de fissuras apenas para as pontes em concreto protendido), para vários possíveis $\beta_{\text {alvo }}$ A influência do índice de confiabilidade desejável e do comprimento do grupo de eixos nos pesos brutos admissíveis é exemplificada na figura 6.3 .
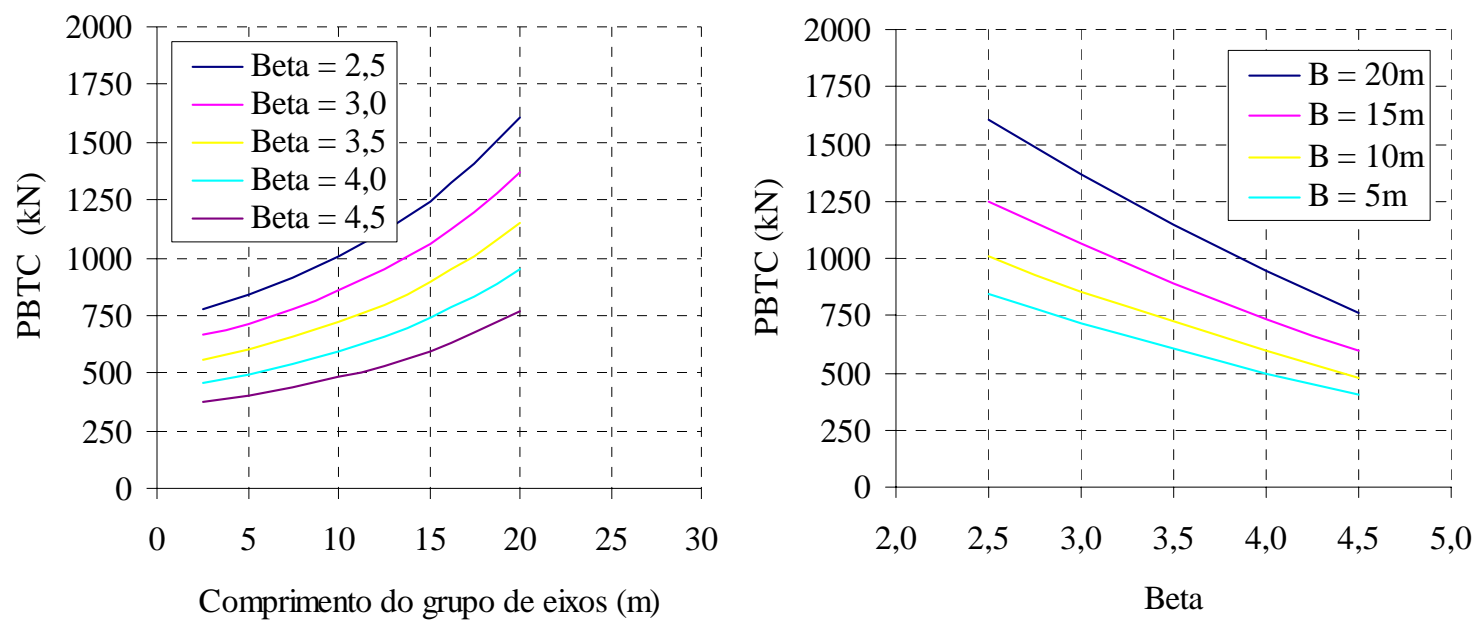

Figura 6.3 - PBTC para a ponte de 2 vigas SA TE V10 TR2 (concreto armado, classe 45).

Devido ao grande número de resultados, serão mostradas a seguir apenas as curvas referentes à classe 45 e à apenas um dos $\beta_{\text {alvo }}$. As curvas relativas à classe 36 são semelhantes quanto à forma e a diferença é basicamente quantitativa. As tabelas completas das classes 36 e 45 para todas as pontes de acordo com sua ordem, correspondentes a 3 betas desejáveis, estão no apêndice E (v. tabelas E15 a E28). 


\subsubsection{Concreto armado (CA), classe 45}

Os pesos brutos admissíveis considerando-se $\beta_{\text {alvo igual a 4,0 estão nas figuras }}$ 6.4 a 6.11. Cada figura contém todas as pontes correspondentes ao sistema estrutural e ao tipo de esforço. Os números nas legendas correspondem à ordem da ponte. (v. tabelas 3.1 a 3.4).

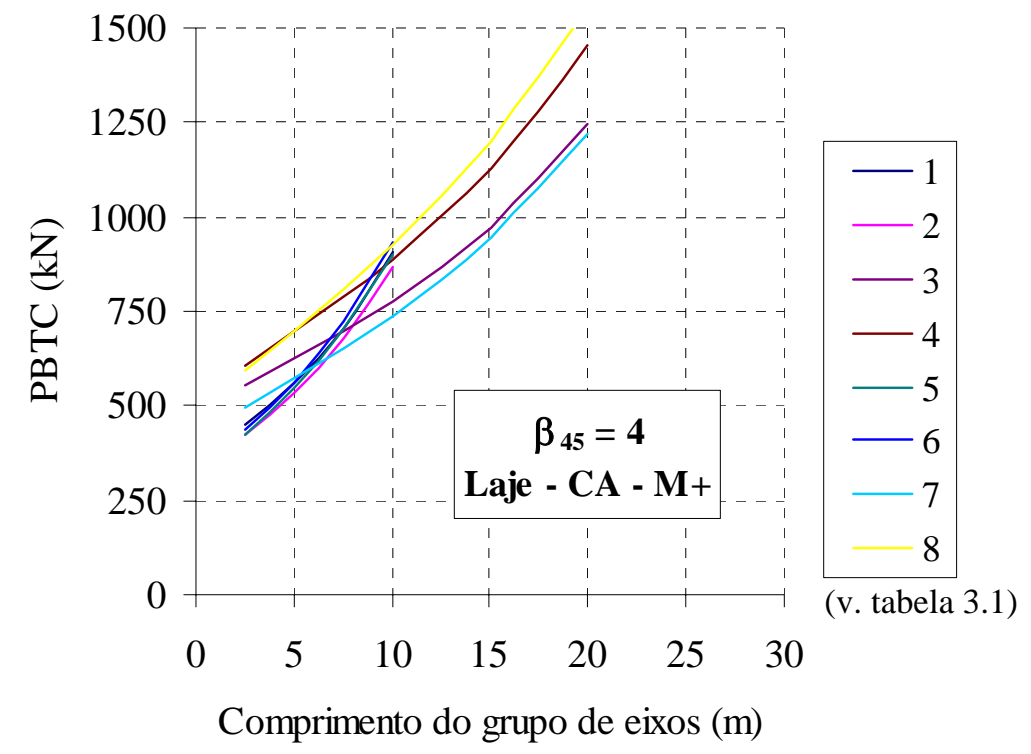

Figura 6.4 - PBTC - LAJE - Momento fletor positivo.

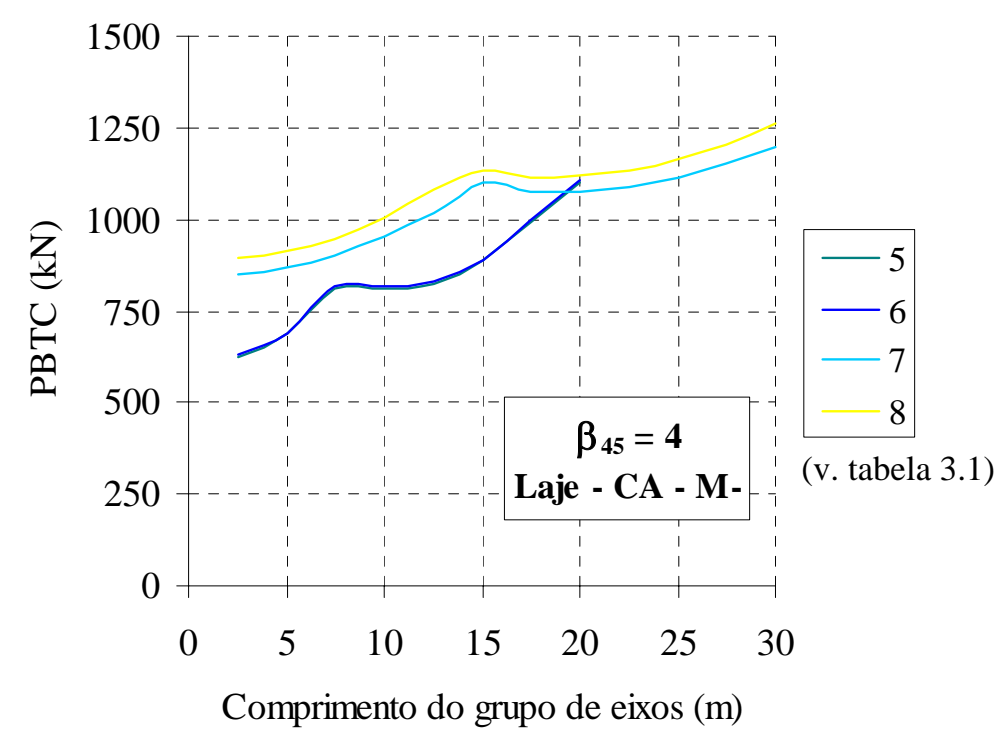

Figura 6.5 - PBTC - LAJE - Momento fletor negativo. 


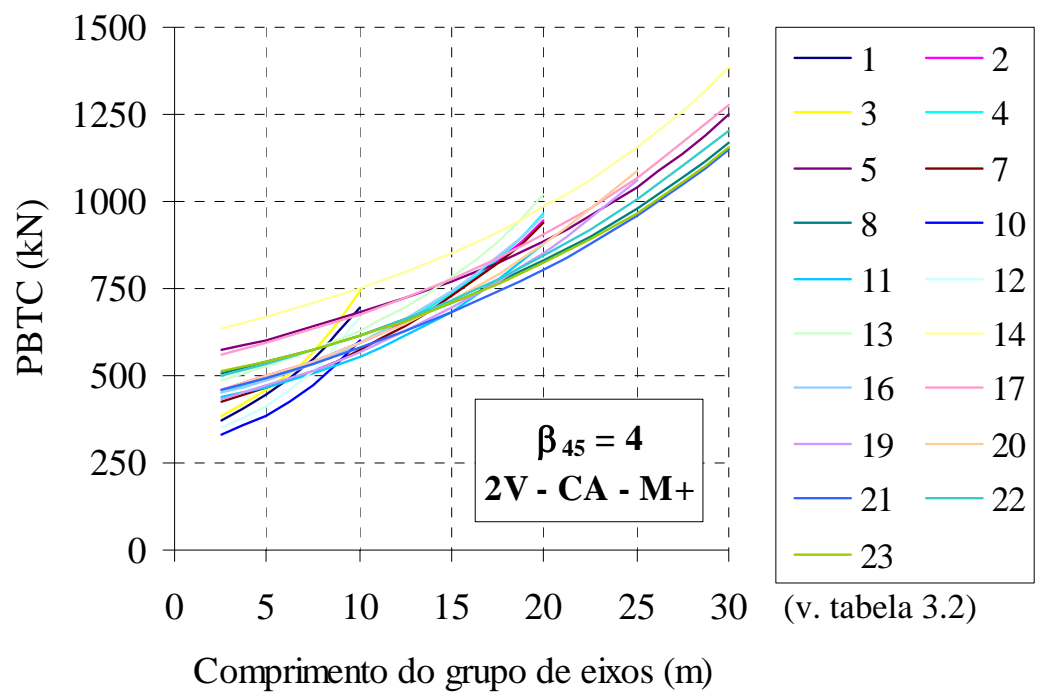

Figura 6.6 - PBTC - VIGA T - 2 VIGAS - Momento fletor positivo.

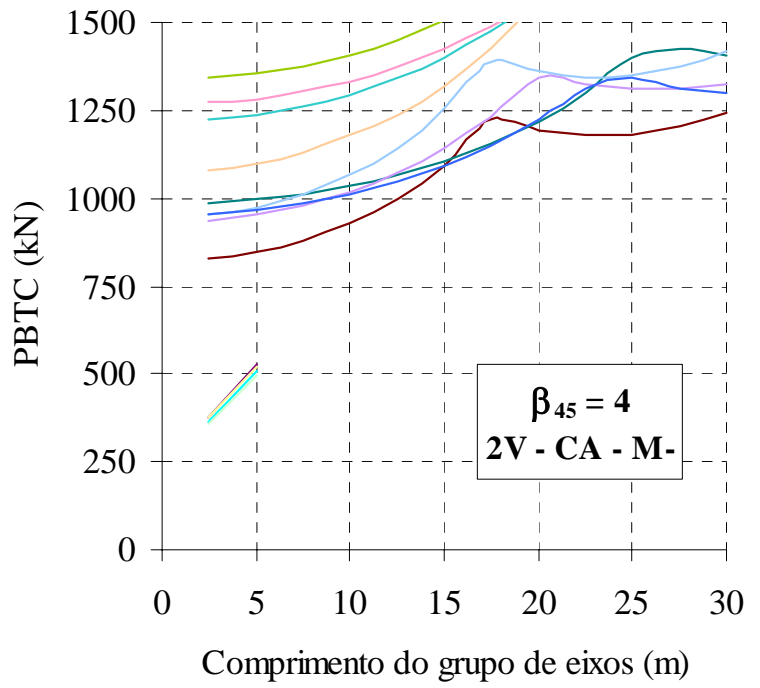

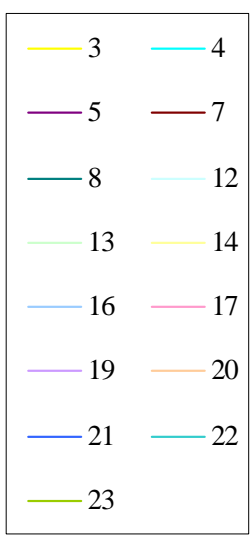

(v. tabela 3.2)

Figura 6.7 - PBTC - VIGA T - 2 VIGAS - Momento fletor negativo.

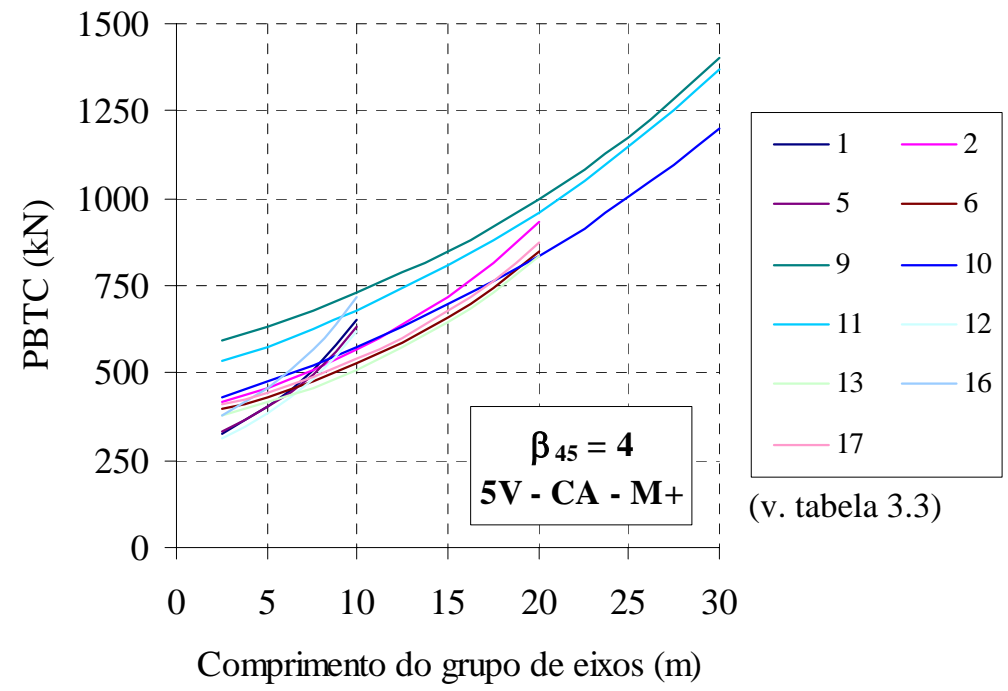

Figura 6.8 - PBTC - VIGA T - 5 VIGAS - Momento fletor positivo. 


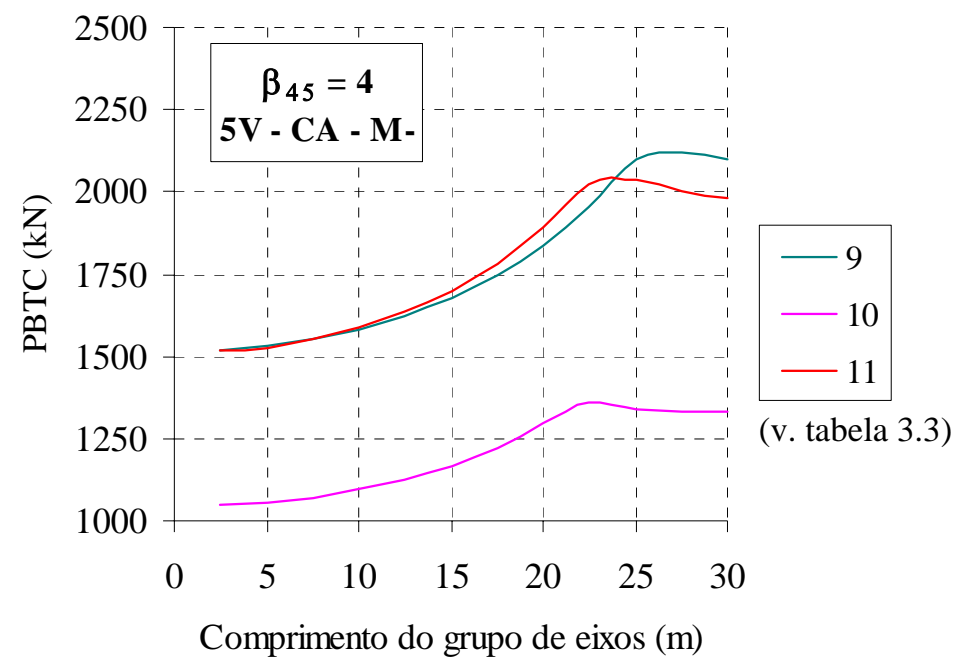

Figura 6.9 - PBTC - VIGA T - 5 VIGAS - Momento fletor negativo.

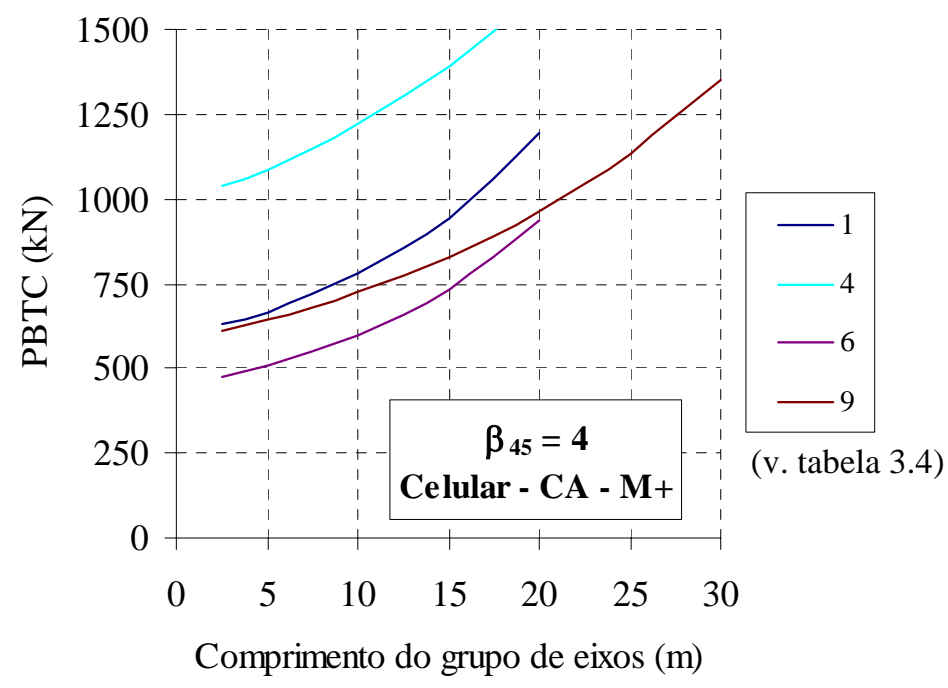

Figura 6.10 - PBTC - SEÇÃO CELULAR - Momento fletor positivo.

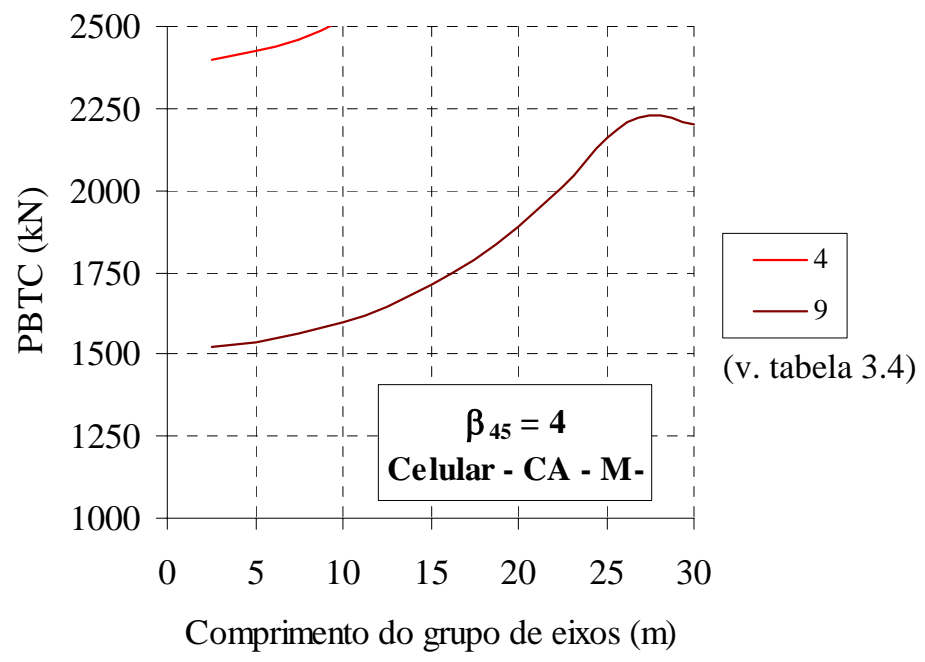

Figura 6.11 - PBTC - SEÇÃO CELULAR - Momento fletor negativo. 
Ressalta-se que, embora seja difícil a identificação individual de cada ponte, as figuras ilustram a forma das curvas $W \times B$ e indicam os limites inferiores que devem ser respeitados pelas ECPLs. O resultado detalhado pode ser visto nas tabelas do apêndice E citadas anteriormente.

As irregularidades nas figuras relativas ao momento fletor negativo se devem à alteração na posição da carga distribuída no tabuleiro em função de seu comprimento.

\subsubsection{Concreto protendido (CP), classe 45}

\subsubsection{Estado limite último, classe 45}

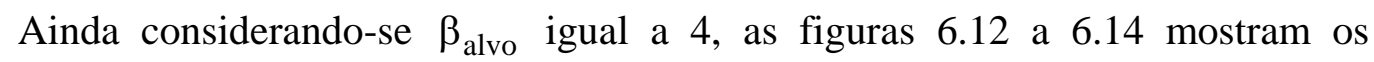
resultados obtidos para as pontes em concreto protendido considerando-se o estado limite último.

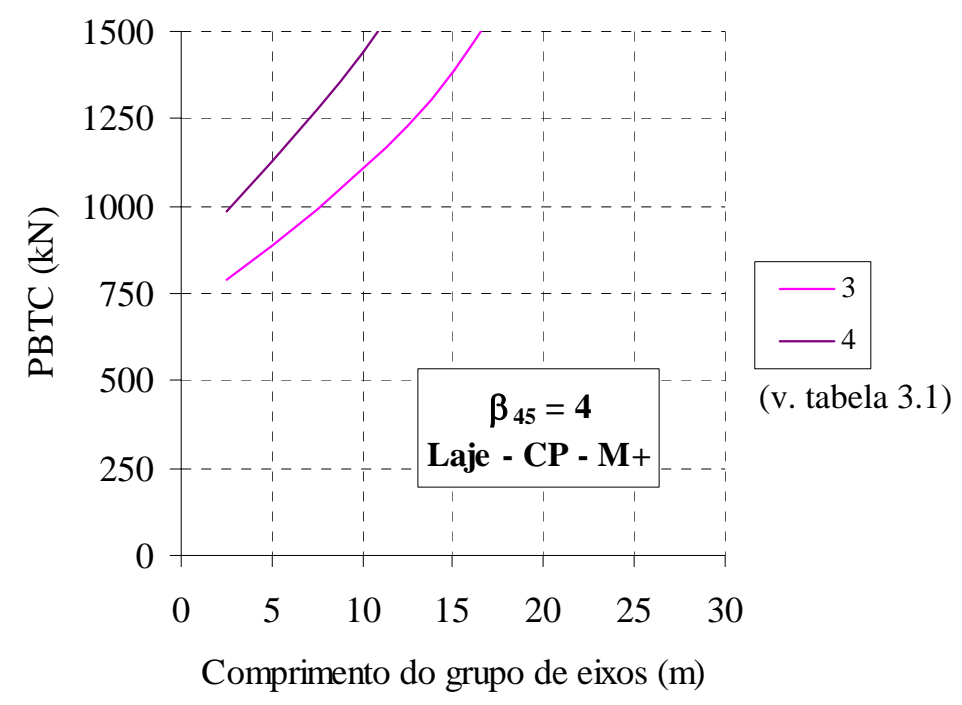

Figura 6.12 - PBTC - LAJE - ELU - Concreto protendido. 


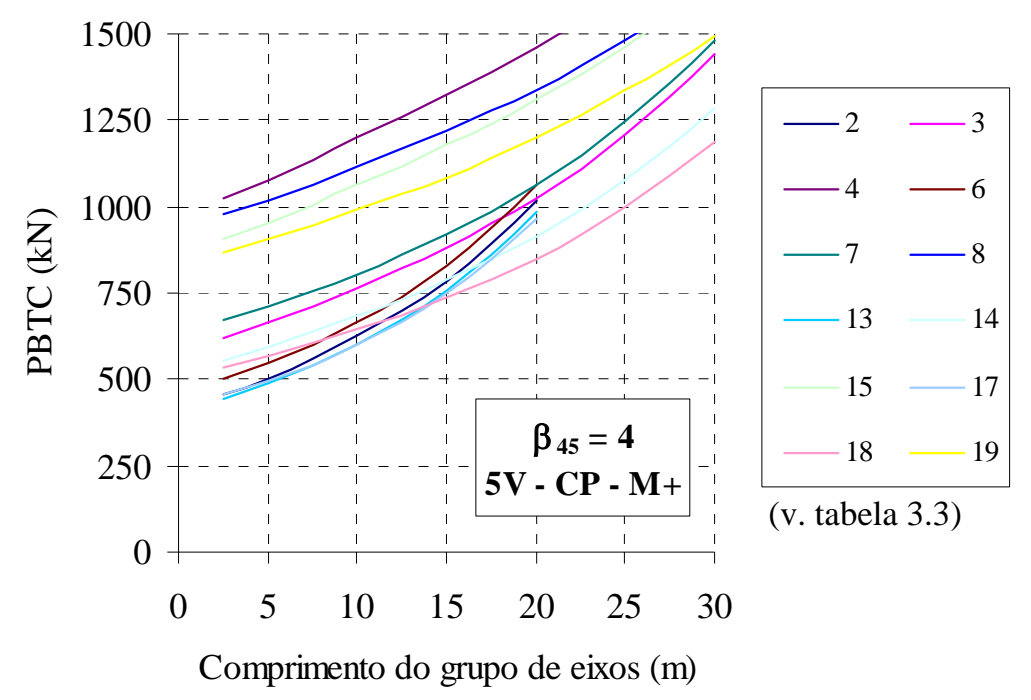

Figura 6.13 - PBTC - VIGA T - 5 VIGAS - ELU - Concreto protendido.

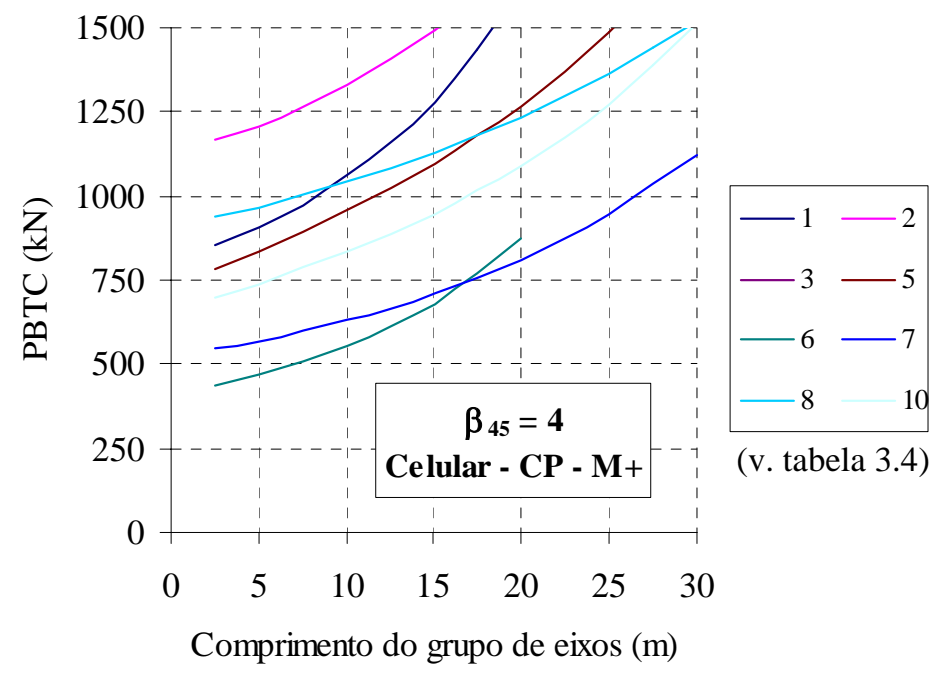

Figura 6.14 - PBTC - SEÇÃO CELULAR - ELU - Concreto protendido.

\subsubsection{Estado limite de formação de fissuras, classe 45}

Considerando-se que os índices de confiabilidade provenientes da análise do estado limite de formação de fissuras são inferiores aos obtidos para o estado limite último, admite-se nas figuras 6.15 a $6.17 \beta_{\text {alvo }}$ igual a 0,5. 


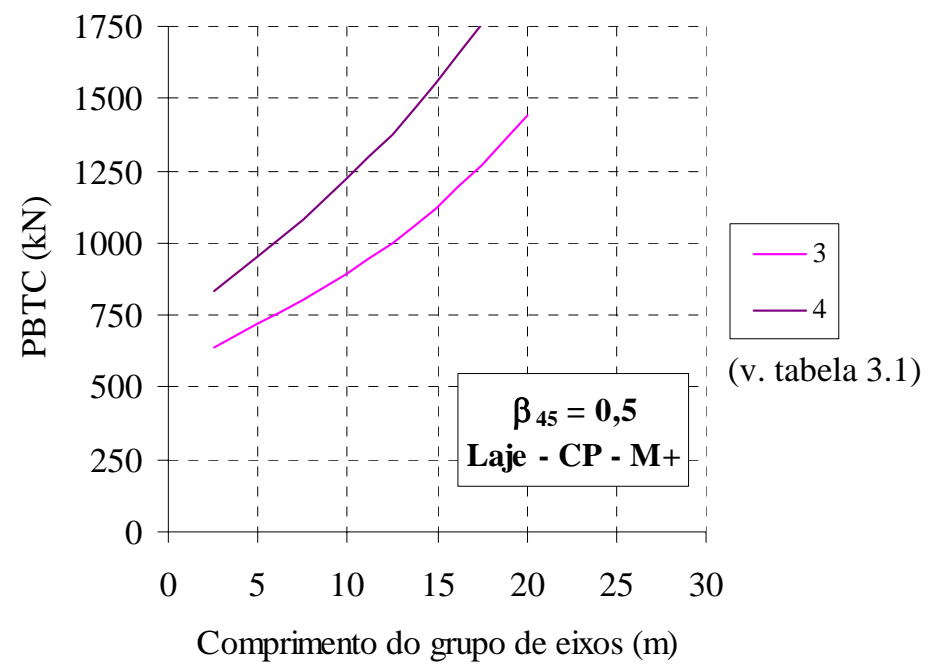

Figura 6.15 - PBTC - LAJE - ELS - Concreto protendido.

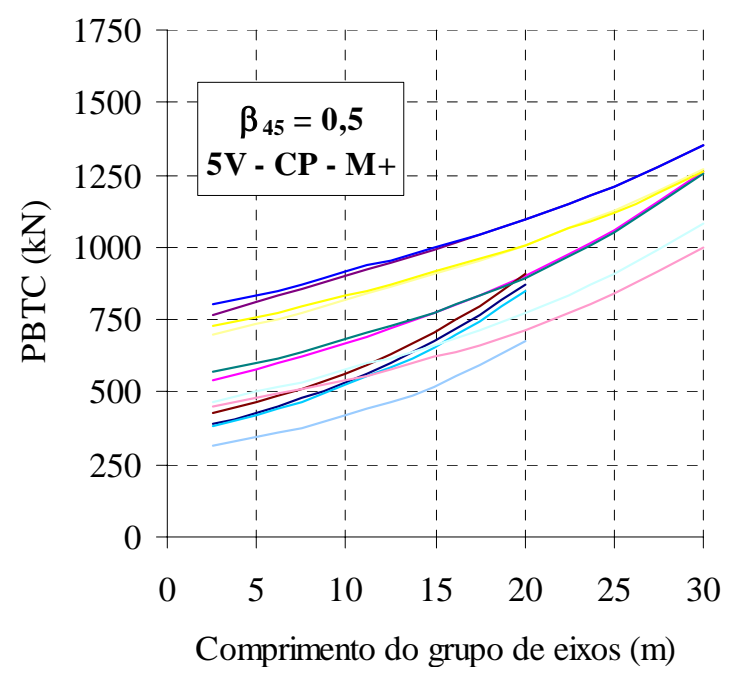

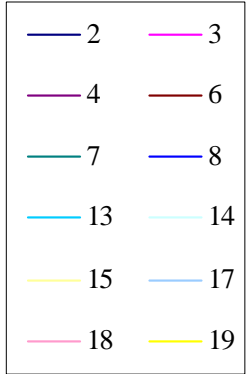

(v. tabela 3.3)

Figura 6.16 - PBTC - VIGA T - 5 VIGAS - ELS - Concreto protendido.

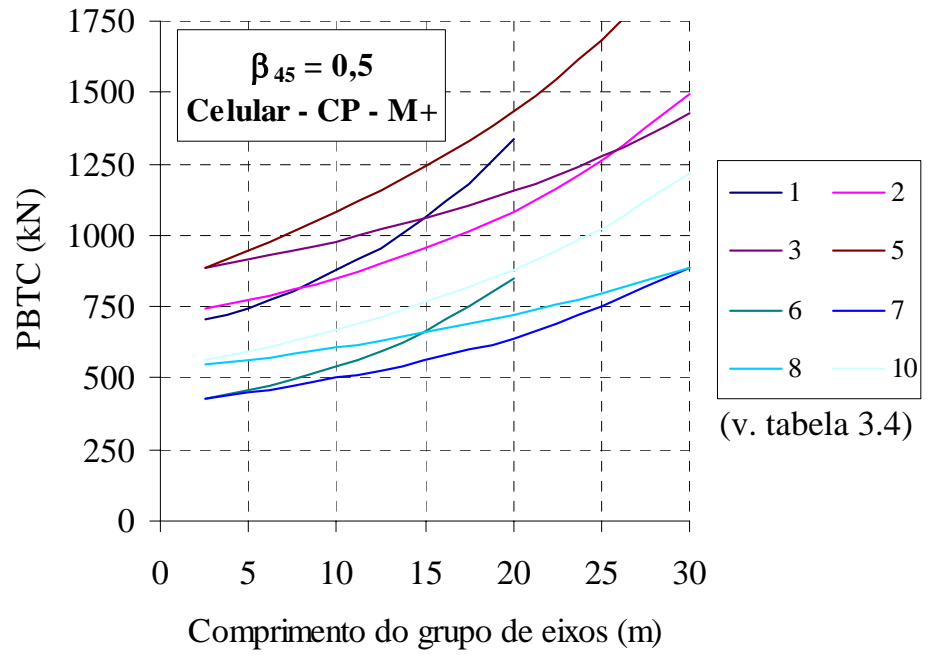

Figura 6.17 - PBTC - SEÇÃO CELULAR - ELS - Concreto protendido. 


\subsection{Carregamento distribuído $x$ veículos reais}

Antes da obtenção das ECPLs, é preciso verificar a eficiência da distribuição uniforme de carregamento em representar os veículos reais. Em outras palavras, há que se garantir que a representação adotada não está contra a segurança em termos de momento fletor. Também é preciso saber, em alguns casos, o quanto se está a favor da segurança. Com base nessa verificação, pequenos ajustes podem ser feitos nas curvas $w$ versus $B$ de modo a se obter resultados mais condizentes com a realidade.

Diante da grande quantidade de estruturas, limitou-se a análise a pontes representativas de cada sistema estrutural e com menores índices de confiabilidade, que, a princípio, devem fornecer os casos críticos para as ECPLs.

Quanto aos veículos, utilizaram-se várias configurações de eixos obtidas a partir dos caminhões 3S3, bitrem, 2S2, bitrenzão e rodotrem. Salienta-se que não foram testados grupos de eixos com comprimento maior que aquele necessário para causar o máximo esforço solicitante em cada ponte. Um resumo das configurações usadas nas verificações está na tabela 6.1. 
Tabela 6.1 - Configurações de eixos para verificação.

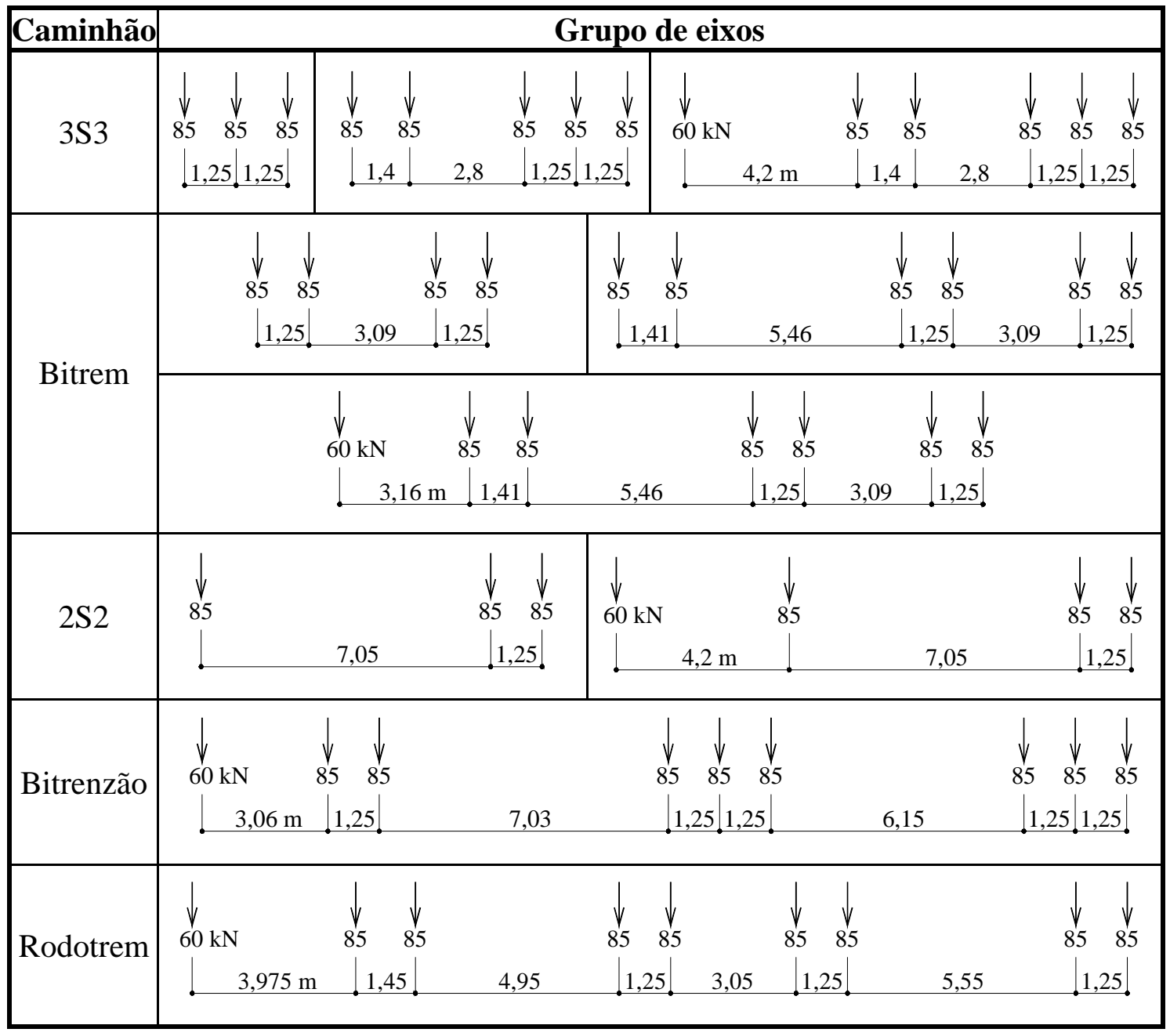

Os resultados podem ser vistos na tabela 6.2 para momento fletor positivo e na tabela 6.3 para momento fletor negativo. Quando a coluna “diferença” indica valor positivo, a representação adotada (11 eixos) está a favor da segurança. Caso contrário, o momento fletor devido ao caminhão real é maior que o efeito de 11 eixos igualmente espaçados e carregados. 
Tabela 6.2 - Comparação entre o caminhão real e a representação adotada - momento fletor positivo.

\begin{tabular}{|c|c|c|c|c|c|c|c|}
\hline \multirow{2}{*}{$\begin{array}{c}\text { Sistema } \\
\text { estrutural }\end{array}$} & \multirow[b]{2}{*}{$\mathbf{n}$} & \multirow[b]{2}{*}{ Arquivo } & \multirow[b]{2}{*}{ Caminhão } & \multirow[b]{2}{*}{ B (m) } & \multicolumn{2}{|c|}{$\overline{M+(k N . m)}$} & \multirow{2}{*}{$\begin{array}{c}\text { Diferença } \\
\text { (\%) }\end{array}$} \\
\hline & & & & & $\begin{array}{c}\text { Caminhão } \\
\text { real }\end{array}$ & 11 eixos & \\
\hline \multirow{16}{*}{ Laje } & \multirow{4}{*}{2} & \multirow{4}{*}{ SA TL V10 MC } & \multirow{2}{*}{$3 S 3$} & 2,50 & 92,1 & 99,8 & 8,3 \\
\hline & & & & 6,70 & 103,0 & 113,3 & 10,0 \\
\hline & & & Bitrem & 5,59 & 83,2 & 100,5 & 20,8 \\
\hline & & & 2S2 & 8,30 & 71,5 & 61,7 & $-13,7$ \\
\hline & \multirow{8}{*}{3} & \multirow{8}{*}{ SA TE V20 VZ } & \multirow{3}{*}{$3 \mathrm{~S} 3$} & 2,50 & 180,3 & 186,9 & 3,6 \\
\hline & & & & 6,70 & 246,8 & 256,3 & 3,9 \\
\hline & & & & 10,90 & 252,5 & 244,2 & $-3,3$ \\
\hline & & & \multirow{3}{*}{ Bitrem } & 5,59 & 198,0 & 215,3 & 8,7 \\
\hline & & & & 12,46 & 227,9 & 238,7 & 4,8 \\
\hline & & & & 15,62 & 227,9 & 231,0 & 1,3 \\
\hline & & & \multirow{2}{*}{$2 \mathrm{~S} 2$} & 8,30 & 145,1 & 152,2 & 4,9 \\
\hline & & & & 12,50 & 146,7 & 154,5 & 5,3 \\
\hline & \multirow{4}{*}{5} & \multirow{4}{*}{ C3 TE V10/10/10 MC } & \multirow{2}{*}{$3 \mathrm{~S} 3$} & 2,50 & 83,2 & 89,3 & 7,3 \\
\hline & & & & 6,70 & 91,1 & 97,6 & 7,1 \\
\hline & & & Bitrem & 5,59 & 74,5 & 87,3 & 17,2 \\
\hline & & & $2 \mathrm{~S} 2$ & 8,30 & 65,5 & 52,8 & $-19,3$ \\
\hline \multirow{32}{*}{2 vigas } & & & c? & 2,50 & 423,7 & 449,8 & 6,2 \\
\hline & 1 & 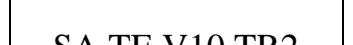 & 353 & 6,70 & 492,6 & 551,7 & 12,0 \\
\hline & 1 & SA IE VIU IRZ & Bitrem & 5,59 & 395,6 & 482,8 & 22,0 \\
\hline & & & $2 \mathrm{~S} 2$ & 8,30 & 316,1 & 302,0 & $-4,5$ \\
\hline & & & & 2,50 & 952,5 & 972,8 & 2,1 \\
\hline & & & $3 \mathrm{~S} 3$ & 6,70 & 1351,5 & 1414,1 & 4,6 \\
\hline & & & & 10,90 & 1390,7 & 1380,1 & $-0,8$ \\
\hline & 7 & אA TE V & & 5,59 & 1076,1 & 1175,0 & 9,2 \\
\hline & 2 & SA IE V $201 K 2$ & Bitrem & 12,46 & 1258,2 & 1359,2 & 8,0 \\
\hline & & & & 15,62 & 1266,7 & 1315,9 & 3,9 \\
\hline & & & ר & 8,30 & 755,2 & 848,3 & 12,3 \\
\hline & & & $2 \mathrm{~S} 2$ & 12,50 & 775,3 & 879,4 & 13,4 \\
\hline & & & & 2,50 & 907,3 & 927,5 & 2,2 \\
\hline & & & $3 \mathrm{~S} 3$ & 6,70 & 1278,1 & 1336,9 & 4,6 \\
\hline & & & & 10,90 & 1309,9 & 1298,5 & $-0,9$ \\
\hline & 1 & SAP TE V & & 5,59 & 1015,7 & 1112,1 & 9,5 \\
\hline & 4 & SAD IL $V J / \angle U / J$ IRZ & Bitrem & 12,46 & 1183,8 & 1276,9 & 7,9 \\
\hline & & & & 15,62 & 1170,0 & 1234,0 & 5,5 \\
\hline & & & 25 & 8,30 & 716,9 & 800,5 & 11,7 \\
\hline & & & 202 & 12,50 & 699,5 & 826,2 & 18,1 \\
\hline & & & & 2,50 & 796,3 & 816,6 & 2,6 \\
\hline & & & $3 \mathrm{~S} 3$ & 6,70 & 1099,7 & 1152,0 & 4,8 \\
\hline & & & & 10,90 & 1125,0 & 1098,1 & $-2,4$ \\
\hline & 7 & C3 TE V20/20/20 & & 5,59 & 873,2 & 963,9 & 10,4 \\
\hline & 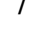 & TR3 & Bitrem & 12,46 & 1000,1 & 1073,9 & 7,4 \\
\hline & & & & 15,62 & 1006,7 & 1029,3 & 2,3 \\
\hline & & & 25 & 8,30 & 623,5 & 684,7 & 9,8 \\
\hline & & & $2 \mathrm{~S} 2$ & 12,50 & 639,3 & 694,9 & 8,7 \\
\hline & & & $353+2>>2$ & 2,50 & 479,0 & 506,6 & 5,8 \\
\hline & 10 & SA TI V10 TR1 & (5) & 6,70 & 565,0 & 630,3 & 11,6 \\
\hline & 10 & SA IL VIUIKI & Bitrem & 5,59 & 456,3 & 550,0 & 20,5 \\
\hline & & & $2 \mathrm{~S} 2$ & 8,30 & 354,5 & 346,9 & $-2,2$ \\
\hline
\end{tabular}


Tabela 6.2 (continuação) - Comparação entre o caminhão real e a representação adotada - momento fletor positivo.

\begin{tabular}{|c|c|c|c|c|c|c|c|}
\hline \multirow{2}{*}{$\begin{array}{c}\text { Sistema } \\
\text { estrutural }\end{array}$} & \multirow{2}{*}{$\mathbf{N}$} & \multirow{2}{*}{ Arquivo } & \multirow{2}{*}{ Caminhão } & \multirow{2}{*}{ B (m) } & \multicolumn{2}{|c|}{$\mathrm{M}+(\mathrm{kN} . \mathrm{m})$} & \multirow{2}{*}{$\begin{array}{c}\text { Diferença } \\
\text { (\%) }\end{array}$} \\
\hline & & & & & $\begin{array}{c}\text { Caminhão } \\
\text { real }\end{array}$ & 11 eixos & \\
\hline \multirow{22}{*}{2 vigas } & \multirow{8}{*}{11} & \multirow{8}{*}{ SA TL V20 TR2 } & \multirow{3}{*}{$3 \mathrm{~S} 3$} & 2,50 & 1099,2 & 1120,3 & 1,9 \\
\hline & & & & 6,70 & 1574,9 & 1645,4 & 4,5 \\
\hline & & & & 10,90 & 1624,7 & 1613,8 & $-0,7$ \\
\hline & & & \multirow{3}{*}{ Bitrem } & 5,59 & 1258,8 & 1364,4 & 8,4 \\
\hline & & & & 12,46 & 1469,9 & 1591,2 & 8,2 \\
\hline & & & & 15,62 & 1479,8 & 1544,3 & 4,4 \\
\hline & & & \multirow{2}{*}{$2 \mathrm{~S} 2$} & 8,30 & 875,3 & 989,2 & 13,0 \\
\hline & & & & 12,50 & 898,7 & 1029,5 & 14,6 \\
\hline & \multirow{4}{*}{12} & \multirow{4}{*}{$\begin{array}{c}\text { SAB TL V3/10/3 } \\
\text { TR1 }\end{array}$} & \multirow{2}{*}{$3 \mathrm{~S} 3$} & 2,50 & 410,6 & 429,7 & 4,6 \\
\hline & & & & 6,70 & 464,5 & 520,0 & 11,9 \\
\hline & & & Bitrem & 5,59 & 367,4 & 455,9 & 24,1 \\
\hline & & & $2 \mathrm{~S} 2$ & 8,30 & 299,9 & 284,5 & $-5,1$ \\
\hline & \multirow{10}{*}{19} & \multirow{10}{*}{$\begin{array}{c}\text { C3B TE } \\
\text { V5-20/25/20-5 } \\
\text { TR3 }\end{array}$} & \multirow{3}{*}{$3 \mathrm{~S} 3$} & 2,50 & 832,3 & 854,7 & 2,7 \\
\hline & & & & 6,70 & 1179,7 & 1233,6 & 4,6 \\
\hline & & & & 10,90 & 1234,0 & 1193,1 & $-3,3$ \\
\hline & & & \multirow{3}{*}{ Bitrem } & 5,59 & 944,6 & 1025,2 & 8,5 \\
\hline & & & & 12,46 & 1114,7 & 1172,9 & 5,2 \\
\hline & & & & 15,62 & 1132,3 & 1156,2 & 2,1 \\
\hline & & & \multirow{2}{*}{$2 \mathrm{~S} 2$} & 8,30 & 682,6 & 730,7 & 7,0 \\
\hline & & & & 12,50 & 691,1 & 758,9 & 9,8 \\
\hline & & & Bitrenzão & 22,49 & 1147,3 & 1124,7 & $-2,0$ \\
\hline & & & Rodotrem & 22,73 & 1204,3 & 1124,0 & $-6,7$ \\
\hline & & & 353 & 2,50 & 191,6 & 203,4 & 6,1 \\
\hline & 1 & SA TF V10 TR? & DSS & 6,70 & 211,7 & 235,5 & 11,2 \\
\hline & 1 & SA IL VIU INL & Bitrem & 5,59 & 166,1 & 207,9 & 25,2 \\
\hline & & & 2S2 & 8,30 & 144,1 & 128,3 & $-11,0$ \\
\hline & & & & 2,50 & 726,8 & 737,8 & 1,5 \\
\hline & & & $3 S 3$ & 6,70 & 1083,5 & 1118,3 & 3,2 \\
\hline & & & & 10,90 & 1157,4 & 1148,7 & $-0,7$ \\
\hline & & & & 5,59 & 865,3 & 918,4 & 6,1 \\
\hline & 7 & SA TI V30 TR2 & Bitrem & 12,46 & 1106,9 & 1158,8 & 4,7 \\
\hline & & Sก 1 & & 15,62 & 1152,5 & 1188,6 & 3,1 \\
\hline & & & 252 & 8,30 & 634,4 & 682,9 & 7,6 \\
\hline 5 vigas & & & 202 & 12,50 & 682,1 & 749,8 & 9,9 \\
\hline & & & Bitrenzão & 22,49 & 1247,8 & 1260,5 & 1,0 \\
\hline & & & Rodotrem & 22,73 & 1299,3 & 1256,7 & $-3,3$ \\
\hline & & & & 2,50 & 956,6 & 967,4 & 1,1 \\
\hline & & & $3 S 3$ & 6,70 & 1469,3 & 1501,5 & 2,2 \\
\hline & & & & 10,90 & 1599,2 & 1591,8 & $-0,5$ \\
\hline & & & & 5,59 & 1171,6 & 1224,5 & 4,5 \\
\hline & 8 & SA TL V40 TR4 & Bitrem & 12,46 & 1578,0 & 1626,8 & 3,1 \\
\hline & & G & & 15,62 & 1682,8 & 1716,4 & 2,0 \\
\hline & & & $2 \mathrm{~S} 2+2$ & 8,30 & 883,3 & 927,5 & 5,0 \\
\hline & & & 202 & 12,50 & 988,3 & 1052,6 & 6,5 \\
\hline & & & Bitrenzão & 22,49 & 1944,9 & 1957,1 & 0,6 \\
\hline & & & Rodotrem & 22,73 & 1993,5 & 1952,9 & $-2,0$ \\
\hline
\end{tabular}


Tabela 6.2 (continuação) - Comparação entre o caminhão real e a representação adotada - momento fletor positivo.

\begin{tabular}{|c|c|c|c|c|c|c|c|}
\hline \multirow{2}{*}{$\begin{array}{c}\text { Sistema } \\
\text { estrutural }\end{array}$} & \multirow[b]{2}{*}{$\mathbf{n}$} & \multirow[b]{2}{*}{ Arquivo } & \multirow{2}{*}{ Caminhão } & \multirow[b]{2}{*}{ B (m) } & \multicolumn{2}{|c|}{$\mathrm{M}+(\mathrm{kN} . \mathrm{m})$} & \multirow{2}{*}{$\begin{array}{c}\text { Diferença } \\
\text { (\%) }\end{array}$} \\
\hline & & & & & $\begin{array}{c}\text { Caminhão } \\
\text { real }\end{array}$ & 11 eixos & \\
\hline \multirow{22}{*}{5 vigas } & \multirow{10}{*}{10} & \multirow{10}{*}{$\begin{array}{c}\text { C3B TE } \\
\text { V5-25/30/25-5 } \\
\text { TR2 }\end{array}$} & \multirow{3}{*}{$3 \mathrm{~S} 3$} & 2,50 & 463,1 & 479,2 & 3,5 \\
\hline & & & & 6,70 & 652,6 & 680,5 & 4,3 \\
\hline & & & & 10,90 & 681,5 & 662,0 & $-2,9$ \\
\hline & & & \multirow{3}{*}{ Bitrem } & 5,59 & 521,2 & 567,5 & 8,9 \\
\hline & & & & 12,46 & 626,3 & 653,7 & 4,4 \\
\hline & & & & 15,62 & 640,5 & 650,5 & 1,6 \\
\hline & & & \multirow{2}{*}{$2 \mathrm{~S} 2$} & 8,30 & 384,2 & 406,9 & 5,9 \\
\hline & & & & 12,50 & 396,3 & 423,0 & 6,7 \\
\hline & & & Bitrenzão & 22,49 & 675,4 & 656,3 & $-2,8$ \\
\hline & & & Rodotrem & 22,73 & 699,9 & 655,9 & $-6,3$ \\
\hline & \multirow{4}{*}{12} & \multirow{4}{*}{ SA TE V10 STR } & \multirow{2}{*}{$3 \mathrm{~S} 3$} & 2,50 & 211,3 & 223,4 & 5,7 \\
\hline & & & & 6,70 & 234,5 & 261,6 & 11,5 \\
\hline & & & Bitrem & 5,59 & 183,6 & 230,6 & 25,6 \\
\hline & & & $2 \mathrm{~S} 2$ & 8,30 & 157,6 & 142,5 & $-9,5$ \\
\hline & \multirow{8}{*}{13} & \multirow{8}{*}{ SA TE V20 STR } & \multirow{3}{*}{$3 \mathrm{~S} 3$} & 2,50 & 464,3 & 477,5 & 2,8 \\
\hline & & & & 6,70 & 639,7 & 671,6 & 5,0 \\
\hline & & & & 10,90 & 654,3 & 641,5 & $-1,9$ \\
\hline & & & \multirow{3}{*}{ Bitrem } & 5,59 & 506,5 & 561,9 & 10,9 \\
\hline & & & & 12,46 & 586,8 & 628,1 & 7,0 \\
\hline & & & & 15,62 & 590,4 & 603,8 & 2,3 \\
\hline & & & \multirow{2}{*}{$2 \mathrm{~S} 2$} & 8,30 & 363,6 & 399,3 & 9,8 \\
\hline & & & & 12,50 & 372,3 & 406,4 & 9,2 \\
\hline \multirow{18}{*}{ Celular } & \multirow{8}{*}{6} & \multirow{8}{*}{ SA TE V20 STR } & & 2,50 & 1141,0 & 1161,6 & 1,8 \\
\hline & & & $3 \mathrm{~S} 3$ & 6,70 & 1640,5 & 1711,4 & 4,3 \\
\hline & & & & 10,90 & 1703,4 & 1689,5 & $-0,8$ \\
\hline & & & & 5,59 & 1322,0 & 1417,2 & 7,2 \\
\hline & & & Bitrem & 12,46 & 1533,3 & 1669,7 & 8,9 \\
\hline & & & & 15,62 & 1543,9 & 1624,8 & 5,2 \\
\hline & & & 2S? & 8,30 & 911,1 & 1030,5 & 13,1 \\
\hline & & & $\angle \mathrm{S}$ & 12,50 & 935,1 & 1080,3 & 15,5 \\
\hline & & & & 2,50 & 1395,8 & 1415,6 & 1,4 \\
\hline & & & $3 \mathrm{~S} 3$ & 6,70 & 2089,4 & 2146,0 & 2,7 \\
\hline & & & & 10,90 & 2232,3 & 2205,7 & $-1,2$ \\
\hline & & & & 5,59 & 1669,8 & 1762,5 & 5,6 \\
\hline & & C3 TE V30/30/30 & Bitrem & 12,46 & 2124,9 & 2224,9 & 4,7 \\
\hline & 9 & STR & & 15,62 & 2211,8 & 2278,5 & 3,0 \\
\hline & & & & 8,30 & 1227,6 & 1310,8 & 6,8 \\
\hline & & & 2S2 & 12,50 & 1320,4 & 1439,6 & 9,0 \\
\hline & & & Bitrenzão & 22,49 & 2349,3 & 2394,8 & 1,9 \\
\hline & & & Rodotrem & 22,73 & 2466,3 & 2387,1 & $-3,2$ \\
\hline
\end{tabular}


Tabela 6.3 - Comparação entre o caminhão real e a representação adotada - momento fletor negativo.

\begin{tabular}{|c|c|c|c|c|c|c|c|}
\hline \multirow{2}{*}{$\begin{array}{c}\text { Sistema } \\
\text { estrutural }\end{array}$} & \multirow{2}{*}{$\mathbf{n}$} & \multirow{2}{*}{ Arquivo } & \multirow{2}{*}{ Caminhão } & \multirow{2}{*}{ B (m) } & \multicolumn{2}{|c|}{ M- (kN.m) } & \multirow{2}{*}{$\begin{array}{l}\text { Diferença } \\
\text { (\%) }\end{array}$} \\
\hline & & & & & $\begin{array}{c}\text { Caminhão } \\
\text { real }\end{array}$ & 11 eixos & \\
\hline \multirow{8}{*}{ Laje } & \multirow{8}{*}{5} & \multirow{8}{*}{ C3 TE V10/10/10 MC } & \multirow{3}{*}{$3 \mathrm{~S} 3$} & 2,50 & 60,6 & 62,2 & 2,7 \\
\hline & & & & 6,70 & 87,5 & 85,4 & $-2,3$ \\
\hline & & & & 10,90 & 95,1 & 91,9 & $-3,4$ \\
\hline & & & \multirow{3}{*}{ Bitrem } & 5,59 & 68,9 & 73,2 & 6,3 \\
\hline & & & & 12,46 & 101,6 & 94,0 & $-7,5$ \\
\hline & & & & 15,62 & 106,5 & 96,4 & $-9,4$ \\
\hline & & & \multirow{2}{*}{$2 \mathrm{~S} 2$} & 8,30 & 63,4 & 49,7 & $-21,6$ \\
\hline & & & & 12,50 & 68,4 & 60,8 & $-11,1$ \\
\hline \multirow{22}{*}{2 vigas } & 4 & $\begin{array}{c}\text { SAB TE V5/20/5 } \\
\text { TR2 }\end{array}$ & $3 \mathrm{~S} 3$ & 2,50 & 740,1 & 740,3 & 0,0 \\
\hline & \multirow{10}{*}{7} & \multirow{10}{*}{$\begin{array}{c}\text { C3 TE V20/20/20 } \\
\text { TR3 }\end{array}$} & \multirow{3}{*}{$3 S 3$} & 2,50 & 440,3 & 442,3 & 0,4 \\
\hline & & & & 6,70 & 691,8 & 704,7 & 1,9 \\
\hline & & & & 10,90 & 741,5 & 735,6 & $-0,8$ \\
\hline & & & \multirow{3}{*}{ Bitrem } & 5,59 & 557,9 & 572,7 & 2,7 \\
\hline & & & & 12,46 & 692,7 & 738,3 & 6,6 \\
\hline & & & & 15,62 & 743,2 & 732,1 & $-1,5$ \\
\hline & & & \multirow{2}{*}{$2 \mathrm{~S} 2$} & 8,30 & 400,4 & 435,0 & 8,7 \\
\hline & & & & 12,50 & 437,9 & 477,7 & 9,1 \\
\hline & & & Bitrenzão & 22,49 & 979,8 & 904,7 & $-7,7$ \\
\hline & & & Rodotrem & 22,73 & 920,6 & 901,9 & $-2,0$ \\
\hline & 12 & $\begin{array}{c}\text { SAB TL V3/10/3 } \\
\text { TR1 }\end{array}$ & $3 \mathrm{~S} 3$ & 2,50 & 333,9 & 362,3 & 8,5 \\
\hline & \multirow{10}{*}{19} & \multirow{10}{*}{$\begin{array}{c}\text { C3B TE } \\
\text { V5-20/25/20-5 } \\
\text { TR3 }\end{array}$} & \multirow{3}{*}{$3 \mathrm{~S} 3$} & 2,50 & 480,5 & 482,0 & 0,3 \\
\hline & & & & 6,70 & 767,5 & 776,9 & 1,2 \\
\hline & & & & 10,90 & 839,9 & 829,8 & $-1,2$ \\
\hline & & & \multirow{3}{*}{ Bitrem } & 5,59 & 618,6 & 629,4 & 1,7 \\
\hline & & & & 12,46 & 811,2 & 844,4 & 4,1 \\
\hline & & & & 15,62 & 852,3 & 869,2 & 2,0 \\
\hline & & & \multirow{2}{*}{ 2S2 } & 8,30 & 460,2 & 483,0 & 4,9 \\
\hline & & & & 12,50 & 516,0 & 546,3 & 5,9 \\
\hline & & & Bitrenzão & 22,49 & 1106,6 & 990,9 & $-10,5$ \\
\hline & & & Rodotrem & 22,73 & 1040,9 & 990,3 & $-4,9$ \\
\hline & & & & 2,50 & 229,9 & 230,8 & 0,4 \\
\hline & & & $3 S 3$ & 6,70 & 375,9 & 377,5 & 0,4 \\
\hline & & & & 10,90 & 419,7 & 416,1 & $-0,9$ \\
\hline & & & & 5,59 & 301,7 & 303,9 & 0,7 \\
\hline 5 vigas & 10 & V5-25/30/25-5 & Bitrem & 12,46 & 420,8 & 428,8 & 1,9 \\
\hline & & 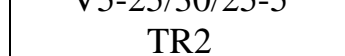 & & 15,62 & 454,5 & 457,9 & 0,7 \\
\hline & & & 25 & 8,30 & 232,8 & 237,3 & 1,9 \\
\hline & & & $2 S 2$ & 12,50 & 271,6 & 277,4 & 2,1 \\
\hline & & & Bitrenzão & 22,49 & 574,1 & 514,9 & $-10,3$ \\
\hline & & & Rodotrem & 22,73 & 548,1 & 514,5 & $-6,1$ \\
\hline
\end{tabular}


Tabela 6.3 (continuação) - Comparação entre o caminhão real e a representação adotada - momento fletor negativo.

\begin{tabular}{|c|c|c|c|c|c|c|c|}
\hline \multirow{2}{*}{$\begin{array}{c}\text { Sistema } \\
\text { estrutural }\end{array}$} & \multirow[b]{2}{*}{$\mathbf{n}$} & \multirow[b]{2}{*}{ Arquivo } & \multirow[b]{2}{*}{ Caminhão } & \multirow[b]{2}{*}{ B (m) } & \multicolumn{2}{|c|}{ M- (kN.m) } & \multirow{2}{*}{$\begin{array}{c}\text { Diferença } \\
(\%)\end{array}$} \\
\hline & & & & & $\begin{array}{c}\text { Caminhão } \\
\text { real }\end{array}$ & 11 eixos & \\
\hline \multirow{10}{*}{ Celular } & \multirow{10}{*}{9} & \multirow{10}{*}{$\begin{array}{c}\text { C3 TE V30/30/30 } \\
\text { STR }\end{array}$} & \multirow{3}{*}{$3 S 3$} & 2,50 & 776,0 & 777,4 & 0,2 \\
\hline & & & & 6,70 & 1259,4 & 1270,1 & 0,8 \\
\hline & & & & 10,90 & 1396,7 & 1394,3 & $-0,2$ \\
\hline & & & \multirow{3}{*}{ Bitrem } & 5,59 & 1011,4 & 1023,3 & 1,2 \\
\hline & & & & 12,46 & 1397,0 & 1437,3 & 2,9 \\
\hline & & & & 15,62 & 1502,2 & 1529,7 & 1,8 \\
\hline & & & \multirow{2}{*}{$2 \mathrm{~S} 2$} & 8,30 & 767,3 & 796,8 & 3,8 \\
\hline & & & & 12,50 & 894,7 & 929,9 & 3,9 \\
\hline & & & Bitrenzão & 22,49 & 1663,0 & 1709,7 & 2,8 \\
\hline & & & Rodotrem & 22,73 & 1715,2 & 1704,6 & $-0,6$ \\
\hline
\end{tabular}

A análise das tabelas indica que, na maior parte das vezes, a representação adotada está a favor da segurança, especialmente nas pontes simplesmente apoiadas sem balanços. Nota-se, por sua vez, que as maiores diferenças contra a segurança ocorrem em pontes de pequenos vão entre apoios. A medida que esses vãos aumentam de comprimento, a diferença negativa tende a diminuir em módulo. Destaca-se também que a relação entre o vão da ponte e o comprimento do grupo de eixos considerado influi na verificação: quando essa relação tende a 1 , maior a ocorrência de desvios contra a segurança.

Alerta-se ainda que, muitas vezes, o comprimento do grupo de eixos e a ponte considerada, apesar de estarem contra a segurança, não correspondem ao caso crítico para a obtenção das ECPLs. Ou seja, para aquele comprimento de grupo de eixos, os limites inferiores são impostos por outra estrutura. A análise da tabela 6.2 também demonstra que apenas as pontes em concreto armado necessitam de alguma correção.

Finalmente, destaca-se que a localização sobre a ponte de um caminhão real ou de eixos igualmente espaçados e carregados, para a obtenção de momentos fletores máximos, pode ser diferente.

\subsection{Resumo das curvas $W \times B$}

A seguir, são apresentados os limites inferiores das curvas $W$ versus $B$ após as devidas correções, que servirão de base para a obtenção das ECPLs. Destaca-se que apenas foram ajustados os casos em que a diferença é igual ou superior a 5\%, contra a 
segurança, através da redução dos pesos admissíveis de acordo com a diferença entre o momento fletor devido ao caminhão real e àquele proveniente da representação adotada. Nas situações a favor da segurança, não houve correção nos valores obtidos inicialmente.

Nas pontes em 5 vigas, diferenciam-se as pontes com transversinas e sem transversinas.

\subsubsection{Concreto armado}

Um resumo dos casos analisados para concreto armado está nas figuras 6.18 a 6.22. Contemplam-se as classes 36 e 45, e $\beta_{\text {alvo }}$ igual a 3, 3,5 e 4. As linhas cheias correspondem ao momento fletor positivo e as linhas tracejadas referem-se ao momento fletor negativo.
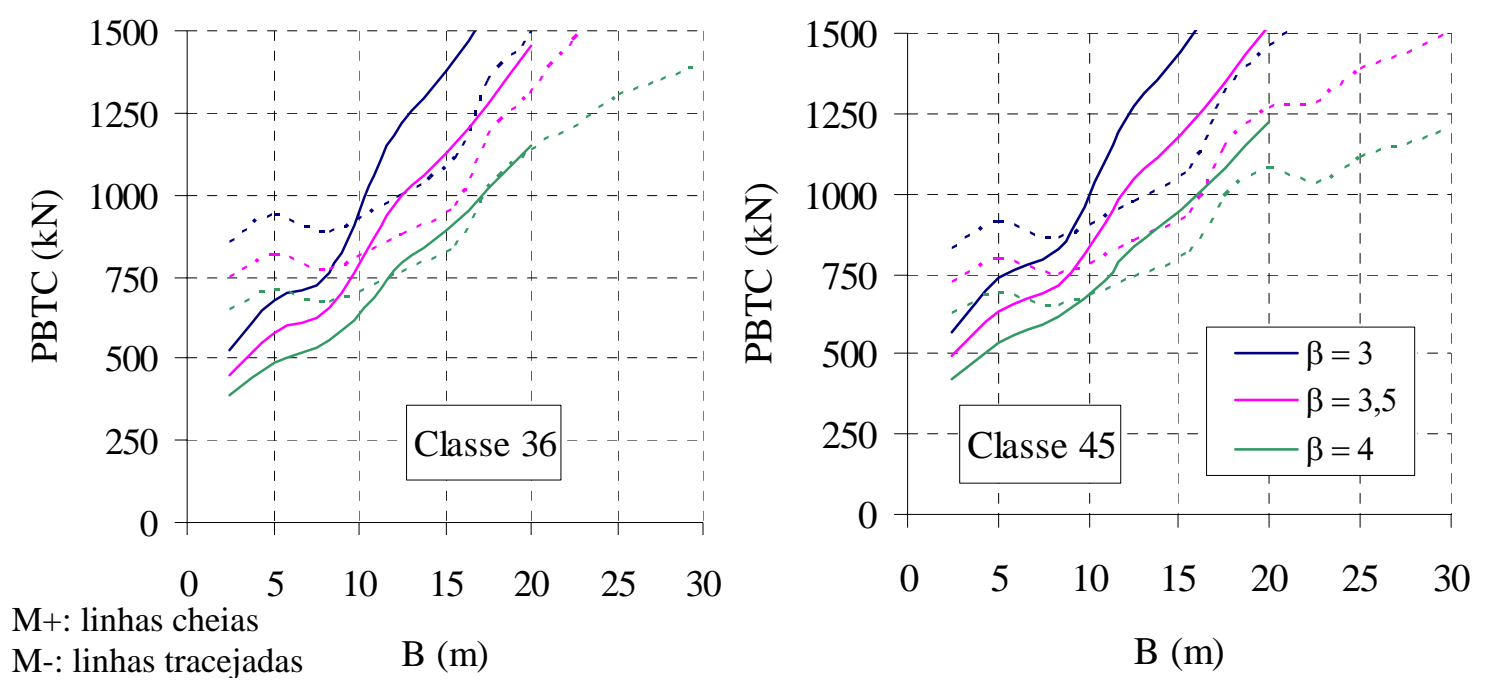

Figura 6.18 - Limites inferiores das curvas W x B - LAJE. 

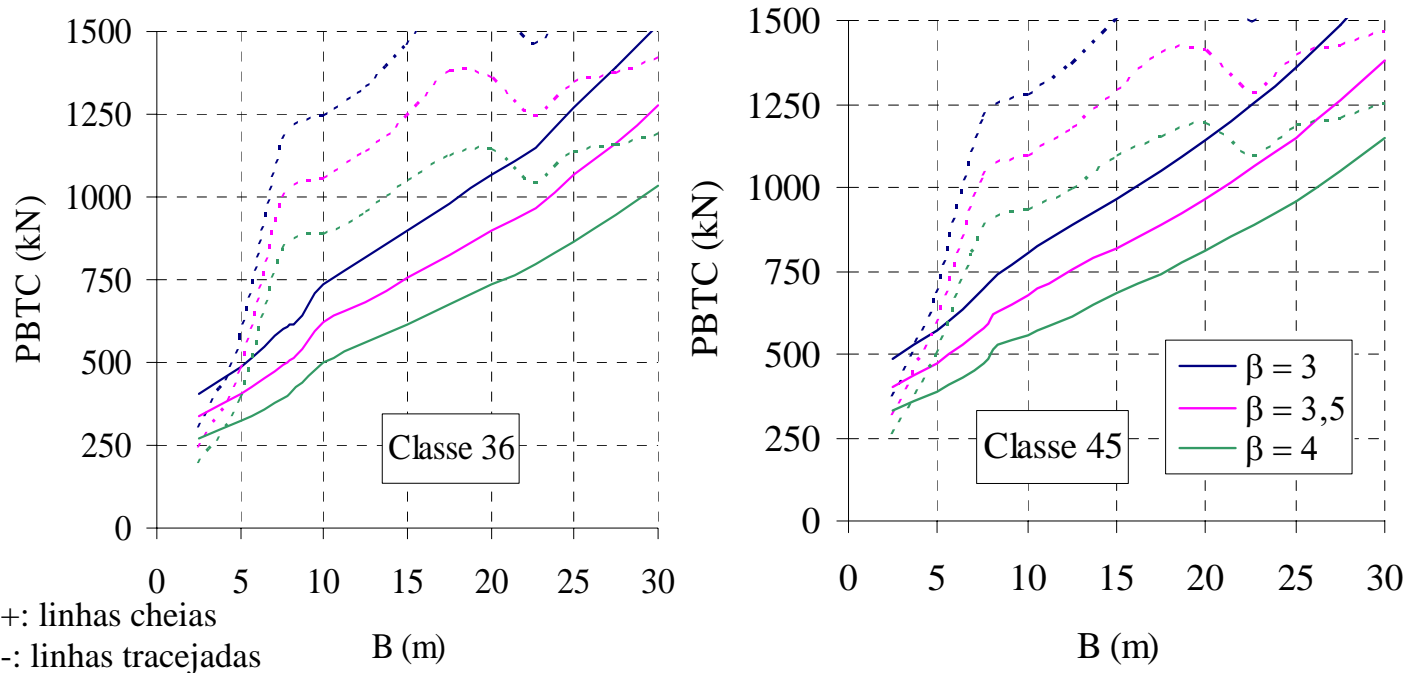

Figura 6.19 - Limites inferiores das curvas W x B - VIGA T - 2 VIGAS.
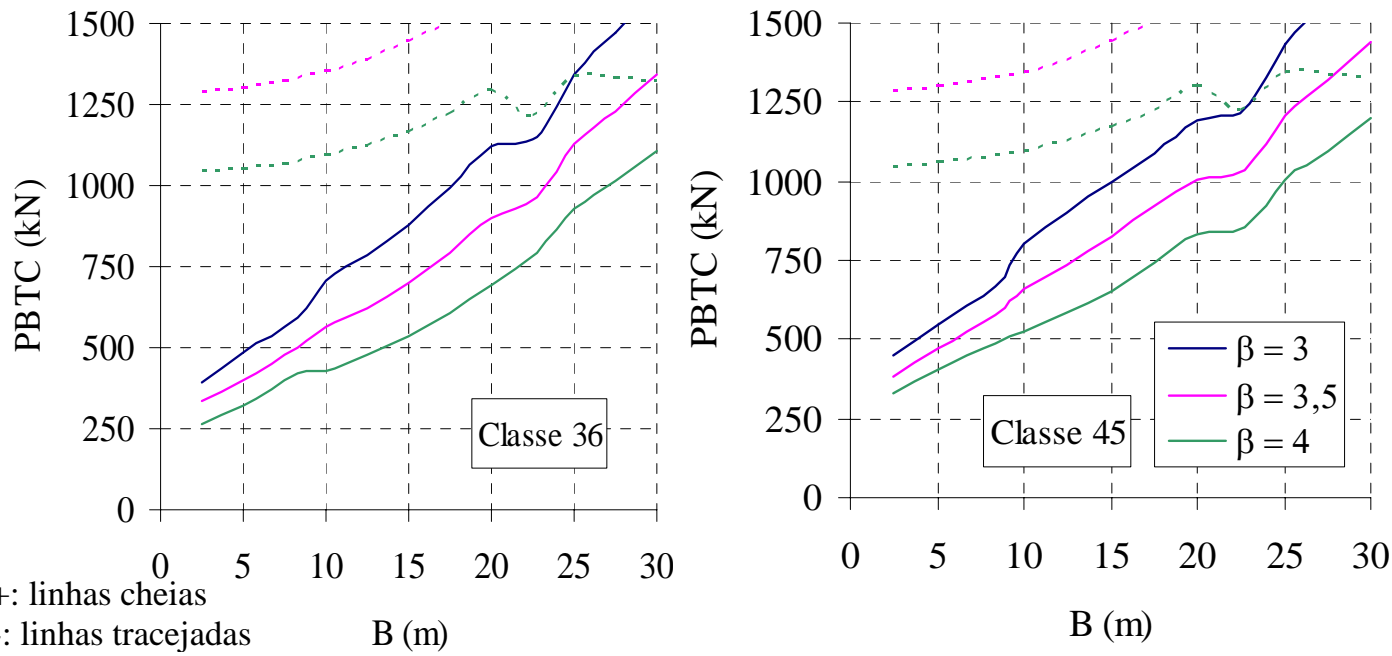

Figura 6.20 - Limites inferiores das curvas W x B - VIGA T - 5 VIGAS

(com transversinas).
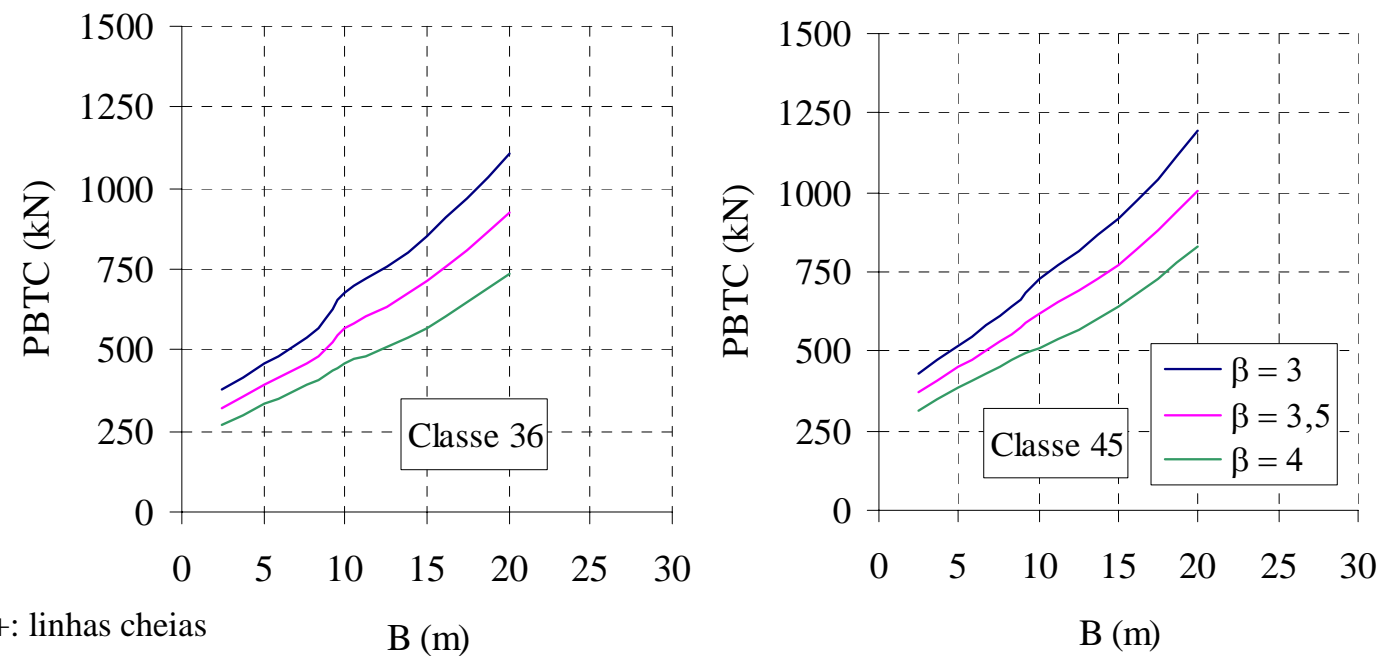

Figura 6.21 - Limites inferiores das curvas W x B - VIGA T - 5 VIGAS (sem transversinas). 

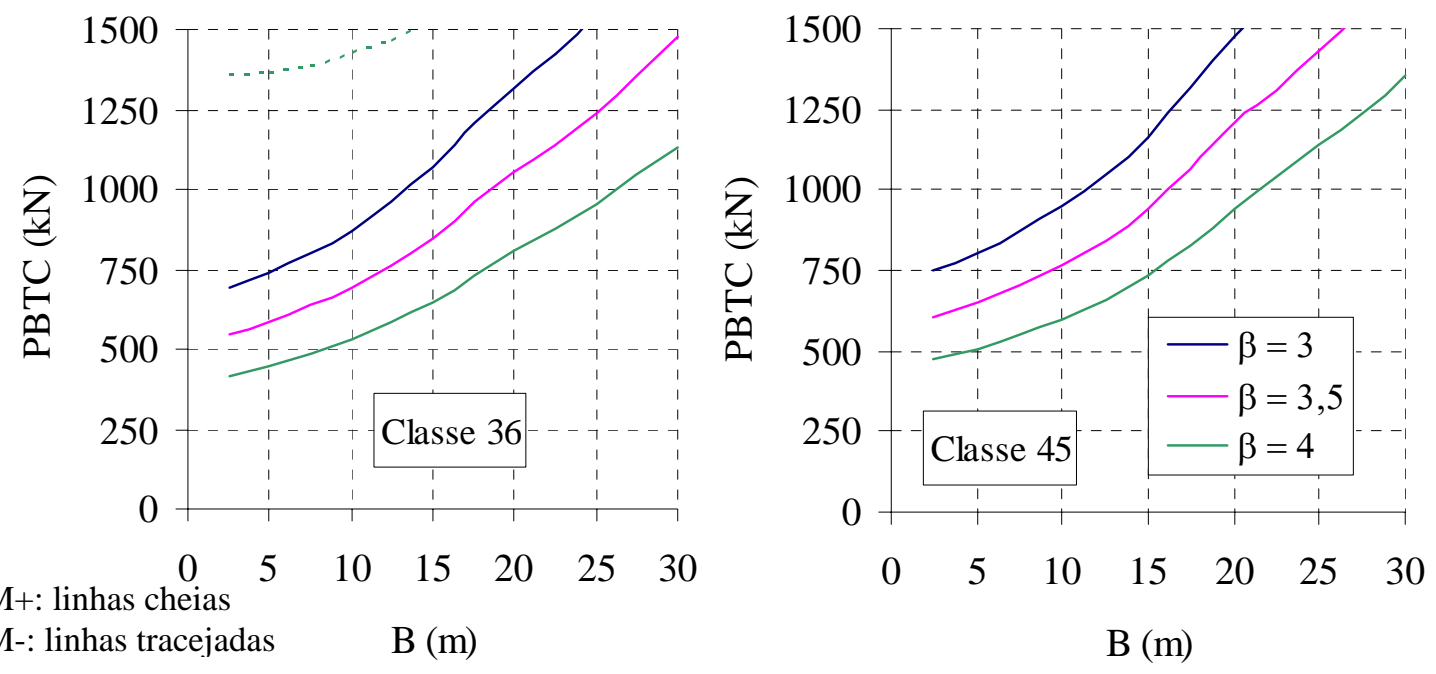

Figura 6.22 - Limites inferiores das curvas W x B - VIGA T - SEÇÃO CELULAR.

\subsubsection{Concreto protendido}

\subsubsection{Estado limite último}

As figuras 6.23 a 6.26 mostram os limites inferiores para o estado limite último das pontes em concreto protendido, referentes ao momento fletor positivo.
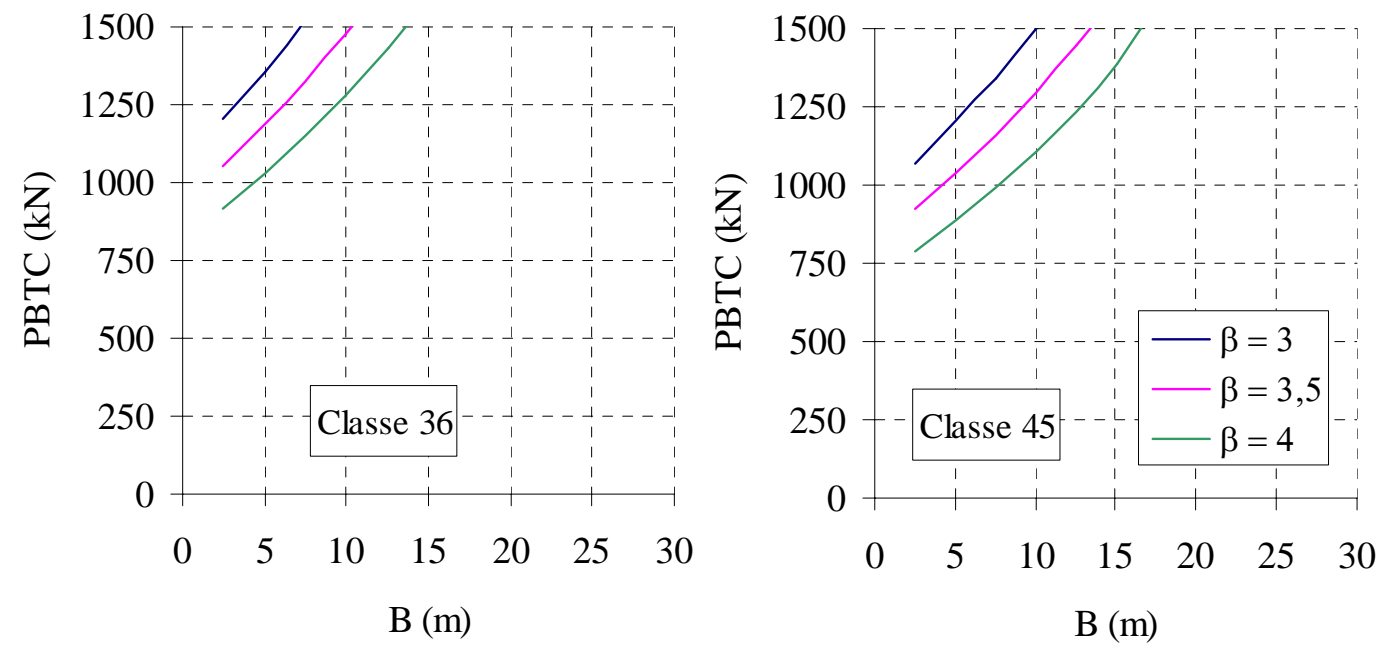

Figura 6.23 - Limites inferiores das curvas W x B - LAJE. 

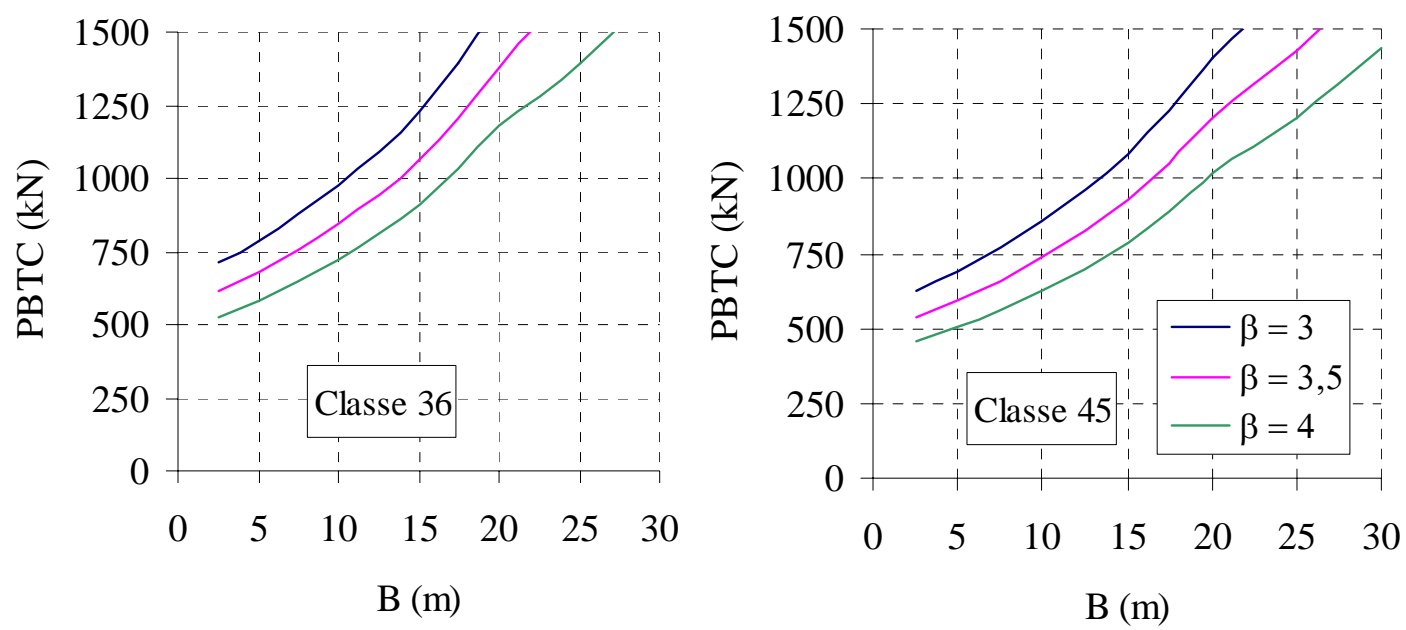

Figura 6.24 - Limites inferiores das curvas W x B - VIGA T - 5 VIGAS (com transversinas).
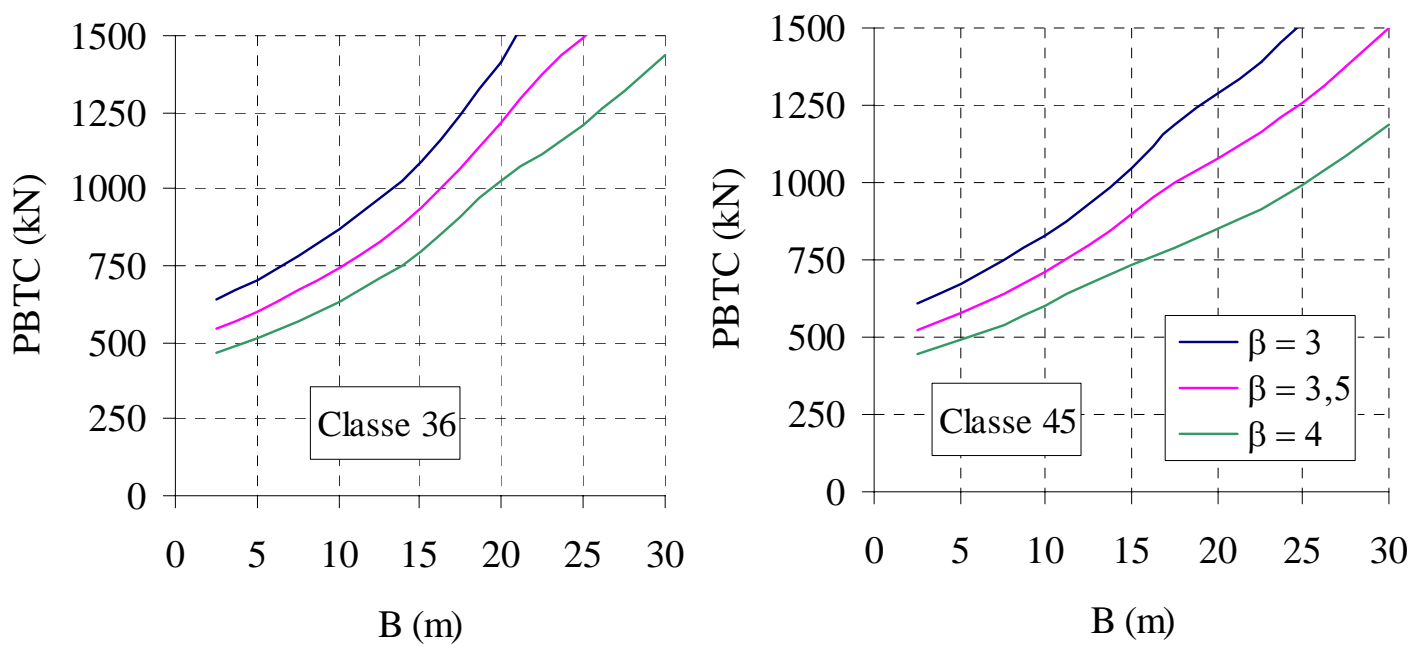

Figura 6.25 - Limites inferiores das curvas W x B - VIGA T - 5 VIGAS (sem transversinas).
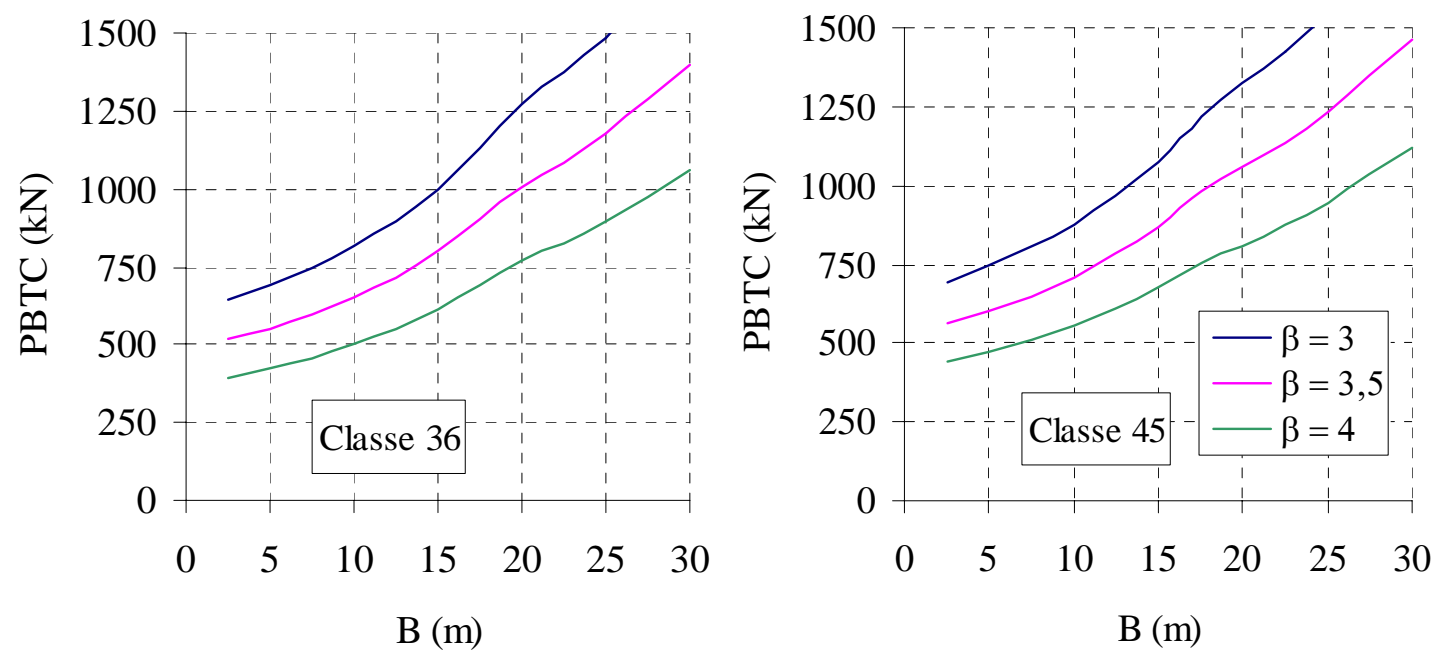

Figura 6.26 - Limites inferiores das curvas W x B - VIGA T - SEÇÃO CELULAR. 


\subsubsection{Estado limite de formação de fissuras}

Os limites inferiores para o estado limite de formação de fissuras estão nas figuras 6.27 a 6.30 .
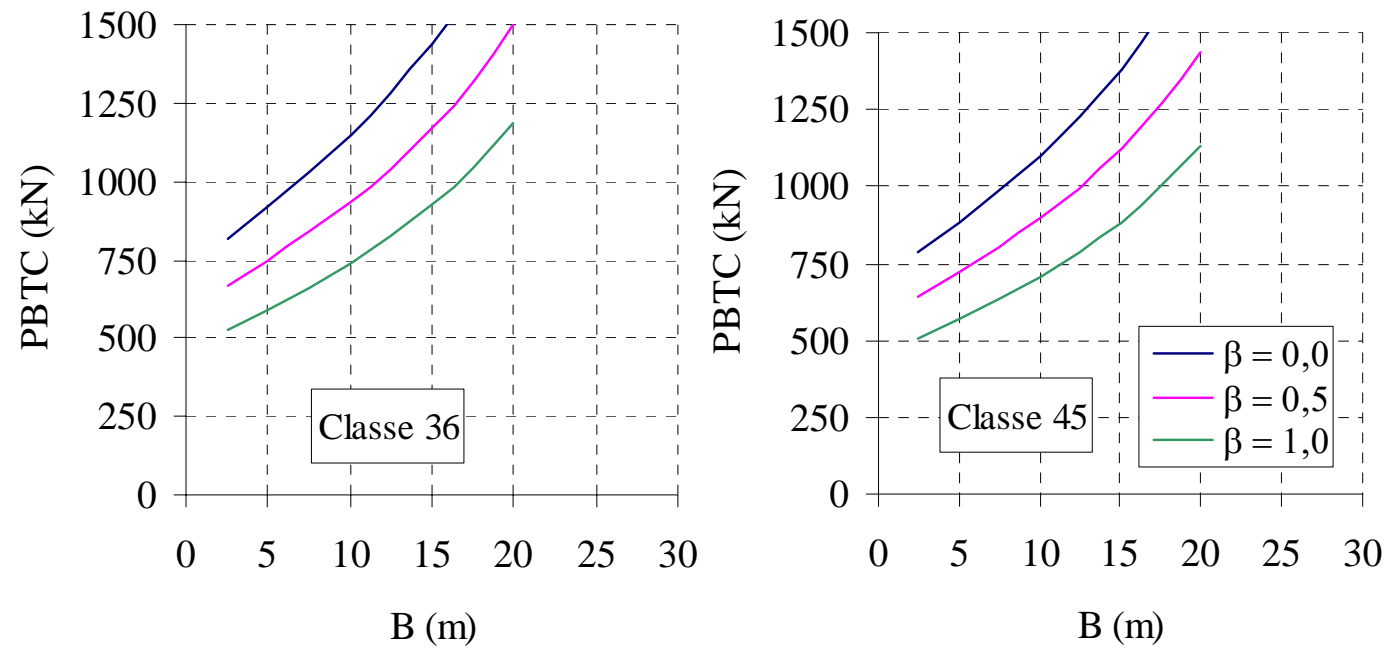

Figura 6.27 - Limites inferiores das curvas W x B - LAJE.
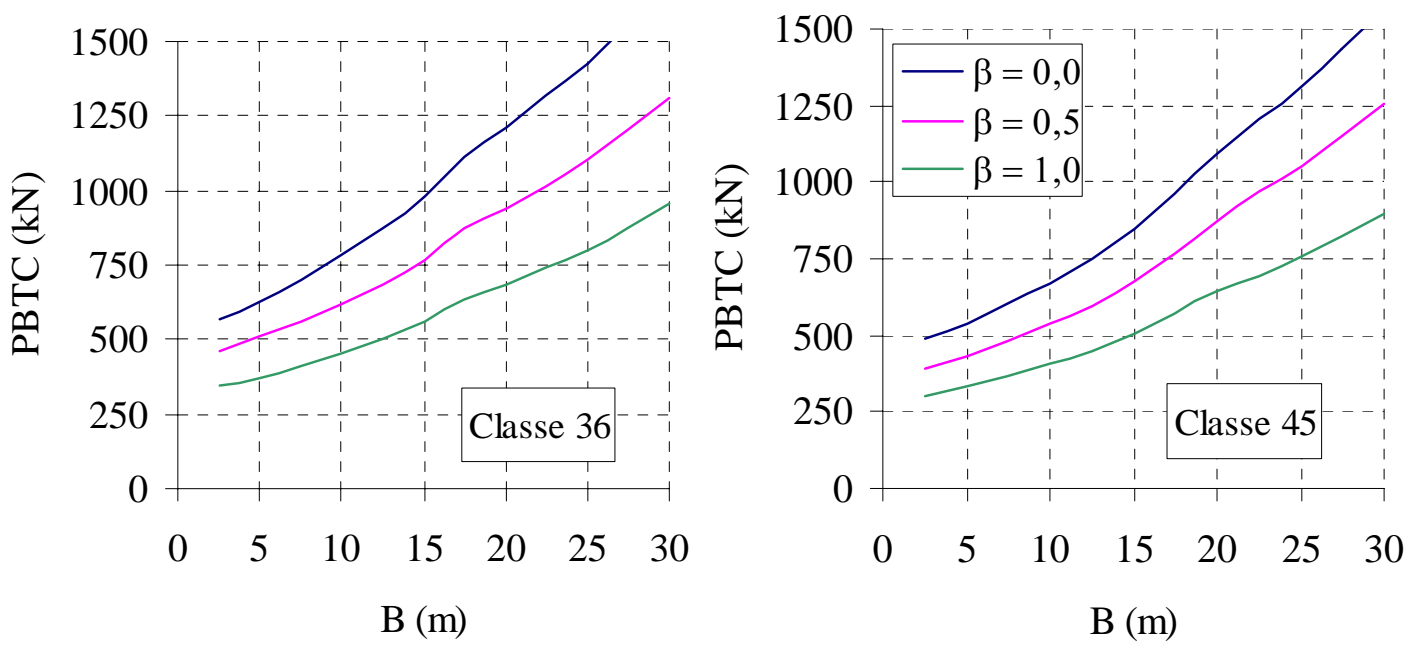

Figura 6.28 - Limites inferiores das curvas W x B - VIGA T - 5 VIGAS (com transversinas). 

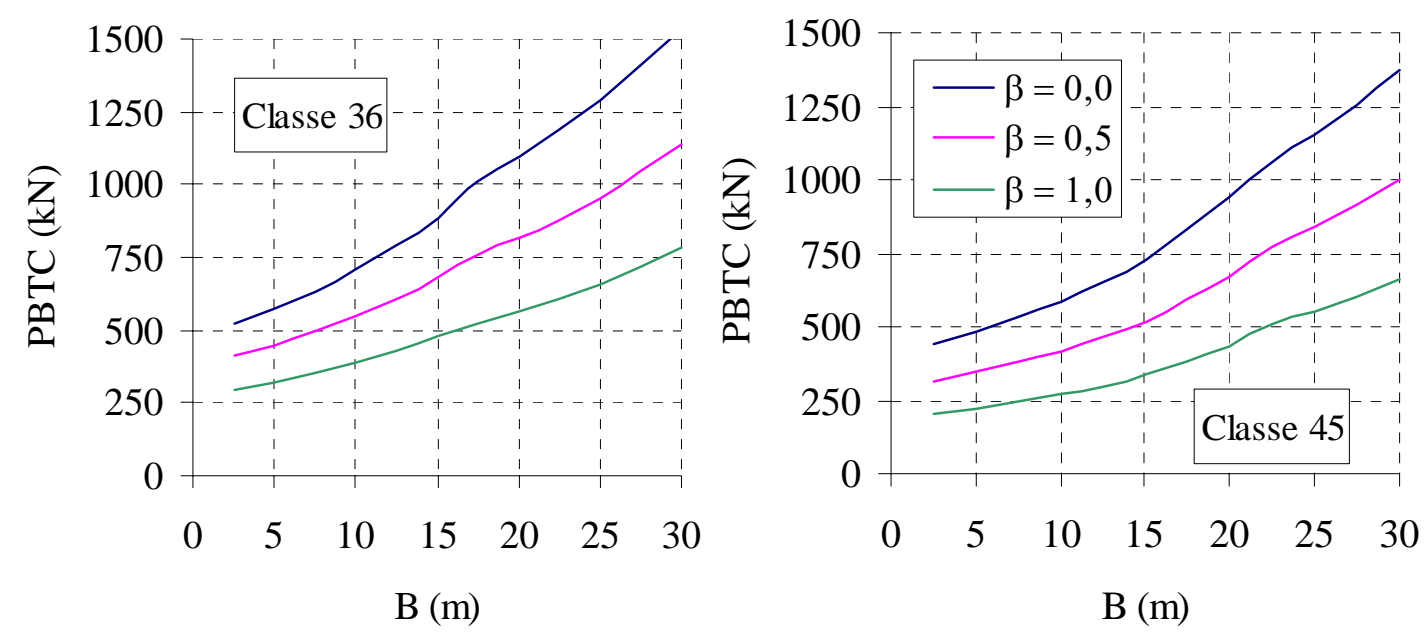

Figura 6.29 - Limites inferiores das curvas W x B - VIGA T - 5 VIGAS (sem transversinas).
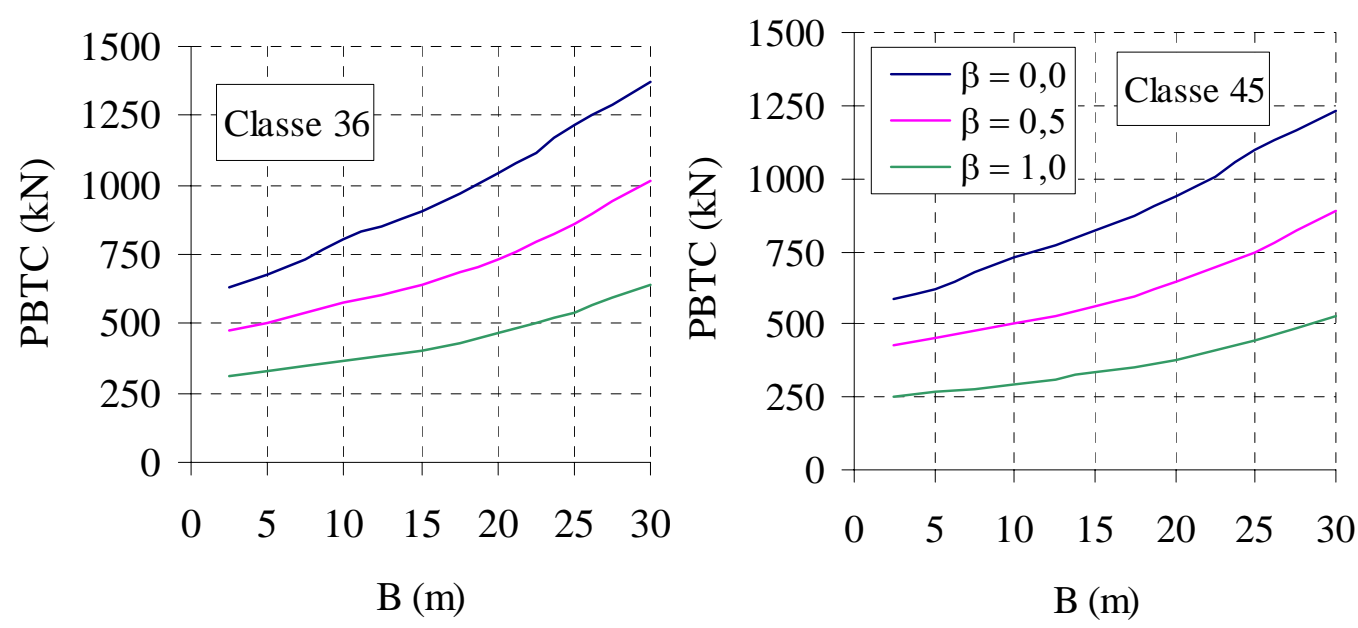

Figura 6.30 - Limites inferiores das curvas W x B - VIGA T - SEÇÃO CELULAR.

\subsection{Fixação de $\beta_{\text {alvo }}$}

A determinação do índice de confiabilidade desejável será baseada no desempenho das pontes existentes submetidas ao carregamento móvel proposto e em recomendações da bibliografia. Em concordância com Nowak (1999) e Ghosn (2000), um único $\beta$ será utilizado, independentemente do sistema estrutural, classe (36 ou 45), comprimento e número de faixas. Também não é feita diferenciação entre momento fletor positivo e negativo. Apenas o conceito de redundância e tipo de estado limite serão levados em consideração para a fixação de $\beta_{\text {alvo }}$.

Dependendo de cada caso em particular, as pontes terão sua capacidade portante aumentada ou diminuída em relação ao carregamento utilizado para determinação do 
índice de confiabilidade. De qualquer forma, a tese fornece subsídios para a alteração do $\beta_{\text {alvo }}$ e para a obtenção de outras ECPLs.

\subsubsection{Estado limite último}

A escolha do índice de confiabilidade em relação ao estado limite último deve abranger as pontes em concreto armado e concreto protendido.

Considerando sistemas redundantes, em que a diferença entre o índice de confiabilidade do sistema e o índice de confiabilidade da seção mais solicitada é adequada, Nowak (1999) utiliza $\beta_{\text {alvo }}$ igual a 3,5 na calibração da AASHTO (1994) e Ghosn (2000) determina sua bridge formula para beta igual a 3 (caso não se considere o crescimento no volume de tráfego). Ambos os autores escolhem seus índices de confiabilidade desejáveis a partir do desempenho de pontes existentes submetidas a condições reais de tráfego. No entanto, Nowak (1999) considera o efeito total do carregamento uma variável normal, enquanto Ghosn (2000) utiliza a distribuição lognormal. Deve-se ressaltar que esse fato interfere nos índices de confiabilidade encontrados e deve ser levado em consideração na análise do trabalho de cada autor.

Moses (1999) recomenda um valor mínimo de 3,5 para $\beta_{\text {alvo em casos de }}$ sistemas não redundantes ou ainda uma diferença de 1,0 entre betas de sistemas redundantes e não redundantes. Partindo-se do trabalho de Ghosn (2000), o valor mínimo recomendado para pontes não redundantes seria então $\beta=4$.

Considerando-se as pontes de 2 vigas, e mesmo as pontes de 5 vigas sem transversinas (devido à sua baixa redistribuição de esforços), como sistemas não redundantes, os índices de confiabilidade médios obtidos para esses sistemas estruturais são aproximadamente 4 para concreto protendido (5 vigas sem transversinas) e variam entre 3 e 3,5 para concreto armado (desconsiderando o momento fletor negativo, que resulta maior devido ao carregamento móvel proposto e às linhas de influência desse esforço solicitante).

Dessa forma, a partir das recomendações da bibliografia e a partir dos resultados obtidos neste trabalho, o $\beta_{\text {alvo }}$ a ser utilizado no cálculo das ECPLs para as pontes de 2 vigas e 5 vigas sem transversinas será 4 .

Nos demais sistemas estruturais, os valores médios dos índices de confiabilidade variam de 3 a 4,5. Representando um valor médio dos casos analisados e em coerência 
com o valor determinado anteriormente, admite-se $\beta$ desejável igual a 3,5 para sistemas redundantes.

As relações entre os índices de confiabilidade discutidos acima e as probabilidades de falha podem ser vistas na tabela 6.4.

Tabela 6.4 - Relações entre índices de confiabilidade e probabilidades de falha.

\begin{tabular}{|c|c|}
\hline Índice de confiabilidade $\boldsymbol{\beta}$ & Probabilidade de falha $\left(\mathrm{P}_{\mathrm{f}}\right)$ \\
\hline 3,0 & $1,35 \cdot 10^{-3}$ \\
\hline 3,5 & $2,33 \cdot 10^{-4}$ \\
\hline 4,0 & $3,17 \cdot 10^{-5}$ \\
\hline
\end{tabular}

Finalmente, lembrando-se que as ECPLs são governadas pelos casos críticos, as pontes de 2 vigas e pontes de 5 vigas sem transversinas, às quais se impõe maior conservadorismo, devem comandar as relações $W \times B$.

\subsubsection{Estado limite de serviço}

São poucas as indicações na bibliografia para índices de confiabilidade desejáveis em estados limites de serviço. Nowak, Szerszen e Park (1998) recomendam

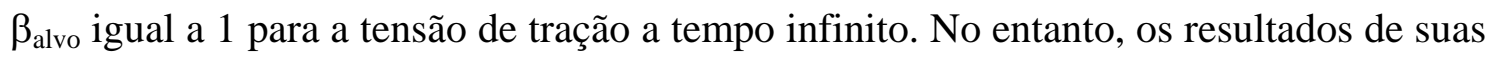
análises em pontes projetadas de acordo com a AASHTO (1996) variam entre 0,3 e 0,8.

As pontes que fazem parte da base de dados deste trabalho apresentam valores entre $-0,25$ e 1,5 , com valores médios entre 0,5 e 1,5 . Destaca-se que mesmo sob o carregamento normativo brasileiro, as pontes apresentam baixos índices de confiabilidade.

Considerando-se que o desrespeito ao estado limite de formação de fissuras apresenta conseqüências menos severas às estruturas em relação ao estado limite último, e admitindo-se que o meio ambiente não seja agressivo, adota-se $\beta_{\text {alvo igual 0,5. }}$

No caso do estado limite de serviço, não se diferencia sistemas redundantes e não redundantes. As relações entre os índices de confiabilidade e as probabilidades de falha podem ser vistas na tabela 6.5.

\subsection{Equações propostas}


Tabela 6.5 - Índices de confiabilidade $x$ probabilidades de falha.

\begin{tabular}{|c|c|}
\hline Índice de confiabilidade $\boldsymbol{\beta}$ & Probabilidade de falha $\left(\mathrm{P}_{\mathrm{f}}\right)$ \\
\hline 0,0 & 0,500 \\
\hline 0,5 & 0,309 \\
\hline 1,0 & 0,159 \\
\hline
\end{tabular}

Considerando-se a natureza dos estados limites e a diferença no comportamento das classes 36 e 45 em relação a cada um deles, optou-se tratar os 2 casos separadamente. Assim, será fornecida uma equação para o estado limite último e outra para o estado limite de serviço. Enquanto a primeira deve ser obedecida de maneira mais rigorosa, a aplicação da segunda compete a uma tomada de decisão do engenheiro.

\subsubsection{Estado limite último}

A partir dos índices de confiabilidade desejáveis determinados no item 6.7.1, a análise das figuras 6.18 a 6.26 indica que as ECPLs teriam seus pesos bastante restringidos para grupos de eixos com comprimento de 2,5 metros, inclusive com valores inferiores aos permitidos em lei. Trata-se de uma configuração de 3 eixos com distância entre eles igual a 1,25 m, utilizada em diversos caminhões e cujo peso permitido pela legislação é de 255 kN. A limitação provém do momento fletor negativo em pontes de 2 vigas simplesmente apoiadas com balanços de $3 \mathrm{~m}$. Admitindo-se que esse balanço curto não é utilizado frequentemente e com o intuito de não sacrificar o caráter geral das ECPLs para uma gama muito maior de estruturas, as equações propostas a seguir não consideram os balanços de 3 metros de comprimento. Essa ressalva deve ser lembrada durante a análise dos resultados.

Os limites de pesos impostos pelos casos críticos de cada sistema estrutural são dados pela figura 6.31 .

A observação da figura 6.31 mostra que uma linha reta de mesma inclinação é capaz de fornecer uma envoltória segura. Considerando-se ainda uma redução de 5\% nos máximos pesos brutos, de modo a se prever 5\% de tolerância permitida pela legislação brasileira, as ECPLs propostas estão na figura 6.32. A equação é obtida fixando-se os comprimentos dos grupos de eixos iguais a 2,5 m e 17,5 m. Para a classe 36, o valor é arredondado no primeiro ponto para o peso permitido pela legislação. Nos demais casos, é mantido o resultado de 0,95 vezes o menor peso bruto da figura 6.31. 

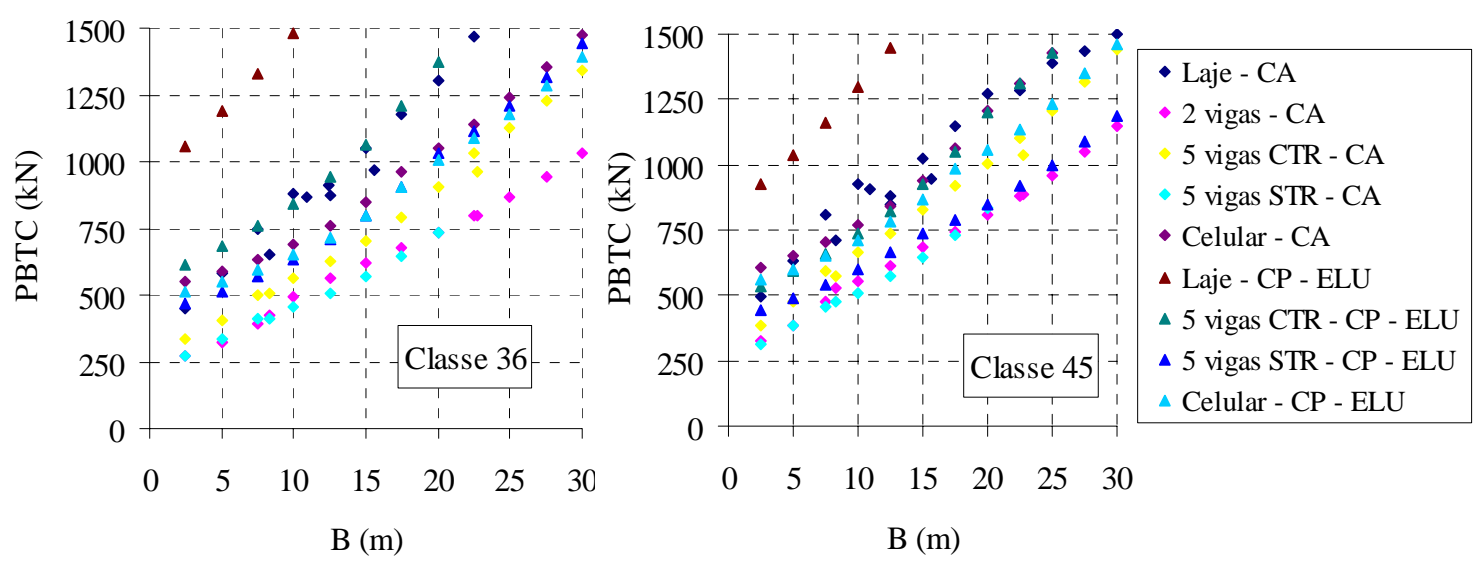

Figura 6.31 - Casos críticos para o estado limite último.

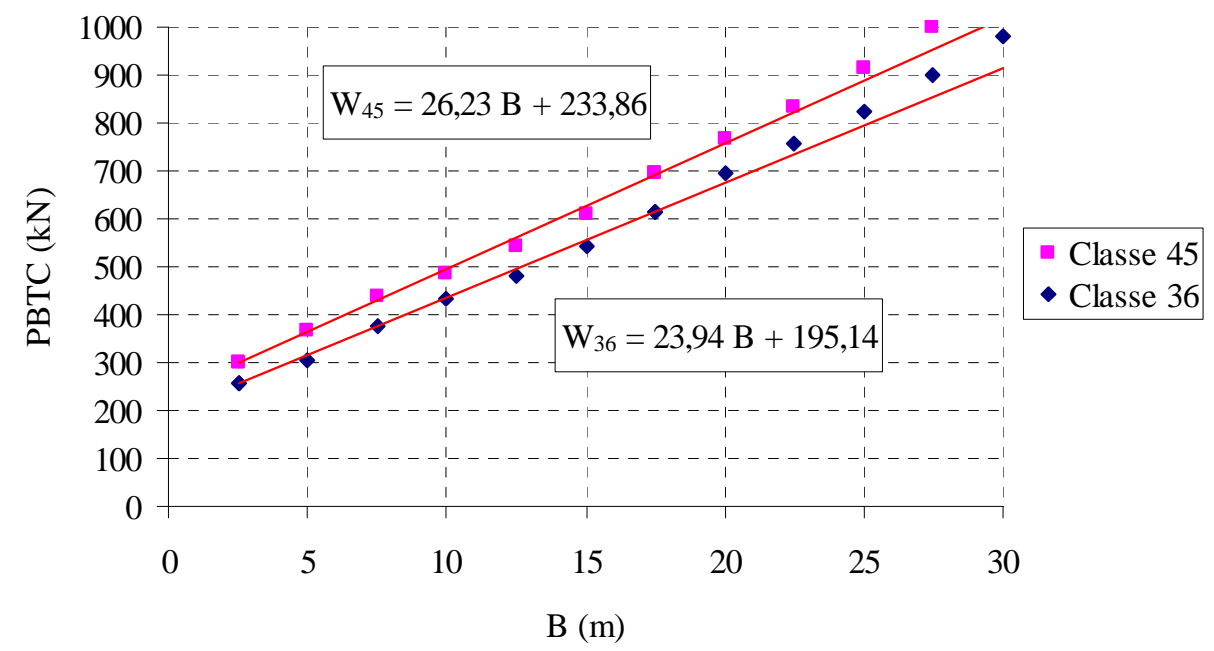

Figura 6.32 - ECPLs para o estado limite último.

O resultado das equações em forma de tabela é mostrado a seguir.

Tabela 6.6 - Pesos brutos provenientes das ECPLs para o ELU.

\begin{tabular}{|c|c|c|}
\hline \multirow{2}{*}{ B (m) } & \multicolumn{2}{|c|}{ PBTC (kN) } \\
\cline { 2 - 3 } & Classe 36 & Classe 45 \\
\hline 2,5 & 255,0 & 299,4 \\
\hline 5,0 & 314,8 & 365,0 \\
\hline 7,5 & 374,7 & 430,6 \\
\hline 10,0 & 434,5 & 496,2 \\
\hline 12,5 & 494,4 & 561,7 \\
\hline 15,0 & 554,2 & 627,3 \\
\hline 17,5 & 614,1 & 692,9 \\
\hline 20,0 & 673,9 & 758,5 \\
\hline 22,5 & 733,8 & 824,0 \\
\hline 25,0 & 793,6 & 889,6 \\
\hline 27,5 & 853,5 & 955,2 \\
\hline 30,0 & 913,3 & 1020,8 \\
\hline
\end{tabular}




\subsubsection{Estado limite de serviço}

Inicialmente, vale lembrar que o estado limite de serviço foi desenvolvido apenas para as pontes protendidas, consideradas sempre simplesmente apoiadas.

Os limites de pesos para cada sistema estrutural, mostrados na figura 6.33, contemplam todas as pontes atribuídas ao concreto protendido por este trabalho.
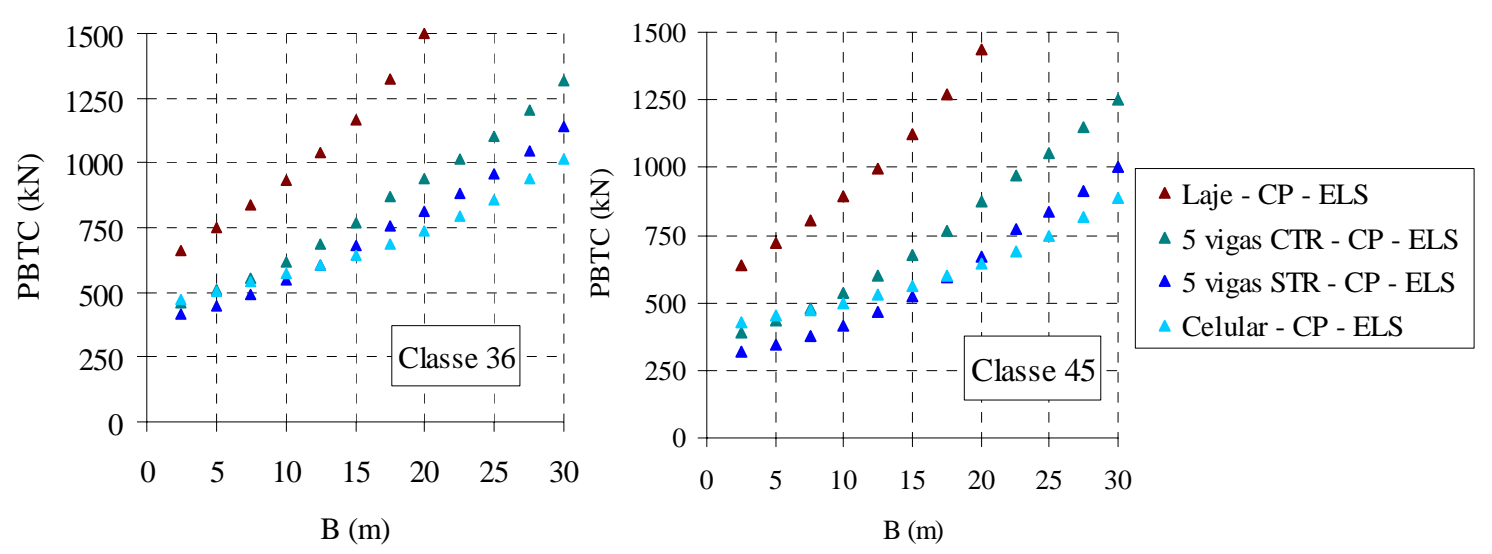

Figura 6.33 - Casos críticos para o estado limite de serviço.

No caso das pontes em concreto protendido, as ECPLs foram obtidas através da construção da melhor reta que representa os limites inferiores dos pesos brutos. De maneira similar ao concreto armado, também se considera a redução de $5 \%$ nos pesos brutos.

As ECPLs propostas para o estado limite de serviço estão na figura 6.34 e na tabela 6.7.

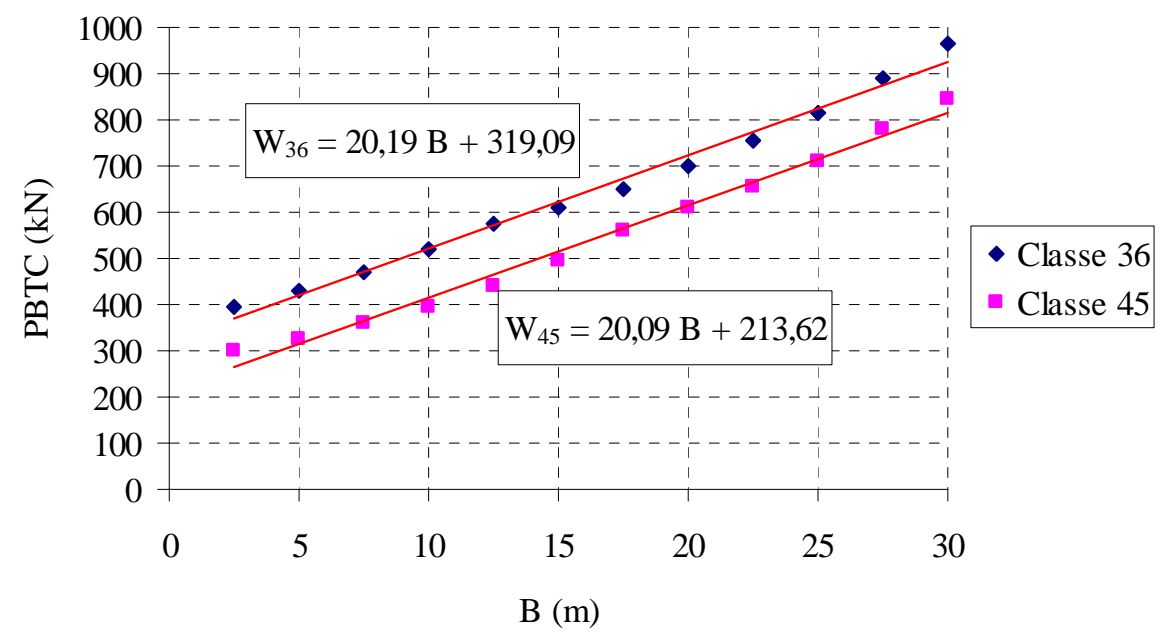

Figura 6.34 - ECPLs para o estado limite de serviço. 
Tabela 6.7 - Pesos brutos provenientes das ECPLs para o ELS.

\begin{tabular}{|c|c|c|}
\hline \multirow{2}{*}{ B (m) } & \multicolumn{2}{|c|}{ PBTC (kN) } \\
\cline { 2 - 3 } & Classe 36 & Classe 45 \\
\hline 2,5 & 369,6 & 263,8 \\
\hline 5,0 & 420,0 & 314,1 \\
\hline 7,5 & 470,5 & 364,3 \\
\hline 10,0 & 521,0 & 414,5 \\
\hline 12,5 & 571,5 & 464,7 \\
\hline 15,0 & 621,9 & 515,0 \\
\hline 17,5 & 672,4 & 565,2 \\
\hline 20,0 & 722,9 & 615,4 \\
\hline 22,5 & 773,4 & 665,6 \\
\hline 25,0 & 823,8 & 715,9 \\
\hline 27,5 & 874,3 & 766,1 \\
\hline 30,0 & 924,8 & 816,3 \\
\hline
\end{tabular}

A análise dos resultados mostra que as pontes classe 36 possuem maior capacidade portante quando se considera o estado limite de formação de fissuras. Isto se deve aos coeficientes de ponderação das ações, que levam a uma menor força de protensão para a classe 45, particularmente quando o período crítico (aquele que resulta em menor momento fletor resistente nominal para cada classe) é a partir de 2003.

\subsection{Emprego das ECPLs}

Quanto ao emprego das ECPLs, é importante salientar que possíveis mudanças nos limites de peso determinadas pela legislação e alterações nas características do tráfego, assim como refinamentos na sua modelagem, podem implicar em alterações nas ECPLs. A aplicabilidade dos resultados encontrados vale para as condições em que foram desenvolvidos, explicitadas ao longo do texto.

Utilizando-se a tabela 6.6, a situação de alguns caminhões quanto ao estado limite último é verificada a seguir. Além do comprimento total (distância entre eixos extremos), grupos de eixos intermediários são também testados em alguns casos. 
Tabela 6.8 - Situação de alguns veículos de acordo com o ELU.

\begin{tabular}{|c|c|c|c|c|c|c|}
\hline \multirow{2}{*}{ Caminhão } & \multirow{2}{*}{$\operatorname{PBTC}(\mathbf{k N})$} & \multirow{2}{*}{ L (m) } & \multirow{2}{*}{ B (m) } & \multirow{2}{*}{ Peso nominal (kN) } & \multicolumn{2}{|c|}{ W (kN) } \\
\hline & & & & & Classe 36 & Classe 45 \\
\hline Basculante & 450 & 13,50 & 10,90 & 450 & 456,1 & 519,8 \\
\hline \multirow{2}{*}{ Bitrem } & \multirow{2}{*}{570} & \multirow{2}{*}{18,72} & 5,59 & 340 & 329,0 & 380,5 \\
\hline & & & 15,62 & 570 & 569,1 & 643,6 \\
\hline \multirow{2}{*}{ Bitrenzão } & \multirow{2}{*}{740} & \multirow{2}{*}{24,90} & 11,15 & 510 & 462,1 & 526,3 \\
\hline & & & 22,49 & 740 & 733,6 & 823,8 \\
\hline \multirow{2}{*}{ Rodotrem } & \multirow{2}{*}{740} & \multirow{2}{*}{19,80} & 4,65 & 340 & 306,5 & 355,8 \\
\hline & & & 17,53 & 740 & 614,8 & 693,7 \\
\hline \multirow{2}{*}{ Rodotrem } & \multirow{2}{*}{740} & \multirow{2}{*}{25,00} & 5,55 & 340 & 328,0 & 379,4 \\
\hline & & & 22,73 & 740 & 739,3 & 830,1 \\
\hline
\end{tabular}

A tabela 6.8 indica as seguintes restrições:

a) Basculante: sem restrições desde que respeite a legislação;

b) Bitrem: não satisfaz à ECPL para a classe 36, especialmente em relação aos 4 eixos traseiros. No entanto, a diferença não é significativa;

c) Bitrenzão: os 6 eixos traseiros da configuração utilizada não respeitam à ECPL para a classe 36. Quanto ao peso total combinado do veículo, a diferença não é significativa;

d) Rodotrem de 19,80 metros: não atende aos limites de peso impostos para a classe 36. Quanto à classe 45, não atende ao máximo PBTC;

e) Rodotrem de 25 metros: quanto ao peso total, pode-se considerar que não há restrições. No entanto, apresenta um grupo de eixos nas mesmas condições do bitrem, que ultrapassa levemente os limites de peso para a classe 36.

O efeito dos mesmos caminhões tratados anteriormente em relação ao estado limite de serviço pode ser visto na tabela 6.9. 
Tabela 6.9 - Situação de alguns veículos de acordo com o ELS.

\begin{tabular}{|c|c|c|c|c|c|c|}
\hline \multirow{2}{*}{ Caminhão } & \multirow{2}{*}{ PBTC (kN) } & \multirow{2}{*}{$\mathbf{L}(\mathbf{m})$} & \multirow{2}{*}{ B (m) } & \multirow{2}{*}{ Peso nominal (kN) } & \multicolumn{2}{|c|}{ W (kN) } \\
\hline & & & & & Classe 36 & Classe 45 \\
\hline Basculante & 450 & 13,50 & 10,90 & 450 & 539,2 & 432,6 \\
\hline \multirow{2}{*}{ Bitrem } & \multirow{2}{*}{570} & \multirow{2}{*}{18,72} & 5,59 & 340 & 432,0 & 325,9 \\
\hline & & & 15,62 & 570 & 634,5 & 527,4 \\
\hline \multirow{2}{*}{ Bitrenzão } & \multirow{2}{*}{740} & \multirow{2}{*}{24,90} & 11,15 & 510 & 544,2 & 437,6 \\
\hline & & & 22,49 & 740 & 773,2 & 665,4 \\
\hline \multirow{2}{*}{ Rodotrem } & \multirow{2}{*}{740} & \multirow{2}{*}{19,80} & 4,65 & 340 & 413,0 & 307,0 \\
\hline & & & 17,53 & 740 & 673,0 & 565,8 \\
\hline \multirow{2}{*}{ Rodotrem } & \multirow{2}{*}{740} & \multirow{2}{*}{25,00} & 5,55 & 340 & 431,1 & 325,1 \\
\hline & & & 22,73 & 740 & 778,0 & 670,3 \\
\hline
\end{tabular}

A análise da tabela 6.9 apenas para as pontes em concreto protendido, mostra:

a) Classe 36: a única restrição apresentada é em relação ao rodotrem de 19,8 metros;

b) Classe 45: apresenta restrições quanto à circulação de todos os caminhões, especialmente no que se refere ao bitrenzão e ao rodotrem, inclusive o de 25 metros.

Salienta-se que outras configurações dos mesmos caminhões podem viabilizar sua utilização para os respectivos estados limites.

Por fim, a figura 6.35 mostra que as equações propostas neste trabalho, em se tratando do estado limite último, são mais permissivas que as desenvolvidas por outros autores a partir das prescrições de projeto da AASHTO (1996).

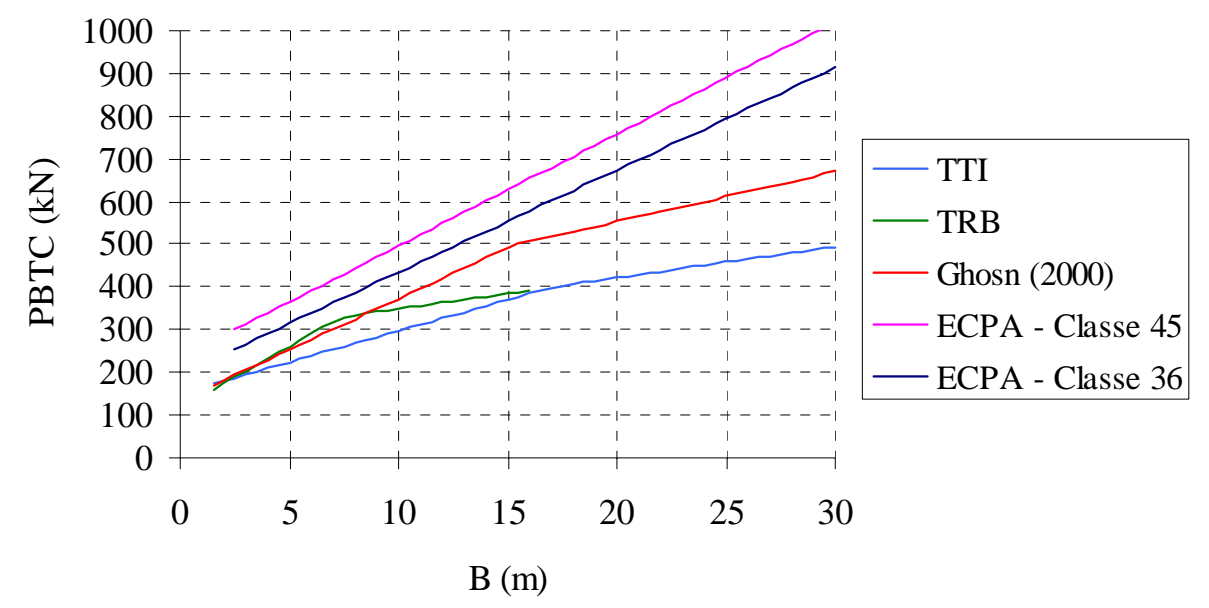

Figura 6.35 - Comparação entre equações para o ELU. 
A eficiência do setor de transportes é certamente um dos requisitos para o desenvolvimento econômico dos países emergentes. Particularmente no que se refere ao transporte rodoviário, é interessante que o país possua uma frota de caminhões moderna, capaz de transportar grandes quantidades de carga sem onerar o custo das mercadorias.

Nesse contexto, o Brasil assiste à proliferação de Combinações de Veículos de Carga em substituição a antigos veículos, hoje obsoletos. Não há dúvidas sobre os benefícios decorrentes da inovação em curso. No entanto, é preciso que a legislação se adapte à nova realidade e determine regras a serem efetivamente cumpridas.

Um dos aspectos a serem cuidadosamente analisados é a segurança estrutural das obras de arte existentes na infra-estrutura viária. A preocupação com a preservação do patrimônio público advém de alguns estudos que indicam restrições à circulação de veículos considerados nocivos sob o ponto de vista das pontes. Além de órgãos governamentais, o assunto interessa diretamente às concessionárias de rodovias, responsáveis pela manutenção adequada dos trechos sob sua responsabilidade.

A determinação de regras gerais para o peso de veículos de carga encontra obstáculos quando se verifica a existência de diversas classes de pontes, com diferentes idades e sistemas estruturais. Embora o poder público tenha recentemente emitido normas que visam garantir a integridade das obras de arte, são necessárias pesquisas que forneçam conhecimento técnico e científico em vista à complexidade do tema.

Este trabalho utiliza a teoria da confiabilidade na determinação de limites máximos de PBTC para quaisquer grupos de eixos consecutivos em pontes de concreto. Entre as atividades desenvolvidas, também se destaca a representação do tráfego real e a análise da segurança das pontes de acordo com diferentes critérios de projeto. 


\subsection{Conclusões}

O trabalho procurou analisar os sistemas estruturais mais comuns encontrados na rede viária do DER-SP e também atender às situações de projeto mais usuais.

Entre as premissas e hipóteses adotadas ao longo do texto, destacam-se:

- Considera-se o momento fletor na superestrutura das pontes classes 36 e 45;

- As pontes são admitidas retas, não esconsas e com apoios nivelados;

- Verifica-se a carga permanente e o efeito vertical da carga móvel;

- O estudo não abrange a questão da fadiga em pontes de concreto;

- As equações comprimento-peso limite não contemplam balanços inferiores a 5 metros;

- Os máximos pesos brutos permitidos pelas ECPLs foram reduzidos em 5\%, prevendo tolerância permitida pela legislação brasileira;

- Admite-se que as pontes tenham sido adequadamente dimensionadas e executadas, além de não apresentar patologias que comprometam sua capacidade portante;

- Inclusive devido a questões relacionadas ao desgaste dos pavimentos, os limites de pesos por eixo estabelecidos pelo CONTRAN devem ser sempre obedecidos.

A comparação entre o carregamento normativo e o tráfego real, representado através de um modelo de carregamento móvel, indica que não há grande uniformidade em relação ao tipo de ponte, vão e seção transversal. Como conseqüência, estruturas projetadas de acordo com os mesmos critérios possuem índices de confiabilidade variáveis.

Considerando-se o estado limite último, são propostas as seguintes equações para regular o tráfego de veículos de carga (ECPLs):

Classe 36: $\quad \mathrm{W}_{36}=23,9 \cdot \mathrm{B}+195,1$

Classe 45: $\quad \mathrm{W}_{45}=26,2 \cdot \mathrm{B}+233,9$

onde:

W: máximo peso bruto em kN para qualquer grupo de eixos consecutivos;

B: comprimento do grupo de eixos (m). 
O emprego dos limites de peso estabelecidos acima indica restrições à circulação de alguns veículos, especialmente na classe 36. Os resultados também mostram que, entre os veículos verificados, o rodotrem de 19,8 metros de comprimento e $740 \mathrm{kN}$ apresenta-se como o mais incompatível às obras de arte.

As ECPLs obtidas para o estado limite de serviço são:

$\begin{array}{ll}\text { Classe 36: } & \mathrm{W}_{36}=20,2 \cdot \mathrm{B}+319,1 \\ \text { Classe 45: } & \mathrm{W}_{45}=20,1 \cdot \mathrm{B}+213,6\end{array}$

Nesse caso, as equações propostas para as estruturas protendidas resultam em baixos pesos brutos para as pontes classe 45, indicando que os atuais coeficientes de ponderação das ações em serviço reduzem a segurança quanto ao estado limite de formação de fissuras em relação a períodos anteriores.

\subsection{Sugestões para futuras pesquisas}

Devido ao grande número de assuntos relacionados ao estudo das pontes, são inúmeras as pesquisas que podem complementar esta tese.

Inicialmente, cita-se a verificação do comportamento dos aparelhos de apoio, dos pilares e das fundações, especialmente quando submetidos à força horizontal de frenagem resultante do tráfego das CVCs.

Quanto aos sistemas estruturais e aos vãos aqui tratados, considera-se que abrangem a grande maioria das pontes nacionais. No entanto, a análise pode ser estendida às estruturas protendidas contínuas e às pontes menos usuais, como as estaiadas. Também podem ser abordados outros estados limites, em particular a compressão excessiva.

Outro campo de atuação está na obtenção de parâmetros estatísticos a respeito das variáveis aleatórias envolvidas na determinação da resistência dos elementos estruturais. Sugere-se a continuação da coleta de dados sobre a resistência à compressão do concreto, de modo a aumentar o número de amostras e diversificar os fornecedores.

Em relação ao modelo de carregamento móvel, vários são os aperfeiçoamentos necessários. Entre eles, estão a aquisição de maior número de pesagens, especialmente em balanças móveis e períodos noturnos, a melhor caracterização das distâncias entre 
eixos dos caminhões e as probabilidades de presença simultânea sobre as pontes. As distribuições de probabilidade dos máximos pesos brutos em 50 anos de vida útil também precisam ser melhor estudadas. Recomenda-se a pesagem de veículos em movimento (weigh-in-motion) e a simulação do tráfego real, capaz de viabilizar a análise de pontes mais longas e a verificação de diferentes cenários.

Um dos principais tópicos a serem explorados em novas pesquisas é a fadiga em pontes de concreto. Trata-se de um tema complexo e que depende substancialmente das características do tráfego.

Recomenda-se a extensão do estudo para as pontes curtas de madeira (até aproximadamente 15 metros de comprimento), muito utilizadas no transporte de cargas agrícolas e que são dominantes nas regiões Centro-Oeste e Amazônica.

Também é interessante a investigação da confiabilidade dos sistemas estruturais em pontes típicas, podendo fornecer melhores subsídios para a definição dos índices de confiabilidade desejáveis.

Por fim, salienta-se que muitas obras de arte apresentam patologias que reduzem sua capacidade portante, não consideradas no desenvolvimento das ECPLs. Dessa forma, faz-se necessária a inspeção e a manutenção periódica, além da adequação dos máximos pesos brutos para condições específicas da ponte deteriorada. 


\section{REFERÊNCIAS BIBLIOGRÁFICAS}

AMERICAN ASSOCIATION OF STATE HIGHWAY AND TRANSPORTATION OFFICIALS (1994). LRFD bridge design specifications. Washington, D.C.

AMERICAN ASSOCIATION OF STATE HIGHWAY AND TRANSPORTATION OFFICIALS (1996). Standard specifications for highway bridges. Washington, D.C.

ANG, A.H-S.; TANG, W.H. (1975). Probability concepts in engineering planning and design: volume 1. Basic principles. New York: John Wiley \& Sons.

ASSOCIAÇÃO BRASILEIRA DE NORMAS TÉCNICAS (1960). NB 1: Cálculo e execução de estruturas de concreto armado. Rio de Janeiro.

(1967). Anexo da EB3: Condições de emprêgo das barras de aço destinadas a armadura de peças de concreto armado. Rio de Janeiro.

. (1978). NB 1: Projeto e execução de estruturas de concreto. Rio de Janeiro.

. (1984). NBR 7188: Carga móvel em ponte rodoviária e passarela de pedestres. Rio de Janeiro.

. (1984, 2003). NBR 8681: Ações e segurança nas estruturas. Rio de Janeiro.

. (1987). NBR 7187: Projeto e execução de pontes de concreto armado e protendido. Rio de Janeiro.

. (1989). NBR 7197: Projeto de obras de concreto protendido. Rio de Janeiro.

(2003). NBR 6118: Projeto de estruturas de concreto. Rio de Janeiro.

BENJAMIN, J.R.; CORNELL, C.A. (1970). Probability, statistics and decision for civil engineers. New York: McGraw-Hill.

BRUHWILER, E.; BAILEY, S.F. (2002). Target safety levels for the evaluation of existing bridges. In: First International Conference on Bridge Maintenance, Safety and Management, 2002, Barcelona.

COMITE EURO-INTERNATIONAL DU BETON (1988). Fatigue of concrete structures. Bulletin d'Information, n. 188.

CONSELHO NACIONAL DE TRÂNSITO (1998a). Resolução n. 12, de 6 de fevereiro de 1998. Estabelece os limites de peso e dimensões para veículos que transitem por vias terrestres. Disponível em <http:// www.denatran.gov.br $>$.

CONSELHO NACIONAL DE TRÂNSITO (1998b). Resolução n. 68, de 23 de setembro de 1998. Requisitos de segurança necessários à circulação de Combinações de Veículos de Carga - CVC. Disponível em <http:// www.denatran.gov.br >. 
CONSELHO NACIONAL DE TRÂNSITO (2004). Resolução n. 164, de 10 de setembro de 2004. Acresce parágrafo único ao art. $1^{\circ}$ da Resolução CONTRAN 68/98. Disponível em <http:// www.denatran.gov.br>.

CONSELHO NACIONAL DE TRÂNSITO (2005). Resolução n. 184, de 21 de outubro de 2005. Altera as Resoluções 12/98 e 68/98 do CONTRAN e revoga a Resolução 76/98 do CONTRAN. Disponível em <http:// www.denatran.gov.br>.

CRESPO-MINGUILLÓN, C.; CASAS, J.R. (1997). A comprehensive traffic load model for bridge safety checking. Structural Safety, v.19, n.4, p.339-359.

DEPARTAMENTO DE ESTRADAS DE RODAGEM DO ESTADO DE SÃO PAULO (2002). Portaria SUP/DER-036 de 12 de abril de 2002. Aprova Norma para concessão de AET- Autorização Especial de Trânsito. Disponível em <http:// www.der.sp.gov.br>.

EAMON, C.D. (2000). Reliability-based resistance model for bridge structural systems. 335p. PhD thesis, University of Michigan, Ann Arbor.

EL DEBS, M.K. et al. (2001). Análise das consequências do tráfego de CVCs (Combinação de veículos de carga) sobre as obras de arte especiais da rede viária do DER-SP. São Carlos, Universidade de São Paulo. Relatório técnico.

EL DEBS, M.K. et al. (2003a). Estudo técnico para avaliação do limite máximo de PBTC para a CVC de nove eixos e comprimento 19,80m tendo em vista a segurança estrutural das obras de arte da rede viária sob jurisdição do DER-SP. São Carlos, Universidade de São Paulo. Relatório técnico.

EL DEBS, M.K. et al. (2003b). Estudo técnico para avaliação das consequências do tráfego de CVC de 65,5t, de oito eixos, com comprimento de 20,43 metros nas obras de arte da rede viária do anel de integração do Paraná. São Carlos, Universidade de São Paulo. Relatório técnico.

ELLINGWOOD, B.; GALAMBOS, T.V.; MACGRAGOR, J.G.; CORNELL, C.A. (1980). Development of a probability based load criterion for American National Standard A58. Washington, National Bureau of Standards. NBS Special Publication 577.

FRANGOPOL, D.M. et al. (1996). A new look at reliability of reinforced concrete columns. Structural Safety, v.18, n2/3, p123-150.

GHOSN, M. (1999). Modeling of bridge dead \& live loads. In: FRANGOPOL, D.M. (Ed). Bridge safety and reliability. Reston: ASCE. Cap.2, p.23-57.

GHOSN, M. (2000). Development of truck weight regulations using bridge reliability model. Journal of Bridge Engineering, p.293-303, nov.

GHOSN, M.; FRANGOPOL, D.M. (1999). Bridge reliability: components and systems. In: FRANGOPOL, D.M. (Ed). Bridge safety and reliability. Reston: ASCE. Cap.4, p.83-112. 
GHOSN, M.; HANG, Y.; MOSES, F. (1997). System reliability analysis of concrete bridge superstructures. In: Reliability and optimization of structural systems Proceedings of the seventh IFIP WG7.5 working conference on reliability and optimization of structural systems, 1996, Boulder. Oxford: Pergamon, p.149-155.

GHOSN, M.; MOSES, F. (1985). Markov renewal model for maximum bridge loading. Journal of Engineering Mechanics, v.111, n.9, p.1093-1104, sep.

GHOSN, M.; MOSES, F. (1998). Redundancy in highway bridge superestructures. Washington, Transportation Research Board. NCHRP Report 406.

GHOSN, M.; MOSES, F.; KHEDEKAR, N. (1994). Response functions and system reliability of bridges. In: Probabilistic structural mechanics: advances in structural reliability methods - IUTAM SYMPOSIUM, 1993, San Antonio. Berlim Heidelbert: Springer-Verlag, p. 220-236.

GHOSN, M.; SCHILLING, C.G.; MOSES, F.; RUNCO, G. (1995). Bridge overstress criteria. McLean, Federal Highway Administration. Report n. FHWA-RD-92-082.

HWANG, E-S.; KOH, H.M. (2000). Simulation of bridge live load effects. In: $16^{\mathrm{TH}}$ CONGRESS OF IABSE, 2000, Lucerne.

HWANG, E-S.; NOWAK, A.S. (1991). Simulation of dynamic load for bridges. Journal of Structural Engineering, v.117, n.5, p.1413-1434.

IMBSEN, R.A.; LIU, W.D.; SCHAMBER, R.A.; NUTT, R.V. (1987). Strenght evaluation of existing reinforced concrete bridges. Washington, Transportation Research Board. NCHRP Report 292.

JAMES, R.W.; NOEL, J.S.; FURR, H.L.; BONILLA, F.E. (1986). Proposed new truck weight limit formula. Journal of Structural Engineering, v.112, n.7, p.1589-1604, july.

LAMAN, J.A.; NOWAK, A.S. (1996). Fatigue-load models for girder bridges. Journal of Structural Engineering, p.726-733, july.

MIRZA, S.A.; HATZINIKOLAS, M.; MACGREGOR, J.G. (1979). Statistical descriptions of the strength of concrete. Journal of the Structural Division, v.105, n.ST6, p.1021-1037, june.

MOSES, F. (1999). Bridge reliability concepts and methods. In: FRANGOPOL, D.M. (Ed). Bridge safety and reliability. Reston: ASCE. Cap.1, p.1-22.

MOSES, F. (2001). Calibration of load factors for LRFR bridge evaluation. Washington, Transportation Research Board. NCHRP Report 454.

MOSES, F.; GHOSN, M. (1985). A comprehensive study of bridge loads and reliability. Columbus, Ohio Department of Transportation. Report n. FHWA/OH-85/005.

MOSES, F.; GHOSN, M. (1987). Discussion on proposed new truck weight limit formula. Journal of Structural Engineering, v.113, n.11, p.2330-2331. 
MOSES, F.; VERMA, D. (1987). Load capacity evaluation of existing bridges. Washington, Transportation Research Board. NCHRP Report 301.

NEVES, R.A. (2004). Desenvolvimento de modelos mecânico-probabilísticos para estruturas de pavimentos de edifícios. 200p. Tese (Doutorado) - Escola de Engenharia de São Carlos, Universidade de São Paulo, São Carlos. 2004.

NOEL, J.S.; JAMES, R.W.; FURR, H.L.; BONILLA, F.E.; CAYES, L.R. (1986). Bridge formula development. Transportation Research Record, n.1072. p.1-5.

NOWAK, A.S. (1999). Calibration of LRFD bridge design code. Washington, Transportation Research Board. NCHRP Report 368.

NOWAK, A.S. (2004). Notas de aula da disciplina CEE 516 Bridge Structures, University of Michigan, Ann Arbor.

NOWAK, A.S. et al. (2005). Reliability-Based Calibration for Structural Concrete. Report UNLCE 05-03, University of Nebraska, Lincoln.

NOWAK, A.S.; COLLINS, K.R. (2000). Reliability of structures. Boston: McGrawHill.

NOWAK, A.S.; EL-HOR (1995). Serviceability criteria for prestressed concrete bridge girders. Transportation Research Board, Conference Proceedings 7, v.2, p.181-187.

NOWAK, A.S.; HONG, Y.K. (1991). Bridge live-load models. Journal of Structural Engineering, v.117, n.9, p.2757-2767, sep.

NOWAK, A.S.; LIND, N.C. (1979). Practical bridge code calibration. Journal of the Structural Division, v.105, n.ST12, p.2497-2510, dec.

NOWAK, A.S.; SZERSZEN, M.M. (1998). Bridge load and resistance models. Engineering Structures, v.20, n.11, p.985-990.

NOWAK, A.S.; SZERSZEN, M.M. (2001). Reliability-based calibration for structural concrete. Report UMCEE 01-04, University of Michigan, Ann Arbor.

NOWAK, A.S.; SZERSZEN, M.M. (2003). Calibration of design code for buildings (ACI 318): Part 1 - Statistical models for resistance. ACI Structural Journal, v.100, n.3, p.377-382, may-june.

NOWAK, A.S.; SZERSZEN, M.M.; PARK, C.H. (1998). Target safety levels for bridges. In: Structural Safety and Reliability - Proceedings of the eighth international conference on structural safety and reliability, 1998, Boulder. Rotterdam: Balkema, p.1897-1903.

NOWAK, A.S.; YAMANI, A.S.; TABSH, S.W. (1994). Probabilistic models for resistance of concrete bridge. ACI Structural Journal, p.269-276, may-june.

NOWAK, A.S.; ZHOU, J. (1985). Reliability models for bridge analysis. Report UMCE 
85-3, University of Michigan, Ann Arbor.

NOWAK, A.S.; ZHOU, J. (1990). System reliability models for bridges. Journal of Structural Safety, v.7, p.247-254.

PFEIL, W. (1969). Concreto armado dimensionamento. Rio de Janeiro: Ao livro técnico s.a.

PRECAST PRESTRESSED CONCRETE INSTITUTE (1997). PCI bridge design manual - loads and load distribution. Chicago.

PRESS, W.H. et al. (1996). Numerical recipes in Fortran 90: The art of parallel scientific computing. Cambridge University Press.

ROCHA, A.M. (1968). Curso prático de concreto armado: estruturas usuais em edifícios. v.1, 9.ed. Rio de Janeiro: Editora Científica.

SCHNEIDER, J. (1997). Introduction to safety and reliability of structures. International Association for Bridge and Structural Engineering.

SZERSZEN, M.M.; NOWAK, A.S. (2000). Fatigue evaluation of steel and concrete bridges. Transportation Research Record, n.1696, p.73-80.

SZERSZEN, M.M.; NOWAK, A.S.; LAMAN, J.A. (1999). Fatigue reliability of steel bridges. Journal of Constructional Steel Research, v.52, p.83-92.

TABSH, S.W. (1990). Reliability-based sensitivity analysis of girder bridges. 209p. PhD thesis, University of Michigan, Ann Arbor.

TANTAWI, H.M. (1986). Ultimate strength of highway girder bridges. 187p. PhD thesis, University of Michigan, Ann Arbor.

THOFT-CHRISTENSEN, P; BAKER, M.J. (1982). Structural reliability theory and its applications. Heidelberg: Springer-Verlag Berlin.

TRANSPORTATION RESEARCH BOARD (1990). Truck weight limits: issues and options. Special Report 225, Washington, D.C.

VISMANN, U.; ZILCH, K. (1995). Non-linear analysis and safety evaluation by finiteelement-reliability method. In: New developments in non-linear analysis methods. Comite Euro-International du beton, Bulletin d’Information, n. 229.

WIDMER, J.A. (2004). Proposta de nomenclatura para caminhões, ônibus, CVCs combinações de veículos de carga e CVPs - combinações de veículos de passageiros. In: Congresso de pesquisa e ensino em transportes, 2004, Florianópolis. Anais... Florianópolis: ANPET, v.1, p.624-635. 


\section{BIBLIOGRAFIA COMPLEMENTAR}

ANG, A.H-S.; TANG, W.H. (1984). Probability concepts in engineering planning and design: volume 2. Decision, risk and reliability. New York: John Wiley \& Sons.

ASSOCIAÇÃO BRASILEIRA DE NORMAS TÉCNICAS. (2003). NBR 7187: Projeto de pontes de concreto armado e protendido. Rio de Janeiro.

BERNARDO, T.R.R. (1999). Contribuição a análise da confiabilidade em pavimentos de edifícios de concreto armado. 159p. Dissertação (Mestrado) - Escola de Engenharia de São Carlos, Universidade de São Paulo, São Carlos. 1999.

CASTRO, L.A. (1997). Análise da segurança no projeto de estruturas: método dos estados limites. 119p. Dissertação (Mestrado) - Escola de Engenharia de São Carlos, Universidade de São Paulo, São Carlos. 1997.

CHOU, K.C.; DEATHERAGE, J.H.; LEATHERWOOD, T.D.; KHAYAT, A.J. (1999). Innovative method for evaluating overweight vehicle permits. Journal of Bridge Engineering, p.221-227, aug.

CONSELHO NACIONAL DE TRÂNSITO (1999). Resolução n. 104, de 21 de dezembro de 1999. Dispõe sobre tolerância máxima de peso bruto de veículos. Disponível em <http:// www.denatran.gov.br $>$.

ELLINGWOOD, B.; MACGRAGOR, J.G.; GALAMBOS, T.V.; CORNELL, C.A. (1982). Probability based load criteria: factors and load combinations. Journal of the Structural Division, v.108, n.ST5, p.978-997, may.

FU, G.; HAG-ELSAFI, O. (2000). Vehicular overloads: load model, bridge safety, and permit checking. Journal of Bridge Engineering, p.49-57, feb.

GALAMBOS, T.V.; ELLINGWOOD, B.; MACGRAGOR, J.G.; CORNELL, C.A. (1982). Probability based load criteria: assessment of current design practice. Journal of the Structural Division, v.108, n.ST5, p.959-977, may.

GHARAIBEH, E.S.; FRANGOPOL, D.M. (2000). Safety assessment of bridges based on system reliability and redundance. In: $16^{\mathrm{TH}}$ CONGRESS OF IABSE, 2000, Lucerne.

GHOSN, M.; MOSES, F. (1986). Reliability calibration of bridge design code. Journal of Structural Engineering, v.112, n.4, p.745-763, apr.

GHOSN, M.; MOSES, F. (1991). Reliability and load modeling for bridge management. Transportation Research Record, n.1290, v.2, p.176-184. Presented in Third Bridge Engineering Conference, Denver, 1991.

GHOSN, M.; MOSES, F. (2000). Effect of changing truck weight regulations on U.S. bridge network. Journal of Bridge Engineering, p.304-310, nov. 
HONG, Y. (1990). Live load models for girder bridges.. 214p. PhD thesis, University of Michigan, Ann Arbor.

JAMES, R.W.; NOEL, J.S.; FURR, H.L.; BONILLA, F.E. (1985). Proposed new truck weight formula. McLean, Federal Highway Administration. Report n. FHWA/RD85/088.

MICIC, T.V.; CHRYSSANTHOPOULOS, M.K. (1997). System reliability of beamand-slab bridges. In: Reliability and optimization of structural systems - Proceedings of the seventh IFIP WG7.5 working conference on reliability and optimization of structural systems, 1996, Boulder. Oxford: Pergamon, p.239-246.

MIRZA, S.A.; MACGREGOR, J.G. (1979). Variations in dimensions of reinforced concrete members. Journal of the Structural Division, v.105, n.ST4, p.751-766, apr.

MOHAMMADI, J.; POLEPEDDI, R. (2000). Bridge rating with consideration for fatigue damage from overloads. Journal of Bridge Engineering, p.259-265, aug.

NOWAK, A.S. (1993). Live load model for highway bridges. Structural Safety, v.13, p.53-66.

NOWAK, A.S. (1994). Load model for bridge design code. Canadian Journal of Civil Engineering,, v.21, p.36-49.

NOWAK, A.S. (1995). Calibration of LRFD bridge code. Journal of Structural Engineering, v.121, n.8, p.1245-1251, aug.

NOWAK, A.S.; EL-HOR, H.H. (1995). Serviceability criteria for prestressed concrete bridge girders. Transportation Research Board, Conference Proceedings 7, vol.2, p.181-187.

NOWAK, A.S.; GROUNI, H.N. (1994). Calibration of the Ontario Highway Bridge Design Code 1991 edition. Canadian Journal of Civil Engineering,, v.21, p.25-35.

NOWAK, A.S.; LAMAN, J.A.; NASSIF, H. (1994). Effect of truck loading on bridges. Report UMCE 94-22, University of Michigan, Ann Arbor.

NOWAK, A.S.; PARK, C.H.; CASAS, J.R. (2001). Reliability analysis of prestressed concrete bridge girders: comparison of Eurocode, Spanish Norma IAP and AASHTO LRFD. Structural Safety, v.23, p.331-344.

NOWAK, A.S.; SZERSZEN, M.M. (2003). Calibration of design code for buildings (ACI 318): Part 2 - Reliability analysis and resistance factors. ACI Structural Journal, v.100, n.3, p.383-391, may-june.

ROCHA, A.M. (1972). Novo curso prático de concreto armado: cálculo das estruturas de concreto protendido. v.5, 2.ed. Rio de Janeiro: Editora Científica.

SANTOS, M.F. (2003). Contribuição ao estudo do efeito de combinação de veículos de carga sobre pontes rodoviárias de concreto. 152p. Dissertação (Mestrado) - Escola de 
Engenharia de São Carlos, Universidade de São Paulo, São Carlos. 2003.

SOARES, R.C. (2001). Um estudo sobre modelos mecânico-probabilísticos para pórticos de concreto armado. 258p. Tese (Doutorado) - Escola de Engenharia de São Carlos, Universidade de São Paulo, São Carlos. 2001.

TABSH, S.W.; NOWAK, A.S. (1991). Reliability of highway girder bridges. Journal of Structural Engineering, v.117, n.8, p.2372-2388, aug.

THOFT-CHRISTENSEN, P. et al (1997). Assessment of the reliability of concrete slab bridges. In: Reliability and optimization of structural systems - Proceedings of the seventh IFIP WG7.5 working conference on reliability and optimization of structural systems, 1996, Boulder. Oxford: Pergamon, p.321-328.

YANG, S-I; GHARAIBEH, E.S.; FRANGOPOL, D.M.; NEVES, L.C. (2002). System reliability for bridge evaluation and service life prediction. In: First International Conference on Bridge Maintenance, Safety and Management, 2002, Barcelona. 
APÊNDICE A - Pesagem de veículos:

Autoban, Autovias e Rodonorte 
De modo a complementar o estudo sobre o carregamento móvel, foram obtidos dados sobre a pesagem de caminhões junto a Autoban, Autovias e Rodonorte. Não se pretende desenvolver novos modelos de carga móvel referentes a cada série de dados, e sim verificar a composição do tráfego e as características das distribuições dos pesos dos veículos, indicando tendências em outras regiões de circulação e outros períodos de coleta.

\section{A.1 Descrição das pesagens}

\section{A.1.1 Autoban}

A Autoban forneceu pesagens de caminhões referentes ao mês de junho de 2005. Os dados referem-se à pesagem lenta (repesagem) em uma balança fixa localizada no km 53 da Rodovia Anhanguera (SP-330). Durante o período, foram amostrados 19.500 veículos. Também foram disponibilizadas pesagens referentes a uma balança móvel. No entanto, nesse caso, os tipos de caminhões não estão identificados, o que inviabiliza sua análise.

\section{A.1.2 Autovias}

Os dados enviados pela Autovias referem-se aos seguintes pontos de pesagem:

\footnotetext{
$\checkmark$ SP-255 - Rodovia Antonio Machado Sant’Anna - km 26 pista sul

$\checkmark$ SP-330 - Rodovia Anhanguera - km 266 pista sul

$\checkmark$ SP-334-Rodovia Cândido Portinari - km 334,1 pista sul
}

Os períodos e o total de veículos amostrados estão na tabela abaixo.

Tabela A1 - Períodos de coleta e total de veículos amostrados.

\begin{tabular}{|c|c|c|c|}
\hline Rodovia & Data inicial & Data final & Número de veículos \\
\hline SP-255 & $13 / 07 / 2005$ & $23 / 08 / 2005$ & 9118 \\
\hline SP-330 & $12 / 04 / 2005$ & $24 / 06 / 2005$ & 7871 \\
\hline SP-334 & $22 / 12 / 2004$ & $12 / 01 / 2005$ & 2223 \\
\hline
\end{tabular}


Todas as pesagens são do tipo dinâmica móvel.

\section{A.1.3 Rodonorte}

A Rodonorte forneceu ao todo 204.047 pesagens, entretanto na maior parte dos dados não há classificação dos veículos. Foram aproveitadas 14.252 amostragens, obtidas na BR-277, km 133 sul, no trecho Curitiba - São Luís do Purunã. O tipo de pesagem utilizada foi a de precisão (lenta). O período de coleta dos dados foi de 15/02/2005 a 04/03/2005.

\section{A.2 Composição do tráfego}

A composição do tráfego de caminhões interfere na extrapolação dos pesos brutos para o desenvolvimento do modelo de carregamento móvel. Mantendo-se os mesmos veículos selecionados no capítulo 4, a figura A1 mostra a comparação entre os dados fornecidos pelas diversas concessionárias de rodovias.

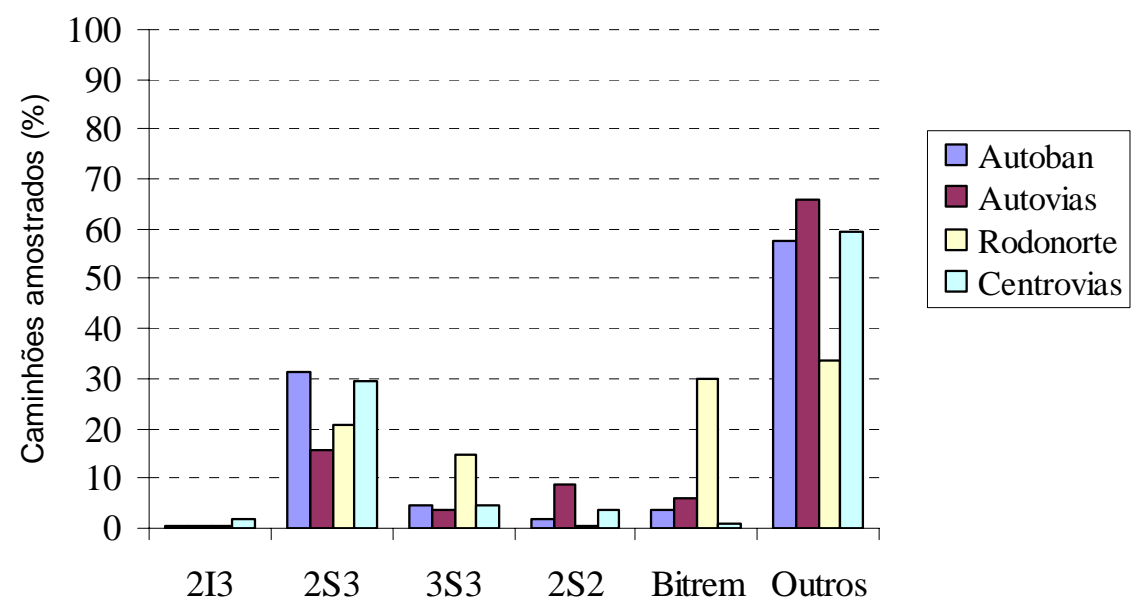

Figura A1 - Resumo das amostragens de acordo com cada conjunto de dados.

A análise da figura A1 não mostra grande diferença entre os dados fornecidos pela Autoban, Autovias e Centrovias. No entanto, as pesagens obtidas junto à Rodonorte apresentam características singulares em relação às demais, especialmente no que se refere à porcentagem dos caminhões bitrem.

A comparação entre os caminhões selecionados para o desenvolvimento do modelo de carregamento móvel está na figura A2. Destaca-se a similaridade entre os 
dados provenientes da Autoban e da Centrovias.

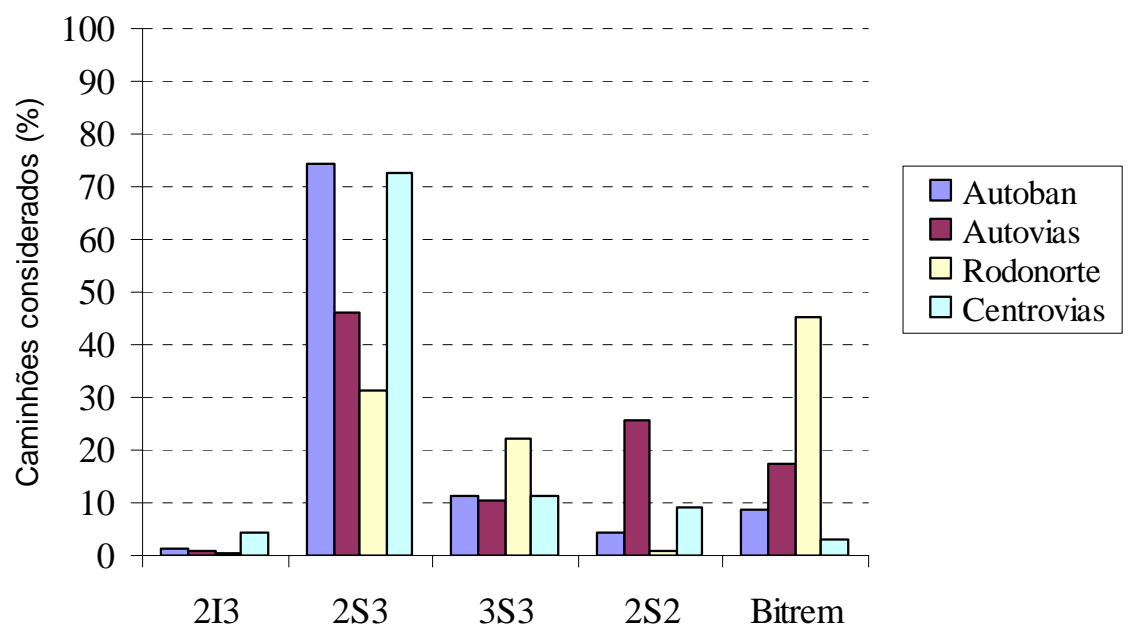

Figura A2 - Porcentagens dos caminhões selecionados.

\section{A.3 Distribuiç̧̃es dos pesos brutos}

As distribuições de pesos brutos em papel de probabilidade normal, para cada caminhão selecionado no capítulo 4, estão nas figuras A3 a A7.

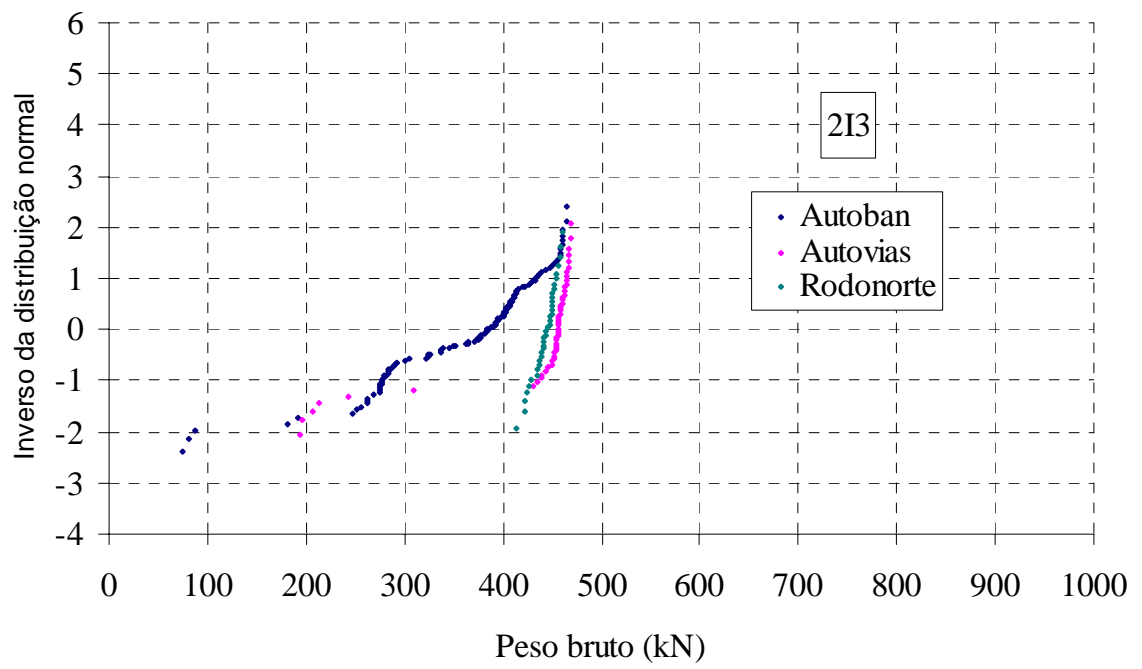

Figura A3 - Distribuições de pesos brutos - caminhão 2I3. 


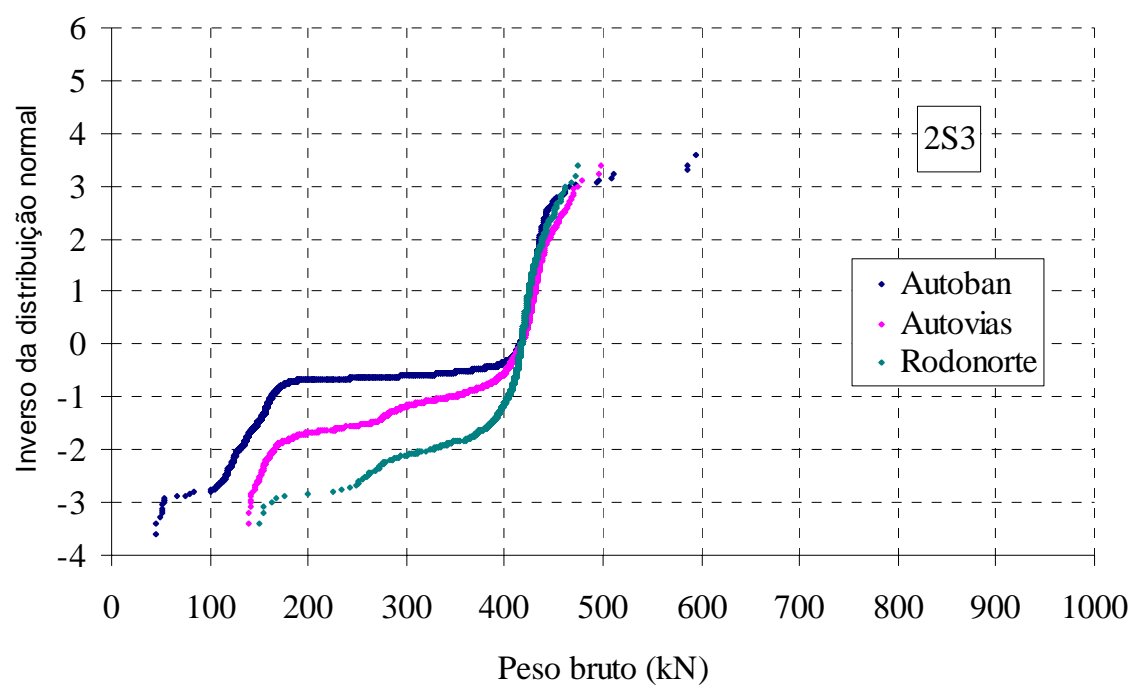

Figura A4 - Distribuições de pesos brutos - caminhão 2S3.

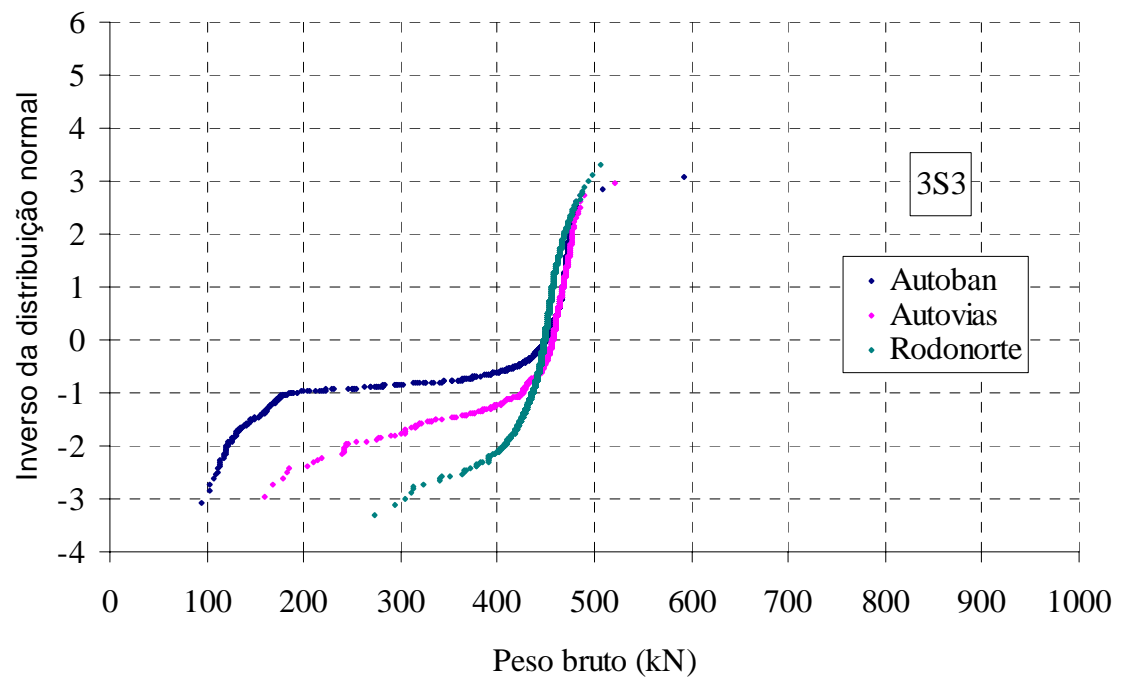

Figura A5 - Distribuições de pesos brutos - caminhão 3 S3.

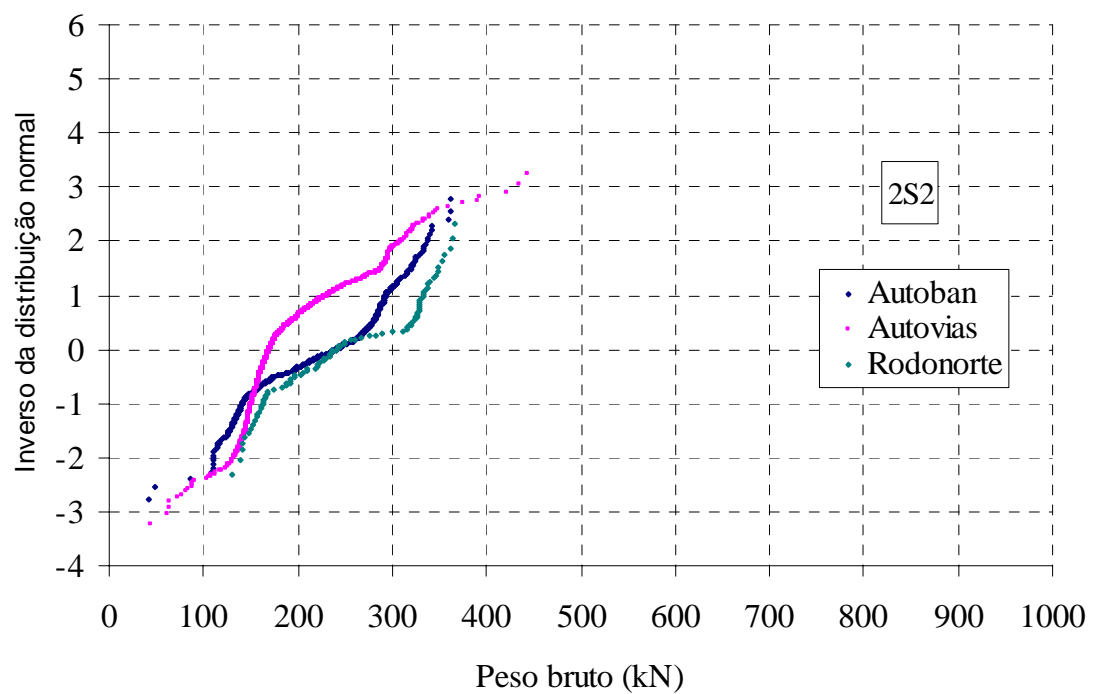

Figura A6 - Distribuições de pesos brutos - caminhão 2S2. 


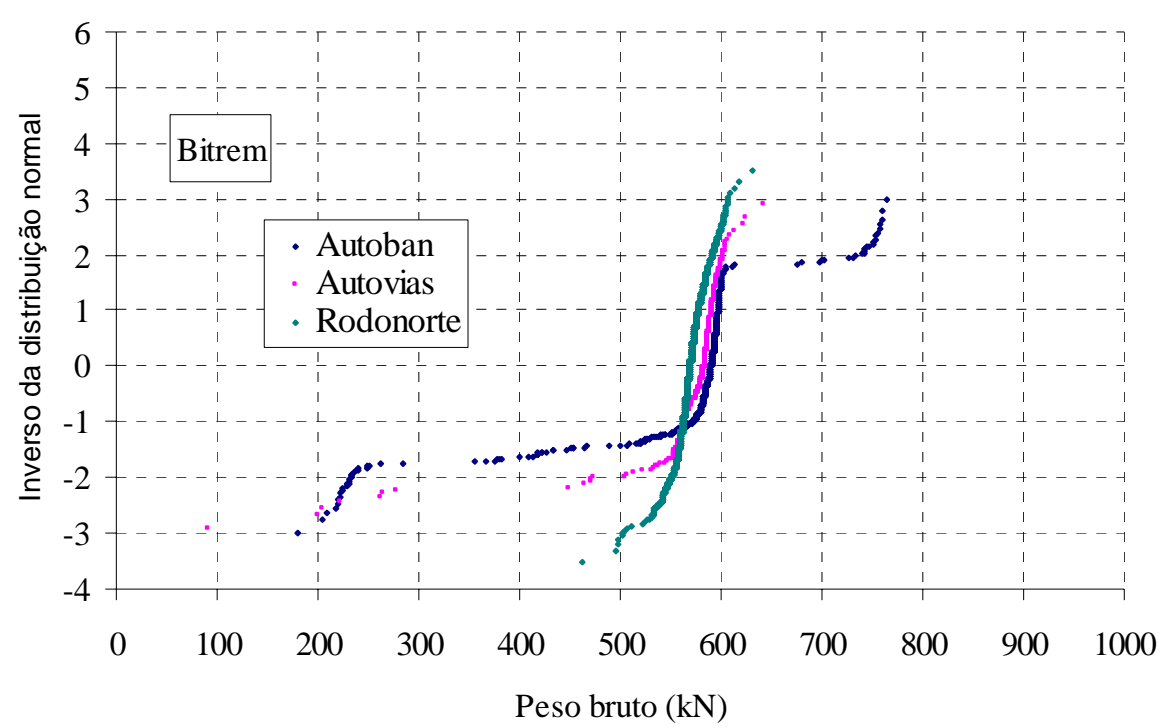

Figura A7 - Distribuições de pesos brutos - bitrem.

A análise das figuras anteriores indica:

a) 2I3: as caudas superiores das distribuições apresentam pequena variabilidade, de maneira similar aos dados da Centrovias. Os pesos brutos, no entanto, são ligeiramente inferiores;

b) 2S3: as pesagens fornecidas pela Autoban se aproximam bastante dos resultados fornecidos pela Centrovias. Os dados da Rodonorte apresentam menor variabilidade se comparadas às demais;

c) 3S3: as curvas referentes à Autoban e à Autovias são semelhantes e indicam a mesma tendência da Centrovias na cauda superior. Entretanto, há poucos registros de caminhões com peso superior a $500 \mathrm{kN}$ e o veículo mais pesado não atinge 600 kN. Por sua vez, as pesagens da Centrovias flagram um caminhão com cerca de 900 kN. Atribui-se esse fato, à grande discrepância no número total de amostragens;

d) 2S2: somente os dados da Rodonorte indicam maior variabilidade nos máximos pesos brutos, porém não apresentam valores elevados e a extrapolação atinge aproximadamente $600 \mathrm{kN}$ apenas;

e) Bitrem: é o único veículo em que as pesagens atuais mostram maior variabilidade e maiores pesos brutos em relação aos dados da Centrovias de 2001 e 2002. No entanto, os veículos mais sobrecarregados apresentam pesos similares aos do bitrenzão, indicando que pode haver um erro de identificação nas planilhas de pesagem. 


\section{A.4 Extrapolação dos pesos brutos}

A partir do conjunto de dados fornecidos pela Autoban, e considerando-se apenas os veículos 2S3 e 3S3 (utilizados no modelo de carregamento móvel), a extrapolação de pesos para o período de vida útil das obras de arte pode ser vista nas figuras A8 e A9. Admitem-se veículos curtos com probabilidade de ocorrência de 20\% em relação aos longos e 650 veículos/dia no posto de pesagem lenta.

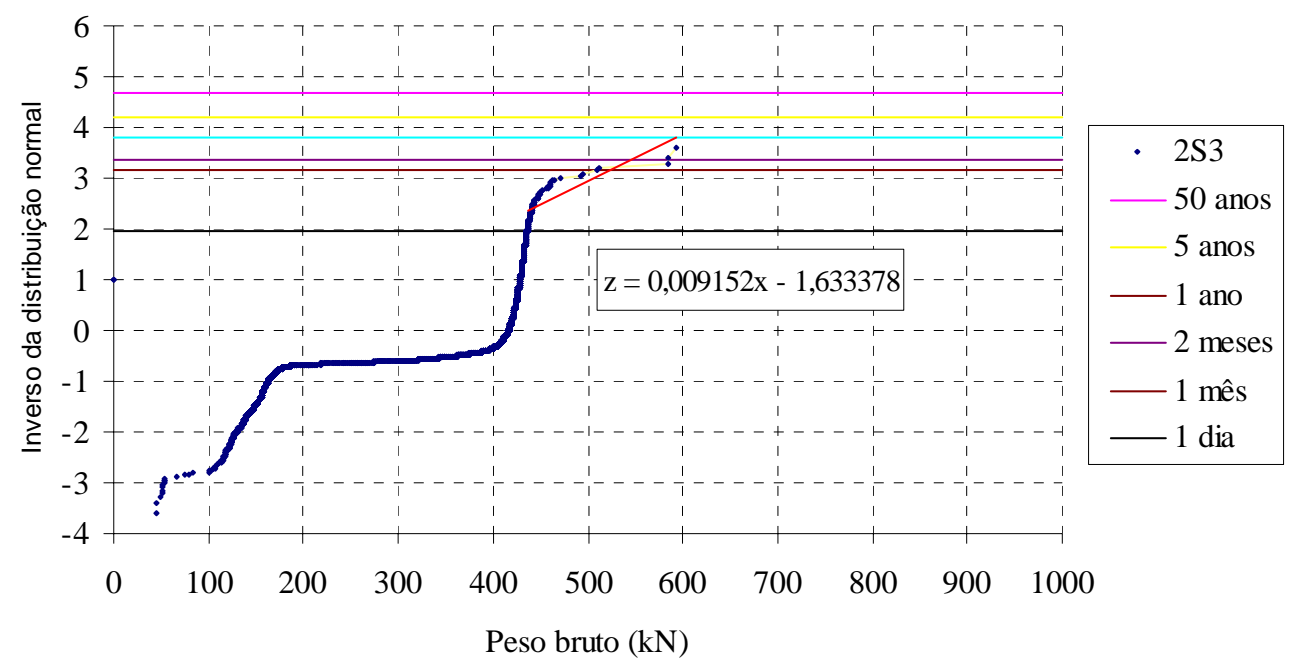

Figura A8 - Extrapolação de pesos brutos - 2S3.

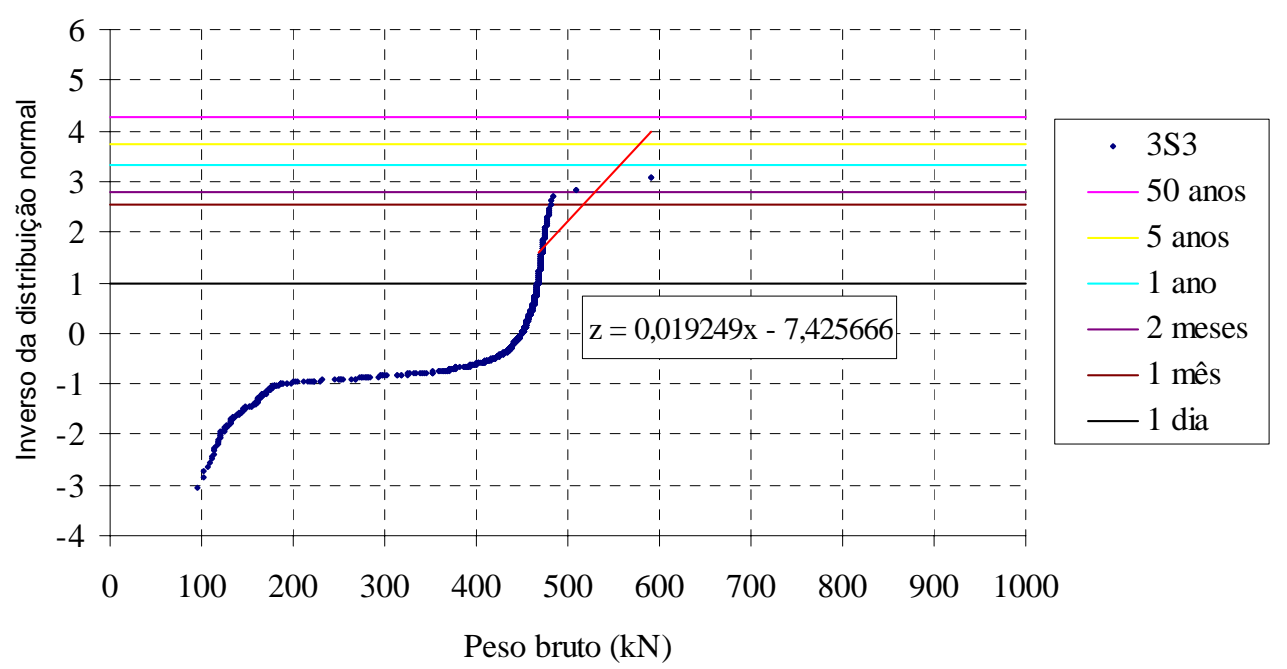

Figura A9 - Extrapolação de pesos brutos - 3S3.

A tabela A2 mostra os pesos que seriam utilizados no modelo de carregamento móvel caso fossem utilizados os dados da Autoban. 
Tabela A2 - Pesos brutos (kN) a partir dos dados da Autoban.

\begin{tabular}{|c|c|c|c|c|}
\hline \multirow{2}{*}{ Probabilidades } & \multicolumn{2}{|c|}{ Peso (kN) } & \multicolumn{2}{c|}{ CV } \\
\cline { 2 - 5 } & 2S3 & 3S3 & 2S3 & 3S3 \\
\hline 50 anos & 691,3 & 608,6 & 0,158 & 0,085 \\
\hline $1 / 500$ & 528,9 & 521,5 & 0,207 & 0,100 \\
\hline $1 / 75$ & - & 552,3 & - & 0,094 \\
\hline $1 / 50$ & - & 558,3 & - & 0,093 \\
\hline Médio & 416,0 & - & 0,036 & - \\
\hline
\end{tabular}

Observa-se que as características do veículo 2S3 provenientes das pesagens da Autoban são muito similares àquelas obtidas através dos dados da Centrovias. A semelhança ocorre tanto na sua porcentagem em relação ao total de veículos amostrados quanto nos pesos e coeficientes de variação. Uma vez fixados os mesmos índices de confiabilidades desejáveis, os dados da Centrovias e da Autoban resultariam então em ECPLs muito parecidas, pois o caminhão secundário seria praticamente o mesmo.

Por outro lado, a diferença entre os dados obtidos junto às 2 concessionárias é marcante em relação à determinação da segurança das obras de arte. Os veículos 3S3 oriundos das pesagens da Autoban possuem pesos muito inferiores aos calculados com os dados da Centrovias. Como conseqüência, o modelo de carregamento móvel desenvolvido com os dados acima resultaria em maiores betas se comparados aos obtidos no capítulo 5. Também haveria a inversão dos veículos principais e secundários. Atribui-se esse conjunto de modificações ao menor número de amostragens e ao tipo de balança (fixa) realizada pela Autoban.

\section{A.5 Conclusões sobre a pesagem de veículos}

A análise dos dados obtidos mostra a importância do número de pesagens. Nesse aspecto, o modelo de carregamento móvel desenvolvido a partir dos dados da Centrovias pode ser considerado confiável, pois o número de amostragens é significativo e bem superior às demais concessionárias. Além disso, os dados foram obtidos com uma balança móvel, que aumenta as chances de identificar veículos sobrecarregados, e o período de coleta é amplo, abrangendo ininterruptamente quase 2 anos completos.

O estudo das pesagens de veículos indica que a quantificação da segurança com base nos dados da Centrovias está a favor da segurança e as ECPLs representam uma 
envoltória adequada para os máximos PBTCs compatíveis com a capacidade estrutural das obras de arte nacionais. 
APÊNDICE B - Alterações no modelo de carregamento móvel 
A seguir, é verificado o efeito que alterações no modelo de carregamento móvel produzem na segurança das pontes. Mais especificamente, é designado outro caminhão como veículo principal e são aumentadas as probabilidades de presença simultânea em uma das hipóteses analisadas.

\section{B.1 Alterações efetuadas}

Considera-se agora que, no caso de 2 caminhões sobre as pontes, o caminhão principal seja um 2S3 curto e que o segundo veículo seja um 3S3 curto. Dessa forma, mantêm-se os mesmos caminhões do modelo original, alterando-se apenas sua denominação (principal ou secundário). Devido às diferentes distribuições de pesos brutos e diferentes porcentagens no total de veículos amostrados, o modelo de carregamento móvel é alterado.

Os novos casos de presença simultânea considerados estão na tabela B1. Salienta-se o aumento nas probabilidades da primeira hipótese em relação aos valores apresentados na tabela 4.4 .

Tabela B1 - Probabilidade de ocorrência simultânea.

\begin{tabular}{|c|c|c|c|c|}
\hline \multirow{2}{*}{ Hipótese } & \multicolumn{2}{|c|}{ Caminhões em fila } & \multicolumn{2}{c|}{ Caminhões lado a lado } \\
\cline { 2 - 5 } & $\mathrm{TE}$ & $\mathrm{TL}$ & $\mathrm{TE}$ & $\mathrm{TL}$ \\
\hline 1 & $1 / 50$ & $1 / 50$ & $1 / 20$ & $1 / 50$ \\
\hline 2 & $1 / 500$ & $1 / 500$ & $1 / 500$ & $1 / 500$ \\
\hline
\end{tabular}

O conjunto dessas alterações reduz em aproximadamente $180 \mathrm{kN}$ o peso do caminhão principal em relação ao modelo original, enquanto o veículo secundário tem seu peso aumentado cerca de $43 \mathrm{kN}$ (hipótese 1). A hipótese 2 se mantém inalterada. $\mathrm{O}$ resumo do novo modelo a ser testado pode ser visto na tabela B2. 
Tabela B2 - Resultado das alterações no modelo de carregamento móvel (kN).

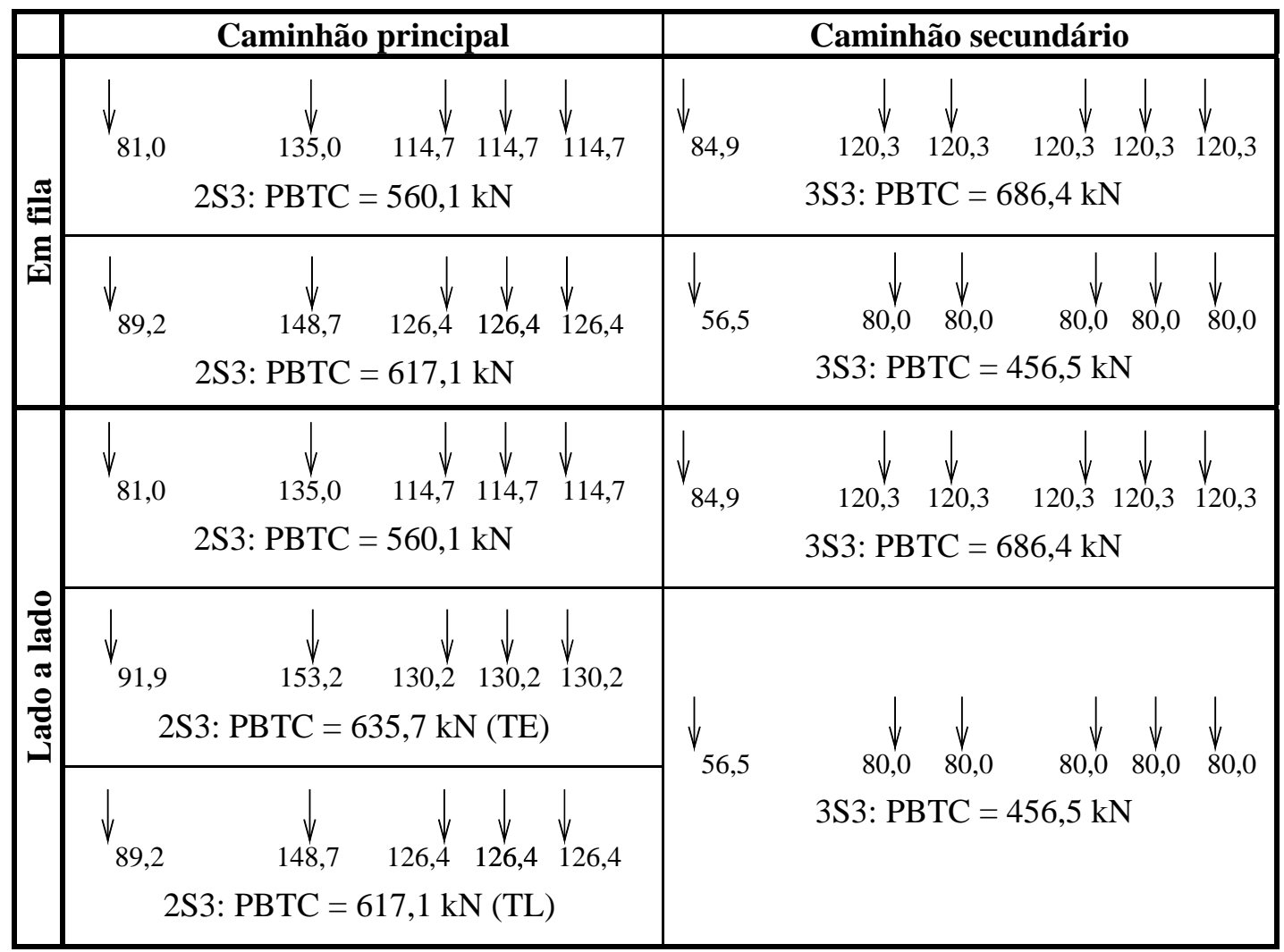

\section{B.2 Índices de confiabilidade}

De modo a limitar o número de análises realizadas no software STRAP, foram calculados os índices de confiabilidade para essa nova situação de carregamento nas 4 pontes de 2 vigas simplesmente apoiadas (v. tabela B3).

Tabela B3 - Índices de confiabilidade após alterações no modelo de carga móvel VIGA T - 2 VIGAS.

\begin{tabular}{|c|c|c|c|}
\hline Ordem & Arquivo & Classe 36 & Classe 45 \\
\hline 1 & SA TE V10 TR2 & 3,11 & 3,47 \\
\hline 2 & SA TE V20 TR2 & 3,37 & 3,48 \\
\hline 10 & SA TL V10 TR2 & 3,07 & 3,47 \\
\hline 11 & SA TL V20 TR2 & 3,40 & 3,57 \\
\hline \multicolumn{2}{|c|}{ MÉDIA } & $\mathbf{3 , 2 4}$ & $\mathbf{3 , 5 0}$ \\
\hline
\end{tabular}

A comparação entre as tabelas B3 e 5.2 (capítulo 5) mostra que a diferença entre os modelos de carregamento em termos dos índices de confiabilidade existe apenas na ponte de ordem 11. Nos demais casos, o carregamento crítico é a presença de 1 caminhão apenas (ordens 1 e 2) e a presença de 2 veículos lado a lado com 
probabilidades iguais (ordem 10). Quanto à ponte de ordem 11, embora o peso do veículo principal seja menor, as diferenças no comprimento do caminhão e no coeficiente de variação, justificam a ligeira redução nos betas.

Apesar do reduzido número de pontes analisadas, nota-se que pequenas modificações na presença simultânea de caminhões praticamente não alteram os índices de confiabilidade.

Considera-se que o modelo de carregamento móvel, devido aos 3 casos considerados (caminhão isolado, caminhões em fila e caminhões lado a lado), além das diferentes relações entre seus pesos brutos, tem capacidade de representar o tráfego real nos sistemas estruturais estudados. 
APÊNDICE C - Presença simultânea de 3 veículos 
Em pontes de tabuleiro largo e/ou pontes longas, o efeito de 3 caminhões pode ser crítico durante a verificação da segurança e posteriormente no cálculo das ECPLs. No entanto, sabe-se que a coincidência de 3 caminhões sobrecarregados atravessando a ponte simultaneamente, com configurações críticas (veículos curtos) e em posições relativas que conduzam a uma situação de máximo momento fletor é bastante baixa.

A título de verificação, desenvolve-se a seguir a inclusão de um terceiro veículo no modelo de carregamento móvel.

\section{C.1 Descrição do modelo de carregamento móvel com 3 veículos}

São admitidas as seguintes hipóteses para a determinação do caso crítico de carregamento:

a) 1 caminhão isolado;

b) 2 caminhões em fila;

c) 3 caminhões lado a lado.

Os casos de 1 caminhão isolado e 2 caminhões em fila se mantêm idênticos ao modelo desenvolvido no capítulo 4 . Na verificação de 3 veículos lado a lado, apenas é acrescentado um terceiro caminhão na faixa adjacente.

Limita-se a análise às pontes de tabuleiro largo, que comportam um caminhão adicional lado a lado. As pontes de tabuleiro estreito, que possuem somente 2 faixas de tráfego, requerem a disposição ou de 3 caminhões em fila (alternativa válida apenas para pontes mais longas que as consideradas neste trabalho) ou de 2 veículos em fila e 1 lado a lado. Entretanto, a disposição de caminhões em fila não é crítica e o modelo com apenas 2 caminhões é adequado para a verificação da segurança estrutural das obras de arte de tabuleiro estreito.

O veículo a ser inserido na terceira faixa de tráfego é um caminhão do tipo 2S2 (terceiro caminhão mais freqüente nas planilhas de pesagem da Centrovias) com peso médio. Embora fosse possível a redução no peso dos caminhões já presentes no modelo (3S3 e 2S3, ambos curtos), devido à redução na probabilidade de ocorrência do evento, a manutenção do carregamento original e a simples inclusão de um terceiro veículo buscam a verificação de um cenário mais pessimista para a segurança das pontes. 
O veículo 2S2 médio é mostrado na figura C1. Apesar do peso bruto não ser elevado, seu coeficiente de variação é significativo

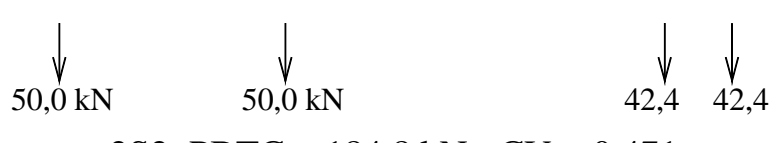

2S2: $\mathrm{PBTC}=184,8 \mathrm{kN}-\mathrm{CV}=0,471$

Figura C1 - Caminhão 2S2 com peso médio.

\section{C.2 Índices de confiabilidade}

Foram calculados os índices de confiabilidade relativos ao modelo de carregamento móvel descrito anteriormente. As pontes que apresentam maior redução em relação aos valores calculados no capítulo 5 são as pontes celulares, em que efeito do novo veículo inserido representa uma parcela maior no efeito do carregamento total. Em algumas estruturas, não há alteração nos betas, devido ao caso crítico ser proveniente de um caminhão isolado.

Numericamente, a diminuição mais significativa no índice de confiabilidade é de 0,42, referente a uma ponte protendida com seção celular (SA TL V20 STR) no estado limite último. Entretanto na maioria dos casos, a redução não ultrapassa 0,25.

A análise dos resultados sugere que as mudanças verificadas não são suficientes para introduzir modificações nos índices de confiabilidade desejáveis utilizados para a calibração das ECPLs.

\section{C.3 ECPLs}

O procedimento a ser desenvolvido para a obtenção das ECPLs é basicamente o mesmo descrito no item 6.3. No entanto, admitindo-se a possibilidade da presença de 3 veículos sobre as pontes, após determinado o momento fletor obtido com o $\beta_{\text {alvo }}$ selecionado, são seguidos os seguintes passos:

a) É subtraído o momento fletor devido à carga permanente;

b) É subtraída a parcela dinâmica do efeito da carga móvel;

c) É subtraído o efeito do primeiro caminhão que acompanha o veículo principal, ou seja, é retirado o momento fletor devido a um caminhão 2S3 com probabilidade de 
1/500. Se a situação crítica de carregamento forem 2 caminhões em fila, o veículo 2S3 é posicionado na mesma faixa do veículo principal. Caso contrário, é disposto na faixa adjacente;

d) É subtraído o efeito devido ao caminhão 2S2, considerado como o segundo veículo que acompanha àquele representado pela ECPL. É sempre disposto em faixa adjacente e, portanto, esta operação não é realizada quando o caso crítico de carregamento forem veículos em fila.

Em se tratando de pontes de tabuleiro largo, onde é implementado o modelo com 3 veículos, apenas 1 caso é governado por caminhões em fila.

Obtido o momento fletor resultante das operações indicadas, o restante do procedimento é idêntico ao utilizado para a análise de 2 veículos sobre as pontes.

Quanto às demais hipóteses, repetem-se as mesmas utilizadas no capítulo 6: são feitas as correções devido à diferença entre o carregamento distribuído e o carregamento de grupo de eixos, e se reduzem os máximos pesos brutos em 5\%, em acordo com a tolerância permitida pela lei.

\section{C.3.1 Estado limite último}

Os limites de pesos resultantes de cada sistema estrutural estão na figura C2. Mantendo-se a coerência com as observações feitas no capítulo 6 sobre as pontes de 2 vigas simplesmente apoiadas com balanços de 3 metros, os momentos fletores negativos provenientes dessas pontes não foram consideradas na análise.
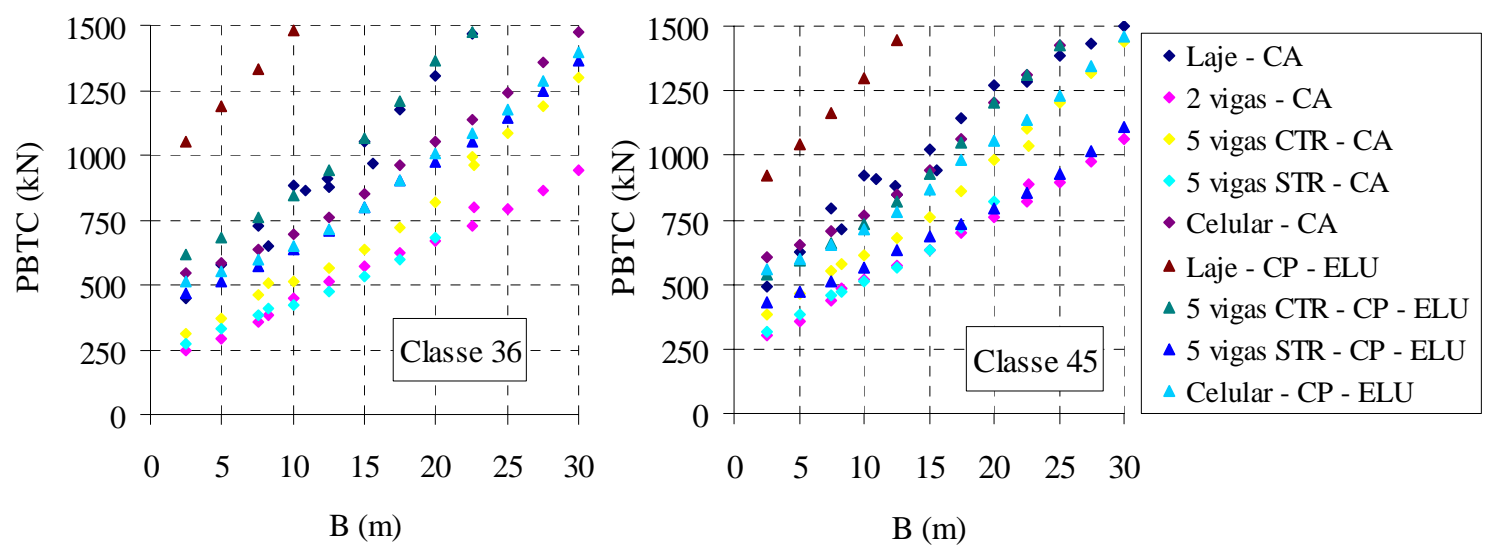

Figura C2 - Casos críticos para o estado limite último 
As ECPLs são obtidas fixando-se os comprimentos dos grupos de eixos iguais a 2,5 m e 17,5 m (v. figura C3).

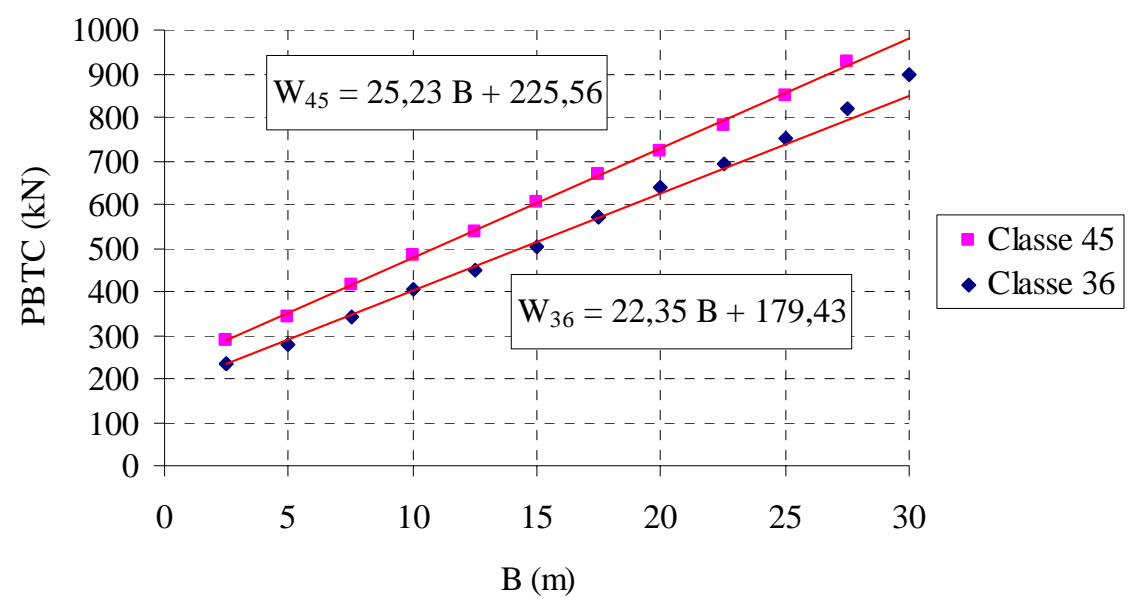

Figura C3 - ECPLs para o estado limite último.

A tabela C1 mostra o resultado numérico das equações acima.

Tabela C1 - Pesos brutos provenientes das ECPLs para o ELU.

\begin{tabular}{|c|c|c|}
\hline \multirow{2}{*}{ B (m) } & \multicolumn{2}{|c|}{ PBTC (kN) } \\
\cline { 2 - 3 } & Classe 36 & Classe 45 \\
\hline 2,5 & 235,3 & 288,6 \\
\hline 5,0 & 291,2 & 351,7 \\
\hline 7,5 & 347,1 & 414,8 \\
\hline 10,0 & 402,9 & 477,9 \\
\hline 12,5 & 458,8 & 540,9 \\
\hline 15,0 & 514,7 & 604,0 \\
\hline 17,5 & 570,6 & 667,1 \\
\hline 20,0 & 626,4 & 730,2 \\
\hline 22,5 & 682,3 & 793,2 \\
\hline 25,0 & 738,2 & 856,3 \\
\hline 27,5 & 794,1 & 919,4 \\
\hline 30,0 & 849,9 & 982,5 \\
\hline
\end{tabular}

\section{C.3.2 Estado limite de serviço}

A consideração de 3 veículos sobre as pontes, em se tratando do estado limite de formação de fissuras, resulta nos limites apresentados na figura C4. 

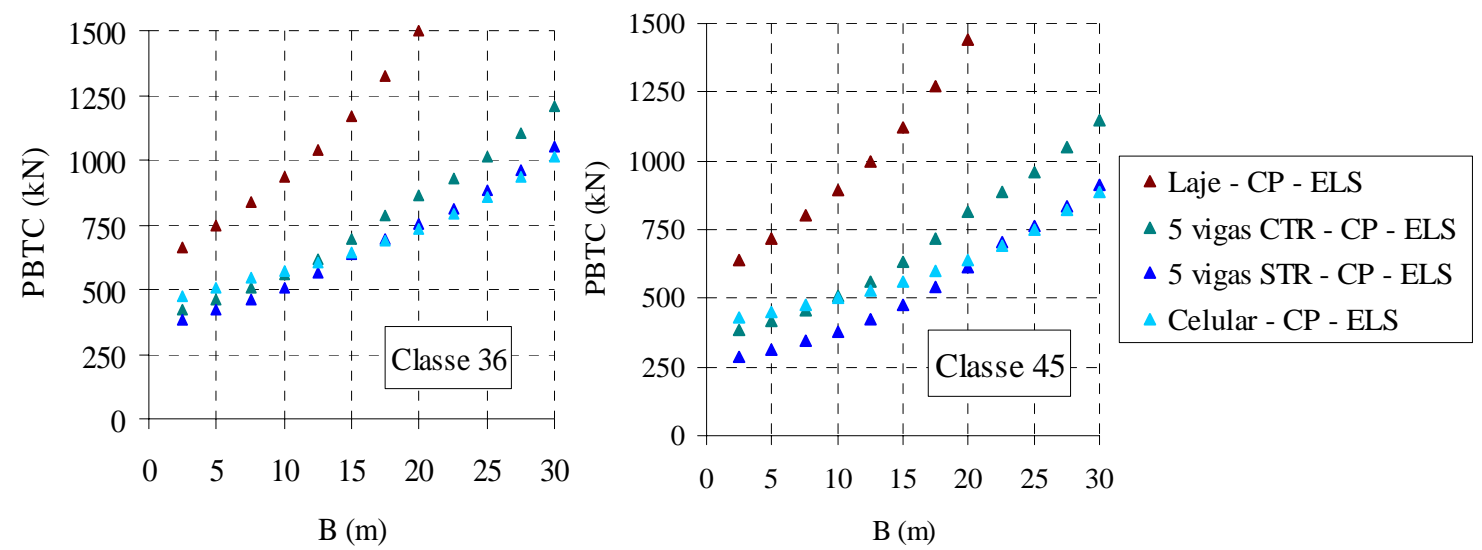

Figura C4 - Casos críticos para o estado limite de serviço.

A envoltória dos menores pesos brutos relativos à classe 36 pode ser bem representada por uma reta que contenha esses pontos. Quanto à classe 45, o conjunto de pontos é melhor descrito por 2 retas de inclinações diferentes. Nesse caso, os PBTCs relativos à B igual a 2,5, 12,5 e 30 metros fixam os parâmetros das equações. Os limites de peso podem ser vistos na figura C5 e na tabela C2.

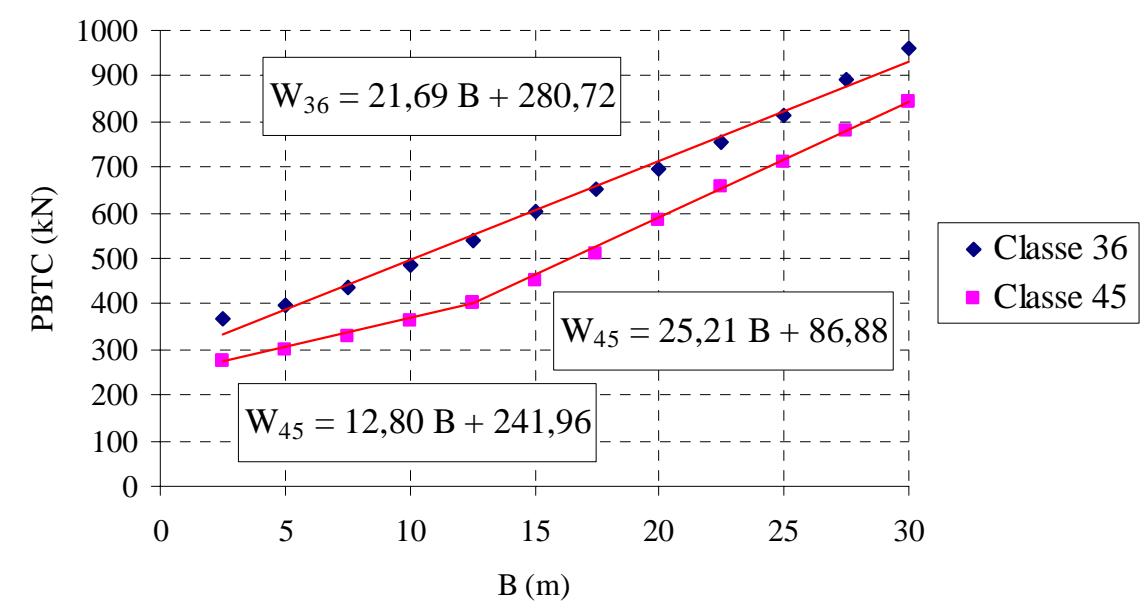

Figura C5 - ECPLs para o estado limite de serviço. 
Tabela C2 - Pesos brutos provenientes das ECPLs para o ELS.

\begin{tabular}{|c|c|c|}
\hline \multirow{2}{*}{ B (m) } & \multicolumn{2}{|c|}{ PBTC (kN) } \\
\cline { 2 - 3 } & Classe 36 & Classe 45 \\
\hline 2,5 & 334,9 & 274,0 \\
\hline 5,0 & 389,2 & 306,0 \\
\hline 7,5 & 443,4 & 338,0 \\
\hline 10,0 & 497,6 & 370,0 \\
\hline 12,5 & 551,8 & 402,0 \\
\hline 15,0 & 606,1 & 465,0 \\
\hline 17,5 & 660,3 & 528,1 \\
\hline 20,0 & 714,5 & 591,1 \\
\hline 22,5 & 768,7 & 654,1 \\
\hline 25,0 & 823,0 & 717,1 \\
\hline 27,5 & 877,2 & 780,2 \\
\hline 30,0 & 931,4 & 843,2 \\
\hline
\end{tabular}

\section{C.4 Verificação dos resultados obtidos}

A comparação entre as ECPLs resultantes da consideração de 2 ou 3 veículos sobre as pontes está nas figuras C6 para o estado limite último. A diminuição nos máximos pesos brutos depende do comprimento do grupo de eixos e da classe da obra de arte.

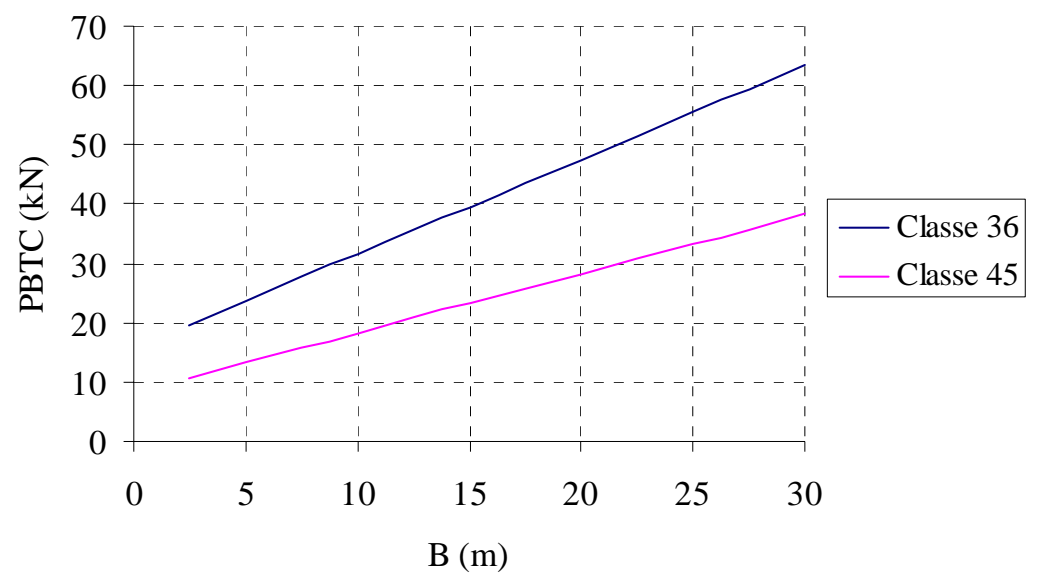

Figura C6 - Redução no PBTC devido à inclusão de um terceiro veículo - ELU.

As conseqüências do emprego das ECPLs nos veículos típicos estão nas tabelas C3 e C4. 
Tabela C3 - Situação de alguns veículos de acordo com o ELU.

\begin{tabular}{|c|c|c|c|c|c|c|}
\hline \multirow{2}{*}{ Caminhão } & \multirow{2}{*}{ PBTC (kN) } & \multirow{2}{*}{$\mathbf{L}(\mathbf{m})$} & \multirow{2}{*}{$\mathbf{B}(\mathbf{m})$} & \multirow{2}{*}{ Peso nominal $(\mathrm{kN})$} & \multicolumn{2}{|c|}{ W (kN) } \\
\hline & & & & & Classe 36 & Classe 45 \\
\hline Basculante & 450 & 13,50 & 10,90 & 450 & 423,0 & 500,6 \\
\hline \multirow{2}{*}{ Bitrem } & \multirow{2}{*}{570} & \multirow{2}{*}{18,72} & 5,59 & 340 & 304,4 & 366,6 \\
\hline & & & 15,62 & 570 & 528,5 & 619,7 \\
\hline \multirow{2}{*}{ Bitrenzão } & \multirow{2}{*}{740} & \multirow{2}{*}{24,90} & 11,15 & 510 & 428,6 & 506,9 \\
\hline & & & 22,49 & 740 & 682,1 & 793,0 \\
\hline \multirow{2}{*}{ Rodotrem } & \multirow{2}{*}{740} & \multirow{2}{*}{19,80} & 4,65 & 340 & 283,4 & 342,9 \\
\hline & & & 17,53 & 740 & 571,2 & 667,8 \\
\hline \multirow{2}{*}{ Rodotrem } & \multirow{2}{*}{740} & \multirow{2}{*}{25,00} & 5,55 & 340 & 303,5 & 365,6 \\
\hline & & & 22,73 & 740 & 687,4 & 799,0 \\
\hline
\end{tabular}

Tabela C4 - Situação de alguns veículos de acordo com o ELS.

\begin{tabular}{|c|c|c|c|c|c|c|}
\hline \multirow{2}{*}{ Caminhão } & \multirow{2}{*}{$\operatorname{PBTC}(\mathbf{k N})$} & \multirow{2}{*}{$\mathbf{L}(\mathbf{m})$} & \multirow{2}{*}{$\mathbf{B}(\mathbf{m})$} & \multirow{2}{*}{ Peso nominal (kN) } & \multicolumn{2}{|c|}{$\mathrm{W}(\mathrm{kN})$} \\
\hline & & & & & Classe 36 & Classe 45 \\
\hline Basculante & 450 & 13,50 & 10,90 & 450 & 517,1 & 381,5 \\
\hline \multirow{2}{*}{ Bitrem } & \multirow{2}{*}{570} & \multirow{2}{*}{18,72} & 5,59 & 340 & 402,0 & 313,5 \\
\hline & & & 15,62 & 570 & 619,5 & 480,7 \\
\hline \multirow{2}{*}{ Bitrenzão } & \multirow{2}{*}{740} & \multirow{2}{*}{24,90} & 11,15 & 510 & 522,6 & 384,7 \\
\hline & & & 22,49 & 740 & 768,5 & 653,9 \\
\hline \multirow{2}{*}{ Rodotrem } & \multirow{2}{*}{740} & \multirow{2}{*}{19,80} & 4,65 & 340 & 381,6 & 301,5 \\
\hline & & & 17,53 & 740 & 660,9 & 528,8 \\
\hline \multirow{2}{*}{ Rodotrem } & \multirow{2}{*}{740} & \multirow{2}{*}{25,00} & 5,55 & 340 & 401,1 & 313,0 \\
\hline & & & 22,73 & 740 & 773,7 & 659,9 \\
\hline
\end{tabular}

A análise do estado limite último mostra que na classe 45 a única restrição claramente observada é quanto à circulação do Rodotrem de 19,8 metros de comprimento. Trata-se do mesmo resultado obtido para o modelo de carregamento móvel com 2 veículos apenas (v. capítulo 6). Em relação à classe 36, aparecem restrições à todos os veículos.

Quanto ao estado limite de serviço, a classe 36 apresenta limitação ao tráfego do rodotrem de 19,8 metros e a classe 45 não é compatível com os veículos apresentados. Nesse caso, os resultados e os comentários são os mesmos já discutidos no capítulo 6. 
APÊNDICE D - ECPLs para a passagem de veículo isolado 
Embora em situações normais de tráfego seja necessário a consideração da presença simultânea de veículos, verificam-se agora os máximos pesos brutos que são obtidos caso se possa garantir que o caminhão correspondente à ECPL está isolado sobre a ponte, sem a presença de nenhum outro veículo comercial. Trata-se de uma situação extraordinária, que pode ser utilizada para o estudo do tráfego de veículos especiais.

\section{D.1 Hipóteses básicas}

O desenvolvimento de ECPLs que abordam a passagem de um veículo isolado sobre o tabuleiro das pontes utiliza as mesmas considerações apresentadas no capítulo 6. Entre elas, citam-se as correções devido à diferença entre o carregamento distribuído e o carregamento de grupo de eixos em relação ao cálculo do momento fletor, a tolerância de 5\% nos pesos brutos permitida pela legislação brasileira e os índices de confiabilidade desejáveis. Também são desenvolvidas separadamente equações para o estado limite último e o estado limite de serviço.

Uma vez determinado o momento fletor correspondente ao $\beta_{\text {alvo }}$ escolhido, são subtraídos apenas o efeito da carga permanente e a parcela dinâmica do carregamento móvel. Assim, não existe veículo secundário que acompanha o caminhão principal. Quanto ao efeito dinâmico, admite-se igual a 15\% da parcela estática devido à presença de um único veículo sobre a ponte (NOWAK, 1999).

\section{D.2 Equações propostas para a passagem de veículo isolado}

\section{D.2.1 Estado limite último}

A figura D1 mostra os limites de pesos impostos por cada sistema estrutural. De maneira similar ao capítulo 6 e ao apêndice C, os momentos fletores negativos provenientes das pontes de 2 vigas simplesmente apoiadas com balanços de 3 metros foram descartados. 

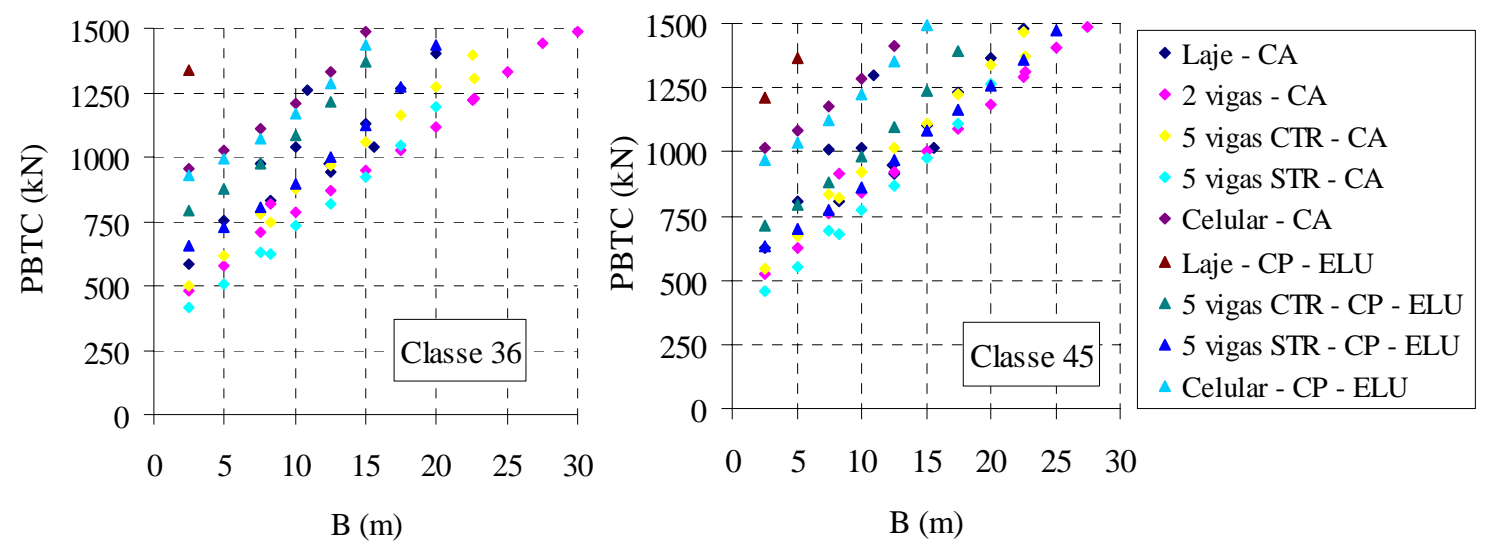

Figura D1 - Casos críticos para o estado limite último - veículo isolado.

Fixando-se os comprimentos dos grupos de eixos iguais a 2,5 m e 17,5 m, as ECPLs obtidas para o estado limite último estão na figura D2.

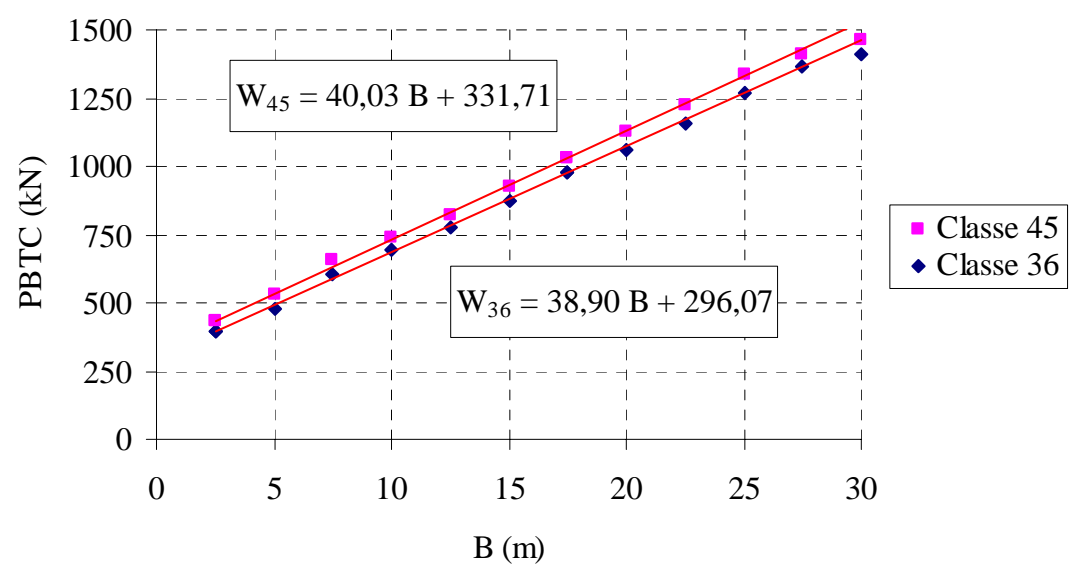

Figura D2 - ECPLs para o estado limite último - veículo isolado.

A tabela D1 mostra o resultado numérico das equações acima. 
Tabela D1 - Pesos brutos provenientes das ECPLs para o ELU.

\begin{tabular}{|c|c|c|}
\hline \multirow{2}{*}{ B (m) } & \multicolumn{2}{|c|}{ PBTC (kN) } \\
\cline { 2 - 3 } & Classe 36 & Classe 45 \\
\hline 2,5 & 393,3 & 431,8 \\
\hline 5,0 & 490,6 & 531,9 \\
\hline 7,5 & 587,8 & 631,9 \\
\hline 10,0 & 685,1 & 732,0 \\
\hline 12,5 & 782,3 & 832,1 \\
\hline 15,0 & 879,6 & 932,2 \\
\hline 17,5 & 976,8 & 1032,2 \\
\hline 20,0 & 1074,1 & 1132,3 \\
\hline 22,5 & 1171,3 & 1232,4 \\
\hline 25,0 & 1268,6 & 1332,5 \\
\hline 27,5 & 1365,8 & 1432,5 \\
\hline 30,0 & 1463,1 & 1532,6 \\
\hline
\end{tabular}

\section{D.2.2 Estado limite de serviço}

Os limites de pesos provenientes do estado limite de serviço considerando-se um veículo isolado sobre a ponte estão na figura D3.
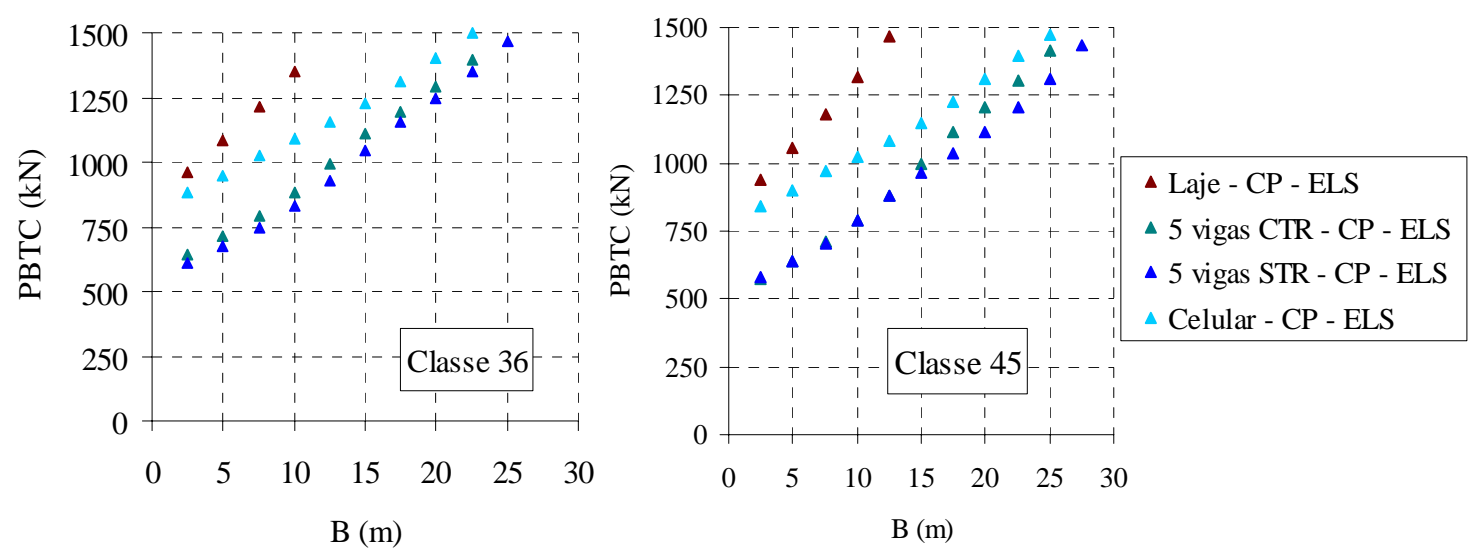

Figura D3 - Casos críticos para o estado limite de serviço - veículo isolado.

A melhor reta que representa os pontos inferiores da figura D3, para as classes 36 e 45, está na figura D4, e os PBTCs resultantes das ECPLs para alguns comprimentos de grupos de eixos estão na tabela D2. 


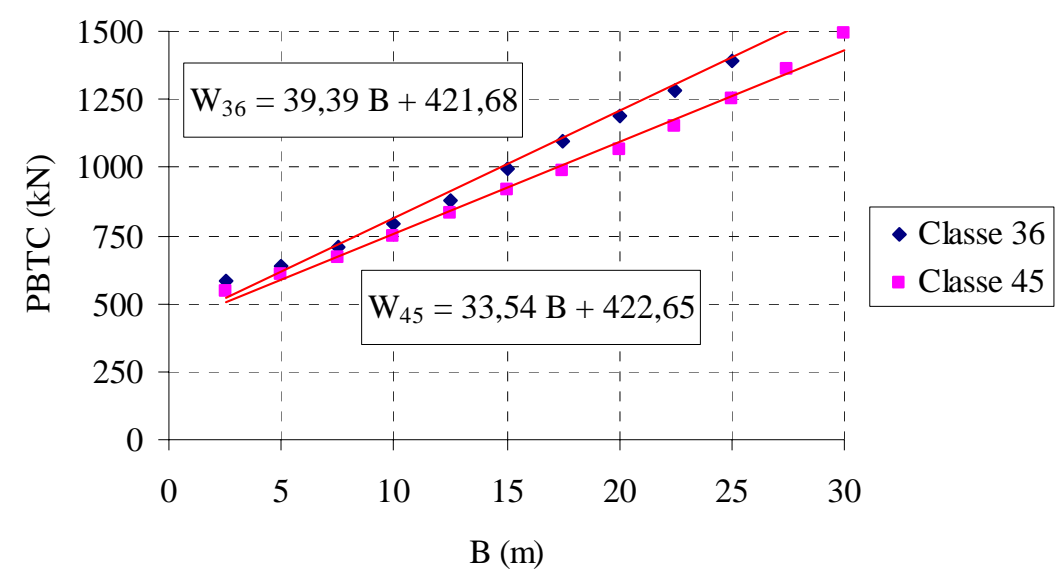

Figura D4 - ECPLs para o estado limite de serviço - veículo isolado.

Tabela D2 - Pesos brutos provenientes das ECPLs para o ELS.

\begin{tabular}{|c|c|c|}
\hline \multirow{2}{*}{ B (m) } & \multicolumn{2}{|c|}{ PBTC (kN) } \\
\cline { 2 - 3 } & Classe 36 & Classe 45 \\
\hline 2,5 & 520,2 & 506,5 \\
\hline 5,0 & 618,6 & 590,4 \\
\hline 7,5 & 717,1 & 674,2 \\
\hline 10,0 & 815,6 & 758,1 \\
\hline 12,5 & 914,1 & 841,9 \\
\hline 15,0 & 1012,5 & 925,8 \\
\hline 17,5 & 1111,0 & 1009,6 \\
\hline 20,0 & 1209,5 & 1093,5 \\
\hline 22,5 & 1308,0 & 1177,3 \\
\hline 25,0 & 1406,4 & 1261,2 \\
\hline 27,5 & 1504,9 & 1345,0 \\
\hline 30,0 & 1603,4 & 1428,9 \\
\hline
\end{tabular}

\section{D.3 Aplicação das ECPLs}

Ressalta-se que as equações propostas nesse apêndice devem ter seu uso limitado a situações específicas, particularmente voltadas à verificação de veículos especiais. O procedimento desenvolvido não requer que esses caminhões transitem obrigatoriamente pelo centro da ponte. 
APÊNDICE E - Tabelas complementares 
Tabela E1 - Momento fletor (kN.m) devido ao carregamento móvel proposto LAJE.

\begin{tabular}{|c|c|c|c|c|c|c|}
\hline Ordem & Arquivo & Esforço & Carregamento & \multicolumn{3}{|c|}{ Momentos fletores } \\
\hline \multirow{5}{*}{1} & \multirow{5}{*}{ SA TE V10 MC } & \multirow{5}{*}{$M+$} & 1 caminhão & 237,1 & & \\
\hline & & & 2 caminhões & \multicolumn{2}{|c|}{ Em fila } & Lado a lado \\
\hline & & & Impacto & sem & com & com \\
\hline & & & Hipótese 1 & 187,2 & 187,2 & 254,0 \\
\hline & & & Hipótese 2 & 161,2 & 161,2 & 244,9 \\
\hline \multirow{5}{*}{2} & \multirow{5}{*}{ SA TL V10 MC } & \multirow{5}{*}{$M+$} & 1 caminhão & \multicolumn{3}{|l|}{217,3} \\
\hline & & & 2 caminhões & \multicolumn{2}{|c|}{ Em fila } & Lado a lado \\
\hline & & & Impacto & sem & com & com \\
\hline & & & Hipótese 1 & 172,4 & 171,6 & 226,0 \\
\hline & & & Hipótese 2 & 148,4 & 147,8 & 221,6 \\
\hline \multirow{5}{*}{3} & \multirow{5}{*}{ SA TE V20 VZ } & \multirow{5}{*}{$M+$} & 1 caminhão & \multicolumn{3}{|l|}{525,2} \\
\hline & & & 2 caminhões & \multicolumn{2}{|c|}{ Em fila } & Lado a lado \\
\hline & & & Impacto & sem & com & com \\
\hline & & & Hipótese 1 & 414,1 & 416,8 & 610,0 \\
\hline & & & Hipótese 2 & 356,8 & 358,9 & 607,0 \\
\hline \multirow{5}{*}{4} & \multirow{5}{*}{ SA TL V20 VZ } & \multirow{5}{*}{$M+$} & 1 caminhão & \multicolumn{3}{|l|}{426,9} \\
\hline & & & 2 caminhões & \multicolumn{2}{|c|}{ Em fila } & Lado a lado \\
\hline & & & Impacto & sem & com & com \\
\hline & & & Hipótese 1 & 337,1 & 339,0 & 475,4 \\
\hline & & & Hipótese 2 & 290,3 & 291,9 & 477,8 \\
\hline & & & 1 caminhão & 190,6 & & \\
\hline & & & 2 caminhões & & & Lado a lado \\
\hline & & $M+$ & Impacto & sem & com & com \\
\hline & & & Hipótese 1 & 154,0 & 151,9 & 196,1 \\
\hline & C3 TE V10/10/10 & & Hipótese 2 & 134,4 & 131,5 & 185,9 \\
\hline 5 & $\mathrm{MC}$ & & 1 caminhão & 197,8 & & \\
\hline & & & 2 caminhões & & & Lado a lado \\
\hline & & M - & Impacto & sem & com & com \\
\hline & & & Hipótese 1 & 156,8 & 156,8 & 176,8 \\
\hline & & & Hipótese 2 & 135,0 & 135,0 & 156,7 \\
\hline & & & 1 caminhão & 183,4 & & \\
\hline & & & 2 caminhões & & & Lado a lado \\
\hline & & $M+$ & Impacto & sem & com & com \\
\hline & & & Hipótese 1 & 147,7 & 146,1 & 184,9 \\
\hline 6 & C3 TL V10/10/10 & & Hipótese 2 & 128,6 & 126,6 & 179,0 \\
\hline 6 & MC & & 1 caminhão & 197,2 & & \\
\hline & & & 2 caminhões & & & Lado a lado \\
\hline & & M - & Impacto & sem & com & com \\
\hline & & & Hipótese 1 & 156,4 & 156,4 & 172,6 \\
\hline & & & Hipótese 2 & 134,7 & 134,7 & 155,8 \\
\hline & & & 1 caminhão & 419,0 & & \\
\hline & & & 2 caminhões & & & Lado a lado \\
\hline & & $M+$ & Impacto & sem & com & com \\
\hline & & & Hipótese 1 & 327,7 & 342,2 & 477,8 \\
\hline 7 & C3 TE V20/20/20 & & Hipótese 2 & 282,1 & 300,3 & 472,0 \\
\hline 7 & $\mathrm{VZ}$ & & 1 caminhão & 318,3 & & \\
\hline & & & 2 caminhões & & & Lado a lado \\
\hline & & M - & Impacto & sem & com & com \\
\hline & & & Hipótese 1 & 351,9 & 259,0 & 315,6 \\
\hline & & & Hipótese 2 & 355,0 & 232,3 & 294,3 \\
\hline
\end{tabular}


Tabela E1 (continuação) - Momento fletor (kN.m) devido ao carregamento móvel proposto - LAJE.

\begin{tabular}{|c|c|c|c|c|c|c|}
\hline Ordem & Arquivo & Esforço & Carregamento & \multicolumn{3}{|c|}{ Momentos fletores } \\
\hline \multirow{10}{*}{8} & \multirow{10}{*}{$\begin{array}{c}\text { C3 TL V20/20/20 } \\
\text { VZ }\end{array}$} & \multirow{5}{*}{$M+$} & 1 caminhão & 353,3 & & \\
\hline & & & 2 caminhões & \multicolumn{2}{|c|}{ Em fila } & Lado a lado \\
\hline & & & Impacto & sem & com & com \\
\hline & & & Hipótese 1 & 277,1 & 286,7 & 387,8 \\
\hline & & & Hipótese 2 & 238,6 & 250,7 & 387,9 \\
\hline & & \multirow{5}{*}{ M - } & 1 caminhão & \multicolumn{3}{|l|}{303,2} \\
\hline & & & 2 caminhões & \multicolumn{2}{|c|}{ Em fila } & Lado a lado \\
\hline & & & Impacto & sem & com & com \\
\hline & & & Hipótese 1 & 336,0 & 246,3 & 297,9 \\
\hline & & & Hipótese 2 & 339,3 & 219,9 & 285,5 \\
\hline
\end{tabular}

Tabela E2 - Momento fletor (kN.m) devido ao carregamento móvel proposto VIGA T - 2 VIGAS.

\begin{tabular}{|c|c|c|c|c|c|c|}
\hline Ordem & Arquivo & Esforço & Carregamento & \multicolumn{3}{|c|}{ Momentos fletores } \\
\hline \multirow{5}{*}{1} & \multirow{5}{*}{ SA TE V10 TR2 } & \multirow{5}{*}{$M+$} & 1 caminhão & 1042,8 & & \\
\hline & & & 2 caminhões & \multicolumn{2}{|c|}{ Em fila } & Lado a lado \\
\hline & & & Impacto & sem & com & com \\
\hline & & & Hipótese 1 & 823,9 & 823,9 & 1077,2 \\
\hline & & & Hipótese 2 & 709,4 & 709,4 & 1022,9 \\
\hline \multirow{5}{*}{2} & \multirow{5}{*}{ SA TE V20 TR2 } & \multirow{5}{*}{$M+$} & 1 caminhão & \multicolumn{3}{|l|}{2892,6} \\
\hline & & & 2 caminhões & \multicolumn{2}{|c|}{ Em fila } & Lado a lado \\
\hline & & & Impacto & sem & com & com \\
\hline & & & Hipótese 1 & 2309,0 & 2309,0 & 2995,3 \\
\hline & & & Hipótese 2 & 1988,4 & 1988,4 & 2847,2 \\
\hline \multirow{10}{*}{3} & \multirow{10}{*}{$\begin{array}{c}\text { SAB TE V3/10/3 } \\
\text { TR2 }\end{array}$} & \multirow{5}{*}{$M+$} & 1 caminhão & \multicolumn{3}{|l|}{947,9} \\
\hline & & & 2 caminhões & \multicolumn{2}{|c|}{ Em fila } & Lado a lado \\
\hline & & & Impacto & sem & com & com \\
\hline & & & Hipótese 1 & 748,5 & 748,5 & 993,2 \\
\hline & & & Hipótese 2 & 644,5 & 644,4 & 948,8 \\
\hline & & \multirow{5}{*}{ M - } & 1 caminhão & \multicolumn{3}{|l|}{736,9} \\
\hline & & & 2 caminhões & \multicolumn{2}{|c|}{ Em fila } & Lado a lado \\
\hline & & & Impacto & sem & com & com \\
\hline & & & Hipótese 1 & 612,1 & 581,9 & 764,2 \\
\hline & & & Hipótese 2 & 527,1 & 501,0 & 737,7 \\
\hline \multirow{10}{*}{4} & \multirow{10}{*}{$\begin{array}{c}\text { SAB TE V5/20/5 } \\
\text { TR2 }\end{array}$} & \multirow{5}{*}{$M+$} & 1 caminhão & \multicolumn{3}{|l|}{2724,6} \\
\hline & & & 2 caminhões & \multicolumn{2}{|c|}{ Em fila } & Lado a lado \\
\hline & & & Impacto & sem & com & com \\
\hline & & & Hipótese 1 & 2180,4 & 2180,4 & 2872,2 \\
\hline & & & Hipótese 2 & 1877,6 & 1877,6 & 2750,9 \\
\hline & & \multirow{5}{*}{ M - } & 1 caminhão & \multicolumn{3}{|l|}{1610,4} \\
\hline & & & 2 caminhões & \multicolumn{2}{|c|}{ Em fila } & Lado a lado \\
\hline & & & Impacto & sem & com & com \\
\hline & & & Hipótese 1 & 1354,9 & 1287,8 & 1681,4 \\
\hline & & & Hipótese 2 & 1207,9 & 1108,9 & 1619,3 \\
\hline
\end{tabular}


Tabela E2 (continuação) - Momento fletor (kN.m) devido ao carregamento móvel proposto - VIGA T - 2 VIGAS.

\begin{tabular}{|c|c|c|c|c|c|c|}
\hline Ordem & Arquivo & Esforço & Carregamento & \multicolumn{3}{|c|}{ Momentos fletores } \\
\hline \multirow{10}{*}{5} & \multirow{10}{*}{$\begin{array}{c}\text { SAB TE V5/30/5 } \\
\text { TR2 }\end{array}$} & \multirow{5}{*}{$M+$} & 1 caminhão & 4629,3 & & \\
\hline & & & 2 caminhões & \multicolumn{2}{|c|}{ Em fila } & Lado a lado \\
\hline & & & Impacto & sem & com & com \\
\hline & & & Hipótese 1 & 3630,6 & 3679,3 & 4881,0 \\
\hline & & & Hipótese 2 & 3117,7 & 3168,7 & 4675,3 \\
\hline & & \multirow{5}{*}{ M - } & 1 caminhão & \multicolumn{3}{|l|}{1654,6} \\
\hline & & & 2 caminhões & \multicolumn{2}{|c|}{ Em fila } & Lado a lado \\
\hline & & & Impacto & sem & com & com \\
\hline & & & Hipótese 1 & 1424,4 & 1386,8 & 1715,8 \\
\hline & & & Hipótese 2 & 1284,9 & 1233,8 & 1643,3 \\
\hline \multirow{10}{*}{7} & \multirow{10}{*}{$\begin{array}{c}\text { C3 TE V20/20/20 } \\
\text { TR3 }\end{array}$} & \multirow{5}{*}{$M+$} & 1 caminhão & \multicolumn{3}{|l|}{2340,0} \\
\hline & & & 2 caminhões & \multicolumn{2}{|c|}{ Em fila } & Lado a lado \\
\hline & & & Impacto & sem & com & com \\
\hline & & & Hipótese 1 & 1850,6 & 1912,0 & 2431,0 \\
\hline & & & Hipótese 2 & 1593,5 & 1678,3 & 2314,0 \\
\hline & & \multirow{5}{*}{ M - } & 1 caminhão & \multicolumn{3}{|l|}{1542,2} \\
\hline & & & 2 caminhões & \multicolumn{2}{|c|}{ Em fila } & Lado a lado \\
\hline & & & Impacto & sem & com & com \\
\hline & & & Hipótese 1 & 1715,8 & 1343,8 & 1559,8 \\
\hline & & & Hipótese 2 & 1724,3 & 1263,5 & 1467,6 \\
\hline \multirow{10}{*}{8} & \multirow{10}{*}{$\begin{array}{c}\text { C3 TE V30/30/30 } \\
\text { TR3 }\end{array}$} & \multirow{5}{*}{$M+$} & 1 caminhão & \multicolumn{3}{|l|}{3916,3} \\
\hline & & & 2 caminhões & $\mathrm{Em}$ & fila & Lado a lado \\
\hline & & & Impacto & sem & com & com \\
\hline & & & Hipótese 1 & 3172,3 & 3081,5 & 4073,6 \\
\hline & & & Hipótese 2 & 2787,0 & 2653,8 & 3879,8 \\
\hline & & & 1 caminhão & 2462,0 & & \\
\hline & & & 2 caminhões & & fila & Lado a lado \\
\hline & & M - & Impacto & sem & com & com \\
\hline & & & Hipótese 1 & 2744,8 & 2727,6 & 2505,6 \\
\hline & & & Hipótese 2 & 2763,4 & 2743,3 & 2364,2 \\
\hline & & & 1 caminhão & 1192,3 & & \\
\hline & & & 2 caminhões & & fila & Lado a lado \\
\hline 10 & SA TL V10 TR1 & $M+$ & Impacto & sem & com & com \\
\hline & & & Hipótese 1 & 945,0 & 945,0 & 1339,7 \\
\hline & & & Hipótese 2 & 813,7 & 813,7 & 1351,0 \\
\hline & & & 1 caminhão & 3379,4 & & \\
\hline & & & 2 caminhões & & fila & Lado a lado \\
\hline 11 & SA TL V20 TR2 & $M+$ & Impacto & sem & com & com \\
\hline & & & Hipótese 1 & 2696,6 & 2696,6 & 3667,3 \\
\hline & & & Hipótese 2 & 2322,2 & 2322,2 & 3652,9 \\
\hline & & & 1 caminhão & 982,3 & & \\
\hline & & & 2 caminhões & & fila & Lado a lado \\
\hline & & $M+$ & Impacto & sem & com & com \\
\hline & & & Hipótese 1 & 778,3 & 775,6 & 1127,9 \\
\hline 12 & SAB TL V3/10/3 & & Hipótese 2 & 670,1 & 667,8 & 1145,7 \\
\hline 12 & TR1 & & 1 caminhão & 773,4 & & \\
\hline & & & 2 caminhões & & fila & Lado a lado \\
\hline & & M - & Impacto & sem & com & com \\
\hline & & & Hipótese 1 & 660,0 & 609,3 & 865,1 \\
\hline & & & Hipótese 2 & 568,3 & 524,6 & 877,0 \\
\hline
\end{tabular}


Tabela E2 (continuação) - Momento fletor (kN.m) devido ao carregamento móvel proposto - VIGA T - 2 VIGAS.

\begin{tabular}{|c|c|c|c|c|c|c|}
\hline Ordem & Arquivo & Esforço & Carregamento & \multicolumn{3}{|c|}{ Momentos fletores } \\
\hline \multirow{10}{*}{13} & \multirow{10}{*}{$\begin{array}{c}\text { SAB TL V5/20/5 } \\
\text { TR2 }\end{array}$} & \multirow{5}{*}{$M+$} & 1 caminhão & 3037,0 & & \\
\hline & & & 2 caminhões & \multicolumn{2}{|c|}{ Em fila } & Lado a lado \\
\hline & & & Impacto & sem & com & com \\
\hline & & & Hipótese 1 & 2424,2 & 2424,2 & 3343,9 \\
\hline & & & Hipótese 2 & 2087,5 & 2087,5 & 3348,1 \\
\hline & & \multirow{5}{*}{ M - } & 1 caminhão & \multicolumn{3}{|l|}{1831,3} \\
\hline & & & 2 caminhões & \multicolumn{2}{|c|}{ Em fila } & Lado a lado \\
\hline & & & Impacto & sem & com & com \\
\hline & & & Hipótese 1 & 1562,3 & 1511,5 & 2042,7 \\
\hline & & & Hipótese 2 & 1408,1 & 1301,5 & 2060,1 \\
\hline \multirow{10}{*}{14} & \multirow{10}{*}{$\begin{array}{l}\text { SAB TL V5/30/5 } \\
\text { TR3 }\end{array}$} & \multirow{5}{*}{$M+$} & 1 caminhão & \multicolumn{3}{|l|}{5357,9} \\
\hline & & & 2 caminhões & \multicolumn{2}{|c|}{ Em fila } & Lado a lado \\
\hline & & & Impacto & sem & com & com \\
\hline & & & Hipótese 1 & 4208,8 & 4270,4 & 5886,6 \\
\hline & & & Hipótese 2 & 3611,9 & 3677,8 & 5889,9 \\
\hline & & \multirow{5}{*}{ M - } & 1 caminhão & \multicolumn{3}{|l|}{1916,1} \\
\hline & & & 2 caminhões & \multicolumn{2}{|c|}{ Em fila } & Lado a lado \\
\hline & & & Impacto & sem & com & com \\
\hline & & & Hipótese 1 & 1684,4 & 1630,5 & 2138,2 \\
\hline & & & Hipótese 2 & 1535,2 & 1462,1 & 2151,2 \\
\hline \multirow{10}{*}{16} & \multirow{10}{*}{$\begin{array}{c}\text { C3 TL V20/20/20 } \\
\text { TR2 }\end{array}$} & \multirow{5}{*}{$M+$} & 1 caminhão & \multicolumn{3}{|l|}{2754,7} \\
\hline & & & 2 caminhões & Em & & Lado a lado \\
\hline & & & Impacto & sem & com & com \\
\hline & & & Hipótese 1 & 2168,3 & 2252,2 & 2969,5 \\
\hline & & & Hipótese 2 & 1867,1 & 1977,7 & 2950,7 \\
\hline & & & 1 caminhão & 1844,5 & & \\
\hline & & & 2 caminhões & Em & & Lado a lado \\
\hline & & M - & Impacto & sem & com & com \\
\hline & & & Hipótese 1 & 2055,5 & 1614,1 & 1968,8 \\
\hline & & & Hipótese 2 & 2067,4 & 1521,2 & 1949,4 \\
\hline & & & 1 caminhão & 4722,2 & & \\
\hline & & $\mathrm{M}+$ & 2 caminhões & Em & & Lado a lado \\
\hline & & $\mathrm{M} 1+$ & Impacto & sem & com & com \\
\hline & & & Hipótese 1 & 3822,5 & 3709,7 & 5113,7 \\
\hline & C3 TL V30/30/30 & & Hipótese 2 & 3362,0 & 3194,8 & 5090,0 \\
\hline 17 & TR3 & & 1 caminhão & 2974,1 & & \\
\hline & & & 2 caminhões & Em & & Lado a lado \\
\hline & & M - & Impacto & sem & com & com \\
\hline & & & Hipótese 1 & 3312,4 & 3295,4 & 3162,8 \\
\hline & & & Hipótese 2 & 3334,0 & 3314,1 & 3127,4 \\
\hline & & & 1 caminhão & 2566,8 & & \\
\hline & & & 2 caminhões & $\mathrm{Em}$ & & Lado a lado \\
\hline & & $\mathrm{M}+$ & Impacto & sem & com & com \\
\hline & & & Hipótese 1 & 1905,9 & 2037,3 & 2661,0 \\
\hline & $\begin{array}{c}\text { CЗВ ТE } \\
\text { V5-20/25/20-5 }\end{array}$ & & Hipótese 2 & 1587,5 & 1767,1 & 2530,8 \\
\hline 19 & $\begin{array}{c}\sqrt{ } 5-20 / 25 / 20-5 \\
\text { TR3 }\end{array}$ & & 1 caminhão & 1747,0 & & \\
\hline & & & 2 caminhões & Em & & Lado a lado \\
\hline & & M - & Impacto & sem & com & com \\
\hline & & & Hipótese 1 & 1939,4 & 1645,2 & 1758,7 \\
\hline & & & Hipótese 2 & 1949,2 & 1616,3 & 1651,4 \\
\hline
\end{tabular}


Tabela E2 (continuação) - Momento fletor (kN.m) devido ao carregamento móvel proposto - VIGA T - 2 VIGAS.

\begin{tabular}{|c|c|c|c|c|c|c|}
\hline Ordem & Arquivo & Esforço & Carregamento & \multicolumn{3}{|c|}{ Momentos fletores } \\
\hline \multirow{10}{*}{20} & \multirow{10}{*}{$\begin{array}{c}\text { C3B TL } \\
\text { V5-20/25/20-5 } \\
\text { TR2 }\end{array}$} & \multirow{5}{*}{$M+$} & 1 caminhão & 2987,2 & & \\
\hline & & & 2 caminhões & \multicolumn{2}{|c|}{ Em fila } & Lado a lado \\
\hline & & & Impacto & sem & com & com \\
\hline & & & Hipótese 1 & 2214,3 & 2387,4 & 3219,1 \\
\hline & & & Hipótese 2 & 1843,8 & 2075,4 & 3201,3 \\
\hline & & \multirow{5}{*}{ M - } & 1 caminhão & \multicolumn{3}{|l|}{2095,5} \\
\hline & & & 2 caminhões & \multicolumn{2}{|c|}{ Em fila } & Lado a lado \\
\hline & & & Impacto & sem & com & com \\
\hline & & & Hipótese 1 & 2325,5 & 1981,2 & 2223,0 \\
\hline & & & Hipótese 2 & 2338,2 & 1947,7 & 2196,1 \\
\hline \multirow{10}{*}{21} & \multirow{10}{*}{$\begin{array}{c}\text { C3B TE } \\
\text { V5-25/30/25-5 } \\
\text { TR3 }\end{array}$} & \multirow{5}{*}{$M+$} & 1 caminhão & \multicolumn{3}{|l|}{3215,6} \\
\hline & & & 2 caminhões & \multicolumn{2}{|c|}{ Em fila } & Lado a lado \\
\hline & & & Impacto & sem & com & com \\
\hline & & & Hipótese 1 & 2522,7 & 2595,3 & 3343,1 \\
\hline & & & Hipótese 2 & 2180,3 & 2253,0 & 3188,9 \\
\hline & & \multirow{5}{*}{ M - } & 1 caminhão & \multicolumn{3}{|l|}{2113,5} \\
\hline & & & 2 caminhões & \multicolumn{2}{|c|}{ Em fila } & Lado a lado \\
\hline & & & Impacto & sem & com & com \\
\hline & & & Hipótese 1 & 2433,5 & 2336,1 & 2134,2 \\
\hline & & & Hipótese 2 & 2472,5 & 2362,6 & 1998,7 \\
\hline \multirow{10}{*}{22} & \multirow{10}{*}{$\begin{array}{c}\text { C3B TL } \\
\text { V5-25/30/25-5 } \\
\text { TR2 }\end{array}$} & \multirow{5}{*}{$M+$} & 1 caminhão & \multicolumn{3}{|l|}{3833,1} \\
\hline & & & 2 caminhões & \multicolumn{2}{|c|}{ Em fila } & Lado a lado \\
\hline & & & Impacto & sem & com & com \\
\hline & & & Hipótese 1 & 3009,8 & 3082,7 & 4143,0 \\
\hline & & & Hipótese 2 & 2601,6 & 2676,6 & 4120,8 \\
\hline & & \multirow{5}{*}{ M - } & 1 caminhão & \multicolumn{3}{|l|}{2548,5} \\
\hline & & & 2 caminhões & \multicolumn{2}{|c|}{ Em fila } & Lado a lado \\
\hline & & & Impacto & sem & com & com \\
\hline & & & Hipótese 1 & 2931,4 & 2819,5 & 2703,0 \\
\hline & & & Hipótese 2 & 2977,1 & 2850,7 & 2670,1 \\
\hline \multirow{10}{*}{23} & & & 1 caminhão & 4789,0 & & \\
\hline & & $\mathrm{Mt}$ & 2 caminhões & & & Lado a lado \\
\hline & & $\mathrm{M}+$ & Impacto & sem & com & com \\
\hline & & & Hipótese 1 & 3880,6 & 3765,6 & 5186,9 \\
\hline & C2 TL V30/30 & & Hipótese 2 & 3413,6 & 3242,9 & 5163,2 \\
\hline & TR3 & & 1 caminhão & 2835,4 & & \\
\hline & & & 2 caminhões & & & Lado a lado \\
\hline & & M - & Impacto & sem & com & com \\
\hline & & & Hipótese 1 & 3370,8 & 3386,0 & 3008,8 \\
\hline & & & Hipótese 2 & 3468,5 & 3485,5 & 2972,9 \\
\hline
\end{tabular}


Tabela E3 - Momento fletor (kN.m) devido ao carregamento móvel proposto VIGA T - 5 VIGAS.

\begin{tabular}{|c|c|c|c|c|c|c|}
\hline Ordem & Arquivo & Esforço & Carregamento & \multicolumn{3}{|c|}{ Momentos fletores } \\
\hline \multirow{5}{*}{1} & \multirow{5}{*}{ SA TE V10 TR2 } & \multirow{5}{*}{$M+$} & 1 caminhão & 447,3 & & \\
\hline & & & 2 caminhões & \multicolumn{2}{|c|}{ Em fila } & Lado a lado \\
\hline & & & Impacto & sem & com & com \\
\hline & & & Hipótese 1 & 354,4 & 353,2 & 473,1 \\
\hline & & & Hipótese 2 & 305,2 & 304,1 & 453,8 \\
\hline \multirow{5}{*}{2} & \multirow{5}{*}{ SA TE V20 TR2 } & \multirow{5}{*}{$M+$} & 1 caminhão & \multicolumn{3}{|l|}{1286,0} \\
\hline & & & 2 caminhões & \multicolumn{2}{|c|}{ Em fila } & Lado a lado \\
\hline & & & Impacto & sem & com & com \\
\hline & & & Hipótese 1 & 1027,6 & 1027,6 & 1321,7 \\
\hline & & & Hipótese 2 & 884,9 & 884,9 & 1252,3 \\
\hline \multirow{5}{*}{3} & \multirow{5}{*}{ SA TE V30 TR2 } & \multirow{5}{*}{$M+$} & 1 caminhão & \multicolumn{3}{|l|}{2269,1} \\
\hline & & & 2 caminhões & \multicolumn{2}{|c|}{ Em fila } & Lado a lado \\
\hline & & & Impacto & sem & com & com \\
\hline & & & Hipótese 1 & 1857,3 & 1807,6 & 2293,1 \\
\hline & & & Hipótese 2 & 1631,6 & 1556,7 & 2156,8 \\
\hline \multirow{5}{*}{4} & \multirow{5}{*}{ SA TE V40 TR4 } & \multirow{5}{*}{$M+$} & 1 caminhão & \multicolumn{3}{|l|}{3052,8} \\
\hline & & & 2 caminhões & \multicolumn{2}{|c|}{ Em fila } & Lado a lado \\
\hline & & & Impacto & sem & com & com \\
\hline & & & Hipótese 1 & 2715,3 & 2424,8 & 3133,9 \\
\hline & & & Hipótese 2 & 2519,6 & 2088,4 & 2968,0 \\
\hline & & & 1 caminhão & 465,2 & & \\
\hline & & & 2 caminhões & & & Lado a lado \\
\hline 5 & SA TL V10 TR2 & $M+$ & Impacto & sem & com & com \\
\hline & & & Hipótese 1 & 367,9 & 367,3 & 575,0 \\
\hline & & & Hipótese 2 & 316,7 & 316,2 & 598,1 \\
\hline & & & 1 caminhão & 1356,4 & & \\
\hline & & & 2 caminhões & & & Lado a lado \\
\hline 6 & SA TL V20 TR2 & $M+$ & Impacto & sem & com & com \\
\hline & & & Hipótese 1 & 1083,3 & 1083,3 & 1564,1 \\
\hline & & & Hipótese 2 & 932,8 & 932,8 & 1591,2 \\
\hline & & & 1 caminhão & 2407,3 & & \\
\hline & & & 2 caminhões & & & Lado a lado \\
\hline 7 & SA TL V30 TR2 & $\mathrm{M}+$ & Impacto & sem & com & com \\
\hline & & & Hipótese 1 & 1972,3 & 1913,8 & 2706,9 \\
\hline & & & Hipótese 2 & 1737,5 & 1648,2 & 2730,5 \\
\hline & & & 1 caminhão & 3326,4 & & \\
\hline & & & 2 caminhões & & & Lado a lado \\
\hline 8 & SA TL V40 TR4 & $M+$ & Impacto & sem & com & com \\
\hline & & & Hipótese 1 & 2971,3 & 2639,3 & 3691,4 \\
\hline & & & Hipótese 2 & 2776,0 & 2273,1 & 3706,7 \\
\hline & & & 1 caminhão & 1816,3 & & \\
\hline & & & 2 caminhões & & & Lado a lado \\
\hline & & $M+$ & Impacto & sem & com & com \\
\hline & & & Hipótese 1 & 1464,1 & 1424,8 & 2078,2 \\
\hline 9 & C3 TL V30/30/30 & & Hipótese 2 & 1286,6 & 1227,0 & 2108,8 \\
\hline 9 & TR2 & & 1 caminhão & 1097,6 & & \\
\hline & & & 2 caminhões & & & Lado a lado \\
\hline & & M - & Impacto & sem & com & com \\
\hline & & & Hipótese 1 & 1222,3 & 1205,6 & 1226,3 \\
\hline & & & Hipótese 2 & 1229,3 & 1210,2 & 1234,3 \\
\hline
\end{tabular}


Tabela E3 (continuação) - Momento fletor (kN.m) devido ao carregamento móvel proposto - VIGA T - 5 VIGAS.

\begin{tabular}{|c|c|c|c|c|c|c|}
\hline Ordem & Arquivo & Esforço & Carregamento & \multicolumn{3}{|c|}{ Momentos fletores } \\
\hline \multirow{10}{*}{10} & \multirow{10}{*}{$\begin{array}{c}\text { C3B TE } \\
\text { V5-25/30/25-5 } \\
\text { TR2 }\end{array}$} & \multirow{5}{*}{$M+$} & 1 caminhão & 1417,6 & & \\
\hline & & & 2 caminhões & \multicolumn{2}{|c|}{ Em fila } & Lado a lado \\
\hline & & & Impacto & sem & com & com \\
\hline & & & Hipótese 1 & 1105,8 & 1133,0 & 1429,2 \\
\hline & & & Hipótese 2 & 953,6 & 982,1 & 1343,0 \\
\hline & & \multirow{5}{*}{$\mathrm{M}-$} & 1 caminhão & \multicolumn{3}{|l|}{872,9} \\
\hline & & & 2 caminhões & \multicolumn{2}{|c|}{ Em fila } & Lado a lado \\
\hline & & & Impacto & sem & com & com \\
\hline & & & Hipótese 1 & 989,5 & 921,8 & 897,8 \\
\hline & & & Hipótese 2 & 1002,5 & 928,5 & 851,0 \\
\hline \multirow{10}{*}{11} & \multirow{10}{*}{$\begin{array}{c}\text { C3B TL } \\
\text { V5-25/30/25-5 } \\
\text { TR2 }\end{array}$} & \multirow{5}{*}{$M+$} & 1 caminhão & \multicolumn{3}{|l|}{1492,4} \\
\hline & & & 2 caminhões & \multicolumn{2}{|c|}{ Em fila } & Lado a lado \\
\hline & & & Impacto & sem & com & com \\
\hline & & & Hipótese 1 & 1169,1 & 1199,5 & 1725,7 \\
\hline & & & Hipótese 2 & 1007,9 & 1041,6 & 1757,2 \\
\hline & & \multirow{5}{*}{ M - } & 1 caminhão & \multicolumn{3}{|l|}{935,5} \\
\hline & & & 2 caminhões & \multicolumn{2}{|c|}{ Em fila } & Lado a lado \\
\hline & & & Impacto & sem & com & com \\
\hline & & & Hipótese 1 & 1077,6 & 1026,1 & 1061,8 \\
\hline & & & Hipótese 2 & 1095,7 & 1038,4 & 1074,6 \\
\hline \multirow{5}{*}{12} & \multirow{5}{*}{ SA TE V10 STR } & \multirow{5}{*}{$M+$} & 1 caminhão & \multicolumn{3}{|l|}{495,7} \\
\hline & & & 2 caminhões & & & Lado a lado \\
\hline & & & Impacto & sem & com & com \\
\hline & & & Hipótese 1 & 392,6 & 391,4 & 505,4 \\
\hline & & & Hipótese 2 & 338,1 & 337,0 & 477,2 \\
\hline & & & 1 caminhão & 1360,9 & & \\
\hline & & & 2 caminhões & & & Lado a lado \\
\hline 13 & SA TE V20 STR & $M+$ & Impacto & sem & com & com \\
\hline & & & Hipótese 1 & 1087,0 & 1087,0 & 1408,5 \\
\hline & & & Hipótese 2 & 936,0 & 936,0 & 1338,6 \\
\hline & & & 1 caminhão & 2324,2 & & \\
\hline & & & 2 caminhões & & & Lado a lado \\
\hline 14 & SA TE V30 STR & $M+$ & Impacto & sem & com & com \\
\hline & & & Hipótese 1 & 1902,5 & 1851,1 & 2396,7 \\
\hline & & & Hipótese 2 & 1671,5 & 1594,2 & 2274,1 \\
\hline & & & 1 caminhão & 3213,0 & & \\
\hline & & & 2 caminhões & & & Lado a lado \\
\hline 15 & SA TE V40 STR & $M+$ & Impacto & sem & com & com \\
\hline & & & Hipótese 1 & 2819,1 & 2553,1 & 3311,3 \\
\hline & & & Hipótese 2 & 2599,6 & 2198,8 & 3141,3 \\
\hline & & & 1 caminhão & 527,6 & & \\
\hline & & & 2 caminhões & & & Lado a lado \\
\hline 16 & SA TL V10 STR & $M+$ & Impacto & sem & com & com \\
\hline & & & Hipótese 1 & 417,4 & 416,6 & 659,1 \\
\hline & & & Hipótese 2 & 359,4 & 358,7 & 687,9 \\
\hline & & & 1 caminhão & 1486,5 & & \\
\hline & & & 2 caminhões & & & Lado a lado \\
\hline 17 & SA TL V20 STR & $\mathrm{M}+$ & Impacto & sem & com & com \\
\hline & & & Hipótese 1 & 1186,9 & 1186,9 & 1817,3 \\
\hline & & & Hipótese 2 & 1022,1 & 1022,1 & 1884,9 \\
\hline
\end{tabular}


Tabela E3 (continuação) - Momento fletor (kN.m) devido ao carregamento móvel proposto - VIGA T - 5 VIGAS.

\begin{tabular}{|c|c|c|c|c|c|c|}
\hline Ordem & Arquivo & Esforço & Carregamento & \multicolumn{3}{|c|}{ Momentos fletores } \\
\hline \multirow{5}{*}{18} & \multirow{5}{*}{ SA TL V30 STR } & \multirow{5}{*}{$M+$} & 1 caminhão & 2500,3 & & \\
\hline & & & 2 caminhões & \multicolumn{2}{|c|}{ Em fila } & Lado a lado \\
\hline & & & Impacto & sem & com & com \\
\hline & & & Hipótese 1 & 2049,1 & 1987,9 & 3039,7 \\
\hline & & & Hipótese 2 & 1804,2 & 1712,0 & 3147,8 \\
\hline \multirow{5}{*}{19} & \multirow{5}{*}{ SA TL V40 STR } & \multirow{5}{*}{$M+$} & 1 caminhão & \multicolumn{3}{|l|}{3456,4} \\
\hline & & & 2 caminhões & \multicolumn{2}{|c|}{ Em fila } & Lado a lado \\
\hline & & & Impacto & sem & com & com \\
\hline & & & Hipótese 1 & 3053,1 & 2742,7 & 4142,5 \\
\hline & & & Hipótese 2 & 2833,8 & 2362,2 & 4267,7 \\
\hline
\end{tabular}

Tabela E4 - Momento fletor (kN.m) devido ao carregamento móvel proposto SEÇÃO CELULAR.

\begin{tabular}{|c|c|c|c|c|c|c|}
\hline Ordem & Arquivo & Esforço & Carregamento & \multicolumn{3}{|c|}{ Momentos fletores } \\
\hline \multirow{5}{*}{1} & \multirow{5}{*}{ SA TL V20 STR } & \multirow{5}{*}{$\mathrm{M}+$} & 1 caminhão & 3527,9 & & \\
\hline & & & 2 caminhões & \multicolumn{2}{|c|}{ Em fila } & Lado a lado \\
\hline & & & Impacto & sem & com & com \\
\hline & & & Hipótese 1 & 2814,3 & 2814,3 & 4311,7 \\
\hline & & & Hipótese 2 & 2423,6 & 2423,6 & 4469,1 \\
\hline \multirow{5}{*}{2} & \multirow{5}{*}{ SA TL V30 STR } & \multirow{5}{*}{$M+$} & 1 caminhão & \multicolumn{3}{|l|}{6045,9} \\
\hline & & & 2 caminhões & \multicolumn{2}{|c|}{ Em fila } & Lado a lado \\
\hline & & & Impacto & sem & com & com \\
\hline & & & Hipótese 1 & 4956,8 & 4802,0 & 7314,8 \\
\hline & & & Hipótese 2 & 4377,8 & 4135,7 & 7567,2 \\
\hline \multirow{5}{*}{3} & \multirow{5}{*}{ SA TL V40 STR } & \multirow{5}{*}{$M+$} & 1 caminhão & \multicolumn{3}{|l|}{8567,5} \\
\hline & & & 2 caminhões & \multicolumn{2}{|c|}{ Em fila } & Lado a lado \\
\hline & & & Impacto & sem & com & com \\
\hline & & & Hipótese 1 & 7651,6 & 6792,8 & 10335,6 \\
\hline & & & Hipótese 2 & 7219,9 & 5850,5 & 10680,4 \\
\hline \multirow{10}{*}{4} & \multirow{10}{*}{$\begin{array}{c}\text { C3 TL V30/30/30 } \\
\text { STR }\end{array}$} & \multirow{5}{*}{$M+$} & 1 caminhão & \multicolumn{3}{|l|}{4640,4} \\
\hline & & & 2 caminhões & \multicolumn{2}{|c|}{ Em fila } & Lado a lado \\
\hline & & & Impacto & sem & com & com \\
\hline & & & Hipótese 1 & 3749,6 & 3655,1 & 5593,0 \\
\hline & & & Hipótese 2 & 3299,7 & 3147,9 & 5795,7 \\
\hline & & \multirow{5}{*}{ M - } & 1 caminhão & \multicolumn{3}{|l|}{2908,9} \\
\hline & & & 2 caminhões & \multicolumn{2}{|c|}{ Em fila } & Lado a lado \\
\hline & & & Impacto & sem & com & com \\
\hline & & & Hipótese 1 & 3200,6 & 3198,8 & 3497,9 \\
\hline & & & Hipótese 2 & 3209,1 & 3206,6 & 3607,4 \\
\hline \multirow{5}{*}{5} & \multirow{5}{*}{ SA TL V30 TR2 } & \multirow{5}{*}{$M+$} & 1 caminhão & \multicolumn{3}{|l|}{1566,0} \\
\hline & & & 2 caminhões & \multicolumn{2}{|c|}{ Em fila } & Lado a lado \\
\hline & & & Impacto & sem & com & com \\
\hline & & & Hipótese 1 & 1287,0 & 1250,9 & 1866,4 \\
\hline & & & Hipótese 2 & 1135,5 & 1077,2 & 1921,6 \\
\hline & & & 1 caminhão & 3543,0 & & \\
\hline & & & 2 caminhões & & & Lado a lado \\
\hline 6 & SA TE V20 STR & $M+$ & Impacto & sem & com & com \\
\hline & & & Hipótese 1 & 2826,6 & 2826,6 & 4395,4 \\
\hline & & & Hipótese 2 & 2434,2 & 2434,2 & 4473,1 \\
\hline
\end{tabular}


Tabela E4 (continuação) - Momento fletor (kN.m) devido ao carregamento móvel proposto - SEÇÃO CELULAR.

\begin{tabular}{|c|c|c|c|c|c|c|}
\hline Ordem & Arquivo & Esforço & Carregamento & \multicolumn{3}{|c|}{ Momentos fletores } \\
\hline \multirow{5}{*}{7} & \multirow{5}{*}{ SA TE V30 STR } & \multirow{5}{*}{$M+$} & 1 caminhão & 6072,7 & & \\
\hline & & & 2 caminhões & \multicolumn{2}{|c|}{ Em fila } & Lado a lado \\
\hline & & & Impacto & sem & com & com \\
\hline & & & Hipótese 1 & 4955,1 & 4799,8 & 7468,6 \\
\hline & & & Hipótese 2 & 4379,0 & 4133,9 & 7584,8 \\
\hline \multirow{5}{*}{8} & \multirow{5}{*}{ SA TE V40 STR } & \multirow{5}{*}{$M+$} & 1 caminhão & \multicolumn{3}{|l|}{8584,0} \\
\hline & & & 2 caminhões & \multicolumn{2}{|c|}{ Em fila } & Lado a lado \\
\hline & & & Impacto & sem & com & com \\
\hline & & & Hipótese 1 & 7661,0 & 6806,4 & 10550,0 \\
\hline & & & Hipótese 2 & 7194,2 & 5862,3 & 10703,2 \\
\hline \multirow{10}{*}{9} & \multirow{10}{*}{$\begin{array}{c}\text { C3 TE V30/30/30 } \\
\text { STR }\end{array}$} & \multirow{5}{*}{$M+$} & 1 caminhão & \multicolumn{3}{|l|}{4643,2} \\
\hline & & & 2 caminhões & \multicolumn{2}{|c|}{ Em fila } & Lado a lado \\
\hline & & & Impacto & sem & com & com \\
\hline & & & Hipótese 1 & 3751,1 & 3661,7 & 5710,1 \\
\hline & & & Hipótese 2 & 3301,1 & 3153,6 & 5810,4 \\
\hline & & \multirow{5}{*}{ M - } & 1 caminhão & \multicolumn{3}{|l|}{2905,1} \\
\hline & & & 2 caminhões & \multicolumn{2}{|c|}{ Em fila } & Lado a lado \\
\hline & & & Impacto & sem & com & com \\
\hline & & & Hipótese 1 & 3195,7 & 3194,5 & 3552,1 \\
\hline & & & Hipótese 2 & 3205,1 & 3202,3 & 3597,3 \\
\hline \multirow{5}{*}{10} & \multirow{5}{*}{ SA TE V20 STR } & \multirow{5}{*}{$M+$} & 1 caminhão & \multicolumn{3}{|l|}{1917,7} \\
\hline & & & 2 caminhões & \multicolumn{2}{|c|}{ Em fila } & Lado a lado \\
\hline & & & Impacto & sem & com & com \\
\hline & & & Hipótese 1 & 1566,6 & 1517,1 & 2300,4 \\
\hline & & & Hipótese 2 & 1385,2 & 1306,5 & 2321,4 \\
\hline
\end{tabular}


Tabela E5 - Parâmetros estatísticos da resistência e da solicitação CONCRETO ARMADO - LAJE.

\begin{tabular}{|c|c|c|c|c|c|c|c|}
\hline $\mathbf{n}$ & Arquivo & Esforço & Va & íveis & Distribuição & Valor médio & $\mathrm{CV}$ \\
\hline \multirow{6}{*}{1} & \multirow{6}{*}{ SA TE V10 MC } & \multirow{6}{*}{$M+$} & \multirow{2}{*}{ Resistência } & Classe 36 & Lognormal & 929,8 & 0,091 \\
\hline & & & & Classe 45 & Lognormal & 960,3 & 0,091 \\
\hline & & & \multirow{4}{*}{ Solicitação } & Peso próprio & Normal & 200,3 & 0,100 \\
\hline & & & & Asfalto & Normal & 30,5 & 0,250 \\
\hline & & & & Carga móvel & ----- & 279,4 & 0,230 \\
\hline & & & & Total & Normal & 510,2 & 0,139 \\
\hline \multirow{6}{*}{2} & \multirow{6}{*}{ SA TL V10 MC } & \multirow{6}{*}{$M+$} & \multirow{2}{*}{ Resistência } & Classe 36 & Lognormal & 888,7 & 0,092 \\
\hline & & & & Classe 45 & Lognormal & 916,1 & 0,091 \\
\hline & & & \multirow{4}{*}{ Solicitação } & Peso próprio & Normal & 202,4 & 0,100 \\
\hline & & & & Asfalto & Normal & 30,9 & 0,800 \\
\hline & & & & Carga móvel & $\begin{array}{ll}--- \\
-\end{array}$ & 249,9 & 0,243 \\
\hline & & & & Total & Normal & 483,2 & 0,148 \\
\hline \multirow{6}{*}{3} & \multirow{6}{*}{ SA TE V20 VZ } & \multirow{6}{*}{$M+$} & \multirow{2}{*}{ Resistência } & Classe 36 & Lognormal & 2252,2 & 0,092 \\
\hline & & & & Classe 45 & Lognormal & 2247,8 & 0,091 \\
\hline & & & \multirow{4}{*}{ Solicitação } & Peso próprio & Normal & 740,9 & 0,100 \\
\hline & & & & Asfalto & Normal & 84,6 & 0,250 \\
\hline & & & & Carga móvel & ----- & 469,7 & 0,218 \\
\hline & & & & Total & Normal & 1295,2 & 0,107 \\
\hline \multirow{6}{*}{4} & \multirow{6}{*}{ SA TL V20 VZ } & \multirow{6}{*}{$M+$} & \multirow{2}{*}{ Resistência } & Classe 36 & Lognormal & 2297,1 & 0,091 \\
\hline & & & & Classe 45 & Lognormal & 2298,9 & 0,091 \\
\hline & & & \multirow{4}{*}{ Solicitação } & Peso próprio & Normal & 784,1 & 0,100 \\
\hline & & & & Asfalto & Normal & 89,6 & 0,800 \\
\hline & & & & Carga móvel & - --- & 386,3 & 0,233 \\
\hline & & & & Total & Normal & 1260,0 & 0,117 \\
\hline \multirow{12}{*}{5} & \multirow{12}{*}{$\begin{array}{c}\text { C3 TE V10/10/10 } \\
\text { MC }\end{array}$} & \multirow{6}{*}{$M+$} & \multirow{2}{*}{ Resistência } & Classe 36 & Lognormal & 658,0 & 0,091 \\
\hline & & & & Classe 45 & Lognormal & 686,4 & 0,091 \\
\hline & & & \multirow{4}{*}{ Solicitação } & Peso próprio & Normal & 115,8 & 0,100 \\
\hline & & & & Asfalto & Normal & 17,7 & 0,250 \\
\hline & & & & Carga móvel & ----- & 219,2 & 0,243 \\
\hline & & & & Total & Normal & 352,6 & 0,166 \\
\hline & & \multirow{6}{*}{ M - } & \multirow{2}{*}{ Resistência } & Classe 36 & Lognormal & 674,6 & 0,091 \\
\hline & & & & Classe 45 & Lognormal & 664,9 & 0,091 \\
\hline & & & & Peso próprio & Normal & 138,7 & 0,100 \\
\hline & & & Solicitar̃̃ & Asfalto & Normal & 21,1 & 0,250 \\
\hline & & & Solıcitaçao & Carga móvel & ----- & 227,4 & 0,243 \\
\hline & & & & Total & Normal & 387,3 & 0,159 \\
\hline
\end{tabular}


Tabela E5 (continuação) - Parâmetros estatísticos da resistência e da solicitação CONCRETO ARMADO - LAJE.

\begin{tabular}{|c|c|c|c|c|c|c|c|}
\hline $\mathbf{n}$ & Arquivo & Esforço & Var & áveis & Distribuição & Valor médio & $\mathbf{C V}$ \\
\hline \multirow{12}{*}{6} & \multirow{12}{*}{$\begin{array}{c}\text { C3 TL V10/10/10 } \\
\text { MC }\end{array}$} & \multirow{6}{*}{$M+$} & \multirow{2}{*}{ Resistência } & Classe 36 & Lognormal & 650,5 & 0,090 \\
\hline & & & & Classe 45 & Lognormal & 679,7 & 0,091 \\
\hline & & & \multirow{4}{*}{ Solicitação } & Peso próprio & Normal & 116,7 & 0,100 \\
\hline & & & & Asfalto & Normal & 17,8 & 0,250 \\
\hline & & & & Carga móvel & ----- & 211,0 & 0,243 \\
\hline & & & & Total & Normal & 345,4 & 0,164 \\
\hline & & \multirow{6}{*}{ M - } & \multirow{2}{*}{ Resistência } & Classe 36 & Lognormal & 677,0 & 0,091 \\
\hline & & & & Classe 45 & Lognormal & 667,2 & 0,091 \\
\hline & & & \multirow{4}{*}{ Solicitação } & Peso próprio & Normal & 139,4 & 0,100 \\
\hline & & & & Asfalto & Normal & 21,3 & 0,250 \\
\hline & & & & Carga móvel & ----- & 226,8 & 0,243 \\
\hline & & & & Total & Normal & 387,5 & 0,159 \\
\hline \multirow{12}{*}{7} & \multirow{12}{*}{$\begin{array}{c}\text { C3 TE V20/20/20 } \\
\text { VZ }\end{array}$} & \multirow{6}{*}{$M+$} & \multirow{2}{*}{ Resistência } & Classe 36 & Lognormal & 1493,4 & 0,091 \\
\hline & & & & Classe 45 & Lognormal & 1514,6 & 0,091 \\
\hline & & & \multirow{4}{*}{ Solicitação } & Peso próprio & Normal & 436,9 & 0,100 \\
\hline & & & & Asfalto & Normal & 49,9 & 0,250 \\
\hline & & & & Carga móvel & ----- & 367,9 & 0,221 \\
\hline & & & & Total & Normal & 854,7 & 0,124 \\
\hline & & \multirow{6}{*}{ M - } & \multirow{2}{*}{ Resistência } & Classe 36 & Lognormal & 1576,8 & 0,091 \\
\hline & & & & Classe 45 & Lognormal & 1509,7 & 0,091 \\
\hline & & & \multirow{4}{*}{ Solicitação } & Peso próprio & Normal & 525,3 & 0,100 \\
\hline & & & & Asfalto & Normal & 60,0 & 0,250 \\
\hline & & & & Carga móvel & $\begin{array}{ll}---- \\
\end{array}$ & 256,2 & 0,243 \\
\hline & & & & Total & Normal & 841,6 & 0,115 \\
\hline \multirow{12}{*}{8} & \multirow{12}{*}{$\begin{array}{c}\text { C3 TL V20/20/20 } \\
\text { VZ }\end{array}$} & \multirow{6}{*}{$M+$} & \multirow{2}{*}{ Resistência } & Classe 36 & Lognormal & 1527,5 & 0,091 \\
\hline & & & & Classe 45 & Lognormal & 1555,8 & 0,091 \\
\hline & & & \multirow{4}{*}{ Solicitação } & Peso próprio & Normal & 462,4 & 0,100 \\
\hline & & & & Asfalto & Normal & 52,8 & 0,250 \\
\hline & & & & Carga móvel & ----- & 313,6 & 0,235 \\
\hline & & & & Total & Normal & 828,8 & 0,122 \\
\hline & & \multirow{6}{*}{ M - } & \multirow{2}{*}{ Resistência } & Classe 36 & Lognormal & 1664,7 & 0,091 \\
\hline & & & & Classe 45 & Lognormal & 1600,6 & 0,091 \\
\hline & & & \multirow{4}{*}{ Solicitação } & Peso próprio & Normal & 558,7 & 0,100 \\
\hline & & & & Asfalto & Normal & 63,8 & 0,250 \\
\hline & & & & Carga móvel & ---- & 256,3 & 0,243 \\
\hline & & & & Total & Normal & 878,8 & 0,114 \\
\hline
\end{tabular}


Tabela E6 - Parâmetros estatísticos da resistência e da solicitação CONCRETO ARMADO - VIGA T - 2 VIGAS.

\begin{tabular}{|c|c|c|c|c|c|c|c|}
\hline n & Arquivo & Esforço & Val & iáveis & Distribuição & Valor médio & $\mathrm{CV}$ \\
\hline \multirow{6}{*}{1} & \multirow{6}{*}{ SA TE V10 TR2 } & \multirow{6}{*}{$M+$} & \multirow{2}{*}{ Resistência } & Classe 36 & Lognormal & 2967,9 & 0,091 \\
\hline & & & & Classe 45 & Lognormal & 3133,6 & 0,091 \\
\hline & & & \multirow{4}{*}{ Solicitação } & Peso próprio & Normal & 422,5 & 0,100 \\
\hline & & & & Asfalto & Normal & 116,3 & 0,250 \\
\hline & & & & Carga móvel & ---- & 1199,2 & 0,243 \\
\hline & & & & Total & Normal & 1738,0 & 0,175 \\
\hline \multirow{6}{*}{2} & \multirow{6}{*}{ SA TE V20 TR2 } & \multirow{6}{*}{$M+$} & \multirow{2}{*}{ Resistência } & Classe 36 & Lognormal & 10343,7 & 0,092 \\
\hline & & & & Classe 45 & Lognormal & 10480,6 & 0,091 \\
\hline & & & \multirow{4}{*}{ Solicitação } & Peso próprio & Normal & 2365,0 & 0,100 \\
\hline & & & & Asfalto & Normal & 475,6 & 0,250 \\
\hline & & & & Carga móvel & $\begin{array}{ll}--- \\
-\end{array}$ & 3326,5 & 0,243 \\
\hline & & & & Total & Normal & 6167,0 & 0,144 \\
\hline \multirow{12}{*}{3} & \multirow{12}{*}{$\begin{array}{c}\text { SAB TE V3/10/3 } \\
\text { TR2 }\end{array}$} & \multirow{6}{*}{$M+$} & \multirow{2}{*}{ Resistência } & Classe 36 & Lognormal & 2424,0 & 0,091 \\
\hline & & & & Classe 45 & Lognormal & 2607,9 & 0,091 \\
\hline & & & \multirow{4}{*}{ Solicitação } & Peso próprio & Normal & 199,1 & 0,100 \\
\hline & & & & Asfalto & Normal & 72,3 & 0,250 \\
\hline & & & & Carga móvel & ----- & 1092,5 & 0,233 \\
\hline & & & & Total & Normal & 1363,9 & 0,192 \\
\hline & & \multirow{6}{*}{ M - } & \multirow{2}{*}{ Resistência } & Classe 36 & Lognormal & 1742,8 & 0,097 \\
\hline & & & & Classe 45 & Lognormal & 1888,9 & 0,091 \\
\hline & & & \multirow{4}{*}{ Solicitação } & Peso próprio & Normal & 134,5 & 0,100 \\
\hline & & & & Asfalto & Normal & 37,4 & 0,250 \\
\hline & & & & Carga móvel & 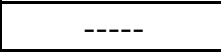 & 847,5 & 0,243 \\
\hline & & & & Total & Normal & 1019,4 & 0,207 \\
\hline \multirow{12}{*}{4} & \multirow{12}{*}{$\begin{array}{c}\text { SAB TE V5/20/5 } \\
\text { TR2 }\end{array}$} & \multirow{6}{*}{$M+$} & \multirow{2}{*}{ Resistência } & Classe 36 & Lognormal & 8219,8 & 0,091 \\
\hline & & & & Classe 45 & Lognormal & 8538,7 & 0,091 \\
\hline & & & \multirow{4}{*}{ Solicitação } & Peso próprio & Normal & 1359,2 & 0,100 \\
\hline & & & & Asfalto & Normal & 355,5 & 0,250 \\
\hline & & & & Carga móvel & $\begin{array}{ll}--- \\
-\end{array}$ & 3159,5 & 0,232 \\
\hline & & & & Total & Normal & 4874,2 & 0,159 \\
\hline & & \multirow{6}{*}{ M - } & \multirow{2}{*}{ Resistência } & Classe 36 & Lognormal & 4523,6 & 0,095 \\
\hline & & & & Classe 45 & Lognormal & 4816,0 & 0,091 \\
\hline & & & \multirow{4}{*}{ Solicitação } & Peso próprio & Normal & 527,0 & 0,100 \\
\hline & & & & Asfalto & Normal & 109,7 & 0,250 \\
\hline & & & & Carga móvel & $\begin{array}{ll}--- \\
-\cdots\end{array}$ & 1851,9 & 0,243 \\
\hline & & & & Total & Normal & 2488,7 & 0,187 \\
\hline
\end{tabular}


Tabela E6 (continuação) - Parâmetros estatísticos da resistência e da solicitação CONCRETO ARMADO - VIGA T - 2 VIGAS.

\begin{tabular}{|c|c|c|c|c|c|c|c|}
\hline n & Arquivo & Esforço & Va & íveis & Distribuição & Valor médio & $\mathrm{CV}$ \\
\hline \multirow{12}{*}{5} & \multirow{12}{*}{$\begin{array}{c}\text { SAB TE V5/30/5 } \\
\text { TR4 }\end{array}$} & \multirow{6}{*}{$\mathrm{M}+$} & \multirow{2}{*}{ Resistência } & Classe 36 & Lognormal & 19083,7 & 0,096 \\
\hline & & & & Classe 45 & Lognormal & 19065,0 & 0,091 \\
\hline & & & \multirow{4}{*}{ Solicitação } & Peso próprio & Normal & 4598,9 & 0,100 \\
\hline & & & & Asfalto & Normal & 954,5 & 0,250 \\
\hline & & & & Carga móvel & $\begin{array}{ll}--- \\
-9\end{array}$ & 5369,1 & 0,232 \\
\hline & & & & Total & Normal & 10922,5 & 0,130 \\
\hline & & \multirow{6}{*}{$\mathrm{M}+$} & \multirow{2}{*}{ Resistência } & Classe 36 & Lognormal & 4965,7 & 0,091 \\
\hline & & & & Classe 45 & Lognormal & 5145,6 & 0,091 \\
\hline & & & \multirow{4}{*}{ Solicitação } & Peso próprio & Normal & 653,1 & 0,100 \\
\hline & & & & Asfalto & Normal & 110,0 & 0,250 \\
\hline & & & & Carga móvel & 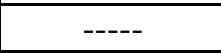 & 1902,8 & 0,243 \\
\hline & & & & Total & Normal & 2665,9 & 0,180 \\
\hline \multirow{12}{*}{7} & \multirow{12}{*}{$\begin{array}{c}\text { C3 TE V20/20/20 } \\
\text { TR3 }\end{array}$} & \multirow{6}{*}{$M+$} & \multirow{2}{*}{ Resistência } & Classe 36 & Lognormal & 7156,6 & 0,091 \\
\hline & & & & Classe 45 & Lognormal & 7426,4 & 0,091 \\
\hline & & & \multirow{4}{*}{ Solicitação } & Peso próprio & Normal & 1284,8 & 0,100 \\
\hline & & & & Asfalto & Normal & 295,1 & 0,250 \\
\hline & & & & Carga móvel & $-\cdots$ & 2690,9 & 0,243 \\
\hline & & & & Total & Normal & 4270,8 & 0,168 \\
\hline & & \multirow{6}{*}{ M - } & \multirow{2}{*}{ Resistência } & Classe 36 & Lognormal & 7354,3 & 0,096 \\
\hline & & & & Classe 45 & Lognormal & 7362,0 & 0,090 \\
\hline & & & \multirow{4}{*}{ Solicitação } & Peso próprio & Normal & 1671,7 & 0,100 \\
\hline & & & & Asfalto & Normal & 372,0 & 0,250 \\
\hline & & & & Carga móvel & $-\cdots$ & 1773,6 & 0,243 \\
\hline & & & & Total & Normal & 3817,3 & 0,137 \\
\hline \multirow{12}{*}{8} & \multirow{12}{*}{$\begin{array}{c}\text { C3 TE V30/30/30 } \\
\text { TR3 }\end{array}$} & \multirow{6}{*}{$\mathrm{M}+$} & \multirow{2}{*}{ Resistência } & Classe 36 & Lognormal & 14756,5 & 0,091 \\
\hline & & & & Classe 45 & Lognormal & 14864,7 & 0,091 \\
\hline & & & \multirow{4}{*}{ Solicitação } & Peso próprio & Normal & 3406,7 & 0,100 \\
\hline & & & & Asfalto & Normal & 657,7 & 0,250 \\
\hline & & & & Carga móvel & ----- & 4503,8 & 0,243 \\
\hline & & & & Total & Normal & 8568,2 & 0,148 \\
\hline & & \multirow{6}{*}{ M - } & \multirow{2}{*}{ Resistência } & Classe 36 & Lognormal & 16330,8 & 0,097 \\
\hline & & & & Classe 45 & Lognormal & 16142,7 & 0,091 \\
\hline & & & \multirow{4}{*}{ Solicitação } & Peso próprio & Normal & 4464,5 & 0,100 \\
\hline & & & & Asfalto & Normal & 848,0 & 0,250 \\
\hline & & & & Carga móvel & ---- & 3017,6 & 0,232 \\
\hline & & & & Total & Normal & 8330,1 & 0,119 \\
\hline
\end{tabular}


Tabela E6 (continuação) - Parâmetros estatísticos da resistência e da solicitação CONCRETO ARMADO - VIGA T - 2 VIGAS.

\begin{tabular}{|c|c|c|c|c|c|c|c|}
\hline $\mathbf{n}$ & Arquivo & Esforço & Va & íveis & Distribuição & Valor médio & $\mathrm{CV}$ \\
\hline \multirow{6}{*}{10} & \multirow{6}{*}{ SA TL V10 TR1 } & \multirow{6}{*}{$M+$} & \multirow{2}{*}{ Resistência } & Classe 36 & Lognormal & 3883,4 & 0,091 \\
\hline & & & & Classe 45 & Lognormal & 4116,6 & 0,091 \\
\hline & & & \multirow{4}{*}{ Solicitação } & Peso próprio & Normal & 649,4 & 0,100 \\
\hline & & & & Asfalto & Normal & 179,1 & 0,800 \\
\hline & & & & Carga móvel & $\begin{array}{ll}--- \\
-9\end{array}$ & 1486,1 & 0,231 \\
\hline & & & & Total & Normal & 2314,6 & 0,168 \\
\hline \multirow{6}{*}{11} & \multirow{6}{*}{ SA TL V20 TR2 } & \multirow{6}{*}{$M+$} & \multirow{2}{*}{ Resistência } & Classe 36 & Lognormal & 13843,0 & 0,091 \\
\hline & & & & Classe 45 & Lognormal & 14197,5 & 0,091 \\
\hline & & & \multirow{4}{*}{ Solicitação } & Peso próprio & Normal & 3452,2 & 0,100 \\
\hline & & & & Asfalto & Normal & 707,7 & 0,800 \\
\hline & & & & Carga móvel & 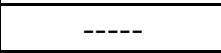 & 4034,0 & 0,228 \\
\hline & & & & Total & Normal & 8193,9 & 0,144 \\
\hline \multirow{12}{*}{12} & \multirow{12}{*}{$\begin{array}{c}\text { SAB TL V3/10/3 } \\
\text { TR1 }\end{array}$} & \multirow{6}{*}{$M+$} & \multirow{2}{*}{ Resistência } & Classe 36 & Lognormal & 2884,5 & 0,091 \\
\hline & & & & Classe 45 & Lognormal & 3125,0 & 0,090 \\
\hline & & & \multirow{4}{*}{ Solicitação } & Peso próprio & Normal & 320,1 & 0,100 \\
\hline & & & & Asfalto & Normal & 108,5 & 0,250 \\
\hline & & & & Carga móvel & $-\cdots$ & 1260,3 & 0,228 \\
\hline & & & & Total & Normal & 1689,0 & 0,177 \\
\hline & & \multirow{6}{*}{ M - } & \multirow{2}{*}{ Resistência } & Classe 36 & Lognormal & 1963,9 & 0,098 \\
\hline & & & & Classe 45 & Lognormal & 2127,6 & 0,091 \\
\hline & & & \multirow{4}{*}{ Solicitação } & Peso próprio & Normal & 212,5 & 0,100 \\
\hline & & & & Asfalto & Normal & 51,8 & 0,250 \\
\hline & & & & Carga móvel & $-\cdots$ & 964,7 & 0,229 \\
\hline & & & & Total & Normal & 1229,0 & 0,185 \\
\hline \multirow{12}{*}{13} & \multirow{12}{*}{$\begin{array}{c}\text { SAB TL V5/20/5 } \\
\text { TR2 }\end{array}$} & \multirow{6}{*}{$M+$} & \multirow{2}{*}{ Resistência } & Classe 36 & Lognormal & 10806,7 & 0,091 \\
\hline & & & & Classe 45 & Lognormal & 11344,4 & 0,091 \\
\hline & & & \multirow{4}{*}{ Solicitação } & Peso próprio & Normal & 2067,8 & 0,100 \\
\hline & & & & Asfalto & Normal & 524,5 & 0,250 \\
\hline & & & & Carga móvel & ----- & 3682,9 & 0,234 \\
\hline & & & & Total & Normal & 6275,1 & 0,149 \\
\hline & & \multirow{6}{*}{ M - } & \multirow{2}{*}{ Resistência } & Classe 36 & Lognormal & 5618,2 & 0,098 \\
\hline & & & & Classe 45 & Lognormal & 6029,0 & 0,091 \\
\hline & & & \multirow{4}{*}{ Solicitação } & Peso próprio & Normal & 757,8 & 0,100 \\
\hline & & & & Asfalto & Normal & 160,7 & 0,250 \\
\hline & & & & Carga móvel & ---- & 2266,1 & 0,231 \\
\hline & & & & Total & Normal & 3184,6 & 0,172 \\
\hline
\end{tabular}


Tabela E6 (continuação) - Parâmetros estatísticos da resistência e da solicitação CONCRETO ARMADO - VIGA T - 2 VIGAS.

\begin{tabular}{|c|c|c|c|c|c|c|c|}
\hline $\mathbf{n}$ & Arquivo & Esforço & Var & íveis & Distribuição & Valor médio & $\mathrm{CV}$ \\
\hline \multirow{12}{*}{14} & \multirow{12}{*}{$\begin{array}{c}\text { SAB TL V5/30/5 } \\
\text { TR3 }\end{array}$} & \multirow{6}{*}{$\mathrm{M}+$} & \multirow{2}{*}{ Resistência } & Classe 36 & Lognormal & 25661,3 & 0,091 \\
\hline & & & & Classe 45 & Lognormal & 26119,1 & 0,091 \\
\hline & & & \multirow{4}{*}{ Solicitação } & Peso próprio & Normal & 6487,4 & 0,100 \\
\hline & & & & Asfalto & Normal & 1442,3 & 0,250 \\
\hline & & & & Carga móvel & ---- & 6478,9 & 0,235 \\
\hline & & & & Total & Normal & 14408,6 & 0,124 \\
\hline & & \multirow{6}{*}{$\mathrm{M}+$} & \multirow{2}{*}{ Resistência } & Classe 36 & Lognormal & 6260,3 & 0,092 \\
\hline & & & & Classe 45 & Lognormal & 6566,8 & 0,091 \\
\hline & & & \multirow{4}{*}{ Solicitação } & Peso próprio & Normal & 900,9 & 0,100 \\
\hline & & & & Asfalto & Normal & 159,6 & 0,250 \\
\hline & & & & Carga móvel & 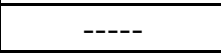 & 2366,3 & 0,232 \\
\hline & & & & Total & Normal & 3426,8 & 0,168 \\
\hline \multirow{12}{*}{16} & \multirow{12}{*}{$\begin{array}{c}\text { C3 TL V20/20/20 } \\
\text { TR2 }\end{array}$} & \multirow{6}{*}{$M+$} & \multirow{2}{*}{ Resistência } & Classe 36 & Lognormal & 9020,9 & 0,091 \\
\hline & & & & Classe 45 & Lognormal & 9474,6 & 0,091 \\
\hline & & & \multirow{4}{*}{ Solicitação } & Peso próprio & Normal & 1618,0 & 0,100 \\
\hline & & & & Asfalto & Normal & 425,6 & 0,250 \\
\hline & & & & Carga móvel & $-\cdots$ & 3266,4 & 0,229 \\
\hline & & & & Total & Normal & 5310,0 & 0,157 \\
\hline & & \multirow{6}{*}{ M - } & \multirow{2}{*}{ Resistência } & Classe 36 & Lognormal & 9702,1 & 0,098 \\
\hline & & & & Classe 45 & Lognormal & 10003,0 & 0,091 \\
\hline & & & \multirow{4}{*}{ Solicitação } & Peso próprio & Normal & 2131,4 & 0,100 \\
\hline & & & & Asfalto & Normal & 554,0 & 0,250 \\
\hline & & & & Carga móvel & $-\cdots$ & 2165,7 & 0,230 \\
\hline & & & & Total & Normal & 4851,0 & 0,130 \\
\hline \multirow{12}{*}{17} & \multirow{12}{*}{$\begin{array}{c}\text { C3 TL V30/30/30 } \\
\text { TR3 }\end{array}$} & \multirow{6}{*}{$M+$} & \multirow{2}{*}{ Resistência } & Classe 36 & Lognormal & 19243,0 & 0,091 \\
\hline & & & & Classe 45 & Lognormal & 19709,8 & 0,091 \\
\hline & & & \multirow{4}{*}{ Solicitação } & Peso próprio & Normal & 4294,3 & 0,100 \\
\hline & & & & Asfalto & Normal & 986,4 & 0,250 \\
\hline & & & & Carga móvel & ----- & 5625,1 & 0,228 \\
\hline & & & & Total & Normal & 10905,8 & 0,140 \\
\hline & & \multirow{6}{*}{ M - } & \multirow{2}{*}{ Resistência } & Classe 36 & Lognormal & 21626,4 & 0,097 \\
\hline & & & & Classe 45 & Lognormal & 21931,9 & 0,091 \\
\hline & & & \multirow{4}{*}{ Solicitação } & Peso próprio & Normal & 5630,0 & 0,100 \\
\hline & & & & Asfalto & Normal & 1269,1 & 0,250 \\
\hline & & & & Carga móvel & ---- & 3645,5 & 0,233 \\
\hline & & & & Total & Normal & 10544,6 & 0,118 \\
\hline
\end{tabular}


Tabela E6 (continuação) - Parâmetros estatísticos da resistência e da solicitação CONCRETO ARMADO - VIGA T - 2 VIGAS.

\begin{tabular}{|c|c|c|c|c|c|c|c|}
\hline$n$ & Arquivo & Esforço & Va & láveis & Distribuição & Valor médio & $\mathrm{CV}$ \\
\hline \multirow{12}{*}{19} & \multirow{12}{*}{$\begin{array}{c}\text { C3B TE } \\
\text { V5-20/25/20-5 } \\
\text { TR3 }\end{array}$} & \multirow{6}{*}{$M+$} & \multirow{2}{*}{ Resistência } & Classe 36 & Lognormal & 7636,0 & 0,091 \\
\hline & & & & Classe 45 & Lognormal & 7930,3 & 0,091 \\
\hline & & & \multirow{4}{*}{ Solicitação } & Peso próprio & Normal & 1371,5 & 0,100 \\
\hline & & & & Asfalto & Normal & 287,3 & 0,250 \\
\hline & & & & Carga móvel & $-\cdots$ & 2951,8 & 0,243 \\
\hline & & & & Total & Normal & 4610,7 & 0,170 \\
\hline & & \multirow{6}{*}{$M+$} & \multirow{2}{*}{ Resistência } & Classe 36 & Lognormal & 9244,6 & 0,097 \\
\hline & & & & Classe 45 & Lognormal & 9234,4 & 0,091 \\
\hline & & & \multirow{4}{*}{ Solicitação } & Peso próprio & Normal & 2272,0 & 0,100 \\
\hline & & & & Asfalto & Normal & 459,2 & 0,250 \\
\hline & & & & Carga móvel & $\begin{array}{ll}--- \\
-\end{array}$ & 2009,1 & 0,243 \\
\hline & & & & Total & Normal & 4740,3 & 0,131 \\
\hline \multirow{12}{*}{20} & \multirow{12}{*}{$\begin{array}{c}\text { C3B TL } \\
\text { V5-20/25/20-5 } \\
\text { TR2 }\end{array}$} & \multirow{6}{*}{$M+$} & \multirow{2}{*}{ Resistência } & Classe 36 & Lognormal & 9607,9 & 0,091 \\
\hline & & & & Classe 45 & Lognormal & 10123,0 & 0,091 \\
\hline & & & \multirow{4}{*}{ Solicitação } & Peso próprio & Normal & 1699,4 & 0,100 \\
\hline & & & & Asfalto & Normal & 412,6 & 0,250 \\
\hline & & & & Carga móvel & $-\cdots$ & 3541,0 & 0,228 \\
\hline & & & & Total & Normal & 5652,9 & 0,159 \\
\hline & & \multirow{6}{*}{ M - } & \multirow{2}{*}{ Resistência } & Classe 36 & Lognormal & 12147,8 & 0,096 \\
\hline & & & & Classe 45 & Lognormal & 12410,5 & 0,090 \\
\hline & & & \multirow{4}{*}{ Solicitação } & Peso próprio & Normal & 2833,8 & 0,100 \\
\hline & & & & Asfalto & Normal & 684,6 & 0,250 \\
\hline & & & & Carga móvel & ----- & 2445,3 & 0,231 \\
\hline & & & & Total & Normal & 5963,7 & 0,125 \\
\hline \multirow{12}{*}{21} & \multirow{12}{*}{$\begin{array}{c}\text { C3B TE } \\
\text { V5-25/30/25-5 } \\
\text { TR3 }\end{array}$} & \multirow{6}{*}{$M+$} & \multirow{2}{*}{ Resistência } & Classe 36 & Lognormal & 10223,6 & 0,092 \\
\hline & & & & Classe 45 & Lognormal & 10524,8 & 0,091 \\
\hline & & & \multirow{4}{*}{ Solicitação } & Peso próprio & Normal & 1966,9 & 0,100 \\
\hline & & & & Asfalto & Normal & 381,9 & 0,250 \\
\hline & & & & Carga móvel & ----- & 3697,9 & 0,243 \\
\hline & & & & Total & Normal & 6046,7 & 0,164 \\
\hline & & \multirow{6}{*}{ M - } & \multirow{2}{*}{ Resistência } & Classe 36 & Lognormal & 13664,4 & 0,097 \\
\hline & & & & Classe 45 & Lognormal & 13524,6 & 0,091 \\
\hline & & & \multirow{4}{*}{ Solicitação } & Peso próprio & Normal & 3665,5 & 0,100 \\
\hline & & & & Asfalto & Normal & 694,2 & 0,250 \\
\hline & & & & Carga móvel & ----- & 2598,9 & 0,229 \\
\hline & & & & Total & Normal & 6958,5 & 0,120 \\
\hline
\end{tabular}


Tabela E6 (continuação) - Parâmetros estatísticos da resistência e da solicitação CONCRETO ARMADO - VIGA T - 2 VIGAS.

\begin{tabular}{|c|c|c|c|c|c|c|c|}
\hline $\mathbf{n}$ & Arquivo & Esforço & Var & láveis & Distribuição & Valor médio & $\mathbf{C V}$ \\
\hline \multirow{12}{*}{22} & \multirow{12}{*}{$\begin{array}{c}\text { C3B TL } \\
\text { V5-25/30/25-5 } \\
\text { TR2 }\end{array}$} & \multirow{6}{*}{$M+$} & \multirow{2}{*}{ Resistência } & Classe 36 & Lognormal & 12934,0 & 0,092 \\
\hline & & & & Classe 45 & Lognormal & 13576,2 & 0,091 \\
\hline & & & \multirow{4}{*}{ Solicitação } & Peso próprio & Normal & 2404,8 & 0,100 \\
\hline & & & & Asfalto & Normal & 555,3 & 0,250 \\
\hline & & & & Carga móvel & ---- & 4557,3 & 0,228 \\
\hline & & & & Total & Normal & 7517,3 & 0,155 \\
\hline & & \multirow{6}{*}{$M+$} & \multirow{2}{*}{ Resistência } & Classe 36 & Lognormal & 17868,6 & 0,098 \\
\hline & & & & Classe 45 & Lognormal & 18165,6 & 0,091 \\
\hline & & & \multirow{4}{*}{ Solicitação } & Peso próprio & Normal & 4518,3 & 0,100 \\
\hline & & & & Asfalto & Normal & 1037,1 & 0,250 \\
\hline & & & & Carga móvel & $\begin{array}{ll}--- \\
-\end{array}$ & 3135,7 & 0,229 \\
\hline & & & & Total & Normal & 8691,1 & 0,118 \\
\hline \multirow{12}{*}{23} & \multirow{12}{*}{$\begin{array}{c}\text { C2 TL V30/30 } \\
\text { TR3 }\end{array}$} & \multirow{6}{*}{$M+$} & \multirow{2}{*}{ Resistência } & Classe 36 & Lognormal & 17413,3 & 0,091 \\
\hline & & & & Classe 45 & Lognormal & 18042,3 & 0,091 \\
\hline & & & \multirow{4}{*}{ Solicitação } & Peso próprio & Normal & 3607,6 & 0,100 \\
\hline & & & & Asfalto & Normal & 829,7 & 0,250 \\
\hline & & & & Carga móvel & ----- & 5705,6 & 0,228 \\
\hline & & & & Total & Normal & 10142,9 & 0,147 \\
\hline & & \multirow{6}{*}{ M - } & \multirow{2}{*}{ Resistência } & Classe 36 & Lognormal & 25036,7 & 0,097 \\
\hline & & & & Classe 45 & Lognormal & 25098,0 & 0,091 \\
\hline & & & \multirow{4}{*}{ Solicitação } & Peso próprio & Normal & 7000,7 & 0,100 \\
\hline & & & & Asfalto & Normal & 1581,9 & 0,250 \\
\hline & & & & Carga móvel & $\begin{array}{ll}--- \\
--\end{array}$ & 3834,1 & 0,223 \\
\hline & & & & Total & Normal & 12416,7 & 0,112 \\
\hline
\end{tabular}

Tabela E7 - Parâmetros estatísticos da resistência e da solicitação CONCRETO ARMADO - VIGA T - 5 VIGAS.

\begin{tabular}{|c|c|c|c|c|c|c|c|}
\hline $\mathbf{n}$ & Arquivo & Esforço & \multicolumn{2}{|c|}{ Variáveis } & Distribuição & Valor médio & CV \\
\hline \multirow{6}{*}{1} & \multirow{6}{*}{ SA TE V10 TR2 } & \multirow{6}{*}{$M+$} & \multirow{2}{*}{ Resistência } & Classe 36 & Lognormal & 1194,9 & 0,092 \\
\hline & & & & Classe 45 & Lognormal & 1269,6 & 0,091 \\
\hline & & & \multirow{4}{*}{ Solicitação } & Peso próprio & Normal & 147,7 & 0,100 \\
\hline & & & & Asfalto & Normal & 51,6 & 0,250 \\
\hline & & & & Carga móvel & ----- & 520,4 & 0,232 \\
\hline & & & & Total & Normal & 719,8 & 0,175 \\
\hline \multirow{6}{*}{2} & \multirow{6}{*}{ SA TE V20 TR2 } & \multirow{6}{*}{$M+$} & \multirow{2}{*}{ Resistência } & Classe 36 & Lognormal & 3987,4 & 0,091 \\
\hline & & & & Classe 45 & Lognormal & 4100,8 & 0,091 \\
\hline & & & \multirow{4}{*}{ Solicitação } & Peso próprio & Normal & 741,3 & 0,100 \\
\hline & & & & Asfalto & Normal & 206,9 & 0,250 \\
\hline & & & & Carga móvel & ----- & 1478,9 & 0,243 \\
\hline & & & & Total & Normal & 2427,1 & 0,158 \\
\hline
\end{tabular}


Tabela E7 (continuação) - Parâmetros estatísticos da resistência e da solicitação CONCRETO ARMADO - VIGA T - 5 VIGAS.

\begin{tabular}{|c|c|c|c|c|c|c|c|}
\hline $\mathbf{n}$ & Arquivo & Esforço & Va & láveis & Distribuição & Valor médio & $\mathrm{CV}$ \\
\hline \multirow{6}{*}{5} & \multirow{6}{*}{ SA TL V10 TR2 } & \multirow{6}{*}{$M+$} & \multirow{2}{*}{ Resistência } & Classe 36 & Lognormal & 1597,1 & 0,091 \\
\hline & & & & Classe 45 & Lognormal & 1714,3 & 0,091 \\
\hline & & & \multirow{4}{*}{ Solicitação } & Peso próprio & Normal & 197,0 & 0,100 \\
\hline & & & & Asfalto & Normal & 78,9 & 0,800 \\
\hline & & & & Carga móvel & $-\cdots$ & 657,9 & 0,219 \\
\hline & & & & Total & Normal & 933,7 & 0,175 \\
\hline \multirow{6}{*}{6} & \multirow{6}{*}{ SA TL V20 TR2 } & \multirow{6}{*}{$M+$} & \multirow{2}{*}{ Resistência } & Classe 36 & Lognormal & 5054,4 & 0,091 \\
\hline & & & & Classe 45 & Lognormal & 5329,4 & 0,091 \\
\hline & & & \multirow{4}{*}{ Solicitação } & Peso próprio & Normal & 942,1 & 0,100 \\
\hline & & & & Asfalto & Normal & 314,8 & 0,800 \\
\hline & & & & Carga móvel & $\begin{array}{ll}--- \\
-\end{array}$ & 1750,3 & 0,228 \\
\hline & & & & Total & Normal & 3007,2 & 0,165 \\
\hline \multirow{12}{*}{9} & \multirow{12}{*}{$\begin{array}{c}\text { C3 TL V30/30/30 } \\
\text { TR2 }\end{array}$} & \multirow{6}{*}{$M+$} & \multirow{2}{*}{ Resistência } & Classe 36 & Lognormal & 8416,8 & 0,092 \\
\hline & & & & Classe 45 & Lognormal & 8779,1 & 0,091 \\
\hline & & & \multirow{4}{*}{ Solicitação } & Peso próprio & Normal & 2040,6 & 0,100 \\
\hline & & & & Asfalto & Normal & 427,1 & 0,250 \\
\hline & & & & Carga móvel & ----- & 2319,7 & 0,229 \\
\hline & & & & Total & Normal & 4787,4 & 0,135 \\
\hline & & \multirow{6}{*}{$\mathrm{M}+$} & \multirow{2}{*}{ Resistência } & Classe 36 & Lognormal & 9550,9 & 0,098 \\
\hline & & & & Classe 45 & Lognormal & 9786,8 & 0,091 \\
\hline & & & \multirow{4}{*}{ Solicitação } & Peso próprio & Normal & 2703,6 & 0,100 \\
\hline & & & & Asfalto & Normal & 571,4 & 0,250 \\
\hline & & & & Carga móvel & ----- & 1357,8 & 0,232 \\
\hline & & & & Total & Normal & 4632,8 & 0,112 \\
\hline \multirow{12}{*}{10} & \multirow{12}{*}{$\begin{array}{c}\text { C3B TE } \\
\text { V5-25/30/25-5 } \\
\text { TR2 }\end{array}$} & \multirow{6}{*}{$M+$} & \multirow{2}{*}{ Resistência } & Classe 36 & Lognormal & 4552,6 & 0,091 \\
\hline & & & & Classe 45 & Lognormal & 4678,3 & 0,091 \\
\hline & & & \multirow{4}{*}{ Solicitação } & Peso próprio & Normal & 1007,1 & 0,100 \\
\hline & & & & Asfalto & Normal & 162,1 & 0,250 \\
\hline & & & & Carga móvel & ----- & 1630,2 & 0,243 \\
\hline & & & & Total & Normal & 2799,4 & 0,159 \\
\hline & & \multirow{6}{*}{$M+$} & \multirow{2}{*}{ Resistência } & Classe 36 & Lognormal & 6372,5 & 0,095 \\
\hline & & & & Classe 45 & Lognormal & 6292,1 & 0,091 \\
\hline & & & \multirow{4}{*}{ Solicitação } & Peso próprio & Normal & 1900,0 & 0,100 \\
\hline & & & & Asfalto & Normal & 306,4 & 0,250 \\
\hline & & & & Carga móvel & ----- & 1021,3 & 0,228 \\
\hline & & & & Total & Normal & 3227,7 & 0,113 \\
\hline
\end{tabular}


Tabela E7 (continuação) - Parâmetros estatísticos da resistência e da solicitação CONCRETO ARMADO - VIGA T - 5 VIGAS.

\begin{tabular}{|c|c|c|c|c|c|c|c|}
\hline $\mathbf{n}$ & Arquivo & \begin{tabular}{|l|} 
Esforço \\
\end{tabular} & Va & áveis & Distribuição & Valor médio & $\mathrm{CV}$ \\
\hline \multirow{12}{*}{11} & \multirow{12}{*}{$\begin{array}{c}\text { C3B TL } \\
\text { V5-25/30/25-5 } \\
\text { TR2 }\end{array}$} & \multirow{6}{*}{$M+$} & \multirow{2}{*}{ Resistência } & Classe 36 & Lognormal & 5853,0 & 0,091 \\
\hline & & & & Classe 45 & Lognormal & 6227,4 & 0,091 \\
\hline & & & \multirow{4}{*}{ Solicitação } & Peso próprio & Normal & 1174,8 & 0,100 \\
\hline & & & & Asfalto & Normal & 249,1 & 0,250 \\
\hline & & & & Carga móvel & ---- & 1932,9 & 0,227 \\
\hline & & & & Total & Normal & 3356,8 & 0,149 \\
\hline & & \multirow{6}{*}{$M+$} & \multirow{2}{*}{ Resistência } & Classe 36 & Lognormal & 8037,9 & 0,095 \\
\hline & & & & Classe 45 & Lognormal & 8209,2 & 0,091 \\
\hline & & & \multirow{4}{*}{ Solicitação } & Peso próprio & Normal & 2215,2 & 0,100 \\
\hline & & & & Asfalto & Normal & 470,6 & 0,250 \\
\hline & & & & Carga móvel & ---- & 1182,0 & 0,230 \\
\hline & & & & Total & Normal & 3867,8 & 0,113 \\
\hline \multirow{6}{*}{12} & \multirow{6}{*}{ SA TE V10 STR } & \multirow{6}{*}{$M+$} & \multirow{2}{*}{ Resistência } & Classe 36 & Lognormal & 1213,1 & 0,091 \\
\hline & & & & Classe 45 & Lognormal & 1294,3 & 0,091 \\
\hline & & & \multirow{4}{*}{ Solicitação } & Peso próprio & Normal & 136,0 & 0,100 \\
\hline & & & & Asfalto & Normal & 52,9 & 0,250 \\
\hline & & & & Carga móvel & ----- & 570,1 & 0,243 \\
\hline & & & & Total & Normal & 759,0 & 0,189 \\
\hline \multirow{6}{*}{13} & \multirow{6}{*}{ SA TE V20 STR } & \multirow{6}{*}{$M+$} & \multirow{2}{*}{ Resistência } & Classe 36 & Lognormal & 3924,8 & 0,091 \\
\hline & & & & Classe 45 & Lognormal & 4060,1 & 0,092 \\
\hline & & & \multirow{4}{*}{ Solicitação } & Peso próprio & Normal & 689,1 & 0,100 \\
\hline & & & & Asfalto & Normal & 214,0 & 0,250 \\
\hline & & & & Carga móvel & ---- & 1565,0 & 0,243 \\
\hline & & & & Total & Normal & 2468,1 & 0,163 \\
\hline \multirow{6}{*}{16} & \multirow{6}{*}{ SA TL V10 STR } & \multirow{6}{*}{$M+$} & \multirow{2}{*}{ Resistência } & Classe 36 & Lognormal & 1843,6 & 0,091 \\
\hline & & & & Classe 45 & Lognormal & 1968,8 & 0,091 \\
\hline & & & \multirow{4}{*}{ Solicitação } & Peso próprio & Normal & 179,6 & 0,100 \\
\hline & & & & Asfalto & Normal & 82,0 & 0,800 \\
\hline & & & & Carga móvel & ---- & 756,7 & 0,217 \\
\hline & & & & Total & Normal & 1018,3 & 0,179 \\
\hline \multirow{6}{*}{17} & \multirow{6}{*}{ SA TL V20 STR } & \multirow{6}{*}{$M+$} & \multirow{2}{*}{ Resistência } & Classe 36 & Lognormal & 5626,9 & 0,091 \\
\hline & & & & Classe 45 & Lognormal & 5888,0 & 0,091 \\
\hline & & & & Peso próprio & Normal & 869,3 & 0,100 \\
\hline & & & Solicitacão & Asfalto & Normal & 334,8 & 0,800 \\
\hline & & & SUIICIIAÇa0 & Carga móvel & ---- & 2073,4 & 0,220 \\
\hline & & & & Total & Normal & 3277,5 & 0,168 \\
\hline
\end{tabular}


Tabela E8 - Parâmetros estatísticos da resistência e da solicitação CONCRETO ARMADO - VIGA T - SEÇÃO CELULAR.

\begin{tabular}{|c|c|c|c|c|c|c|c|}
\hline $\mathbf{n}$ & Arquivo & Esforço & Va & íveis & Distribuição & Valor médio & $\mathrm{CV}$ \\
\hline \multirow{6}{*}{1} & \multirow{6}{*}{ SA TL V20 STR } & \multirow{6}{*}{$M+$} & \multirow{2}{*}{ Resistência } & Classe 36 & Lognormal & 23165,3 & 0,091 \\
\hline & & & & Classe 45 & Lognormal & 24071,4 & 0,091 \\
\hline & & & \multirow{4}{*}{ Solicitação } & Peso próprio & Normal & 6458,1 & 0,100 \\
\hline & & & & Asfalto & Normal & 1458,8 & 0,800 \\
\hline & & & & Carga móvel & $\begin{array}{ll}--- \\
-9\end{array}$ & 4916,0 & 0,221 \\
\hline & & & & Total & Normal & 12832,9 & 0,140 \\
\hline \multirow{12}{*}{4} & \multirow{12}{*}{$\begin{array}{c}\text { C3 TL V30/30/30 } \\
\text { STR }\end{array}$} & \multirow{6}{*}{$M+$} & \multirow{2}{*}{ Resistência } & Classe 36 & Lognormal & 32860,4 & 0,098 \\
\hline & & & & Classe 45 & Lognormal & 34338,5 & 0,091 \\
\hline & & & \multirow{4}{*}{ Solicitação } & Peso próprio & Normal & 8717,5 & 0,100 \\
\hline & & & & Asfalto & Normal & 1945,8 & 0,250 \\
\hline & & & & Carga móvel & 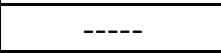 & 6375,3 & 0,221 \\
\hline & & & & Total & Normal & 17038,6 & 0,118 \\
\hline & & \multirow{6}{*}{$M+$} & \multirow{2}{*}{ Resistência } & Classe 36 & Lognormal & 39291,0 & 0,094 \\
\hline & & & & Classe 45 & Lognormal & 40704,0 & 0,091 \\
\hline & & & \multirow{4}{*}{ Solicitação } & Peso próprio & Normal & 11634,9 & 0,100 \\
\hline & & & & Asfalto & Normal & 2586,2 & 0,250 \\
\hline & & & & Carga móvel & $\begin{array}{ll}--- \\
-9\end{array}$ & 3968,1 & 0,223 \\
\hline & & & & Total & Normal & 18189,2 & 0,106 \\
\hline \multirow{6}{*}{6} & \multirow{6}{*}{ SA TE V20 STR } & \multirow{6}{*}{$M+$} & \multirow{2}{*}{ Resistência } & Classe 36 & Lognormal & 17075,3 & 0,091 \\
\hline & & & & Classe 45 & Lognormal & 17562,2 & 0,091 \\
\hline & & & \multirow{4}{*}{ Solicitação } & Peso próprio & Normal & 4443,1 & 0,100 \\
\hline & & & & Asfalto & Normal & 958,3 & 0,250 \\
\hline & & & & Carga móvel & $-\cdots$ & 4920,4 & 0,221 \\
\hline & & & & Total & Normal & 10321,8 & 0,123 \\
\hline \multirow{12}{*}{9} & \multirow{12}{*}{$\begin{array}{c}\text { C3 TE V30/30/30 } \\
\text { STR }\end{array}$} & \multirow{6}{*}{$M+$} & \multirow{2}{*}{ Resistência } & Classe 36 & Lognormal & 24017,0 & 0,096 \\
\hline & & & & Classe 45 & Lognormal & 24736,0 & 0,091 \\
\hline & & & \multirow{4}{*}{ Solicitação } & Peso próprio & Normal & 5997,7 & 0,100 \\
\hline & & & & Asfalto & Normal & 1286,2 & 0,250 \\
\hline & & & & Carga móvel & ----- & 6391,4 & 0,221 \\
\hline & & & & Total & Normal & 13675,3 & 0,129 \\
\hline & & \multirow{6}{*}{$M+$} & \multirow{2}{*}{ Resistência } & Classe 36 & Lognormal & 27811,5 & 0,096 \\
\hline & & & & Classe 45 & Lognormal & 28308,2 & 0,091 \\
\hline & & & \multirow{4}{*}{ Solicitação } & Peso próprio & Normal & 8008,2 & 0,100 \\
\hline & & & & Asfalto & Normal & 1713,8 & 0,250 \\
\hline & & & & Carga móvel & ---- & 3957,1 & 0,223 \\
\hline & & & & Total & Normal & 13679,1 & 0,110 \\
\hline
\end{tabular}


Tabela E9 - Parâmetros estatísticos da resistência e da solicitação CONCRETO PROTENDIDO - ELU - LAJE.

\begin{tabular}{|c|c|c|c|c|c|c|c|}
\hline n & Arquivo & Esforço & \multicolumn{2}{|c|}{ Variáveis } & Distribuição & Valor médio & $\mathbf{C V}$ \\
\hline \multirow{6}{*}{3} & \multirow{6}{*}{ SA TE V20 VZ } & \multirow{6}{*}{$M+$} & \multirow{2}{*}{ Resistência } & Classe 36 & Lognormal & 2281,5 & 0,069 \\
\hline & & & & Classe 45 & Lognormal & 2167,7 & 0,069 \\
\hline & & & \multirow{4}{*}{ Solicitação } & Peso próprio & Normal & 630,0 & 0,100 \\
\hline & & & & Asfalto & Normal & 84,6 & 0,250 \\
\hline & & & & Carga móvel & ---- & 469,7 & 0,218 \\
\hline & & & & Total & Normal & 1184,3 & 0,111 \\
\hline \multirow{6}{*}{4} & \multirow{6}{*}{ SA TL V20 VZ } & \multirow{6}{*}{$M+$} & \multirow{2}{*}{ Resistência } & Classe 36 & Lognormal & 2291,7 & 0,069 \\
\hline & & & & Classe 45 & Lognormal & 2191,6 & 0,069 \\
\hline & & & \multirow{4}{*}{ Solicitação } & Peso próprio & Normal & 643,8 & 0,100 \\
\hline & & & & Asfalto & Normal & 89,6 & 0,250 \\
\hline & & & & Carga móvel & ----- & 386,3 & 0,233 \\
\hline & & & & Total & Normal & 1119,7 & 0,108 \\
\hline
\end{tabular}

Tabela E10 - Parâmetros estatísticos da resistência e da solicitação CONCRETO PROTENDIDO - ELU - VIGA T - 5 VIGAS.

\begin{tabular}{|c|c|c|c|c|c|c|c|}
\hline $\mathbf{n}$ & Arquivo & Esforço & Val & iáveis & Distribuição & Valor médio & $\mathrm{CV}$ \\
\hline \multirow{6}{*}{2} & \multirow{6}{*}{ SA TE V20 TR2 } & \multirow{6}{*}{$M+$} & \multirow{2}{*}{ Resistência } & Classe 36 & Lognormal & 4729,1 & 0,070 \\
\hline & & & & Classe 45 & Lognormal & 4471,6 & 0,069 \\
\hline & & & \multirow{4}{*}{ Solicitação } & Peso próprio & Normal & 1082,2 & 0,100 \\
\hline & & & & Asfalto & Normal & 206,9 & 0,250 \\
\hline & & & & Carga móvel & $\begin{array}{ll}---- \\
\end{array}$ & 1478,9 & 0,243 \\
\hline & & & & Total & Normal & 2768,0 & 0,143 \\
\hline \multirow{6}{*}{3} & \multirow{6}{*}{ SA TE V30 TR2 } & \multirow{6}{*}{$M+$} & \multirow{2}{*}{ Resistência } & Classe 36 & Lognormal & 10476,4 & 0,070 \\
\hline & & & & Classe 45 & Lognormal & 9867,1 & 0,069 \\
\hline & & & \multirow{4}{*}{ Solicitação } & Peso próprio & Normal & 2898,6 & 0,100 \\
\hline & & & & Asfalto & Normal & 466,0 & 0,250 \\
\hline & & & & Carga móvel & ----- & 2609,4 & 0,243 \\
\hline & & & & Total & Normal & 5973,9 & 0,125 \\
\hline \multirow{6}{*}{4} & \multirow{6}{*}{ SA TE V40 TR4 } & \multirow{6}{*}{$M+$} & \multirow{2}{*}{ Resistência } & Classe 36 & Lognormal & 20603,1 & 0,070 \\
\hline & & & & Classe 45 & Lognormal & 19565,9 & 0,069 \\
\hline & & & \multirow{4}{*}{ Solicitação } & Peso próprio & Normal & 6420,8 & 0,100 \\
\hline & & & & Asfalto & Normal & 824,8 & 0,250 \\
\hline & & & & Carga móvel & $\begin{array}{ll}---- \\
\end{array}$ & 3510,7 & 0,243 \\
\hline & & & & Total & Normal & 10756,3 & 0,109 \\
\hline \multirow{6}{*}{6} & \multirow{6}{*}{ SA TL V20 TR2 } & \multirow{6}{*}{$M+$} & \multirow{2}{*}{ Resistência } & Classe 36 & Lognormal & 6422,8 & 0,070 \\
\hline & & & & Classe 45 & Lognormal & 6134,4 & 0,069 \\
\hline & & & \multirow{4}{*}{ Solicitação } & Peso próprio & Normal & 1483,5 & 0,100 \\
\hline & & & & Asfalto & Normal & 314,8 & 0,800 \\
\hline & & & & Carga móvel & ----- & 1750,3 & 0,228 \\
\hline & & & & Total & Normal & 3548,6 & 0,145 \\
\hline
\end{tabular}


Tabela E10 (continuação) - Parâmetros estatísticos da resistência e da solicitação CONCRETO PROTENDIDO - ELU - VIGA T - 5 VIGAS.

\begin{tabular}{|c|c|c|c|c|c|c|c|}
\hline $\mathbf{n}$ & Arquivo & Esforço & Var & áveis & Distribuição & Valor médio & $\mathrm{CV}$ \\
\hline \multirow{6}{*}{7} & \multirow{6}{*}{ SA TL V30 TR2 } & \multirow{6}{*}{$M+$} & \multirow{2}{*}{ Resistência } & Classe 36 & Lognormal & 13768,8 & 0,070 \\
\hline & & & & Classe 45 & Lognormal & 13320,0 & 0,069 \\
\hline & & & \multirow{4}{*}{ Solicitação } & Peso próprio & Normal & 3798,7 & 0,100 \\
\hline & & & & Asfalto & Normal & 703,2 & 0,800 \\
\hline & & & & Carga móvel & ---- & 3003,6 & 0,231 \\
\hline & & & & Total & Normal & 7505,4 & 0,135 \\
\hline \multirow{6}{*}{8} & \multirow{6}{*}{ SA TL V40 TR4 } & \multirow{6}{*}{$M+$} & \multirow{2}{*}{ Resistência } & Classe 36 & Lognormal & 24996,0 & 0,070 \\
\hline & & & & Classe 45 & Lognormal & 24364,4 & 0,070 \\
\hline & & & \multirow{4}{*}{ Solicitação } & Peso próprio & Normal & 7680,8 & 0,100 \\
\hline & & & & Asfalto & Normal & 1245,5 & 0,800 \\
\hline & & & & Carga móvel & $-\cdots$ & 4077,3 & 0,233 \\
\hline & & & & Total & Normal & 13003,6 & 0,128 \\
\hline \multirow{6}{*}{13} & \multirow{6}{*}{ SA TE V20 STR } & \multirow{6}{*}{$M+$} & \multirow{2}{*}{ Resistência } & Classe 36 & Lognormal & 4632,4 & 0,070 \\
\hline & & & & Classe 45 & Lognormal & 4546,3 & 0,069 \\
\hline & & & \multirow{4}{*}{ Solicitação } & Peso próprio & Normal & 1030,3 & 0,100 \\
\hline & & & & Asfalto & Normal & 214,0 & 0,250 \\
\hline & & & & Carga móvel & $-\cdots$ & 1565,0 & 0,243 \\
\hline & & & & Total & Normal & 2809,3 & 0,147 \\
\hline \multirow{6}{*}{14} & \multirow{6}{*}{ SA TE V30 STR } & \multirow{6}{*}{$M+$} & \multirow{2}{*}{ Resistência } & Classe 36 & Lognormal & 10237,2 & 0,070 \\
\hline & & & & Classe 45 & Lognormal & 9623,0 & 0,069 \\
\hline & & & \multirow{4}{*}{ Solicitação } & Peso próprio & Normal & 2781,8 & 0,100 \\
\hline & & & & Asfalto & Normal & 480,2 & 0,250 \\
\hline & & & & Carga móvel & ----- & 2672,9 & 0,243 \\
\hline & & & & Total & Normal & 5934,9 & 0,127 \\
\hline \multirow{6}{*}{15} & \multirow{6}{*}{ SA TE V40 STR } & \multirow{6}{*}{$M+$} & \multirow{2}{*}{ Resistência } & Classe 36 & Lognormal & 19787,7 & 0,070 \\
\hline & & & & Classe 45 & Lognormal & 18770,7 & 0,069 \\
\hline & & & & Peso próprio & Normal & 6021,8 & 0,100 \\
\hline & & & Solicitacão & Asfalto & Normal & 844,1 & 0,250 \\
\hline & & & sollcilaçao & Carga móvel & ----- & 3695,0 & 0,243 \\
\hline & & & & Total & Normal & 10560,8 & 0,112 \\
\hline & & & Resistência & Classe 36 & Lognormal & 6700,8 & 0,070 \\
\hline & & & Kesistencid & Classe 45 & Lognormal & 6462,9 & 0,069 \\
\hline 17 & SA TL V20 STR & $M+$ & & Peso próprio & Normal & 1404,4 & 0,100 \\
\hline & | & & Solif & Asfalto & Normal & 334,8 & 0,800 \\
\hline & & & Solicildç̧0 & Carga móvel & ----- & 2073,4 & 0,220 \\
\hline & & & & Total & Normal & 3812,6 & 0,149 \\
\hline & & & Resistência & Classe 36 & Lognormal & 13929,3 & 0,070 \\
\hline & & & 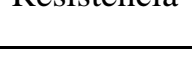 & Classe 45 & Lognormal & 13247,2 & 0,069 \\
\hline 18 & SA TL V30 STR & $M+$ & & Peso próprio & Normal & 3620,5 & 0,100 \\
\hline & & & Solicitacão & Asfalto & Normal & 753,1 & 0,800 \\
\hline & & & sollcilaçaO & Carga móvel & ----- & 3462,6 & 0,221 \\
\hline & & & & Total & Normal & 7836,2 & 0,139 \\
\hline
\end{tabular}


Tabela E10 (continuação) - Parâmetros estatísticos da resistência e da solicitação CONCRETO PROTENDIDO - ELU - VIGA T - 5 VIGAS.

\begin{tabular}{|l|c|c|c|c|c|c|c|}
\hline n & Arquivo & Esforço & \multicolumn{2}{|c|}{ Variáveis } & Distribuição & Valor médio & CV \\
\hline \multirow{4}{*}{19} & \multirow{3}{*}{ SA TL V40 STR } & \multirow{3}{*}{ M + } & \multirow{2}{*}{ Resistência } & Classe 36 & Lognormal & 24342,1 & 0,070 \\
\cline { 4 - 8 } & & & Classe 45 & Lognormal & 24043,2 & 0,069 \\
\cline { 4 - 8 } & & \multirow{3}{*}{ Solicitação } & Peso próprio & Normal & 7071,8 & 0,100 \\
\cline { 4 - 8 } & & & Asfalto & Normal & 1321,8 & 0,800 \\
\cline { 4 - 8 } & & & Carga móvel & ----- & 4694,4 & 0,223 \\
\cline { 4 - 8 } & & & Total & Normal & 13088,0 & 0,132 \\
\hline
\end{tabular}

Tabela E11 - Parâmetros estatísticos da resistência e da solicitação CONCRETO PROTENDIDO - ELU - SEÇÃO CELULAR.

\begin{tabular}{|c|c|c|c|c|c|c|c|}
\hline $\mathbf{n}$ & Arquivo & Esforço & Val & iáveis & Distribuição & Valor médio & $\mathrm{CV}$ \\
\hline \multirow{6}{*}{1} & \multirow{6}{*}{ SA TL V20 STR } & \multirow{6}{*}{$M+$} & \multirow{2}{*}{ Resistência } & Classe 36 & Lognormal & 20857,3 & 0,069 \\
\hline & & & & Classe 45 & Lognormal & 21628,8 & 0,069 \\
\hline & & & \multirow{4}{*}{ Solicitação } & Peso próprio & Normal & 5449,5 & 0,100 \\
\hline & & & & Asfalto & Normal & 1458,8 & 0,250 \\
\hline & & & & Carga móvel & $\begin{array}{ll}---- \\
\end{array}$ & 4916,0 & 0,221 \\
\hline & & & & Total & Normal & 11824,3 & 0,114 \\
\hline \multirow{6}{*}{2} & \multirow{6}{*}{ SA TL V30 STR } & \multirow{6}{*}{$M+$} & \multirow{2}{*}{ Resistência } & Classe 36 & Lognormal & 45359,4 & 0,069 \\
\hline & & & & Classe 45 & Lognormal & 46998,3 & 0,069 \\
\hline & & & \multirow{4}{*}{ Solicitação } & Peso próprio & Normal & 13764,5 & 0,100 \\
\hline & & & & Asfalto & Normal & 3257,0 & 0,250 \\
\hline & & & & Carga móvel & ----- & 8323,9 & 0,221 \\
\hline & & & & Total & Normal & 25345,5 & 0,104 \\
\hline \multirow{6}{*}{3} & \multirow{6}{*}{ SA TL V40 STR } & \multirow{6}{*}{$M+$} & \multirow{2}{*}{ Resistência } & Classe 36 & Lognormal & 82609,6 & 0,069 \\
\hline & & & & Classe 45 & Lognormal & 83962,6 & 0,068 \\
\hline & & & \multirow{4}{*}{ Solicitação } & Peso próprio & Normal & 26985,0 & 0,100 \\
\hline & & & & Asfalto & Normal & 5774,4 & 0,250 \\
\hline & & & & Carga móvel & $\begin{array}{ll}---- \\
\end{array}$ & 11748,4 & 0,222 \\
\hline & & & & Total & Normal & 44507,8 & 0,099 \\
\hline \multirow{6}{*}{5} & \multirow{6}{*}{ SA TL V30 TR2 } & \multirow{6}{*}{$M+$} & \multirow{2}{*}{ Resistência } & Classe 36 & Lognormal & 12083,4 & 0,069 \\
\hline & & & & Classe 45 & Lognormal & 12323,8 & 0,069 \\
\hline & & & \multirow{4}{*}{ Solicitação } & Peso próprio & Normal & 3989,0 & 0,100 \\
\hline & & & & Asfalto & Normal & 743,9 & 0,800 \\
\hline & & & & Carga móvel & ----- & 2113,8 & 0,223 \\
\hline & & & & Total & Normal & 6846,7 & 0,132 \\
\hline \multirow{6}{*}{6} & \multirow{6}{*}{ SA TE V20 STR } & \multirow{6}{*}{$M+$} & \multirow{2}{*}{ Resistência } & Classe 36 & Lognormal & 16524,1 & 0,069 \\
\hline & & & & Classe 45 & Lognormal & 16899,6 & 0,069 \\
\hline & & & \multirow{4}{*}{ Solicitação } & Peso próprio & Normal & 4383,8 & 0,100 \\
\hline & & & & Asfalto & Normal & 958,3 & 0,800 \\
\hline & & & & Carga móvel & ----- & 4920,4 & 0,221 \\
\hline & & & & Total & Normal & 10262,5 & 0,142 \\
\hline
\end{tabular}


Tabela E11 (continuação) - Parâmetros estatísticos da resistência e da solicitação CONCRETO PROTENDIDO - ELU - SEÇÃO CELULAR.

\begin{tabular}{|c|c|c|c|c|c|c|c|}
\hline $\bar{n}$ & Arquivo & Esforço & Var & áveis & Distribuição & Valor médio & $\mathbf{C V}$ \\
\hline \multirow{6}{*}{7} & \multirow{6}{*}{ SA TE V30 STR } & \multirow{6}{*}{$M+$} & \multirow{2}{*}{ Resistência } & Classe 36 & Lognormal & 35230,9 & 0,069 \\
\hline & & & & Classe 45 & Lognormal & 35622,1 & 0,069 \\
\hline & & & \multirow{4}{*}{ Solicitação } & Peso próprio & Normal & 10858,6 & 0,100 \\
\hline & & & & Asfalto & Normal & 2153,7 & 0,800 \\
\hline & & & & Carga móvel & $\begin{array}{ll}--- \\
-4\end{array}$ & 8343,3 & 0,222 \\
\hline & & & & Total & Normal & 21355,6 & 0,135 \\
\hline \multirow{6}{*}{8} & \multirow{6}{*}{ SA TE V40 STR } & \multirow{6}{*}{$M+$} & \multirow{2}{*}{ Resistência } & Classe 36 & Lognormal & 63131,2 & 0,069 \\
\hline & & & & Classe 45 & Lognormal & 62956,8 & 0,069 \\
\hline & & & \multirow{4}{*}{ Solicitação } & Peso próprio & Normal & 20968,5 & 0,100 \\
\hline & & & & Asfalto & Normal & 3831,8 & 0,250 \\
\hline & & & & Carga móvel & $\begin{array}{ll}--- \\
-\end{array}$ & 11773,5 & 0,222 \\
\hline & & & & Total & Normal & 36573,8 & 0,103 \\
\hline \multirow{6}{*}{10} & \multirow{6}{*}{ SA TE V30 TR2 } & \multirow{6}{*}{$M+$} & \multirow{2}{*}{ Resistência } & Classe 36 & Lognormal & 11123,2 & 0,069 \\
\hline & & & & Classe 45 & Lognormal & 11263,9 & 0,069 \\
\hline & & & \multirow{4}{*}{ Solicitação } & Peso próprio & Normal & 3509,2 & 0,100 \\
\hline & & & & Asfalto & Normal & 638,7 & 0,250 \\
\hline & & & & Carga móvel & $\begin{array}{ll}--- \\
-\cdots\end{array}$ & 2553,6 & 0,224 \\
\hline & & & & Total & Normal & 6701,4 & 0,110 \\
\hline
\end{tabular}

Tabela E12 - Parâmetros estatísticos da resistência CONCRETO PROTENDIDO - ELS - LAJE.

\begin{tabular}{|c|c|c|c|c|c|}
\hline \multirow{2}{*}{$\mathbf{n}$} & \multirow{2}{*}{ Arquivo } & \multicolumn{2}{|c|}{ Classe 36 } & \multicolumn{2}{c|}{ Classe 45 } \\
\cline { 3 - 6 } & & Valor médio & CV & Valor médio & CV \\
\hline 3 & SA TE V20 VZ & 1371,5 & 0,071 & 1354,1 & 0,068 \\
\hline 4 & SA TL V20 VZ & 1396,6 & 0,071 & 1388,5 & 0,068 \\
\hline
\end{tabular}

Tabela E13 - Parâmetros estatísticos da resistência CONCRETO PROTENDIDO - ELS - VIGA T - 5 VIGAS.

\begin{tabular}{|c|c|c|c|c|c|}
\hline \multirow{2}{*}{$\mathbf{n}$} & \multirow{2}{*}{ Arquivo } & \multicolumn{2}{|c|}{ Classe 36 } & \multicolumn{2}{c|}{ Classe 45 } \\
\cline { 3 - 6 } & & Valor médio & CV & Valor médio & CV \\
\hline 2 & SA TE V20 TR2 & 2827,0 & 0,068 & 2671,4 & 0,066 \\
\hline 3 & SA TE V30 TR2 & 6327,6 & 0,067 & 6144,1 & 0,066 \\
\hline 4 & SA TE V40 TR4 & 12287,0 & 0,067 & 11994,4 & 0,066 \\
\hline 6 & SA TL V20 TR2 & 3758,0 & 0,067 & 3672,9 & 0,066 \\
\hline 7 & SA TL V30 TR2 & 8207,8 & 0,067 & 8110,2 & 0,066 \\
\hline 8 & SA TL V40 TR4 & 14863,7 & 0,066 & 14907,4 & 0,066 \\
\hline 13 & SA TE V20 STR & 2774,9 & 0,068 & 2699,0 & 0,066 \\
\hline 14 & SA TE V30 STR & 6202,6 & 0,067 & 5917,5 & 0,066 \\
\hline 15 & SA TE V40 STR & 11840,9 & 0,067 & 11548,2 & 0,066 \\
\hline 17 & SA TL V20 STR & 3914,8 & 0,067 & 3682,0 & 0,066 \\
\hline
\end{tabular}


Tabela E13 (continuação) - Parâmetros estatísticos da resistência CONCRETO PROTENDIDO - ELS - VIGA T - 5 VIGAS.

\begin{tabular}{|c|c|c|c|c|c|}
\hline \multirow{2}{*}{$\mathbf{n}$} & \multirow{2}{*}{ Arquivo } & \multicolumn{2}{|c|}{ Classe 36 } & \multicolumn{2}{c|}{ Classe 45 } \\
\cline { 3 - 6 } & & Valor médio & CV & Valor médio & CV \\
\hline 18 & SA TL V30 STR & 8302,8 & 0,067 & 8074,0 & 0,066 \\
\hline 19 & SA TL V40 STR & 14504,5 & 0,067 & 14730,4 & 0,066 \\
\hline
\end{tabular}

Tabela E14 - Parâmetros estatísticos da resistência CONCRETO PROTENDIDO - ELS - SEÇÃO CELULAR.

\begin{tabular}{|c|c|c|c|c|c|}
\hline \multirow{2}{*}{$\mathbf{n}$} & \multirow{2}{*}{ Arquivo } & \multicolumn{2}{|c|}{ Classe 36 } & \multicolumn{2}{c|}{ Classe 45 } \\
\cline { 3 - 6 } & & Valor médio & CV & Valor médio & CV \\
\hline 1 & SA TL V20 STR & 13757,1 & 0,069 & 13530,3 & 0,067 \\
\hline 2 & SA TL V30 STR & 28798,2 & 0,068 & 28273,8 & 0,066 \\
\hline 3 & SA TL V40 STR & 51194,5 & 0,067 & 50347,7 & 0,066 \\
\hline 5 & SA TL V30 TR2 & 8196,6 & 0,069 & 8139,7 & 0,067 \\
\hline 6 & SA TE V20 STR & 10812,0 & 0,070 & 10556,2 & 0,067 \\
\hline 7 & SA TE V30 STR & 22285,7 & 0,068 & 21750,3 & 0,066 \\
\hline 8 & SA TE V40 STR & 39089,3 & 0,067 & 38215,9 & 0,066 \\
\hline 10 & SA TE V30 TR2 & 7286,8 & 0,069 & 7148,5 & 0,067 \\
\hline
\end{tabular}


Tabela E15 - PBTC (kN) em função do comprimento do grupo de eixos (m) - LAJE - CA - $\mathrm{M}_{+}$

\begin{tabular}{|c|c|c|c|c|c|c|c|c|c|}
\hline \multirow{9}{*}{ 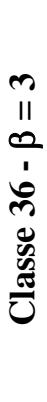 } & B & 1 & 2 & 3 & 4 & 5 & 6 & 7 & 8 \\
\hline & 2,5 & 574,8 & 557,1 & 861,0 & 970,0 & 525,8 & 538,6 & 725,4 & 839,91 \\
\hline & 5,0 & 717,1 & $\begin{array}{l}698,1 \\
\end{array}$ & 970,1 & 1113,3 & 676,1 & $\begin{array}{l}696,8 \\
\end{array}$ & 835,4 & 985,64 \\
\hline & 7,5 & 903,8 & 885,5 & 1084,1 & 1262,6 & 870,8 & 900,3 & 951,7 & 1140,18 \\
\hline & 10,0 & 1161,1 & 1133,4 & 1208,1 & 1423,2 & 1116,0 & 1154,1 & 1077,7 & 1306,30 \\
\hline & 12,5 & - & - & 1348,0 & 1600,8 & - & - & 1218,6 & 1488,71 \\
\hline & 15,0 & - & - & 1512,9 & 1805,0 & - & - & 1380,1 & 1693,83 \\
\hline & 17,5 & - & - & 1713,0 & 2046,6 & - & - & 1569,5 & 1928,34 \\
\hline & 20,0 & - & - & 1943,2 & 2320,4 & - & - & 1777,8 & 2190,30 \\
\hline \multirow{8}{*}{ 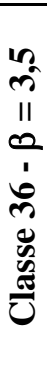 } & 2,5 & 490,1 & 469,2 & 698,1 & $\begin{array}{l}779,8 \\
\end{array}$ & 452,2 & 463,8 & 592,5 & 692,32 \\
\hline & 5,0 & 611,4 & 587,9 & 786,6 & 895,1 & 581,5 & 599,9 & 682,4 & 812,45 \\
\hline & 7,5 & 770,6 & 745,7 & 879,0 & 1015,1 & 749,0 & 775,2 & 777,4 & 939,83 \\
\hline & 10,0 & 990,0 & 954,5 & 979,5 & 1144,2 & 959,9 & 993,7 & 880,3 & 1076,77 \\
\hline & 12,5 & - & - & 1092,9 & 1286,9 & - & - & 995,4 & 1227,12 \\
\hline & 15,0 & - & - & 1226,6 & 1451,1 & - & - & 1127,4 & 1396,20 \\
\hline & 17,5 & - & - & 1388,9 & 1645,4 & - & - & 1282,0 & 1589,51 \\
\hline & 20,0 & - & - & 1575,6 & 1865,5 & - & - & 1452,2 & 1805,44 \\
\hline \multirow{8}{*}{ 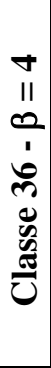 } & 2,5 & 412,4 & 388,9 & 546,9 & 604,1 & 385,5 & 395,8 & 470,1 & 556,18 \\
\hline & 5,0 & 514,6 & 487,3 & 616,2 & 693,3 & 495,7 & 512,1 & 541,4 & 652,68 \\
\hline & 7,5 & 648,5 & 618,1 & 688,7 & 786,3 & 638,4 & 661,6 & 616,7 & 755,02 \\
\hline & 10,0 & 833,2 & 791,1 & 767,4 & 886,3 & 818,2 & 848,1 & 698,4 & 865,03 \\
\hline & 12,5 & - & - & 856,3 & 996,9 & - & - & 789,7 & 985,82 \\
\hline & 15,0 & - & - & 961,0 & 1124,1 & - & - & 894,4 & 1121,65 \\
\hline & 17,5 & - & - & 1088,1 & 1274,5 & - & - & 1017,1 & 1276,94 \\
\hline & 20,0 & - & - & 1234,4 & 1445,0 & - & - & 1152,1 & 1450,41 \\
\hline
\end{tabular}


Tabela E15 (continuação) - PBTC (kN) em função do comprimento do grupo de eixos (m) - LAJE - CA - M $_{+}$

\begin{tabular}{|c|c|c|c|c|c|c|c|c|c|}
\hline \multirow{9}{*}{ 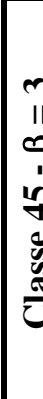 } & B & 1 & 2 & 3 & 4 & 5 & $\overline{6}$ & 7 & $\overline{8}$ \\
\hline & 2,5 & 617,3 & 599,4 & 864,9 & 972,8 & 571,0 & 584,6 & 756,6 & 884,51 \\
\hline & 5,0 & 770,2 & 751,0 & 974,5 & 1116,5 & 734,2 & 756,2 & 871,4 & 1037,98 \\
\hline & 7,5 & 970,7 & 952,6 & 1089,1 & 1266,2 & 945,6 & 977,1 & 992,6 & 1200,73 \\
\hline & 10,0 & 1247,1 & 1219,3 & 1213,5 & 1427,2 & 1211,9 & 1252,6 & 1124,0 & 1375,68 \\
\hline & 12,5 & - & - & 1354,1 & 1605,3 & - & - & 1271,0 & 1567,77 \\
\hline & 15,0 & - & - & 1519,7 & 1810,2 & - & - & 1439,5 & 1783,79 \\
\hline & 17,5 & - & - & 1720,8 & 2052,4 & - & - & 1637,0 & 2030,75 \\
\hline & 20,0 & - & - & 1952,1 & 2327,0 & - & - & 1854,2 & 2306,63 \\
\hline \multirow{8}{*}{ 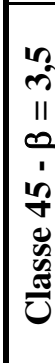 } & 2,5 & 529,9 & 509,0 & 703,3 & 782,5 & 494,3 & 506,2 & 622,0 & 734,37 \\
\hline & 5,0 & 661,2 & 637,8 & 792,4 & 898,1 & 635,6 & 654,8 & 716,4 & 861,79 \\
\hline & 7,5 & 833,3 & 809,0 & 885,5 & 1018,5 & 818,6 & 846,1 & 816,1 & $\begin{array}{l}996,92 \\
\end{array}$ \\
\hline & 10,0 & 1070,6 & 1035,4 & 986,7 & 1148,0 & 1049,1 & 1084,6 & 924,1 & 1142,17 \\
\hline & 12,5 & - & - & 1101,0 & 1291,3 & - & - & 1045,0 & 1301,66 \\
\hline & 15,0 & - & - & 1235,7 & 1456,1 & - & - & 1183,5 & 1481,00 \\
\hline & 17,5 & - & - & 1399,2 & 1650,9 & - & - & 1345,9 & 1686,05 \\
\hline & 20,0 & - & - & 1587,2 & 1871,8 & - & - & 1524,5 & 1915,10 \\
\hline \multirow{8}{*}{ 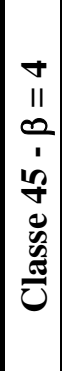 } & 2,5 & 449,8 & 426,4 & 553,2 & 606,6 & 424,7 & 435,0 & 498,0 & 595,86 \\
\hline & 5,0 & 561,2 & 534,3 & 623,3 & 696,3 & 546,1 & 562,8 & 573,6 & 699,25 \\
\hline & 7,5 & 707,3 & 677,7 & 696,6 & 789,6 & 703,4 & 727,1 & 653,4 & 808,89 \\
\hline & 10,0 & 908,8 & 867,5 & 776,2 & 890,0 & 901,5 & 932,2 & 739,9 & 926,74 \\
\hline & 12,5 & - & - & 866,1 & 1001,1 & - & - & 836,7 & 1056,15 \\
\hline & 15,0 & - & - & 972,1 & 1128,8 & - & - & 947,6 & 1201,67 \\
\hline & 17,5 & - & - & 1100,6 & 1279,9 & - & - & 1077,6 & 1368,04 \\
\hline & 20,0 & - & - & 1248,6 & 1451,1 & - & - & 1220,6 & 1553,89 \\
\hline
\end{tabular}


Tabela E16 - PBTC (kN) em função do comprimento do grupo de eixos (m) - LAJE - CA - M.

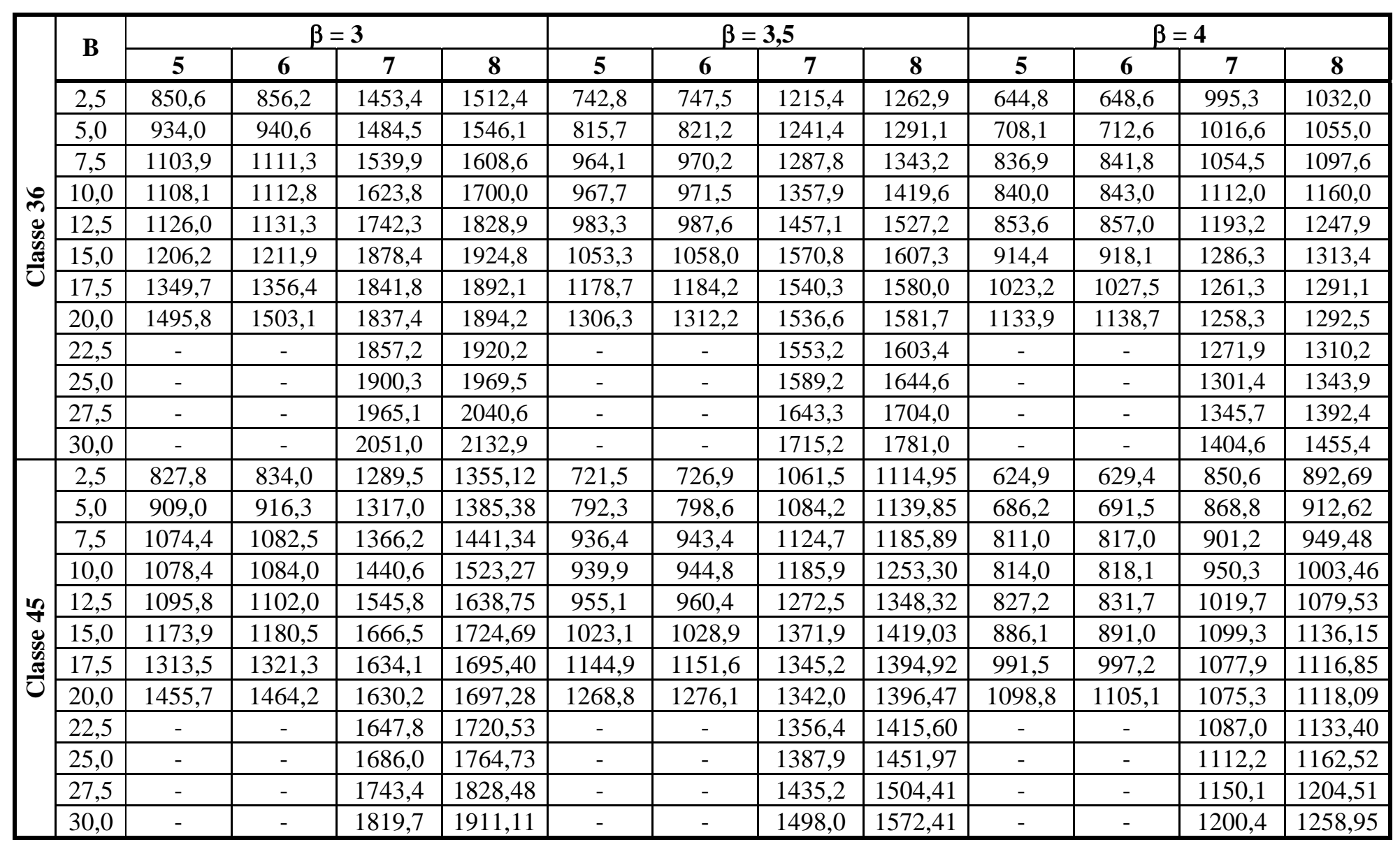


Tabela E17 - PBTC (kN) em função do comprimento do grupo de eixos (m) - 2 VIGAS - CA - $\mathrm{M}_{+}$

\begin{tabular}{|c|c|c|c|c|c|c|c|c|c|c|c|c|c|c|c|c|c|c|c|c|}
\hline & $\mathbf{S}$ & 1 & 2 & 3 & 4 & 5 & I & 8 & 10 & 11 & 12 & 13 & 14 & 16 & 17 & 19 & 20 & 21 & 22 & 23 \\
\hline & 2,5 & 54,8 & 39,8 & 43,4 & 80,0 & 10,7 & 50,6 & 20,7 & 19,2 & 30,6 & $\overline{08,6}$ & 20,5 & 390,4 & $\overline{771,8}$ & 769,1 & 559,0 & 883,2 & 10,4 & 635,7 & 82,4 \\
\hline & 5,0 & 9,7 & 0,7 & 1 & &, 5 & 5,7 & & & & 6,6 & & 6.8 & & & 0,8 & & & & \\
\hline & 7,5 & 6,8 & 3,6 & 7,5 & 9,5 & 3,7 & 1,3 & & 41 & 4,2 & 2,7 & 9,4 & 1,5 & & 4 & 70,7 & 4,5 & & 1 & \\
\hline II & 10,0 & 6,8 & 27,5 & 7,2 & 9,5 & 59,1 & 77,7 & 0,2 & 62,2 & 3,9 & 82,1 & 2,2 & 52,6 & 3,9 & 25,5 & 38,0 & 3,9 & & & \\
\hline & 12,5 & - & 15,9 & & 2,6 & 20,3 & 837,3 & 44,3 & & 88,1 & & 89,4 & 1120,3 & 41,3 & 91,1 & 14,7 & 22,4 & & 1 & 7,0 \\
\hline m. & 15,0 & - & 24,1 & - & 3,7 & 88,7 & 944,3 & 3 & & 91,2 & & 995,9 & 119 & 46,5 & 4 & 01,0 &, 5 & & 9 & \\
\hline : & 17,5 & - & 59,3 & - & 69,0 & 65,3 & 1073,7 & , 2 & & 119,9 & & 1128,1 & 9 & 1074,5 & 1146,1 & $\begin{array}{l}997,3 \\
\end{array}$ & 1002,4 & 0 & 4 & 3, \\
\hline$\frac{\pi}{51}$ & 20,0 & - & 220,0 & - & 229,4 & 52,4 & 223,8 & 82,8 & & 273,2 & & 1297,2 & 1377,0 & 1222,9 & 1237,9 & 1107,9 & 1112,1 & 1067,8 & & \\
\hline & 22,5 & - & - & - & - & 552,0 & - & 5 & & & & & 148 & - & & 1233,3 & 1237,4 & 1164,3 & & 84,7 \\
\hline & 25,0 & . & - & - & - & 467,1 & - & & & & & & & & & 1377,6 & 1380,0 & 1271,5 & & 1288,3 \\
\hline & 27,5 & - & - & - & - & 01,9 & - & & & & & & & - & & & & & & 407,0 \\
\hline & 30,0 & & - & - & - & 61,9 & - & & 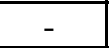 & & - & 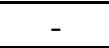 & & - & & - & - & & & 7,5 \\
\hline & 2,5 & 6 & $\overline{5,2}$ & 4,6 & & 677,2 & 463,0 & & 42. & & $\overline{1,2}$ & 0 & & 3,0 & & 69,6 & 36,0 & & & 5,6 \\
\hline & 5,0 & 1,1 & 577,8 & 9,8 & 9 & 713,0 & 509,4 & 641,1 & 4 & 546,2 &, 3 & 1 & 777,0 & 5,2 & 3 & 3,1 & 4,0 & & & 7,9 \\
\hline & 7,5 & 569,7 & 630,3 & 570,2 & 584,7 & 754,9 & 564,6 & 685,6 &, 7 & 59 & 503,2 & 6 & 822,4 & 566,9 & 72 & 563,5 & 0,5 & & & 636,2 \\
\hline mी & 10,0 & 723,5 & 692,2 & 743,5 & 644,0 & 801,2 & 628,8 & 73 & 622,9 & 64 & 653,1 & 667,1 & 8 & 627,7 & 769,2 & 620,0 & 24,2 & 9 & 652,3 & 679,2 \\
\hline$\|$ & 12,5 & - & 766,1 & 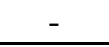 & 5 & 852,3 & 704,2 & & - & 717,2 & & 73 & 2 & 700,4 & 8 & 684,4 & 35,4 & & & 726,9 \\
\hline & 15,0 & - & 856,7 & - & & 909,5 & 794,2 & & . & & 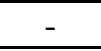 & 828,2 & 992,1 & 788,0 & 884,7 & 756,9 & \begin{tabular}{|l|l}
755,5 \\
\end{tabular} & 757,7 & & 780,2 \\
\hline 它 & 17,5 & - & 9,8 & - & & 3,4 & & & & & & & 100 & 6 & & 837,8 & 5,4 & & & 39,6 \\
\hline $\bar{y}$ & 20,0 & - & 84,1 & - & 42,4 & 46,2 & 029,3 & & & 028 & & 1078,7 & & 1018,1 & & & 26,9 & & & 06,4 \\
\hline$\frac{\pi}{0}$ & 22,5 & - & - & - & - & 9,4 & - & & & & & & & & & 6,0 & 1,3 & & & 1,9 \\
\hline & 25,0 & - & - & - & - & 5,6 & - & & & & & & & & & 1157,2 & 1150,1 & 7,0 & 4,9 & 067, \\
\hline & 27,5 & - & - & - & - & 38,2 & - & & & & & & & & & & & 1167,1 & 1164,5 & 1166,2 \\
\hline & 30,0 & & 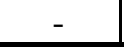 & & & 1471,8 & & 1389,7 & & & & & 1605,7 & & 1447,4 & & & 1278,2 & 1275,6 & 1274,4 \\
\hline
\end{tabular}


Tabela E17 (continuação) - PBTC (kN) em função do comprimento do grupo de eixos (m) - 2 VIGAS - CA - $\mathrm{M}_{+}$

\begin{tabular}{|c|c|c|c|c|c|c|c|c|c|c|c|c|c|c|c|c|c|c|c|c|}
\hline \multirow{8}{*}{ 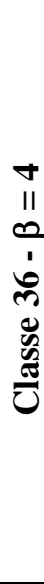 } & B & 1 & 2 & 3 & 4 & 5 & 7 & 8 & 10 & 11 & 12 & 13 & 14 & 16 & 17 & 19 & 20 & 21 & 22 & 23 \\
\hline & 2,5 & 328,7 & 439,5 & 331,7 & 411,6 & 554,5 & 383,7 & 492,5 & 273,1 & 398,3 & 280,2 & 420,6 & 598,6 & 388,9 & 520,3 & 388,6 & \begin{tabular}{|l}
397,7 \\
\end{tabular} & 423,1 & 433,5 & 458,9 \\
\hline & 7,5 & 481,9 & 517,6 & 491,8 & 489,3 & 618,2 & 467,8 & 561,5 & 393,6 & 463,7 & 413,4 & 494,4 & 666,5 & 463,2 & 586,1 & \begin{tabular}{|l|l}
466,3 \\
\end{tabular} & 466,8 & 492,3 & 495,9 & 516,2 \\
\hline & 15,0 & - & 703,5 & - & 669,7 & 744,8 & 658,1 & 693,8 & - & 626,0 & - & 675,0 & 804,0 & 643,8 & 720,0 & 626,3 & \begin{tabular}{|l|}
618,1 \\
\end{tabular} & 625,9 & 622,5 & 533,0 \\
\hline & 17,5 & - & 796,4 & - & 758,7 & 797,1 & 748,4 & 747,8 & - & 707,3 & 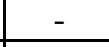 & 764,7 & 861,0 & 730,8 & 775,3 & 693,3 & 683,5 & 680,0 & 674,8 & 681,2 \\
\hline & 20,0 & - & 906,7 & - & 872,5 & 856,7 & 852,9 & 808,3 & - & 804,1 & - & 879,2 & 925,6 & 831,8 & 837,4 & 770,2 & \begin{tabular}{|l|l|}
758,3 \\
\end{tabular} & 740,2 & 733,1 & 735,5 \\
\hline & 27,5 & - & - & - & - & 1095,8 & - & \begin{tabular}{|l|l}
1042,1 \\
\end{tabular} & - & - & - & - & \begin{tabular}{|l|l}
1183,7 \\
\end{tabular} & - & 1078,1 & 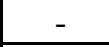 & & 964,1 & \begin{tabular}{|l|l|}
952,7 \\
\end{tabular} & \begin{tabular}{|l|l}
946,2 \\
\end{tabular} \\
\hline & 30,0 & - & - & - & - & 1205,2 & - & 1138,0 & - & - & - & - & 1301,4 & - & 1178,0 & - & - & 1055,9 & 1043,6 & 1034,0 \\
\hline & 2,5 & 506,4 & 662,6 & 503,6 & 629,4 & 826,7 & 596,7 & 734,8 & 483,8 & 674,9 & 487,1 & 696,5 & 933,3 & 641,5 & 818,0 & 607,5 & 656,7 & 653,4 & 712,7 & 744,1 \\
\hline & 5,0 & 600,9 & 715,4 & 602,1 & 683,3 & 870,4 & 656,5 & 783,3 & 568,9 & 723,8 & 580,1 & 750,6 & 981,9 & 695,6 & 865,3 & 663,8 & \begin{tabular}{|l|l}
707,9 \\
\end{tabular} & 703,6 & 759,8 & 786,6 \\
\hline & 7,5 & 742,4 & 780,4 & 746,7 & 748,2 & 921,5 & 727,5 & 837,7 & 697,2 & 785,7 & 718,5 & 818,7 & 1039,2 & 764,0 & 921,4 & 729,0 & \begin{tabular}{|l|}
770,7 \\
\end{tabular} & 760,2 & 815,2 & 837,0 \\
\hline$m$ & 10,0 & 942,8 & 857,0 & 973,6 & 824,2 & 978,0 & 810,4 & 897,4 & 879,7 & 860,3 & 932,4 & 900,4 & 1103,3 & 845,9 & 984,3 & 802,1 & 843,3 & 822,6 & 877,4 & 893,6 \\
\hline & 25,0 & - & - & - & - & 1496,1 & - & 1423,0 & 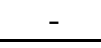 & - & - & - & 1690,6 & - & 1551,8 & 1497,1 & 1553,8 & 1361,1 & 1432,3 & 1404,8 \\
\hline & 27,5 & - & - & - & - & 1633,5 & - & 1554,9 & - & - & - & - & 1845,6 & - & 1694,9 & - & - & 1488,7 & 1566,3 & 1534,3 \\
\hline & 30,0 & - & 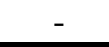 & 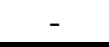 & 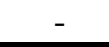 & 1796,6 & - & 1698,0 & 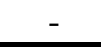 & 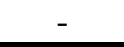 & - & 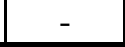 & 2029,1 & - & 1852,1 & 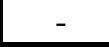 & - & 1630,4 & 1715,7 & 1676,6 \\
\hline
\end{tabular}


Tabela E17 (continuação) - PBTC (kN) em função do comprimento do grupo de eixos (m) - 2 VIGAS - CA - M+

\begin{tabular}{|c|c|c|c|c|c|c|c|c|c|c|c|c|c|c|c|c|c|c|c|c|}
\hline \multirow{13}{*}{$\begin{array}{l}m \\
11 \\
0 \\
1 \\
1\end{array}$} & D & 1 & 2 & 3 & 4 & 5 & 7 & 0 & 10 & 11 & 12 & 13 & 14 & 16 & 17 & 19 & 20 & 21 & 22 & 23 \\
\hline & 2,5 & 36,6 & 56,9 & 40,4 & 37,9 & 95,1 & $\overline{05,9}$ & 14,8 & 402,6 & 50,2 & 14,2 & 886,8 & 778,7 & 841,0 & 685,2 & 514,7 & $\overline{554,2}$ & $\overline{52,6}$ & 501,8 & 23,1 \\
\hline & 5,0 & 0 & 12 & 6,5 & & 9 & 6,6 & & 34 & & 3,3 & 2,3 & 9,3 & 366 & 4,8 & 2,4 & & & & 8,7 \\
\hline & 7,5 & 0,0 & 5,8 & 3,0 & 9,4 & 4,9 & 6,8 & 0,9 & 0,2 & 05 & 0 & 39,8 & 7,2 & 4,3 & 8 & 7,6 & & & 88,4 & \\
\hline & 10,0 & 2,8 & 20,2 & 1,4 & 4,3 & 22,4 & 37,0 & 0,9 & 2,1 & 114 & 2,9 & 88,6 & 20,6 & 13,4 & 4,5 & 79,6 & & & 0,8 & \\
\hline & 12,5 & & 7,1 & & 1,4 & 74,9 & 769,4 & 05,6 & & 748 & & 41,1 & 79,8 & 796,0 & 82,9 & 50,2 &, 5 & & 99,1 & 00,8 \\
\hline & 15,0 & - & 91,3 & - & 5,1 & 3,6 & 867,7 & 66,1 & & 54 & & 41,7 & 1046,0 & 895,6 & 8,2 & 29,6 & 1,4 &, 4 & 2 & 59,6 \\
\hline & 17,5 & - & 09,0 & - & 991,3 & 99,2 & 986,7 & 933,5 & & 977 & & 1066,8 & 1120,2 & 1016,7 & 1021,0 & 18,3 & 952,5 & 888,1 & 936,7 & 25,0 \\
\hline & 20,0 & - & 448,8 & - & 1140,0 & 773,9 & 1124,5 & 1009,0 & & 1110,8 & & 1226,7 & 1204,2 & 1157,1 & 1102,8 & 1020,1 & 1056,8 & 966,7 & 1017,7 & 998,6 \\
\hline & 22,5 & - & 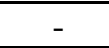 & - & - & 1159,3 & - & 0941 & & & & & 1300,1 & - & 1195,0 & 1135,6 & 1175,9 & 1054,1 & 108,3 & 081,8 \\
\hline & 25,0 & - & - & - & - & 50 & - & & & - & & & & - & 9,8 & 1268,4 & 1311,3 & & & 1176,3 \\
\hline & 27,5 & - & 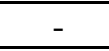 & - & - & & - & & - & & & - &, 0 & - & & & & & & 1284,7 \\
\hline & 30,0 & - & - & - & - & & - & 7 & - & - & & - & & - & 3 & - & - & & & 403,9 \\
\hline & 2,5 & 4 & 0,1 & 6 & 4,6 & 574,2 & 23,6 & 505,2 & 29,0 & & 3 & 86,6 & 36,3 &, 5 & & 30,7 & 0 & & 00,8 & 512,5 \\
\hline & 5,0 & 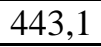 & 96,7 & 6 & 4 & 604,6 & 466,0 & 538,5 & 3 & 46 & 9 & 24,4 & 669,5 & 487,5 & 1 & 470,5 & 497,0 &, 5 & 533,9 & 541,8 \\
\hline & 7,5 & 4 & 41,9 & 8,7 & 5 & 640,1 & 516,5 & 575,9 & 47 & 50 & 8 & 72,0 & 708,6 & 535,4 & 634,7 & 516,7 & 541,1 & & 572,8 & 576,6 \\
\hline$\gamma$ & 10,0 & 695,2 & 95,1 & 741,5 & 5 & 679,3 & 575,2 & 617,0 & 598,3 & 55 & 666,8 & 629,0 & 752,2 & 592,8 & 678,0 & 568,6 & \begin{tabular}{|l|}
592,0 \\
\end{tabular} & 580,5 & 616,5 & 615,5 \\
\hline & 12,5 & 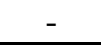 & 658,6 & - & 660,4 & 722,7 & 644,2 & 0 & - & & & 7,5 & 800,6 & 661,4 & 726,1 & 627,7 & \begin{tabular}{|l|}
650,1 \\
\end{tabular} & 3,7 &, 0 & 658,8 \\
\hline & 15,0 & 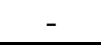 & 736,4 & 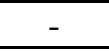 & & 771,1 & 26,5 & 711,7 & & & & 781 & 854,7 & \begin{tabular}{|l|l|}
744, \\
\end{tabular} & 779,8 & 694,1 & \begin{tabular}{|l|}
716,6 \\
\end{tabular} & 0 & 719,1 & 707,1 \\
\hline & 17,5 & - & 3,7 & - & 8 & 825 & 826,1 & 67 & & 77 & & \begin{tabular}{|l|}
884,7 \\
\end{tabular} & 915,3 & \begin{tabular}{|l|}
844,8 \\
\end{tabular} & 6 & 768,3 & \begin{tabular}{|l|}
792,4 \\
\end{tabular} & 0 & 779,5 & 760,9 \\
\hline & 20,0 & - & 49,2 & - & 963, & 87 & 941,5 & 29 & & 880 , & & \begin{tabular}{|l}
1017,2 \\
\end{tabular} & 984,0 & 961,5 & 906,9 & 353,5 & \begin{tabular}{|l|}
879,1 \\
\end{tabular} & ,6 & \begin{tabular}{|l|}
846,9 \\
\end{tabular} & 321,4 \\
\hline & 22,5 & - & - & - & - & & - & & & & & & 1062,4 & & & 50,1 &, 2 & 9,5 & 922,3 & 889,9 \\
\hline & 25, & - & - & - & - & & - & & & & & & & & 1068,9 & 1061,3 & 1090,9 & 60,4 & 006,5 & 967,6 \\
\hline & 27,5 & - & - & - & - & & - & $0, \mathrm{C}, \mathrm{C}$ & & & & & 8,3 & & & & & 1050,5 & 1100,6 & 1056,8 \\
\hline & 30,0 & & & - & & 1247,9 & & 1167,4 & & & & & 1383,4 & & 1275,8 & & & 1150,5 & 1205,6 & 1154, \\
\hline
\end{tabular}


Tabela E18 - PBTC (kN) em função do comprimento do grupo de eixos (m) - 2 VIGAS - CA - M.

\begin{tabular}{|c|c|c|c|c|c|c|c|c|c|c|c|c|c|c|c|c|}
\hline & B & 3 & 4 & 5 & 7 & 8 & 12 & 13 & 14 & 16 & 17 & 19 & 20 & 21 & 22 & 23 \\
\hline & 2,5 & 341,2 & 28,6 & 73,3 & 1111,7 & 1426,7 & 301,9 & 414,4 & 466,2 & \begin{tabular}{|l|l}
1183,7 \\
\end{tabular} & 1659,8 & 1261,5 & \begin{tabular}{|l}
1373,5 \\
\end{tabular} & 1379,9 & 1586,7 & 1865, \\
\hline & \begin{tabular}{|l|}
5,0 \\
\end{tabular} & - & 0,7 & 53,8 & 135,3 & 14 & - & 6,4 & 649,3 & 209,3 & 74,4 & 1282,0 & 1396,4 & 1395,2 & 94,3 & 382,3 \\
\hline & \begin{tabular}{|l|}
7,5 \\
\end{tabular} & - & - & - & 77,6 & 3 & & 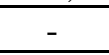 & - & 4,6 & 1,2 & 17,6 & 36,6 & 22,7 & 35,5 & 1912, \\
\hline II & 10,0 & - & - & - & 41,3 & 1496,9 & - & - & - & 22,9 & 1740,0 & 1370,7 & 1494,5 & 1460,9 & 0,1 & 1956, \\
\hline & 12,5 & - & - & - & 32,0 & 1541,4 & - & - & 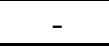 & 19,8 & 1792,0 & 1440,2 & 1572,5 & 1511,6 & 8,9 & 2014, \\
\hline$\stackrel{m}{m}$ & 15,0 & - & - & - & 9,6 & 1599,1 & - & - & - & 54,9 & 859,5 & 538,2 & 1675,9 & \begin{tabular}{|l|l}
1577,8 \\
\end{tabular} & & 0 , \\
\hline ע & 17,5 & - & - & - & 5,3 & 1671,9 & - & - & - & 1721,3 & 1944,7 & 1657,8 & 1808,9 & 1661,5 & & 2185 , \\
\hline & 20,0 & - & - & - & 97,8 & 1763,4 & - & - & - & 1685,3 & 051,5 & 807,5 & 1969,6 & 1765,9 & 7,9 & 2305 \\
\hline & 22,5 & - & - & - & 1577,9 & 1877,7 & - & - & - & 1666,3 & 2185,1 & 1781,4 & 1934,6 & 1895,1 & 3,5 & 2455, \\
\hline & 25,0 & - & - & - & 1582,4 & 2021,2 & - & - & - & 1672,5 & 2351,0 & 1765,0 & 1917,1 & 1936,8 & & 2611 , \\
\hline & 27,5 & - & 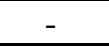 & - & 612,1 & 2060 & - & - & - & 1704,6 & 2390,9 & 1764,2 &, 7 & 5,9 & & 2525 , \\
\hline & 30,0 & - & - & - & 1665,4 & 2035,1 & - & - & - & 1761,5 & 2363,1 & 782,7 &, 2 & 5,1 & & 2466,9 \\
\hline & 2,5 & 290,8 & 66,4 & 07,6 & 946,8 & 1183,8 & 246,3 & 345,9 & 395,0 & 1002,0 & 1394,0 & 1071,6 & 3,3 & 1145,6 & & 1546,0 \\
\hline & 5,0 & 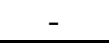 & 13,6 & 571,7 & 966,9 & 119 & - & 481,1 & 550,1 & 1023,7 & 1406,3 & 1089,0 & 1187,8 & 1158,4 & 7,3 & 1559,6 \\
\hline & 7,5 & - & - & - & 1002,9 & 1214,2 & - & 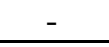 & - & 1062,1 & 1428,8 & 1119,2 & 1222,0 & 1181,2 & 3,6 & 1584, \\
\hline ल & 10,0 & - & - & - & 1057,1 & 1242,1 & - & - & - & 11 & 1461,3 & 4 & 1271,2 & 1212,9 & & 1620 \\
\hline II & 12,5 & $\pi$ & - & - & 1134,4 & 127 & & - & - & & 5,0 & & 13 & 12 & & 16 \\
\hline & 15,0 & - & 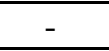 & 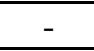 & 1243,1 & 132 & 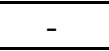 & 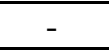 & - & 1316,3 & 1561,7 & 1306,6 & 1425,5 & 1309,9 & & 1731 \\
\hline ल & 17,5 & 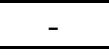 & - & - & 1392,7 & 1387 & & - & - & 1457,2 & 1633,2 & 1408,2 & 153 & 1379,4 & & 181 \\
\hline & 20,0 & - & - & - & 1360,7 & 1463 & - & - & - & 1426,7 & 1723,0 & 1535,4 & 1675,3 & 1466,1 & & 1910 \\
\hline U & 22,5 & - & - & - & 1343,8 & 1558, & - & - & - & 1410,6 & 1835,1 & 1513,3 & 1645,5 & \begin{tabular}{|l|}
1573,4 \\
\end{tabular} & & 2034, \\
\hline & 25,0 & - & - & - & 1347,6 & 1677 & - & - & - & 1415,8 & 1974,5 & 1499,3 & 1630,7 & 1608,0 & 8,8 & 2163, \\
\hline & 27,5 & - & - & 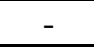 & 1372,9 & 1709,9 & - & - & - & 1443,0 & 2008,0 & 1498,6 & 1634,6 & \begin{tabular}{|l|}
1574,1 \\
\end{tabular} & 1829,9 & 2092, \\
\hline & 30,0 & - & - & - & 1418,4 & 1688,7 & $\pi$ & - & - & 1491,2 & 1984,6 & 1514,4 & 1657,9 & 1556,8 & 1810,4 & 2044 \\
\hline
\end{tabular}


Tabela E18 (continuação) - PBTC (kN) em função do comprimento do grupo de eixos (m) - 2 VIGAS - CA - M.

\begin{tabular}{|c|c|c|c|c|c|c|c|c|c|c|c|c|c|c|c|c|}
\hline & B & 3 & 4 & 5 & 7 & 8 & 12 & 13 & 14 & 16 & 17 & 19 & 20 & 21 & 22 & 23 \\
\hline \multirow{12}{*}{$\begin{array}{l}\nabla \\
11 \\
0 \\
1 \\
0 \\
0 \\
0 \\
0 \\
0 \\
0 \\
0\end{array}$} & \begin{tabular}{|l|}
2,5 \\
\end{tabular} & 245,7 & 310,4 & 348,3 & 795,7 & 959,7 & 196,2 & 283,9 & 330,5 & 835,2 & 1148,6 & 897,2 & 979,3 & 929,6 & 1098,0 & 1250,0 \\
\hline & \begin{tabular}{|l|}
5,0 \\
\end{tabular} & - & 435,1 & 488,5 & \begin{tabular}{|l|}
812,6 \\
\end{tabular} & 968,8 & - & 394,9 & 460,3 & 853,2 & 1158,7 & 911,8 & \begin{tabular}{|l|}
995,7 \\
\end{tabular} & \begin{tabular}{|l|}
939,9 \\
\end{tabular} & 1110,2 & 1261,1 \\
\hline & 7,5 & - & - & - & 842,8 & 984,4 & - & - & - & 885,2 & 1177,3 & 937,1 & 1024,4 & 958,4 & 1131,9 & 1281,2 \\
\hline & 10,0 & - & - & - & \begin{tabular}{|l|}
888,4 \\
\end{tabular} & 1007,0 & - & - & - & 933,4 & 1204,1 & \begin{tabular}{|l|}
974,9 \\
\end{tabular} & 1065,6 & \begin{tabular}{|l|}
984,2 \\
\end{tabular} & 1162,7 & 1310,4 \\
\hline & 12,5 & - & - & - & \begin{tabular}{|l|}
953,3 \\
\end{tabular} & 1037,0 & - & - & - & 1001,8 & 1240,1 & 1024,3 & 1121,2 & 1018,3 & 1203,4 & 1349,5 \\
\hline & 15,0 & - & - & - & 1044,6 & 1075,8 & - & - & - & 1097,1 & 1286,8 & 1094,0 & 1195,0 & 1062,9 & 1255,8 & 1400,3 \\
\hline & 17,5 & - & - & - & 1170,4 & 1124,7 & - & - & - & 1214,5 & 1345,8 & 1179,0 & 1289,8 & 1119,3 & 1321,6 & 1464,3 \\
\hline & 20,0 & - & - & - & 1143,6 & 1186,3 & - & - & - & 1189,1 & 1419,7 & 1285,5 & 1404,3 & 1189,6 & 1403,4 & 1544,7 \\
\hline & 22,5 & - & - & - & 1129,3 & 1263,2 & - & - & - & 1175,7 & 1512,1 & 1267,0 & 1379,4 & 1276,6 & 1504,2 & 1645,2 \\
\hline & 25,0 & - & - & - & 1132,5 & 1359,7 & - & - & - & 1180,1 & 1627,0 & 1255,3 & 1366,9 & 1304,8 & 1539,9 & 1749,3 \\
\hline & 27,5 & - & - & - & 1153,8 & 1386,3 & - & - & - & 1202,7 & 1654,6 & 1254,7 & 1370,2 & 1277,2 & 1507,9 & 1691,9 \\
\hline & 30,0 & - & - & - & 1192,0 & 1369,1 & - & - & - & 1242,9 & 1635,3 & 1267,9 & 1389,8 & 1263,2 & \begin{tabular}{|l|l}
1491,8 \\
\end{tabular} & 1652,7 \\
\hline & 2,5 & 401,8 & 488,1 & 507,3 & 1141,5 & 1437,3 & 373,0 & 495,3 & 516,8 & 1306,5 & 1778,6 & 1295,2 & 1477,6 & 1392,0 & 1709,0 & 1946,9 \\
\hline & 5,0 & - & 684,2 & 711,5 & 1165,7 & 1450,7 & - & 689,0 & 719,8 & 1334,8 & 1794,2 & 1316,2 & 1502,3 & 1407,5 & 1728,0 & 1964,1 \\
\hline & 7,5 & - & - & - & 1209,1 & 1474,2 & - & - & - & 1384,9 & 1823,0 & 1352,7 & 1545,6 & 1435,2 & 1761,7 & 1995,5 \\
\hline$m$ & 10,0 & - & - & - & 1274,5 & 1508,1 & - & 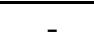 & - & 1460,2 & 1864,5 & 1407,3 & 1607,8 & 1473,8 & 1809,7 & 2040,9 \\
\hline 0 & 12,5 & - & - & - & 1367,7 & 1552,9 & 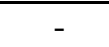 & 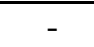 & 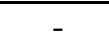 & 1567,1 & 1920,2 & 1478,6 & 1691,7 & 1524,9 & 1873,0 & 2101,8 \\
\hline ما & 15,0 & - & - & - & 1498,6 & 1611,0 & 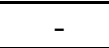 & 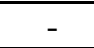 & 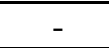 & 1716,3 & 1992,6 & 1579,2 & 1803,0 & 1591,7 & 1954,5 & 2180,9 \\
\hline$\stackrel{f}{s}$ & 17,5 & - & - & - & 1679,0 & 1684,3 & - & 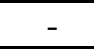 & - & 1900,0 & 2083,8 & 1702,0 & 1946,1 & 1676,1 & 2057,0 & 2280,6 \\
\hline w & 20,0 & - & - & - & 1640,5 & 1776,5 & - & - & - & 1860,2 & 2198,3 & 1855,7 & 2118,9 & 1781,5 & 2184,3 & 2405,8 \\
\hline U & 22,5 & - & - & - & 1620,1 & 1891,7 & - & - & - & 1839,2 & 2341,4 & 1828,9 & 2081,3 & 1911,8 & 2341,1 & 2562,4 \\
\hline & 25,0 & - & - & - & 1624,7 & 2036,2 & - & - & - & 1846,1 & 2519,3 & 1812,0 & 2062,5 & 1953,9 & 2396,8 & 2724,5 \\
\hline & 27,5 & - & - & - & 1655,2 & \begin{tabular}{|l|l}
2076,0 \\
\end{tabular} & - & - & - & 1881,5 & 2562,0 & 1811,2 & 2067,4 & 1912,6 & 2347,0 & 2635,1 \\
\hline & 30,0 & 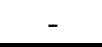 & - & - & 1710,0 & 2050,3 & 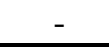 & - & - & 1944,3 & 2532,2 & 1830,2 & 2097,0 & 1891,6 & 2321,9 & 2574,0 \\
\hline
\end{tabular}


Tabela E18 (continuação) - PBTC (kN) em função do comprimento do grupo de eixos (m) - 2 VIGAS - CA - M.

\begin{tabular}{|c|c|c|c|c|c|c|c|c|c|c|c|c|c|c|c|c|}
\hline & B & 3 & 4 & 5 & 7 & 8 & 12 & 13 & 14 & 16 & 17 & 19 & 20 & 21 & 22 & 23 \\
\hline & 2,5 & 347,9 & 422,6 & 39,4 & 979,2 & 1202,6 & 313,8 & 423,1 & 442,4 & 123,2 & 1515,2 & 1109,2 & 1271,7 & 1165,1 & 1456,5 & 1633,2 \\
\hline & 5,0 & - & 92,4 & 16,2 & 999,9 & 213,9 & - & 88,6 & 16,1 & 147,5 & 528,5 & 1127,2 & 1292,9 & 1178,1 & 72,6 & 47,6 \\
\hline & 7,5 & - & - & 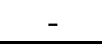 & 1037,1 & 1233 & - & 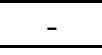 & - & 190,5 & 553,0 & 1158,5 & 1330,2 & 1201,2 & 1501,4 & $16 / 3$, \\
\hline & 10,0 & - & - & - & 93,3 & 8 & & - & - & 5,3 & 88,4 & 5,2 & 3,8 & 3,6 & 42,3 & 1712,1 \\
\hline & 12,5 & - & - & - & 2 & & & & &, 2 & 5,8 & & & 6,3 & & 1763, \\
\hline$\stackrel{1}{\square}$ & 15,0 & - & - & - &, 5 & 1 & & - & - &, 4 & 97,5 & 2,4 & & & & \\
\hline & 17,5 & - & - & - & ,2 & & & & & & 775,2 & 7,6 & 1,8 & & & \\
\hline & 20,0 & 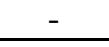 & - & - & 07,2 & 1486,4 & & - & &, 2 & 872,7 & 9,2 & 3,6 & & & \\
\hline U & 22,5 & - & - & - & 89,7 & 1582,8 & - & - & - & 1581,1 & 994,6 & 1566,3 & 1,2 &, 1 & 5,2 & 2 \\
\hline & 25,0 & - & - & - & 93,7 & 1 & - & - & 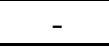 & 1587,0 & 146,1 & 1,8 & 5,0 & 5,4 & 2,6 & 2 \\
\hline & 27,5 & -5 & - & - & 8 & 1737,0 & - & - & - & 1617,5 & 2182,6 & ,1 & ,3 &, 8 & & \\
\hline & 30,0 & - & - & 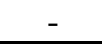 & 1466,8 & 1715,5 & - & - & - & 1671,5 & 2157,1 & 1567,4 & 1804,7 & & 1978,8 & 2159,2 \\
\hline & 2,5 & 99,7 & 63,6 & 78,1 & 830,3 & 985,8 & 260,5 & 357,8 & 374,9 & 954,6 & 1271,7 & 938,2 & 1081,9 & 955,6 & 3,2 & 1342,6 \\
\hline & 5,0 & - & 509,6 & 30,3 & 847,9 & 995,1 & & 497,7 & 522,1 & 975,2 & 1282,9 & 953,4 & 1100,0 & 966,2 & & 1354,4 \\
\hline & 7,5 & - & - & - & 879,4 & 101 & & - & - & & 1303,4 & & 11 & & & 1376,1 \\
\hline$\nabla$ & 10,0 & - & - & - & 927,0 & 1034,4 & - & - & - & 1066,9 & 1333,1 & 1019,4 & 1177,3 & 1011,7 & 1295,2 & 1407,4 \\
\hline$\infty$ & 12,5 & - & - & - & 994,8 & 1065,1 & - & - & - & 1145,0 & 1373,0 & 1071,1 & 1238,7 & 1046,8 & 1340,5 & 1449,4 \\
\hline & 15,0 & - & - & - & 1090,1 & 1105,0 & 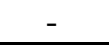 & - & 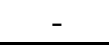 & 1254,0 & 1424,7 & 1143,9 & 1320,2 & 1092,6 & 1398,9 & 1503,9 \\
\hline & 17,5 & - & - & - & 1221,3 & 1155,3 & - & - & 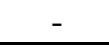 & 1388,2 & 1490,0 & 1232,9 & 1424,9 & 1150,6 & 1472,2 & 1572 \\
\hline & 20,0 & - & - & - & 1193,3 & 1218,5 & - & - & - & 1359,1 & \begin{tabular}{|l|l}
1571,8 \\
\end{tabular} & 1344,2 & 1551,5 & 1222,9 & 1563,3 & 1659 \\
\hline 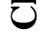 & 22,5 & - & - & - & 1178,4 & 1297,5 & & - & - & 13 & 1674,1 & 1324,9 & 1523,9 & 1312,3 & & 1767 \\
\hline & 25,0 & - & - & - & \begin{tabular}{|l|l}
1181,8 \\
\end{tabular} & & & & - & 13 & 1801,3 & 1312,6 & 1510,2 & 1341,3 & 5,4 & 1878 \\
\hline & 27,5 & - & - & - & 1204,0 & & & & & 1374,7 & & 1312,0 & 1513,8 & 1312,9 & 1679,8 & 1817, \\
\hline & 30,0 & $\pi$ & $\pi$ & -1 & 1243,8 & 1406,3 & & $\pi$ & -5 & 1420,6 & 1810,5 & 1325,8 & 1535,4 & 1298,5 & 1661,8 & 1775 \\
\hline
\end{tabular}


Tabela E19 - PBTC (kN) em função do comprimento do grupo de eixos (m) - 5 VIGAS - CA - $\mathrm{M}_{+}$

\begin{tabular}{|c|c|c|c|c|c|c|c|c|c|c|c|c|}
\hline & B & 1 & 2 & 5 & 6 & 9 & 10 & 11 & 12 & 13 & 16 & 17 \\
\hline & 2,5 & 395,8 & 549,8 & 416,3 & 534,4 & 785,3 & 579,7 & 666,7 & 376,9 & 498,8 & 466,5 & 557,4 \\
\hline & 5,0 & 487,0 & 609,1 & 497,5 & 581,1 & \begin{tabular}{|l|}
838,6 \\
\end{tabular} & \begin{tabular}{|l|}
637,8 \\
\end{tabular} & \begin{tabular}{|l|}
719,4 \\
\end{tabular} & $\begin{array}{l}459,7 \\
\end{array}$ & 550,0 & 558,7 & 606,2 \\
\hline & 7,5 & 612,4 & 677,9 & 617,8 & 638,3 & 900,1 & \begin{tabular}{|l|}
702,3 \\
\end{tabular} & 780,5 & 576,1 & 609,8 & 695,7 & 665,7 \\
\hline II & 10,0 & 787,9 & 755,8 & 785,2 & 704,9 & \begin{tabular}{|l|}
968,3 \\
\end{tabular} & \begin{tabular}{|l|}
773,1 \\
\end{tabular} & 848,6 & 740,4 & 678,5 & 885,3 & 735,3 \\
\hline & $\sqrt[2]{12,5}$ & - & 845,5 & - & 783,5 & 1042,6 & \begin{tabular}{|l|l|}
849,9 \\
\end{tabular} & \begin{tabular}{|l|}
923,1 \\
\end{tabular} & - & 758,4 & - & 817,8 \\
\hline$\stackrel{m}{m}$ & 15,0 & - & 951,8 & - & 878,7 & 1124,9 & \begin{tabular}{|l|}
933,3 \\
\end{tabular} & 1005,3 & 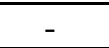 & 853,1 & - & 917,3 \\
\hline ڤ్ & 17,5 & - & 1080,0 & - & 995,8 & 1215,7 & 1023,7 & 1095,7 & - & 968,1 & - & 1040,2 \\
\hline & 20,0 & - & 1232,2 & - & 1133,8 & 1316,9 & 1122,0 & 1195,7 & - & 1104,5 & - & 1184,9 \\
\hline & 22,5 & - & - & - & - & 1430,5 & 1228,9 & 1306,2 & - & - & - & - \\
\hline & 25,0 & - & - & - & - & 1558,2 & 1344,8 & 1427,9 & - & - & - & - \\
\hline & 27,5 & - & - & - & - & 1702,8 & 1469,8 & 1561,8 & - & - & - & - \\
\hline & 30,0 & - & - & - & - & 1859,7 & 1606,3 & \begin{tabular}{|l|}
1710,1 \\
\end{tabular} & - & - & - & - \\
\hline & 2,5 & 336,8 & 462,7 & 337,6 & 425,8 & 641,3 & 485,2 & 548,1 & 322,1 & 416,8 & 386,6 & 446,7 \\
\hline & 5,0 & 414,4 & 512,6 & 403,4 & 463,1 & 684,9 & \begin{tabular}{|l|l|}
533,9 \\
\end{tabular} & 591,4 & 392,9 & 459,7 & 463,0 & 485,9 \\
\hline & 7,5 & 521,1 & 570,6 & 501,0 & 508,7 & \begin{tabular}{|l|l}
735,1 \\
\end{tabular} & \begin{tabular}{|l|l}
587,8 \\
\end{tabular} & 641,6 & 492,4 & 509,6 & 576,5 & 533,5 \\
\hline | & 10,0 & 670,4 & 636,2 & 636,7 & 561,8 & \begin{tabular}{|l|}
790,8 \\
\end{tabular} & 647,1 & \begin{tabular}{|l|}
697,6 \\
\end{tabular} & $\begin{array}{l}632,9 \\
\end{array}$ & 567,1 & 733,6 & 589,4 \\
\hline & 12,5 & - & 711,6 & 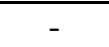 & \begin{tabular}{|l|l|}
624,4 \\
\end{tabular} & 851,5 & 711,4 & \begin{tabular}{|l|}
758,9 \\
\end{tabular} & - & $\begin{array}{l}633,8 \\
\end{array}$ & - & 655,4 \\
\hline & 15,0 & - & 801,1 & - & \begin{tabular}{|l|l|}
700,3 \\
\end{tabular} & \begin{tabular}{|l|}
918,7 \\
\end{tabular} & \begin{tabular}{|l|l|}
781,2 \\
\end{tabular} & \begin{tabular}{|l|}
826,4 \\
\end{tabular} & - & 713,0 & - & 735,2 \\
\hline 20 & 17,5 & - & 909,0 & - & 793,6 & 992,9 & 856,8 & 900,8 & - & 809,1 & - & 833,7 \\
\hline & 20,0 & - & 1037,1 & - & 903,5 & 1075,6 & \begin{tabular}{|c|}
939,1 \\
\end{tabular} & \begin{tabular}{|l|}
982,9 \\
\end{tabular} & - & 923,1 & - & 949,7 \\
\hline U. & 22,5 & - & - & - & - & 1168,3 & 1028,6 & 1073,8 & - & 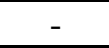 & - & - \\
\hline & 25,0 & - & - & - & - & 1272,6 & 1125,6 & 1173,8 & - & - & - & - \\
\hline & 27,5 & - & - & - & - & 1390,7 & 1230,2 & 1283,9 & - & - & - & - \\
\hline & 30,0 & - & 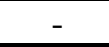 & 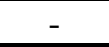 & - & \begin{tabular}{|l|l}
1518,9 \\
\end{tabular} & 1344,5 & 1405,8 & - & 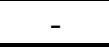 & - & - \\
\hline
\end{tabular}


Tabela E19 (continuação) - PBTC (kN) em função do comprimento do grupo de eixos (m) - 5 VIGAS - CA - M+

\begin{tabular}{|c|c|c|c|c|c|c|c|c|c|c|c|c|}
\hline \multirow{13}{*}{ 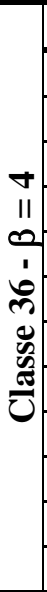 } & B & 1 & 2 & 5 & 6 & 9 & 10 & 11 & 12 & 13 & 16 & 17 \\
\hline & 2,5 & 283,4 & 383,5 & 266,4 & 327,3 & 509,2 & \begin{tabular}{|l|}
399,3 \\
\end{tabular} & 439,8 & 272,9 & 342,4 & 314,4 & 346,4 \\
\hline & 5,0 & 348,8 & 424,9 & 318,3 & 355,9 & 543,8 & \begin{tabular}{|l|}
439,3 \\
\end{tabular} & 474,6 & 332,8 & 377,6 & 376,6 & 376,8 \\
\hline & 7,5 & 438,6 & 472,9 & 395,3 & 391,0 & 583,7 & 483,7 & 514,8 & 417,1 & 418,7 & 468,9 & 413,7 \\
\hline & 10,0 & 564,2 & 527,3 & 502,4 & 431,8 & 627,9 & 532,5 & \begin{tabular}{|l|}
559,8 \\
\end{tabular} & 536,1 & 465,9 & 596,7 & 457,0 \\
\hline & $\sqrt[2]{12,5}$ & - & 589,8 & - & 480,0 & 676,1 & \begin{tabular}{|l|}
585,4 \\
\end{tabular} & \begin{tabular}{|l|}
608,9 \\
\end{tabular} & - & 520,7 & - & 508,2 \\
\hline & 15,0 & - & 664,0 & - & 538,3 & 729,5 & \begin{tabular}{|l|}
642,8 \\
\end{tabular} & 663,2 & - & 585,7 & - & 570,1 \\
\hline & 17,5 & - & 753,4 & - & 610,0 & 788,4 & 705,0 & 722,8 & - & 664,7 & - & 646,5 \\
\hline & 20,0 & - & 859,6 & - & 694,5 & 854,0 & \begin{tabular}{|l|}
772,7 \\
\end{tabular} & \begin{tabular}{|l|l}
788,7 \\
\end{tabular} & - & 758,4 & - & 736,5 \\
\hline & 22,5 & - & - & - & - & 927,7 & 846,4 & 861,7 & - & - & - & - \\
\hline & 25,0 & - & - & - & - & 1010,5 & \begin{tabular}{|l|}
926,1 \\
\end{tabular} & 941,9 & - & - & - & 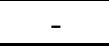 \\
\hline & 27,5 & - & - & - & - & 1104,3 & 1012,3 & 1030,3 & - & - & - & - \\
\hline & 30,0 & - & - & - & - & 1206,0 & 1106,3 & 1128,1 & - & - & - & - \\
\hline & 2,5 & 447,7 & 585,7 & 496,6 & 617,1 & 880,8 & \begin{tabular}{|l|}
617,4 \\
\end{tabular} & \begin{tabular}{|l|}
776,4 \\
\end{tabular} & 426,1 & 537,7 & 541,1 & 630,8 \\
\hline & 5,0 & 550,8 & 648,8 & 593,4 & 671,0 & 940,6 & \begin{tabular}{|l|}
679,3 \\
\end{tabular} & \begin{tabular}{|l|l}
837,7 \\
\end{tabular} & 519,8 & 592,9 & 648,0 & 686,1 \\
\hline & 7,5 & 692,7 & 722,2 & 737,0 & 737,1 & 1009,6 & \begin{tabular}{|l|}
747,9 \\
\end{tabular} & 908,8 & 651,4 & 657,4 & 806,8 & 753,4 \\
\hline$m$ & 10,0 & \begin{tabular}{|l|}
891,1 \\
\end{tabular} & 805,2 & 936,7 & 814,0 & 1086,0 & \begin{tabular}{|l|}
823,4 \\
\end{tabular} & \begin{tabular}{|c|}
988,1 \\
\end{tabular} & 837,2 & 731,5 & 1026,8 & 832,3 \\
\hline & 12,5 & - & 900,7 & - & 904,8 & 1169,4 & 905,2 & 1074,9 & - & 817,5 & - & 925,6 \\
\hline مُ & 15,0 & - & 1013,9 & - & 1014,7 & 1261,7 & \begin{tabular}{|l|}
993,9 \\
\end{tabular} & 1170,6 & - & 919,6 & - & 1038,2 \\
\hline & 17,5 & - & 1150,5 & - & 1149,9 & 1363,5 & 1090,2 & 1275,9 & - & 1043,6 & - & 1177,3 \\
\hline 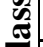 & 20,0 & - & 1312,6 & - & 1309,3 & 1477,1 & 1194,9 & 1392,2 & - & 1190,7 & - & 1341,1 \\
\hline U. & 22,5 & - & - & - & - & 1604,5 & 1308,8 & 1521,0 & - & - & - & - \\
\hline & 25,0 & - & - & - & - & 1747,7 & 1432,1 & 1662,6 & - & - & - & - \\
\hline & 27,5 & - & - & - & - & 1909,9 & 1565,3 & 1818,6 & - & - & - & - \\
\hline & 30,0 & - & - & - & - & 2085,9 & 1710,7 & 1991,3 & - & - & - & - \\
\hline
\end{tabular}


Tabela E19 (continuação) - PBTC (kN) em função do comprimento do grupo de eixos (m) - 5 VIGAS - CA - M+

\begin{tabular}{|c|c|c|c|c|c|c|c|c|c|c|c|c|}
\hline \multirow{13}{*}{ 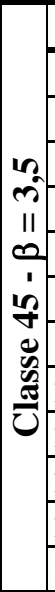 } & B & 1 & 2 & 5 & 6 & 9 & 10 & 11 & 12 & 13 & 16 & 17 \\
\hline & 2,5 & 385,1 & 496,2 & 412,2 & 502,6 & 730,8 & 520,3 & 650,0 & 367,8 & 452,8 & 455,8 & 515,2 \\
\hline & 5,0 & 473,8 & 549,7 & 492,6 & 546,5 & 780,5 & 572,5 & 701,3 & 448,6 & 499,3 & 545,9 & 560,4 \\
\hline & 7,5 & 595,9 & \begin{tabular}{|l|}
611,8 \\
\end{tabular} & 611,7 & 600,4 & \begin{tabular}{|l|}
837,7 \\
\end{tabular} & 630,3 & \begin{tabular}{|l|}
760,9 \\
\end{tabular} & 562,2 & 553,6 & 679,6 & 615,3 \\
\hline & 10 & \begin{tabular}{|l|l|}
766,5 \\
\end{tabular} & \begin{tabular}{|l|}
682,2 \\
\end{tabular} & 777,4 & 663,0 & \begin{tabular}{|l|}
901,1 \\
\end{tabular} & 693,9 & \begin{tabular}{|l|}
827,3 \\
\end{tabular} & 722,5 & 616,1 & 864,9 & 679,7 \\
\hline & 12,5 & - & 763,1 & - & 736,9 & \begin{tabular}{|l|}
970,3 \\
\end{tabular} & 762,8 & \begin{tabular}{|l|}
900,0 \\
\end{tabular} & - & \begin{tabular}{|c|}
688,5 \\
\end{tabular} & - & 755,9 \\
\hline & 15,0 & - & 859,1 & - & 826,5 & 1046,9 & 837,7 & 980,1 & - & 774,5 & - & 848,0 \\
\hline & 17,5 & - & \begin{tabular}{|l|}
974,8 \\
\end{tabular} & - & 936,6 & 1131,4 & 918,8 & 1068,2 & - & 878,9 & - & 961,6 \\
\hline & 20,0 & - & 1112,1 & - & 1066,4 & 1225,6 & 1007,0 & 1165,6 & - & 1002,8 & - & 1095,4 \\
\hline & 22,5 & - & - & - & - & 1331,3 & 1103,0 & 1273,4 & - & 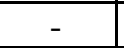 & - & 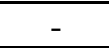 \\
\hline & 25,0 & - & - & - & - & 1450,1 & 1207,0 & 1392,0 & - & - & - & - \\
\hline & 27,5 & - & - & - & - & 1584,8 & 1319,2 & 1522,6 & - & - & - & - \\
\hline & 30,0 & - & - & - & - & 1730,8 & 1441,7 & 1667,2 & - & - & - & - \\
\hline \multirow{12}{*}{ 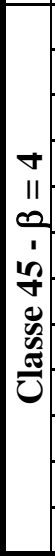 } & 2,5 & 328,5 & 414,8 & 335,9 & 398,7 & 593,2 & 432,0 & 534,7 & 315,2 & 375,8 & 378,7 & 410,4 \\
\hline & 5,0 & 404,2 & 459,5 & 401,3 & 433,5 & 633,5 & 475,3 & 576,9 & 384,4 & 414,4 & 453,6 & 446,4 \\
\hline & 7,5 & 508,3 & 511,5 & 498,4 & 476,3 & 680,0 & 523,4 & 625,9 & 481,8 & 459,4 & 564,8 & 490,2 \\
\hline & 10,0 & 653,9 & 570,3 & 633,4 & 526,0 & 731,4 & 576,1 & 680,5 & 619,2 & 511,2 & 718,7 & 541,5 \\
\hline & 12,5 & - & 637,9 & - & 584,6 & 787,6 & 633,4 & 740,3 & - & 571,4 & - & 602,2 \\
\hline & 15,0 & - & 718,1 & - & 655,6 & 849,8 & 695,5 & \begin{tabular}{|l|}
806,2 \\
\end{tabular} & - & 642,7 & - & 675,5 \\
\hline & 17,5 & - & \begin{tabular}{|l|}
814,8 \\
\end{tabular} & - & 743,0 & 918,3 & 762,9 & \begin{tabular}{|l|}
878,7 \\
\end{tabular} & - & \begin{tabular}{|l|}
729,4 \\
\end{tabular} & - & 766,0 \\
\hline & 20,0 & - & 929,7 & - & 845,9 & 994,8 & 836,1 & 958,8 & - & 832,2 & - & 872,6 \\
\hline & 22,5 & - & - & - & - & 1080,6 & 915,8 & 1047,5 & - & - & - & - \\
\hline & 25,0 & - & - & - & - & 1177,1 & 1002,1 & 1145,0 & - & - & - & - \\
\hline & 27,5 & - & - & - & - & 1286,3 & 1095,3 & 1252,5 & - & - & - & - \\
\hline & 30,0 & - & - & - & - & 1404,9 & 1197,1 & 1371,4 & - & - & - & - \\
\hline
\end{tabular}


Tabela E20 - PBTC (kN) em função do comprimento do grupo de eixos (m) - 5 VIGAS - CA - M.

\begin{tabular}{|c|c|c|c|c|c|c|c|c|c|c|}
\hline \multirow{14}{*}{ 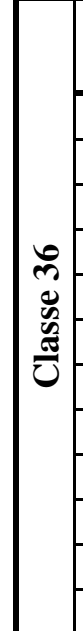 } & \multirow{2}{*}{ B } & \multicolumn{3}{|c|}{$\beta=3$} & \multicolumn{3}{|c|}{$\beta=3,5$} & \multicolumn{3}{|c|}{$\beta=4$} \\
\hline & & 9 & 10 & 11 & 9 & 10 & 11 & 9 & 10 & 11 \\
\hline & 2,5 & 1934,1 & 1554,2 & 1961,9 & 1615,1 & 1287,8 & 1651,2 & 1320,1 & 1041,4 & 1363,7 \\
\hline & 5,0 & 1949,4 & 1570,1 & 1977,7 & 1627,9 & 1301,0 & 1664,5 & 1330,6 & 1052,1 & 1374,7 \\
\hline & 7,5 & 1975,6 & 1592,9 & 2007,6 & 1649,8 & 1319,9 & 1689,7 & 1348,4 & 1067,3 & 1395,5 \\
\hline & 10,0 & 2013,6 & 1627,0 & 2053,5 & 1681,5 & 1348,1 & 1728,2 & 1374,4 & 1090,1 & 1427,3 \\
\hline & 12,5 & 2065,5 & 1673,4 & 2116,7 & 1724,8 & 1386,5 & 1781,5 & 1409,8 & 1121,2 & 1471,3 \\
\hline & 15,0 & 2134,8 & 1737,6 & 2200,8 & 1782,8 & 1439,7 & 1852,2 & 1457,1 & 1164,2 & 1529,7 \\
\hline & 17,5 & 2224,6 & 1820,0 & 2308,7 & 1857,7 & 1508,1 & 1943,1 & 1518,4 & 1219,5 & 1604,8 \\
\hline & 20,0 & 2339,7 & 1926,5 & 2446,8 & 1953,9 & 1596,3 & 2059,2 & 1597,0 & 1290,8 & 1700,7 \\
\hline & 22,5 & 2485,9 & 2022,9 & 2620,2 & 2075,9 & 1676,1 & 2205,2 & 1696,8 & 1355,4 & 1821,2 \\
\hline & 25,0 & 2671,5 & 1994,8 & 2634,7 & 2230,9 & 1652,9 & 2217,4 & 1823,5 & 1336,6 & 1831,3 \\
\hline & 27,5 & 2697,7 & 1979,5 & 2589,6 & 2252,8 & 1640,2 & 2179,5 & 1841,3 & 1326,4 & 1800,0 \\
\hline & 30,0 & 2671,6 & 1976,7 & 2569,0 & 2231,0 & 1637,9 & 2162,1 & 1823,5 & 1324,5 & 1785,6 \\
\hline \multirow{12}{*}{ 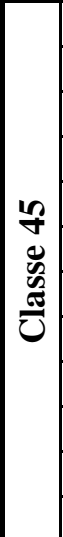 } & 2,5 & 2134,6 & 1543,5 & 2116,8 & 1815,6 & 1284,8 & 1804,5 & 1520,2 & 1045,2 & 1515,3 \\
\hline & 5,0 & 2151,6 & 1559,3 & 2133,8 & 1830,0 & 1298,0 & 1819,0 & 1532,3 & 1056,0 & 1527,5 \\
\hline & 7,5 & 2180,5 & 1581,9 & 2166,1 & 1854,6 & 1316,8 & 1846,5 & 1552,8 & 1071,3 & 1550,7 \\
\hline & 10,0 & 2222,4 & 1615,8 & 2215,5 & 1890,3 & 1344,9 & 1888,7 & 1582,7 & 1094,2 & 1586,1 \\
\hline & 12,5 & 2279,6 & 1661,9 & 2283,8 & 1939,0 & 1383,3 & 1946,9 & 1623,4 & 1125,4 & 1634,9 \\
\hline & 15,0 & 2356,2 & 1725,6 & 2374,4 & 2004,1 & 1436,4 & 2024,2 & 1678,0 & 1168,5 & 1699,8 \\
\hline & 17,5 & 2455,3 & 1807,5 & 2490,9 & 2088,4 & 1504,5 & 2123,5 & 1748,5 & 1224,0 & 1783,2 \\
\hline & 20,0 & 2582,4 & 1913,3 & 2639,9 & 2196,4 & 1592,6 & 2250,4 & 1839,0 & 1295,6 & 1889,8 \\
\hline & 22,5 & 2743,7 & 2009,0 & 2826,9 & 2333,7 & 1672,2 & 2409,9 & 1953,9 & 1360,4 & 2023,7 \\
\hline & 25,0 & 2948,6 & 1981,1 & 2842,6 & 2507,9 & 1649,0 & 2423,2 & 2099,8 & 1341,6 & 2034,9 \\
\hline & 27,5 & 2977,5 & 1965,9 & 2794,0 & 2532,5 & 1636,4 & 2381,8 & 2120,4 & 1331,3 & 2000,2 \\
\hline & 30,0 & 2948,6 & 1963,1 & 2771,7 & 2508,0 & 1634,1 & 2362,8 & 2099,9 & 1329,4 & 1984,2 \\
\hline
\end{tabular}


Tabela E21 - PBTC (kN) em função do comprimento do grupo de eixos (m) - SEÇÃO CELULAR - CA - $\mathrm{M}_{+}$

\begin{tabular}{|c|c|c|c|c|c|c|c|c|c|c|c|c|c|}
\hline \multirow{14}{*}{ 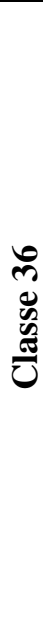 } & \multirow{2}{*}{ B } & \multicolumn{4}{|c|}{$\beta=3$} & \multicolumn{4}{|c|}{$\beta=3,5$} & \multicolumn{4}{|c|}{$\beta=4$} \\
\hline & & 1 & 4 & 6 & 9 & 1 & 4 & 6 & 9 & 1 & 4 & 6 & 9 \\
\hline & 2,5 & 906,3 & 1269,8 & 689,2 & 831,0 & 707,0 & 1039,3 & 547,8 & 664,0 & 524,5 & 826,5 & 417,4 & 510,5 \\
\hline & 5,0 & 961,0 & 1329,8 & $\begin{array}{l}738,0 \\
\end{array}$ & 876,5 & 749,7 & 1088,4 & 586,6 & 700,4 & 556,2 & 865,6 & 447,0 & 538,5 \\
\hline & 7,5 & 1034,5 & 1405,4 & 799,3 & 930,6 & 807,1 & 1150,3 & 635,3 & 743,6 & 598,8 & 914,8 & 484,1 & 571,7 \\
\hline & 10,0 & 1126,2 & 1493,0 & 871,7 & 991,3 & 878,6 & 1222,0 & $\begin{array}{l}692,9 \\
\end{array}$ & 792,1 & 651,8 & 971,9 & 528,0 & 609,0 \\
\hline & 12,5 & 1230,3 & 1592,6 & 959,0 & 1057,4 & 959,8 & 1303,5 & 762,2 & 844,9 & 712,1 & 1036,7 & 580,8 & 649,6 \\
\hline & 15,0 & 1357,7 & 1705,7 & 1068,3 & 1132,9 & 1059,2 & 1396,0 & 849,1 & 905,3 & 785,8 & 1110,3 & 647,0 & 696,0 \\
\hline & 17,5 & 1520,9 & 1827,7 & 1207,0 & 1218,4 & 1186,6 & 1495,9 & 959,4 & $\begin{array}{l}973,6 \\
\end{array}$ & 880,3 & 1189,7 & $\begin{array}{l}731,0 \\
\end{array}$ & $\begin{array}{l}748,5 \\
\end{array}$ \\
\hline & 20,0 & 1721,3 & 1968,2 & 1369,3 & 1315,5 & 1342,9 & 1610,9 & 1088,4 & 1051,1 & 996,2 & 1281,2 & 829,3 & 808,2 \\
\hline & 22,5 & - & 2129,8 & - & 1426,1 & - & 1743,1 & - & 1139,5 & - & 1386,4 & - & 876,1 \\
\hline & 25,0 & - & 2315,8 & - & 1552,5 & - & 1895,4 & - & 1240,5 & - & 1507,5 & - & $\begin{array}{l}953,8 \\
\end{array}$ \\
\hline & 27,5 & - & 2530,6 & - & 1697,9 & - & 2071,2 & - & 1356,7 & - & 1647,3 & - & 1043,1 \\
\hline & 30,0 & - & 2750,1 & - & 1846,5 & - & 2250,9 & - & 1475,5 & - & 1790,2 & - & 1134,4 \\
\hline \multirow{12}{*}{ 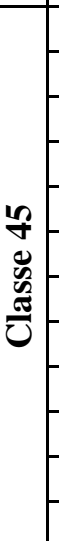 } & 2,5 & 1025,9 & 1488,5 & $\begin{array}{l}752,3 \\
\end{array}$ & 933,2 & 819,1 & 1253,7 & 606,8 & $\begin{array}{l}764,0 \\
\end{array}$ & 629,8 & 1036,6 & 472,7 & $\begin{array}{l}608,3 \\
\end{array}$ \\
\hline & 5,0 & 1087,8 & 1558,9 & 805,6 & 984,4 & 868,6 & 1312,9 & 649,8 & 805,9 & 667,8 & 1085,6 & 506,2 & 641,7 \\
\hline & 7,5 & 1171,1 & 1647,5 & 872,5 & 1045,1 & 935,1 & 1387,6 & 703,8 & 855,6 & 718,9 & 1147,4 & 548,2 & 681,3 \\
\hline & 10,0 & 1274,8 & 1750,2 & $\begin{array}{l}951,5 \\
\end{array}$ & 1113,3 & 1017,9 & 1474,1 & $\begin{array}{l}767,6 \\
\end{array}$ & 911,4 & $\begin{array}{l}782,6 \\
\end{array}$ & 1218,9 & 597,9 & 725,7 \\
\hline & 12,5 & 1392,6 & 1866,9 & 1046,8 & 1187,5 & 1112,0 & 1572,4 & 844,4 & 972,2 & 854,9 & 1300,2 & 657,8 & 774,1 \\
\hline & 15,0 & 1536,9 & 1999,5 & 1166,1 & 1272,3 & 1227,2 & 1684,1 & 940,7 & 1041,6 & 943,5 & 1392,5 & 732,8 & 829,4 \\
\hline & 17,5 & 1721,6 & 2142,5 & 1317,5 & 1368,3 & 1374,7 & 1804,5 & 1062,8 & 1120,2 & 1056,9 & 1492,1 & 827,9 & 892,0 \\
\hline & 20,0 & 1948,4 & 2307,3 & 1494,7 & 1477,3 & 1555,8 & 1943,2 & 1205,7 & 1209,4 & 1196,1 & 1606,8 & 939,2 & 963,0 \\
\hline & 22,5 & - & 2496,6 & - & 1601,5 & - & 2102,8 & - & 1311,1 & - & 1738,7 & - & 1044,0 \\
\hline & 25,0 & - & 2714,7 & - & 1743,5 & - & 2286,4 & - & 1427,4 & - & 1890,6 & - & 1136,5 \\
\hline & 27,5 & - & 2966,5 & - & 1906,8 & - & 2498,5 & - & 1561,0 & - & 2066,0 & - & 1242,9 \\
\hline & 30,0 & - & 3223,8 & - & 2073,7 & - & 2715,2 & - & 1697,7 & - & 2245,2 & - & 1351,8 \\
\hline
\end{tabular}


Tabela E22 - PBTC (kN) em função do comprimento do grupo de eixos (m) - SEÇÃO CELULAR - CA - M.

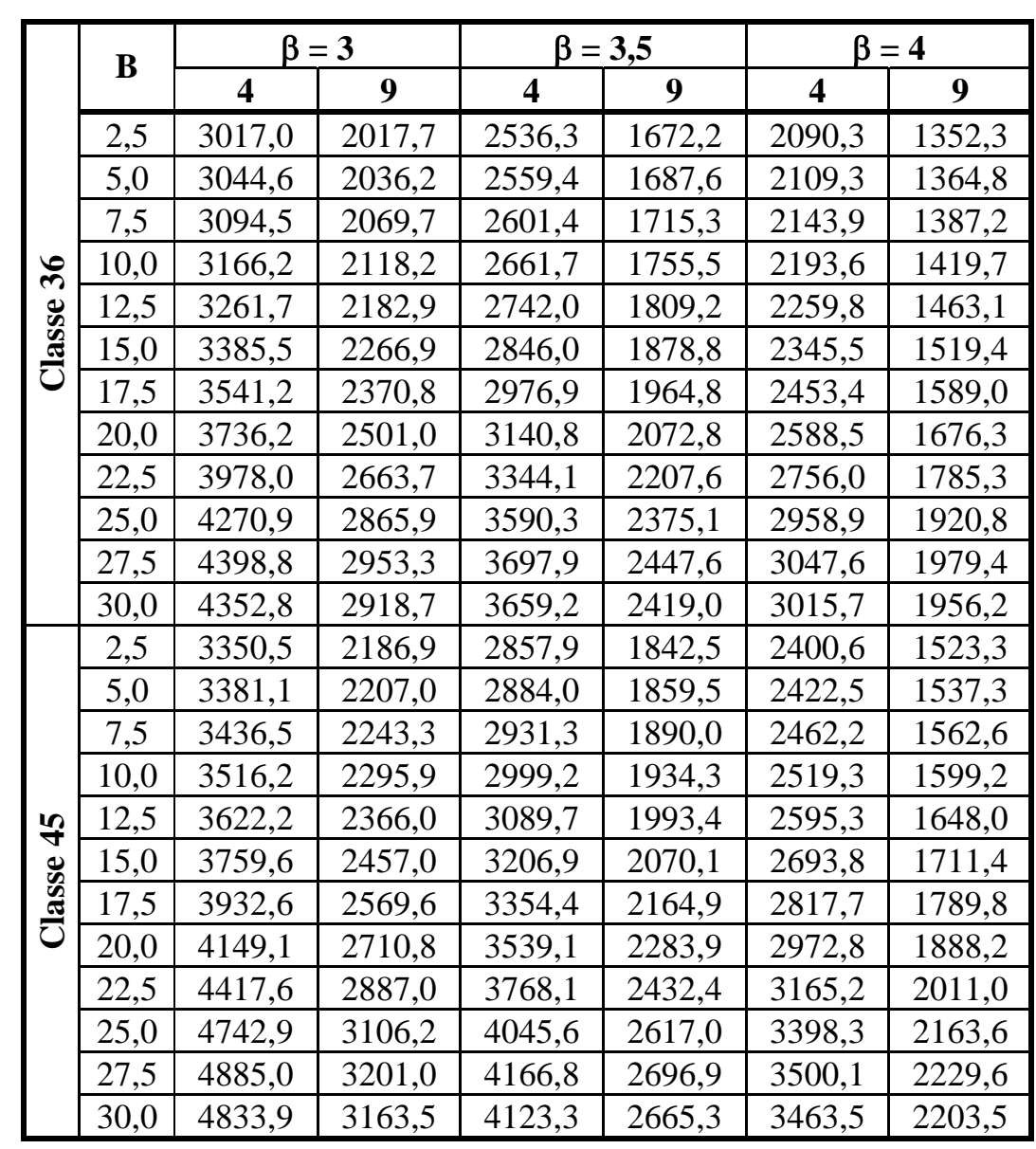


Tabela E23 - PBTC (kN) em função do comprimento do grupo de eixos (m) - LAJE - CP - ELU - M+

\begin{tabular}{|c|c|c|c|c|c|c|c|}
\hline \multirow{10}{*}{ 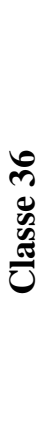 } & \multirow{2}{*}{ B } & \multicolumn{2}{|c|}{$\beta=3$} & \multicolumn{2}{|c|}{$\beta=3,5$} & \multicolumn{2}{|c|}{$\beta=4$} \\
\hline & & 3 & 4 & 3 & 4 & 3 & 4 \\
\hline & 2,5 & 1206,5 & 1437,1 & 1055,1 & 1265,8 & 914,4 & 1106,3 \\
\hline & 5,0 & 1359,4 & 1649,5 & 1188,8 & 1452,8 & 1030,3 & 1269,7 \\
\hline & 7,5 & 1519,1 & 1870,6 & 1328,5 & 1647,5 & 1151,4 & 1440,0 \\
\hline & 10,0 & 1692,8 & 2108,5 & 1480,4 & 1857,1 & 1283,0 & 1623,1 \\
\hline & 12,5 & 1888,9 & 2371,6 & 1651,9 & 2088,8 & 1431,6 & 1825,7 \\
\hline & 15,0 & 2119,9 & 2674,2 & 1853,9 & 2355,3 & 1606,7 & 2058,6 \\
\hline & 17,5 & 2400,3 & 3032 & 2099,1 & 2670,6 & 1819,2 & 2334,1 \\
\hline & 20,0 & 9 & 343 & 23 & 7,8 & & ,3 \\
\hline \multirow{8}{*}{ 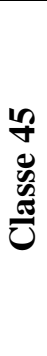 } & 2,5 & & & & & 78 & 982,8 \\
\hline & 5,0 & 120 & 149 & 1040,0 & & 889,4 & 1128,0 \\
\hline & 7,5 & 1343,2 & 1690,5 & 1162,2 & 1477,5 & 993,9 & 1279,2 \\
\hline & 10,0 & 1496,7 & 1905,5 & 1295,0 & 4 & 1107,5 & 1441,9 \\
\hline & 12,5 & 1670,1 & 2143,3 & 1445,0 & 1873,2 & 1235,8 & 1621,9 \\
\hline & 15,0 & 1874,4 & 2416,7 & 1621,8 & 2112,2 & 1387,0 & 1828,8 \\
\hline & 17,5 & 2122,3 & 2740,2 & 1836,3 & 2394,9 & 1570,5 & 2073,5 \\
\hline & 20,0 & 2407,6 & 3106,7 & 2083,1 & 2715,2 & 1781,5 & 2350,9 \\
\hline
\end{tabular}


Tabela E24 - PBTC (kN) em função do comprimento do grupo de eixos (m) - 5 VIGAS - CP - ELU - M $_{+}$

\begin{tabular}{|c|c|c|c|c|c|c|c|c|c|c|c|c|c|}
\hline & B & 2 & 3 & 4 & 6 & 7 & 8 & 13 & 14 & 15 & 17 & 18 & 19 \\
\hline & 2,5 & 709,3 & \begin{tabular}{|l|}
988,1 \\
\end{tabular} & 1564,1 & 825,2 & 1079,6 & 1513,3 & 636,9 & 912,3 & 1404,3 & 46,1 & 69,5 & 327,1 \\
\hline & 5,0 & 785,8 & 1057,3 & 10 & 7,4 & 1138,7 & 1575,8 & &, 9 & 1477,1 &, 5 & 25,3 & 0,1 \\
\hline & 7,5 & 874,6 & 134,2 & 738,8 & 55,8 & 1209,4 & 1646,8 & 778,7 & 1044,1 & 1555,7 & 91,1 & 090,0 & 1441,0 \\
\hline 11 & 10,0 & 975,2 & 17,9 & 31,6 & 88,7 & 1288,5 & 1721,4 & 866,5 & 9,4 & 1639,0 & 984,4 & 161,6 & 1507,1 \\
\hline & 12,5 & 1090,8 & 1307,9 & 926,7 & 210,0 & 1374,8 & 1799,8 & 968,4 &, 2 & 1727,2 & 1094,7 & 0,2 & ש, \\
\hline हे & 15,0 & 1228,0 & 1 & 24,7 & 1357,1 & 1470,6 & 1883,2 & 1089,4 & 0 &, 7 & 3,0 &, 7 & 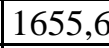 \\
\hline 岗 & 17,5 & 1393,4 & 1513,7 & 2127,1 & 1537,9 & 1577,1 & 1972,4 & 1236,2 & 1389,7 & 1920,2 & 1392,5 & 1,3 &, 0 \\
\hline & 20,0 & 1589,7 & 1633,3 & 235,2 & 1750,9 & 1697,4 & 2068,3 & 1410,5 & 1499,5 & 2026,6 & 1586,2 & 29,4 & 29,5 \\
\hline & 22,5 & - & 1768,1 & 2349,2 & - & 1834,5 & 2171,6 & & 1622,8 & 2140,9 & & 652,4 & 1927,9 \\
\hline & 25,0 & - & 1920,5 & 2473,1 & - & 1991,3 & 2285,1 & - & 1762,7 & 2263,9 & - & 3,7 & 035,1 \\
\hline & 27,5 & - & 2095,6 & 2609,9 & - & 2173,3 & 2410,7 & - & 19 & 2397,7 & & 88,8 & 2152,7 \\
\hline & 30,0 & - & 2291,1 & 2761,0 & - & 2373,7 & 2550,6 & - & 2104,0 & 2544,0 & & 138,5 & 2282,3 \\
\hline & 2,5 & 614,2 & 857,6 & 1368,1 & 698,0 & 910,3 & 1281,4 & 547,6 & 787,0 & 1224,2 & 624,4 & 804,5 & 1108,2 \\
\hline & 5,0 & 680,4 & 917,7 & 1441,7 & 759,0 & 960,1 & 1334,3 & 603,9 & 0 & 1287,6 & 679,1 & 850,8 & 1152,6 \\
\hline & 7,5 & 757,3 & 984,4 & 1520,9 & 833,9 & 1019,7 & 1394,5 & 669,5 & 900,7 & 1356,2 & 745,7 & 04,5 & 1203,4 \\
\hline m & 10,0 & 844,4 & \begin{tabular}{|l|}
1057,1 \\
\end{tabular} & 1602,0 & 920,9 & 1086,5 & 1457,7 & 745,0 & 965,6 & 1428,8 & 823,8 & 963,9 & 1258,6 \\
\hline$\|$ & 12,5 & 944,5 & 1135,2 & 1685,2 & 1023,5 & 1159,2 & 1524,0 & 832,7 & 1036,2 & 1505,7 & 916,1 & 29,1 & 1318,0 \\
\hline & 15,0 & 1063,3 & 1220,5 & 1770,9 & 1147,9 & 1240,0 & 1594,6 & 936,6 & 1113,6 & 1587,3 & 1027,6 & 1100,1 & 1382,6 \\
\hline m & 17,5 & 1206,5 & 1313,8 & 1860,5 & 1300,8 & 1329,8 & 1670,1 & 1062,9 & 1198,8 & 1674,0 & 1165,3 & 1179,4 & 1452,2 \\
\hline & 20,0 & 1376,5 & 1417,7 & 1955,0 & 1481,0 & 1431,2 & 1751,4 & 1212,7 & 1293,5 & 1766,7 & 1327,4 & 1269,1 & 1527,9 \\
\hline 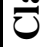 & 22,5 & - & 1534,6 & 2054,7 & - & 1546,8 & 1838,8 & - & 1399,9 & 1866,3 & - & 1371,2 & 1610,1 \\
\hline & 25,0 & - & 1666,9 & 2163,1 & - & 1679,0 & 1934,9 & 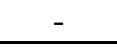 & 1520,6 & 1973,6 & - & 1488,5 & 1699,6 \\
\hline & 27,5 & - & 1818,9 & 2282,8 & - & 1832,4 & 2041,3 & - & 1659,8 & 2090,2 & - & 1625,4 & 1797,8 \\
\hline & 30,0 & - & \begin{tabular}{|l}
1988,6 \\
\end{tabular} & 2415,0 & - & 2001,4 & 2159,8 & - & 1814,9 & 2217,8 & & 1774,6 & 1906,0 \\
\hline
\end{tabular}


Tabela E24 (continuação) - PBTC (kN) em função do comprimento do grupo de eixos (m) - 5 VIGAS - CP - ELU - M+

\begin{tabular}{|c|c|c|c|c|c|c|c|c|c|c|c|c|c|}
\hline & B & 2 & 3 & 4 & 6 & 7 & 8 & 13 & 14 & 15 & 17 & 18 & 19 \\
\hline & 2,5 & \begin{tabular}{|l|}
527,0 \\
\end{tabular} & 737,1 & \begin{tabular}{|l}
1185,7 \\
\end{tabular} & 581,6 & \begin{tabular}{|l|}
754,6 \\
\end{tabular} & 1067,5 & 465,9 & 671,3 & \begin{tabular}{|l|}
1056,9 \\
\end{tabular} & 513,1 & 653,1 & 906,8 \\
\hline & 5,0 & 583,8 & 788,8 & 1249,5 & 632,4 & 796,0 & 1111,6 & 513,8 & 717,4 & 1111,7 & 558,1 & 690,6 & 943,1 \\
\hline & 7,5 & 649,8 & 846,1 & 1318,1 & 694,7 & 845,3 & 1161,7 & 569,7 & 768,3 & 1170,8 & 612,8 & 734,2 & 984,7 \\
\hline II & 10,0 & \begin{tabular}{|l|}
724,5 \\
\end{tabular} & 908,6 & 1388,5 & 767,2 & 900,7 & 1214,4 & 633,9 & 823,7 & 1233,6 & 677,0 & 782,4 & 029,8 \\
\hline & 12,5 & 810,4 & 975,8 & 1460,6 & 852,7 & 961,0 & 1269,7 & 708,4 & 883,9 & 1299,9 & 752,8 & 835,4 & 078,5 \\
\hline 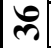 & 15,0 & \begin{tabular}{|l|}
912,3 \\
\end{tabular} & 1049,0 & 1534,8 & 956,4 & 1028,0 & 1328,5 & 796,9 & 950,0 & 1370,3 & 844,5 & 893,0 & 1131,3 \\
\hline & 17,5 & 1035,2 & 1129,3 & 612,5 & 1083,8 & 1102,4 & 1391,4 & 904,3 & 2,6 & 1445,2 & 957,6 & 957,4 & 38,3 \\
\hline & 20,0 & 1181,0 & 218,5 & 694,4 & 1233,9 & 1186,4 & 1459,0 & 1031,8 & 1103,4 & 1525,3 & 1090,9 & \begin{tabular}{|l|l}
1030,2 \\
\end{tabular} & 1250,2 \\
\hline & 22,5 & - & 1319,0 & 780,8 & 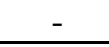 & 1282,3 & 1531,9 & - & 1194,2 & 1611,3 & & 1113,0 & 1317,4 \\
\hline & 25,0 & - & 1432,8 & 1874,7 & - & 1391,9 & 1612,0 & - & 1297,1 & 1703,8 & & 1208,2 & 1390,6 \\
\hline & 27,5 & - & 1563,4 & 1978,4 & - & 1519,1 & 1700,6 & - & 1415,9 & 1804,6 & & 1319,4 & 1471,0 \\
\hline & 30,0 & - & 1709,2 & 2093,0 & - & 1659,2 & 1799,3 & - & 1548,3 & 1914,7 & - & 1440,5 & 1559,6 \\
\hline & 2,5 & 625,5 & 856,3 & 1381,9 & 734,4 & 988,2 & 1413,8 & 610,9 & 782,5 & 1236,9 & 679,5 & 837,9 & 1284,4 \\
\hline & 5,0 & 692,9 & 916,3 & 1456,3 & 798,6 & 1042,3 & 1472,1 & 673,6 & 836,2 & 1301,0 & 739,0 & 886,1 & 1335,8 \\
\hline & 7,5 & \begin{tabular}{|l}
71,2 \\
\end{tabular} & 982,9 & 1536,3 & 877,3 & 1106,9 & 1538,5 & 746,8 & 895,6 & 1370,2 & 811,5 & 942,0 & 1394,6 \\
\hline$\|$ & 10,0 & \begin{tabular}{|l|l|}
859,9 \\
\end{tabular} & 1055,5 & 1618,3 & 968,9 & 1179,4 & 1608,2 & 831,1 & 960,2 & 1443,6 & 896,4 & 1003,9 & 1458,6 \\
\hline$\infty$ & 12,5 & 961,8 & 1133,5 & 1702,3 & 1076,8 & 1258,4 & 1681,4 & 928,8 & 1030,4 & 1521,3 & 996,9 & 1071,8 & 1527,5 \\
\hline & 15,0 & 1082,8 & 1218,6 & 1788,8 & 1207,7 & 1346,1 & 1759,3 & 1044,8 & 1107,4 & 1603,7 & 1118,2 & 1145,7 & 1602,3 \\
\hline & 17,5 & 1228,7 & 1311,8 & 1879,4 & 1368,6 & 1443,5 & 1842,6 & 1185,6 & 1192,0 & 1691,3 & 1268,1 & 1228,3 & 1683,1 \\
\hline & 20,0 & 1401,8 & 1415,5 & 1974,8 & 1558,2 & 1553,6 & 1932,3 & 1352,8 & 1286,3 & 1785,0 & 1444,5 & 1321,7 & 1770,7 \\
\hline$t$ & 22,5 & - & 1532,3 & 2075,6 & - & 1679,1 & 2028,8 & - & 1392,0 & 1885,6 & - & 1428,0 & 1866,0 \\
\hline & 25,0 & - & 1664,4 & 2185,0 & 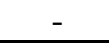 & 1822,6 & 2134,8 & - & 1512,0 & 1994,0 & - & 1550,1 & 1969,7 \\
\hline & 27,5 & _ & 1816,1 & 2305,9 & 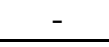 & 1989,2 & 2252,2 & - & 1650,5 & 2111,9 & - & 1692,8 & 2083,5 \\
\hline & 30,0 & & 1985,5 & 2439,5 & & 2172,6 & 2382,9 & - & 1804,8 & 2240,7 & & \begin{tabular}{|l|l|}
1848,1 \\
\end{tabular} & {$[\angle \angle 09,0$} \\
\hline
\end{tabular}


Tabela E24 (continuação) - PBTC (kN) em função do comprimento do grupo de eixos (m) - 5 VIGAS - CP - ELU - M+

\begin{tabular}{|c|c|c|c|c|c|c|c|c|c|c|c|c|c|}
\hline & B & 2 & 3 & 4 & 6 & 7 & 8 & 13 & 14 & 15 & 17 & 18 & 19 \\
\hline & 2,5 & 535,7 & 733,6 & 1196,0 & 613,3 & \begin{tabular}{|l|}
824,6 \\
\end{tabular} & 1188,0 & 523,3 & 664,9 & 1066,4 & 562,5 & 681,4 & 1068,7 \\
\hline & 5,0 & 593,5 & 785,0 & 1260,3 & 666,9 & 869,8 & 1237,1 & 577,1 & 710,5 & 1121,7 & 611,8 & 720,6 & 111,4 \\
\hline م2 & \begin{tabular}{|l|}
7,5 \\
\end{tabular} & 660,6 & 842,1 & 1329,6 & 732,6 & 923,7 & 1292,9 & 639,9 & 761,0 & 1181,4 & 671,8 & 766,1 & 160,4 \\
\hline & 10,0 & 736,5 & 904,3 & 1400,5 & 809,1 & 984,2 & 1351,4 & 712,0 & 815,9 & 1244,7 & 742,1 & 816,4 & 13,6 \\
\hline$c$ & 12,5 & \begin{tabular}{|l|}
823,9 \\
\end{tabular} & 971,1 & 1473,3 & 899,2 & 1050,1 & 1413,0 & 795,7 & 875,5 & 1311,6 & 825,2 & 1,7 & 1271,0 \\
\hline 导 & 15,0 & \begin{tabular}{|l|}
927,5 \\
\end{tabular} & 1044,0 & 548,1 & 1008,5 & 1123,3 & 1478,4 & 895,1 & 940,9 & 1382,7 & \begin{tabular}{|l|}
925,7 \\
\end{tabular} & 7 & 3,2 \\
\hline & 17,5 & 1052,4 & 1123,9 & 626,5 & 1142,9 & 1204,6 & 1548,4 & 1015,8 & 1012,8 & 1458,2 & 1049,7 & 9 & 0,4 \\
\hline & 20,0 & 1200,7 & 1212,7 & \begin{tabular}{|l}
1709,1 \\
\end{tabular} & 1301,2 & 1296,5 & 1623,7 & 1159,0 & 1092,9 & 1539,0 & 1195,8 & 4,9 & 3,3 \\
\hline ש & 22,5 & - & 1312,8 & 1796,3 & - & 1401,2 & 1704,8 & & 1182,8 & 162 & & 3 & 2,6 \\
\hline & 25,0 & - & 1426,0 & 891,0 & - & 1521,0 & 17 & - & 1284,7 & 171 & - &, 7 & 3,9 \\
\hline & 27,5 & - & 1556,0 & 995,6 & - & 0,0 & 18 & - & 2,4 & 1820,8 & & 6,7 & 3,6 \\
\hline & 30,0 & - & 1701,1 & 2111,2 & - & 1813,1 & 2002,4 & - & 1533,5 & 1931,9 & & 503,0 & 7,9 \\
\hline & 2,5 & 453,5 & 620,4 & 1023,0 & 502,4 & \begin{tabular}{|l|l|}
674,3 \\
\end{tabular} & 979,8 & 443,3 & 556,4 & 908,1 & 455,5 & 537,8 & 70,1 \\
\hline & 5,0 & 502,4 & 663,8 & 1078,0 & 546,3 & 711,2 & 1020,3 & 488,8 & 594,6 & 955,1 & 495,5 & 568,7 & 904,9 \\
\hline & 7,5 & 559,2 & 712,1 & 1137,3 & 600,1 & 755,3 & 1066,3 & 542,0 & 636,8 & 1005,9 & 544,0 & 604,6 & 944,8 \\
\hline$\nabla$ & 10,0 & 623,5 & 764,7 & 1197,9 & 662,8 & \begin{tabular}{|l|l|}
804,8 \\
\end{tabular} & 1114,6 & 603,1 & 682,7 & 1059,8 & 601,0 & 644,3 & \begin{tabular}{|l|}
988,1 \\
\end{tabular} \\
\hline 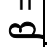 & 12,5 & 697,4 & 821,2 & 1260,2 & 736,6 & 858,6 & 1165,3 & 674,0 & 732,6 & 1116,9 & 668,3 & 687,9 & 1034,8 \\
\hline & 15,0 & \begin{tabular}{|l|}
785,1 \\
\end{tabular} & 882,8 & 1324,2 & 826,2 & 918,5 & 1219,3 & 758,2 & 787,3 & 1177,4 & 749,7 & 735,3 & 1085,5 \\
\hline & 17,5 & 890,9 & 950,4 & 1391,2 & 936,2 & 985,0 & 1277,1 & 860,4 & 847,5 & 1241,7 & 850,1 & 788,4 & 1140,1 \\
\hline & 20,0 & 1016,4 & 1025,5 & 1461,9 & 1065,9 & 1060,1 & 1339,2 & 981,7 & 914,5 & 1310,5 & 968,4 & 848,3 & 1199,5 \\
\hline 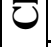 & 22,5 & - & 1110,1 & 1536,4 & - & 1145,8 & 1406,0 & - & 989,7 & 1384,3 & - & 916,5 & 1264,0 \\
\hline & 25,0 & - & 1205,8 & 1617,5 & - & 1243,7 & 1479,5 & - & 1075,0 & 1463,9 & - & 994,9 & 1334,3 \\
\hline & 27,5 & - & 1315,7 & 1707,0 & - & \begin{tabular}{|l|}
1357,3 \\
\end{tabular} & 1560,9 & - & 1173,5 & 1550,4 & - & 1086,5 & 1411,4 \\
\hline & 30,0 & - & 1438,4 & 1805,8 & - & 1482,5 & 1651,4 & - & 1283,2 & 1645,0 & - & 1186,2 & 1496,4 \\
\hline
\end{tabular}


Tabela E25 - PBTC (kN) em função do comprimento do grupo de eixos (m) - SEÇÃO CELULAR - CP - ELU - M $_{+}$

\begin{tabular}{|c|c|c|c|c|c|c|c|c|c|}
\hline \multirow{13}{*}{ II } & D & 1 & 2 & 3 & 0 & & 1 & 0 & 10 \\
\hline & 2,5 & 65,5 & 50,9 & 987,7 & 37,3 & 5,0 & 5,3 & & \\
\hline & 5,0 & & & & & & & & \\
\hline & 7,5 & & & & & & & & \\
\hline & 10,0 & 24,1 & | & & & & & & \\
\hline & 2,5 & & & & & & & & \\
\hline & 5,0 & & & & & & & & \\
\hline & 7,5 & & & & & 12 & & & \\
\hline & 0,0 & & & & & $-E_{2}$ & & & \\
\hline & 22,5 & & & & & & & & \\
\hline & 25,0 & & & & & & & & \\
\hline & 27,5 & & & & & & & & \\
\hline & 30,0 & & & & & & & & \\
\hline & 2,5 & & & & & & & & \\
\hline & 5,0 & & & 8 & & & & & \\
\hline & 7,5 & & 年 & 06,3 & (5, & 5 & 744,6 & & \\
\hline & 10,0 & & & 73,7 & . & 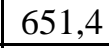 & 5 & & \\
\hline & 12,5 & & & 3 & & & & & \\
\hline & 15,0 & & & 27,4 & ,5 & (ט, & 31,5 & & \\
\hline & \begin{tabular}{|l|}
17,5 \\
\end{tabular} & 1519,7 & 79,3 & 0 & 80,2 & 02,0 & 0,5 & & \\
\hline & 20,0 & 1719,9 & 96,1 & 11,0 & 85,1 & 023,3 & 8,2 & & \\
\hline & 22,5 & - & 32,1 & ,8 & & & 6,6 & & \\
\hline & 25,0 & - & & 38,4 & , & & & & \\
\hline & 27,5 & & & ,9 & & &, 6 & & \\
\hline & S & & $24 / 0,0$ & $27<1,0$ & 2001 & & 政 & 101 & 117 \\
\hline
\end{tabular}


Tabela E25 (continuação) - PBTC (kN) em função do comprimento do grupo de eixos (m) - SEÇÃO CELULAR - CP - ELU - M+

\begin{tabular}{|c|c|c|c|c|c|c|c|c|c|}
\hline & D & 1 & 2 & 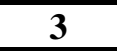 & 5 & 6 & 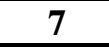 & 0 & 10 \\
\hline & 2,5 & 757,1 & 29,6 & 29,1 & 12,8 & & & & \\
\hline & 5,0 & 802,8 & & & & & & & \\
\hline & 7,5 & 864,3 & & & & & & & \\
\hline & 10,0 & 940,8 & & & & & & & \\
\hline & 12,5 & & & & & & & & \\
\hline & 15,0 & & & & & & & & \\
\hline & 7,5 & 1 & & & & & & & \\
\hline & 0,0 & 1 & & & & & & & \\
\hline & 22,5 & & & & & & & & \\
\hline & 25,0 & - & & & & & & & \\
\hline & 27,5 & & & & & & & & \\
\hline & 30,0 & & & & & &, 4 & & \\
\hline & 2,5 & 73,3 & & & & & & & \\
\hline & 5,0 & & & 2 & & & 9 & & \\
\hline & 7,5 & & & 2 & & & & & \\
\hline & 10,0 & & & 9 & & & 9,3 & & \\
\hline & 12,5 & & & 88,4 & & & 3,1 & & \\
\hline & 15,0 & & & 85,2 & 6 & & 5,9 & & \\
\hline & \begin{tabular}{|l|}
17,5 \\
\end{tabular} & 1969,2 & & 91,4 & 8 & , & 3,1 & & \\
\hline & 20,0 & 2228,6 & & 10,4 & 68,8 & 379,0 & 1322,0 & 6,4 & 692,2 \\
\hline & 22,5 & - & & 2842,5 & ,1 & & 1424,8 & 1885,5 & 17,0 \\
\hline & 25,0 & - & 6,6 & 89,1 &, 2 & & 1544,8 & 1983,8 & 361 , \\
\hline & 27,5 & - & & & & & 9 & 3,1 & 07 \\
\hline & 30,0 & & 3215,0 & ה, מנSבג & $274 \mathrm{~J}, 0$ & & $18 \angle 8, /$ & 2214 , & $2<-1$ \\
\hline
\end{tabular}


Tabela E25 (continuação) - PBTC (kN) em função do comprimento do grupo de eixos (m) - SEÇÃO CELULAR - CP - ELU - M+

\begin{tabular}{|c|c|c|c|c|c|c|c|c|c|}
\hline \multirow{13}{*}{$\stackrel{L}{m}$} & B & 1 & 2 & 3 & 5 & 6 & 7 & 8 & 10 \\
\hline & 2,5 & 1007,4 & 1375,4 & 1789,5 & 989,5 & 561,2 & \begin{tabular}{|l|l|}
709,8 \\
\end{tabular} & 1141,9 & 850,6 \\
\hline & 5,0 & 1068,2 & 1428,6 & 1839,9 & 1060,1 & 600,9 & 741,6 & 1179,0 & 04,3 \\
\hline & 7,5 & 1150,0 & 1496,0 & 1902,5 & 1134,5 & 650,8 & 779,5 & 1222,4 & 960,8 \\
\hline & 10,0 & 1251,8 & 1574,8 & 1973,6 & 1213,2 & 709,8 & \begin{tabular}{|l|l|}
821,8 \\
\end{tabular} & 1269,4 & 1021,2 \\
\hline & 12,5 & 1367,6 & 1664,6 & 2052,2 & 1297,6 & 780,8 & \begin{tabular}{|l|l|}
868,8 \\
\end{tabular} & 1320,0 & 1086,7 \\
\hline & 15,0 & 1509,2 & 1761,7 & 2135,4 & 1389,3 & 869,8 & 922,9 & 1376,3 & 1159,2 \\
\hline & 17,5 & 1690,6 & 1873,4 & 2226,7 & 1490,5 & 982,8 & 984,6 & 1438,0 & 1240,1 \\
\hline & 20,0 & 1913,3 & 2003,6 & 2328,9 & 1603,7 & 1114,9 & 1055,5 & 1505,9 & 1331 \\
\hline & 22,5 & - & 2155,4 & 2442,4 & 1731,9 & & 1137,6 & 1580,6 & 14 \\
\hline & 25,0 & - & 2333,3 & 2568,4 & 1878,6 & . & 1233,4 & 1663,1 & 1556,6 \\
\hline & 27,5 & - & 2544,4 & 2708,9 & 2049,2 & . & 1346,9 & 1754,7 & 1698,2 \\
\hline & 30,0 & - & 2765,3 & 2866,1 & 2236,1 & & 1460,1 & 1856,8 & $1851, \mathrm{~S}$ \\
\hline \multirow{12}{*}{ 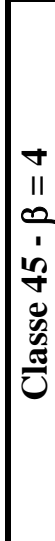 } & 2,5 & 853,4 & 1164,7 & 1515,5 & 782,1 & 439,3 & 545,0 & 936,5 & 695,8 \\
\hline & 5,0 & 904,9 & 1209,7 & 1558,1 & \begin{tabular}{|l|l|}
837,9 \\
\end{tabular} & 470,4 & 569,5 & 966,9 & 739,7 \\
\hline & 7,5 & 974,2 & 1266,9 & 1611,2 & 896,7 & 509,5 & 598,6 & 1002,5 & 786,0 \\
\hline & 10,0 & 1060,5 & 1333,6 & 1671,4 & 958,9 & 555,7 & 631,0 & 1041,0 & \begin{tabular}{|l|l|}
835,4 \\
\end{tabular} \\
\hline & 2,5 & 1158,5 & 1409,7 & 1737,9 & 1025,6 & 611,3 & 667,1 & 1082,5 & 889,0 \\
\hline & 15,0 & 1278,5 & 1491,8 & 1808,4 & 1098,1 & 681,0 & 708,6 & \begin{tabular}{|l}
1128,7 \\
\end{tabular} & 948,3 \\
\hline & 17,5 & 1432,2 & 1586,5 & 1885,7 & 1178,1 & 769,4 & 756,0 & 1179,3 & 1014,4 \\
\hline & 20,0 & 1620,8 & 1696,8 & 1972,3 & 1267,6 & 872,8 & 810,5 & 1235,0 & 1089,2 \\
\hline & 22,5 & - & 1825,3 & 2068,4 & 1368,9 & - & 873,5 & 1296,2 & 1174,6 \\
\hline & 25,0 & - & 1975,9 & 2175,1 & 1484,8 & - & 947,1 & 1363,9 & 1273,4 \\
\hline & 27,5 & - & 2154,7 & 2294,1 & 1619,7 & - & 1034,2 & 1439,0 & 1389,2 \\
\hline & 30,0 & & 2341,7 & 2427,2 & 1767,4 & & 1121,1 & 1522,7 & 1514,9 \\
\hline
\end{tabular}


Tabela E26 - PBTC (kN) em função do comprimento do grupo de eixos (m) - LAJE - CP - ELS - $\mathrm{M}_{+}$

\begin{tabular}{|c|c|c|c|c|c|c|c|}
\hline \multirow{10}{*}{$\begin{array}{l}\mathscr{2} \\
\ddot{W} \\
0 \\
\frac{\sigma}{U}\end{array}$} & \multirow{2}{*}{ B } & \multicolumn{2}{|c|}{$\beta=\mathbf{0}$} & \multicolumn{2}{|c|}{$\beta=0,5$} & \multicolumn{2}{|c|}{$\beta=1$} \\
\hline & & 3 & 4 & 3 & 4 & 3 & 4 \\
\hline & 2,5 & 816,1 & 1018,9 & 664,4 & 846,3 & 526,3 & 688,8 \\
\hline & 5,0 & 919,4 & 1169,4 & 748,5 & 971,3 & 592,9 & 790,6 \\
\hline & 7,5 & 1027,5 & 1326,2 & 836,5 & 1101,5 & 662,6 & 896,6 \\
\hline & 10,0 & 1144,9 & 1494,9 & 932,1 & 1241,6 & 738,4 & 1010,6 \\
\hline & 12,5 & 1277,6 & 1681,4 & 1040,1 & 1396,6 & 823,9 & 1136,7 \\
\hline & 15,0 & 1433,8 & 1895,9 & 1167,3 & 1574,8 & 924,7 & 1281,7 \\
\hline & 17,5 & 1623,5 & 2149,7 & 1321,7 & 1785,5 & 1047,0 & 1453,3 \\
\hline & 20,0 & 1841,7 & 24 & 1499,4 & 024,4 & 118 & 7,7 \\
\hline \multirow{8}{*}{ 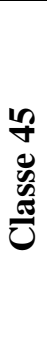 } & 2,5 & & & 637,7 & & 502,9 & 678,9 \\
\hline & 5,0 & 885,4 & 115 & 718,5 & 956,7 & 566,6 & 779,2 \\
\hline & 7,5 & 989,5 & 1305,7 & 803,0 & 1085,0 & 633,2 & 883,7 \\
\hline & 10,0 & 1102,6 & 1471,8 & 894,8 & 1223,0 & 705,6 & 996,1 \\
\hline & 12,5 & 1230,3 & 1655,4 & 998,4 & 1375,6 & 787,3 & 1120,4 \\
\hline & 15,0 & 1380,8 & 1866,7 & 1120,5 & 1551,2 & 883,7 & 1263,4 \\
\hline & 17,5 & 1563,4 & 2116,5 & 1268,8 & 1758,7 & 1000,5 & 1432,5 \\
\hline & 20,0 & 1773,5 & 2399,6 & 1439,3 & 1994,0 & 1135,0 & 1624,1 \\
\hline
\end{tabular}


Tabela E27 - PBTC (kN) em função do comprimento do grupo de eixos (m) - 5 VIGAS - CP - ELS - M $_{+}$

\begin{tabular}{|c|c|c|c|c|c|c|c|c|c|c|c|c|c|}
\hline & B & 2 & 3 & 4 & 6 & 7 & 8 & 13 & 14 & 15 & 17 & 18 & 19 \\
\hline & 2,5 & 568,1 & 735,4 & 1025,9 & 606,7 & \begin{tabular}{|l|}
780,7 \\
\end{tabular} & 1034,1 & 519,3 & 685,6 & 42,0 & 549,9 & 696,7 & 915,6 \\
\hline & 5,0 & 629,3 & 786,9 & 1081,0 & 659,7 & 823,4 & 1076,8 & & & $\begin{array}{l}990,7 \\
\end{array}$ & 8,1 & ,8 & 952,2 \\
\hline & 7,5 & 700,4 & 844,1 & 40,5 & 4,8 & \begin{tabular}{|l|}
874,5 \\
\end{tabular} & 1125,4 & 634,9 & 784,7 & 1043,5 & 656,7 & 33,3 & 994,2 \\
\hline II & 10,0 & 781,0 & 906,5 & 1201,3 & 800,4 & 931,8 & 1176,4 & 706,5 & 1,3 & 1099,4 & 725,4 & 34,7 & 39,8 \\
\hline & 12,5 & 873,6 & 973,5 & 1263,7 & 889,6 & 994,1 & 1229,9 & 789,6 & 2,8 & 1158,5 & 806,7 & 1,2 & 8,9 \\
\hline है & 15,0 & 983,4 & 1046,5 & 1327,9 & 997,7 & 1063,4 & 1286,9 & 888,2 &, 2 & 1,3 & \begin{tabular}{|l|l|}
904,9 \\
\end{tabular} & 6 & 1142,3 \\
\hline 岗 & 17,5 & 11115,9 & 1126,6 & 395,1 & 1130,6 & 1140,4 & 1347,9 & 1008,0 & 044,4 & 1288,0 & 1026,2 & 1,3 & 9,8 \\
\hline & 20,0 & 1273,2 & 1215,6 & 1466,0 & 1287,2 & 1227,4 & 1413,4 & 1150,1 & 1127,0 & 1359,4 & 1169,0 & 1099,0 & 1262,3 \\
\hline & 22,5 & - & 1315,9 & 1540,8 & - & 1326,6 & 1484,0 & - & 1219,7 & 1436,0 & & 1187,4 & 30,2 \\
\hline & 25,0 & - & 1429,4 & 1622,0 & - & 1439,9 & 1561,6 & - & 1324,8 & 1518,5 & - & 1288,9 & 1404,1 \\
\hline & 27,5 & - & 1559,7 & 1711,8 & - & 1571,5 & 1647,4 & 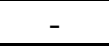 & 1446,1 & 1608,3 & & 1407,5 & 1485,3 \\
\hline & 30,0 & - & 1705,1 & 1810,9 & - & 1716,5 & 1743,0 & - & 1581,3 & 1706,4 & & 1536,7 & 1574,7 \\
\hline & 2,5 & 461,7 & 598,3 & 836,1 & 466,6 & 597,7 & 792,4 & 417,4 & 552,2 & 764,9 & 413,9 & 516,4 & 682,9 \\
\hline & 5,0 & 511,5 & 640,2 & 881,1 & 507,4 & 630,4 & 825,1 & 460,3 & 590,1 & 804,5 & 450,2 & 546,1 & 710,2 \\
\hline & 7,5 & 569,3 & 686,8 & 929,5 & 557,4 & 669,5 & 862,3 & 510,3 & 632,0 & 847,3 & 494,4 & 580,5 & 741,5 \\
\hline 0 & 10,0 & 634,8 & 737,5 & 979,1 & 615,6 & 713,4 & 901,4 & 567,9 & 677,6 & 892,7 & 546,1 & 618,7 & 775,5 \\
\hline$\|$ & 12,5 & 710,0 & 792,0 & 1030,0 & 684,2 & 761,1 & 942,4 & 634,7 & 727,1 & 940,8 & 607,3 & 660,5 & 812,2 \\
\hline & 15,0 & \begin{tabular}{|l|l|}
799,4 \\
\end{tabular} & 851,5 & 1082,3 & 767,3 & 814,2 & 986,1 & 713,9 & 781,5 & 991,7 & 681,2 & 706,1 & 851,9 \\
\hline m & 17,5 & 907,0 & 916,6 & 1137,1 & 869,6 & 873,1 & 1032,8 & 810,2 & 841,2 & 1045,9 & 772,5 & 757,0 & 894,9 \\
\hline & 20,0 & 1034,8 & 989,0 & 1194,8 & 990,0 & 939,7 & 1083,0 & 924,4 & 907,7 & 1103,9 & 880,0 & 814,6 & 941,5 \\
\hline 0 & 22,5 & - & 1070,6 & 1255,8 & - & 1015,6 & 1137,1 & - & 982,3 & 1166,1 & - & 880,1 & 992,1 \\
\hline & 25,0 & - & 1162,9 & 1322,0 & - & 1102,4 & 1196,5 & - & 1067,0 & 1233,1 & - & 955,3 & 1047,3 \\
\hline & 27,5 & - & 1269,0 & 1395,2 & - & \begin{tabular}{|l|}
1203,2 \\
\end{tabular} & 1262,3 & - & 1164,7 & 1306,0 & - & 1043,2 & 1107,8 \\
\hline & 30,0 & 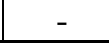 & 1387,3 & 1476,0 & 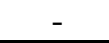 & 1314,1 & 1335,6 & - & 1273,6 & 1385,7 & - & 1139,0 & 1174,5 \\
\hline
\end{tabular}


Tabela E27 (continuação) - PBTC (kN) em função do comprimento do grupo de eixos (m) - 5 VIGAS - CP - ELS - M $_{+}$

\begin{tabular}{|c|c|c|c|c|c|c|c|c|c|c|c|c|c|}
\hline \multirow{13}{*}{$\begin{array}{l}11 \\
0 \\
1 \\
0 \\
0 \\
\vdots \\
0 \\
0 \\
0 \\
ن\end{array}$} & B & 2 & 3 & 4 & 6 & 7 & 8 & 13 & 14 & 15 & 17 & 18 & 19 \\
\hline & 2,5 & 367,6 & 475,1 & 663,2 & 342,9 & 434,8 & 575,7 & 327,6 & 432,6 & 603,9 & 294,3 & 356,3 & 475,1 \\
\hline & 5,0 & \begin{tabular}{|l|l}
407,3 \\
\end{tabular} & 508,4 & 698,8 & 372,9 & 458,6 & 599,5 & 361,3 & 462,3 & 35,2 & 320,1 & 376,8 & 494,1 \\
\hline & \begin{tabular}{|l|}
7,5 \\
\end{tabular} & 453,3 & 545,4 & 737,2 & 409,7 & 487,0 & 626,5 & 400,5 & 495,1 & 669,0 & 351,5 & 400,6 & 515,9 \\
\hline & 10,0 & 505,4 & 585,7 & 776,6 & 452,4 & 518,9 & 654,9 & 445,7 & 530,8 & 704,8 & 388,3 & 426,9 & 539,5 \\
\hline & 12,5 & 565,4 & 628,9 & 816,9 & 502,8 & 553,7 & 684,7 & 498,1 & 569,6 & 742,7 & 431,9 & 55,7 & 565,0 \\
\hline & 15,0 & 636,5 & 676,1 & 858,4 & 563,9 & 592,3 & 716,4 & 560,3 & 612,1 & 783,0 & 484,4 & 7,2 & 92,7 \\
\hline & 7,5 & 722,2 & 727,9 & 901,8 & 639,1 & 635,1 & 750,4 & 635,9 & 658,9 & 825,7 & 549,3 & 522,3 & 222,6 \\
\hline & 0,0 & 824,0 & 785,4 & 947,7 & 727,6 & 683,6 & 786,8 & 725,5 & 711,0 & 871,5 & 625,8 & 62,0 & 55,0 \\
\hline & 22,5 & - & 850,2 & 996,0 & - & 738,8 & 826,1 & & 69,5 &, 6 & & 307,2 & 690,2 \\
\hline & 25,0 & - & 923,5 & 1048,5 & - & \begin{tabular}{|l|}
801,9 \\
\end{tabular} & 869,3 & - & 835,8 & 73,5 & - & 59,1 & 728,6 \\
\hline & 27,5 & - & 1007,7 & 06,5 & - & 875,2 & 917,1 & - & 12,4 & 1031,1 & - & 19,8 & 770,7 \\
\hline & 30,0 & - & 1101,7 & 1170,6 & - & \begin{tabular}{|l|}
955,9 \\
\end{tabular} & 970,3 & - & 997,6 & 1094,0 & & 785,8 & 817,1 \\
\hline \multirow{12}{*}{$\begin{array}{c}0 \\
11 \\
0 \\
1 \\
\vdots \\
5 \\
0 \\
0 \\
0 \\
0 \\
0\end{array}$} & 2,5 & 489,2 & 676,3 & 951,7 & 564,5 & 750,3 & 1044,7 & 482,6 & 595,6 & 871,5 & 444,1 & 628,1 & 967,7 \\
\hline & 5,0 & 541,9 & 723,7 & 1002,9 & 613,8 & 791,4 & 1087,8 & 532,2 & 636,5 & 916,7 & 483,0 & 664,2 & 1006,4 \\
\hline & 7,5 & 603,1 & 776,3 & 1058,0 & 674,3 & 840,5 & 1136,9 & 590,1 & 681,7 & 965,5 & 530,4 & 706,2 & 1050,8 \\
\hline & 10,0 & 672,5 & 833,7 & 1114,5 & 744,7 & 895,5 & 1188,4 & 656,6 & 730,8 & 1017,2 & 585,9 & 752,5 & 1099,0 \\
\hline & 2,5 & 752,2 & 895,3 & 1172,4 & 827,7 & 955,4 & 1242,5 & 733,9 & 784,2 & 1071,9 & 651,6 & 803,5 & 1150,9 \\
\hline & 15,0 & 846,8 & 962,5 & 1231,9 & 928,3 & 1022,0 & 1300,1 & 825,5 & 842,9 & 1130,0 & 730,9 & 858,8 & 1207,3 \\
\hline & 17,5 & 960,9 & 1036,1 & 1294,3 & 1052,0 & 1096,0 & 1361,6 & 936,8 & 907,3 & 1191,7 & 828,8 & 920,8 & 1268,1 \\
\hline & 20,0 & 1096,3 & 1118,0 & 1360,0 & 1197,7 & 1179,6 & 1427,9 & 1068,8 & 979,0 & 1257,7 & 944,1 & 990,8 & 1334,1 \\
\hline & 22,5 & - & 1210,2 & 1429,4 & - & 1274,9 & 1499,2 & - & 1059,5 & 1328,6 & - & 1070,5 & 1405,9 \\
\hline & 25,0 & - & 1314,6 & 1504,8 & - & 1383,9 & 1577,5 & - & 1150,9 & 1405,0 & - & 1162,0 & 1484,0 \\
\hline & 27,5 & - & 1434,4 & 1588,0 & - & 1510,3 & 1664,3 & - & 1256,3 & 1488,0 & - & 1269,0 & 1569,8 \\
\hline & 30,0 & - & 1568,2 & 1680,0 & - & 1649,6 & 1760,8 & - & 1373,7 & 1578,8 & - & 1385,4 & 1664,3 \\
\hline
\end{tabular}


Tabela E27 (continuação) - PBTC (kN) em função do comprimento do grupo de eixos (m) - 5 VIGAS - CP - ELS - M $_{+}$

\begin{tabular}{|c|c|c|c|c|c|c|c|c|c|c|c|c|c|}
\hline & B & 2 & 3 & 4 & 6 & 7 & 8 & 13 & 14 & 15 & 17 & 18 & 19 \\
\hline & 2,5 & 389,0 & 543,7 & 767,0 & 428,0 & 570,1 & 802,7 & 383,9 & 468,8 & \begin{tabular}{|l|}
699,4 \\
\end{tabular} & 316,6 & 453,3 & 731,7 \\
\hline & 5,0 & 431,0 & 581,8 & 808,2 & 465,4 & 601,3 & 835,8 & 423,3 & 501,0 & \begin{tabular}{|l|l|}
735,6 \\
\end{tabular} & 344,3 & 479,3 & 761,0 \\
\hline & 7,5 & 479,7 & 624,1 & 852,6 & 511,3 & 638,6 & 873,5 & 469,4 & 536,5 & \begin{tabular}{|l|l|}
774,7 \\
\end{tabular} & 378,1 & 509,6 & 794,5 \\
\hline & 10,0 & 534,9 & 670,2 & 898,1 & 564,7 & 680,4 & 913,1 & 522,3 & 575,2 & \begin{tabular}{|l|}
816,3 \\
\end{tabular} & 417,7 & 543,0 & \begin{tabular}{|l|l}
831,0 \\
\end{tabular} \\
\hline$\infty$ & $-12,5$ & \begin{tabular}{|l|l|}
598,3 \\
\end{tabular} & 719,7 & 944,8 & 627,6 & 726,0 & 954,7 & 583,7 & 617,3 & 860,2 & 464,5 & 579,8 & \begin{tabular}{|l|l|}
870,2 \\
\end{tabular} \\
\hline 10 & 15,0 & 673,5 & 773,8 & 992,8 & 703,9 & 776,6 & 998,9 & 656,6 & 663,4 & 906,8 & 521,0 & 619,8 & 912,8 \\
\hline & 17,5 & 764,2 & 833,0 & 1043,0 & 797,7 & 832,8 & 1046,2 & 745,1 & 714,1 & 956,3 & 590,8 & 664,5 & 958,8 \\
\hline & 20,0 & \begin{tabular}{|l|l|}
871,9 \\
\end{tabular} & 898,8 & 1096,0 & 908,2 & 896,3 & 1097,1 & 850,2 & 770,6 & 1009,3 & 673,0 & 715,0 & 1008,8 \\
\hline & 22,5 & - & 973,0 & 1151,9 & - & 968,7 & 1151,9 & - & 833,9 & 1066,2 & - & 772,5 & 1063,0 \\
\hline & 25,0 & - & 1056,8 & 1212,7 & - & 1051,5 & 1212,1 & - & 905,8 & 1127,4 & & 838,6 & 1122,1 \\
\hline & 27,5 & - & 1153,2 & 1279,8 & - & 1147,6 & 1278,7 & - & 988,8 & 1194,1 & - & 915,7 & 1187,0 \\
\hline & 30,0 & - & 1260,8 & 1353,9 & - & 1253,4 & 1352,9 & - & 1081,2 & 1267,0 & - & 999,8 & 1258,4 \\
\hline & 2,5 & 300,5 & 424,6 & 598,6 & 307,6 & 409,7 & 585,8 & 296,9 & 355,1 & 542,8 & 204,4 & 298,1 & 521,0 \\
\hline & 5,0 & 332,9 & 454,3 & 630,7 & 334,4 & 432,1 & 609,9 & 327,4 & 379,5 & 571,0 & 222,3 & 315,2 & 541,8 \\
\hline & 7,5 & 370,5 & 487,4 & 665,4 & 367,4 & 458,9 & 637,4 & 363,0 & 406,4 & 601,4 & 244,1 & 335,1 & 565,7 \\
\hline & 10,0 & 413,1 & 523,4 & 700,9 & 405,7 & 489,0 & 666,3 & 403,9 & 435,7 & \begin{tabular}{|l|}
633,6 \\
\end{tabular} & 269,7 & 357,1 & 591,7 \\
\hline$\infty$ & 12,5 & 462,1 & 562,0 & 737,3 & 451,0 & 521,7 & 696,7 & 451,4 & 467,5 & 667,7 & 299,9 & 381,3 & 619,6 \\
\hline & 15,0 & 520,2 & 604,2 & \begin{tabular}{|l|l|}
774,8 \\
\end{tabular} & 505,8 & 558,1 & 728,9 & 507,8 & 502,5 & \begin{tabular}{|l|l|}
703,8 \\
\end{tabular} & 336,4 & 407,5 & 650,0 \\
\hline & 17,5 & 590,3 & 650,4 & 814,0 & 573,2 & 598,5 & 763,5 & 576,3 & 540,9 & 742,3 & 381,5 & 436,9 & 682,7 \\
\hline & 20,0 & 673,5 & 701,9 & 855,3 & 652,6 & 644,1 & 800,6 & 657,5 & 583,6 & 783,4 & 434,6 & 470,2 & 718,3 \\
\hline 10 & 22,5 & - & 759,8 & 899,0 & - & 696,2 & 840,6 & - & 631,6 & 827,6 & - & 508,0 & 756,9 \\
\hline & 25,0 & - & 825,3 & 946,4 & 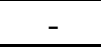 & 755,7 & 884,5 & - & 686,1 & \begin{tabular}{|l|}
875,1 \\
\end{tabular} & - & 551,4 & 799,0 \\
\hline & 27,5 & 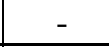 & 900,5 & 998,7 & - & 824,7 & 933,1 & - & 748,9 & \begin{tabular}{|l|}
926,9 \\
\end{tabular} & - & 602,2 & 845,1 \\
\hline & 30,0 & & 984,5 & 1056,6 & & 900,8 & 987,3 & - & 818,9 & 983,4 & - & 657,4 & 896,0 \\
\hline
\end{tabular}


Tabela E28 - PBTC (kN) em função do comprimento do grupo de eixos (m) - SEÇÃO CELULAR - CP - ELS - $\mathrm{M}_{+}$

\begin{tabular}{|c|c|c|c|c|c|c|c|c|c|}
\hline \multirow{13}{*}{$\begin{array}{l}1 \\
11 \\
0 \\
1 \\
0 \\
0 \\
\ddot{y} \\
0 \\
0 \\
0\end{array}$} & B & 1 & 2 & 3 & 5 & 6 & 7 & 8 & 10 \\
\hline & 2,5 & 923,5 & 1028,3 & 1243,2 & 1177,4 & 633,3 & \begin{tabular}{|l|l}
698,3 \\
\end{tabular} & 841,5 & 787,3 \\
\hline & 5,0 & 979,3 & 1068,0 & 1278,2 & 1261,3 & 678,2 & 729,6 & 868,9 & \begin{tabular}{|l|}
837,1 \\
\end{tabular} \\
\hline & 7,5 & 1054,3 & 1118,5 & 1321,8 & 1349,8 & 734,5 & 766,9 & 900,8 & 889,4 \\
\hline & 10,0 & 1147,6 & 1177,4 & 1371,1 & 1443,6 & 801,1 & \begin{tabular}{|l|l}
808,5 \\
\end{tabular} & 935,5 & 945,3 \\
\hline & 12 & 1253,7 & 1244,6 & 1425,7 & 1543,9 & 881,2 & \begin{tabular}{|l|}
854,7 \\
\end{tabular} & 972,8 & 1005,9 \\
\hline & 角 & 1383,6 & 1317,1 & 1483,6 & 1653,1 & 981,7 & 907,9 & 1014,2 & 10 \\
\hline & 17,5 & $1549, \mathrm{c}$ & 1400,7 & 1547,0 & 1773,4 & 1109,2 & 968,6 & 1059,7 & 11 \\
\hline & 20,0 & 1754,1 & 1498,0 & 1618,0 & 1908,2 & 1258,3 & 1038,4 & 1109,8 & 12 \\
\hline & 22,5 & - & 1611,5 & 1696,8 & 2060,7 & & 1119,2 & 1164,8 & 13 \\
\hline & 25,0 & - & 1744,4 & 1784,3 & 2235,2 & - & 1213,4 & 1225,6 & 144 \\
\hline & 27,5 & - & 1902,3 & 1882,0 & 2438,3 & 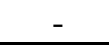 & 1325,1 & 1293,1 & 1572,0 \\
\hline & 30,0 & - & 2067,5 & 1991,1 & 2660,5 & - & 1436,4 & 1368,3 & 1714,2 \\
\hline & 2,5 & 745,9 & \begin{tabular}{|l|l|}
805,9 \\
\end{tabular} & 963,1 & 907,4 & 473,4 & 494,2 & 623,1 & 609,2 \\
\hline & 5,0 & 791,0 & \begin{tabular}{|l|}
837,1 \\
\end{tabular} & 990,2 & 972,1 & 506,9 & 516,4 & 643,3 & 647,7 \\
\hline & 7,5 & 851,5 & \begin{tabular}{|l|l|}
876,6 \\
\end{tabular} & 1023,9 & 1040,3 & 549,0 & 542,8 & 667,0 & 688,1 \\
\hline & 10,0 & 926,9 & 922,8 & 1062,1 & 1112,5 & 598,7 & 572,2 & 692,7 & 731,4 \\
\hline & 12,5 & $1012, \epsilon$ & \begin{tabular}{|l|l|}
975,4 \\
\end{tabular} & 1104,4 & 1189,9 & 658,7 & 605,0 & 720,3 & \begin{tabular}{|l|l|}
778,3 \\
\end{tabular} \\
\hline & 15,0 & 1117,5 & 1032,3 & 1149,2 & 1274,0 & 733,8 & 642,6 & 751,0 & 830,2 \\
\hline & 17,5 & 1251,8 & 1097,8 & 1198,4 & 1366,8 & 829,0 & 685,6 & 784,7 & 888,1 \\
\hline & 20,0 & 1416,7 & 1174,1 & 1253,4 & 1470,6 & 940,5 & 735,0 & 821,7 & 953,6 \\
\hline 10 & 22,5 & - & 1263,0 & 1314,5 & 1588,2 & - & 792,1 & 862,5 & 1028,4 \\
\hline & 25,0 & - & 1367,2 & 1382,2 & 1722,7 & - & 858,8 & 907,5 & 1114,8 \\
\hline & 27,5 & - & 1490,9 & 1457,9 & 1879,2 & 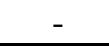 & 937,8 & 957,5 & 1216,3 \\
\hline & 30,0 & - & 1620,4 & 1542,5 & 2050,5 & 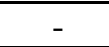 & 1016,7 & 1013,2 & 1326,3 \\
\hline
\end{tabular}


Tabela E28 (continuação) - PBTC (kN) em função do comprimento do grupo de eixos (m) - SEÇÃO CELULAR - CP - ELS - M+

\begin{tabular}{|c|c|c|c|c|c|c|c|c|c|}
\hline \multirow{13}{*}{ II } & $\mathbf{D}$ & 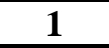 & - & 3 & ت & 0 & 1 & 8 & \\
\hline & ,5 & 84,7 & 02,4 & 05,4 & & & & & \\
\hline & 0 & & & & & & & & \\
\hline & 7,5 & & & & & & & & \\
\hline & 10,0 & & 7 & 8,0 & & & & & \\
\hline & 12,5 & 3,8 & 9,1 & 9,0 & 3,5 & & & & \\
\hline & 15,0 & 6,0 & 6 & 8 & 35,2 & & & & \\
\hline & 17,5 & 981,4 & 8 & 77,8 & 03,4 & & 4 & & \\
\hline & 20,0 & 1110,6 & 7,5 & 1 & 6 & 59,2 & 64,6 & & \\
\hline & 22,5 & & 0 & 8 & 9 & &, 7 & & \\
\hline & 25,0 & - & & 5 & & & 9 & & \\
\hline & 27,5 & & & & & & & & \\
\hline & 30,0 & & & & & & & & \\
\hline &, 5 & & & & & & & & \\
\hline & 5,0 & & & & , & & 9 & & \\
\hline & 7,5 & 2 & 8 & 0 & 19,8 & & 5 & & \\
\hline & 10,0 & & 8 & ,2 & 4 & & & & \\
\hline & 12,5 & & & & & & & & \\
\hline & 15,0 & & & & & & & & \\
\hline & 17,5 & & & & 3,9 & & & & \\
\hline & 20,0 & 1667,5 & & & & 157,8 & & & \\
\hline & 2,5 & & & & 4,8 & & 1009,1 & & \\
\hline & 25,0 & 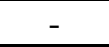 & & & & & 4,1 & & \\
\hline & 7,5 & - & & & & & &, 2 & \\
\hline & $30,0_{1}$ & & IUUD, L & $100<, 0$ & 2001,0 & & $12 \mathrm{JJ}, 2$ & 1234,1 & 1596 , \\
\hline
\end{tabular}


Tabela E28 (continuação) - PBTC (kN) em função do comprimento do grupo de eixos (m) - SEÇÃO CELULAR - CP - ELS - M+

\begin{tabular}{|c|c|c|c|c|c|c|c|c|c|}
\hline \multirow{13}{*}{$\begin{array}{l}10 \\
0 \\
1 \\
8\end{array}$} & B & 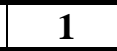 & 2 & 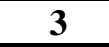 & 2 & & 7 & 8 & 10 \\
\hline & 2,5 & 704 & 43,8 & 388,7 & ד & & & & ב, \\
\hline & 5,0 & 747 & 772,6 & 3,7 & & & & & \\
\hline & 7,5 & 804,5 & 809,1 & & & & & & \\
\hline & 10,0 & & & & & & & & \\
\hline & 2,5 & & & & & & & & \\
\hline & 5,0 & & & & & & & & \\
\hline & 7,5 & & & & & & & & \\
\hline & 0,0 & 1 & & & & & & & \\
\hline & 22,5 & & 7 & & & & & & \\
\hline & 25,0 & - & 9 & & & & & & \\
\hline & 27,5 & & 1 & & & & & & \\
\hline & 30,0 & & & & & & & & \\
\hline & 2,5 & 547,7 & 545,5 & & & & & & \\
\hline & 5,0 & 580 & 566,6 & & & & & & (5) \\
\hline & 7,5 & 625 & 593,3 & & & & & & \\
\hline & 10,0 & 680 & 624,6 & & & & 1 & & \\
\hline & 12,5 & & 660,2 & & & & 0 & & \\
\hline & 15,0 & $0<0,0$ & 698,7 & & & & 4 & & \\
\hline & 17,5 & 919,2 & 743,0 & & & & 53,5 & & \\
\hline & 20,0 & 1040,2 & 794,7 & & & 576,8 & 379,0 & & \\
\hline & 22,5 & & 854,8 & & & & 08,5 & 37,4 & 3,5 \\
\hline & 25,0 & & 925,4 & & 2 & & 42,9 & 2,8 & 5,6 \\
\hline & 27,5 & - & $\overline{09,1}$ & & & & 33,6 & 1,1 & \\
\hline & 30,0 & & $1096, /$ & 1019,9 & $1401, y$ & & 524,3 & 572,6 & $0 / \mathrm{J}, 1$ \\
\hline
\end{tabular}

